\title{
Integrated Low Emissions Cleanup System for Coal Fueled Turbines Phase III Bench-Scale Testing and Evaluation
}

\section{Final Report}

September 1987 - July 1995

R.A. Newby

M.A. Alvin

D.M. Bachovchin

E.E. Smeltzer

T.E. Lippert

August 1995

Work Performed Under Contract No.: DE-AC21-87MC24257

For

U.S. Department of Energy

Office of Fossil Energy

Morgantown Energy Technology Center

Morgantown, West Virginia

By

Westinghouse Electric Corporation

Pittsburgh, Pennsylvania 


\section{DISCLAIMER}

This report was prepared as an account of work sponsored by an agency of the United States Government. Neither the United States Government nor any agency thereof, nor any of their employees, makes any warranty, express or implied, or assumes any legal liability or responsibility for the accuracy, completeness, or usefulness of any information, apparatus, product, or process disclosed, or represents that its use would not infringe privately owned rights. Reference herein to any specific commercial product, process, or service by trade name, trademark, manufacturer, or otherwise does not necessarily constitute or imply its endorsement, recommendation, or favoring by the United States Government or any agency thereof. The views and opinions of authors expressed herein do not necessarily state or reflect those of the United States Government or any agency thereof.

This report has been reproduced directly from the best available copy.

Available to DOE and DOE contractors from the Office of Scientific and Technical Information, 175 Oak Ridge Turnpike, Oak Ridge, TN 37831; prices available at (615) 576-8401.

Available to the public from the National Technical Information Service, U.S. Department of Commerce, 5285 Port Royal Road, Springfield, VA 22161; phone orders accepted at (703) 487-4650. 


\title{
Integrated Low Emissions Cleanup System for Coal Fueled Turbines Phase III Bench-Scale Testing and Evaluation
}

\author{
Final Report \\ R.A. Newby \\ M.A. Alvin \\ D.M. Bachovchin \\ E.E. Smeltzer \\ T.E. Lippert
}

September 1987 - July 1995

Work Performed Under Contract No.: DE-AC21-87MC24257

\author{
For \\ U.S. Department of Energy \\ Office of Fossil Energy \\ Morgantown Energy Technology Center \\ P.O. Box 880 \\ Morgantown, West Virginia 26507-0880 \\ By \\ Westinghouse Electric Corporation \\ Science and Technology Center \\ 1310 Beulah Road \\ Pittsburgh, Pennsylvania 15235-5098
}




\begin{abstract}
The United States Department of Energy, Morgantown Energy Research Center (DOE/METC), is sponsoring the development of coal-fired turbine technologies such as Pressurized Fluidized Bed Combustion (PFBC), coal Gasification Combined Cycles (GCC), and Direct Coal-Fired Turbines (DCFT). A major technical development challenge remaining for coal-fired turbine systems is high-temperature gas cleaning to meet environmental emissions standards, as well as to ensure acceptable turbine life.

The Westinghouse Electric Corporation, Science \& Technology Center, has evaluated an Integrated Low Emissions Cleanup (ILEC) concept that has been configured to meet this technical challenge. This ceramic hot gas filter (HGF), ILEC concept controls particulate emissions, while simultaneously contributing to the control of sulfur and alkali vapor contaminants in high-temperature, high-pressure, fuel gases or combustion gases. This document reports on the results of Phase III of the ILEC evaluation program, the final phase of the program. In Phase III, a bench-scale ILEC facility has been tested to 1) confirm the feasibility of the ILEC concept, and 2) to resolve some major filter cake behavior issues identified in PFBC, HGF applications.
\end{abstract}




\section{LIST OF TABLES}

Table

Page

2.1 Westinghouse PFBC, HGF System Characteristics.......................................................... 2-2

2.2 Westinghouse PFBC, HGF Filter Cake Observations........................................................ 2-4

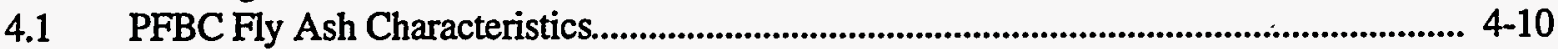

4.2 Sorbent and Additive Characteristics................................................................................ 4-12

4.3 Filter Cake Permeability Test Matrix (Series 1)........................................................... 4-15

4.4 Filter Cake Additives Test Matrix (Series 2).................................................................... 4-16

4.5 Filter Cake Pulse Cleaning Test Matrix (Series 3)............................................................... 4-18

$4.6 \mathrm{SO}_{2}$ Removal Test Record (Series 4)............................................................................. 4-21

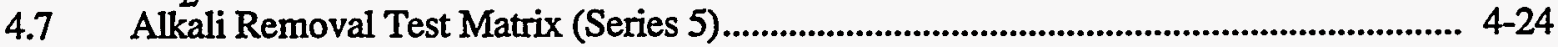

5.1 General Particle Cohesion/Adhesion Phenomena............................................................ 5-3

5.2 Deposit and Bridging Mechanisms in HTHP Coal-Based, High-Calcium Filter Cakes................................................................................................... 5-4

5.3 Filter Cake Permeability Test Results............................................................................. 5-8

5.4 Laboratory and Field Cake Permeabilities................................................................. 5-10

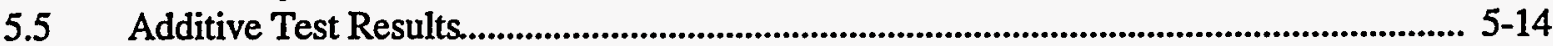

5.6 Filter Cake Pulse Cleaning Test Conditions............................................................... 5-17

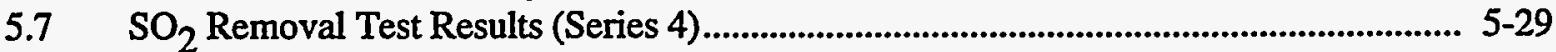

$5.8 \quad$ Alkali Removal Test Results (Test Series 5)........................................................... 5-33 


\section{LIST OF FIGURES}

Figure

Page

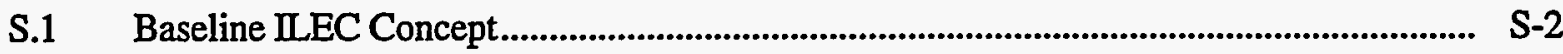

S.2 Test Facility Drawing.................................................................................................... S-4

$2.1 \quad$ Hot Gas Filter ILEC Concept........................................................................................... 2-6

$2.2 \quad$ Fluid Bed ILEC Concept........................................................................................................ 2-7

4.1 Bench-Scale HGF, IIEC Facility.................................................................................. 4-2

4.2 Bench-Scale HGF, Outlet Gas Analysis System............................................................. 4-4

4.3 Bench-Scale HGF, Outlet Gas Alkali Sampling System................................................... 4.. 4.5

4.4 Candle Arrangement in the Bench-Scale HGF............................................................... 4-7

5.1 PFBC, HGF Field Test Conditions and Bench-Scale ILEC Test Conditions................... 5-12

$5.2 \quad$ Pulse Cleaning Pulse Intensities (Tidd Fine Fly Ash)................................................. 5-18

5.3 Pulse Cleaning Pulse Intensities (Karhula I Fly Ash)...................................................... 5-19

5.4 Pulse Gas Received and Released (Tidd Fine Fly Ash)................................................... 5-20

5.5 Pulse Gas Received and Released (Karhula I Fly Ash)................................................... 5-21

5.6 Pulse Cleaning Performance (Tidd Fine Fly Ash)...................................................... 5-23

5.7 Pulse Cleaning Performance (Karhula I Fly Ash) ........................................................... 5-25

5.8 High-Pressure Pulse Cleaning (Tidd Fine Fly Ash) .......................................................... 5-26

5.9 High-Pressure Pulse Cleaning (Karhula I Fly Ash)..................................................... 5-27 


\section{LIST OF ACRONYMS}

$\begin{array}{ll}\text { AEP: } & \text { American Electric Power } \\ \text { APFBC: } & \text { Advanced or Second-Generation PFBC } \\ \text { DCFT: } & \text { Direct coal-fired turbine } \\ \text { DMEC: } & \text { Des Moines Energy Center } \\ \text { DOE: } & \text { U.S. Department of Energy } \\ \text { FREMP: } & \text { Four Rivers Energy Modernization Project } \\ \text { FWDC: } & \text { Foster Wheeler Development Corporation } \\ \text { GCC: } & \text { Gasification combined cycle } \\ \text { HGF: } & \text { Hot gas filter } \\ \text { ILEC: } & \text { Integrated Low Emission Cleanup } \\ \text { METC: } & \text { Morgantown Energy Technology Center } \\ \text { PCD: } & \text { Particulate Control Device } \\ \text { PFBC: } & \text { Pressurized fluidized bed combustion }\end{array}$




\section{EXECUTIVE SUMMARY}

An integrated, low emissions cleanup (ILEC) concept has previously been proposed by Westinghouse that combines ceramic barrier, hot gas filter (HGF) technology with sorbent particle injection for gas phase contaminant removal. Figure S-1 illustrates the IIEC concept. The concept extends similar concepts for integrated, low-temperature gas cleaning in conventional steam power plants to high-temperature, high-pressure conditions and enhances the HGF technology. The concept can be applied to both oxidizing environments, such as the combustion gas in Pressurized Fluidized Bed Combustion (PFBC), or to reducing environments, such as the fuel gas in Gasification Combined Cycles (GCC).

\section{Program Objectives and Scope}

The overall objectives of this program were to:

- assess the feasibility of the ILEC concept at a bench-scale level;

- produce process data for use in subsequent field testing.

The ILEC test conditions have focused on PFBC applications, using sorbents injected into the HGF for sulfur and alkali removal. In addition, several issues with the behavior of HGF filter cakes have been identified in PFBC, HGF field testing. These issues relate to filter cake permeability and pulse cleaning performance, and, in particular, to the observed formation of "hard" filter cakes and bridges under some circumstances. It has also been an objective of the Phase III program to assess these issues, determining the key phenomena responsible for adverse filter cake behavior, and identifying possible means to improve filter cake behavior.

The IIEC development program consisted of three phases:

- Phase I - Laboratory-Scale Testing

- Phase II - Bench-Scale Equipment Design and Fabrication

- Phase III - Bench-Scale Testing 


\section{WESTINGHOUSE ILEC CONCEPT}

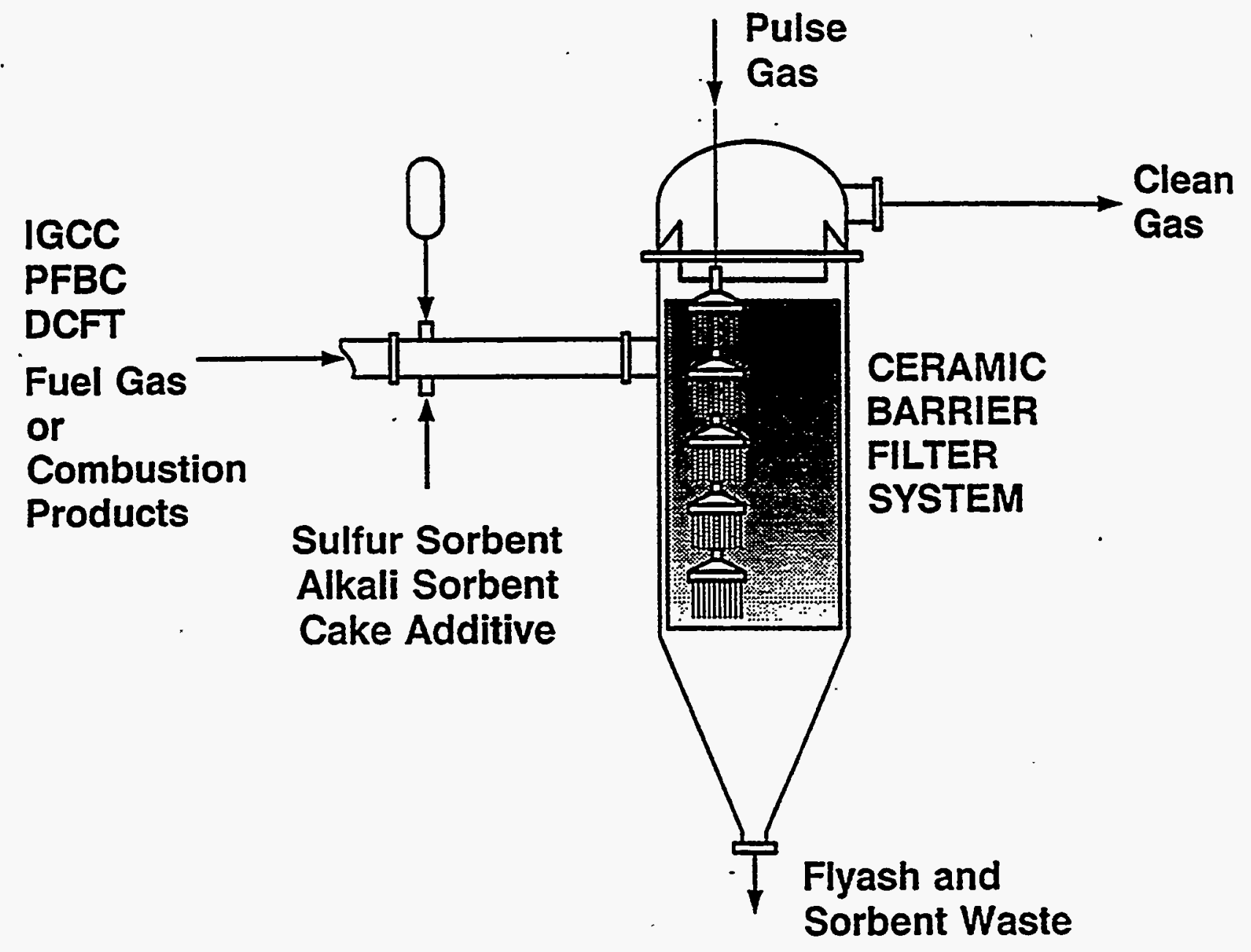

Figure S.1 - Baseline ILEC Concept 
Phases I and II had been previously completed and their results reported. Included in Phase I was an evaluation of alternative ILEC concepts, from which the ceramic barrier filter IIEC concept was selected for bench-scale testing. The Phase III test program has focused on PFBC filter cake issues, as well as in-filter sulfur and alkali removal. The Phase III testing, and the evaluation of the results, are the subject of this report.

Five test series have been conducted at simulated PFBC conditions in Phase III:

1. Cake Permeability Tests

2. Additive Tests

3. Cake Pulse Cleaning Tests

4. Sulfur Removal Tests

5. Alkali Removal Tests

The testing activities generated 52 sets of test data, representing more than $\mathbf{7 7 0}$ total hours of hot filter exposure. The first series of tests were highly controlled tests measuring changes in filter cake permeability primarily as a function of temperature and PFBC fly ash source. The second series examined the ability of various filter cake additives, and the additive application procedure, to improve the filter cake permeability. The third series of tests were directed toward measuring the impact of temperature, PFBC fly ash source, and pulse intensity on pulse cleaning effectiveness. Test series four and five have characterized the potential for sulfur removal and alkali removal within the HGF. The final two test series have also measured the influence of the injected sorbents on the filter cake behavior.

\section{Bench-Scale Facility Description and Test Conditions}

A natural gas fired, bench-scale, high-pressure, high-temperature, ceramic barrier filter test facility was modified to study ILEC performance under simulated PFBC conditions. The objective of the bench-scale simulation was to produce a filter inlet gas having pressure, temperature, gas composition $\left(\mathrm{SO}_{2}\right.$, alkali content, and particulate content), and fly ash particulate characteristics representative of coalfired PFBC. A drawing of the facility is shown in Figure S-2. A horizontal, natural 


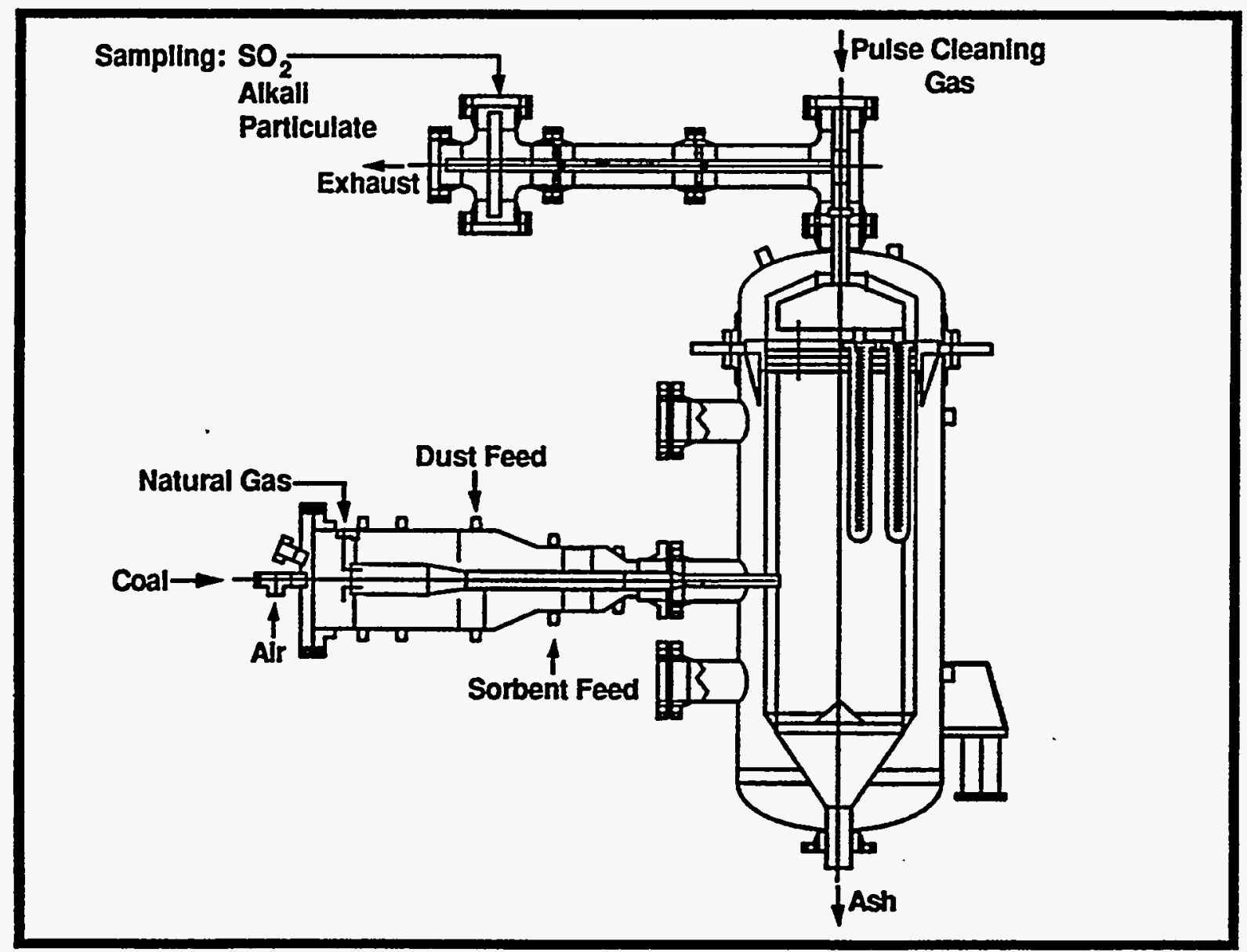

Figure S.2 - Test Facility Drawing 
gas combustor is attached to the filter pressure vessel inlet nozzle. The combustor is a carbon steel, refractory-lined, pipe with internal, high-alloy liner sections. The burner has been designed to operate entirely on natural gas, or with coal and natural gas combinations. PFBC fly ashes, sulfur sorbents, alkali sorbents, or deposit additives may be injected into the secondary zone of the combustor as required by the specific test. Sulfur and alkali contaminants may also be injected into the filter inlet gas through the combustor.

The uncooled tubesheet, with a 31-inch plate diameter, has been designed with commercial candle holder features that included fail-safe/regenerator devices. The tubesheet, capable of holding up to 19 candles, supported four commercial, ceramic candle filter elements in this program, each 1.5-meter in length. The inlet gas enters the vessel horizontally, near the level of the base of the candles, with no baffles to deflect the inlet jet. The four candles were located so that direct impaction by the inlet gas stream was avoided. The four candles were pulse cleaned simultaneously. The filter vessel outlet piping section incorporated gas sampling for particulate, alkali vapor, sulfur oxides, and $\mathrm{CO}_{2}$.

Almost all of the bench-scale tests were conducted with the face velocity fixed at $7 \mathrm{ft} / \mathrm{min}$, and the pressure fixed at $100 \mathrm{psig}$, while other conditions, such as temperature and fly ash source were varied. Key measurements made during the tests were:

- Inlet gas and fly ash mass flow rates,

- Gas inlet and outlet temperature,

- Tubesheet pressure drop,

- Plenum pressure and pulse tank pressure during pulse cleaning events,

- Outlet gas mass flow rate, and particulate, $\mathrm{CO}_{2}, \mathrm{SO}_{2}$, and alkali vapor content.

\section{Filter Cake Permeability Test Results}

Sixteen controlled tests of PFBC fly ash filter cakes were conducted to develop an understanding of filter cake behavior, and in particular, adverse behavior such as hard filter cakes and bridge formation that might occur in PFBC 
applications under some circumstances. The bench-scale testing, combined with laboratory testing (Appendix A) and related information in the literature, identified the key phenomena resulting in adverse filter cake behavior as "sintering" of the filter cake calcium constituents induced by $\mathrm{SO}_{2}$ and $\mathrm{CO}_{2}$ in the gas.

The bench-scale filter cake permeability "trends" were consistent with PFBC, HGF field test trends - that is, the relative ranking of permeabilities of the tested PFBC fly ashes were identical to the ranking extracted from HGF field results, and the filter cake permeability sensitivity to temperature is similar to that suggested by PFBC, HGF field tests. The laboratory filter cake permeabilities were generally greater in magnitude than the estimated PFBC, HGF field test permeabilities, and the formation of "hard" filter cakes and bridges were never observed in the benchscale testing. These differences between bench-scale and field testing probably resulted because 1) the bench-scale permeability tests did not include $\mathrm{SO}_{2}$ in the simulated $\mathrm{PFBC}$ gas, 2) the $\mathrm{CO}_{2}$ partial-pressures were lower in the bench-scale tests than in the PFBC, HGF field tests, and 3) the PFBC fly ashes tested were reentrained particles, having reduced reactivity due to previous exposure to the HGF environment in field units.

Conclusions reached in the bench-scale filter cake permeability testing, confirmed by supporting laboratory tests (Appendix A), and suggested by the literature on related technologies, were:

- PFBC filter cake permeability and sintering is largely controlled by limestone-derived, calcium constituents in the fly ash;

- More extensive PFBC filter cake sintering results from:

- finer fly ash particles size,

- higher temperatures,

- higher $\mathrm{CO}_{2}$ and $\mathrm{SO}_{2}$ partial-pressures,

- longer filter cake-gas contact times,

- use of calcitic limestone vs dolomitic limestone in the PFBC. 


\section{Additive Test Results}

Filter cake additives were addressed in the test program to see if some might be identified that could minimize the occurrence of adverse filter cake behavior. Five additive tests were performed, focusing on the influence of additives on the filter cake permeability, with the additives premixed with PFBC fly ashes having low permeabilities. The additives tested were pulverized dolomite, kaolin, and Neutralite. Also, one test was performed with Neutralite applied as a precoat on the filter elements.

The results showed that the use of pulverized dolomite benefitted the filter cake permeability significantly. The filter cake permeability was increased about $50 \%$, even though only $10 \mathrm{wt \%}$, or about 5 vol\%, dolomite additive was used. It is expected that the tendency for fly ash filter cake sintering and bridging would also be reduced by this dolomite additive.

Precoating the candle elements with Neutralite, a commercial baghouse filter aid, initially resulted in a filter precoat having relatively high permeability, but exhibiting a large reduction in filter cake permeability as the temperature was increased to PFBC temperature. The test of a cake of PFBC fly ash on the Neutralite precoat showed that the cake permeability was slightly lower than it had . been in earlier tests having no precoat. It was found that the Neutralite precoat was very thick (about $1 / 2^{\prime \prime}$ to $5 / 8^{\prime \prime}$ ) and was a hard, stable layer that needed to be cut out in sections. A thinner precoat should be used, and the stable layer might provide some protection to the candle if no detrimental reactions occur with the candle materials. Such a stable precoat might also provide an aid to pulse cleaning. Further assessment of the precoat concept should be considered.

Neutralite was also tested as an additive to fly ash. A cake of PFBC fly ash mixed with 5 wt\% Neutralite was formed and resulted in a cake permeability much lower than previously measured with the PFBC fly ash alone. A further series of continuous pulse cleanings and cake buildups showed a significant deterioration in the baseline pressure drop, further exposing the poor performance of Neutralite as a direct additive. Neutralite would not appear to be a useful filter cake permeability aid for PFBC applications. Neutralite might be a useful aid to reduce re- 
entrainment with filter cakes having low cohesion, such as may be obtained in some GCC applications.

Finally, an additive test was performed using a mixture of $10 \mathrm{wt} \%$ Kaolin in PFBC fly ash. The results showed little influence of the Kaolin on the filter cake permeability compared to prior tests without the additive. The kaolin size distribution was roughly comparable to the PFBC fly ash size distribution, and its major clay constituents were similar to the major coal ash constituents of the PFBC fly ash.

In general, the practicality of filter cake additive use is uncertain based on the testing. The dolomite additive had the most positive results, and its low cost combined with the possibility for additional sulfur removal within the filter, makes dolomite an additive candidate for PFBC applications.

\section{Pulse Cleaning Test Results}

Controlled pulse cleaning tests were performed over a range of parameters to determine if ineffective pulse cleaning might contribute to the adverse filter cake behavior observed in PFBC, HGF field tests under some circumstances. Pulse cleaning performance was characterized by building filter cakes at specified temperatures, and measuring the recovery of the baseline pressure drop over a range of pulse cleaning intensities. Two PFBC fly ashes were tested, a Tidd fine fly ash, and a Karhula PFBC fly ash. While the Tidd fine fly ash was prone to adverse filter cake behavior, the Karhula fly ash was free from adverse behavior in PFBC, HGF field tests. Twelve tests were conducted at temperatures of 1300,1450 , and $1550^{\circ} \mathrm{F}$. The solenoid valve opening and closing characteristics were fixed at near optimum values in all of the testing.

The pulse intensities were measured in all of the tests and were a monotonic function of the pulse gas tank pressure. The pulse intensity is defined as the maximum pressure reached in the filter plenum during the pulse event. It is assumed that the maximum plenum pressure is the same as the maximum pressure in the candles during a pulse. The pulse gas tank pressure is the pulse gas source 
pressure in the accumulator that is applied at the start of the pulse. The pulse intensity rises almost linearly as the tank pressure increases, but it also appears that the intensity is slightly higher as the temperature is increased. This probably resulted because the filter cake and "residue" permeabilities had decreased as the temperature was increased.

The "baseline pressure drop" is the plenum pressure drop following the pulse cleaning event. The "residue" pressure drop is defined as the baseline pressure drop minus the pressure drop if perfect cleaning were achieved. A lower value of this residue pressure drop means that a more effective pulse cleaning was performed. At each temperature in the test program, as the pulse intensity was decreased a clear increase in the residue resulted. As the temperature increased, the residue pressure drop was higher at the same pulse intensity. For example, at $1300^{\circ} \mathrm{F}$ a pulse intensity of 5 psi resulted in a residue pressure drop of about $0.5^{\mathrm{H}} \mathrm{O}$, while at $1450^{\circ} \mathrm{F}$ the same $5 \mathrm{psi}$ pulse intensity resulted in a residue pressure drop of about $3 \mathrm{psi}$, and at $1550^{\circ} \mathrm{F}$ the same $5 \mathrm{psi}$ pulse intensity resulted in a residue pressure drop of about $7 \mathrm{psi}$.

The Tidd fine fly ash and the Karhula fly ash showed very similar pulse cleaning behavior. Even though the Karhula fly ash had a significantly higher filter cake permeability than the Tidd fine fiy ash, with also much less sensitivity to temperature, a significant influence of temperature and time on the pulse cleaning effectiveness was observed.

There are two factors that have contributed simultaneously to these results. First, higher temperature results in lower cake permeability and greater residue accumulation. Secondly, the tests were performed in the order of ascending temperatures, so that as the temperatures increased, the cumulative test time also increased. This second factor resulted in more opportunity for residue accumulation on the candles, or within the candle surface pores, as time, and temperature progressed. The results imply that, with both the Tidd fine fly ash and the Karhula fly ash, a steady accumulation of residue might occur that cannot be effectively cleaned even at the highest pulse intensity conditions used in these tests. This residue accumulation, though, appears to be representative of normal filter element 
"conditioning". It is not expected to be a contributor to the adverse filter cake behavior observed in some PFBC, HGF field tests, so long as the pulse intensity is maintained greater than about $10 \mathrm{psi}$, and uniform pulse cleaning of all elements is provided.

Two final tests were conducted to measure the benefits of a higher pulse source pressure on the pulse cleaning performance. Both tests resulted in a pulse intensity of about 35 psi. The results imply that with the fine Tidd fly ash, $a$ continued buildup of residue occurred on the candles that increased as the temperature increased, while this temperature sensitivity was not shown for the Karhula fly ash. A significant residue resistance remained on the candles even with this high pulse intensity.

\section{Sulfur Removal Test Results}

The testing was conducted to measure the in-filter $\mathrm{SO}_{2}$ removal performance of PFBC fly ashes and calcium-based sorbents. Another objective of the sulfur removal testing was to determine the influence of $\mathrm{SO}_{2}$ exposure on $\mathrm{PFBC}$ fly ash filter cake permeability, since $\mathrm{SO}_{2}$ is known to accelerate filter cake sintering. The test parameters were:

- Fly ash source: Tidd and Karhula PFBC

- Sorbent type: -325 mesh dolomite alone or mixed with PFBC fly ash

- Temperature: $1450-1550^{\circ} \mathrm{F}$

- Pressure: 100 and 150 psig

Two types of $\mathrm{SO}_{2}$ removal tests were performed. The primary procedure provided a test of the influence of $\mathrm{SO}_{2}$ on the cake permeability and characterized the ability of the predeposited filter cake to removal sulfur. The second procedure, applied in one test only, was a test of the particulate (sorbent) to remove $\mathrm{SO}_{2}$ while being fed in the suspended state and simultaneously building a filter cake.

Eight tests were performed. The sulfur removal tests included $\mathrm{SO}_{2}$ sampling system calibration runs. All of the tests were performed at a temperature of $1550^{\circ} \mathrm{F}$ and a pressure of $100 \mathrm{psig}$, with the exception of one sorbent test performed at 
$1450^{\circ} \mathrm{F}$ and $150 \mathrm{psig}$. Estimates of the "free calcium/sulfur ratio", or the molar ratio of unsulfated calcium fed during the entire test divided by the total sulfur fed during the test, were made. Estimated percent retentions of sulfur in the HGF were also made. There were uncertainties in the tests as a result of a relatively high background $\mathrm{SO}_{2}$ level that was indicated by the instrumentation. This is believed to be instrument error due to interference by other gas components as well as actual $\mathrm{SO}_{2}$ release from the filter internals.

No significant differences in filter cake behavior or $\mathrm{SO}_{2}$ removal performance were observed during the transient entrained sorbent test, or at the lower temperature/higher pressure conditions, relative to other comparable tests. While the sulfur removal measurements have a large uncertainty, the results do provide representative and significant trends:

- The inclusion of $\mathrm{SO}_{2}$ in the filter inlet gas had a negligible impact on the filter cake permeability with the two relatively coarse PFBC fly ashes tested, as well as with the dolomite sorbent tested.

- The Tidd fly ash, from the partially-spoiled cyclone testing on the Tidd HGF, showed little ability to capture sulfur, while the Karhula fly ash had significant sulfur capture capability. This may be because the Karhula ash contained more free calcium than the Tidd fly ash.

- The PFBC fly ash-sorbent mixtures and the sorbent alone showed significant sulfur capture ability, being greater than $90 \%$ at calcium-to-sulfur ratios of 1 to 2.

- No indication of hard filter cake formation, or deposits that would initiate filter bridging, was found on observation of the filter elements after testing, even for the tests with dolomite alone. This is probably because the dolomite fed was of relatively coarse particle size.

These trends indicate that relatively coarse (-325 mesh) sorbent injection for in-filter sulfur removal would be very efficient and would not result in adverse filter cake formation. It is expected that injection of much finer sorbent particles (mean size $5 \mu \mathrm{m}$ or less) into the filter would result in a high degree of filter cake sintering. The fact that $\mathrm{SO}_{2}$ exposure did not result in sintered filter cakes when using the PFBC 
fly ashes probably is due to 1) the previous exposure and sulfation of these fly ashes in PFBC, HGF field units, and 2) their relatively coarse particle size.

\section{Alkali Removal Tests}

The objectives of the alkali removal tests were to 1) to measure the in-filter alkali removal performance, and 2) observe the filter cake permeability to see if adverse filter cakes were generated at temperatures where the reacted alkali sorbent particles may become relatively soft. Alkali removal tests were performed by injecting PFBC fly ashes and alkali sorbent (emathlite powder) premixed with micro-pulverized sodium chloride, the alkali vapor source. The feed rate of pulverized emathlite was maintained at about 10 times the saturation feed rate. At saturation, emathlite can adsorb about 20 wt\% sodium.

Test procedures similar to those used in the sulfur removal testing were applied. Alkali was sampled at two locations using an extractive, condensing probe. The first location was downstream of the filter exit pipe, where particle, and $\mathrm{SO}_{2}$ sampling was performed. The temperature drop was too great at this location and was expected to result in significant alkali vapor condensation within the piping prior to extraction. The second location was directly from within the vessel head, with minimal temperature loss occurring. The probe extracted gas during the entire alkali salt feeding period.

All of the tests were performed with fixed conditions of a face velocity of $7 \mathrm{ft} / \mathrm{min}$, a pressure of $100 \mathrm{psig}$, and a temperature of about $1550^{\circ} \mathrm{F}$. Ten tests were completed. Test periods for calibration of the alkali probe and for determination of alkali background reading were also conducted. The tests were performed with probe samples (condensate water-soluble sodium) collected and analyzed.

Uncertainties in the results arise from the possibility of alkali vapor condensation, alkali vapor reactions with the metal internals in the filter vessel, and incomplete vaporization of the injected alkali salt. 
The results, though uncertain, indicate that significant alkali removal was obtained with emathlite injection into the filter, and adverse filter cake behavior was not observed, even though the reacted alkali sorbent might be relatively soft at the test temperature.

\section{Conclusions and Recommendations}

The bench-scale testing has shown that the ILEC concept is a viable extension of HGF technology for PFBC applications.

The bench-scale $\mathrm{SO}_{2}$ removal test results showed significant removal, though the results are uncertain. The results also indicated that dolomite injection will not generate adverse filter cake behavior, at least if the dolomite size is -325 mesh.

Supplemental laboratory sorbent-sulfur oxide reaction kinetics testing and evaluation performed in this program provides estimates that a calcium-to-sulfur ratio of 1.5 to 2 should be sufficient to provide greater than $80 \%$ sulfur removal in the HGF.

Pulverized emathlite, and probably several other clays, could be injected into the HGF to achieve sufficient alkali removal for turbine protection. Again, the bench-scale alkali vapor removal test results are quite uncertain, but they do indicate that significant alkali removal can be obtained within the filter without adverse filter cake formation due to emathlite softening. Supplemental laboratory testing of alkali-sorbent reaction kinetics conducted in this program has produced estimates that a pulverized emathlite feed rate of about 10 times the saturation rate is sufficient to meet turbine alkali vapor criteria.

The bench-scale ILEC testing, combined with supplemental laboratory testing, HGF field test data and observations, and information from related technologies, indicates that the source of adverse filter cake behavior in PFBC, HGF applications is primarily filter cake calcium-constituent sintering induced by the gas phase $\mathrm{SO}_{2}$ and $\mathrm{CO}_{2}$. Reliable PFBC, HGF operation, without adverse filter cake behavior, can be maintained by selecting conditions, to the extent that the 
application allows, that promote slower filter cake sintering rates. Options available to accomplish this can be applied individually or in combination:

- reduced HGF temperature,

- increased filter cake particle size,

- lower partial-pressures of $\mathrm{CO}_{2}$ and $\mathrm{SO}_{2}$

- use of dolomitic limestone rather than calcitic limestone in the PFBC

Pulverized dolomite ( -325 mesh) could be injected into the HGF to act both as a filter cake permeability aid, probably reducing the potential for hard filter cake and bridge formation, and to perform supplemental sulfur removal in the HGF. A feed rate of about $10 \mathrm{wt} \%$ dolomite, relative to the fly ash feed rate, should be ample for significant filter cake permeability enhancement.

It is expected that the ILEC concept can also be applied in other HGF applications, such as GCC, where the sorbent types and functions may differ substantially from those for PFBC. It is recommended that the ILEC concept be tested at available PFBC and GCC, HGF field facilities to provide larger scale, steady-state performance data on in-filter contaminant control functions, and their influence on the filtering performance. 


\section{INTRODUCTION}

Coal has maintained its status as the prevalent fuel for utility-scale power generation in the United States and in the developing countries of the World, even with the climate of mounting environmental concerns and regulations, as well as in the face of high availability of alternative fuels, such as natural gas. The United States Department of Energy, Morgantown Energy Technology Center, is sponsoring the development of advanced, coal-fueled power generation systems that improve the economics and environmental performance of coal-based power generation through advances in power plant thermal efficiency and emissions control technologies. Advanced power generation systems using coal-fueled turbine combined cycles, such as Pressurized Fluidized Bed Combustion (PFBC), Advanced Pressurized Fluidized Bed Combustion (APFBC), and coal Gasification Combined Cycle (GCC), have been developed to the state where they are now nearing full-scale demonstration in Clean Coal Technology programs.

These advanced, coal-fueled power generation systems demand high levels of performance from hot-gas cleaning systems that remove process gas contaminants at high-temperature, high-pressure conditions to meet power plant environmental requirements and to satisfy turbine protection requirements. The hot gas cleaning systems represent technologies critical to the success of the Clean Coal Technology programs, and development programs, focused on the individual cleanup functions of sulfur removal, alkali removal, and particulate removal, have been placed to support the demonstration programs. The development of integrated, multi-functional, gas cleanup equipment might provide additional economic and efficiency benefits for the advanced power generation systems. The program described in this document has tested and assessed the feasibility of such an integrated hot gas cleaning approach. 


\section{BACKGROUND}

The incentives for conducting the program described in this document were two-fold:

- An Integrated Low Emission Cleanup (ILEC) concept has been proposed that has the potential to provide cost and contaminant control benefits to advanced, coal-fueled power generation technologies. Small-scale demonstration testing and evaluation was needed to assess the ILEC concept and guide its future development.

- PFBC, HGF field testing had identified some major performance issues relating to adverse behavior of filter cakes under some circumstances. The phenomena involved, and the options available to minimize adverse behavior, needed to be identified and assessed.

\subsection{HGF Filter Cake Issues for PFBC Applications}

Westinghouse hot gas filter (HGF) field testing has recently been completed at three major PFBC test installations (Lippert and Newby, 1995): the American Electric Power (AEP) Tidd Plant, a bubbling-PFBC; the Foster Wheeler Development Corporation (FWDC), Phase 2, circulating-PFBC development facility; and the Ahlstrom-Pyropower, circulating-PFBC pilot plant. The characteristics of the HGF facilities at these PFBC installations are summarized in Table 2.1. These HGF facilities have provided critical data supporting the design of new HGF systems associated with several PFBC development facilities and demonstration programs:

- Foster Wheeler Development Corporation (FWDC), Phase 3, AdvancedPFBC subscale test facility (Livingston, $\mathrm{NJ}$ ),

- Southern Company Services, PCD test facility (Wilsonville, Alabama),

- Foster Wheeler, Wilsonville Advanced-PFBC pilot facility (Wilsonville, Alabama), 


\begin{tabular}{|c|c|c|c|c|c|}
\hline \multicolumn{6}{|c|}{ Table 2.1 - Westinghouse PFBC, HGF System Characteristics } \\
\hline & \multicolumn{3}{|c|}{$\begin{array}{l}\text { AEP Tidd Bubbling-PFBC } \\
\text { Brilliant, } \mathrm{OH}\end{array}$} & $\begin{array}{c}\text { FWDC Phase } \\
2 \\
\text { Circ-PFBC } \\
\text { Livingston, } \mathrm{NJ}\end{array}$ & $\begin{array}{c}\text { Ahlstrom } \\
\text { Pilot } \\
\text { Circ-PFBC } \\
\text { Karhula, } \\
\text { Finland }\end{array}$ \\
\hline Facility Size $\left(\mathrm{MW}_{\mathrm{t}}\right)$ : & \multicolumn{3}{|c|}{30} & 1.2 & 10 \\
\hline Gas Flow (acfm): & \multicolumn{3}{|c|}{7600} & 300 & 3070 \\
\hline Pressure (psig): & \multicolumn{3}{|c|}{135} & $100-200$ & 160 \\
\hline Fuels/Sorbents: & \multicolumn{3}{|c|}{$\begin{array}{l}\text { Pgh \#8/Plum } \\
\text { Run dolomite }\end{array}$} & $\begin{array}{c}3 \\
\text { Variations }\end{array}$ & $\begin{array}{c}7 \\
\text { Variations }\end{array}$ \\
\hline \multicolumn{6}{|l|}{ Hours of Operation } \\
\hline - Max. Continuous: & \multicolumn{3}{|c|}{600} & 72 & 280 \\
\hline - Cumulative: & \multicolumn{3}{|c|}{6000} & 800 & 2050 \\
\hline Preclean Cyclone: & Yes & Spoiled & No & No & No \\
\hline Number Candles: & 384 & $288-384$ & 288 & $14-22$ & 128 \\
\hline $\begin{array}{l}\text { Face Velocity } \\
\text { (ft/min): }\end{array}$ & 6.5 & $4.5-8.7$ & 8.9 & $2-8$ & $3-8$ \\
\hline Temperature $\left({ }^{\circ} \mathrm{F}\right):$ & $1150-1450$ & $1200-1400$ & $1400-1550$ & $1450-1700$ & $1300-1650$ \\
\hline
\end{tabular}


- Pyropower circulating-PFBC, DMEC-1 Clean Coal Technology Program,

- Air Products, Advanced-PFBC, FREMP, Clean Coal Technology Program.

Test observations made at the three PFBC, HGF facilities are summarized in Table 2.2. Issues with filter cake permeability, ash bridging, and ash bulk flow can arise in PFBC, depending on the nature of the fly ash and the HGF operating conditions. The Tidd HGF tests had discrete test periods using an efficient precleaning cyclone; a spoiled, precleaning cyclone; and, most recently, eliminating the precleaning cyclone. The Tidd tests established that ash bridging is coincident with very fine, reactive particle size distributions in the filter cake when operating at higher temperatures, and is essentially eliminated when the precleaning cyclone is removed. The circulating-PFBC facilities had only recycle cyclones and hard filter cakes and ash bridging were observed only during periods of extreme temperatures.

The occurrence of "hard" filter cakes and ash bridging, particularly at the Tidd HGF when using an efficient precleaning cyclone, led to conjecture as to the phenomena leading to this behavior. The ILEC test program has attempted to identify the key phenomena leading to this behavior. It is also important to note that significant $\mathrm{SO}_{2}$ removal, about 50\%, has been consistently measured across the Tidd HGF (Radian, 1995) and is consistent with the high conversion of calcium and magnesium to sulfate forms found in the filter cakes. The content of alkali in the filter outlet gas is an issue to turbine protection when the HGF operates at temperatures greater than about $1400^{\circ} \mathrm{F}$, based on alkali sampling conducted at the FWDC Advanced-PFBC facility (Robertson, et al., 1994).

\subsection{Westinghouse ILEC Concepts}

Two ILEC concepts have been proposed for evaluation in this program: 1) a ceramic barrier filter with injected sorbent particles for in-filter, gas-phase contaminant control; and 2) a fluidized bed filter with immersed ceramic filter elements, and fluidized bed sorbents for contaminant control. 


\begin{tabular}{|l|c|c|c|c|c|}
\hline \multicolumn{5}{|c|}{ Table 2.2 - Westinghouse PFBC, HGF Filter Cake Observations } \\
\hline & \multicolumn{3}{|c|}{$\begin{array}{c}\text { AEP Tidd } \\
\text { Brilliant, OH }\end{array}$} & $\begin{array}{c}\text { FWDC Phase 2 } \\
\text { Livingston, NJ }\end{array}$ & $\begin{array}{c}\text { Ahlstrom Pilot } \\
\text { Karhula, } \\
\text { Finland }\end{array}$ \\
\hline Cyclone: & Yes & Spoiled & No & No & No \\
\hline $\begin{array}{c}\text { Fly Ash Size: } \\
\text { (mean, } \mu \mathrm{m})\end{array}$ & $1-3$ & $5-7$ & $25-30$ & $5-25$ & $12-22$ \\
\hline $\begin{array}{c}\text { Dust Loading: } \\
(1000 \text { ppmw) }\end{array}$ & $0.5-1$ & $3-4$ & $15-20$ & $2-30$ & $4-18$ \\
\hline $\begin{array}{c}\text { Permeability: } \\
\left(10^{-10} \text { lb/ft) }\right.\end{array}$ & $0.2-0.6$ & $1-2$ & $5-6$ & $2-5$ & $2-6$ \\
\hline $\begin{array}{c}\text { Pulse Frequency: } \\
(1 \text { hr) }\end{array}$ & $1-2$ & $2-4$ & 4 & $0.5-3$ & $1-3$ \\
\hline $\begin{array}{c}\text { Occurrence of } \\
\text { Bridging and } \\
\text { Hard Cake: }\end{array}$ & $>1400^{\circ} \mathrm{F}$ & $\begin{array}{c}\text { Less } \\
\text { Severe }\end{array}$ & $\begin{array}{c}\text { Very } \\
\text { Little }\end{array}$ & $>1600^{\circ} \mathrm{F}$ & Tery Little \\
\hline $\begin{array}{c}\text { Vessel Drainage } \\
\text { Performance }\end{array}$ & Poor & $\begin{array}{c}\text { Little } \\
\text { Problem }\end{array}$ & Good & Periods of Poor & Good \\
\hline
\end{tabular}


The ceramic barrier filter ILEC concept is illustrated in Figure 2.1. A process gas from an advanced, power generation gas producer, such as a PFBC or a coal gasifier, is first treated with injected sorbent particles upstream of the HGF to obtain uniform gas-particle mixing. The process gas and suspended sorbent particles enter the HGF where contaminant-sorbent reactions occur both within the gas-particle suspension and within the fly ash-sorbent filter cake. The mean gas residence time within the HGF may be 5 to 10 seconds, much longer than the gas residence time within the hot gas piping. The ILEC unit operates identically to a HGF dedicated to particulate control, with periodic pulse cleaning to remove a portion of the filter cake from the HGF.

The sorbents may be any appropriate sorbent materials, selected for the specific contaminants to be removed, for the HGF temperature, and for their operability as a filter cake component. Additives might also be injected into the process gas solely for the purpose of improving the behavior of the filter cake, or the sorbent particles might be selected and sized for their ability to also act as filter cake aids. In a PFBC application, for example, injected sorbent materials might be a pulverized limestone applied for supplemental $\mathrm{SO}_{2}$ removal, and a pulverized clay material applied for alkali vapor removal. In a coal gasification application, the injected sorbents might be a pulverized, calcium-based sorbent for supplemental sulfur and/or $\mathrm{HCl}$ removal, a catalyst for ammonia or tar cracking, and a pulverized clay material for alkali vapor removal. This ILEC concept is a direct extrapolation of similar concepts proposed and developed for application in conventional, steam power plants, with the particle removal equipment being primarily conventional, low-temperature equipment (fabric filters, or electrostatic precipitators).

The second ILEC concept, the fluidized bed filter, is more novel in nature and is at a lower state of development. The concept is illustrated in Figure 2.2. A process gas from an advanced, coal-fueled power generation, gas generator flows into a fluidized bed of sorbent particles, or inert bed particles. Fine sorbent particles might also be injected into the process gas before it enters the fluid bed. Ceramic filter elements, most likely candle forms, are suspended into the fluidized bed. The process gas mixes with the fluid bed sorbent particles, and injected sorbent particles, 


\section{WESTINGHOUSE ILEC CONCEPT}

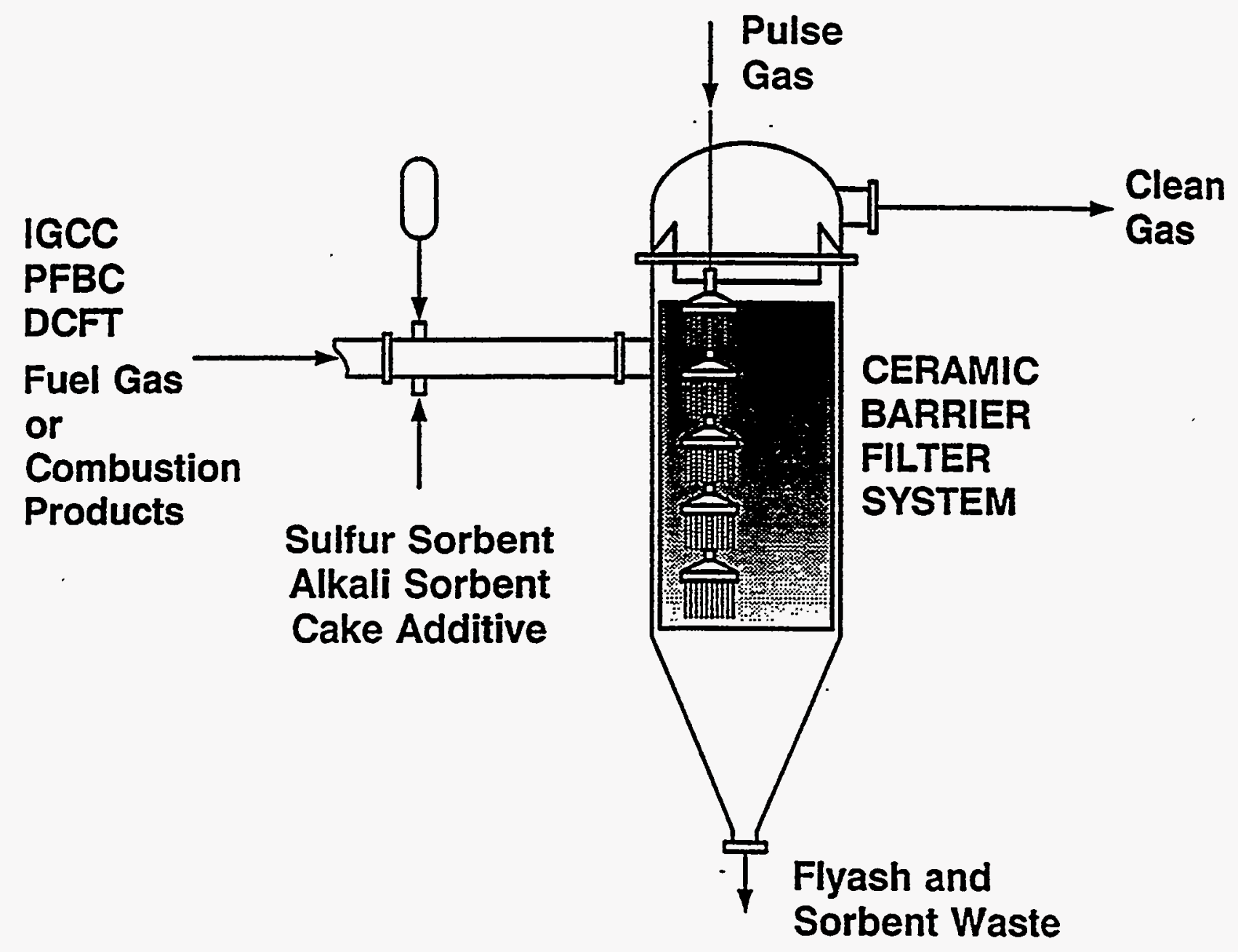

Figure 2.1 - Hot Gas Filter ILEC Concept 


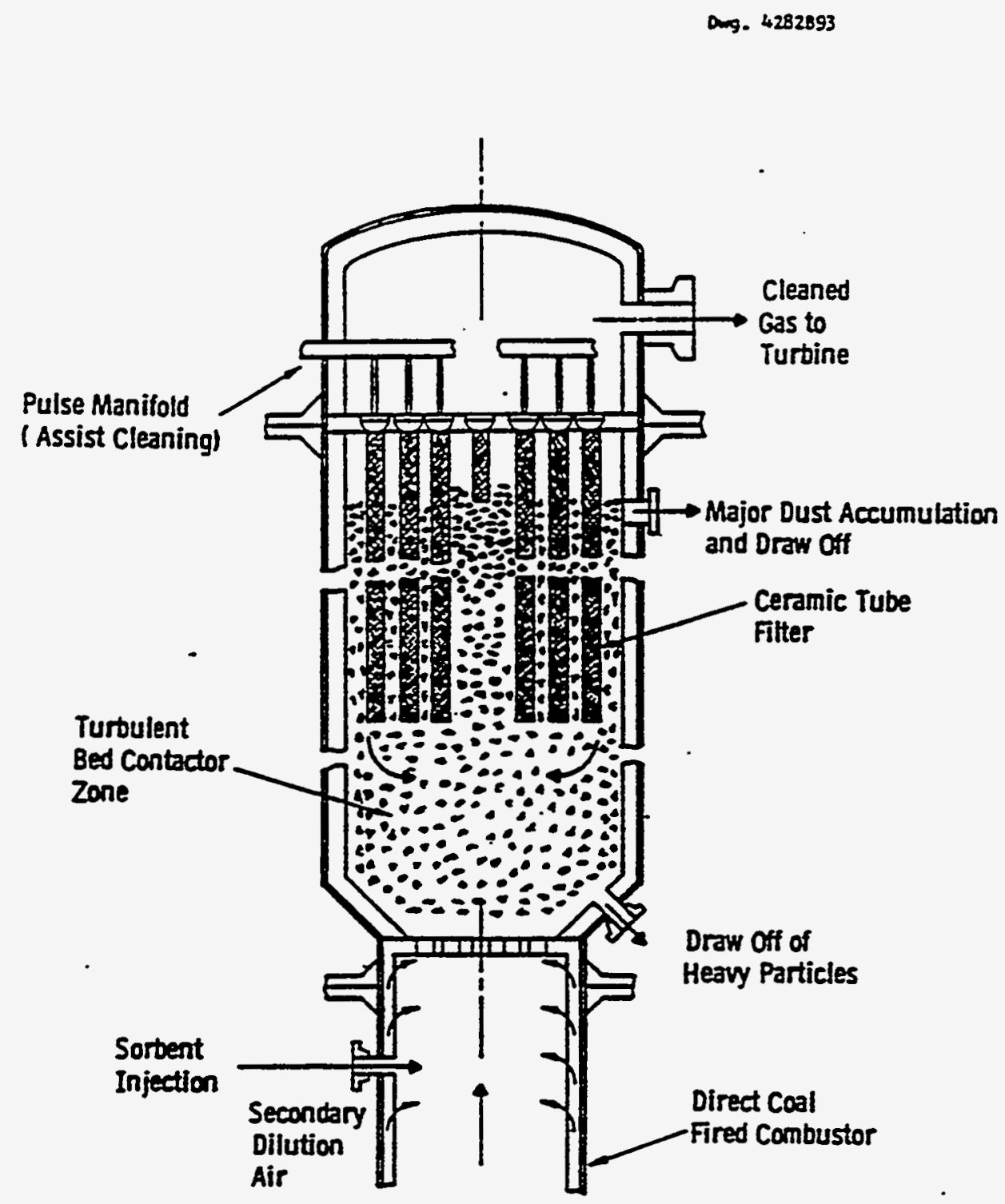

Figure 2.2 - Fluid Bed ILEC Concept 
reacting to remove contaminants. Adhesive ash particles in the process gas might also be directly removed by the fluid bed particles, as in fluid bed filter concepts, but the ceramic filter elements act to maintain all of the particulate materials in the vessel while removing fly ash particles from the process gas.

The vigorous mixing action of the fluid bed continuously removes portions of the filter cake from the filter elements, and the filter cake is continuously drawn off the vessel. Ideally, the ceramic filter elements do not need to be pulse cleaned, but a means for periodic pulse cleaning would be provided. A similar fluid bed filter concept, using immersed candle filter elements in the bed has been previously proposed for use in catalytic reactor systems (Degnen, et al., 1951). Cold model testing of the fluid bed ILEC was previously performed by Westinghouse and reported (Newby, et al., 1990). Supplemental testing of the fluid bed ILEC was conducted in Phase III of this program and is reported in Appendix D.

Based on the state-of-readiness of the technologies, and the technical uncertainties identified in the fluid bed ILEC testing, the primary concept of interest is the ceramic barrier filter concept. Cold model testing of the fluid bed ILEC was previously performed by Westinghouse and reported (Newby, et al., 1990). Supplemental testing of the fluid bed ILEC was conducted in Phase III of this program and is reported in Appendix D. 


\section{PROGRAM OBJECTIVES AND STRUCTURE}

The overall objectives of this program were to:

- assess the feasibility of the ILEC concept at a bench-scale level;

- produce process data for use in future design and field testing. The bench-scale ILEC test conditions have focused on PFBC applications, using sorbents injected into the HGF for sulfur and alkali removal. Several issues with the behavior of HGF filter cakes had been identified in PFBC, HGF field testing. These issues relate to filter cake permeability and pulse cleaning performance, and, in particular, to the observed formation of "hard" filter cakes and bridges under some circumstances. It was also the objective of the Phase III program to assess these issues, determining the key phenomena responsible for adverse filter cake behavior, and identifying possible means to improve filter cake behavior.

The ILEC development program consisted of three phases:

- Phase I - Laboratory-Scale Testing

- Phase II - Bench-Scale Equipment Design and Fabrication

- Phase III - Bench-Scale Testing

Phases I and II had been previously completed and their results reported (Newby, et al., 1990). Included in Phase I was an evaluation of alternative ILEC concepts, from which the ceramic barrier filter ILEC concept was selected for bench-scale testing. The Phase III test program focused on PFBC filter cake issues, as well as in-filter sulfur and alkali removal, and this testing, and the evaluation of the results, are the subject of this report. Some cold flow model testing of an alternative ILEC concept, a fluidized bed ILEC, was also continued in the Phase III activities.

Five test series were performed in Phase III:

1. Cake Permeability Tests

2. Additive Tests

3. Cake Pulse Cleaning Tests

4. Sulfur Removal Tests

5. Alkali Removal Tests 
The first series of tests were highly controlled tests measuring changes in filter cake permeability primarily as a function of temperature and PFBC fly ash source. The second series examined the ability of various filter cake additives and the additive application procedures to improve the filter cake permeability. The third series of tests were directed toward measuring the impact of temperature, PFBC fly ash source, and pulse intensity on pulse cleaning effectiveness. Test series four and five characterized the potential for sulfur removal and alkali removal within the HGF. The final two test series also measured the influence of the injected sorbents on the filter cake behavior.

Phase III included some supplemental laboratory testing to complement the bench-scale testing. This has included some Westinghouse in-house testing as well as the DOE-sponsored work:

- filter cake sintering tests (Appendix A);

- entrained sorbent, sulfur removal kinetics (Appendix B);

- entrained sorbent, alkali removal kinetics (Appendix C);

- continuation of fluidized bed ILEC cold flow modeling (Appendix D).

The entrained sulfur sorbent and alkali sorbent reaction kinetics measurements in the supplemental laboratory testing were made at temperatures of 1850 and $2100^{\circ} \mathrm{F}$, of interest in some DCFT concepts, but considerably higher than PFBC temperatures. The kinetic test results can, none-the-less, be applied to guide and interpret the bench-scale testing at PFBC conditions. 


\section{TESTING METHODOLOGY}

This section describes the test equipment, materials, test procedures, and test matrices applied in the program.

\subsection{Bench-Scale Facility Description}

An existing Westinghouse HGF test facility was modified for ILEC testing in the program. Figure 4.1 is a layout drawing of the bench-scale ILEC facility, the major components being the combustor, the filter pressure vessel and internals (tubesheet, candles, metal liner and insulation), and the gas outlet piping. The pressure vessel overall dimensions are 10-ft height and 40 -inch outer diameter. The tubesheet supported four, $1.5-\mathrm{m}$ long ceramic candles in the test program, although it is capable of supporting up to 19 candles. The gas outlet piping included a sampling section with two ports used for downstream gas sampling in the test program. Nozzles were also available in the vessel head that could be used as sampling locations.

The bench-scale HGF range of operating requirements in the test program were:

- Temperature ( $\left.{ }^{\circ} \mathrm{F}\right): 1300$ - 1650

- Pressure (psig): 50 - 150

- Gas volumetric flow (acfm): 80

- Gas mass flow (lb/hr): $750-850$

- Fly ash/additive/sorbent feed rate (lb/hr): 0.2 - 5

For the ILEC test program, several modifications were made to the existing HGF test facility during Phase II, followed by shakedown testing to confirm operability: 


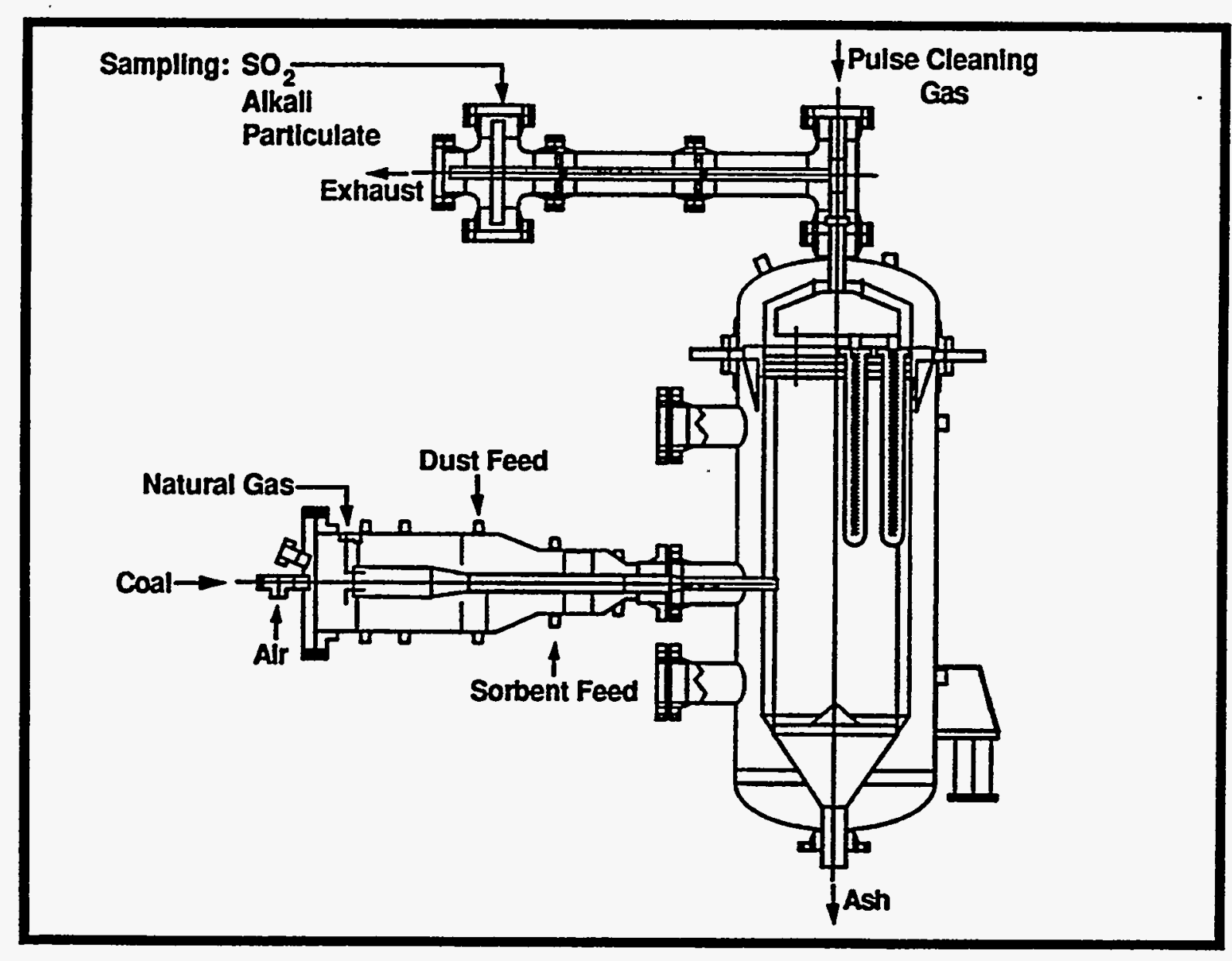

Figure 4.1 - Bench-Scale HGF, ILEC Facility 
- A new combustor was designed, fabricated, and installed that had the capability of firing entirely natural gas, or partial coal combustion (up to about $10 \%$ heat input). The new combustor section included nozzles for sampling, instrumentation, and injection of secondary gas streams (e.g., $\mathrm{SO}_{2}$-air mixture), and solids streams (e.g., sorbents, additives, and fly ashes).

- A new support structure to hold the combustor and its associated instruments and controls was assembled.

- An additional solids feed system, for coal, sorbents, and fly ashes, was procured and installed. The feed system consisted of a Ktron screw feeder device installed in a pressure vessel, with associated controls, instruments, and piping to pneumatically transport the solids to the combustor section.

- Additional, high-temperature insulation and new internal, high-alloy liners were inserted into the filter vessel and head to increase the filter temperature capabilities to about $1800^{\circ} \mathrm{F}$.

- The water-cooled exhaust gas piping wạs modified to accommodate higher temperature capabilities.

- Instrumentation for measuring the natural gas feed rate, and for determination of the filter outlet gas $\mathrm{CO}_{2}, \mathrm{SO}_{2}$ contents were installed. Figure 4.2 is a sketch of the filter outlet gas infrared $\mathrm{CO}_{2} / \mathrm{SO}_{2}$ measuring equipment. The $\mathrm{CO}_{2}$ and $\mathrm{SO}_{2}$ outlet gas measuring system was a standard laboratory design that included appropriate traps, flow meters, filters and valves.

A sampling system was installed to measure outlet gas alkali content. Figure 4.3 is a sketch of the outlet gas alkali vapor sampling system. The alkali measuring system is a Westinghouse design based on gas sample extraction, condensation of alkali vapor, and pressure reduction. The samples were withdrawn either from the outlet piping or from the HGF vessel head. Heat tracing was used to maintain gas sample temperature 


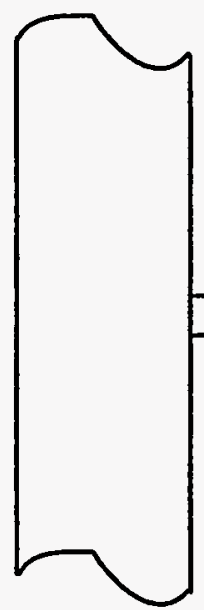

HGF

Outlet

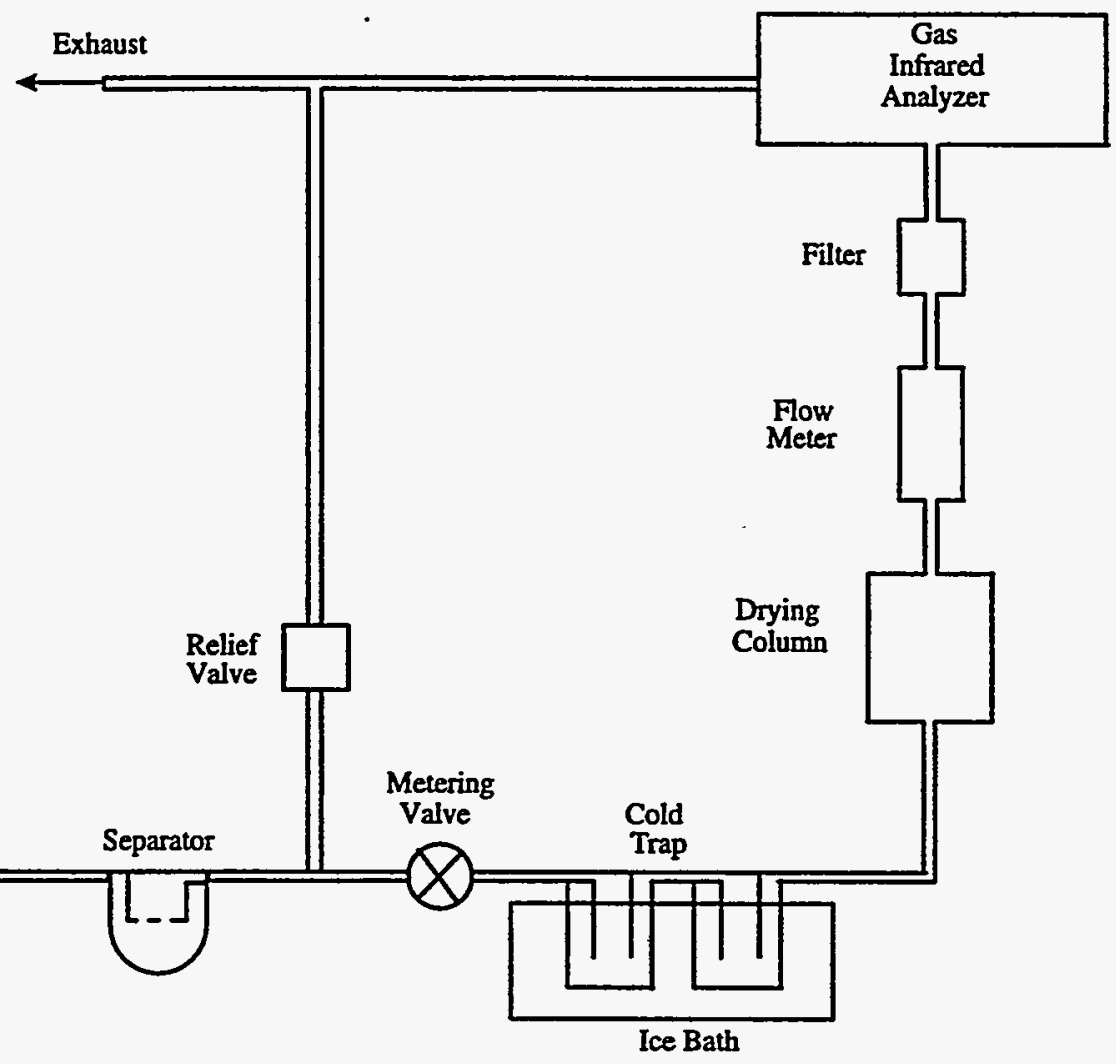

Figure 4.2 - Bench-Scale HGF, Outlet Gas Analysis System 


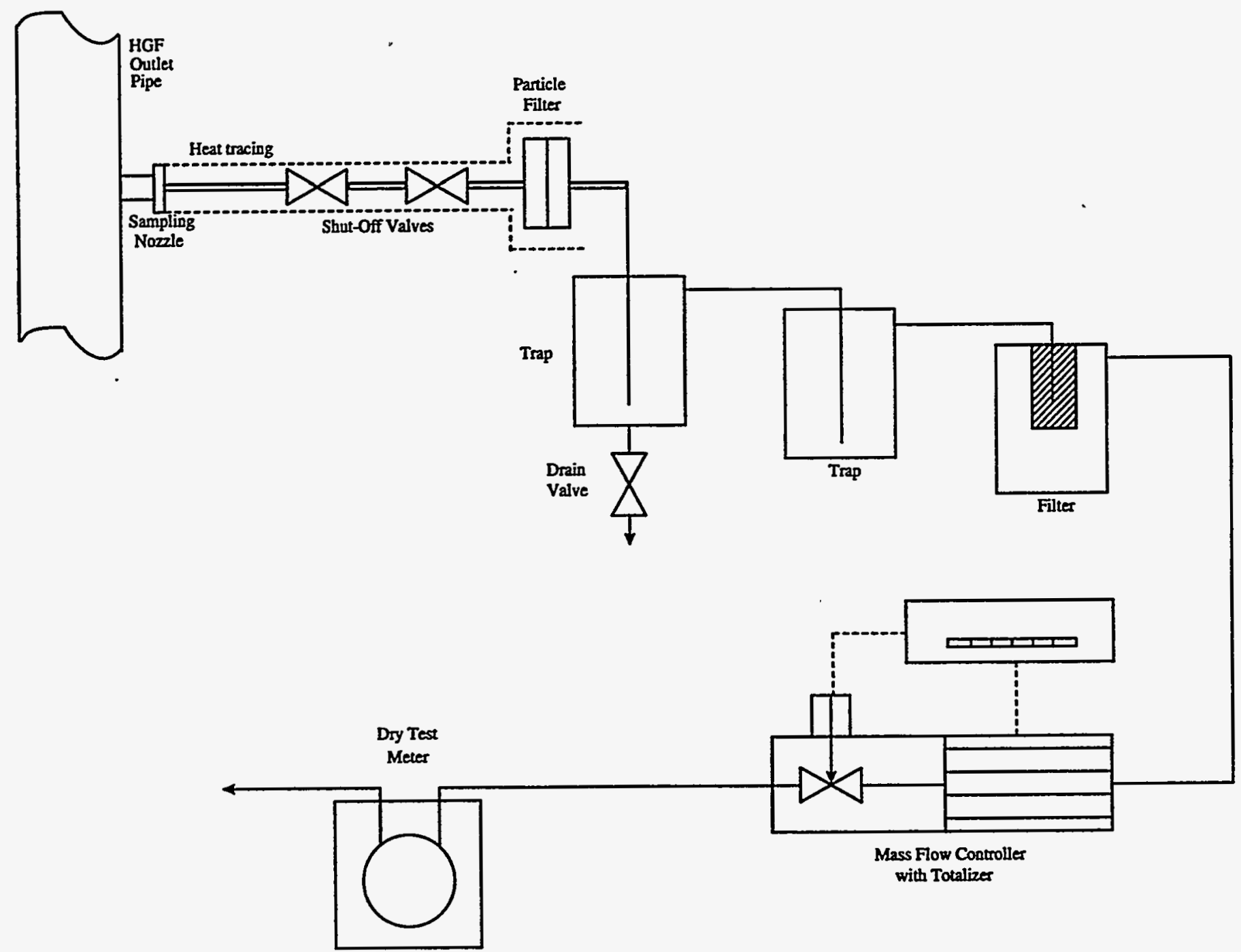

Figure 4.3 - Bench-Scale HGF, Outlet Gas Alkali Sampling System 
- to the location of the hot particle filter. Traps and gas flow meters followed in the sampling line. Following each sample period, the collected particulate was removed and the condensed alkali was washed from the alkali sampling system for chemical analysis to determine water-soluble alkali content.

- An activated alumina, packed bed, $\mathrm{SO}_{2}$ removal system was installed at the cold gas test facility exhaust to control sulfur oxide emissions during the testing.

- The pulse gas piping and pulse nozzles were relocated to a single, central nozzle that would pulse clean all four of the candles simultaneously. The pulse nozzle and eductor designs were established by calculational estimates of performance to ensure effective pulse cleaning would be achieved.

The tubesheet used in the program has a design that is representative of the commercial tubesheet and candles holder design offered by Westinghouse, and failsafe/regenerators were included in the configuration during most of the testing.

The gas enters the filter vessel radially through a 2 " ID nozzle at a velocity of nominally $70 \mathrm{ft} / \mathrm{s}$. Figure 4.4 shows the arrangement of the candles relative to the gas inlet. No baffles was placed at the nozzle exit to deflect the gas, this being specifically avoided so that particle impaction deposition, in the event some of the sorbent particles became adhesive, would not occur. The inlet nozzle is 8 " below the bottom of the candles, and the four candles were arranged so that the upward directed eddy that is produced would not impinge directly on the candles. A concern existed that local gas velocities over the candle elements might be excessive and cause vibration or impact damage to the candles. A cold flow model test of the inlet gas configuration to the filter vessel was conducted to confirm the operability of the gas inlet configuration relative to the positioning of the four ceramic candles in the vessel. 


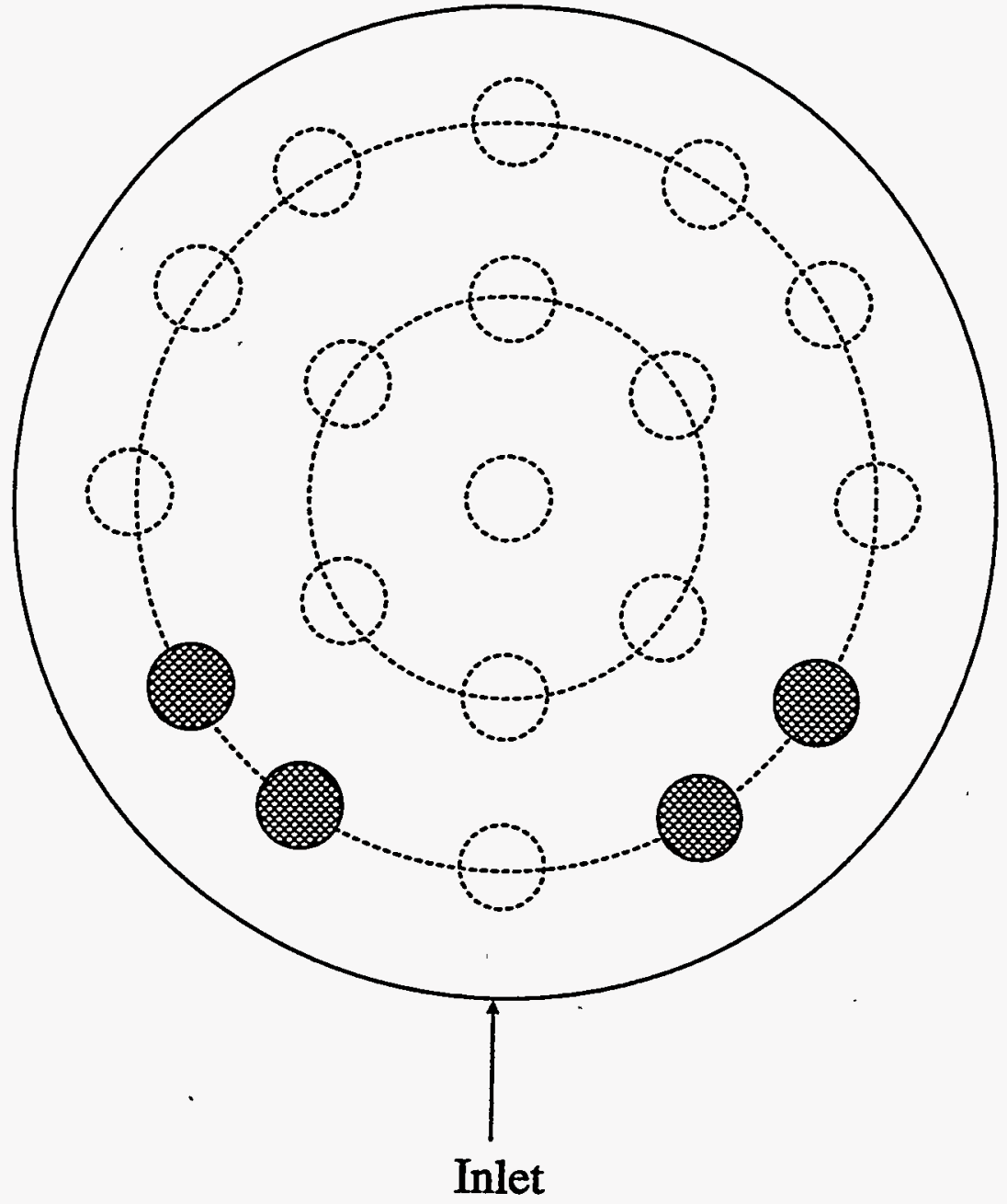

I 
An existing filter cold flow model facility was used to conduct some tests to verify visually that no concern would exist, at least for the relatively short duration testing in this program. The cold flow model was a Plexiglas vessel having dimensions almost identical to the bench-scale HGF unit. A radial gas inlet was inserted in the cold model facility at a level where inlet air was introduced eight inches below the candles. Candles were arranged in the vessel to have a configuration similar to the bench-scale HGF candle configuration. The air flow was set to have an inlet flow and velocity identical with the bench-scale HGF unit. Smoke generators where dropped into the conical base of the vessel and observations made of the gas flow profile from the nozzle and throughout the vessel. The jet issued from the nozzle reached across the vessel and was deflected tangentially outward causing two recirculating gas loops that traveled up the vessel, and $a$ stream moving down the center of the vessel must also have existed, although it could not be seen through the dense smoke. Gas velocities were relative low after the jet was deflected, and no vibration or motion of the candles was detected. It is possible that erosion might occur on the metal liner directly across from the nozzle; or a deposit might form on the liner at that point. Neither of these would be of significant concern over that duration of the IIEC test program.

A second phase of cold model testing was conducted to compare the observed gas flow profiles when using a simple inlet flow device that would direct the inlet gas slightly downward to dissipate the jet further from the candles. This inlet configuration was selected for its simplification of design and ease of support at the high temperature conditions. The gas flow pattern was not improved by having a baffle on the inlet to deflect the gas downward. The mixing within the vessel was just as intense as without the baffle and the gas flow pattern was very similar except that there was more mixing within the conical region at the base of the vessel. It was concluded that the design having no inlet gas baffle was acceptable for the test program. 


\subsection{Materials}

The sources and the characteristics of the PFBC fly ashes tested in the program are listed in Table 4.1. All of the fly ash samples were particulate materials drained from HGF units, except for the Tidd cyclone drain material. The Tidd cyclone drain material was a 50\% mixture of the precleaning cyclone drain and Tidd fine fly ash material, and was prepared as an attempt to simulate the filter cake material that might have resulted if the precleaning cyclone were eliminated. The characteristics listed are approximate, representative values based on incomplete information from various sources. Particle size and chemical characterization was not performed on the specific samples tested in this program in the bench-scale HGF. In many cases, the PFBC facilities that provided samples were undergoing parametric test programs and the fluid bed combustor operating conditions were not well defined, and may have varied significantly, during the generation of HGF ash drain samples.

Four, distinct fly ash samples from the Tidd bubbling-PFBC, HGF facility were tested, representing a broad range of fly ash particle sizes resulting from modifications made to the precleaning cyclone during the Tidd, HGF test operations. The Tidd "fine" fly ash had very small mean particle size and a relatively small calcium content, and the calcium, and magnesium were sulfated extensively while residing in the HGF. Two fly ash samples from the Karhula circulating-PFBC pilot unit HGF were tested. Their specific source conditions are uncertain, and complete data on their size distributions and compositions are not available. It is known, though, that both Karhula samples were relatively coarse in size, with the Karhula I material being considerably coarser than the Karhula II fly ash. The Karhula samples are also known to contain less calcium, and with lower degree of calcium sulfation, than the Tidd bubbling-PFBC samples, possibly because the coals tested at Karhula may have been low-sulfur, Western subbituminous coals.

The Grimethorpe bubbling-PFBC sample, Grimethorpe "Red", had size similar to the Tidd fine fly ash, but had lower levels of sulfation. The Grimethorpe Red fly ash was reported to have formed a difficult filter cake in the Grimethorpe 


\begin{tabular}{|c|c|c|c|c|}
\hline \multicolumn{5}{|c|}{ Table 4.1 - PFBC Fly Ash Characteristics } \\
\hline PFBC Source & Reference Run & $\begin{array}{c}\text { Mean } \\
\text { Diameter } \\
(\mu \mathrm{m})\end{array}$ & $\begin{array}{c}\text { Bulk } \\
\text { Density } \\
\text { (gm/cc) }\end{array}$ & $\begin{array}{c}\text { Ca Content (wt\%l } \\
\text { Ca-Sulfation (\%) }\end{array}$ \\
\hline \multicolumn{5}{|l|}{ Tidd bubbling } \\
\hline Fine: & Run 11 (1993) & $1-3$ & 0.35 & $8 / 55-82^{* *}$ \\
\hline Spoiled cyclone: & Run 19-24 (1994) & $5-7$ & NA & $9 / \mathrm{NA}$ \\
\hline Cyclone drain ${ }^{*}:$ & Run 19-24 (1994) & $10-20$ & NA & $10 / 50$ \\
\hline No cyclone: & Run 25-33 (1995) & $25-30$ & NA & $\mathrm{NA}$ \\
\hline \multicolumn{5}{|l|}{ Karhula circulating } \\
\hline$I$ & Period 1 (1993) & $20-40$ & 0.45 & $5-7 / 35-70$ \\
\hline II & Period 3 (1994) & $\begin{array}{l}\text { Finer than } \\
\text { Karhula I }\end{array}$ & NA & $10 / 90$ \\
\hline $\begin{array}{l}\text { Grimethorpe "Red" } \\
\text { bubbling }\end{array}$ & Run 129 & $1-3$ & 0.38 & $5-12 / 40-80$ \\
\hline FWDC circulating & $\begin{array}{l}\text { Phase 2, TRC-5 } \\
\text { SP\#6 (11/93) }\end{array}$ & $\begin{array}{l}20-40 \% \\
>44 \mu \mathrm{m}\end{array}$ & 0.45 & $20-40 / 20-30$ \\
\hline $\begin{array}{l}\text { *: } 50 \% \text { mixture of } \\
* *: 18-25 \% \text { of the } \\
\text { NA: Not available }\end{array}$ & drain and HGF & $\begin{array}{l}\text { fine ash } d r \\
\mathrm{aMg}_{3}\left(\mathrm{SO}_{4}\right)\end{array}$ & & \\
\hline
\end{tabular}


HGF testing. The FWDC circulating-PFBC sample had a large content of very coarse particles (>325 mesh) and was not sulfated as extensively as the Tidd bubbling-PFBC, HGF samples. The FWDC fly ash sample is significant because it was generated from the FREMP, Clean Coal Technology, feedstocks.

The additive and sorbent characteristics used in the program are listed in Table 4.2. The particle sizes and compositions listed are those provided by the suppliers. Premixed $\mathrm{SO}_{2}$ gas (1.5 vol\% in air) was purchased for the $\mathrm{SO}_{2}$ segment of the testing. Standard sodium chloride, micro-pulverized, was used as the alkali vapor source for the alkali removal testing.

Several ceramic candle types were used throughout the testing (Schumacher Dia Schumalith F40; Pall/Refractron Vitropore 442T; Coors alumina/mullite). The testing performed showed no sensitivity to the type of candles used, and the candle type was excluded as a parameter in the test program.

\subsection{Test Matrices and Procedures}

\subsubsection{Filter Cake Permeability Tests}

The permeability tests (Test Series 1) were conducted to determine the influence of temperature, fly ash type, and other key parameters (pressure and face velocity) on the filter cake permeability. A major objective of the testing was to identify the sources of adverse filter cake behavior observed in some PFBC, HGF field testing. The fixed test conditions applied were:

- Face velocity $7 \mathrm{ft} / \mathrm{min}$ (with one variation to $12 \mathrm{ft} / \mathrm{min}$ )

- Pressure 100 psig (with single variations to 150 and 50 psig)

- 4, 1.5-m long candles (with fail-safe/regenerators installed) 


\begin{tabular}{|l|l|l|l|}
\hline \multicolumn{4}{|c|}{ Table 4.2 - Sorbent and Additive Characteristics } \\
\hline Sorbent/Additive & \multicolumn{1}{|c|}{ Supplier } & \multicolumn{1}{|c|}{ Composition } & Particle Size \\
\hline Dolomite & $\begin{array}{l}\text { Espoma garden } \\
\text { lime }\end{array}$ & $\begin{array}{l}21 \mathrm{wt} \% \mathrm{Ca} \\
12 \mathrm{wt} \% \mathrm{Mg}\end{array}$ & $\begin{array}{l}99.9 \%-200 \\
\text { mesh }\end{array}$ \\
\hline Neutralite & $\begin{array}{l}\text { BHA commercial } \\
\text { bag house aid }\end{array}$ & $\begin{array}{l}\text { aluminum silicate } \\
\text { (proprietary) }\end{array}$ & Very fine \\
\hline Kaolin & Thiele Kaolin Co. & $\begin{array}{l}\text { hydrous aluminum } \\
\text { silicate }\end{array}$ & $\begin{array}{l}100 \%-325 \\
\text { mesh } \\
56 \%<2 ~ \mu m\end{array}$ \\
\hline Emathlite & $\begin{array}{l}\text { MFM Industries, } \\
\text { Inc }\end{array}$ & $\begin{array}{l}\text { Ca-Mg-Al-Si } \\
\text { fuller's earth }\end{array}$ & -325 mesh \\
\hline
\end{tabular}


The major test parameters were:

- Fly ash type: Tidd samples (4 types), Karhula I, Grimethorpe Red, and FWDC TRC-5

- Temperature: $1300^{\circ} \mathrm{F}$ to $1650^{\circ} \mathrm{F}$

The test measurements compiled during each test were:

- Gas mass flow rate,

- Gas pressure and temperature,

- Filter tubesheet pressure drop,

- Mass of fly ash fed,

- Gas $\mathrm{CO}_{2}$ content.

Calculations were performed, based on the test data to determine:

- The mass permeability of the filter cake,

- The "clean system" pressure drop and "residue" pressure drop.

The procedures applied in the filter cake permeability testing were:

1. Raise gas inlet temperature to $1300^{\circ} \mathrm{F}$ following normal heatup procedure.

2. Build filter cake on new candles until cake pressure drop (tubesheet minus baseline) of prescribed value ( 20 to $50^{\mathrm{H}} \mathrm{H}_{2} \mathrm{O}$ ) is reached - fly ash flow is discontinued at this point.

3. Raise filter cake temperature in increments ( 100 to $\left.200^{\circ} \mathrm{F}\right)$, holding at each temperature level long enough (1/2 to 1 hour) to determine if a stable cake permeability has been reached.

4. Continue until temperature reaches the maximum facility capability (about $1700^{\circ} \mathrm{F}$ )

5. Cool the vessel slowly to $1300^{\circ} \mathrm{F}$, in similar temperature increments, continuing to record the tubesheet pressure drop for comparison with the heatup record.

6. Pulse clean the candles with several vigorous pulses. 
Periodically, the bench-scale HGF was shut down without pulse cleaning, the candles were observed for the appearance of the filter cake (cake thickness, uniformity and morphology and well as cake weight).

The test numbers, test date, and test parameters for the 16 filter cake permeability tests completed are listed in Tables 4.3. Where no value appears in the tables, the last value reported above in the column applies. The 16 tests required 22 . full test days to complete, with about 218 hours of hot filter exposure time accumulated in the tests.

\subsubsection{Additive Tests}

The objective of this testing (Test Series 2) was to determine the influence of additives on the filter cake permeability. The fixed conditions of the tests were the same as those used in the filter cake permeability testing (face Velocity $7 \mathrm{ft} / \mathrm{min}$; Pressure 100 psig).

The procedure applied in the additive tests was identical to that outlined for the filter cake permeability tests. The additives were premixed with the PFBC fly ash in all tests, except for one that applied an additive as a precoat to the filter elements. The test matrix is shown in Table 4.4. The five additive tests occupied 11 full test days, and accumulated about 105 hours of hot filter exposure time.

\subsubsection{Pulse Cleaning Tests}

The objective of the pulse cleaning tests (Test Series 3) was to measure the performance of pulse cleaning over a range of key PFBC parameters to understand their relative importance and their relations. Again, the fixed conditions were identical to those of the filter cake permeability testing and the additive testing. In this series, the fail-safe regenerators were not installed so that the transient pressure measured in the filter plenum would represent a good approximation of the pressure in the candles, or the pulse intensity. 


\begin{tabular}{|c|c|c|c|c|c|}
\hline \multicolumn{6}{|c|}{ Table 4.3 - Filter Cake Permeability Test Matrix (Series 1) } \\
\hline Test & Date & Fly Ash & Candles & $\begin{array}{l}\text { Pressure } \\
\text { (psig) }\end{array}$ & $\begin{array}{l}\text { Face Velocity } \\
\text { (ft/min) }\end{array}$ \\
\hline 1.01 & $11 / 08 / 93$ & Tidd Fine ${ }^{\mathrm{a}}$ & 4 Schumacher & 100 & 7 \\
\hline 1.02 & $11 / 09 / 93$ & & & & \\
\hline 1.03 & $11 / 10 / 93$ & & & & \\
\hline 1.04 & $11 / 11 / 93$ & & & & \\
\hline 1.05 & $11 / 12 / 93$ & & & & 12 \\
\hline 1.06 & $11 / 15 / 93$ & Grimethorpe $\mathrm{b}^{b}$ & & & 7 \\
\hline 1.07 & $11 / 16 / 93$ & Karhula Ic & & & \\
\hline 1.08 & $11 / 17 / 93$ & None & & & 7,12 \\
\hline 1.09 & $11 / 23 / 93$ & Tidd Fine & & 150 & 7 \\
\hline 1.10 & $\begin{array}{l}2 / 21 / 94 \\
-2 / 22 / 94 \\
\end{array}$ & $\begin{array}{l}\text { Tidd Cycloned } \\
\text { Drain }\end{array}$ & $\begin{array}{l}\text { 2 Schumacher } \\
\text { and } 2 \text { Coors }\end{array}$ & 100 & \\
\hline 1.11 & $3 / 1 / 94$ & Karhula I & 4 Coors & 150 & \\
\hline 1.12 & $3 / 3-4 / 94$ & Karhula I & & 50 & \\
\hline 1.13 & $3 / 9 / 94$ & Tidd Fine & & 50 & \\
\hline 1.14 & $7 / 6-7 / 94$ & FWDC TRC5 ${ }^{\mathrm{e}}$ & 4 Schumacher & 100 & \\
\hline 1.15 & $7 / 11-12 / 94$ & $\begin{array}{l}\text { Tidd Spoiled } \\
\text { Cyclonef }\end{array}$ & & & \\
\hline 1.16 & $4 / 24-25 / 95$ & $\begin{array}{l}\text { Tidd No } \\
\text { Cyclone }\end{array}$ & & & \\
\hline \multicolumn{6}{|c|}{$\begin{array}{l}\text { a: AEP, Tidd bubbling-PFBC fly ash collected from filter during initial test period through } \\
\text { Run 11. } \\
\text { b: Grimethorpe Red fly ash collected from Grimethorpe bubbling-PFBC filter during } \\
\text { Run } 129 . \\
\text { c: Ahlstrom, Karhula, Finland circulating-PFBC pilot filter fly ash } \\
\text { d: AEP, Tidd bubbling-PFBC fly ash from primary cyclone, mixed with } 50 \% \text { Tidd } \\
\text { fine fly ash. } \\
\text { e: Foster Wheeler Development Corp. CPFB fly ash from test run TRC5 using FREMP } \\
\text { feed stock. } \\
\text { f: AEP, Tidd bubbling-PFBC fly ash collected from filter during test period Run } 12-13 \text { when } \\
\text { the primary cyclone was partially spoiled. } \\
\text { g: Emathlite alkali sorbent sized to - } 325 \text { mesh. }\end{array}$} \\
\hline
\end{tabular}




\begin{tabular}{|c|c|c|l|l|}
\hline \multicolumn{5}{|c|}{ Table 4.4 - Filter Cake Additives Test Matrix (Series 2) } \\
\hline \multicolumn{5}{|c|}{ FIXED CONDITIONS: Face Velocity $7 \mathrm{ft} / \mathrm{min}$} \\
Pressure 100 psig \\
\hline Test & Date & Fly Ash & \multicolumn{1}{c|}{ Additive } & Candles \\
\hline 2.01 & $11 / 24 / 93$ & Tidd fine & 10 wt\% Dolomite & 4 Schumacher \\
\hline 2.02 & $\begin{array}{l}1 / 24 / 94- \\
2 / 02 / 94\end{array}$ & None & $\begin{array}{l}\text { Neutralite } \\
\text { Precoat }\end{array}$ & \\
\hline 2.03 & $2 / 03 / 94$ & Grimethorpe & On to Precoat & \\
\hline 2.04 & $\begin{array}{l}2 / 04 / 94- \\
2 / 07 / 94\end{array}$ & Grimethorpe & 5 wt\% Neutralite & \\
\hline 2.05 & $2 / 16 / 94$ & Grimethorpe & 10 wt\% Kaolin & $\begin{array}{l}\text { 2 Schumacher and } \\
\text { 2 Coors }\end{array}$ \\
\hline
\end{tabular}


The test matrix is outlined in Table 4.5. The test parameters were:

- Fly ash type: Tidd fine, Karhula I

- Temperature: $1300^{\circ} \mathrm{F}, 1450^{\circ} \mathrm{F}, 1550^{\circ} \mathrm{F}$

- Pulse tank pressure: range from about 9 to 70 atmospheres

The measurements made during each test were:

- Filter inlet gas mass flow.

- Filter inlet gas pressure and temperature

- Filter tubesheet pressure drop

- Mass of fly ash fed at each pulse sequence

- Pulse gas tank pressure before and during pulse event

- Plenum pressure before and during pulse event

The calculations performed based on the measured data were:

- the mass of pulse gas delivered from the pulse tank,

- the mass of pulse gas received by the candles,

- the filter residue and cake pressure drops.

Prior to testing, four new candles were installed in the bench-scale HGF, and clean gas measurements of the filter pressure drop as a function of gas flow, at several temperature, and pressure levels were made to characterize the clean candle and plenum pressure drop behavior. Typical procedures followed for the pulse cleaning tests were:

1. - Heat system to $1300^{\circ} \mathrm{F}$ at pressure of $100 \mathrm{psig}$ and face velocity of $7 \mathrm{ft} / \mathrm{min}$,

- Feed predetermined mass of fly ash and hold 15 minutes,

- Pulse at maximum tank pressure and normal valve open time; hold for 15 minutes.

2. - Feed same mass of fly ash, hold 15 minutes,

- Pulse at $3 / 4 \times$ (max tank-system pressure), hold 15 minutes,

- Pulse at maximum tank pressure. 


\begin{tabular}{|l|l|l|c|c|}
\hline \multicolumn{5}{|c|}{ Table 4.5 - Filter Cake Pulse Cleaning Test Matrix (Series 3) } \\
\hline \multicolumn{5}{|c|}{$\begin{array}{c}\text { FIXED CONDITIONS: Face velocity 7 ft/min } \\
\text { Pressure 100 psig }\end{array}$} \\
\hline Test & Date & Fly Ash & $\begin{array}{c}\text { Temperature } \\
\left({ }^{\circ} \mathrm{F}\right)\end{array}$ & $\begin{array}{c}\text { Maximum Tank } \\
\text { Pulse Pressure } \\
\text { (psig) }\end{array}$ \\
\hline 3.11 & $5 / 23 / 94-5 / 25 / 95$ & Tidd fine & 1300 & 26 \\
\hline 3.12 & $5 / 27 / 94-6 / 02 / 94$ & & 1450 & \\
\hline 3.13 & $6 / 08 / 94$ & & 1550 & \\
\hline 3.21 & $6 / 14 / 94-6 / 17 / 94$ & Karhula I & 1300 & \\
\hline 3.22 & $6 / 21 / 94-6 / 23 / 94$ & & 1450 & \\
\hline 3.33 & $6 / 24 / 94-6 / 29 / 94$ & & 1550 & \\
\hline 3.31 & $11 / 2 / 94$ & Tidd fine & 1300 & \\
\hline 3.32 & $11 / 2 / 94$ & & 1450 & \\
\hline 3.33 & $11 / 3 / 94$ & & 1550 & \\
\hline 3.41 & $11 / 7 / 94$ & Karhula I & 1300 & \\
\hline 3.42 & $11 / 8 / 94$ & & 1450 & \\
\hline 3.43 & $11 / 9 / 94$ & & 1550 & \\
\hline
\end{tabular}


3. - Feed same mass of fly ash, hold 15 minutes,

ᄃ - Pulse at 1/2 x (max tank-system pressure), hold 15 minutes,

- Pulse at maximum tank pressure.

4. - Feed same mass of fly ash, hold 15 minutes,

- Pulse at 1/3 $\mathrm{x}$ (max tank-system pressure), hold 15 minutes,

- Pulse at maximum tank pressure.

5. - Feed same mass of fly ash, hold 15 minutes,

- Pulse at $1 / 4 \times$ (max tank-system pressure), hold 15 minutes,

- Pulse at maximum tank pressure.

6. - Increase temperature to $1450^{\circ} \mathrm{F}$ at $100 \mathrm{psig}$ and $7 \mathrm{ft} / \mathrm{min}$;

- Repeat the above sequence of pulse cleanings.

7. - Increase temperature to $1550^{\circ} \mathrm{F}$ at $100 \mathrm{psig}$ at $7 \mathrm{ft} / \mathrm{min}$;

- Repeat the above sequence of pulse cleanings.

The 12 pulse cleaning tests occupied about 21 full test days, with 212 total hours of hot filter exposure compiled. A total of 47 test pulses were completed in the tests.

\subsubsection{Sulfur Removal Tests}

The objectives of the sulfur removal testing (Test Series 4) were 1) to determine the influence of $\mathrm{SO}_{2}$ on the filter cake permeability, and 2) to measure the $\mathrm{SO}_{2}$ removal performance of PFBC fly ashes and calcium-based sorbents as entrained, dispersed particulate and as predeposited filter cakes. The fixed test conditions were: 
- Face velocity $7 \mathrm{ft} / \mathrm{min}$,

- Pressure 100 psig,

- Inlet gas $\mathrm{SO}_{2}$ content about $200 \mathrm{ppmv}$.

The inlet gas $\mathrm{SO}_{2}$ content was selected to be representative of the inlet $\mathrm{SO}_{2}$ level in the Tidd HGF program, typically about $200 \mathrm{ppmv}$.

The test matrix is listed in Table 4.6. The test parameters were:

- Fly ash type: Tidd spoiled cyclone; Karhula II

- Sorbent type: -325 mesh dolomite alone or mixed with PFBC fly ash

- Temperature: $1550^{\circ} \mathrm{F}$ (with one variation to $1450^{\circ} \mathrm{F}$ )

- Pressure: $100 \mathrm{psig}$ (with one variation to $150 \mathrm{psig}$ )

The principal procedure followed was a test of the influence of $\mathrm{SO}_{2}$ on the cake permeability and of the ability of the filter cake to removal sulfur. These tests are designated "cake tests":

1. Test Initiation: Raise gas inlet temperature to prescribed level (1450 $1550^{\circ} \mathrm{F}$ ) following normal heatup procedure.

2. Build a filter cake on the candles until cake pressure drop (tubesheet minus baseline) of prescribed value (20 to $30^{\mathrm{H}} \mathrm{H}_{2} \mathrm{O}$ ) is reached -- fly ash flow is discontinued at this point.

3. Inject premixed $\mathrm{SO}_{2}$-gas into the vessel inlet gas, at levels of about $200 \mathrm{ppmv}$, continuing long enough to exhaust 1 to 4 gas bottles of $\mathrm{SO}_{2}$-gas.

4. Pulse clean the candles with several vigorous pulses at the completion of the test.

The second procedure was a test of the particulate (PFBC fly ash and/or sorbent) to remove $\mathrm{SO}_{2}$ while being fed in the suspended state and while building a filter cake. This procedure is designated a "feed test", and it was applied only once in the testing, Test 4.4: 


\begin{tabular}{|c|c|c|c|c|c|}
\hline \multicolumn{6}{|c|}{ Table 4.6 - $\mathrm{SO}_{2}$ Removal Test Record (Series 4) } \\
\hline \multicolumn{6}{|c|}{$\begin{aligned} \text { FIXED CONDITIONS: } & \text { Face velocity } 7 \mathrm{ft} / \mathrm{min} \\
& \mathrm{SO}_{2} \text { feed level about } 200 \mathrm{ppmv}\end{aligned}$} \\
\hline Test & Date & Fly Ash & Sorbent & $\begin{array}{c}\text { Temperature } \\
\left({ }^{\circ} \mathrm{F}\right)\end{array}$ & $\begin{array}{c}\text { Pressure } \\
\text { (psig) }\end{array}$ \\
\hline $\begin{array}{l}4.0 \\
\text { (Calibrate) }\end{array}$ & $\begin{array}{l}1 / 17 \\
1 / 18 / 95\end{array}$ & None & None & 1550 & 100 \\
\hline $\begin{array}{l}.1 \\
\text { (Cake test) }\end{array}$ & $\begin{array}{l}1 / 19- \\
1 / 23 / 95\end{array}$ & $\begin{array}{l}\text { Tidd spoiled } \\
\text { cyclone }\end{array}$ & None & 1550 & 100 \\
\hline $\begin{array}{l}4.2 \\
\text { (Cake test) }\end{array}$ & $\begin{array}{l}1 / 24- \\
1 / 25 / 95\end{array}$ & Karhula II & None & 1550 & 100 \\
\hline $\begin{array}{l}4.3 \\
\text { (Cake test) }\end{array}$ & $1 / 26 / 95$ & None & Dolomite & 1550 & 100 \\
\hline $\begin{array}{l}4.4 \\
\text { (Feed test) }\end{array}$ & $1 / 27 / 95$ & None & Dolomite & 1550 & 100 \\
\hline $\begin{array}{l}4.5 \\
\text { (Cake test) }\end{array}$ & $1 / 30 / 95$ & $\begin{array}{l}\text { Tidd spoiled } \\
\text { cyclone }\end{array}$ & $\begin{array}{l}\text { Dolomite } \\
(50 \%)\end{array}$ & 1550 & 100 \\
\hline $\begin{array}{l}4.6 \\
\text { (Cake test) }\end{array}$ & $1 / 31 / 95$ & Karhula II & $\begin{array}{l}\text { Dolomite } \\
(50 \%)\end{array}$ & 1550 & 100 \\
\hline $\begin{array}{l}4.7 \\
\text { (Cake test) }\end{array}$ & $2 / 01 / 95$ & None & Dolomite & 1450 & 150 \\
\hline $\begin{array}{l}4.8 \\
\text { (Cake test) }\end{array}$ & $2 / 02 / 95$ & None & Dolomite & 1550 & 100 \\
\hline
\end{tabular}


1. Test Initiation: Raise gas inlet temperature to prescribed level (1450 $1550^{\circ} \mathrm{F}$ ) following normal heatup procedure.

2. Start building a filter cake on the candles, and injecting $\mathrm{SO}_{2}$-gas simultaneously. Pulse clean the filter unit at prescribed cake pressure drops (tubesheet minus baseline).

3. Continue injecting premixed $\mathrm{SO}_{2}$-gas into the vessel inlet gas, at levels of about 200 ppmv, long enough to exhaust 1 to 4 gas bottles.

4. Pulse clean the candles with several vigorous pulses at the completion of the test.

The nine sulfur removal tests occupied 14 full test days, with a total of 133 hours of hot filter exposure accumulated.

\subsubsection{Alkali Removal Tests}

The objectives of the alkali removal testing (Series 5) were 1) to measure the filter cake permeability to see if difficult filter cakes were generated at temperatures where the reacted emathlite may become relatively soft, and 2) to measure the alkali removal performance. All of the tests were performed at the following fixed conditions:

- Face velocity: $7 \mathrm{ft} / \mathrm{min}$,

- Pressure: 100 psig,

- Temperature: 1550 to $1600^{\circ} \mathrm{F}$.

The alkali removal tests were performed by injecting a PFBC fly ash or an alkali sorbent (emathlite powder) premixed with micro-pulverized sodium chloride, following procedures identical to those used in the sulfur removal, continuous feed testing:

1. Test Initiation: Raise gas inlet temperature to prescribed level (1550$1600^{\circ}$ F) following normal heatup procedure. 
2. Start building a filter cake of fly ash or emathlite on the candles, and injecting alkali salt simultaneously. No pulse cleaning of the filter unit is performed.

3. Sample the filter outlet gas continuously over the entire period of feeding alkali salt to the filter.

4. Pulse clean the candles with several vigorous pulses at the completion of the test.

The emathlite-to-alkali feed ratio was held at about 10 times stoichiometric based on the alkali kinetic testing performed in the program and reported in Appendix C. In one test, Test 5.9, $\mathrm{SO}_{2}$ was also injected into the filter inlet gas to observe its impact on the performance. Alkali was sampled at two alternate locations using an extractive, condensing probe. The first location was downstream of the filter exit pipe, where particle, and $\mathrm{SO}_{2}$ sampling was performed. The gas temperature was too low at this location, being 1200 to $1350^{\circ} \mathrm{F}$, and was expected to result in significant alkali vapor condensation within the piping prior to extraction. The second location was directly from within the vessel head, with minimal temperature loss occurring. The probe extracted gas during the entire alkali salt feeding period.

Test periods for calibration of the alkali probe and for determination of alkali background reading were also conducted. The test matrix is outlined in Table 4.7. The tests listed were performed, and probe samples (condensate water-soluble sodium content) were analyzed, representing the alkali vapor passing through the HGF unit. In many cases the alkali probe internal filter also accumulated a significant mass. Vessel drain solids were not analyzed for sodium content, as it is known from prior testing that alkali material balances over a system are very inaccurate. Estimates were made of the alkali vapor removal efficiency, as well as calculations of the filter cake permeability. The 10 tests completed required 11 full test days, with 103 total hours of hot filter exposure accumulated. 


\begin{tabular}{|c|c|c|c|c|c|}
\hline \multicolumn{6}{|c|}{ Table 4.7 - Alkali Removal Test Matrix (Series 5) } \\
\hline \multicolumn{6}{|c|}{$\begin{aligned} \text { FIXED CONDITIONS: } & \text { Face velocity: } 7 \mathrm{ft} / \mathrm{min} \\
& \text { Pressure: } 100 \mathrm{psig} \\
& \text { Temperature: } 1550-1600^{\circ} \mathrm{F}\end{aligned}$} \\
\hline Test & Date & Fly Ash & Sorbent & $\begin{array}{l}\text { NaCl Feed } \\
\text { (wt\%) }\end{array}$ & $\begin{array}{c}\text { Probe } \\
\text { Location }\end{array}$ \\
\hline$\overline{5.1}$ & $\begin{array}{c}7 / 14- \\
7 / 15 / 94\end{array}$ & None & Emathlite & 0 & None \\
\hline 5.2 & $3 / 7 / 95$ & None & None & 0 & Pipe \\
\hline 5.3 & $3 / 8 / 95$ & $\begin{array}{l}\text { Tidd spoiled } \\
\text { cyclone }\end{array}$ & None & 5 & Pipe \\
\hline 5.4 & $3 / 9 / 95$ & None & Emathlite & 5 & Pipe \\
\hline 5.5 & $3 / 14 / 95$ & $\begin{array}{l}\text { Tidd spoiled } \\
\text { cyclone }\end{array}$ & None & 5 & Head \\
\hline 5.6 & $3 / 15 / 95$ & None & Emathlite & 5 & Head \\
\hline$\overline{5.7}$ & $3 / 23 / 95$ & None & Emathlite & 5 & Head \\
\hline 5.8 & $4 / 17 / 95$ & None & Emathlite & 5 & Head \\
\hline 5.9 & $4 / 19 / 95$ & $\begin{array}{c}\text { None/SO } 2 \\
(200 \text { ppmv) }\end{array}$ & Emathlite & 5 & Head \\
\hline 5.10 & $4 / 28 / 95$ & None & Emathlite & 5 & Head \\
\hline
\end{tabular}




\section{RESULTS AND DISCUSSION}

A general discussion of filter cake phenomena in the HGF environment is provided in this section. This is followed by a description of all of the bench-sale test results.

\subsection{Filter Cake Chemical/Physical Transformations}

The HGF primary function is to remove suspended particles from a process gas stream to protect downstream equipment and/or to satisfy process particulate emissions requirements. Ideally, the suspended particles entering the HGF will not deposit heavily on internal surfaces by impaction or diffusional phenomena. Ideally, the suspended inlet gas particles will form a filter cake having only limited adhesive force with the filter elements such that tenacious deposits will not form. Ideally, the filter cake will have sufficient cohesion force, and agglomerate formation, so that the filter cake can be effectively detached from the filter elements during the back pulse flow, and remain in weakly agglomerated formations dropping to the vessel hopper, so that little re-entrainment occurs. Further, the detached filter cake, ideally, will be free-flowing as it hits internal surfaces, such as the vessel hopper surface, and will slide directly down the hopper surface and out through the solids drain nozzles. Nonideal behavior is often observed in field units, as described in Table 2.2.

The suspended inlet particles are widely dispersed within the process gas, and they accumulate on the ceramic filter element surfaces, where they reside for a relatively long period of time (10 minutes to several hours) compared to their residence time as suspended particles in the inlet gas (on-the-order of 1 second in process piping, and 3-10 seconds suspended within the HGF vessel). The particles, once accumulated as a filter cake, may be subject to physical and chemical changes resulting from 1) chemical reactions with constituents in the gas phase, 2) compaction from gas drag forces, 3) agglomeration with other particles induced by several mechanisms, and 4) sintering transformations. Pulse cleaning of the 
ceramic filter elements drops the filter cake material into the HGF hopper in the form of agglomerated masses that may be subject to additional forces (e.g., compaction) and chemical transformations (e.g., acid condensate reactions) as they are withdrawn from the vessel and travel through the ash handling system.

The properties of the suspended inlet particles and the particles making up the filter cake and ash withdrawal material may differ substantially. Thus, a sample of the suspended inlet particles, withdrawn from the inlet gas, may have bulk properties differing substantially from the bulk properties of a filter cake sample withdrawn from the surface of the filter elements. Also, if a filter cake sample, or filter vessel drain sample, is redispersed into the inlet gas of a HGF test system, the redispersed particles may not be representative of the original suspended inlet particles, and the filter cake that they form in the test HGF may have properties/behavior differing from the actual HGF filter cake. These potential particle transformations make filter cake characterization and identification of difficult filtering behavior in laboratory tests uncertain.

Table 5.1 lists general phenomena that influence cohesion and adhesion in powders, and many of these may come into play in the HGF filter cake. Generally, the cohesion or adhesion forces developed by these phenomena increase from top to bottom in this list for HGF applications. Table 5.2 lists mechanisms that might result in heavy deposits and bridging of particles, specifically in mixtures of particles containing high contents of calcium, at HTHP conditions, such as in PFBC. Some of the calcium sintering trends indicated in Table 5.2 can be explained by the characteristic sintering temperatures of the calcium constituents in the filter cake. For example, the Tammann bulk diffusion temperature of the major PFBC fly ash, calcium constituents are:

- $\mathrm{CaO}$

- $\mathrm{MgO}$

- $\mathrm{CaCO}_{3}$

- $\mathrm{CaSO}_{4}$

- $\mathrm{MgSO}_{4}$ $2139^{\circ} \mathrm{F}$ $2306^{\circ} \mathrm{F}$ $991^{\circ} \mathrm{F}$ $1091^{\circ} \mathrm{F}$ $890^{\circ} \mathrm{F}$ 
Table 5.1 - General Particle Cohesion/Adhesion Phenomena

- Van der Waals forces

- Electrostatic forces

- Mechanical interlock

- Condensed-vapor liquid bridges (e.g., $\mathrm{Na}$ and $\mathrm{K}$ salts)

- Eutectic liquid bridges (e.g., C-CaS-CaSO ${ }_{4}$ )

- Sintering solid bridges

- Chemical reaction-induced solid bridges 
Table 5.2 - Deposit and Bridging Mechanisms in HTHP Coal-Based, High-Calcium Filter Cakes

Possible Deposit Mechanisms:

- calcium-based sorbent material sintering

- alkali-condensate or eutectic adhesion

- coal ash melt adhesion (e.g., iron, silica)

Observed trends for increased calcium sintering:

- increased temperature

- reduced particle size

- increased $\mathrm{CO}_{2}$ and $\mathrm{H}_{2} \mathrm{O}$ in gas

- increased content of $\mathrm{Na}$ and $\mathrm{K}$ in cake

- increased content of $\mathrm{CaCO}_{3}$ and $\mathrm{CaSO}_{4}$ vs $\mathrm{CaO}$ and $\mathrm{MgO}$

- occurrence of sulfation and carbonation reactions 
At temperatures exceeding the Tammann temperature there is high molecular mobility coupled with a thermodynamic driving force to reduce the free energy of the filter cake by reducing surface area, leading to the particle sintering phenomena. Thus, carbonated, sulfated PFBC ashes would be expected to be more prone to sintering than calcined, lightly sulfated PFBC ashes.

The trends listed in Table 5.2 for sintering and agglomeration tendencies related to calcium constituent sintering have been substantiated to lead to heavy deposits in phenomena studies and industrial experience with applications other than hot gas filtration:

- Calcium-based sulfur sorbent surface area sintering studies (Borgwardt, 1989),

- Conventional boiler tube deposit studies with injected limestone for $\mathrm{SO}_{2}$ control (Skrifvars, et al., 1990),

- AFBC observations of boiler tube deposits (Johnk, et al., 1995)

- PFBC observations of plugs in lines and cyclones (Robertson, et al., 1994). The alternative possibilities listed in Table 5.2, alkali condensation and coal ash melts, have been rejected as major contributors to heavy deposits in these referenced studies, and are considered unlikely to be major factors in PFBC, HGF applications.

\subsection{Filter Cake Permeability Results}

Three types of figures are presented in Appendix E that display the test data and calculated quantities for the 16 tests conducted, Tests 1.01 through 1.16. The first figure type displays the time history of the test, showing the temperature, face velocity, mass of fly ash fed per unit of filter surface area, and the tubesheet pressure drop (total for filter element, residue, cake, fail-safe, and other losses). It is assumed that all of the fly ash fed deposits on the candle filter surfaces, although it is clear that only a portion actually reaches the filtering surface (about 70\%-80\% based on weights measured on the filter elements at the end of some of the testing). 
The second figure type shows the time history of the distribution of the tubesheet pressure drop between the cake, residue and the clean system (filter element plus fail-safe plus other losses):

$$
\Delta \mathrm{P}=\Delta \mathrm{P}_{\mathrm{f}} \text { (element) }+\Delta \mathrm{P}_{\mathrm{r}} \text { (residue) }+\Delta \mathrm{P}_{\mathrm{c}} \text { (cake) }+\Delta \mathrm{P}_{\mathrm{p}} \text { (others) }
$$

The clean system pressure drop is a calculated value based on a correlation of the clean system pressure drop as a function of the gas flow, gas density, and viscosity:

$$
\begin{aligned}
\mathrm{DP} \text { (clean system) } & =\Delta \mathrm{P}_{\mathrm{f}} \text { (element) }+\Delta \mathrm{P}_{\mathrm{p}} \text { (others) } \\
& =\mathrm{A} \mu \mathrm{U}+\mathrm{B} \rho \mathrm{U}^{2}
\end{aligned}
$$

The correlation values $A$ and $B$ were developed from initial flow testing of the clean system over a range of flows, temperatures and pressures, and this correlation testing was repeated each time the elements were changed. The "residue" pressure drop was estimated from the difference between the system pressure drop and the clean system pressure drop at the start, prior to feeding fly ash. The residue pressure drop results from fine particle contamination of the ceramic element pores, as well as any deposited fly ash not removable by normal pulse cleaning, and any other physical/chemical changes occurring to the ceramic element that modifies its permeability. The residue pressure drop represents the impact of "conditioning" on the filter element pressure drop. The cake pressure drop was then calculated as the difference between the measured tubesheet pressure drop and the sum of the clean system and residue pressure drops.

The third figure type displays the temperature history and the calculated mass permeability of the filter cake. The mass permeability, $\mathrm{k}_{\mathrm{m}}$, is defined by the following equation:

$$
\Delta \mathrm{P}_{\mathrm{c}}=\mu \mathrm{U} \mathrm{M} / \mathrm{k}_{\mathrm{m}}
$$

where $\Delta P_{c}$ is the cake pressure drop, $\mu$ is the gas viscosity, $U$ is the face velocity, and $M$ is the mass of filter cake per unit area.

In three cases, Tests 1.10, 1.11, and 1.13, plots are included for the $\mathrm{CO}_{2^{-}}$ pressure in the gas against the temperature. Test 1.10 was a $100 \mathrm{psig}$ test, Test 1.11 was a 150 psig test, and Test 1.13 was a 50 psig test, and these plots are characteristic of all of the tests performed at the same respective pressure. The 
plots appear to have a "historesis" shape, the higher $\mathrm{CO}_{2}$ values occurring as the temperature is increased, and the lower values as the temperature is subsequently decreased.

Sixteen cake permeability tests were performed, with the first 3 tests being replications and procedure optimization tests. The procedure appears to be a reproducible method of determining the filter cake permeability. The same general permeability behavior trend was observed in all of tests as a function of temperature. The filter cake permeability falls as the temperature is initially increased above $1300^{\circ} \mathrm{F}$, and it reaches a minimum value at the temperature where the calcium in the filter cake calcines from $\mathrm{CaCO}_{3}$ to $\mathrm{CaO}$. As the temperature is reduced from the maximum, the filter cake permeability increases slightly, but does not return to its original value because irreversible structural changes in the filter cake have occurred. One test, Test 1.08, was performed without feeding fly ash to observe the behavior of the residue material. The residue "total" permeability $\left(\mu \mathrm{U} / \Delta \mathrm{P}_{\mathrm{r}}\right.$ ) plot for Test 1.08 shows very low temperature sensitivity compared to the behavior of the filter cakes mass permeability.

The overall testing results are listed in Table 5.3. The table lists the major test parameters (the fly ash type, pressure and face velocity) and the test results (the initial cake permeability at $1300^{\circ} \mathrm{F}$, the minimum permeability achieved, and the temperature at which the minimum permeability occurred). Higher pressures resulted in lower minimum permeabilities, and higher face velocity also appears to reduce the cake permeability slightly. The tests performed at pressures of 50 and 150 psi show a shift in the temperature that results in minimum cake permeability, and this results from the ship in the temperature of $\mathrm{CaCO}_{3}$ calcination as the pressure is changed, again demonstrating the significant of the filter cake calcium constituent.

. The major aspects of this behavior appear to result primarily from calciumbased sorbent material sintering phenomena. It is known from prior evidence (e.g., studies of calcium sorbent surface area on injection into hot gas streams, and calcium-based deposits on boiler heat transfer surfaces) that sintering is a fast 


\begin{tabular}{|c|c|c|c|c|c|}
\hline \multicolumn{6}{|c|}{ Table 5.3 - Filter Cake Permeability Test Results } \\
\hline $\begin{array}{l}\text { Fly Ash } \\
\text { Source }\end{array}$ & $\begin{array}{c}\text { Pressure } \\
\text { (psig) }\end{array}$ & $\begin{array}{c}\text { Face } \\
\text { Velocity } \\
\text { (ft/min) }\end{array}$ & $\begin{array}{c}\text { Cake } \\
\text { Permeability } \\
\text { at } 1300^{\circ} \mathrm{F} \\
\left(10^{-10} \mathrm{lb} / \mathrm{ft}\right)\end{array}$ & $\begin{array}{l}\text { Minimum } \\
\text { Permeability } \\
\left(10^{-10} \mathrm{lb} / \mathrm{ft}\right)\end{array}$ & $\begin{array}{l}\text { Temperature } \\
\text { at Minimum } \\
\left({ }^{\circ} \mathrm{F}\right)\end{array}$ \\
\hline Tidd fine & 100 & 7 & 3.0 & 1.8 & 1550 \\
\hline Tidd fine & 150 & 7 & 3.3 & 1.6 & 1550 \\
\hline Tidd fine & 50 & 7 & 3.3 & 2.1 & 1500 \\
\hline Tidd fine & 100 & 12 & 2.4 & 1.6 & 1550 \\
\hline $\begin{array}{l}\text { Tidd cyclone } \\
\text { drain }\end{array}$ & 100 & 7 & 5.0 & 4.4 & 1535 \\
\hline $\begin{array}{l}\text { Tidd spoiled } \\
\text { cyclone }\end{array}$ & 100 & 7 & 3.8 & 3.2 & 1550 \\
\hline $\begin{array}{l}\text { Tidd no } \\
\text { cyclone }\end{array}$ & 100 & 7 & 6.8 & 6.1 & 1550 \\
\hline $\begin{array}{l}\text { Grimethorpe } \\
\text { Red }\end{array}$ & 100 & 7 & 1.3 & 1.0 & 1550 \\
\hline Karhula I & 100 & 7 & 9.3 & 8.2 & 1600 \\
\hline Karhula I & 150 & 7 & 7.3 & 7.5 & 1550 \\
\hline Karhula I & 50 & 7 & 8.2 & 8.2 & 1400 \\
\hline FWDC TRC-5 & 100 & 7 & 9.0 & 8.5 & 1600 \\
\hline
\end{tabular}


process at these temperatures. It is important to note that the filter cake permeability tests did not include $\mathrm{SO}_{2}$ in the simulated $\mathrm{PFBC}$ gas environment. Also, none of the tests performed resulted in the formation of hard filter cake deposits, even those with the Tidd fine fly ash that gave deposits and bridging in field tests.

Small scale testing with PFBC fly ashes, and with fresh limestones and dolomites where performed as part of a Westinghouse in-house program, exposing simulated filter cake disks to representative $\mathrm{PFBC}$ environments that included $\mathrm{SO}_{2}$. These tests identified the conditions where hard filter cakes are generated and clearly indicated the relations between the filter cake properties and the gas conditions. These tests and their results are described briefly in Appendix A.

The results are consistent with field test trends, and direct comparison of the laboratory test and field test permeabilities are shown in Table 5.4. In the field tests, the mass permeability is extracted from the plant data using the equation

$$
\Delta \mathrm{P}_{\mathrm{c}}=\mu \mathrm{U}^{2} \rho \mathrm{L} \mathrm{T}_{\mathrm{p}} / \mathrm{k}_{\mathrm{m}}
$$

where $\Delta \mathrm{P}_{\mathfrak{c}}$ is taken as the difference between the trigger and the baseline system pressure drops, $\mathrm{L}$ is the dust loading in the gas (mass ratio particulate to gas), $\rho$ is the gas density, and $\mathrm{T}_{\mathrm{p}}$ is the time duration between pulses. There are significant uncertainties in the values inserted into this equation. The baseline system pressure drop in a filter vessel containing multiple plenums is never actually recorded because of the significant time delay in completing the pulse cleaning of all of the plenums. The dust loading is generally an estimate based on the mass of material periodically removed from the filter vessel, or based on limited particle sampling measurements. Again, it is assumed that all of the fly ash in the gas is deposited onto the active filtering surfaces. It is also assumed that the pulse cleaning is effective, with all of the fly ash deposited being removed by the pulse.

The laboratory permeabilities are greater than the field test permeabilities, and this may be because the $\mathrm{CO}_{2}$ and $\mathrm{SO}_{2}$ partial pressures are lower in the laboratory tests than in the field tests, and the fly ash samples are re-entrained particles previously exposed to PFBC filter environment. The uncertainties in the 


\begin{tabular}{|l|c|c|}
\hline \multicolumn{3}{|c|}{ Table 5.4 - Laboratory and Field Cake Permeabilities } \\
\hline & $\begin{array}{c}\text { Laboratory } \\
\text { Mass Permeability } \\
\left(10^{-10} \mathrm{lb} / \mathrm{ft}\right)\end{array}$ & $\begin{array}{c}\text { Field } \\
\text { Mass Permeability } \\
\left(10^{-10} \mathrm{lb} / \mathrm{ft}\right)\end{array}$ \\
\hline $\begin{array}{l}\text { Tidd Fly Ash } \\
\text { Fine }{ }^{\mathrm{a}:}\end{array}$ & 1.6 & $\begin{array}{c}0.2-0.6 \\
\text { Spoiled cyclone }\end{array}$ \\
$\begin{array}{l}\text { Cyclone drainc: } \\
\text { No cycloned: }\end{array}$ & 3.2 & -2 \\
\hline Karhulae: & 4.4 & $5-6$ \\
\hline Grimethorpe Redf: & 6.1 & $2-6$ \\
\hline FWDC (TRC5)g: & $3.3-8$ & - \\
\hline
\end{tabular}

a: AEP, Tidd bubbling-PFBC fly ash collected from filter during initial test period through Run 11

b: AEP, Tidd bubbling-PFBC fly ash collected from filter following testing with partially-spoiled primary cyclone

c: AEP, Tidd bubbling-PFBC fly ash collected from primary cyclone mixed with HGF drain ash (50/50)

d: AEP, Tidd bubbling-PFBC fly ash collected from HGF during testing with precleaning cyclone removed

e: Ahlstrom, Karhula, Finland cirçulating-PFBC pilot filter fly ash

f: Grimethorpe Red fly ash collected from Grimethorpe bubbling-PFBC filter during Run 129

g: Foster Wheeler Development Corp. circulation-PFBC fly ash collected from the filter vessel during Test TRC5 run using FREMP feed stocks 
values used to calculate the mass permeabilities might also result in differences between the two sets of values. Figure 5.1 plots the $\mathrm{CO}_{2}$ partial pressure and filter operating temperature for Tidd PFBC filter tests, for Karhula CPFB filter tests, for FWDC filter tests, and for the bench-scale filter cake permeability tests. The equilibrium line for $\mathrm{CaCO}_{3}-\mathrm{CaO}$ stability is also plotted in the figure. In most cases, the $\mathrm{HGF}$ field testing did not operate at conditions yielding calcined $\mathrm{CaCO}_{3}$ in the filter cake. The figure also displays the much lower levels of $\mathrm{CO}_{2}$ in the bench-scale tests compared to the field tests.

The cake permeability conclusions reached, based on the bench-scale testing, the supporting laboratory testing, and the available information in the literature are:

- Bench-scale filter cake trends are consistent with field unit data trends;

- Bench-scale filter cake permeabilities are higher in magnitude than the estimated field unit cake permeabilities, but are closer together as the fly ash becomes coarser;

- PFBC filter cake permeability and sintering is largely controlled by limestone constituents in the fly ash;

- Filter cake sintering is induced by $\mathrm{CO}_{2}$ and $\mathrm{SO}_{2}$ in the gas;

- Increased sintering results from:

- higher $\mathrm{CO}_{2}$ and $\mathrm{SO}_{2}$ partial-pressures,

- higher temperatures,

- finer fly ash particles,

- calcitic limestone vs dolomitic limestone;

- Control of cake permeability and bridging might be realized by:

- limiting the PFBC temperature (especially in Advanced-PFBC)

- limiting primary cyclone performance,

- PFBC sorbent selection,

- use of additives. 


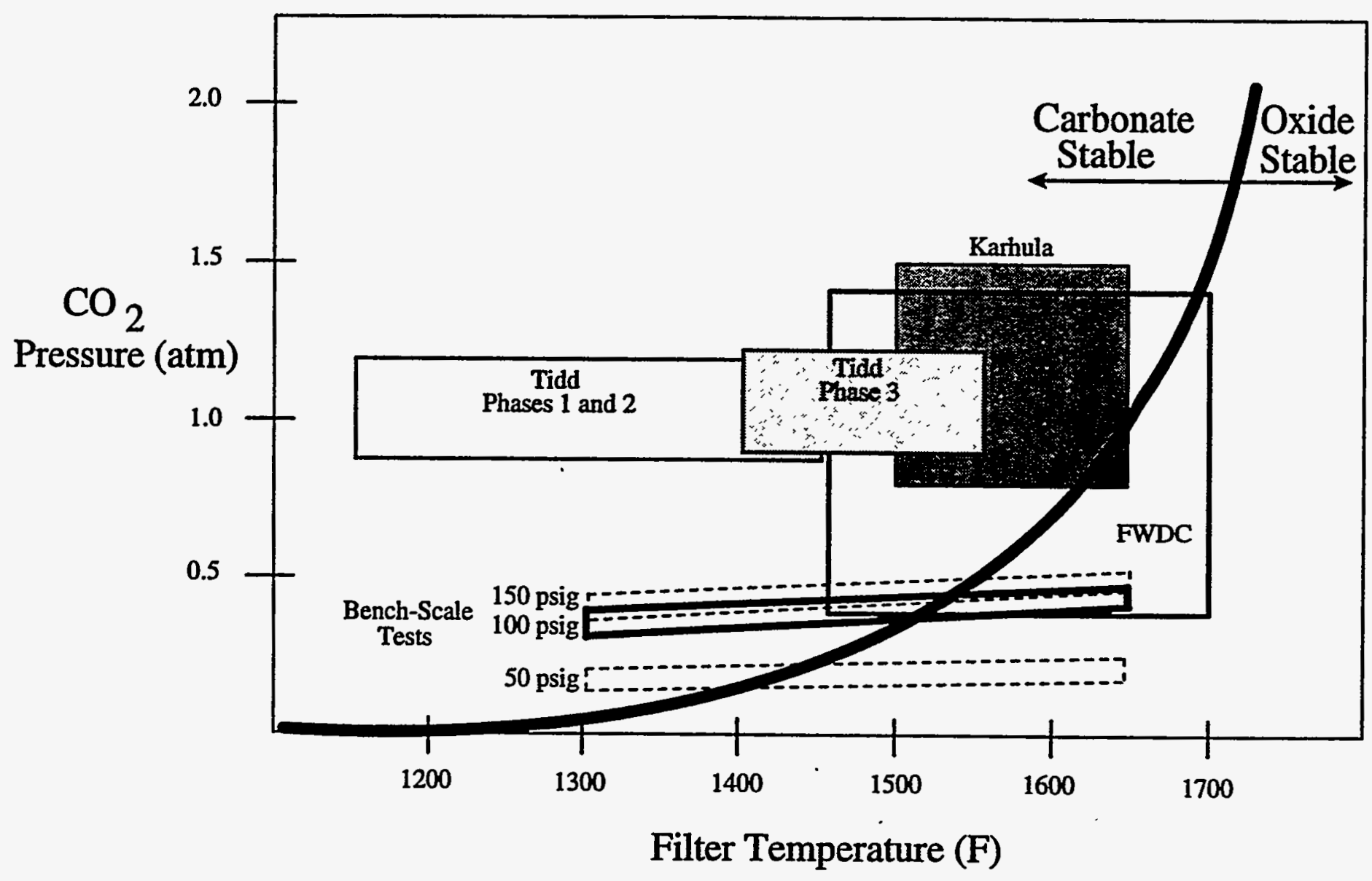

Figure 5.1 - PFBC, HGF Field Test Conditions and Bench-Scale ILEC Test Conditions 


\subsection{Filter Cake Additives Results}

The additive tests focused on the influence of additives on the cake permeability and were of two types: additive premixed with PFBC fly ash, and additive applied as a precoat to the filter elements. The five additive tests reviewed in Table 5.5 were performed. The additive characteristics are listed in Table 4.2.

The test history and results are plotted in Appendix E for Tests 2.01 through 2.05. The three figures for Test 2.01 show the test history (temperature, face velocity, filter total pressure drop, and mass of cake deposited per unit area plotted against the time-of-day), the pressure drop distribution (cake, clean system, and residue), and the cake mass permeability. The results of Test 2.01 show that the use of pulverized dolomite benefitted the Tidd Fine fly ash permeability significantly even though only 10 wt\%, or about 5 volume\%, additive was used. It was not known if such a great benefit would result if the gas contained $\mathrm{SO}_{2}$, but this was to be clarified during the sulfur removal testing (Series 4) of the program.

Test 2.02 (6 total days of testing) precoated the candle elements with Neutralite. Neutralite was fed for 4 days to obtain a standard filter cake pressure drop of about $40{ }^{~} \mathrm{H}_{2} \mathrm{O}$ and figures showing the run history for each of those days are attached in Appendix E. A cake having relatively high permeability resulted, and temperature variations were performed on two days. Figures showing run history, pressure drop distribution, and mass permeability plots for those two days are attached in Appendix E. The reduction in the filter cake permeability as the temperature increased was very great on the first day. The Neutralite filter cake permeability was measured to be slightly lower on the second day, but was still a relatively high value.

The next test, Test 2.03, built a cake of fly ash, Grimethorpe Red, on the Neutralite precoat to see if a measurable impact on the cake permeability resulted. The plotted results show that the cake permeability was slightly lower than it had been in Permeability Test 1.06, having no precoat. Following this test, the vessel was opened for inspection and it was found that the Neutralite precoat was very thick (about 1/2" to 5/8") and was a hard, stable layer that needed to be cut out in 


\begin{tabular}{|c|l|l|l|}
\hline \multicolumn{4}{|c|}{ Table 5.5 - Additive Test Results } \\
\hline Test & \multicolumn{1}{|c|}{ Fly Ash } & \multicolumn{1}{|c|}{ Additive } & $\begin{array}{c}\text { Results/Change in Mass } \\
\text { Permeability (lb/tt } \times 10^{-10}\end{array}$ \\
\hline 2.01 & $\begin{array}{l}\text { Tidd fine; } \\
\text { (Preclean } \\
\text { cyclone) }\end{array}$ & $\begin{array}{l}10 \mathrm{wt} \% \text { pulverized } \\
\text { dolomite }\end{array}$ & $\begin{array}{l}\text { Permeability increased from } \\
1.6 \text { to } 2.7\end{array}$ \\
\hline 2.02 & None & $\begin{array}{l}\text { Neutralite } \\
\text { precoat }\end{array}$ & $\begin{array}{l}1 / 2 \text { to } 5 / 8^{\prime \prime}-\text {-thick precoat } \\
\text { generated }\end{array}$ \\
\hline 2.03 & $\begin{array}{l}\text { Grimethorpe } \\
\text { Red }\end{array}$ & $\begin{array}{l}\text { On Neutralite } \\
\text { precoat }\end{array}$ & $\begin{array}{l}\text { Permeability decreased from } \\
1.0 \text { to } 0.9\end{array}$ \\
\hline 2.04 & $\begin{array}{l}\text { Grimethorpe } \\
\text { Red }\end{array}$ & 5 wt\% Neutralite & $\begin{array}{l}\text { Permeability decreased from } \\
1.0 \text { to 0.4 }\end{array}$ \\
\hline 2.05 & $\begin{array}{l}\text { Grimethorpe } \\
\text { Red }\end{array}$ & 10 wt\% kaolin & $\begin{array}{l}\text { Permeability increased from } \\
1.0 \text { to 1.1 }\end{array}$ \\
\hline
\end{tabular}


sections. The mass permeability calculations performed to yield the plotted results in the figure were corrected for this thick coating since it changes the actual face velocity through the fly ash cake. A thinner precoat should be used, and the stable layer could provide some protection to the candle if no detrimental reactions occurred with the candle materials, and the precoat might provide an aid to pulse cleaning. Further assessments of the precoat concept should be considered.

The next test, Test 2.04, built a cake of Grimethorpe Red fly ash mixed with $5 \mathrm{wt} \%$ Neutralite, and resulted in a cake permeability much lower than previously measured with Grimethorpe Red. Neutralite would not appear to be a useful cake permeability aid. A further series of continuous pulse cleanings and cake buildups (Test 2.04) showed a significant deterioration in the baseline pressure drop, further exposing the poor performance of Neutralite as a direct additive for PFBC applications.

The final additive test performed to date, Test 2.05, used a mixture of $10 \mathrm{wt} \%$ Kaolin with Grimethorpe Red fly ash. Again, the test history, pressure drop distribution, and cake mass permeability is shown in 3 attached figures in Appendix E. The results showed little influence of the Kaolin on the Grimethorpe Red cake permeability compared to prior Permeability Test 1.06, without the additive.

\subsection{Pulse Cleaning Results}

Some key terms used in the pulse cleaning tests are defined as:

- The "tank pressure" is the absolute pressure in the pulse gas accumulation reservoir prior to the pulse event. The "relative tank pressure" is the absolute tank pressure minus the filter operating pressure (100 psig).

- The "pulse intensity" is the maximum pressure measured in the filter plenum during a pulse event minus the filter operating pressure. It is assumed that the maximum plenum pressure is very close to the maximum pressure in the candles during a pulse event. 
- The "baseline" pressure drop is the pressure drop across the plenum that is measured following the pulse event.

- The "residue" pressure drop is the baseline pressure drop minus the plenum pressure drop that would be achieved if "perfect cleaning" occurred. In some figures this residue pressure drop is designated as "baseline - Clean DP."

- The "pulse gas released" is the mass of pulse gas released from the pulse gas tank during a pulse event. The "pulse gas received" is the mass of pulse gas that passes through the candles during a pulse event.

The pulse cleaning test (Series 3 ) histories (temperature, face velocity, and filter pressure drop) are plotted against the time-of-day, for the tests with Tidd fine fly ash only (Tests 3.11 - 3.13), in Appendix E. The Tidd fine fly ash results were very similar to the testing with Karhula I fly ash. Each figure in Appendix $E$ also indicates the pulse gas tank pressure applied during the pulses performed. Each pulse was conducted with a pulse valve open-time of 0.4 seconds. Table 5.6 lists the test conditions and the residue pressure drop, or baseline minus clean pressure drop, that resulted at the end of each pulse cleaning test.

The pulse intensity measured in the tests $(3.11-3.13)$ is plotted in Figure 5.2, for Tidd fine, and Figure 5.3, for Karhula I, against the relative tank pressure. The pulse intensity rises almost linearly as the relative tank pressure increases, but it also appears that the intensity is slightly higher as the temperature is increased. This probably results because the filter cake and residue flow resistances have increased as the temperature was increased.

Figures 5.4 and 5.5 plot the pulse gas received by the candle elements against the pulse gas released from the pulse tank, both quantities expressed as mass of pulse gas per candle element. The quantity of pulse gas released from the pulse tank is a calculated quantity based on the pulse gas tank pressure before and after the pulse event. The quantity of pulse gas received by the filter elements is an estimated quantity based on the filter element pressure drop before the pulse and the pulse intensity measured during the pulse. Roughly,

Pulse gas received $=U_{p} \times A \times T_{p} \times \rho$ 


\begin{tabular}{|c|c|c|c|c|}
\hline \multicolumn{5}{|c|}{ Table 5.6 - Filter Cake Pulse Cleaning Test Conditions } \\
\hline \multicolumn{5}{|c|}{$\begin{aligned} \text { FIXED CONDITIONS: } & \text { Face velocity } 7 \mathrm{ft} / \mathrm{min} \\
& \text { Pressure } 100 \mathrm{psig}\end{aligned}$} \\
\hline Test & Fly Ash & $\begin{array}{l}\text { Temperature } \\
\left({ }^{\circ} \mathrm{F}\right)\end{array}$ & $\begin{array}{c}\text { Maximum Relative } \\
\text { Pulse Tank } \\
\text { Pressure (atm) }\end{array}$ & $\begin{array}{l}\text { Final Residue } \\
\text { Pressure Drop } \\
\quad\left({ }^{\circ} \mathrm{H}_{2} \mathrm{O}\right)\end{array}$ \\
\hline 3.11 & Tidd fine & 1300 & 26 & 1 \\
\hline 3.12 & & 1450 & & 2 \\
\hline 3.13 & & 1550 & & 5 \\
\hline 3.21 & Karhula I & 1300 & 26 & 8 \\
\hline 3.22 & & 1450 & & 10 \\
\hline 3.23 & & 1550 & & 13 \\
\hline 3.31 & Tidd Fine & 1300 & 61 & 7 \\
\hline 3.32 & & 1450 & & 10 \\
\hline 3.33 & & 1550 & & 11 \\
\hline 3.41 & Karhula I & 1300 & 61 & 13 \\
\hline 3.42 & & 1450 & - & 13 \\
\hline 3.43 & & 1550 & & 13 \\
\hline
\end{tabular}




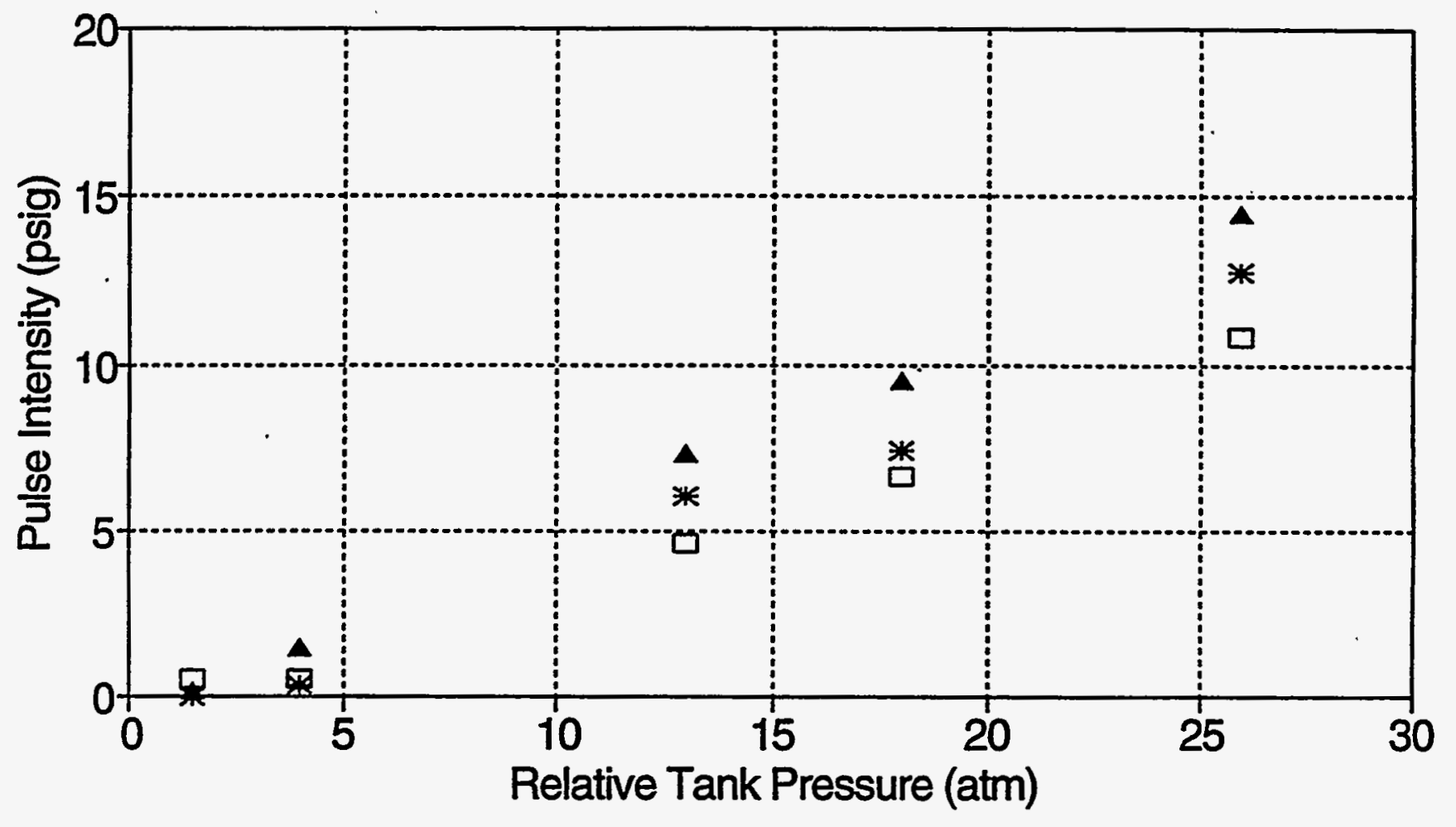

\section{ㅁ 1300F $* 1450 \mathrm{~F} \triangle 1550 \mathrm{~F}$}

Figure 5.2 - Pulse Cleaning Pulse Intensities (Tidd Fine Fly Ash) 


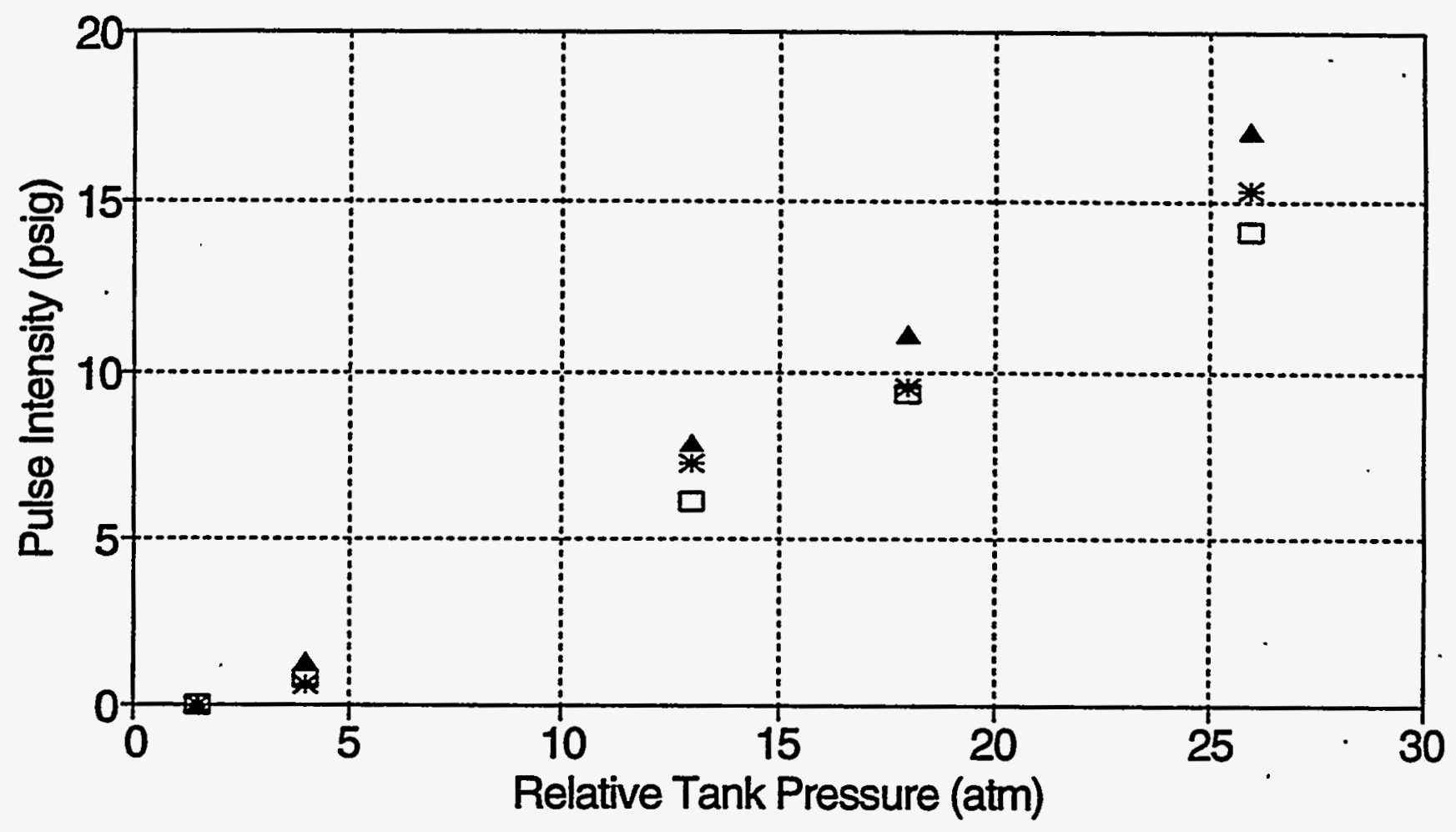

\section{ㅁ $1300 \mathrm{~F} * 1450 \mathrm{~F} \triangle 1550 \mathrm{~F}$}

Figure 5.3 - Pulse Cleaning Pulse Intensities (Karhula I Fly Ash) 


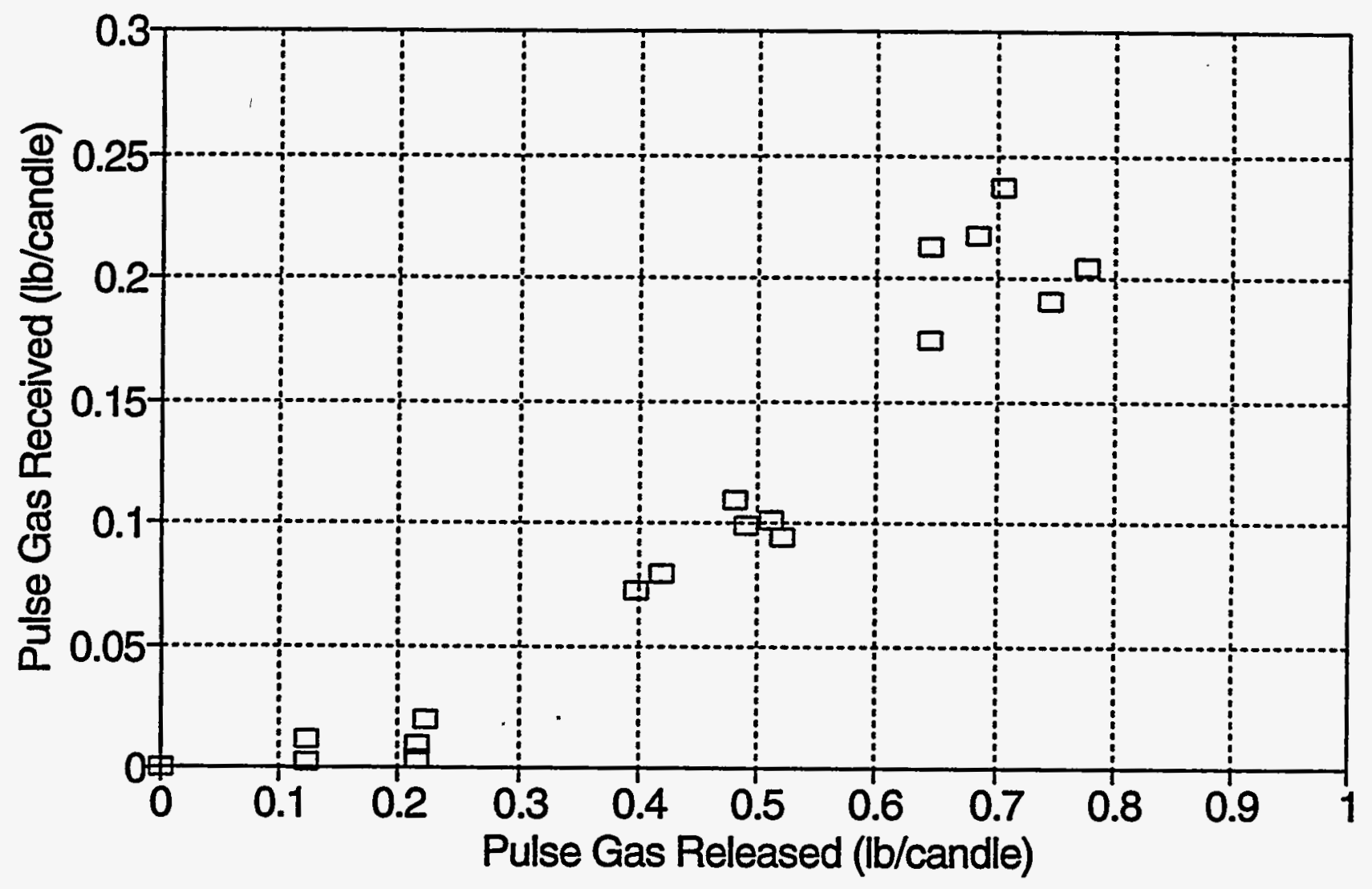

Figure 5.4 - Pulse Gas Received and Released (Tidd Fine Fly Ash) 


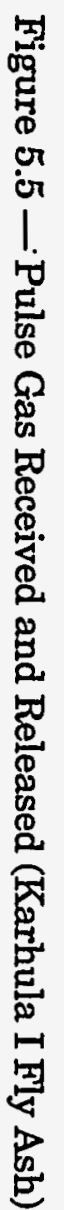

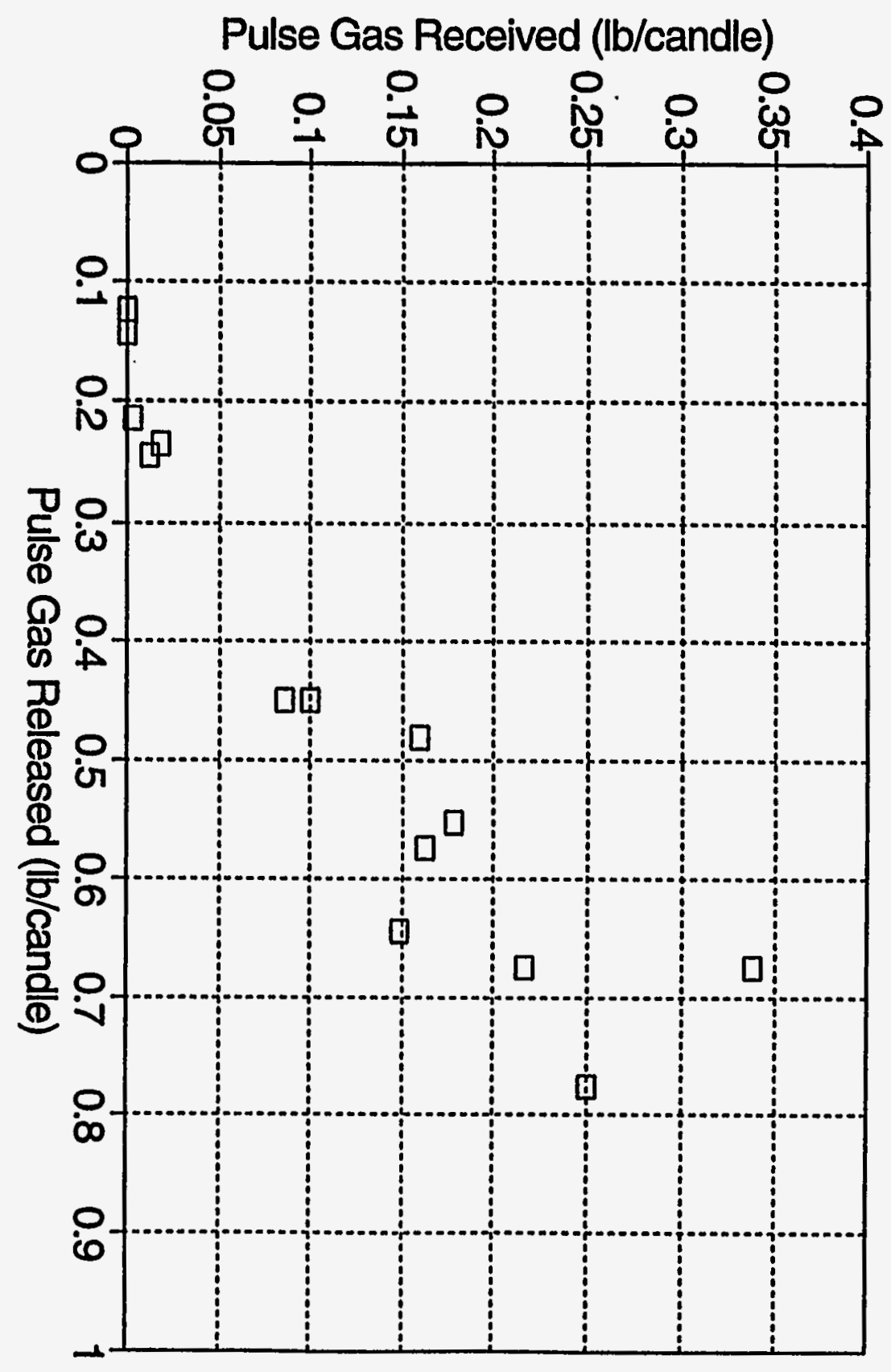


where $A$ is the outside surface area of the four filter elements, $T_{p}$ is the duration of the pulse ( 0.4 seconds), $\rho$ is the gas density at the pressure and temperature of the filter vessel, and $U_{p}$ is the gas face velocity through the candles, based on the outside surface area, during the pulse event. $U_{p}$ is estimated by

$$
\mathrm{U}_{\mathrm{p}}=\mathrm{U} \mathrm{X} \Delta \mathrm{P} \mathrm{p} / \Delta \mathrm{P}_{\mathrm{f}}
$$

where $U$ is the forward face velocity before the pulse event, $\Delta P_{p}$ is the sum of the filter element, residue, and filter cake pressure drop during the pulse event (equivalent to the pulse intensity), and $\Delta \mathrm{P}_{\mathrm{f}}$ is the sum of the forward element, residue, and cake pressure drop with forward gas flow prior to the pulse event. The relation between the released and the received pulse gas quantities is a function of the specific equipment design, and is nearly identical for both types of fly ashes. The received pulse gas is significantly less than the released pulse gas in the test equipment, with the ratio of received to released gas quantity increasing as the released pulse gas quantity increases.

In Figure 5.6, for Tidd fine, the pulse intensity and the residue pressure drop or, baseline minus the clean DP are plotted against the cumulative, hot operating hours in the tests. The three sets of data at $1300^{\circ} \mathrm{F}, 1450^{\circ} \mathrm{F}$, and $15550^{\circ} \mathrm{F}$ are shown. A lower value of the residue pressure drop means a more effective pulse cleaning was performed. At each temperature, as the pulse intensity was decreased a clear increase in the residue pressure drop resulted. As the temperature increased, the residue pressure drop was higher at the same pulse intensity. For example, at $1300^{\circ} \mathrm{F}$ a pulse intensity of $5 \mathrm{psi}$ resulted in a residue pressure drop of about 0.5 " $\mathrm{H}_{2} \mathrm{O}$, while at $1450^{\circ} \mathrm{F}$ the same 5 psi pulse intensity resulted in a residue pressure drop of about $3 \mathrm{psi}$, and at $1550^{\circ} \mathrm{F}$ the same 5 psi pulse intensity resulted in a residue pressure drop of about $7 \mathrm{psi}$. Figure 5.7, for Karhula I, is a similar plot, but showing the tank relative pressure rather than the pulse intensity. This figure is similar in its trends to Figure 5.6, except that since the Karhula I tests followed the Tidd fine tests, the residue pressure drop has continued to increase due to normal residue accumulation. 


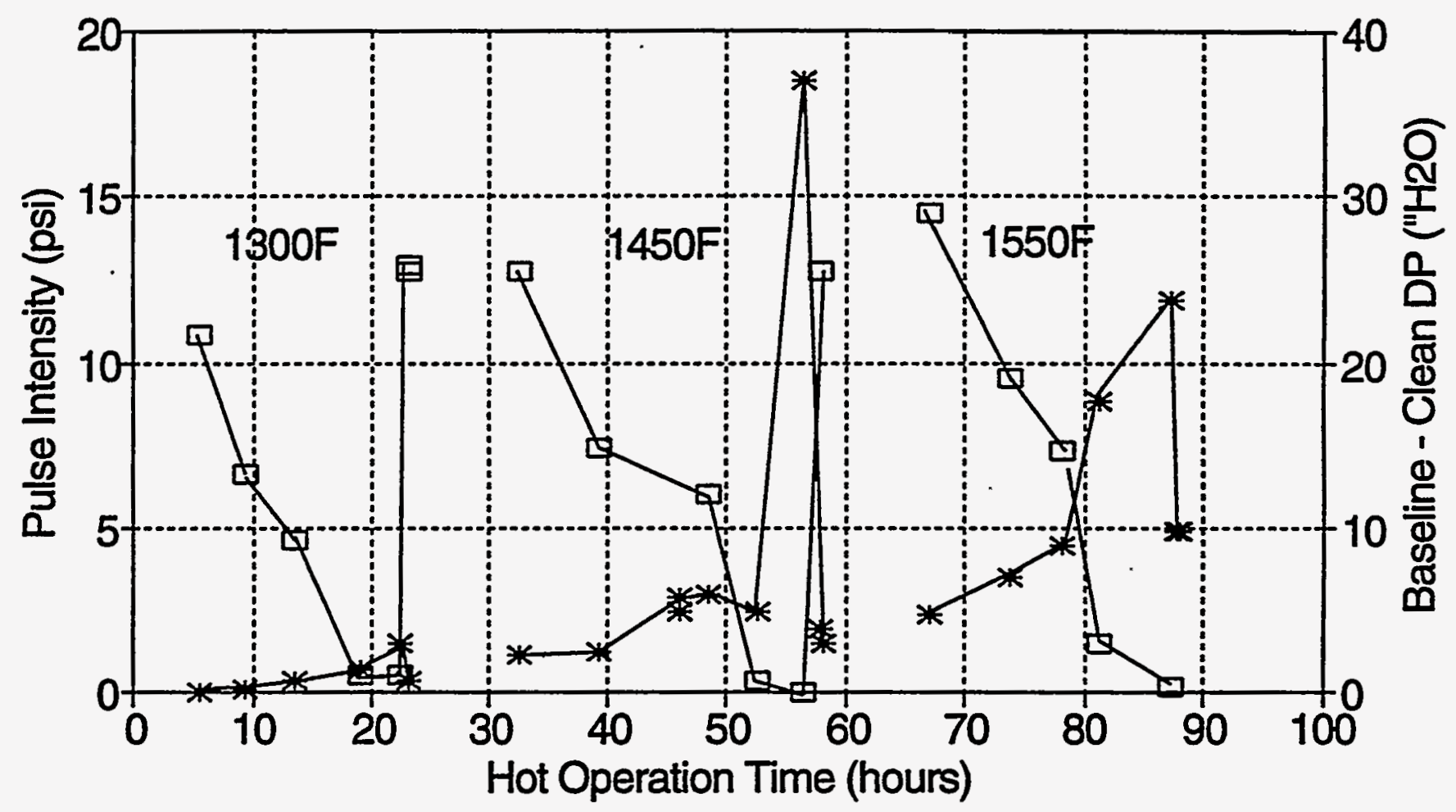

Figure 5.6 - Pulse Cleaning Performance (Tidd Fine Fly Ash) 
Even though the Karhula I fly ash has a significantly higher permeability than the Tidd fine fly ash, with also much less sensitivity to temperature, a significant influence of temperature and time on the pulse cleaning effectiveness is demonstrated in Figure 5.7. Two factors have contributed simultaneously to these results. First, higher temperature results in lower cake permeability and greater residue accumulation, so that a lower pulse gas quantity yields the same measured pulse intensity. Secondly, the tests were performed in the order of ascending temperatures, so that as the temperatures increases the cumulative test time also increased. This second factor resulted in more opportunity for residue accumulation on the candles as time, and temperature progressed. The results imply that, with both the Tidd fine fly ash and the Karhula I fly ash, a steady accumulation of residue occurs that cannot be effectively cleaned even at the highest pulse intensity conditions used in these tests. This residue accumulation, though, appears to be representative of normal filter element "conditioning" and is not expected to be a contributor to the adverse filter cake behavior observed in PFBC, HGF field tests, so long as the pulse intensity is maintained at greater than about $10 \mathrm{psi}$, and uniform pulse cleaning of all elements is provided.

Tests 3.31 - 3.33 and 3.41 - 3.43 were conducted to observe the benefits of a higher pulse source pressure on the candle cleaning. The Tidd fine fly ash was used in Tests 3.31 - 3.33, and the Karhula I fly ash in Tests 3.41 - 3.43. Both test series used a tank relative pressure of $61 \mathrm{~atm}$, and both resulted in a large pulse intensity of 35 psi. Figures 5.8 and 5.9 imply that with the Tidd fine fly ash, a buildup of residue occurred on the candles that increased as the temperature increased, while this temperature sensitivity was not shown for the Karhula I fly ash. A significant residue resistance remains on the candles even with the high pulse intensity used. Table 5.6 lists the final value of the residue pressure drop after each test, showing the steady accumulation of residue over the 210 hours of testing performed on the pulse cleaning performance. 


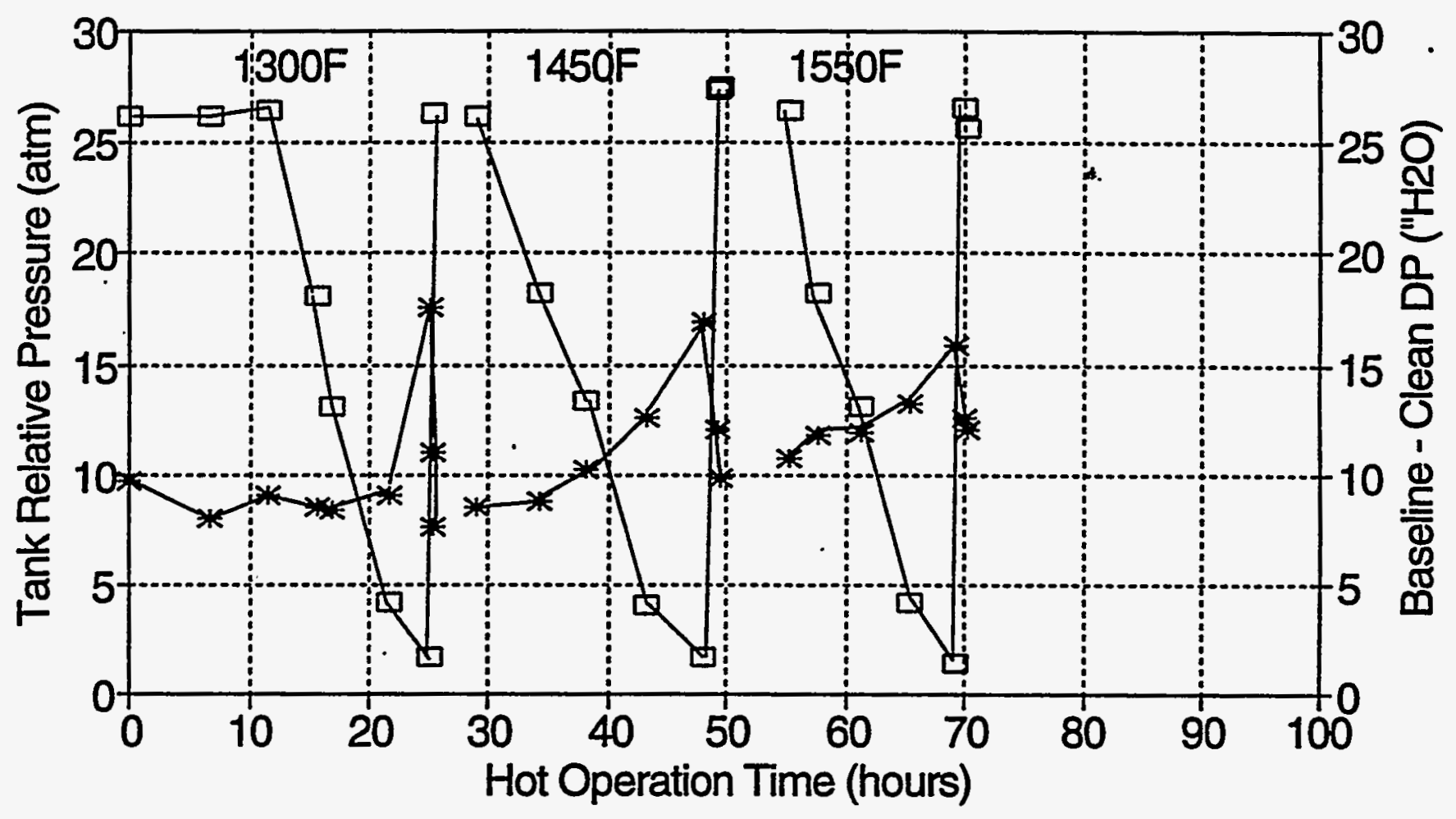

Figure 5.7 - Pulse Cleaning Performance (Karhula I Fly Ash) 


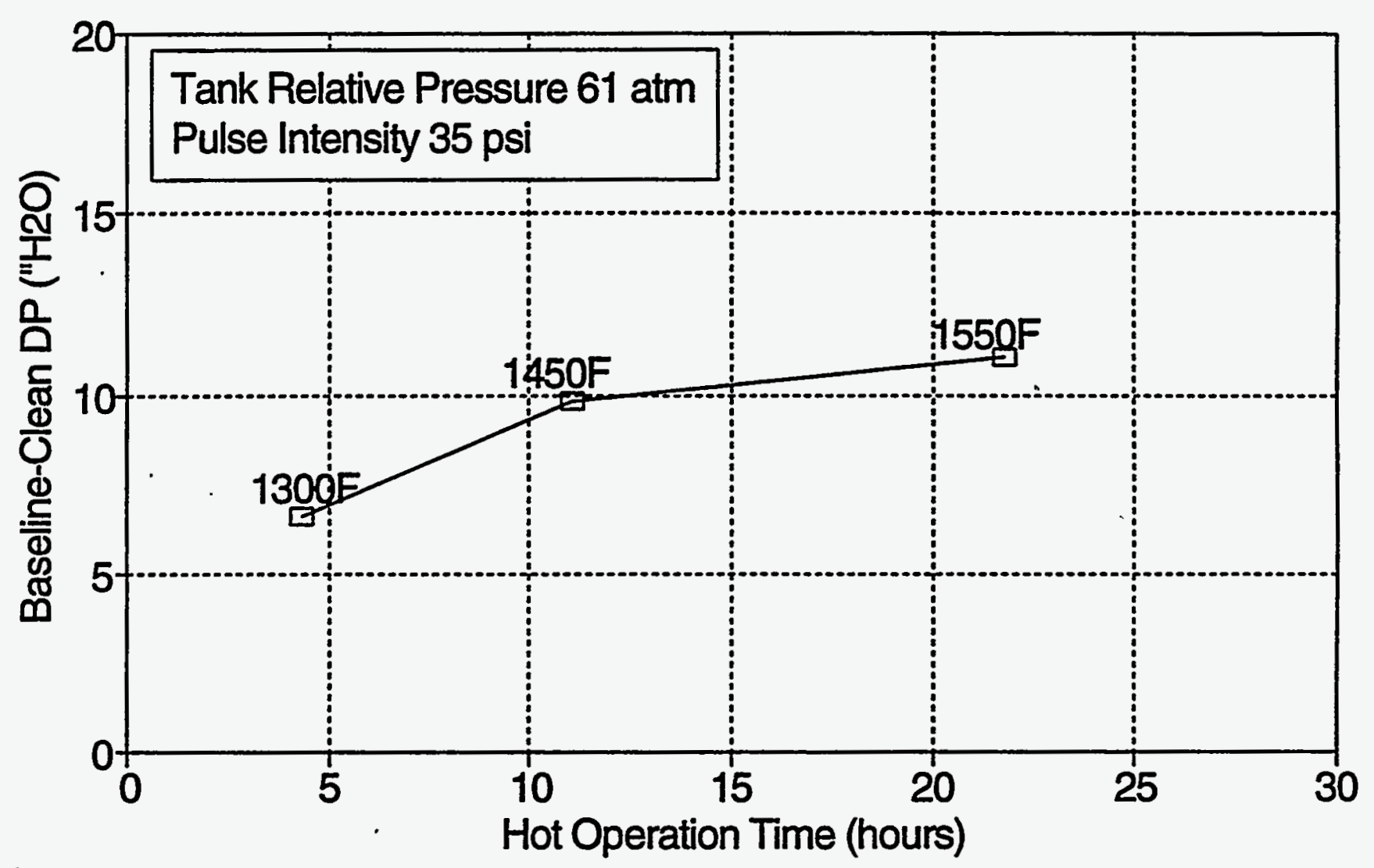

Figure 5.8 - High-Pressure Pulse Cleaning (Tidd Fine Fly Ash) 


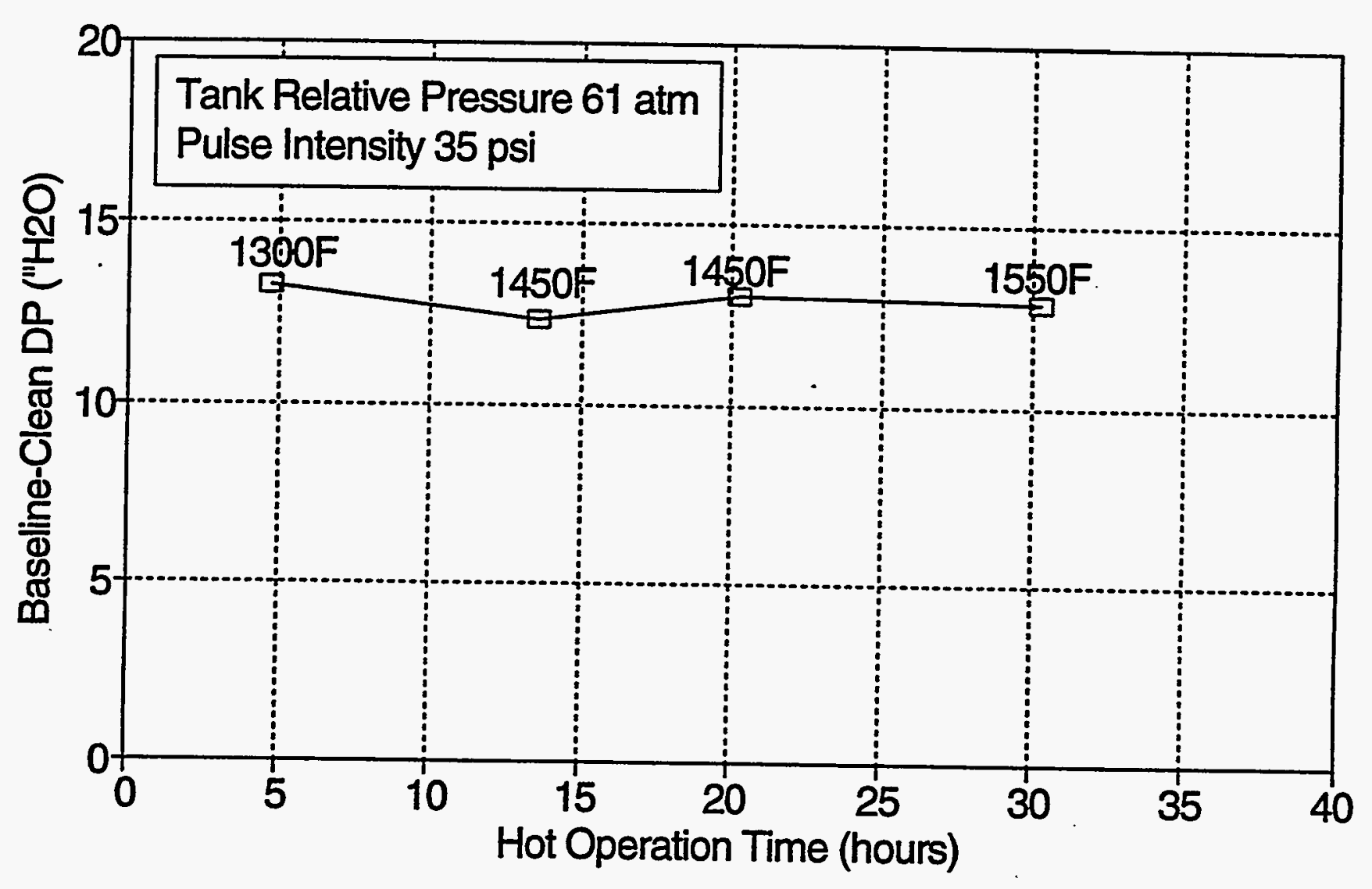

Figure 5.9 - High-Pressure Pulse Cleaning (Karhula I Fly Ash) 


\subsection{Sulfur Removal Results}

Eight sulfur removal tests, as well as sulfur removal calibration runs, were performed in Test Series 4. The tests were performed with Karhula II and Tidd spoiled cyclone fly ashes, and pulverized dolomite sulfur sorbent. All of the tests were conducted at $1550^{\circ} \mathrm{F}$ and $100 \mathrm{psig}$, except for test 4.7 that was performed at $1450^{\circ} \mathrm{F}$ and $150 \mathrm{psig}$.

The sulfur removal test plots are presented in Appendix E, including the $\mathrm{SO}_{2}$ calibration runs. Three types of plots are shown for most test run days, one showing the test condition history during the run (temperature, pressure drop, face velocity, and filter cake accumulation on the candles), one showing the calculated filter cake mass permeability and temperature history during the run, and one plotting the $\mathrm{SO}_{2}$ outlet reading during the run.

There are significant uncertainties in some of the runs performed. In Test 4.2, the Karhula II ash was deposited on the candles the first test day (1/24/95) and was left overnight before being subjected to $\mathrm{SO}_{2}$ exposure. The filter cake pressure drop was observed to increase overnight from 55 " $\mathrm{H}_{2} \mathrm{O}$ to 67 " $\mathrm{H}_{2} \mathrm{O}$, leading to a large reduction in the calculated cake permeability. The filter cake permeability reported in the continuous feed test of Test 4.4 resulted in an unusually high filter cake permeability. Although the test was a transient test and not expected to give a good filter cake permeability value, it may have also been high due to pressure tap plugging or an error in the filter cake feed rate reading.

The test results are summarized in Table 5.7. The table includes the estimated values for the free-calcium-to-sulfur feed ratio, and the sulfur removal efficiency, as well as the calculated filter cake mass permeability. The free-calciumto-sulfur feed ratio is defined as the moles of unsulfated calcium fed to the benchscale HGF during the test (either predeposited on the candles or continuously fed), divided by the moles of sulfur fed during the test. The sulfur removal efficiency represents the estimate of the average level of sulfur captured by the sorbent or fly ash during the test, based on the measured outlet gas $\mathrm{SO}_{2}$ content during the $\mathrm{SO}_{2}$ 


\begin{tabular}{|c|c|c|c|c|}
\hline \multicolumn{5}{|c|}{ Table 5.7- $\mathrm{SO}_{2}$ Removal Test Results (Series 4) } \\
\hline \multicolumn{5}{|c|}{$\begin{aligned} \text { FIXED CONDITIONS: } & \text { Face velocity } 7 \mathrm{ft} / \mathrm{min} \\
& \mathrm{SO}_{2} \text { feed level about } 200 \mathrm{ppmv} \\
& \text { Temperature } 1550^{\circ} \mathrm{F}\left(1450^{\circ} \mathrm{F} \text { in Test } 4.7\right) \\
& \text { Pressure } 100 \mathrm{psig}(150 \mathrm{psig} \text { in Test } 4.7)\end{aligned}$} \\
\hline Test & Fly Ash/Sorbent & $\begin{array}{c}\text { Free Calcium/ } \\
\text { Sulfur Ratio }\end{array}$ & $\begin{array}{c}\text { Cake Mass } \\
\text { Permeability } \\
\left(\mathrm{lb} / \mathrm{ft}, 10^{-10}\right)\end{array}$ & $\begin{array}{c}\text { Sulfur } \\
\text { Removal } \\
(\%)\end{array}$ \\
\hline $\begin{array}{l}4.1 \\
\text { (Cake test) }\end{array}$ & $\begin{array}{l}\text { Tidd spoiled } \\
\text { cyclone }\end{array}$ & small & 5.3 & none \\
\hline $\begin{array}{l}4.2 \\
\text { (Cake test) }\end{array}$ & Karhula II & $1-2$ & 3.3 & 80 \\
\hline $\begin{array}{l}4.3 \\
\text { (Cake test) }\end{array}$ & Dolomite & 25.7 & 5.7 & $60-80$ \\
\hline $\begin{array}{l}4.4 \\
\text { (Feed test) }\end{array}$ & Dolomite & 2.3 & $-*_{-}$ & $60-80$ \\
\hline $\begin{array}{l}4.5 \\
\text { (Cake test) }\end{array}$ & $\begin{array}{l}\text { Tidd cyclone/ } \\
\text { dolomite (50\%) }\end{array}$ & 3.1 & 5.6 & 80 \\
\hline $\begin{array}{l}4.6 \\
\text { (Cake test) }\end{array}$ & $\begin{array}{l}\text { Karhula II/ } \\
\text { dolomite (50\%) }\end{array}$ & 2.2 & 3.5 & 95 \\
\hline $\begin{array}{l}4.7 \\
\text { (Cake test) }\end{array}$ & Dolomite & 1.0 & 4.6 & 95 \\
\hline $\begin{array}{l}4.8 \\
\text { (Cake test) }\end{array}$ & Dolomite & 1.0 & 4.4 & 98 \\
\hline
\end{tabular}


feeding period. No significant difference in sulfur removal performance between the single continuous sorbent feed test (Test 4.4) and comparable predeposited filter cake tests could be detected due to the uncertainty in the outlet $\mathrm{SO}_{2}$ measurements. Some of the uncertainty arises from the relatively large dispersion occurring in the filter vessel with its relatively long gas residence time. While the sulfur removal measurements have a large uncertainty because of a high background $\mathrm{SO}_{2}$ indicated by the $\mathrm{SO}_{2}$ monitoring system, the results do provide representative and significant trends:

- The inclusion of $\mathrm{SO}_{2}$ in the filter inlet gas had a very small impact on the filter cake permeability with the two PFBC fly ashes tested, as well as with the dolomite. The permeability appears to drop only slightly during the $\mathrm{SO}_{2}$-gas injection periods, as is seen in the permeability plots in Appendix E.

- The Tidd spoiled cyclone fly ash, from the partially-spoiled cyclone testing on the Tidd HGF, showed little ability to capture sulfur, while the Karhula II fly ash had significant sulfur capture capability. This may be because the Karhula II fly ash was less sulfated than the Tidd spoiled cyclone fly ash.

- The PFBC fly ash-dolomite mixtures and the dolomite alone showed . significant sulfur capture ability, greater than $90 \%$ at moderate calciumto-sulfur ratios.

- No indication of hard filter cake formation, or deposits that would initiate filter bridging, was found on observation of the filter elements after testing, even for the tests with dolomite alone. This is probably because the dolomite fed was of relatively coarse particle size.

These trends indicate that relatively coarse (-325 mesh) dolomite injection into a HGF would result in improved sulfur removal and would not result in adverse filter cake formation. It is expected that injection of much finer sorbent particles (mean size $5 \mu \mathrm{m}$ or less) into a HGF would result in high degree of filter cake sintering. 
In the Tidd HGF testing, the available data shows that the sulfur content of the process gas dropped by about $50 \%$ across the HGF, from about $200 \mathrm{ppmv}$ inlet to about 100 ppmv outlet, without any sorbent addition. Unfortunately, this data was not available for all of the Tidd HGF test runs. The bench-scale ILEC test results do not provide sufficient kinetic information to project large-scale HGF sulfur removal sorbent feed requirements and efficiencies. Supplemental laboratory sulfur removal kinetic testing is reported in Appendix B, although relating to higher temperatures than are applicable to PFBC.

\subsection{Alkali Removal Results}

The objectives of the alkali removal tests (Test Series 5) were to 1) observe the filter cake permeability to see if adverse filter cakes were generated at temperatures where the reacted emathlite particles may become relatively soft, and 2) measure the in-filter alkali removal performance. Alkali removal tests were performed by injecting PFBC fly ashes and alkali sorbent (emathlite powder) premixed with micro-pulverized sodium chloride, the alkali vapor source. The feed rate of pulverized emathlite was maintained at about 10 times the saturation feed rate. The "saturation" feed rate is the mass feed rate of alkali sorbent that would completely use the sorbent alkali vapor adsorption capability while capturing all of the available alkali vapor. emathlite can hold about $20 \mathrm{wt} \%$ sodium at saturation, so it was fed at 50 times the mass feed rate of sodium.

The test data plots are compiled in Appendix E, with plots showing the test histories and the filter cake permeability behavior. In Test 5.9 both alkali and $\mathrm{SO}_{2}$ were fed simultaneously, and the outlet gas $\mathrm{SO}_{2}$ content in Test 5.9 is also displayed in a plot in Appendix E. All of the tests were at the following fixed conditions:

- Face velocity: $7 \mathrm{ft} / \mathrm{min}$,

- Pressure: 100 psig,

- Temperature: $1550-1600^{\circ} \mathrm{F}$.

Fly ash and emathlite were fed with a 5 wt\% content of $\mathrm{NaCl}$. The alkali $(\mathrm{NaCl})$ feed rate was selected to result in a level of about $15 \mathrm{ppmv}$ sodium within the HGF in the tests. 
The test results are summarized in Table 5.8. The tests were performed with probe samples (condensate water-soluble sodium) collected and analyzed. The first test, Test 5.1, was conducted using emathlite alone, with no $\mathrm{NaCl}$ injection, to measure the filter cake permeability in the absence of alkali reaction. Three tests with $\mathrm{NaCl}$ feed had the alkali probe at a location having relatively low temperature, while the last 6 tests had the probe penetrating the head, with high temperature resulting.

The table indicates the filter cake permeability, and the outlet gas alkali content (ppbv Na) for each test. The filter cake permeabilities appear higher when alkali was fed than when no alkali was present (Test 5.1). Test 5.9 implies that the cake permeability was reduced by the presence of $\mathrm{SO}_{2}$ in the gas, and approximately $50 \% \mathrm{SO}_{2}$ removal was obtained in the tests. All tests with alkali fed show alkali removal efficiencies greater than $99.98 \%$. Uncertainties in the results arise from the possibilities of alkali vapor condensation, alkali vapor reactions with the metal internals in the filter vessel, and incomplete vaporization of the injected alkali salt. Some evidence of metal corrosion was found in the bench-scale HGF following the testing.

The results, though uncertain, indicate that significant alkali removal was obtained with emathlite injection into the filter, as well as with Tidd spoiled cyclone ash injection. Adverse filter cake behavior was not observed in the tests, even though the reacted alkali sorbent would be relatively soft at the maximum test temperature.

The bench-scale HGF test data do not provide sufficient kinetic information to make large-scale HGF alkali removal performance estimates. Supplemental alkali kinetics testing performed in the program is reported in Appendix $\mathbf{C}$. 


\begin{tabular}{|c|c|c|c|c|c|}
\hline \multicolumn{6}{|c|}{ Table 5.8 - Alkali Removal Test Results (Test Series 5) } \\
\hline \multicolumn{6}{|c|}{$\begin{array}{l}\text { FIXED CONDITIONS: Face velocity } 7 \mathrm{ft} / \mathrm{min} \\
\text { Pressure } 100 \mathrm{psig} \\
\text { Temperature } 1550-1600^{\circ} \mathrm{F} \\
\text { Emathlite/NaCl ratio: } 10 \text { times saturation } \\
\text { Fly ash and emathlite mixed with } 5 \mathrm{wt} \% \mathrm{NaCl}\end{array}$} \\
\hline Test & $\begin{array}{c}\text { Probe } \\
\text { Temperature } \\
\left({ }^{\circ} \mathrm{F}\right)\end{array}$ & Fly Ash & Sorbent & $\begin{array}{l}\text { Cake Mass } \\
\text { Permeability } \\
\left(\mathrm{lb} / \mathrm{ft} \times 10^{-10}\right)\end{array}$ & $\begin{array}{l}\text { Outlet Gas } \\
\text { Alkali } \\
\text { (ppbv) }\end{array}$ \\
\hline 5.1 & No probe & None & $\begin{array}{l}\text { Emathlite } \\
\text { (no } \mathrm{NaCl} \text { ) }\end{array}$ & 4.3 & no $\mathrm{NaCl}$ \\
\hline 5.2 & 1200 & None & None & no cake & $\begin{array}{c}5 \\
\text { (background) }\end{array}$ \\
\hline 5.3 & 1330 & $\begin{array}{l}\text { Tidd spoiled } \\
\text { cyclone }\end{array}$ & None & 10 & 2 \\
\hline 5.4 & 1390 & None & Emathlite & - & 2 \\
\hline 5.5 & 1550 & $\begin{array}{l}\text { Tidd spoiled } \\
\text { cyclone }\end{array}$ & None & 7 & 4 \\
\hline 5.6 & 1550 & None & Emathlite & 8 & 18 \\
\hline 5.7 & 1550 & None & Emathlite & - & 15 \\
\hline 5.8 & 1550 & None & Emathlite & 9 & 5 \\
\hline 5.9 & 1550 & None & $\begin{array}{l}\text { Emathlite } \\
\text { and } \mathrm{SO}_{2} \\
(200 \mathrm{ppm})\end{array}$ & 4 & $\begin{array}{c}17 \\
\text { (about } 50 \% \\
\text { SO, removed) }\end{array}$ \\
\hline 5.10 & 1550 & None & Emathlite & 5.5 & 6 \\
\hline
\end{tabular}




\section{CONCLUSIONS AND RECOMMENDATIONS}

The bench-scale testing has shown that the ILEC concept is a viable extension of HGF technology for PFBC applications.

The bench-scale $\mathrm{SO}_{2}$ removal test results showed significant removal, though the results are uncertain. The results also indicated that dolomite injection will not generate adverse filter cake behavior, at least if the dolomite size is $\mathbf{- 3 2 5}$ mesh. Supplemental laboratory sorbent-sulfur oxide reaction kinetics testing and evaluation performed in this program provides estimates that a calcium-to-sulfur ratio of 1:5 to 2 should be sufficient to provide greater than $80 \%$ sulfur removal in the HGF.

Pulverized emathlite, and probably several other clays, could be injected into the HGF to achieve sufficient alkali removal for turbine protection. Again, the bench-scale alkali vapor removal test results are quite uncertain, but they do indicate that significant alkali removal can be obtained within the filter without adverse filter cake formation due to emathlite softening. Supplemental laboratory testing of alkali-sorbent reaction kinetics conducted in this program has produced estimates that a pulverized emathlite feed rate of about 10 times the saturation rate is sufficient to meet turbine alkali vapor criteria.

The bench-scale ILEC testing, combined with supplemental laboratory testing, HGF field test data and observations, and information from related technologies, indicates that the source of adverse filter cake behavior in PFBC, HGF applications is primarily filter cake calcium-constituent sintering induced by the gas phase $\mathrm{SO}_{2}$ and $\mathrm{CO}_{2}$. Reliable PFBC, $\mathrm{HGF}$ operation, without adverse filter cake behavior, can be maintained by selecting conditions, to the extent that the application allows, that promote slower filter cake sintering rates. Options available to accomplish this can be applied individually or in combination:

- reduced HGF temperature,

- increased filter cake particle size, 
- lower partial-pressures of $\mathrm{CO}_{2}$ and $\mathrm{SO}_{2}$

- use of dolomitic limestone rather than calcitic limestone in the PFBC

Pulverized dolomite ( -325 mesh) could be injected into the HGF to act both as a filter cake permeability aid, probably reducing the potential for hard filter cake and bridge formation, and to perform supplemental sulfur removal in the HGF. A feed rate of about $10 \mathrm{wt} \%$ dolomite, relative to the fly ash feed rate, should be ample for significant filter cake permeability enhancement.

It is expected that the ILEC concept can also be applied in other HGF applications, such as GCC, where the sorbent types and functions may differ substantially from those for PFBC. It is recommended that the ILEC concept be tested at available PFBC and GCC, HGF field facilities to provide larger scale, steady-state performance data on in-filter contaminant control functions, and their influence on the filtering performance. 


\section{REFERENCES}

Borgwardt, R. H., 1989, Calcium Oxide Sintering in Atmospheres Containing Water and Carbon Dioxide, Ind. Eng. Chem. Res., 28, 493.

Johnk, C., M. A. Friedman, and N. W. Andrews, 1995, Early Experience with Nova Scotia Power's Point Aconi Station, $165 \mathrm{MW}$ Ahlstrom Pyroflow CFB, Proceedings of 13th Int. Conf. on Fluidized Bed Combustion, May 1995, Kissimmee, Florida.

Newby, R. A., et al., May 1990, Integrated Low Emissions Cleanup System for Direct Coal Fueled Turbines, Phase I Final Report to DOE under Contract No. DEAC21-87MC24257.

Robertson, A., et al., Second-Generation PFBC Research and Development, Foster Wheeler Development Corporation, Phase 2 - Task 4 Circulating PFB Combustor, Volume I - Test Results, DOE Contract DE-AC21-86MC21023, October 1994.

Skrifvars, B-J., M. Hupa, and P. Hyoty, 1990, Superheater Fouling in Coal-Fired Boilers Due to Lime Injection, In Proceedings of the Second Nordic conference on control of sulfur and nitrogen oxides from combustion of solid fuels, Lyngby, Denmark, 12-13, November 1990. 


\section{APPENDIX A}

FILTER CAKE SINTERING LABORATORY TESTING

A-1 


\section{APPENDIX A}

\section{FILTER CAKE SINTERING LABORATORY TESTING}

Westinghouse has constructed and operated a small-scale test unit, the HTHP gas exposure unit, that can subject small samples of fly ashes or sorbents to simulated process conditions at high temperatures and high pressures. The unit is specifically designed to test the impact of process conditions on HGF filter cake sintering. The HTHP gas exposure unit is illustrated in Figure A.1. It consists of a pressure vessel that contains an electric tube heater. Along the axis of the heater, a quartz reactor tube is located. Simulated process gases of desired composition are mixed externally to the reactor tube and are passed through the tube, flowing downward. Contaminants such as $\mathrm{HCl}, \mathrm{SO}_{2}$, or $\mathrm{H}_{2} \mathrm{~S}$ can be included in the gas stream, and alkali vapors can be added, and monitored through evaporation of an alkali salt solution placed in the thermobalance pan within the reactor tube. At the base of the reactor tube, a ceramic filter disk is located to separate out particles injected into the gas, or to allow particles to be placed on the disk prior to a test run, to simulate a filter cake. It can simulate PFBC, gasification, and industrial gas environments and can subject filter cakes to gas exposure for relatively long time period, simulating the HGF environment.

Following the test exposure period, the filter cake "pellet" produced is removed from the unit and is qualitatively or quantitatively assessed for appearance and hardness. Ninety tests have been conducted on this unit as part of a Westinghouse in-house program, using PFBC filter drain ashes, as well as several limestones and dolomites that have been used as PFBC sorbents. The testing has shown under what conditions hard, strong pellets of PFBC ashes can be formed, and the results appear to be consistent with HGF field observations. Photos showing typical pellet appearance after exposure to three types of conditions (nitrogen exposure at $1500^{\circ} \mathrm{F}, \mathrm{CO}_{2}$ exposure at $1500^{\circ} \mathrm{F}$, and $\mathrm{SO}_{2}$ exposure at $1500^{\circ} \mathrm{F}$ ) are shown in Figure A.2. 


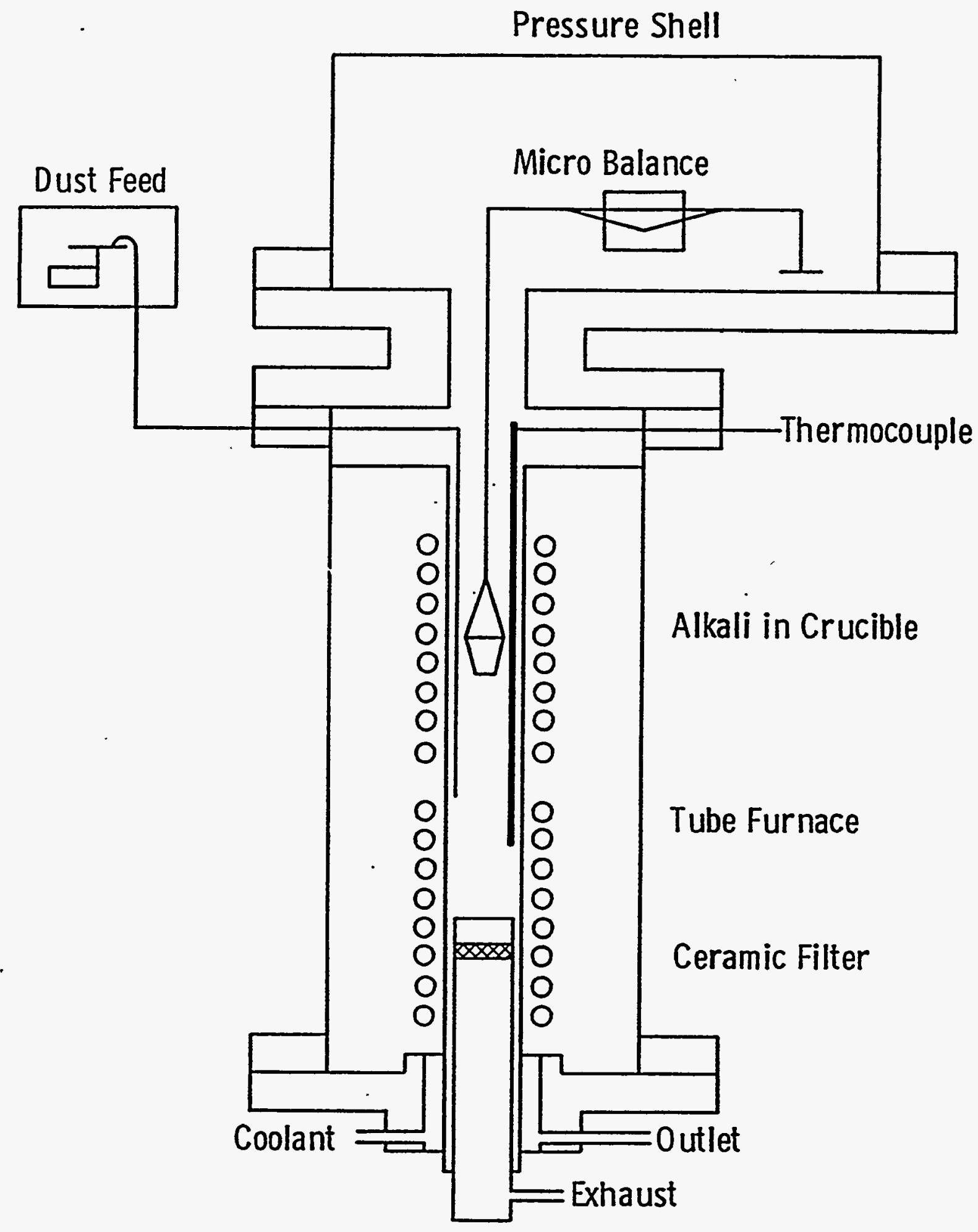

Figure A.1 - HTHP Gas Exposure Unit 


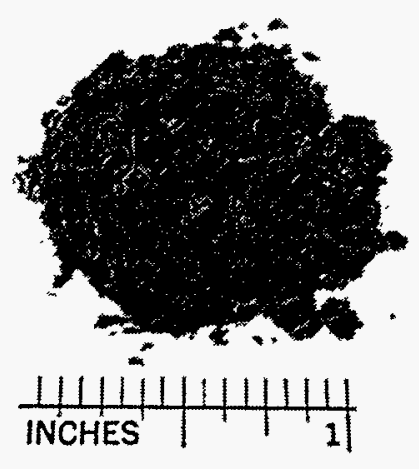

a) Packed Powder: crumbles to original loose powder state (hot $\mathrm{N}_{2}$ exposure of limestones and HGF drain samples)

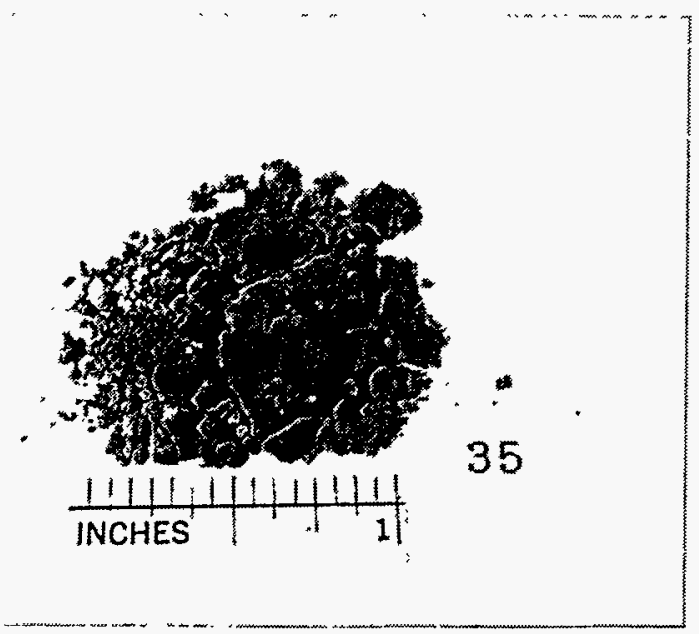

c) Agglomerated Pellet: breaks in a few hard agglomerates (hot $\mathrm{CO}_{2}$ exposure of limestones; hot $\mathrm{SO}_{2}$ exposure of $\mathrm{HGF}$ drain samples)

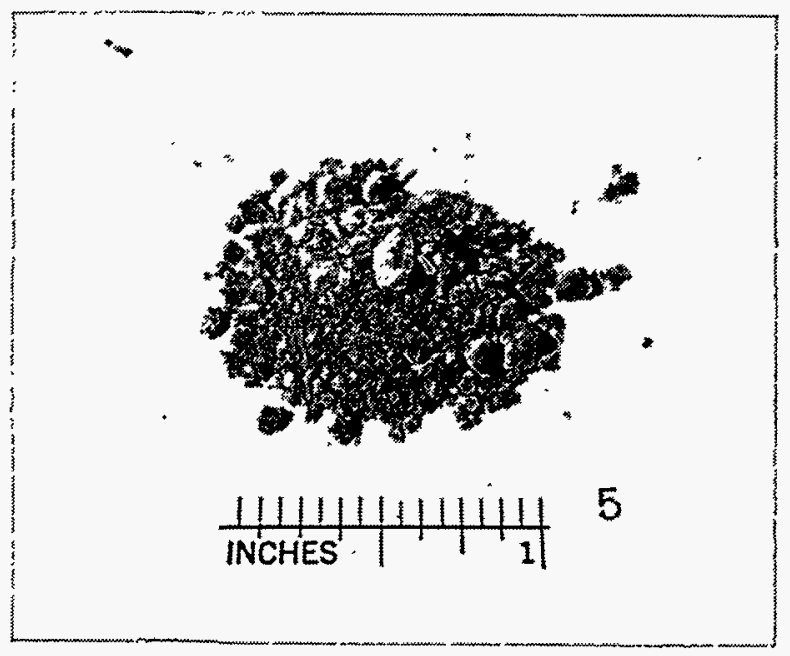

b) Loose Pellet: crumbles to soft agglomerates (hot $\mathrm{CO}_{2}$ exposure of HGF drain samples)

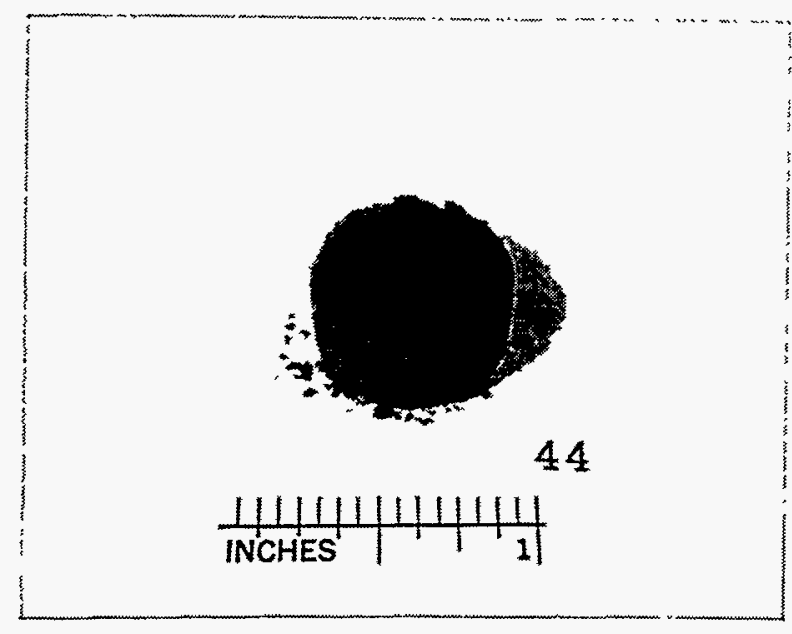

d) Strong Pellet: breaks with difficulty (hot $\mathrm{SO}_{2}$ exposure of limestones)

Figure A.2 - Representative HTHP Gas Exposure Pellet Photos 


\section{APPENDIX B}

SUPPLEMENTAL ENTRAINED SULFUR REMOVAL

LABORATORY TESTING

B-1 


\section{APPENDIX B}

\section{SUPPLEMENTAL ENTRAINED SULFUR REMOVAL \\ LABORATORY TESTING}

\section{B.1 Summary and Conclusions}

$\mathrm{SO}_{2}$ removal under entrained, calcium-based sorbent conditions representative of DCFT dilution zones has been evaluated by:

- developing a simple model of small, calcium-based particle sulfation kinetics

- developing a simple model for $\mathrm{SO}_{2}$ removal under cocurrent, entrained reactor conditions

- analyzing kinetic data collected by an atmospheric-pressure entrained test reactor (Milne, 1988), a 6-atmosphere entrained DCFT dilution zone (Solar Turbines), and the Westinghouse STC 10-atmosphere entrained reactor

- estimating commercial ILEC SO ${ }_{2}$ performance and limitations based on the kinetic data and models generated

It has been concluded that:

- The kinetic data produced by the three experimental sources considered are consistent and yield a general framework applicable to DCFT dilution zone conditions.

- The simple entrained reactor model is sufficient for simple reactor configurations where gas and particle flow are generally cocurrent and where large-scale mixing does not limit performance. In large-scale DCFT applications the injection and dispersion of sorbent particles into the gas stream must be very effective to give $\mathrm{SO}_{2}$ removal performance 
comparable to that reported here. In applications that use the ceramic barrier filter as an $\mathrm{SO}_{2}$ reaction chamber, such as the Westinghouse STC ILEC, the projected results are probably valid based on the observed flow patterns within such filters, with the exception that additional removal obtained on gas passage through the filter cake has not been estimated.

- The projected commercial performance of the $\mathrm{DCFT} \mathrm{SO}_{2}$ removal using the Westinghouse ILEC concept is sensitive to the temperature and the coal sulfur content for the three generic types of calcium-based sorbents considered. The optimum temperature appears to be about 1900 to $2000^{\circ} \mathrm{F}$. At temperatures above $2100^{\circ} \mathrm{F}$ the performance becomes thermodynamically limited for $90 \%$ sulfur removal. On a molar feed basis dolomitic limestone and hydrated lime appear to be almost comparable in performance, while on a mass feed basis dolomitic and calcitic limestones are nearly comparable.

- Possible concern for detrimental interactions between injected sulfur sorbent particles and coal ash/slag, and other injected materials (alkali sorbents, deposit additives) that may occur in the ILEC should be assessed when operating the integrated bench-scale tests.

\section{B.2 Kinetic Model}

It is postulated, based on past experimental observations reported in the literature on the $\mathrm{SO}_{2}$ reaction with very small calcium-based sorbents under highly mixed conditions, and at temperatures where thermodynamics do not limit the sulfur removal, that

- Sorbent particles injected into the gas are heated very quickly (on-theorder of 2-5 msec), calcine very quickly developing high porosity and surface area, and the surface area then begins to be reduced by sintering at a relatively slow rate when $\mathrm{SO}_{2}$ is present in the gas. 
- The initial rate of the $\mathrm{SO}_{2}$ reaction by chemisorption on the internal surface area of the sorbent particle is very fast, almost instantaneous, and for practical purposes some level of instantaneous, initial sulfation may be assumed.

- This initial, instantaneous reaction period is followed by a period where the reaction behaves as essentially diffusion controlled reaction through the sulfate product layer - the actual chemical reaction is so fast that its resistance may be neglected.

Mathematically, based on the above premises and simple shrinking core models

$$
\alpha=\alpha_{0}+\mathrm{k}\left(\mathrm{C}-\mathrm{C}^{*}\right)^{0.5} \mathrm{t}^{0.5}
$$

where $\alpha$ is the fraction of the calcium sulfated, $\alpha_{0}$ is the instantaneous sulfation fraction, $\mathrm{C}$ is the $\mathrm{SO}_{2}$ concentration in the gas, $\mathrm{C}^{*}$ is the equilibrium $\mathrm{SO}_{2}$ concentration at the bulk gas composition and temperature, and $t$ is the time. This simple form based on slab geometry is expected to be valid for conversions up to about $\mathbf{0 . 6}$, and at conversions above this the more complex form representing spherical particles must be used.

\section{B.3 Entrained Reactor Model}

A simple model of an entrained sulfur removal reactor can be developed by assuming the above kinetic expression along with:

- cocurrent flow of gas and injected particles with a very small particle acceleration time after injection into the gas and good lateral gas-particle mixing

- uniform and constant gas temperature and gas composition $\left(\mathrm{CO}_{2}, \mathrm{O}_{2}\right.$, $\mathrm{H}_{2} \mathrm{O}$ )

The resulting design equation, using the simple kinetic form of Equation B1 is

$$
\left(\mathrm{E}^{*}-\mathrm{E}\right)^{0.5}=\left[\mathrm{E}^{*}-(\mathrm{Ca} / \mathrm{S}) \alpha_{0}\right]^{0.5}-(\mathrm{Ca} / \mathrm{S}) \mathrm{C}_{\mathrm{o}}^{0.5} \mathrm{k} \mathrm{t}_{\mathrm{r}}^{0.5}
$$


where $E$ is the sulfur removal efficiency, $E^{*}$ is the sulfur removal efficiency at equilibrium at the prevailing temperature and inlet gas composition, $\mathrm{Ca} / \mathrm{S}$ is the molar calcium-to-sulfur feed ratio, $\mathrm{C}_{\mathrm{O}}$ is the $\mathrm{SO}_{2}$ concentration at the point of sorbent injection, and $t_{r}$ is the gas residence time, or sorbent-gas contact time in the system.

\section{B.4 Evaluation of Atmospheric-Pressure Entrained Data}

Milne (1988) collected and reported a large set of entrained sulfur removal data at atmospheric-pressure conditions in a gas-fired test system doped with $\mathrm{SO}_{2}$ that can be used to test the kinetic model and to characterize the sulfation rate factors $\alpha_{0}$ and $\mathrm{k}$. The Milne data probably represents the best and most detailed set of entrained sulfur removal data available in the literature. The following parameters were considered in the test program:

Sorbents:

Source: Linwood Limestone

Forms: raw limestone, precalcined limestone, hydrated lime, and precalcined hydrate

Temperatures: 1800 to $2150^{\circ} \mathrm{F}$ with most test runs at about $2000^{\circ} \mathrm{F}$ Gas Compositions: nominally $7.5 \% \mathrm{CO}_{2}, 14.05 \% \mathrm{H}_{2} \mathrm{O}$, and $\mathrm{O}_{2}$ varied from 5 to $8 \%$; $\mathrm{SO}_{2}$ ranged from 330 to $3100 \mathrm{ppmv}$ with most test runs at $2000 \mathrm{ppmv}$

Particle sizes:

raw limestone: 4.4 to $54 \mu \mathrm{m}$ mass-mean

precalcined limestone: 4.4 to $54 \mu \mathrm{m}$

hydrated lime: 1.9 to $42 \mu \mathrm{m}$

precalcined hydrate: 5.4 rm

Contact Times: 24 to $704 \mathrm{msec}$

Ca/S Ratio: 1 to 4.38 
Each of the sorbent materials was characterized for surface area, and in each test the sulfur removal efficiency was reported, ranging from $0.5 \%$ up to $66 \% .183$ data points where selected from the large data collection based on the quality of the data.

Plots of the selected Milne data are shown in Figures B.1 through B.9 showing the influence of $\mathrm{SO}_{2}$ concentration, temperature, and particle size and surface area on the fractional sulfation as a function of time. Nonlinear regression was used to fit the data to the proposed kinetic expression and to determine the best values for the parameters $\alpha_{0}$ and $\mathrm{k}$ for each set of operating conditions. The data was found to fit the proposed (time) ${ }^{0.5}$ form very closely. The ranges of the calculated parameter $\alpha_{0}$ were:

Raw Limestone: -.02 to 0.1

Precalcined Limestone: -.02 to 0.06

Hydrated Lime: 0 to 0.17

Precalcined Hydrate: insufficient data for correlation

Next, the best values for the two parameters were correlated as functions of the operating conditions using multiple regression techniques. The $\alpha_{0}$ term was found to be sensitive to the gas temperature, the particle diameter, and the gas $\mathrm{SO}_{2}$ content. The correlation form for $\alpha_{0}$ is:

$$
\alpha_{0}=\mathrm{A}+\mathrm{B} / \mathrm{d}+\mathrm{C}\left(\mathrm{Y}-\mathrm{Y}^{*}\right) / \mathrm{T}+\mathrm{D} \mathrm{T}
$$

where $d$ is the mass-mean particle diameter $(\mu \mathrm{m}), Y$ is the volume fraction $\mathrm{SO}_{2}$ in the inlet gas, $\mathrm{Y}^{*}$ is the equilibrium volume fraction $\mathrm{SO}_{2}$, and $\mathrm{T}$ is the absolute gas temperature $(R)$. The coefficient values and standard error of the correlations are
A
B
C
D
Standard

$\begin{array}{lllrll}\text { Raw Limestone } & -0.0237 & 0.561 & -11,222 & 0 & 0.00559 \\ \text { Precalcined Limestone } & -0.0029 & 0.363 & -24,714 & 0 & 0.00589 \\ \text { Hydrated Lime } & -1.1279 & 0.274 & 57,857 & 0.00045 & 0.0219\end{array}$




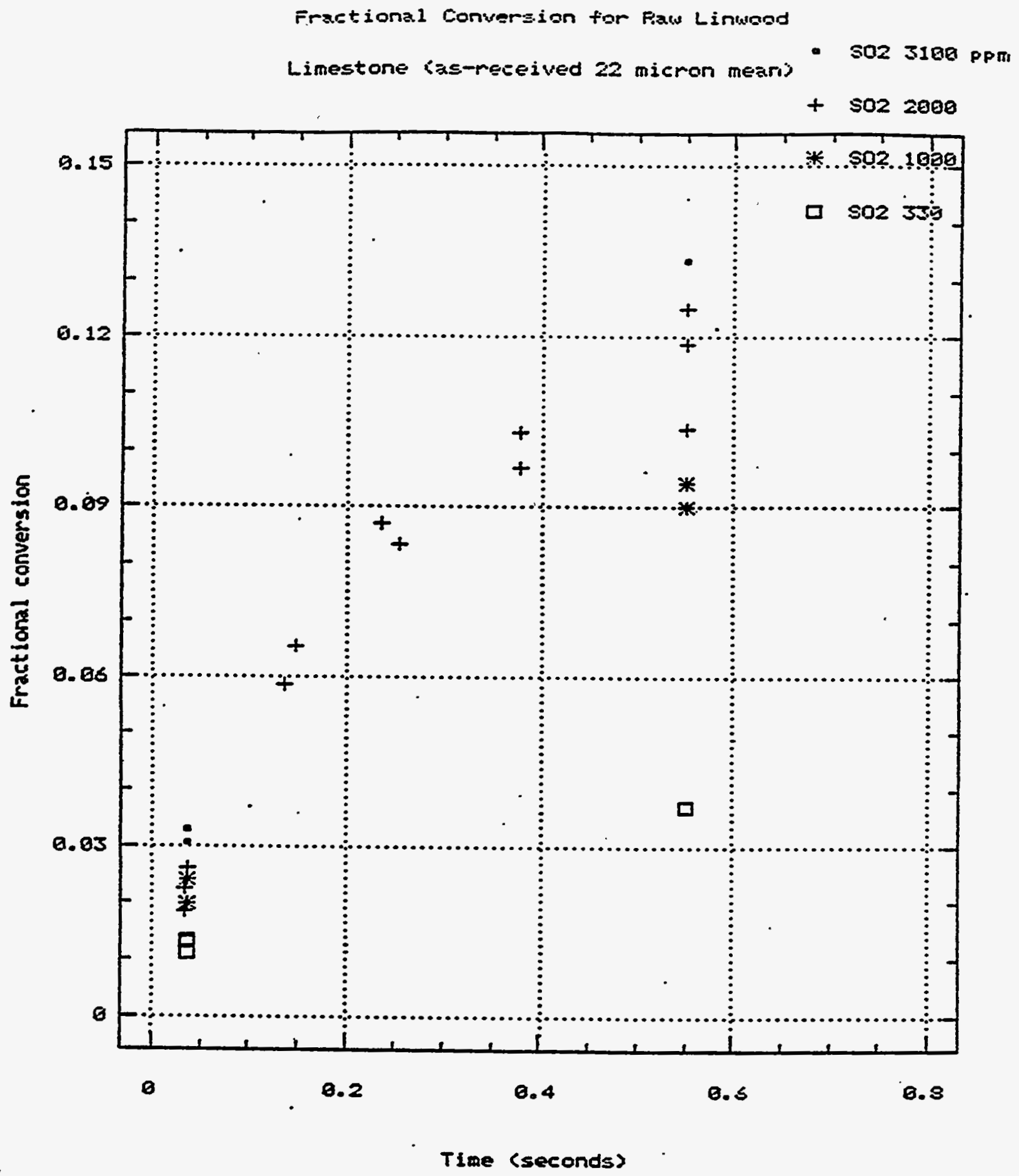

Figure B.1 - Milne Data for Raw Linwood Limestone as a Function of the $\mathrm{SO}_{2}$ Content at $2000^{\circ} \mathrm{F}$ 


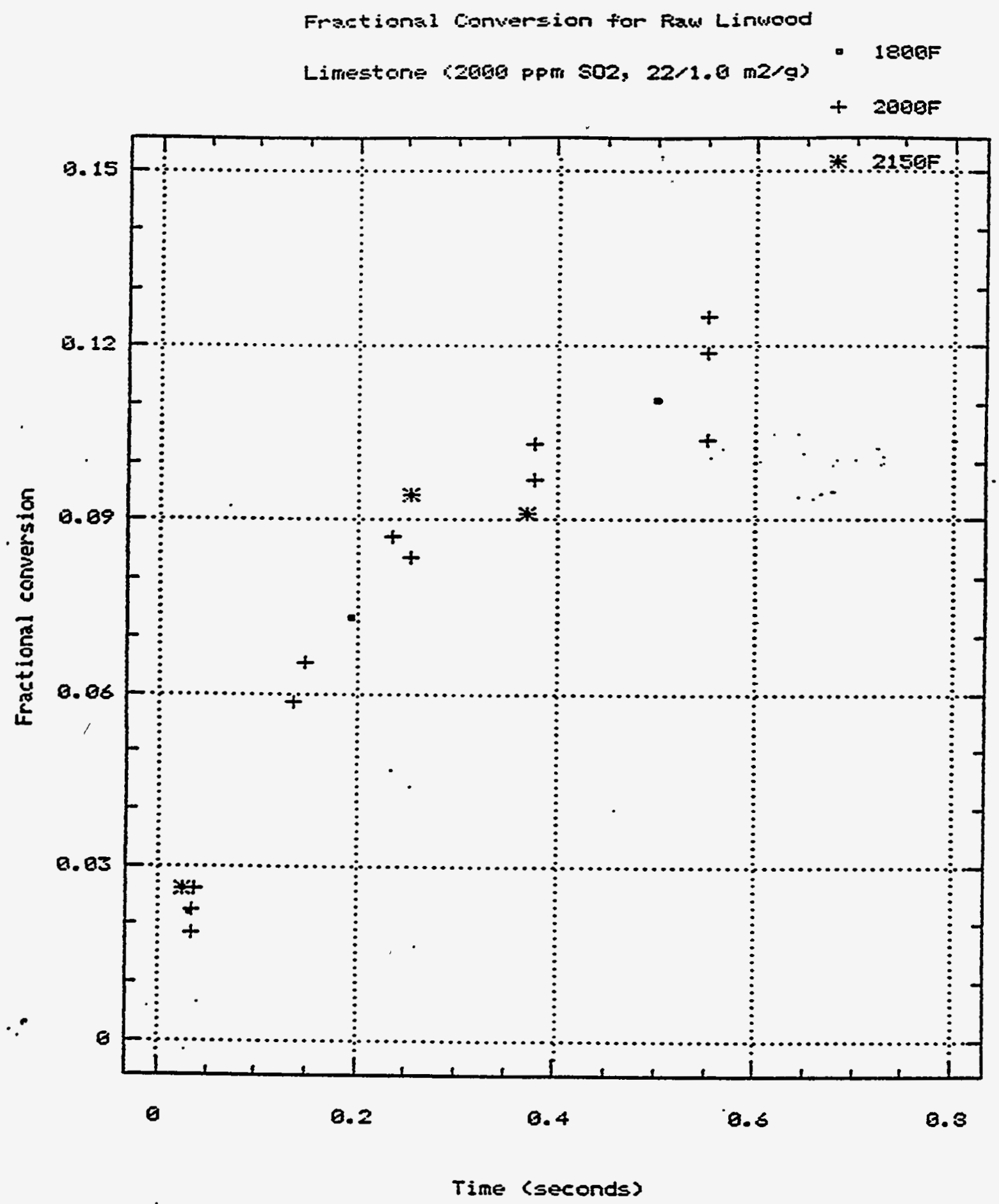

Figure B.2 - Milne Data for Raw Linwood Limestone as a Function of Temperature at an $\mathrm{SO}_{2}$ Content of $2000 \mathrm{ppmv}$ 


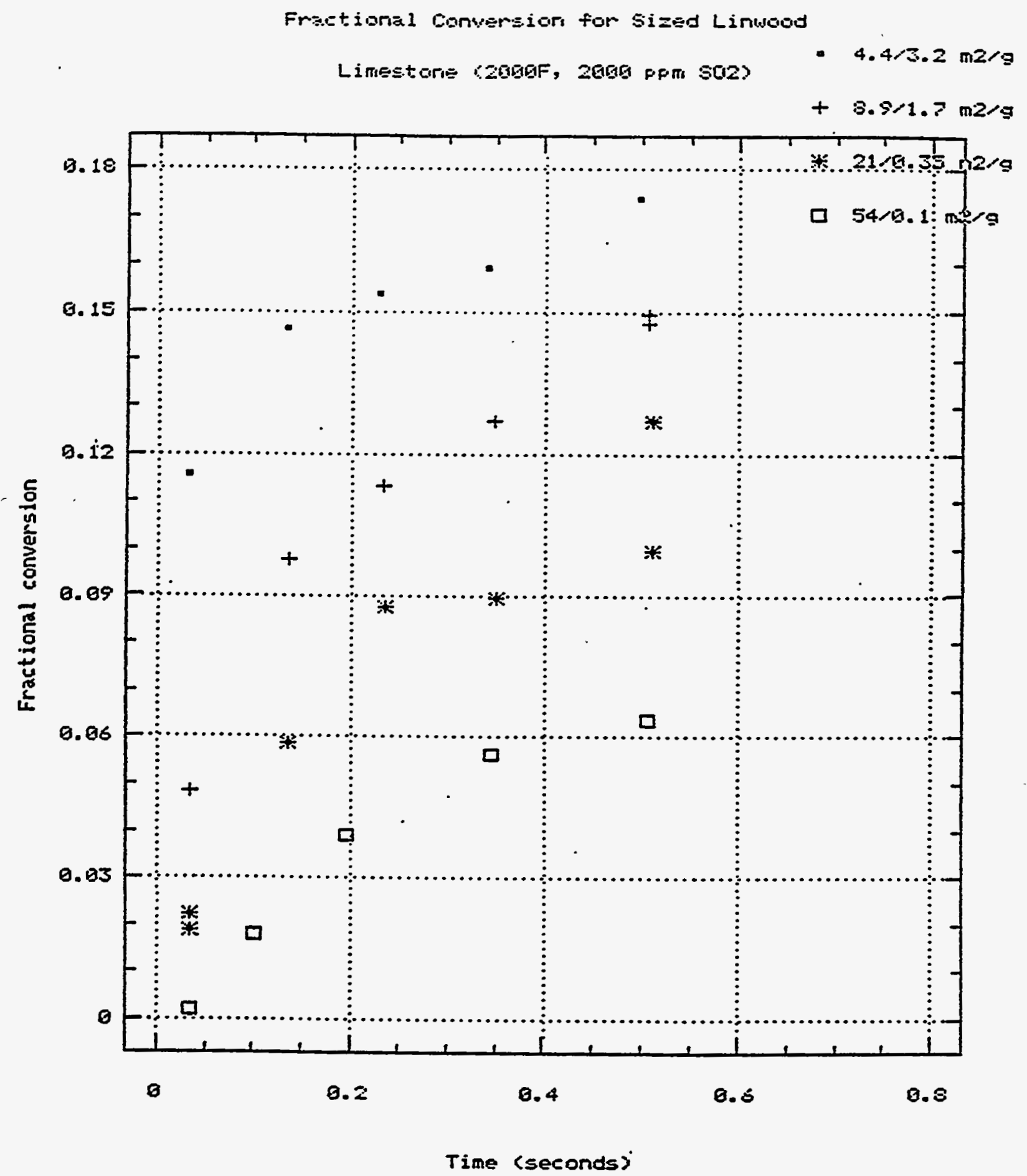

Figure B.3 - Milne Data Showing Effect of Particle Mean Diameter $(\mu \mathrm{m})$ and Specific Surface Area $\left(\mathrm{m}^{2} / \mathrm{g}\right)$ 


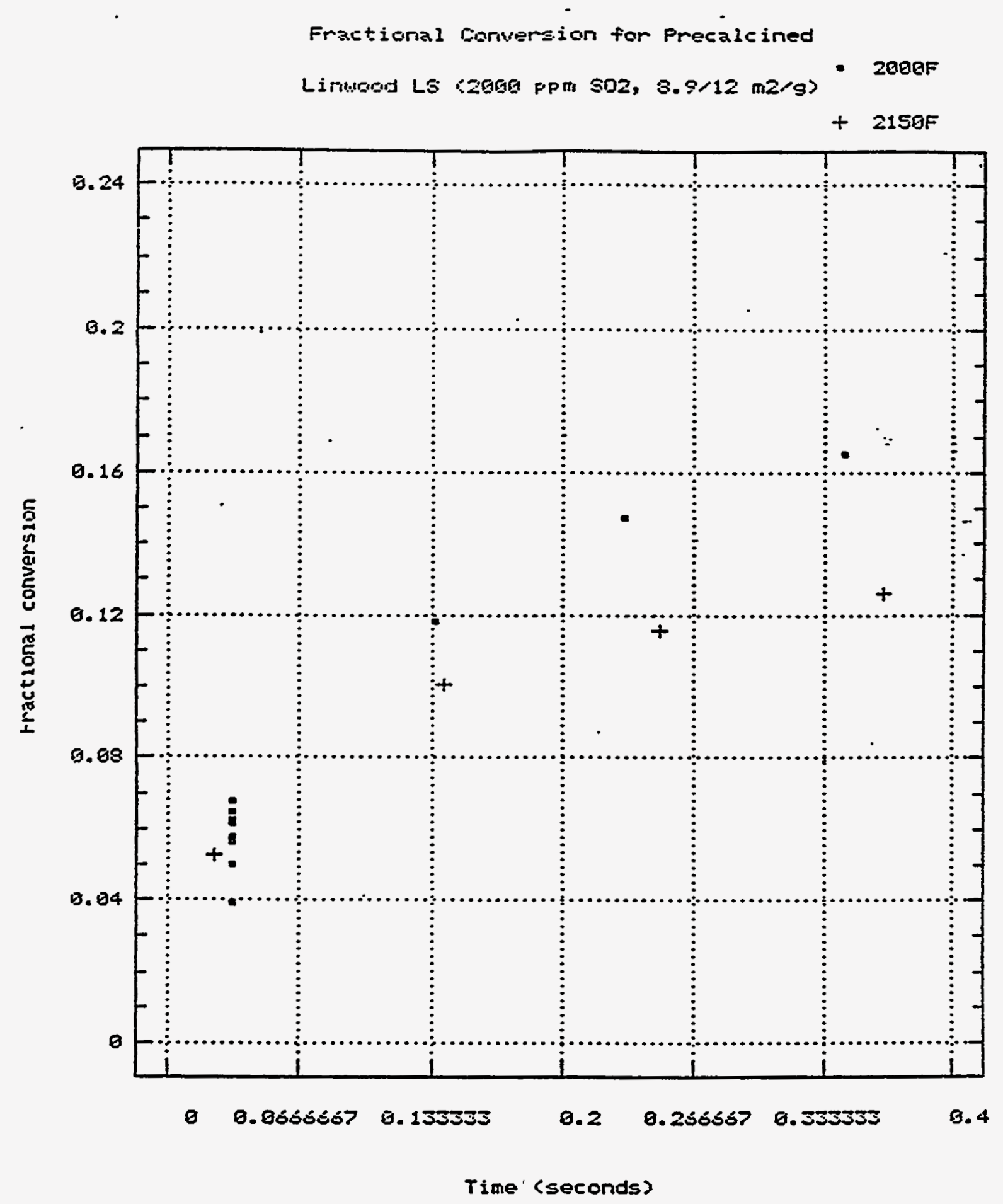

Figure B.4 - Milne Data for Precalcined Limestone as Function of Temperature 


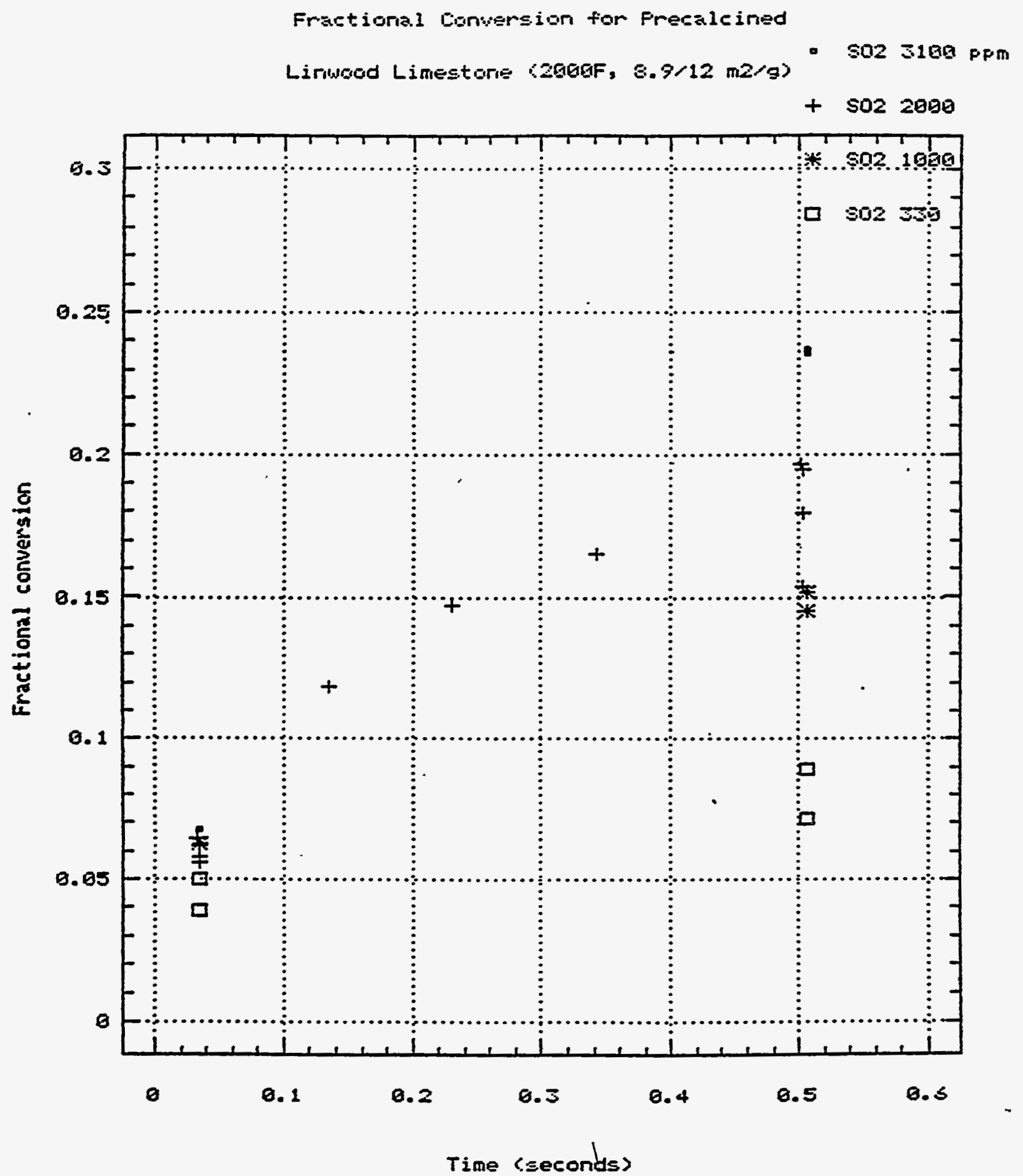

Figure B.5 - Milne Data for Precalcined Limestone Showing Effect of $\mathrm{SO}_{2}$ Content at $2000^{\circ} \mathrm{F}$ 


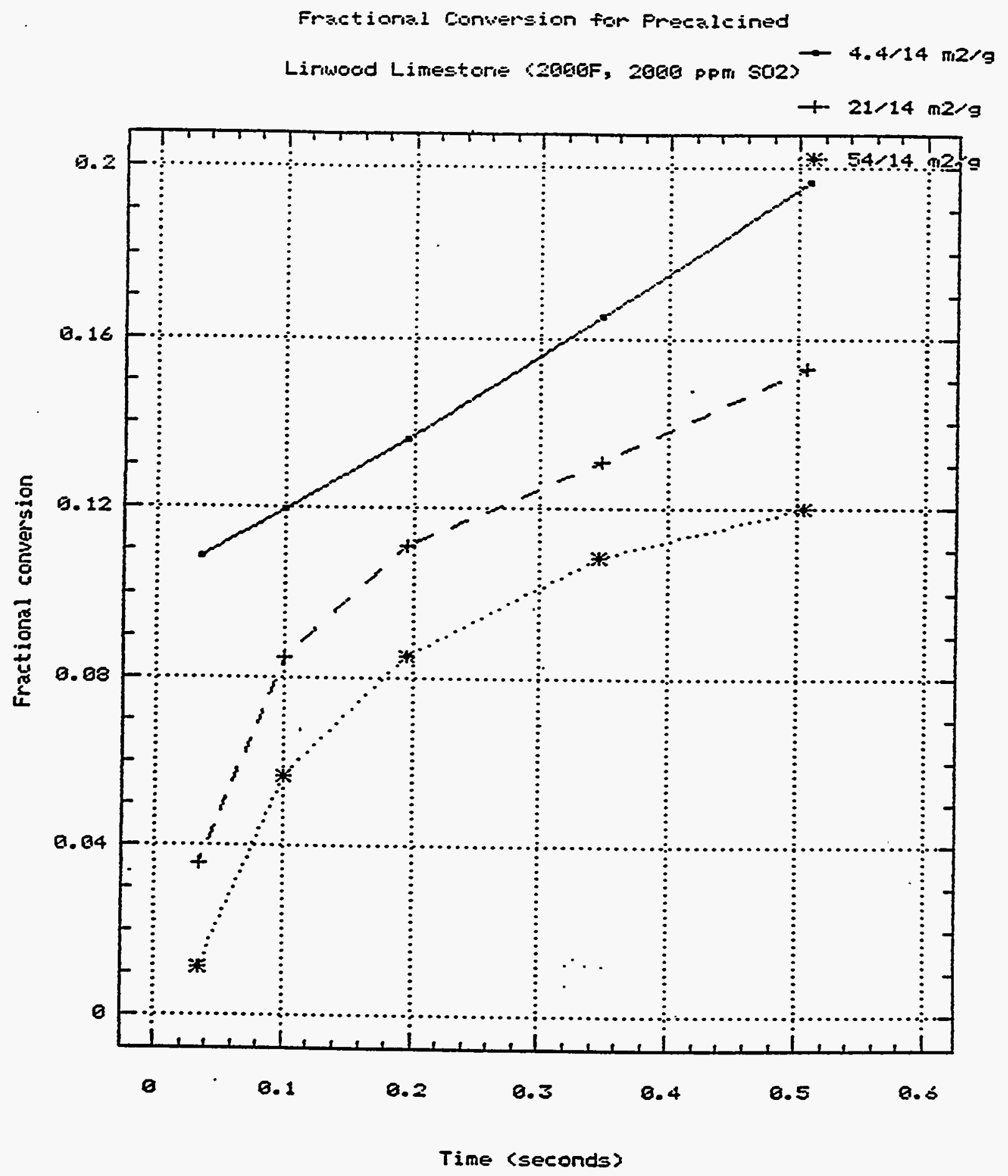

Figure B.6 - Milne Data for Precalcined Limestone Showing Effect of Particle Mean Diameter $(\mu \mathrm{m})$ and Specific Surface Area $\left(\mathrm{m}^{2} / \mathrm{g}\right)$ 


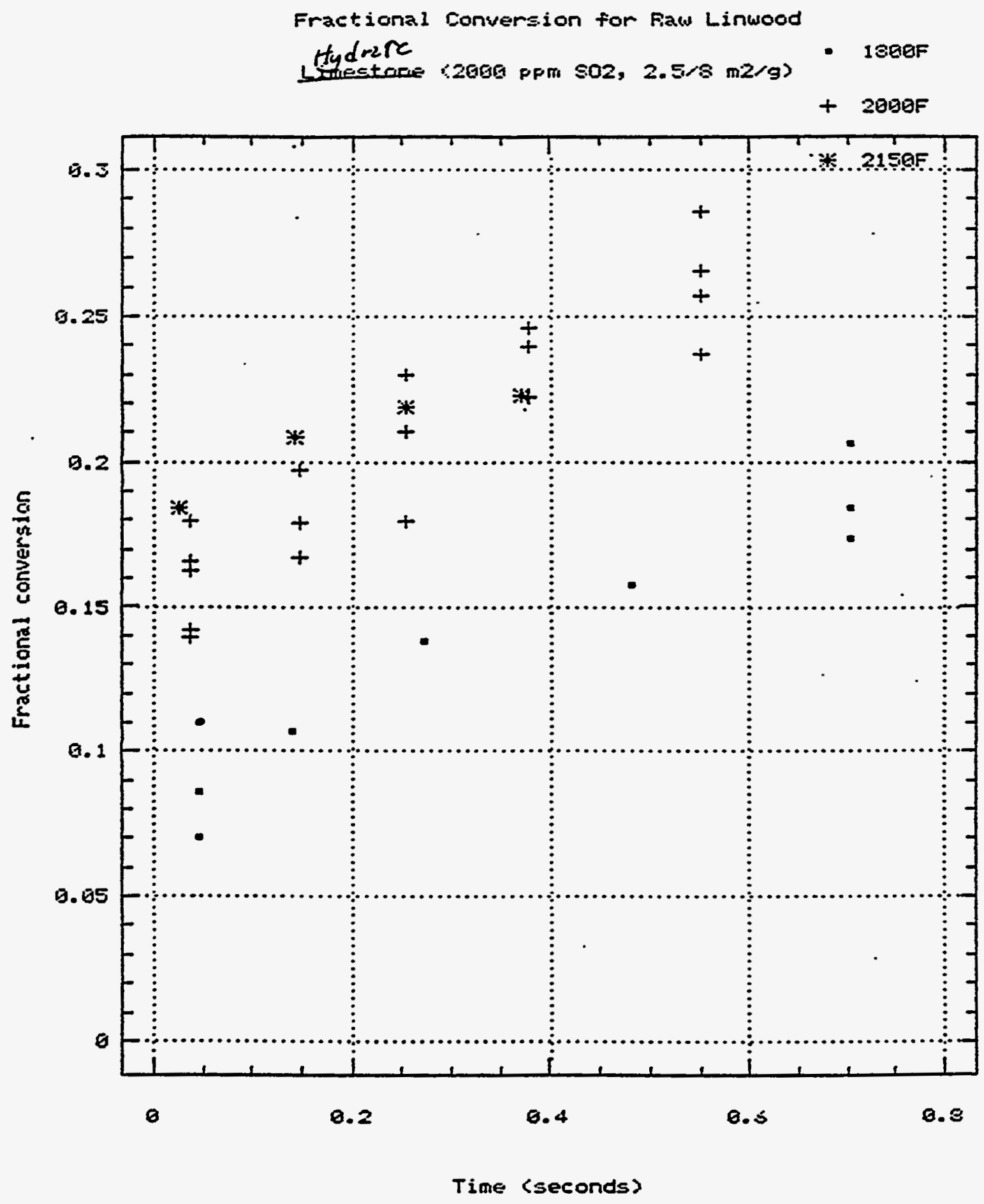

Figure B.7 - Milne Data for Raw Linwood Hydrate as Function of Temperature 


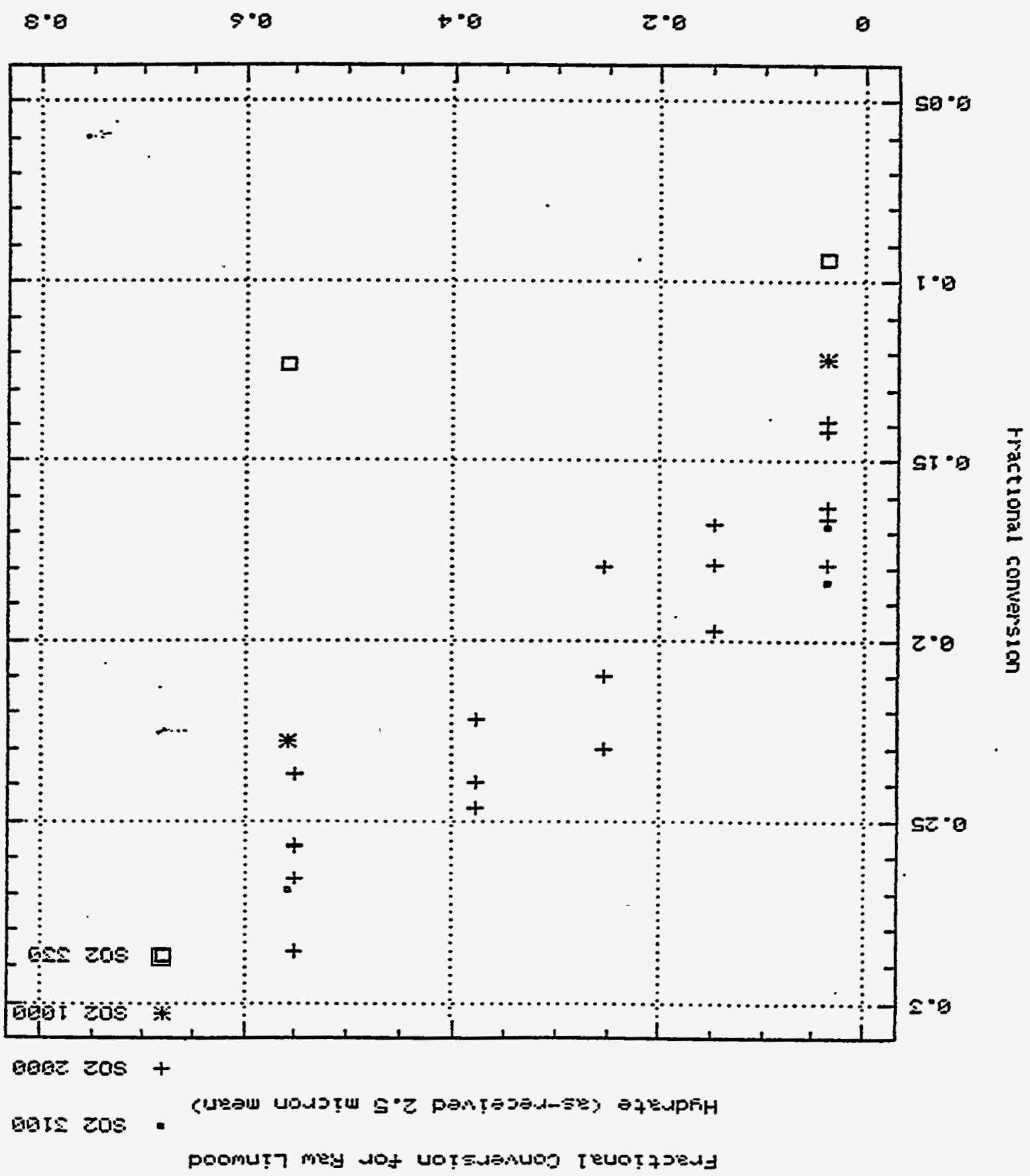




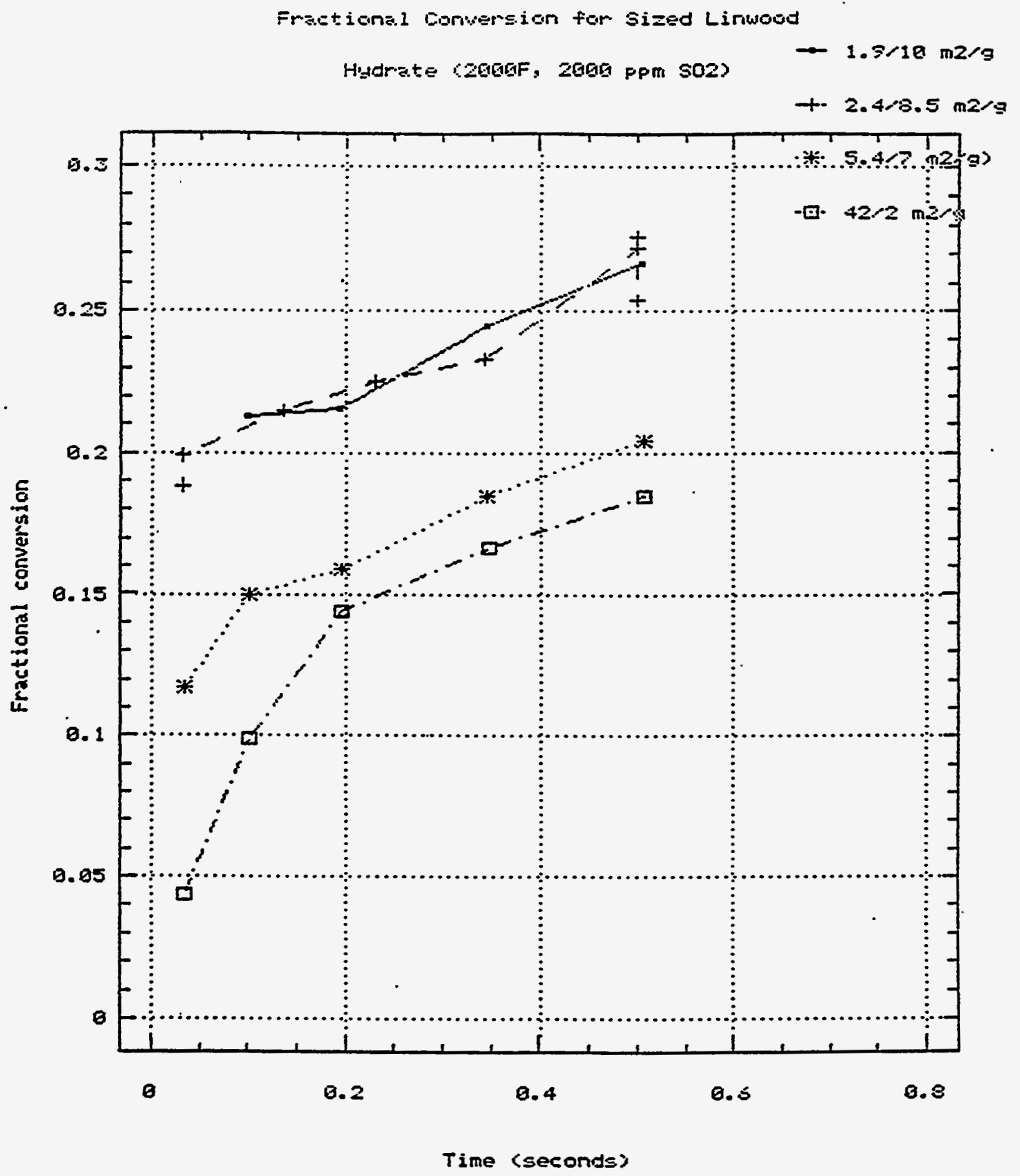

Figure B.9 - Milne Data for Linwood Hydrate Showing Effect of Particle Mean Diameter $(\mu \mathrm{m})$ and Specific Surface Area $\left(\mathrm{m}^{2} / \mathrm{g}\right)$ 
Plots of the data points against the correlation predicted values are shown in Figures B.10, B.11, and B.12.

The values of the rate constants $k$, expressed in units of $1 /\left(\text { sec-mole/ } \mathrm{ft}^{3}\right)^{0.5}$, were found to be insensitive to the operating parameters and had average values in the tests of

Raw Limestone: $81.4+-15.7$

Precalcined Limestone: $106.4+-26.3$

Hydrated Lime: $107.2+-25.4$

Precalcined Hydrate: 102.1

\section{B.5 Evaluation of Solar Turbine Entrained Data}

Solar Turbines has conducted $\mathrm{SO}_{2}$ removal tests in their DCFT test facility that have been reported in their semi-annual report to DOE (Dec. 1988 - June 1989). Tests were conducted with a dolomitic limestone, a pressure-hydrated dolomitic lime (PHDL) and a hydrated lime (HL) operating with a nominal inlet temperature to the dilution zone of $1850^{\circ} \mathrm{F}$, a gas pressure of $75 \mathrm{psig}$, and nominal residence time of 150 to $200 \mathrm{msec}$. While detailed data was not presented, estimates were made of some of the parameters used in the testing, and these are compiled in Table B.1.

The particle diameter listed (d) is the estimated mass-mean diameter for the sorbents. Note that a relatively large dolomitic limestone size was used in these tests. The temperature listed is the estimated mean temperature within the dilution reaction zone during the tests.

Figure B.13 plots the Solar data in a form suggested by the simple model if it is assumed that the equilibrium value of $E$ is very nearly unity, and that the term $\alpha_{0}$ is zero:

$$
(1-E)^{0.5}=1-(\mathrm{Ca} / \mathrm{S}) \mathrm{C}_{0} 0.5 \mathrm{k} \mathrm{tr}^{0.5}
$$


Filot of MB.30 SELECT MI.SOrb EQ 3

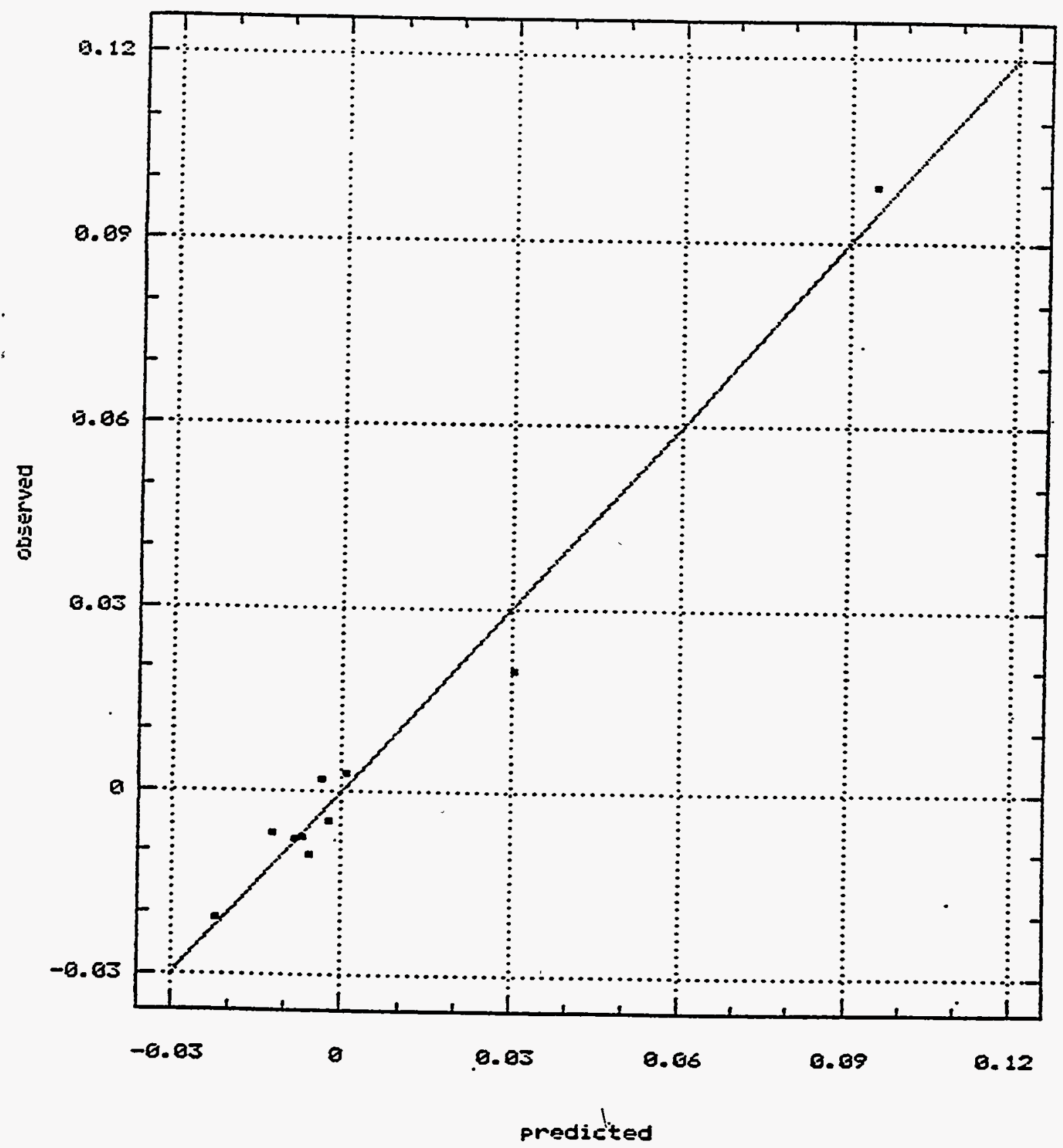

Figure B.10 - Correlation of a $\alpha_{0}$ from Milne Data for Linwood Limestone 
Plot of M3.30 BELECT MS. sarb EQ \&

$(\because 1 E-3)$

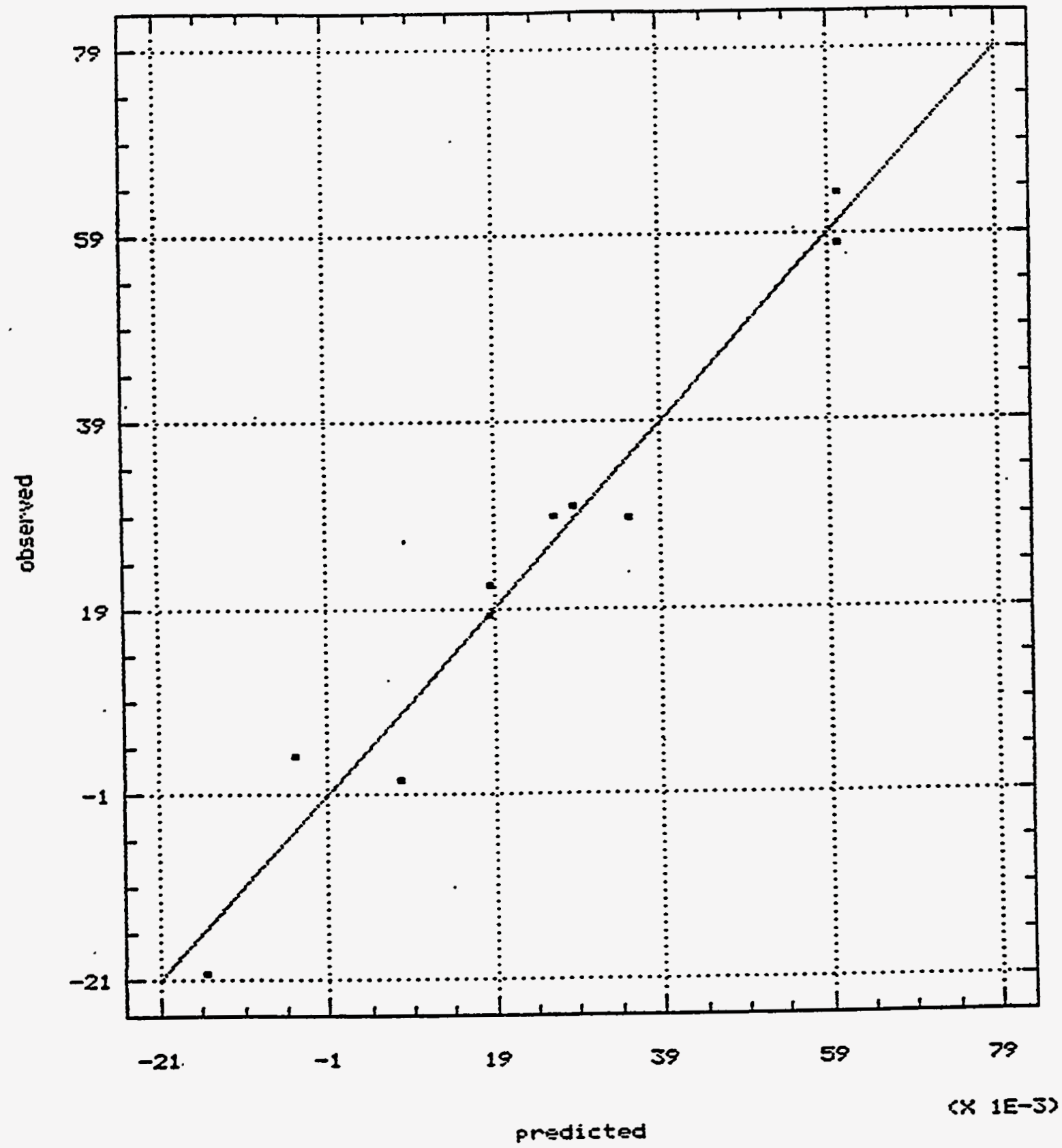

Figure B.11 - Correlation of $\alpha_{0}$ from Milne Data for Precalcined Limestone 
Flat of MS.SO SELECT ME.sorb EQ 1

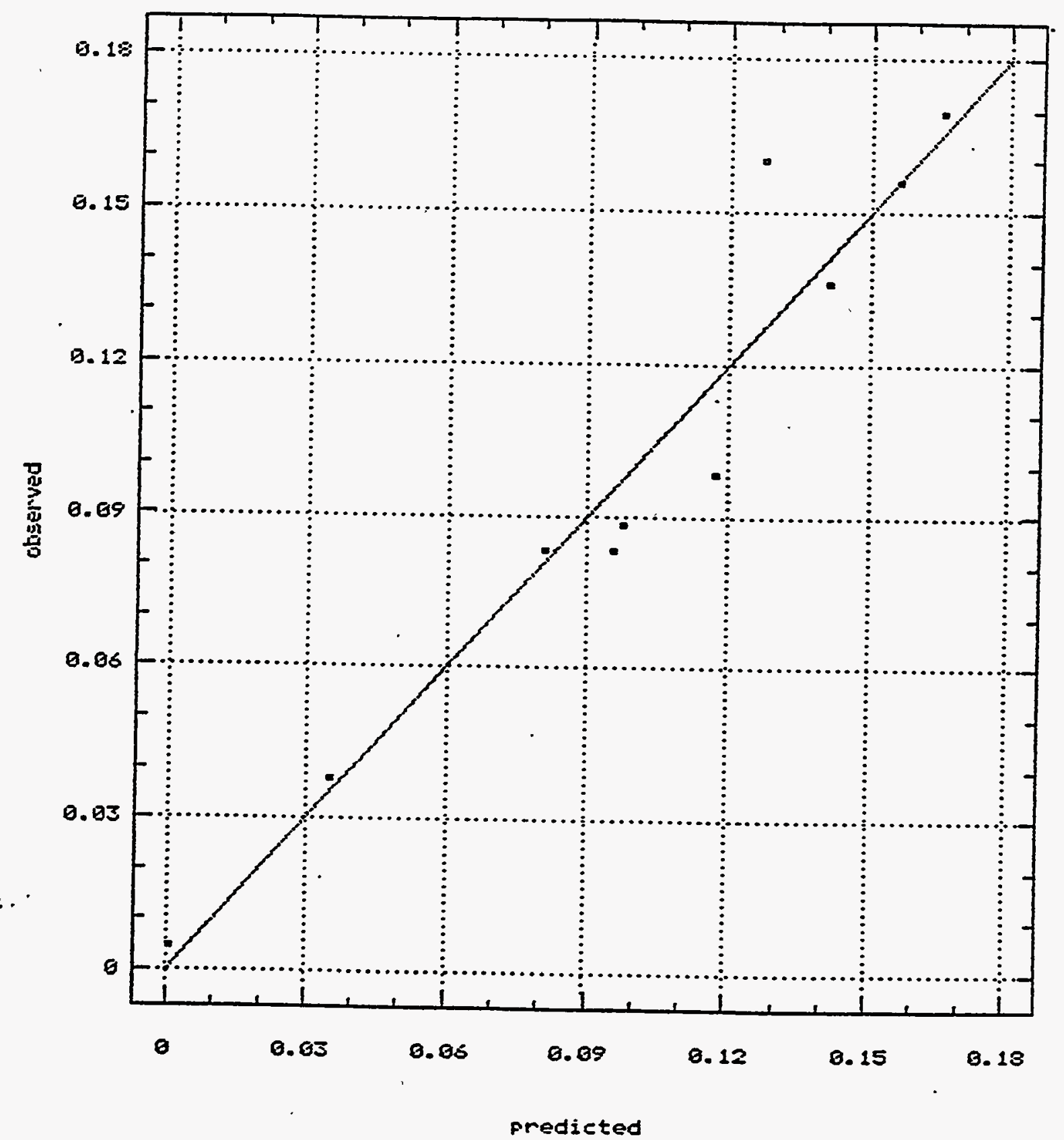

Figure B.12 - Correlation of $\alpha_{0}$ from Milne Data for Linwood Hydrate 


\begin{tabular}{|r|l|c|c|c|c|c|c|}
\hline \multicolumn{7}{|c|}{ Table B.1 - Solar Turbine $\mathrm{SO}_{2}$ Removal Test Conditions and Performance } \\
\hline $\begin{array}{r}\text { Test } \\
\text { No. }\end{array}$ & $\begin{array}{c}\text { Sorbent } \\
\text { Type }\end{array}$ & $\begin{array}{c}\mathrm{d} \\
(\mu \mathrm{m})\end{array}$ & $\begin{array}{c}\mathrm{T} \\
(\mathrm{F})\end{array}$ & $\begin{array}{c}\mathrm{Y}_{\mathrm{o}} \\
(\mathrm{ppmv})\end{array}$ & $\begin{array}{c}\mathrm{t}_{r} \\
(\mathrm{msec})\end{array}$ & $\mathrm{Ca} / \mathrm{S}$ & $\begin{array}{c}\mathrm{E} \\
(\%)\end{array}$ \\
\hline $29-1$ & Dolomitic & 65 & 1791 & 205 & 200 & 0.94 & 10 \\
-2 & limestone & & & & & 1.0 & 13 \\
-3 & & & & & & 2.75 & 43 \\
-4 & & & & & & 2.80 & 52 \\
-5 & & & & & & 4.7 & 85 \\
-6 & & & & & & 5.75 & 91 \\
\hline $31-1$ & PHDL & 10 & 1794 & 307 & 200 & 0.55 & 11 \\
-2 & & & & & & 1.1 & 44 \\
-3 & & & & & & 2.9 & 84 \\
-4 & & 5 & 1818 & 251 & 200 & 1.1 & 49 \\
\hline $32-1$ & Hydrated & 5 & & & & 2.0 & 92 \\
-2 & lime & & & & & 3.0 & 88 \\
\hline
\end{tabular}


Curve 783673-A

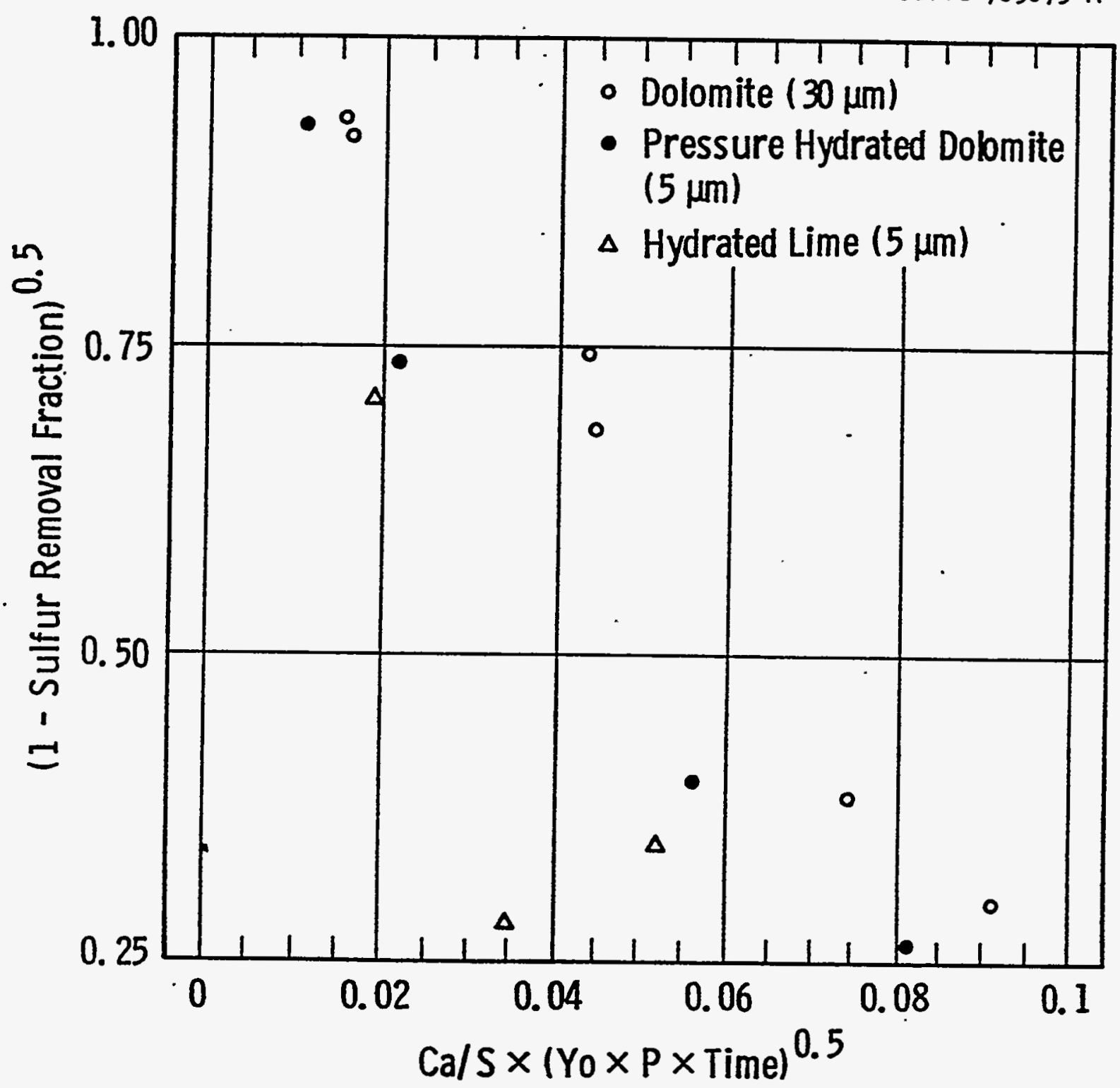

Figure B.13 - Comparison of Solar Turbine Sulfur Removal Data with Model Form 
The plot shows a generally linear behavior as expected. Sufficient data is not available to estimate the values of $\alpha_{0}$, but if the simpler form above is used, the best values of the factor $k$ can be estimated:

Dolomitic Limestone: $305.91 /\left(\text { sec-mole/ft }{ }^{3}\right)^{0.5}$

PHDL: 394.4

Hydrated Lime: 610.9

The differences in the three $\mathrm{k}$ values relate directly to the differences in the physical characteristics of the three test sorbents.

\section{B.6 Generation and Evaluation of Westinghouse Entrained Data}

The Westinghouse pressurized entrained reactor was operated as described in the program test plan following the modified test matrix shown in Table B.2. These tests differ from the tests conducted by Milne and Solar Turbines in that the $\mathrm{SO}_{2}$ content of the test gas is essentially fixed at a constant value throughout the reactor in the Westinghouse tests by operating with very low $\mathrm{Ca} / \mathrm{S}$ ratio, and the performance is determined by analyzing the product sorbents for their extent of sulfation. Twenty-seven tests, including replicates, have been completed in this phase of the program, looking primarily at the influence of temperature and residence time on the extent of sulfation. Additional tests are identified in the test matrix to confirm the effects of pressure and $\mathrm{SO}_{2}$ concentration, but will not be conducted until these initial test results are assessed.

The test data generated in this phase of the program has been compiled with the test results obtained in the earlier phase of the program to check the consistency of the data and conclusions. This results in a data base of 43 points over a broad range of conditions:

Sorbent Type: dolomitic limestone, calcitic limestone, hydrated

lime, hydrated dolomitic lime

Particle Size: primarily $\mathbf{- 3 2 5}$ mesh or as commercially-received 


\begin{tabular}{|c|c|c|c|c|}
\hline Sorbent & $\begin{array}{c}\text { Temperature } \\
\left({ }^{\circ} \mathrm{F}\right)\end{array}$ & $\begin{array}{l}\text { Pressure } \\
\text { (atm) }\end{array}$ & $\begin{array}{c}\mathrm{SO}_{2} \\
\text { (vol\%) }\end{array}$ & $\begin{array}{l}\text { Time } \\
\text { (sec) }\end{array}$ \\
\hline Dolomite & 1850 & 10 & 0.3 & $\begin{array}{l}0.1 \\
0.2 \\
0.3 \\
\end{array}$ \\
\hline Limestone & 1850 & 10 & 0.3 & $\begin{array}{l}0.1 \\
0.2 \\
0.3 \\
\end{array}$ \\
\hline Hydrated lime & 1850 & 10 & 0.3 & $\begin{array}{l}0.1 \\
0.2 \\
0.3\end{array}$ \\
\hline Dolomite & 2100 & 10 & 0.3 & $\begin{array}{l}0.1 \\
0.2 \\
0.3\end{array}$ \\
\hline Limestone & 2100 & 10. & 0.3 & $\begin{array}{l}0.1 \\
0.2 \\
0.3 \\
\end{array}$ \\
\hline Hydrated lime & 2100 & 10 & 0.3 & $\begin{array}{l}0.1 \\
0.2 \\
0.3\end{array}$ \\
\hline Dolomite & 1850 & $\begin{array}{c}10 \\
6 \\
15\end{array}$ & $\begin{array}{l}0.1 \\
0.5 \\
0.1 \\
0.3 \\
0.5 \\
0.1 \\
0.3 \\
0.5\end{array}$ & 0.2 \\
\hline Hydrated lime & 1850 & $\begin{array}{c}10 \\
6 \\
15\end{array}$ & $\begin{array}{l}0.1 \\
0.5 \\
0.1 \\
0.3 \\
0.5 \\
0.1 \\
0.3 \\
0.5\end{array}$ & 0.2 \\
\hline
\end{tabular}


Temperature (Nominal): $1850-2300^{\circ} \mathrm{F}$

Pressure: $10 \mathrm{~atm}$

Gas Composition: $\mathrm{O}_{2} 5$ - 10 vol\%, $\mathrm{CO}_{2} 0$ - 10 vol\%, $\mathrm{SO}_{2} 3000-5000 \mathrm{ppmv}$

Contact Time: $80-267 \mathrm{msec}$

Following the testing and sorbent analyses the actual temperature profiles existing within the entrained reactor were measured and found to have significant temperature gradients in the reaction zone that were used to obtained mean temperatures of exposure during the tests. In most cases tests that were conducted with longer contact times in any series of runs resulted in higher mean temperature exposure, so the two variables were not really independently varied in the tests.

Values of the constant $\mathrm{k}$ were determined from the data, assuming the term $\alpha_{0}$ is zero, and are plotted in Figures B.14 through B.17 as a function of the gas temperature for dolomitic limestone, calcitic limestone, hydrated lime, and dolomitic hydrate. The inconsistent behavior of the data with respect to the temperature is due to the two temperature zones that resulted in the reactor during the Westinghouse tests. The rate constants extracted from the Solar tests and from the Milne data are also plotted in the figure, and are consistent with the Westinghouse tests.

\section{B.7 Projection of Commercial ILEC Sulfur Removal Performance}

The simple entrained reactor model developed here can be used to estimate the expected performance of the commercial Westinghouse STC ILEC concept. The following conditions are considered:

Sorbent Type: dolomitic limestone, calcitic limestone, hydrated lime

Particle Size: -325 mesh, commercial grade

Dilution Gas Temperature: 1850 and $2100^{\circ} \mathrm{F}$

Pressure: 10 atm 


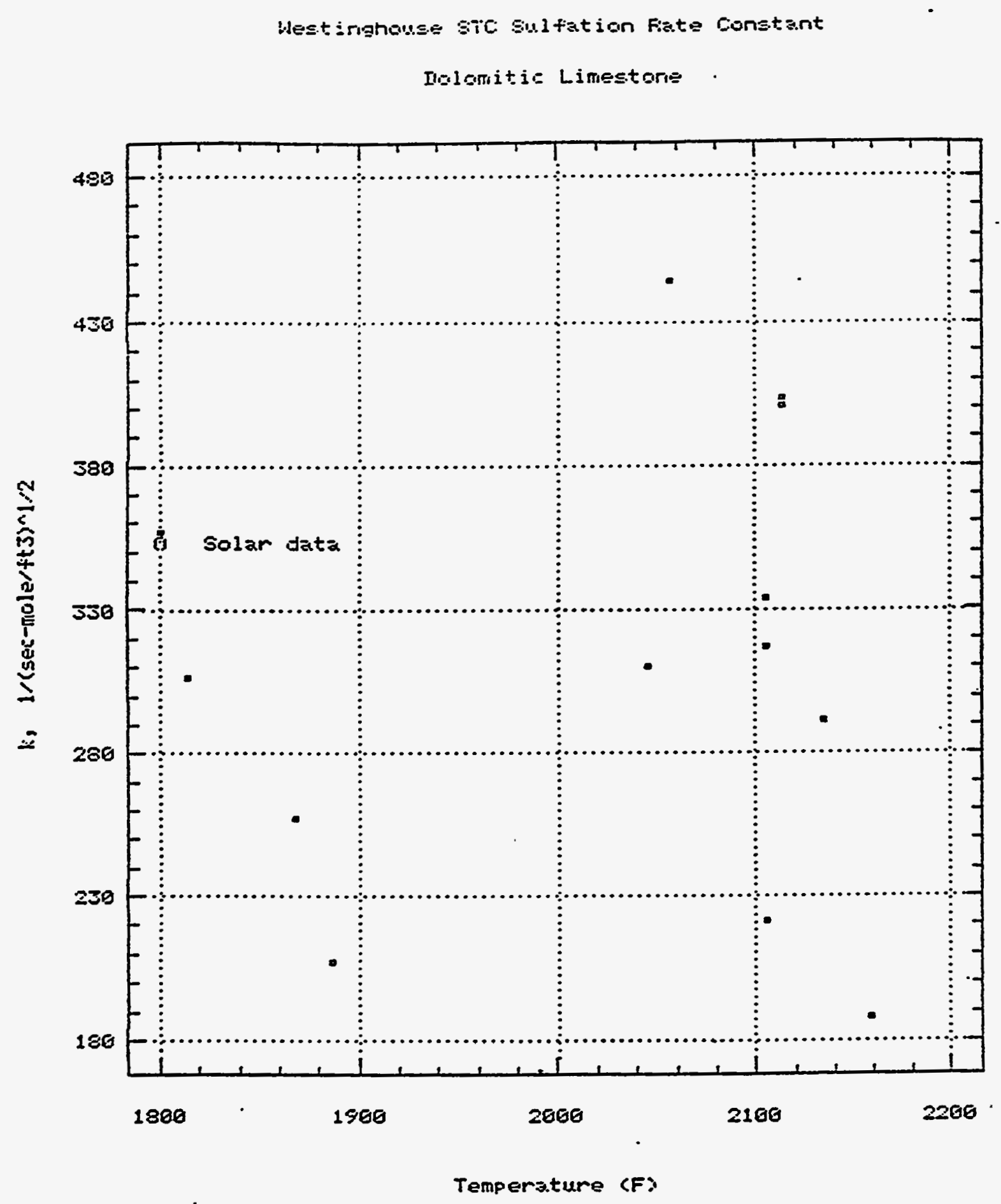

Figure B.14 - Westinghouse STC Rate Constant for Dolomite Limestone 

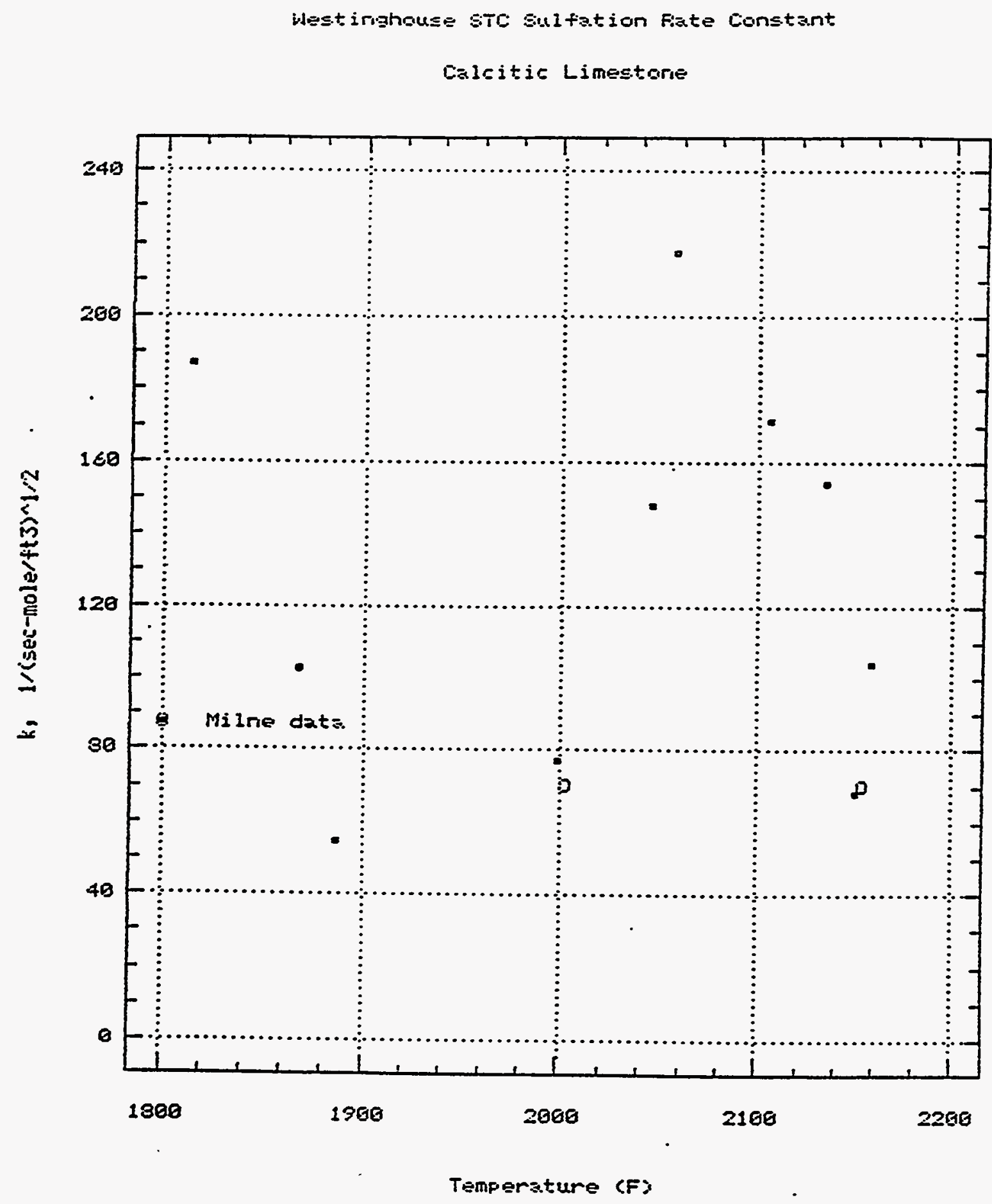

Figure B.15 - Westinghouse STC Rate Constant for Calcitic Limestone 


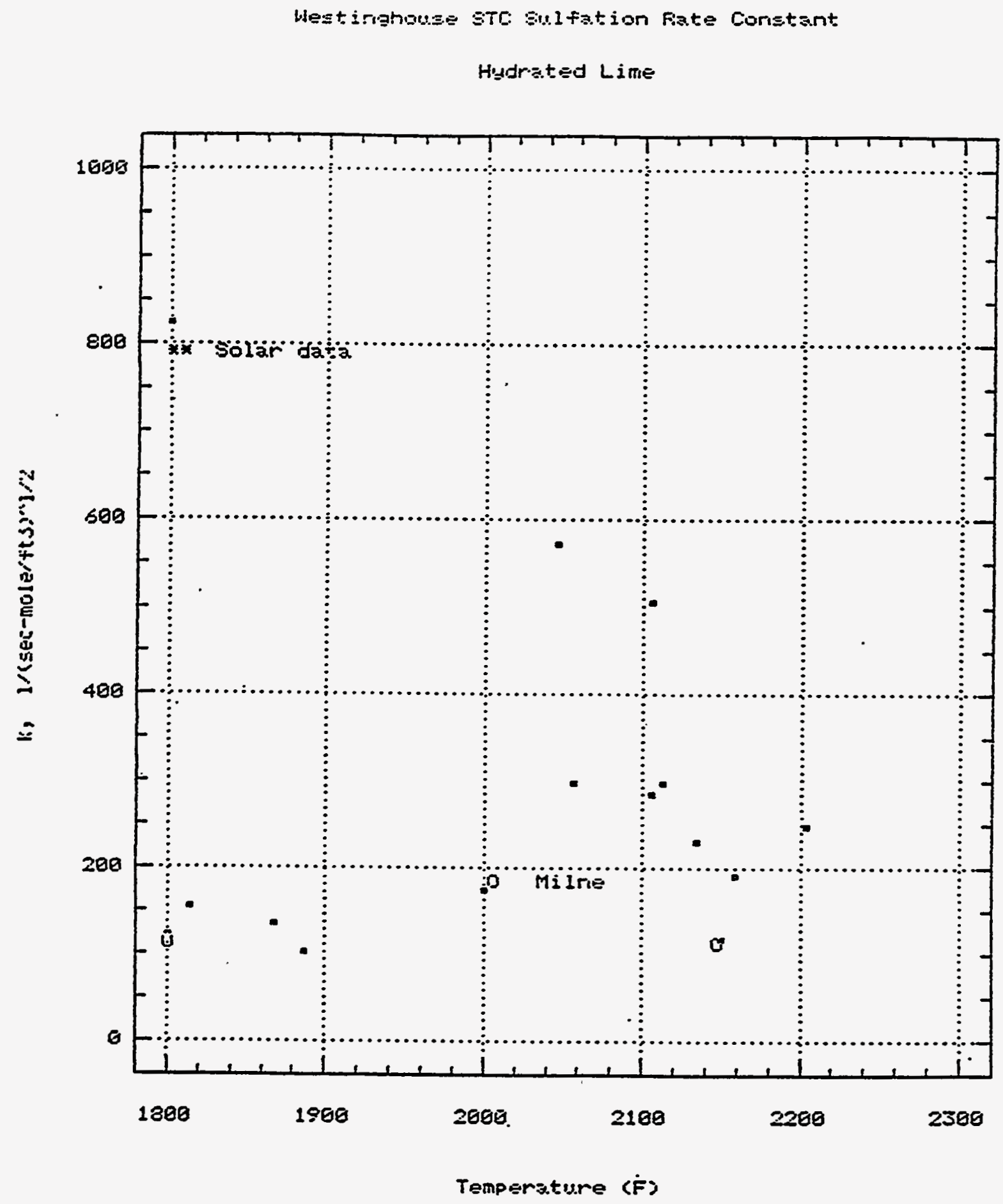

Figure B.16 - Westinghouse STC Rate Constant for Hydrated Lime 


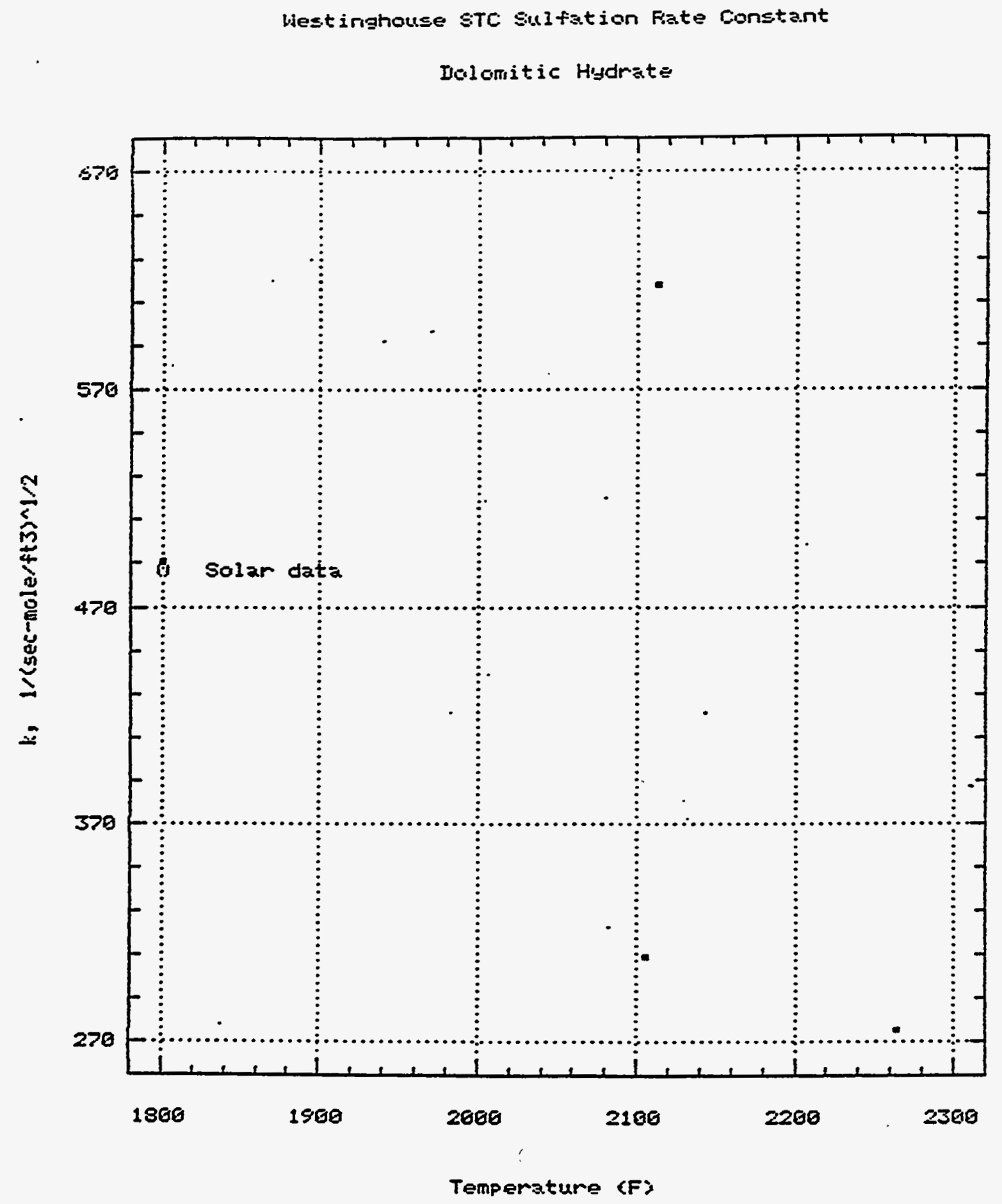

Figure B.17 - Westinghouse STC Rate Constant for Dolomitic Hydrate 
Gas composition:

At $1850^{\circ} \mathrm{F}: \mathrm{O}_{2} 14.0$ vol\%, $\mathrm{CO}_{2} 4.8$ vol\%

At $2100^{\circ} \mathrm{F}: \mathrm{O}_{2} 12.6$ vol\%, $\mathrm{CO}_{2} 5.7$ vol\%

Contact time:

In Injection Pipe: 100 msec

In Filter Vessel: 1-2 sec with good gas-particle contact

Figures B.18 and B.19 show the required $\mathrm{Ca} / \mathrm{S}$ ratio as a function of the coal sulfur content in order to meet $90 \%$ sulfur removal at temperatures of 1850 and $2100^{\circ} \mathrm{F}$. This is not to imply that the required sulfur removal performance will be $90 \%$ for all of these coals, but simply is a consideration to illustrate the sensitivity to coal sulfur content. Little overall difference is seen in the results between the two temperature because the higher reactivity at $2100^{\circ} \mathrm{F}$ is countered by the greater thermodynamic limitation at the higher temperature. At $2100^{\circ} \mathrm{F}$ the $\mathrm{Ca} / \mathrm{S}$ ratio will rise dramatically if the coal sulfur content is reduced below $1.1 \mathrm{wt} \%$ due to equilibrium limitations. If the temperature is increase beyond $2100^{\circ} \mathrm{F}$ the sulfur removal performance will also become poor.

\section{B.8 References}

Milne, C. R., 1988, High-Temperature, Short-Time Sulfation of Calcium-Base Sorbents, Ph.D. Thesis, Univ. of Utah.

Solar Turbines Inc., Advanced Coal-Fueled Industrial Cogeneration Gas Turbine System, Semi-Annual Report to DOE/METC, Dec. 2, 1988 - June 1, 1989. 
Curve $783670-A$

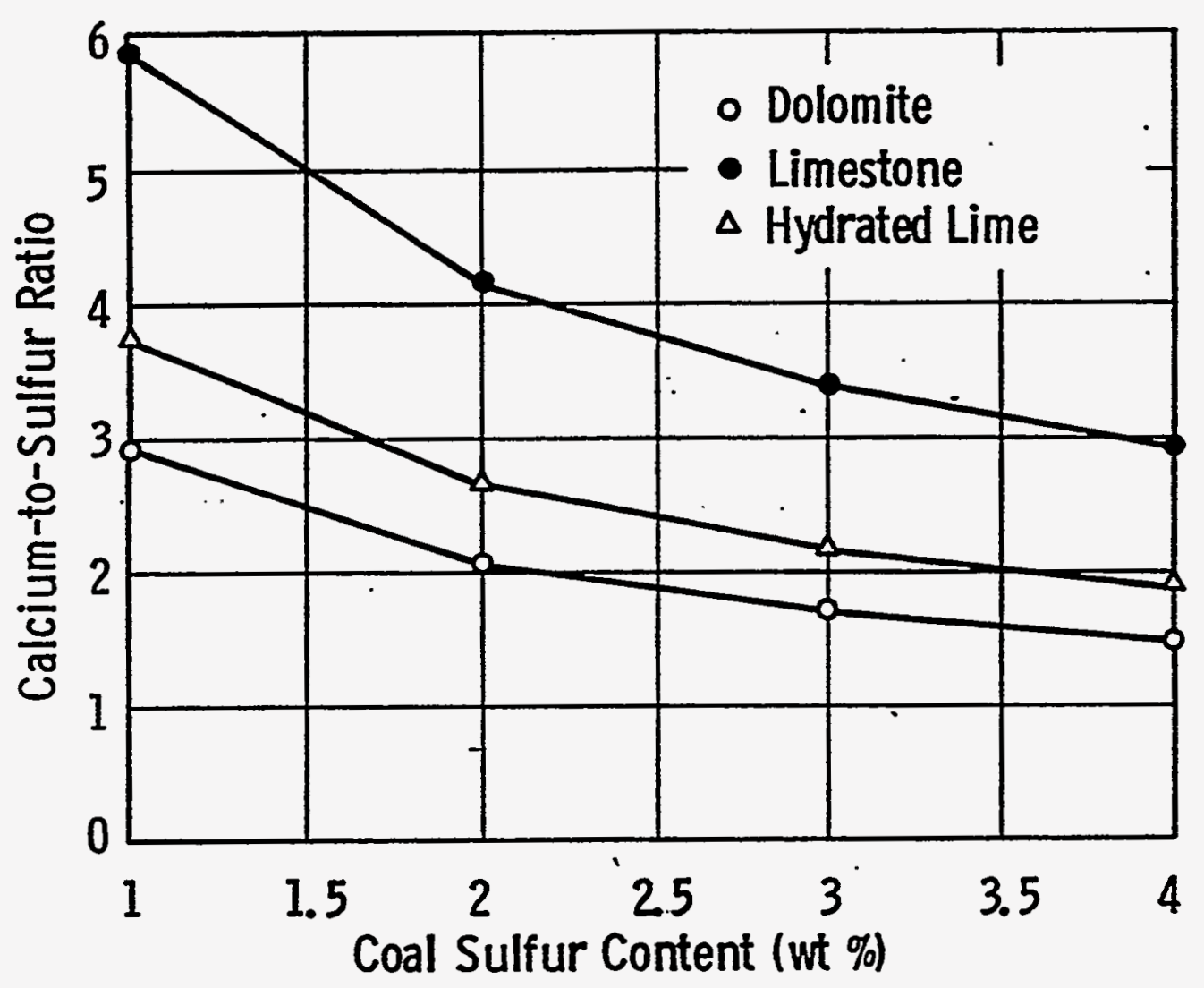

Figure B.18 - Projected ILEC Sulfur Removal Performance for $1850^{\circ} \mathrm{F}$ Temperature 
Curve 783674-A

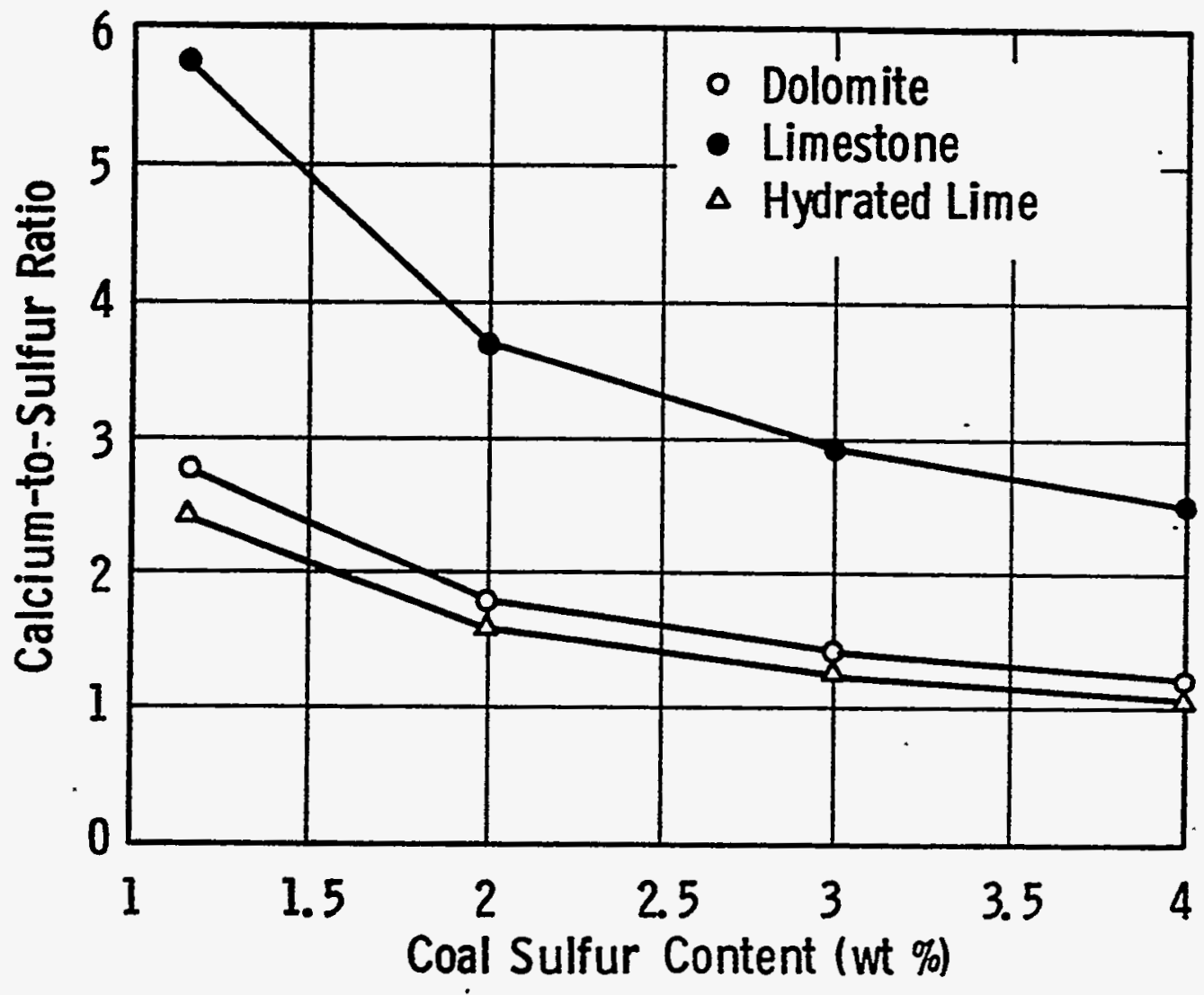

Figure B19 - Projected ILEC Sulfur Removal Performance for $2100^{\circ} \mathrm{F}$ Temperature 


\section{APPENDIX C}

SUPPLEMENTAL ENTRAINED ALKALI REMOVAL

LABORATORY TESTING 


\section{APPENDIX C \\ SUPPLEMENTAL ENTRAINED ALKALI REMOVAL \\ LABORATORY TESTING}

The supplemental alkali sorbent laboratory-scale kinetic testing performed in Phase III complements and builds upon the alkali removal testing performed in Phase I of the program. The Phase I testing was reported in the Phase I Topical Report, and was conducted to select candidate alkali sorbents and to identify some major reaction behavior trends. The objective of the testing was to determine the reaction kinetics and potential performance of emathlite, and hectorite as alkali sorbents at temperatures from $1850^{\circ} \mathrm{F}$ to $2100^{\circ} \mathrm{F}$. This temperature range, much higher than the operating temperatures in PFBC or GCC hot gas cleanup systems, was selected for application to advanced, direct coal-fired turbine systems.

\section{Test Equipment and Procedure Description}

The kinetic testing was to focus on the use of "fine" alkali sorbent particle sizes that might be injected into high temperature combustion products or fuel gases for subsequent accumulation on ceramic filter elements. The application required the use of a laboratory reactor that could simulate high-temperature, high-pressure, entrained reaction conditions as well as filter cake conditions.

.The entrained alkali test reactor designed for this purpose is illustrated in Figure C.1. The reactor is a pressure vessel that contains a vertical, quartz reaction tube, $1^{\prime \prime}$ in inner diameter. The reaction tube is surrounded by two electric heater zones that can be independently controlled to provide optimum temperature profiles in the reaction tube. The total length of the reaction tube is 38 inches, and each electric heater zone is 12 "long. The upper heater zone heats a suspended platinum crucible that holds an alkali salt solution. Sodium chloride was used as the alkali salt in all of the tests performed. The weight of the crucible and its contained 
Dw3. 9423A09

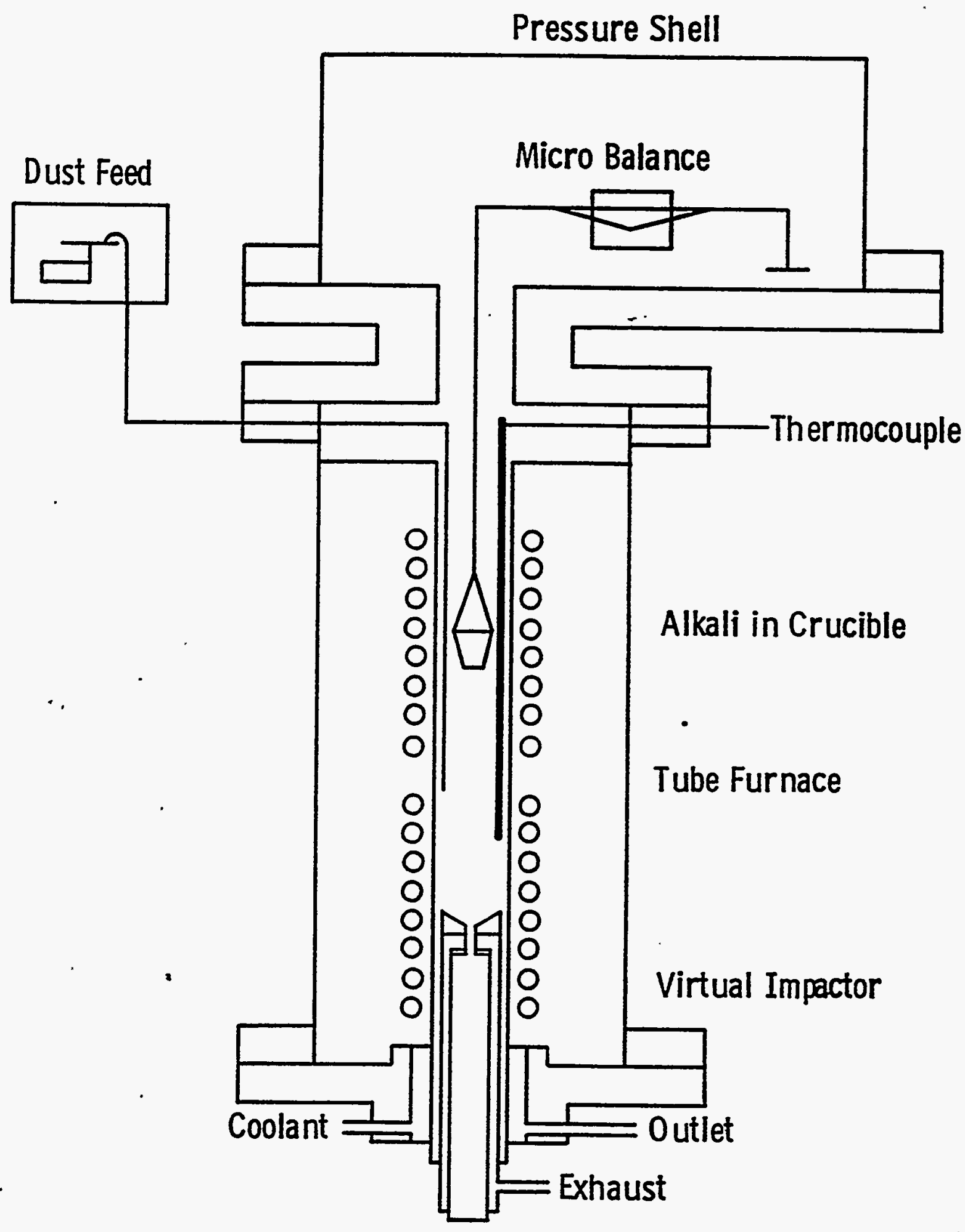

Figure C.1 - Schematic of the Alkali Removal Reactor with Virtual Impactor 
solution is recorded continuously by a microbalance to provide a means of controlling and measuring the alkali content in the reaction gas. Mixed reaction gases flow downward path the alkali crucible carrying the evaporated alkali solution with it. Alkali sorbent particles are injected into the alkali-containing gas, using an external fine particle feeder designed for low particle feed rate capability, at a point downstream of the crucible. The sorbent particles react with the alkali vapor and are separated from the hot reaction gas and analyzed to determine their alkali pickup during their residence time in the reaction zone. The crucible temperature and position in the upper heater zone is selected to give the desired alkali content in the reaction gas, while the lower temperature zone is selected to give the temperature desired for the kinetic rate determination. The sorbent particle residence time is determined by the point of injection into the reaction tube, and the gas flow velocity through the reaction tube.

Two methods of separation of the injected sorbent particles from the reaction gas were tested in the program. The first method used a "virtual impactor" to inertially separate the particles from the gas, and this configuration is shown in Figure C.1. The advantage of the virtual impactor is that the sorbent particles are maintained hot once separated so that alkali vapor condensation is minimized, and the sorbent particle measured conversion will represent primarily the reaction conversion occurring as entrained, suspended particles. The second configuration, shown in Figure C.2, places a ceramic filter disk within the hot reaction zone to filter out the injected sorbent particles. This configuration again avoids condensation conditions, but it represents both the entrained and the filter cake alkali removal kinetics.

Concerns with the experimental techniques were:

- ability to maintain acceptable temperature profiles,

- achieving effective sorbent particle separation with the virtual impactor,

- minimizing crucible weight "noise" in the thermal balance system caused by gas flow effects, 


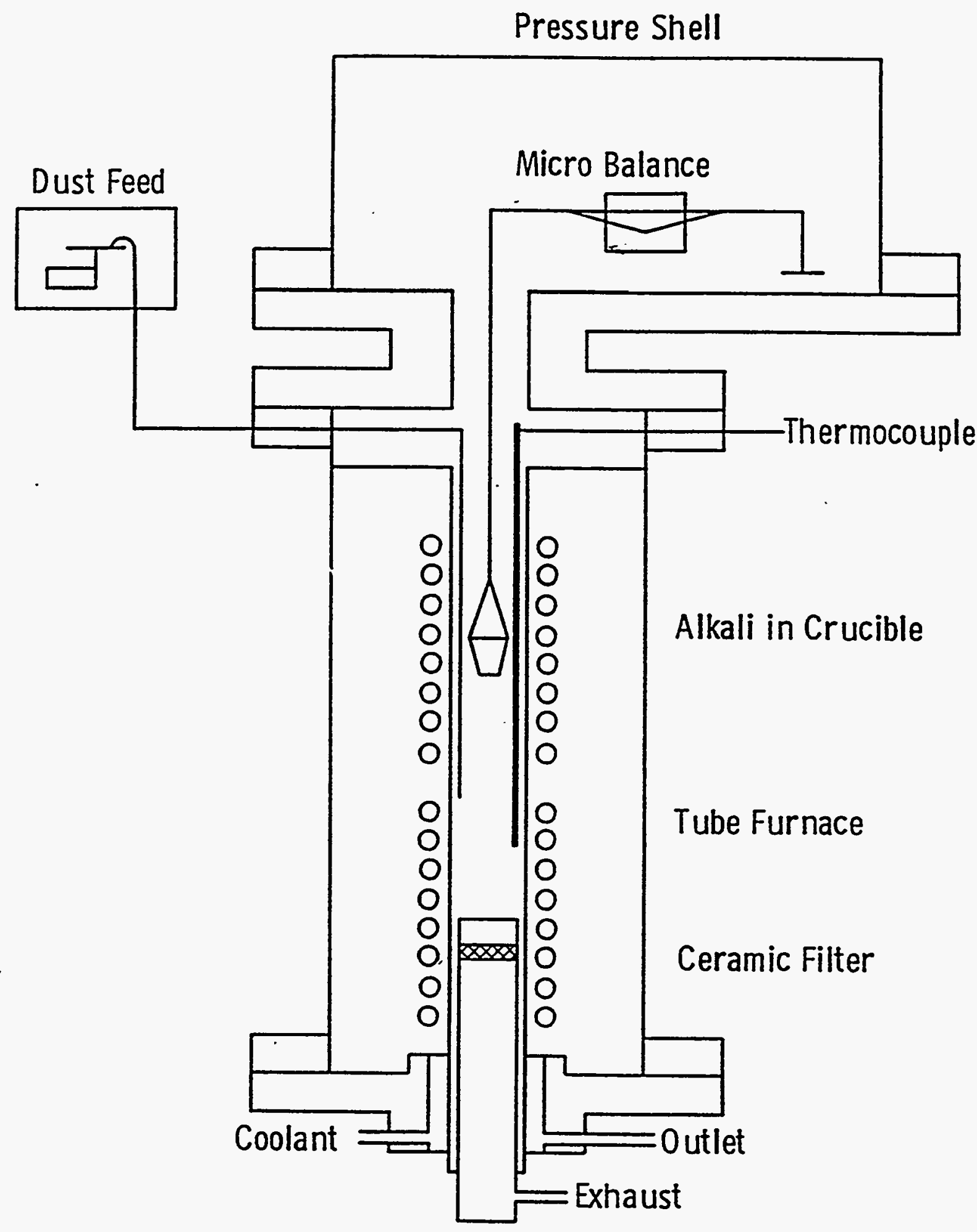

Figure C.2 - Schematic of the Alkali Removal Reactor with Ceramic Filter 
- achieving good injected sorbent particle dispersion and gas mixing in the reaction tube

Initial, shakedown testing was conducted using the virtual impactor for particle separation. The tests were conducted at about $970^{\circ} \mathrm{F}$ and a pressure of 10 atmospheres. The gas residence time in the hot zone of the reactor was about 2 seconds, and the gas alkali content, $\mathrm{NaCl}$, as determined by the on-line thermal balance record, was about 14 ppmw. Emathlite, reduced to -400 mesh, was fed for about 30 minutes, feeding a total of about $1 \mathrm{gm}$. The emathlite feeder worked very well during the test, delivering a smooth, continuous flow of powder. The thermal balance for the alkali release also worked well, giving a weight' loss record with acceptable levels of noise. Following the test the reactor was opened and examined. About 9\% of the emathlite fed was deposited on the inside of the reaction tube, near the point of feeding; about $90 \%$ of the emathlite fed bypassed the virtual impactor, and a total of only $1 \%$ of the feed material was collected by the virtual impactor. Additional, parametric shakedown tests of the alkali removal reactor using the virtual impactor for gas-particle separation did not show acceptable effectiveness of the impactor over a sufficiently broad range of operating conditions to be useful in the test program. Attempts to improve the virtual impactor design and the reactor flow conditions showed that the internal separation of reacted alkali sorbent particles from the hot gases using the virtual impactor was not sufficiently effective to produce reliable data.

The reactor configuration was modified to incorporate an internal, hot ceramic filter disk. The reactor design was modified by fabricating ceramic (mullite) filter disks and a filter disk holder and seals to be placed in the hot zone of the reactor vessel. The new configuration simulates the combined entrained sorbent alkali removal with the removal obtained within the filter cake. The sorbent injector jet nozzle configuration was also improved to minimize sorbent deposition on the reaction tube walls, but deposition could not be entirely eliminated. The alkali-containing crucible system was also modified so that it could be remotely 
raised and lowered within the pressurized, high-temperature reactor to initiate or stop the release of alkali vapor into the gas stream. Shakedown testing of the second configuration was successful, but burnout of some of the reactor heaters resulted. These were replaced by a new type of heater, and testing was continued.

Two operating modes for the tests were devised. In the first mode, the emathlite powder was fed to the hot reactor without any alkali vapor in the gas; the alkali vapor was "switched on" by lowering the alkali-salt containing vessel into the hot gas stream once the alkali sorbent powder has accumulated on the filter disk. Once exposed to the alkali vapor for about 15 minutes the alkali-salt crucible was removed from the reactor hot zone and the reactor cooled down for analysis of the reacted sorbent particles. In the second mode, the emathlite alkali sorbent was fed and accumulate on the filter element for about 15 minutes simultaneously with the alkali vapor being released. Comparison of the alkali content of the sorbent products from these two modes provided the relative removal by entrained and filter cake removal mechanisms.

\section{Test Data Description}

Twenty-two sorbent-alkali kinetic tests were completed and have been analyzed. All of the tests used emathlite sorbent and sodium chloride alkali salt. They were performed at nominal reaction temperatures of $1850^{\circ} \mathrm{F}$ and $2100^{\circ} \mathrm{F}$, and at a pressure of $10 \mathrm{~atm} .14$ of the tests were conducted by first loading emathlite on the internal filter disk by feeding emathlite powder ( -400 mesh) for 15 minutes under hot conditions, but without alkali vapor in the gas. The gas was nitrogen containing a small amount of added water vapor. The gas composition used in the kinetic testing is most representative of reducing gas conditions. A total of about 0.5 to $0.25 \mathrm{gm}$ of emathlite powder was accumulated on the filter. Then the alkali crucible was lowered into the heated zone to vaporize $\mathrm{NaCl}$, the vapor being carried into the reaction zone and through the emathlite layer on the filter disk. This was continued for 15 minutes of alkali exposure. The reacted emathlite sample was removed and analyzed for total sodium content. The other tests were conducted by 
feeding emathlite powder for 15 minutes simultaneously with the release of alkali vapor to compare the entrained performance with the filter cake performance. The particles resided in the entrained reaction zone for about 2 seconds, and accumulated on the filter disk for an average residence time of 7.5 minutes on the filter during the test period.

The tests were conducted at different levels of alkali vapor in the gas, ranging from 1.3 to $112.2 \mathrm{ppmw} \mathrm{NaCl}$, controlled by the temperature-position of the alkali crucible within the reactor. The gas temperature profiles were measured through the reactor zone and were fairly uniform, but the filter disk temperature was about $150^{\circ} \mathrm{F}$ lower than the average entrained zone temperature.

The test results are tabulated in Table C.1. The unreacted emathlite powder contains $0.13 \mathrm{wt} . \%$ sodium, and totally saturated emathlite is expected to contain about $20 \mathrm{wt} . \%$ sodium. The emathlite reaction product contained between 0.21 and 9.24 wt\% sodium over the range of the test conditions. The emathlite reaction product was observed to be tan in color and a loose powder, to lightly fused in appearance for the $1850^{\circ} \mathrm{F}$ tests. In the $2100^{\circ} \mathrm{F}$ tests, the emathlite product was brown in color and was glassy to sintered looking.

The last column in Table C.1 represents a sodium material balance between the amount of sodium fed and the amount captured by the emathlite. It indicates two things: 1) obvious test accuracy concerns are identified, such as in run A4 where much more sodium was collected than was fed -- it is believed that the operating procedure used in this specific run led to this discrepancy, and this procedure was not used in the other entrained test runs; 2) the extent of the change in the gasphase alkali vapor content through the reactor is indicated -- nearly 50 to $100 \%$ of the alkali vapor is removed as the gas passes through the reactor. While these tests show very high emathlite reactivity, the gas phase alkali content changes so much that it is difficult to extract reliable kinetic parameters from the data.

The gas phase $\mathrm{NaCl}$ content was estimated both from the thermobalance crucible weight record during the test period, and by the externally measured crucible weight loss over the test period. In most cases these were consistent, but in 


\begin{tabular}{|l|l|c|c|c|c|}
\hline \multicolumn{5}{|c|}{ Table C.1-Alkali Removal Kinetic Test Results } \\
\hline Run & Test Type & $\begin{array}{c}\text { Temperature } \\
\left({ }^{\circ} \text { F) }\right.\end{array}$ & $\begin{array}{c}\text { Gas NaCl } \\
\text { Content } \\
\text { (ppmv) }\end{array}$ & $\begin{array}{c}\text { Sample Sodium } \\
\text { Wt. Percent }\end{array}$ & $\begin{array}{c}\text { Alkali Vapor } \\
\text { Removed (\%) }\end{array}$ \\
\hline A1 & Cake & 1803 & 9.6 & 0.87 & 93.5 \\
\hline A2 & Cake & 1843 & 2.1 & 0.21 & 53.8 \\
\hline A3 & Cake & 1850 & 2.1 & 0.23 & 68.9 \\
\hline A4 & Entrained & 1846 & 2.1 & 0.89 & 522 \\
\hline A5 & Cake & 1839 & 1.3 & 0.22 & 92.0 \\
\hline A6 & Cake & 1841 & 12.7 & 1.36 & 143.4 \\
\hline A7 & Entrained & 1834 & 9.9 & 1.15 & 161.2 \\
\hline A8 & Cake & 1846 & 28.5 & 1.34 & 64.7 \\
\hline A9 & Entrained & 1841 & 28.0 & 2.14 & 103.8 \\
\hline A10 & Cake & 1843 & 35.0 & 2.35 & 42.0 \\
\hline A11 & Cake & 1854 & 112.2 & 4.87 & 36.8 \\
\hline A12 & Entrained & 1855 & 52.4 & 3.96 & 35.6 \\
\hline A13 & Cake & 1852 & 57.7 & 3.24 & 37.4 \\
\hline A14 & Cake & 2106 & 91.9 & 2.72 & 26.4 \\
\hline A15 & Cake & 2102 & 38.4 & 3.38 & 85.0 \\
\hline A16 & Entrained & 2102 & 59.4 & 9.24 & 44.4 \\
\hline A17 & Cake & 2100 & 42.7 & 2.48 & 49.7 \\
\hline A18 & Entrained & 2100 & 34.1 & 7.43 & 111.4 \\
\hline A19 & Cake & 2100 & 27.9 & 3.81 & 111.0 \\
\hline A20 & Cake & 2100 & 8.9 & 1.68 & 187.8 \\
\hline A21 & Entrained & 2100 & 4.9 & 4.23 & 518.0 \\
\hline A22 & Entrained & 2100 & 9.5 & 1.85 & 177.0 \\
\hline
\end{tabular}


some cases they differed sufficiently to result in uncertainty in the actual gas alkali vapor content.

The test results are plotted in Figure C.3, showing the emathlite sodium content as a function of the product of reaction time and gas-phase sodium-vapor content. The sample sodium content shows a clear trend to increase as the gas alkali vapor content increased, and was higher in the entrained tests than in the filter cake tests for comparable conditions.

\section{Data Correlation}

The reaction conversion data collected in the program was correlated and compared with prior alkali removal data collected in this program during the Phase I oven tests, and in other Westinghouse programs that utilized large emathlite pellets. Figure C.4 shows the correlation results for particle sizes varying over a large range of particle size, from -400 mesh to pellet sizes $\left(1 / 4^{\prime \prime} \times 1 / 2^{\prime \prime}\right)$. The correlation plots the reacted emathlite sodium content against the quantity

$$
t \times C \times P^{0.2} \times d_{p}-0.6 \times \operatorname{Exp}[-1540 / T\}
$$

where $t$ is the particle reaction time (minutes), $\mathrm{C}$ is the vapor-phase alkali content (ppmv), $\mathrm{P}$ is the pressure (atm), $\mathrm{d}_{\mathrm{p}}$ is the mean particle diameter ( $\left.\mu \mathrm{m}\right)$, and $\mathrm{T}$ is the gas temperature $\left.{ }^{\circ} \mathrm{R}\right)$. The test results do appear consistent with prior testing and seem to substantiate prior estimates of entrained alkali removal performance.

The tests performed here are representative of alkali removal under reducing conditions, where the primary alkali form would be $\mathrm{NaCl}$. Prior Phase I testing clearly has shown that the alkali form $\left(\mathrm{NaCl}, \mathrm{Na}_{2} \mathrm{SO}_{4} \mathrm{KCl}\right.$, etc.) is not important when using emathlite or hectorite for removal, and the difference between reducing and oxidizing conditions will not be significant except that much higher alkali concentrations are expected in the gas under reducing conditions than under oxidizing conditions. 


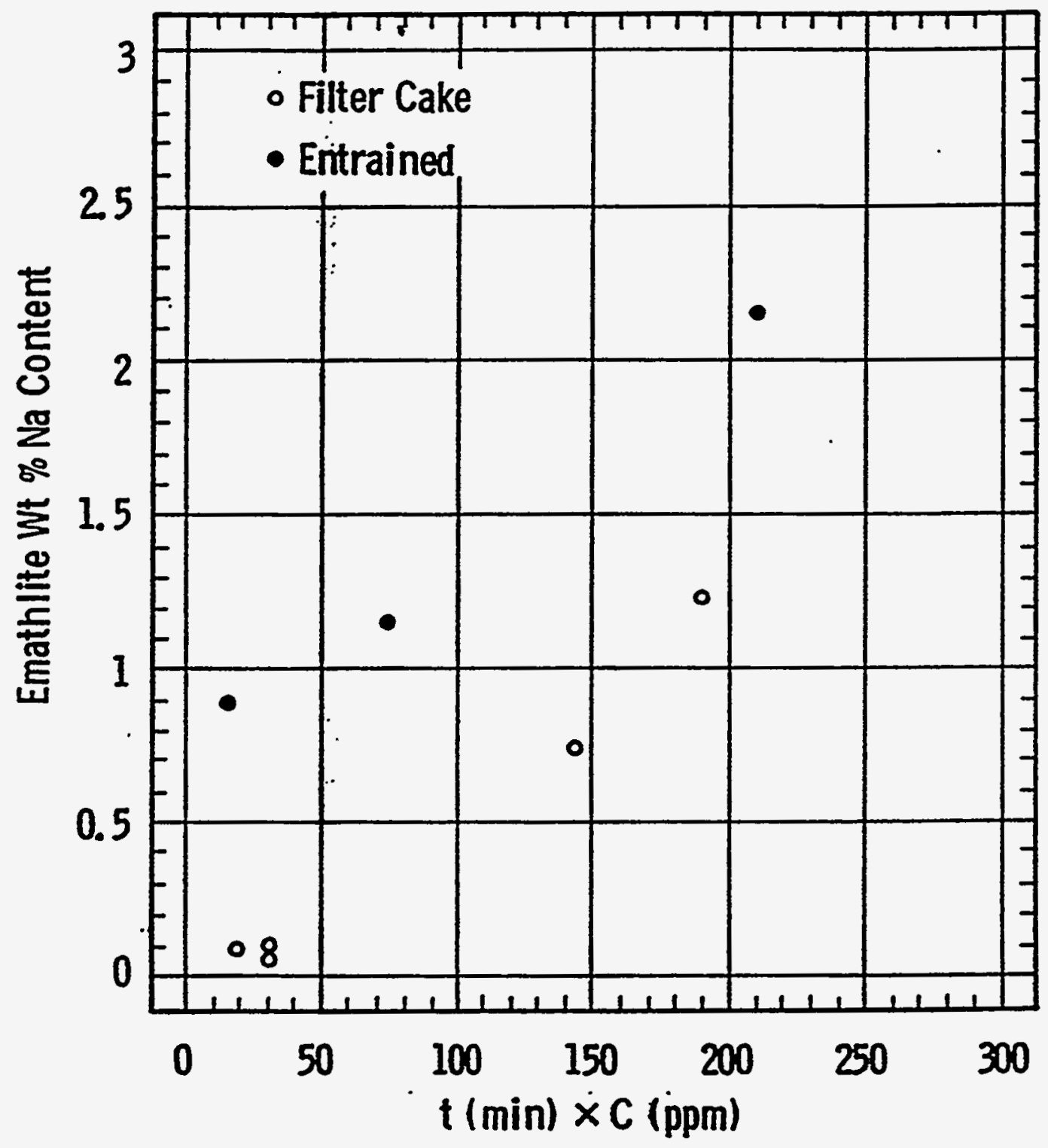

Figure C.3 - Entrained Emathlite- $\mathrm{NaCl}$ Conversion 


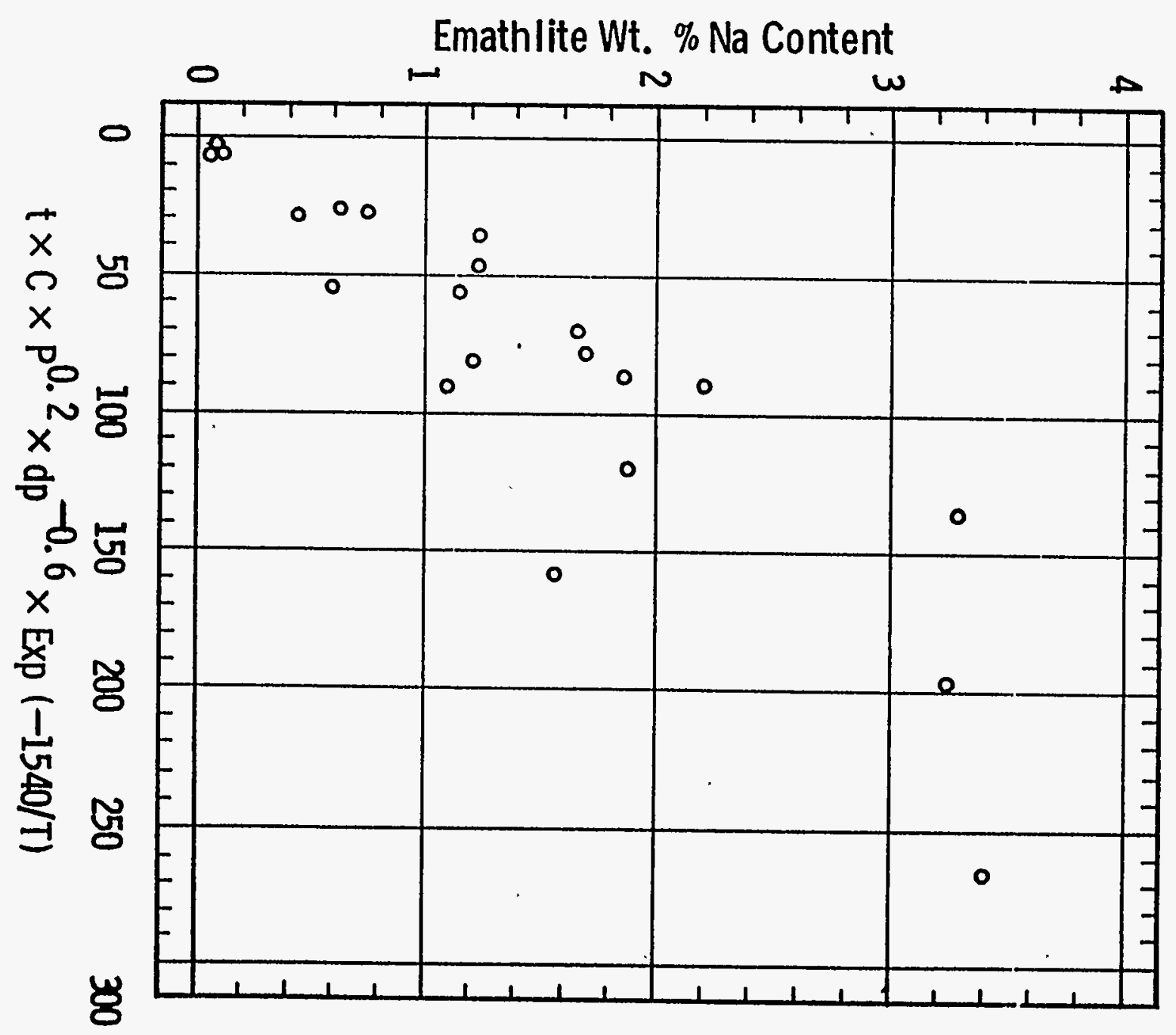




\section{Testing Conclusions}

It has been concluded from the combined Phase I alkali oven tests, and Phase III supplemental alkali sorbent testing that:

- Both emathlite and hectorite are effective alkali sorbents at temperatures up to at least $2100^{\circ} \mathrm{F}$.

- The affinity of these sorbents for reaction with $\mathrm{NaCl}, \mathrm{KCl}$, and $\mathrm{Na}_{2} \mathrm{SO}_{4}$ is comparable over this temperature range.

- It is expected that the gas alkali content of the combustion gas will range between 1 and $10 \mathrm{ppmv}$ for a typical bituminous coal over the range of temperatures of interest. The acceptable level of alkali in the gas is uncertain, but is expected to range from 20 to $50 \mathrm{ppmv}$. Roughly, 99\% alkali removal is required.

- The required emathlite feed rate is estimated to be about 10 times the stoichiometric feed rate. The corresponding emathlite mass feed rate is about $0.5 \%$ of the coal feed rate, depending on the specific coal alkali content and the alkali release conditions. 


\section{APPENDIX D}

SUPPLEMENTAL FLUIDIZED BED ILEC LABORATORY TESTING

D-1 


\section{APPENDIX D}

\section{SUPPLEMENTAL FLUIDIZED BED ILEC LABORATORY TESTING}

The scope of the fluidized bed ILEC program consisted primarily of cold flow model testing and commercial conceptual design evaluation. The Phase I cold model test activities were extensive, and used a fluidized bed of dolomite particles. The Phase I fluidized bed ILEC cold model facility was described, and the test results were reported in the Phase I Topical Report.

The objective of the Phase III supplemental testing in the area of the fluidized bed ILEC was to perform cold flow model testing to address specific issues relating to the quality of the cold model data, and the ability of separating collected dust particle from the fluidized bed by a practical approach.

Testing was performed with a new, lower density bed materials, crushed acrylic, over a range of gas velocities and bed depths to compare results with the prior, denser bed material (dolomite) behavior. The lower density particles provided a closer simulation of the bed behavior at high-pressure, high-temperature conditions. The testing was continued and showed that stable slugs still formed in the fluid bed at certain conditions, dependent on the bed depth and the fluidization velocity, just as they had during the Phase I testing. The overall pressure drop across the fluid bed ILEC cold model was much lower than those measured in Phase

I. The general fluidization quality was much better with the lower density bed material. It was found that operating at a static bed depth of about 25 inches resulted in a bed that could be well fluidized at all velocities and that could be expanded periodically and vigorously reach the entire surfaces of the candles.

Following the bed behavior mapping, fine acrylic dust particles were added to the bed and the accumulation patterns of fly ash in the bed was observed. When the fly ash was added to the bed, the gas flow through the bed became nonuniform. This was due to the fact that one of the four candles immersed in the bed had a much greater permeability than the others. This effect was not observed in the prior tests with the denser, dolomite bed material. Substitute ceramic candles Coors 
alumina/mullite), having very similar permeability, replaced the old set of candles, and this behavior was eliminated. Figure A3.1 shows the system pressure drop, in inches of water, as a function of operating time for a range of flows after a quantity of acrylic dust (equivalent to about $10 \%$ of the static bed volume) was added to the bed. A fairly steady pressure drop was quickly reaches. The bed behavior results were promising.

The fine particle accumulation patterns in the bed were examined, as well as the self cleaning behavior of the ceramic candles in the vigorously fluidized bed. Various options were proposed to separate the fine particle from the bed and to eliminate the rapid re-entrainment of the fine particles onto the ceramic filter elements:

- use a top overflow pipe to drain off the fine particles as they accumulate near the top of the fluid bed;

- drain the bed continuously, separating out the fine particles and recirculating the coarse particles;

- inject additives to promote agglomeration of the fine particles.

None of these functioned well or appeared to be practical solutions. The fluidized bed ILEC concept was not investigated further in the program. 


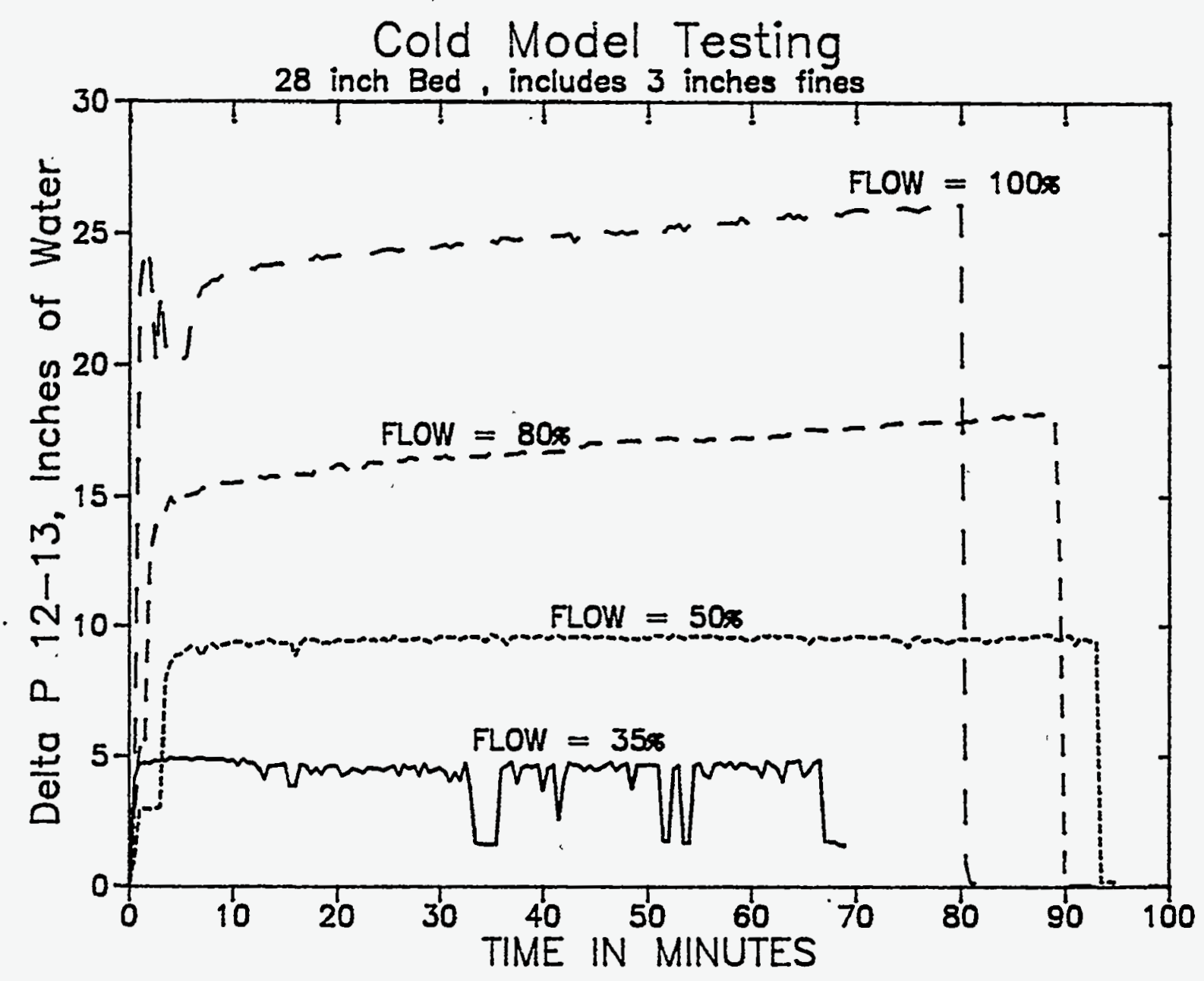

Figure D.1 - Fluid Bed ILEC Cold Flow Model Pressure Drop with Acrylic Dust Added 


\section{APPENDIX E \\ BENCH-SCALE TEST DATA PLOTS}

$\mathrm{E}-1$ 


\section{PERMEABILITY TESTS (SERIES 1)}

E-3 


\section{Permeability Test 1.01 (11/8/93)}

Tidd Fine Fly Ash

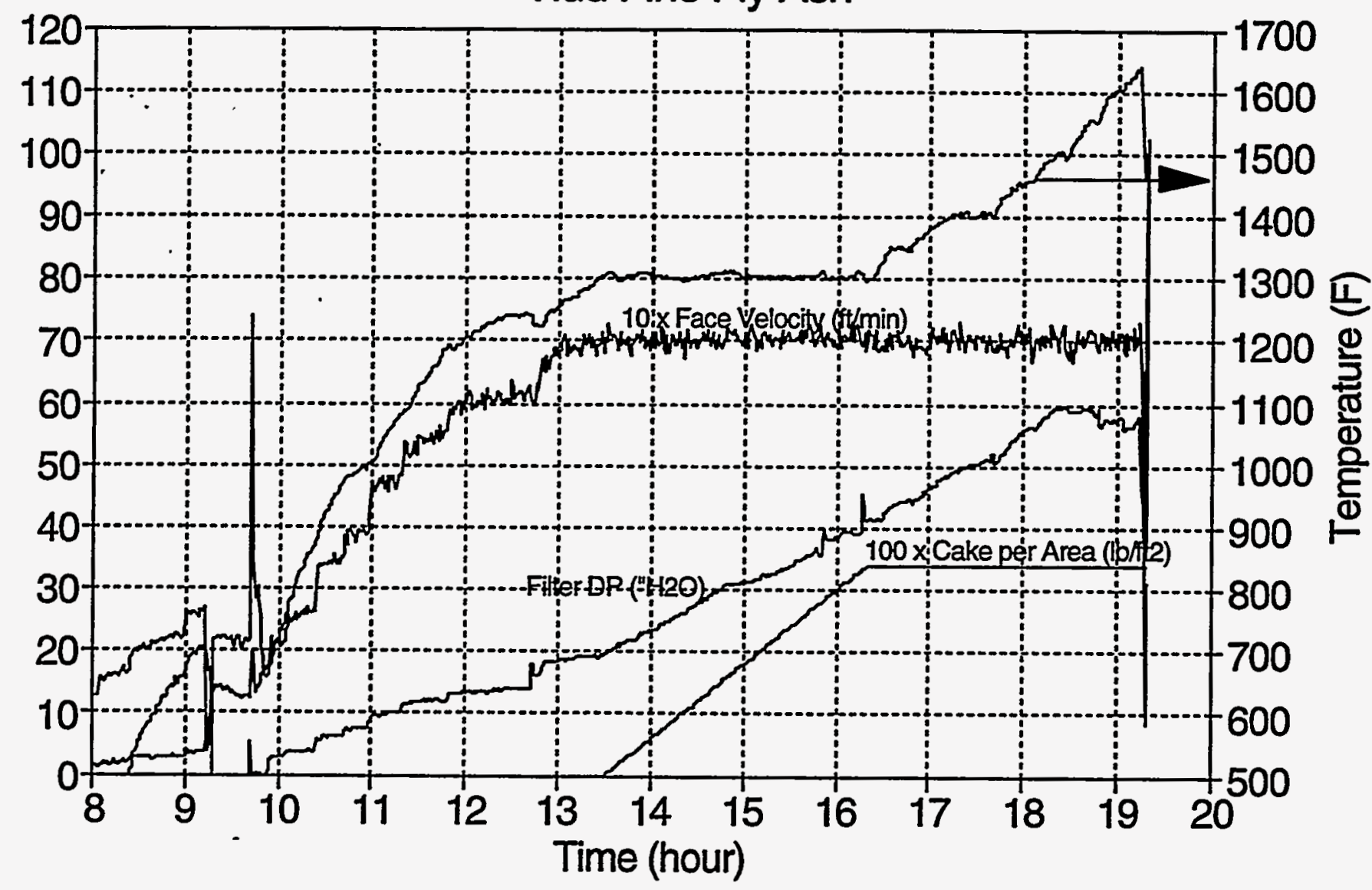




\section{Permeability Test 1.01 (11/8/93) Tidd Fine Fly Ash}

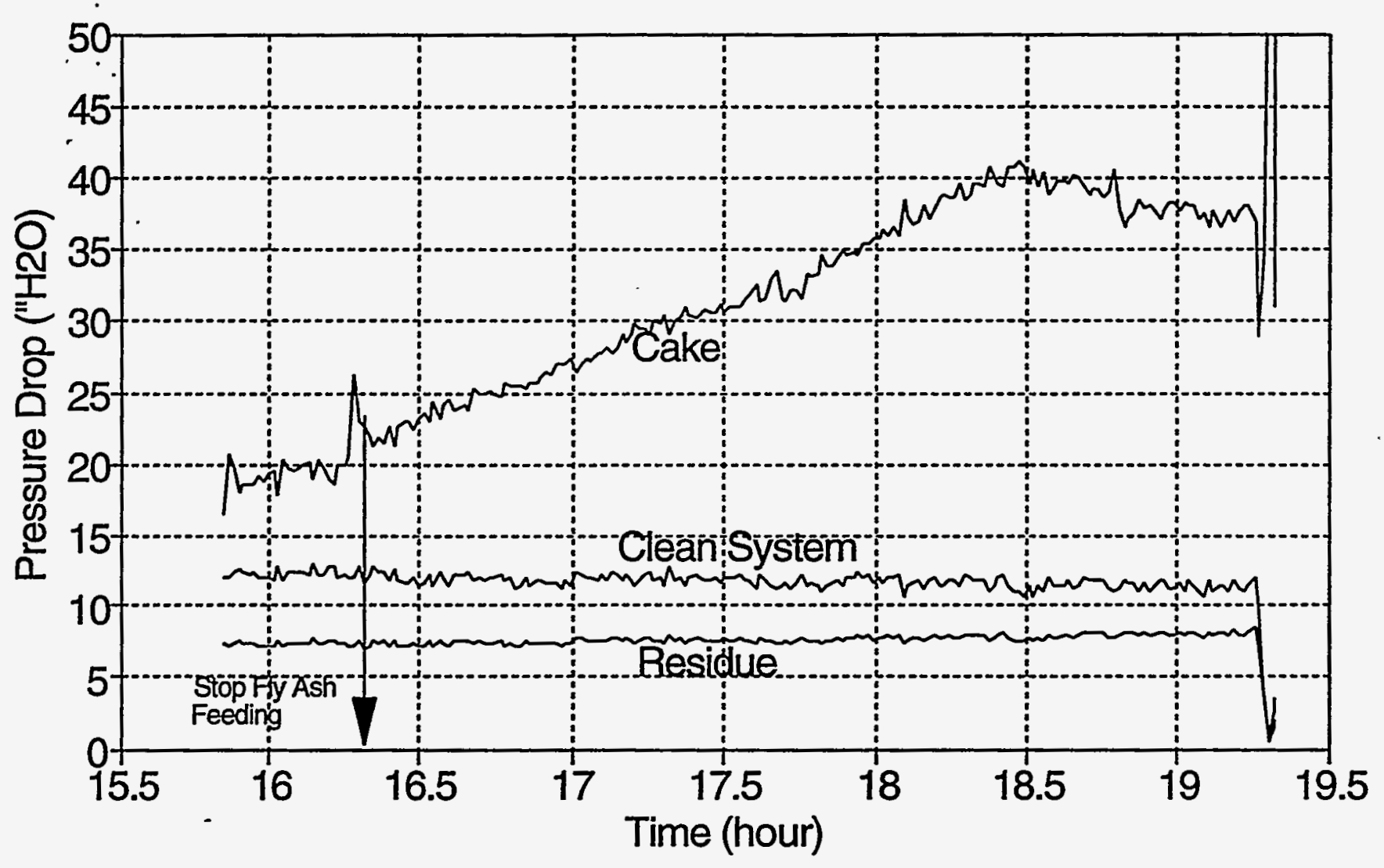




\section{Permeability Test 1.01 (11/8/93) Tidd Fine Fly Ash}

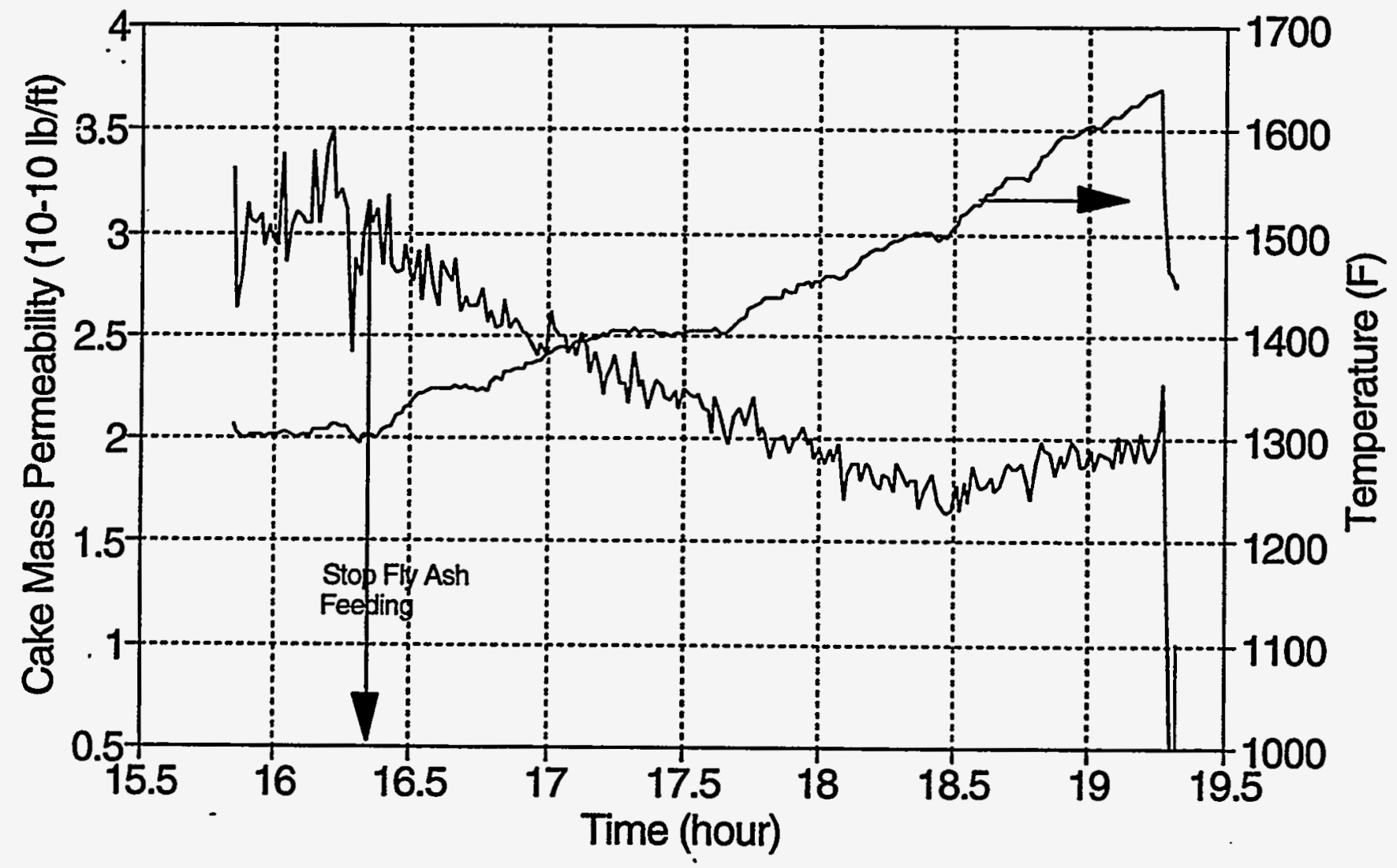




\section{Permeability Test 1.02 (11/9/93) Tidd Fine Fly Ash}

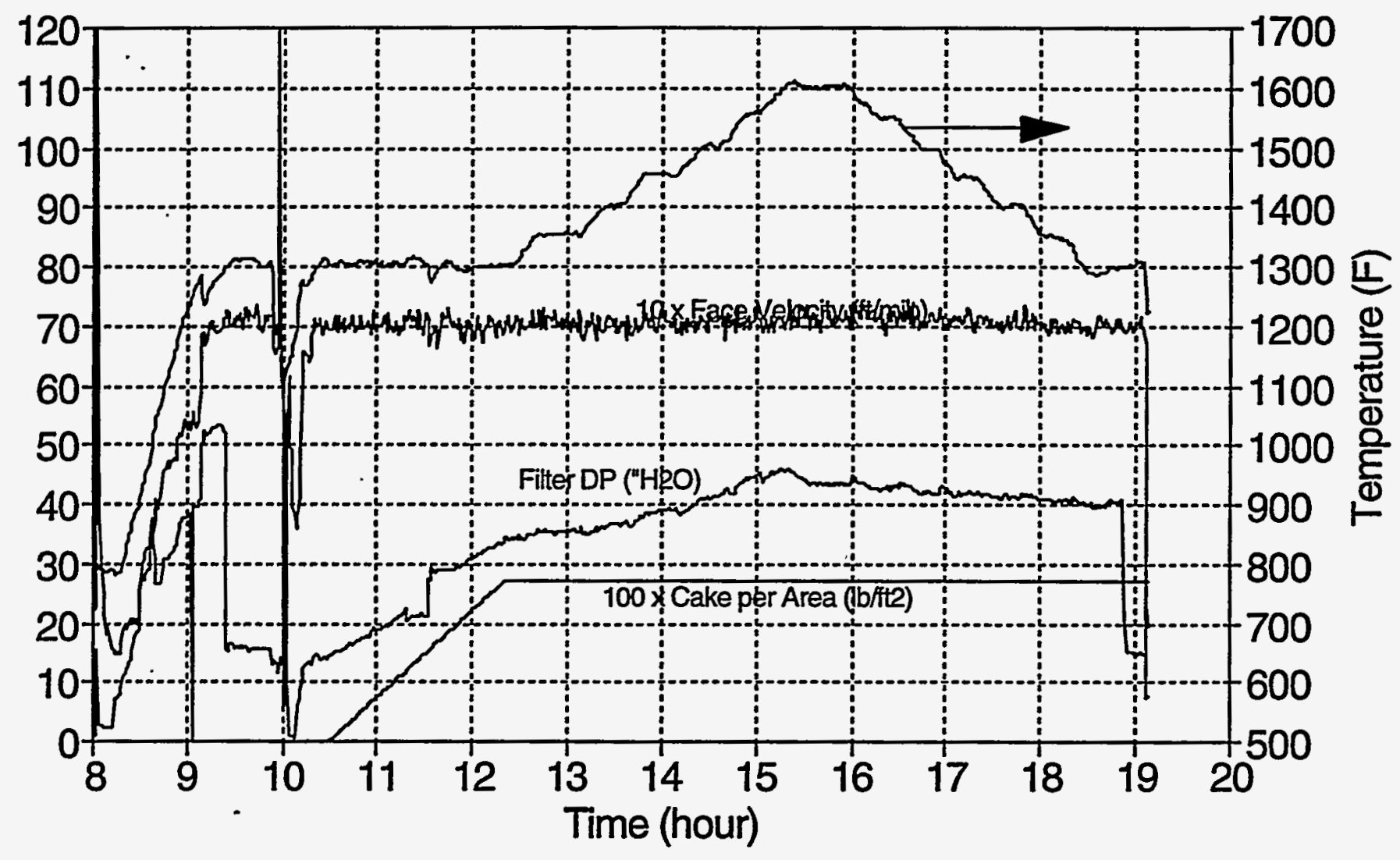




\section{Permeability Test 1.02 (11/9/93) Tidd Fine Fly Ash}

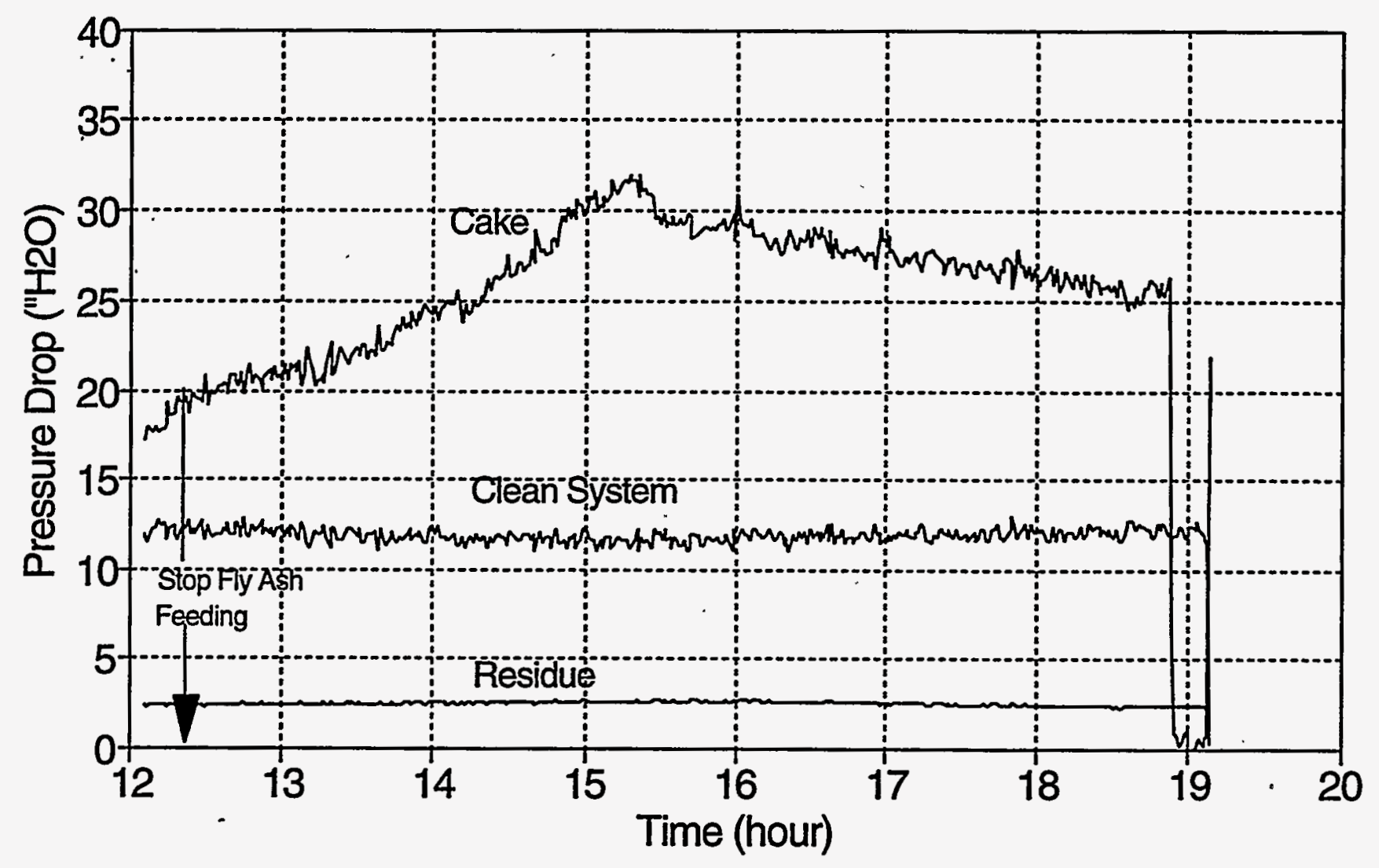




\section{Permeability Test 1.02 (11/9/93) Tidd Fine Fly Ash}

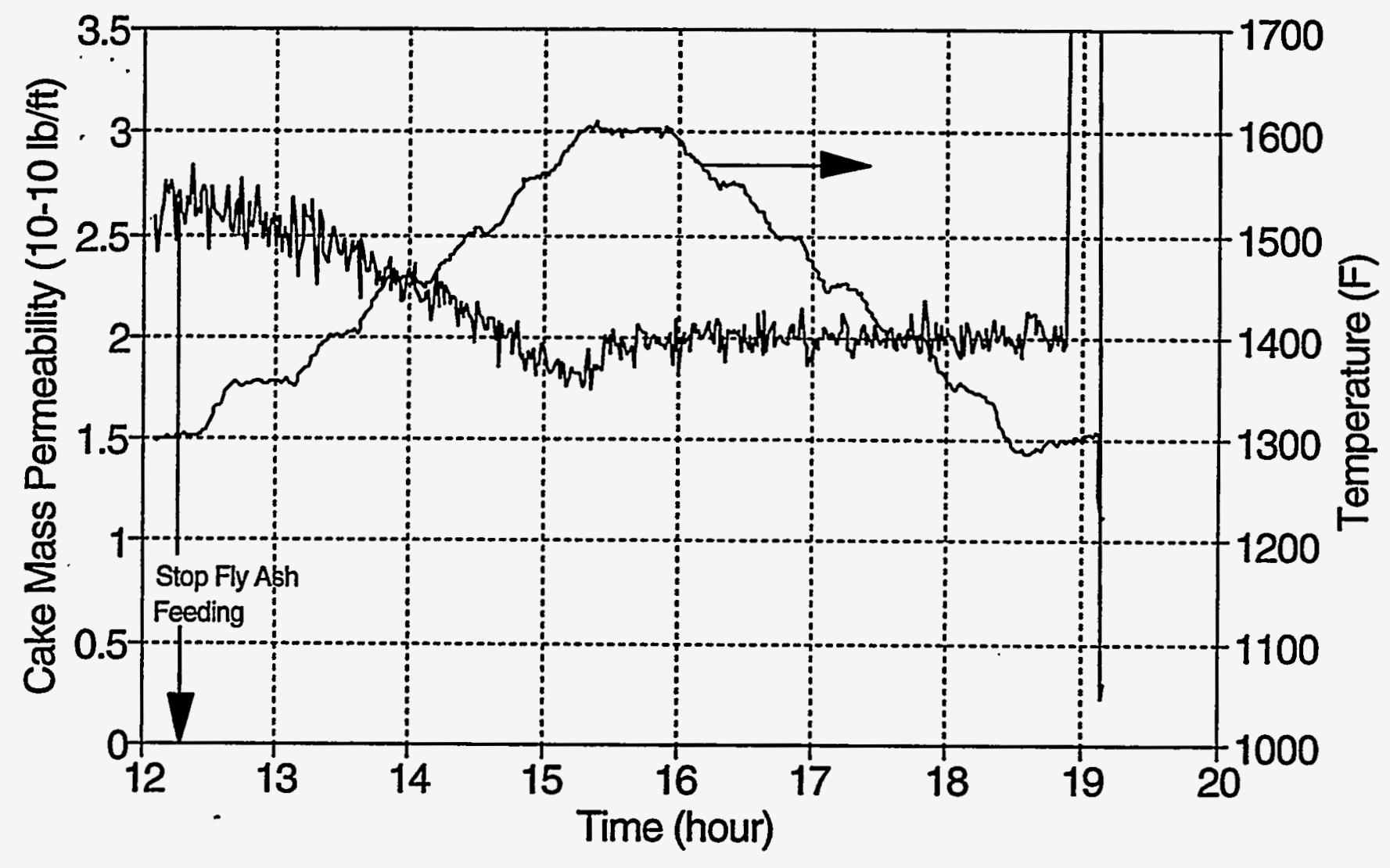




\section{Permeability Test 1.03 (11/10/93) Tidd Fine Fly Ash}

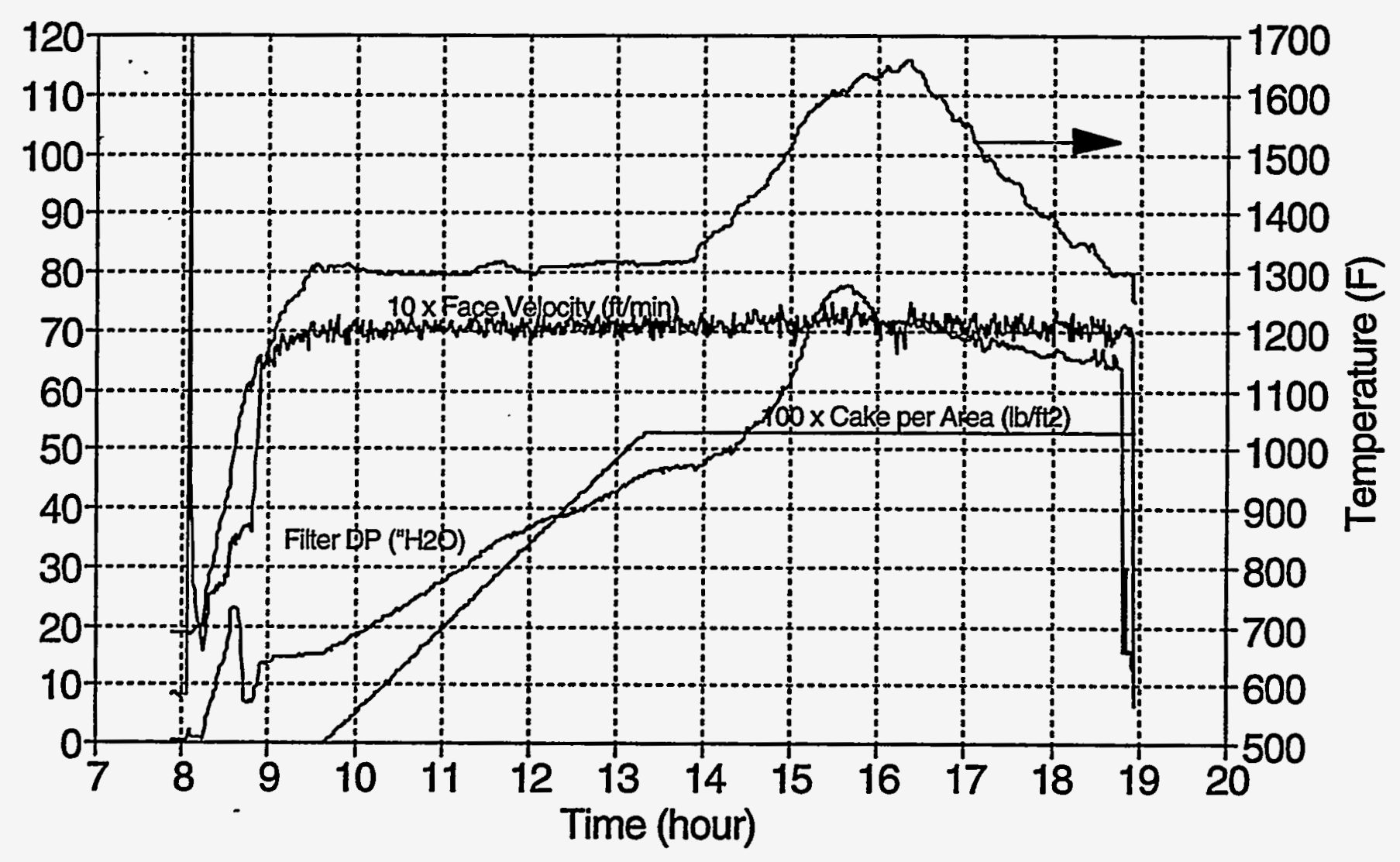




\section{Permeability Test 1.03 (11/10/93) Tidd Fine Fly Ash}

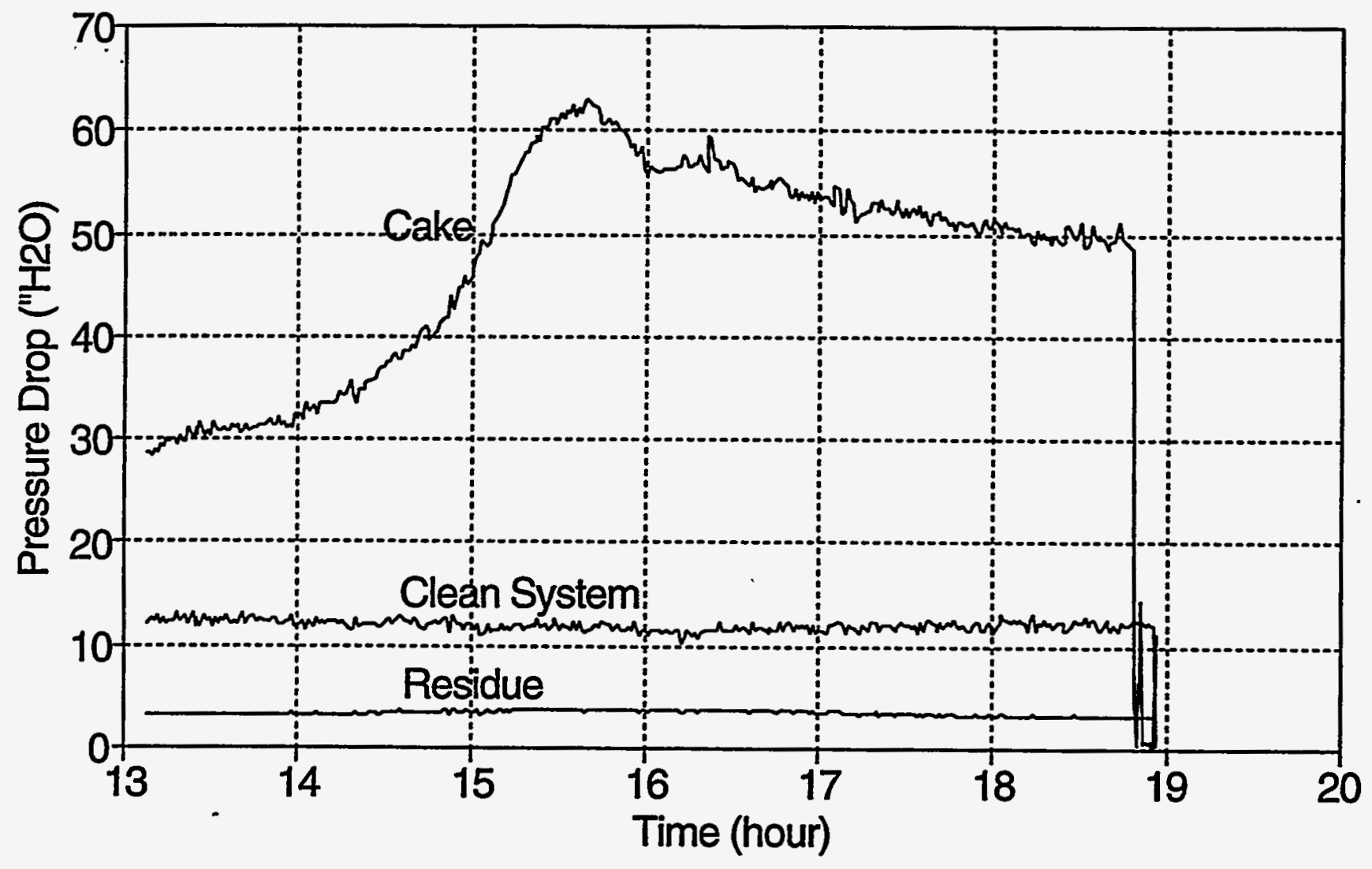




\section{Permeability Test 1.03 (11/10/93) Tidd Fine Fly Ash}

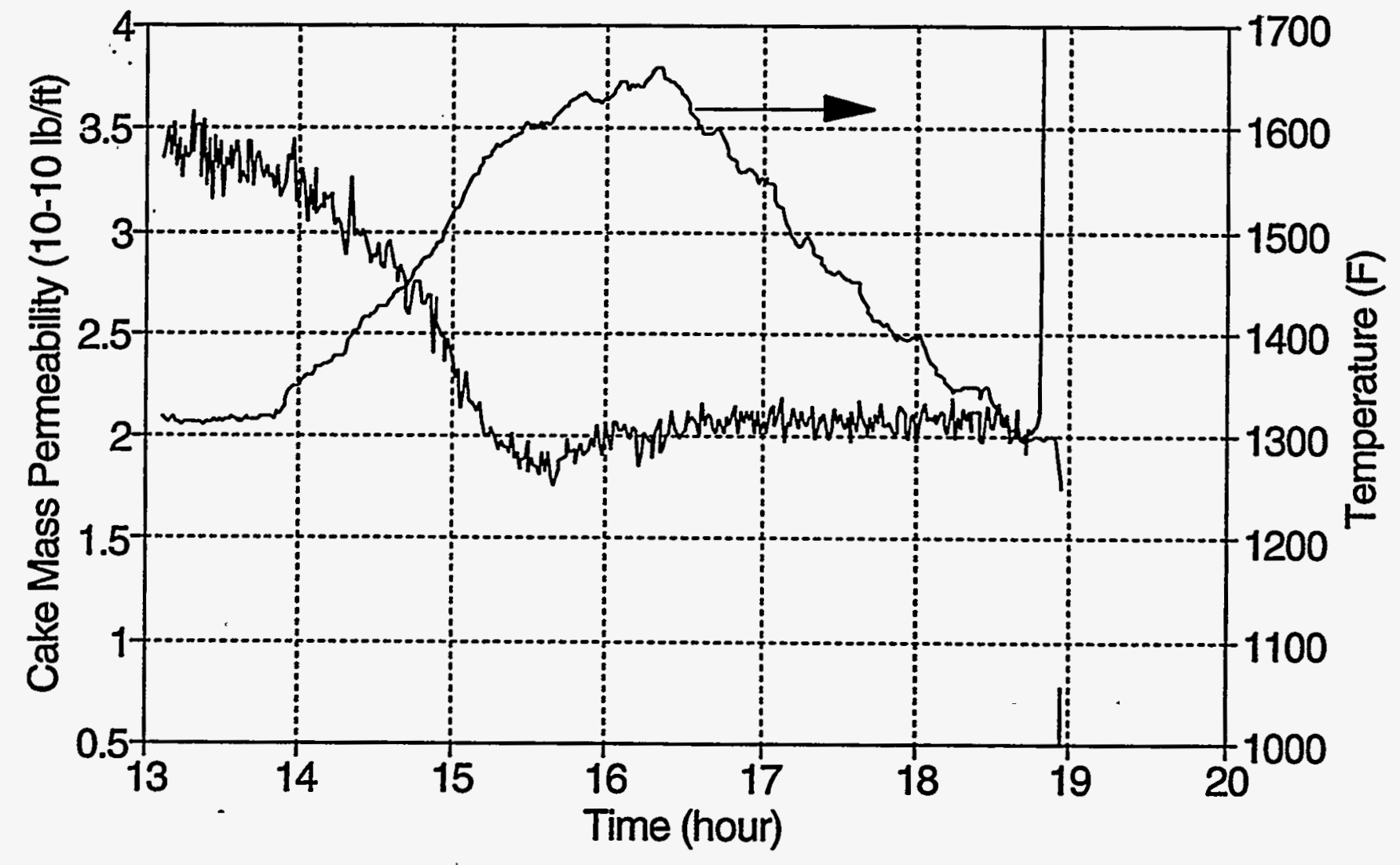




\section{Permeability Test 1.04 (11/11/93) Tidd Fine Fly Ash}

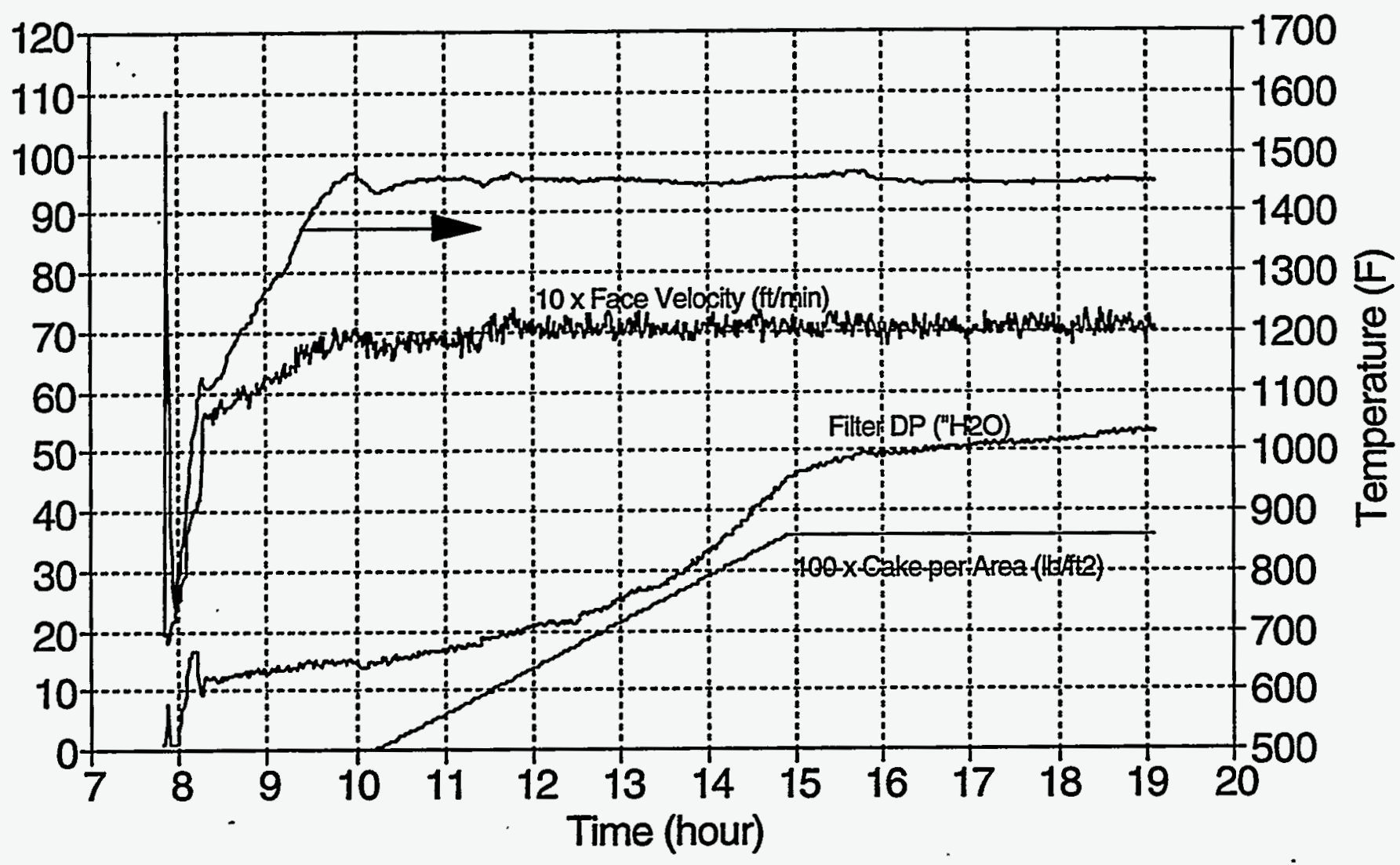




\section{Permeability Test 1.04 (11/11/93) Tidd Fine Fly Ash}

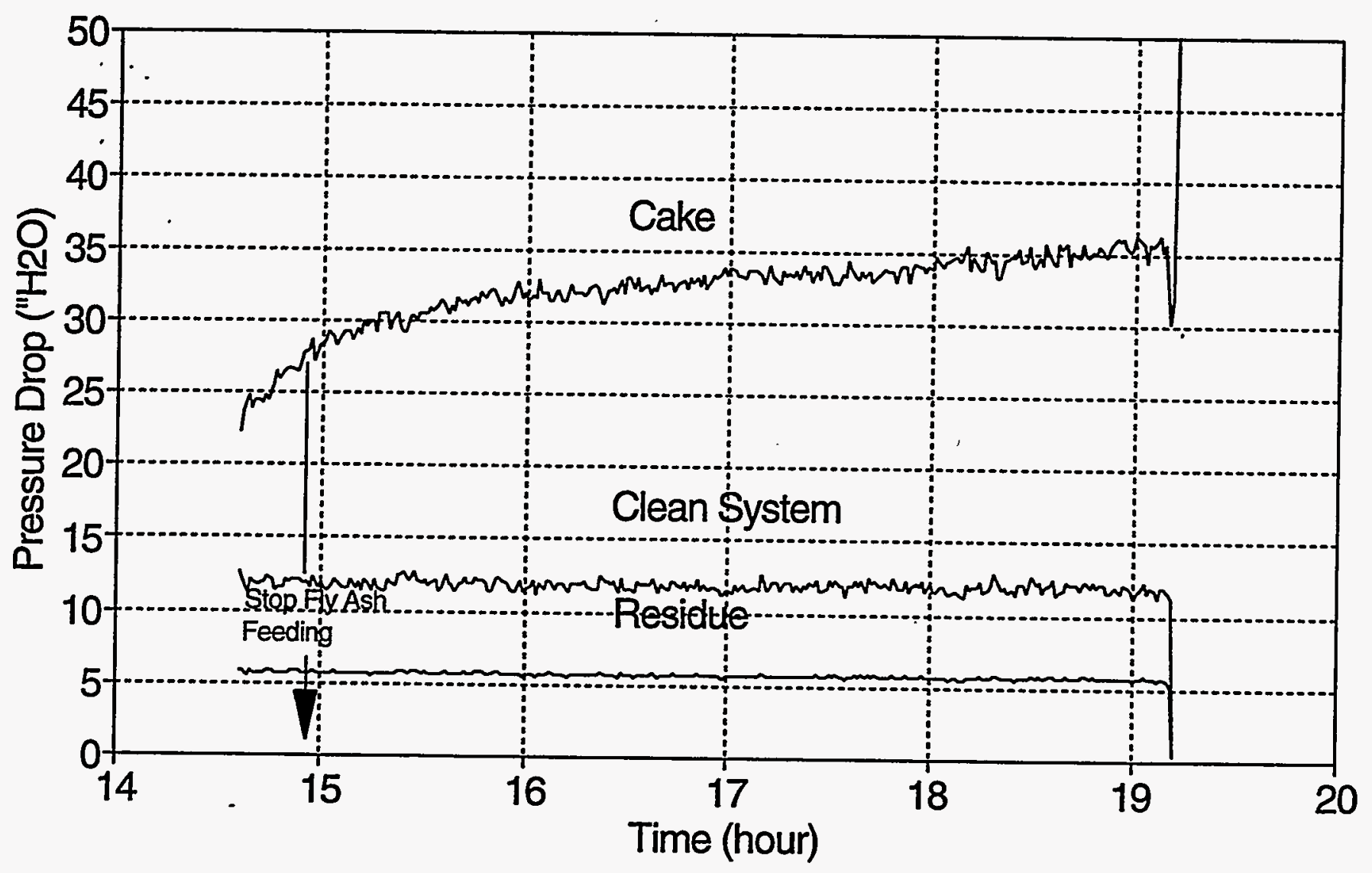




\section{Permeability Test 1.04 (11/11/93) Tidd Fine Fly Ash}

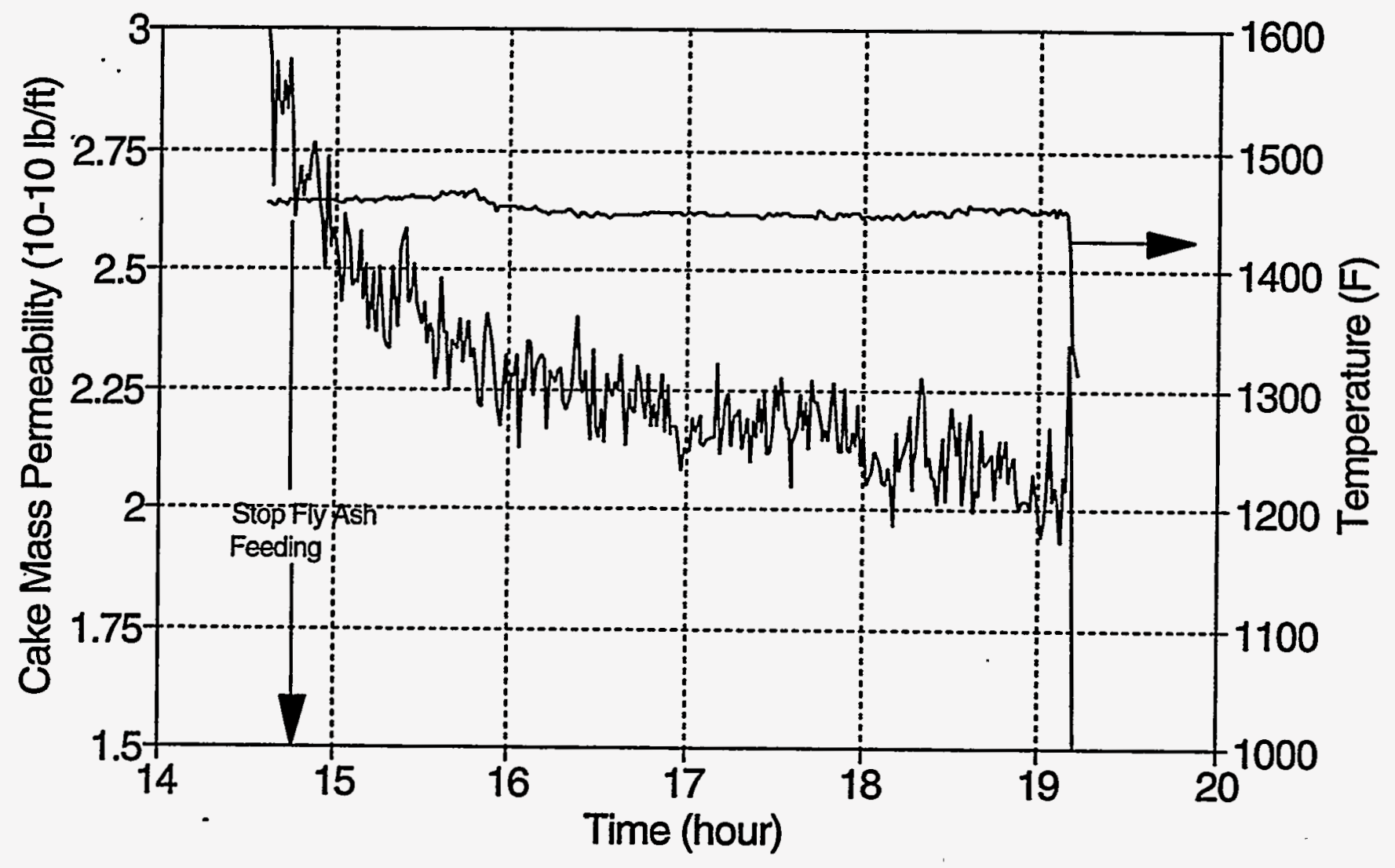




\section{Permeability Test 1.05 (11/12/93) Tidd Fine Fly Ash}

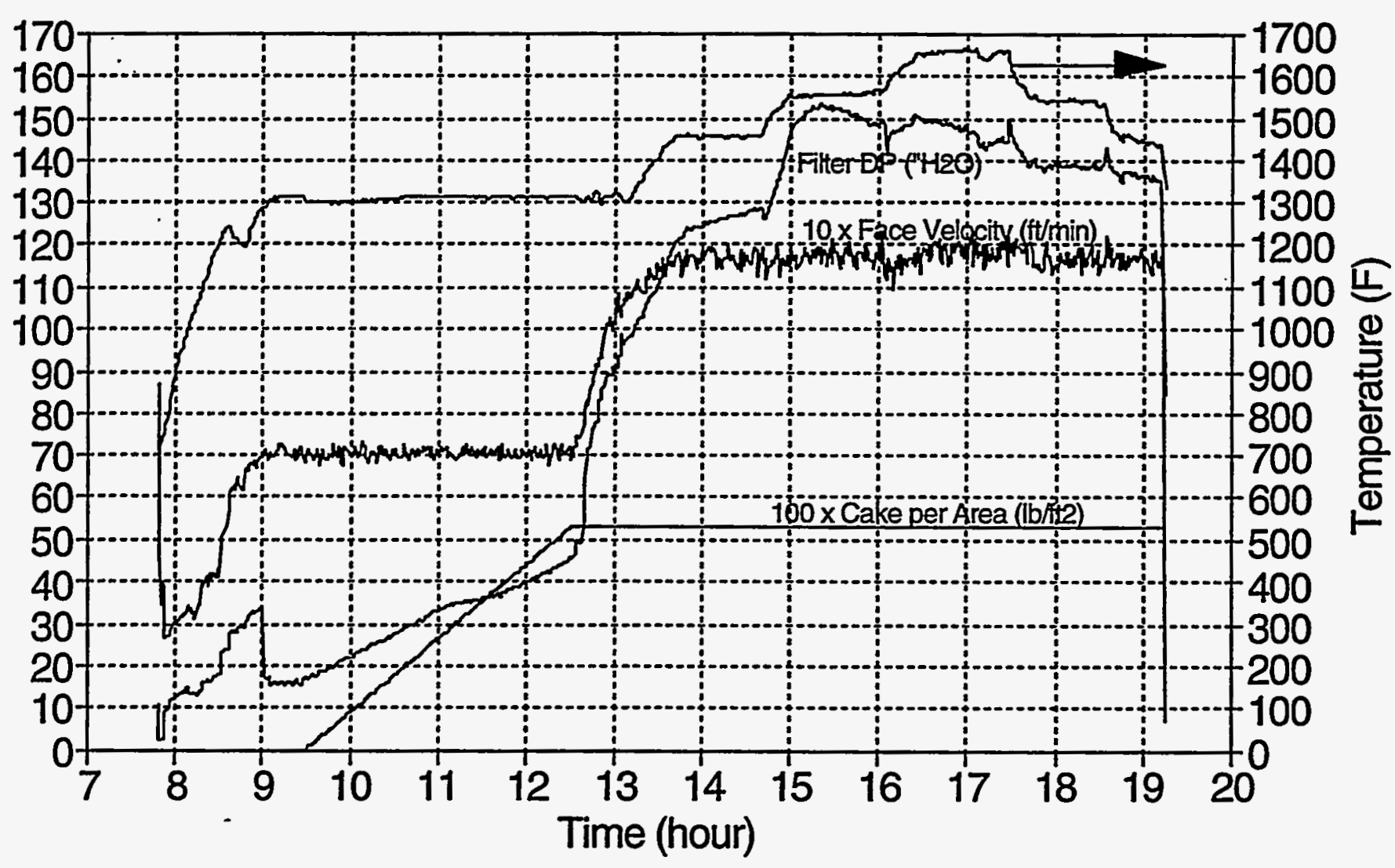




\section{Permeability Test 1.05 (11/12/93) Tidd Fine Fly Ash}

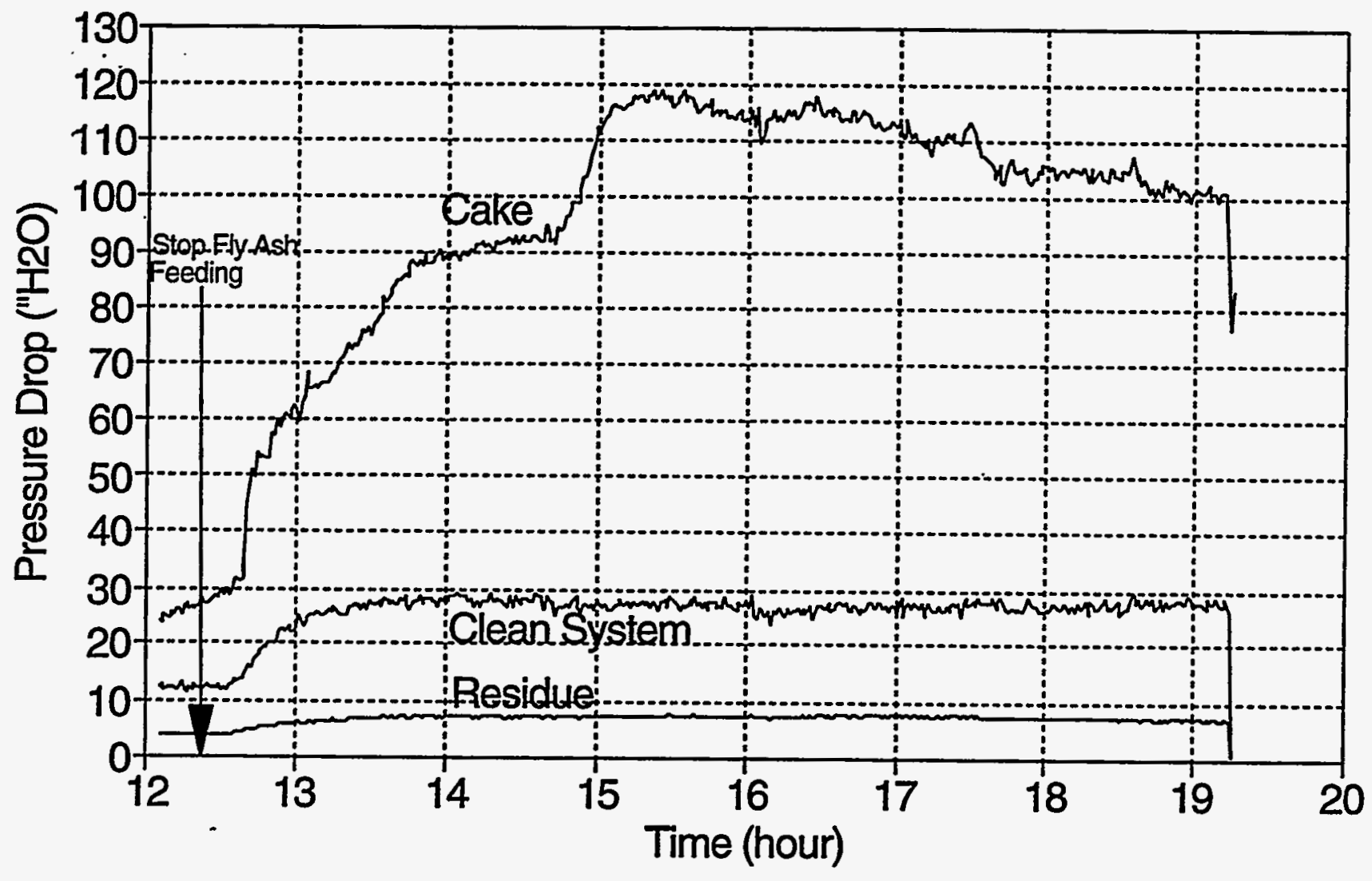




\section{Permeability Test 1.05 (11/12/93) Tidd Fine Fly Ash}

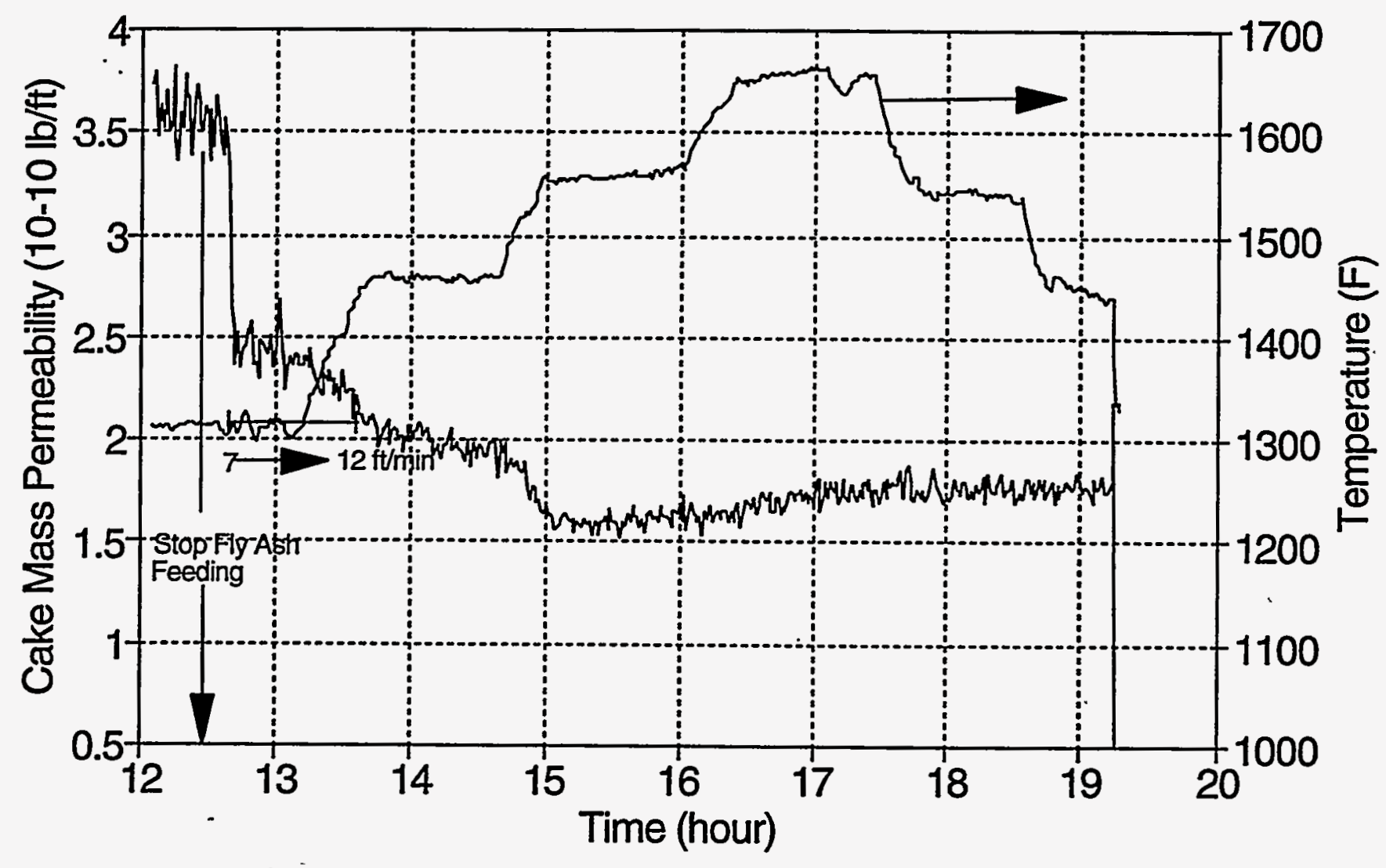




\section{Permeability Test 1.06 (11/15/93) Grimethorpe Red Fly Ash}

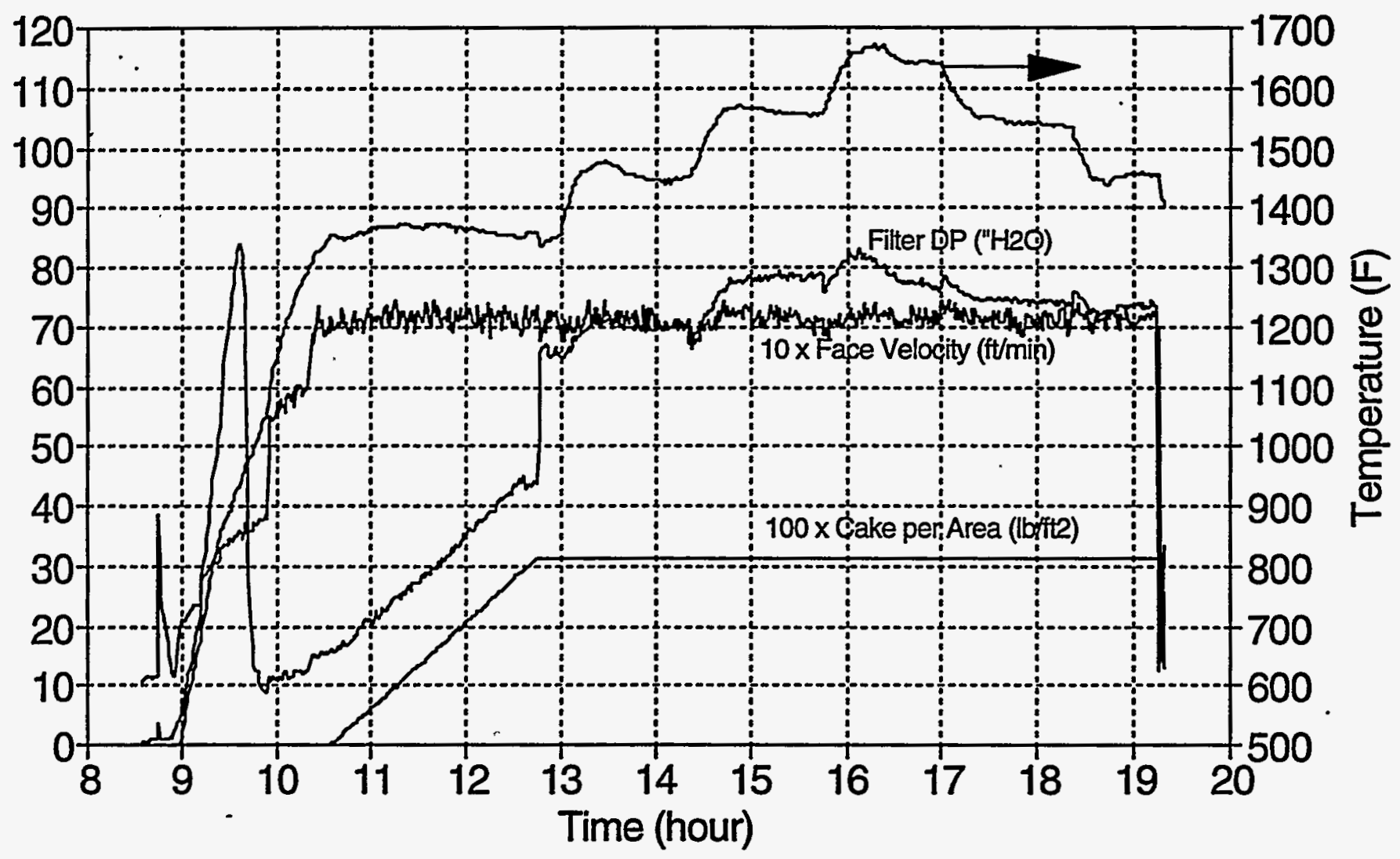




\section{Permeability Test 1.06 (11/15/93) Grimethorpe Red Fly Ash}

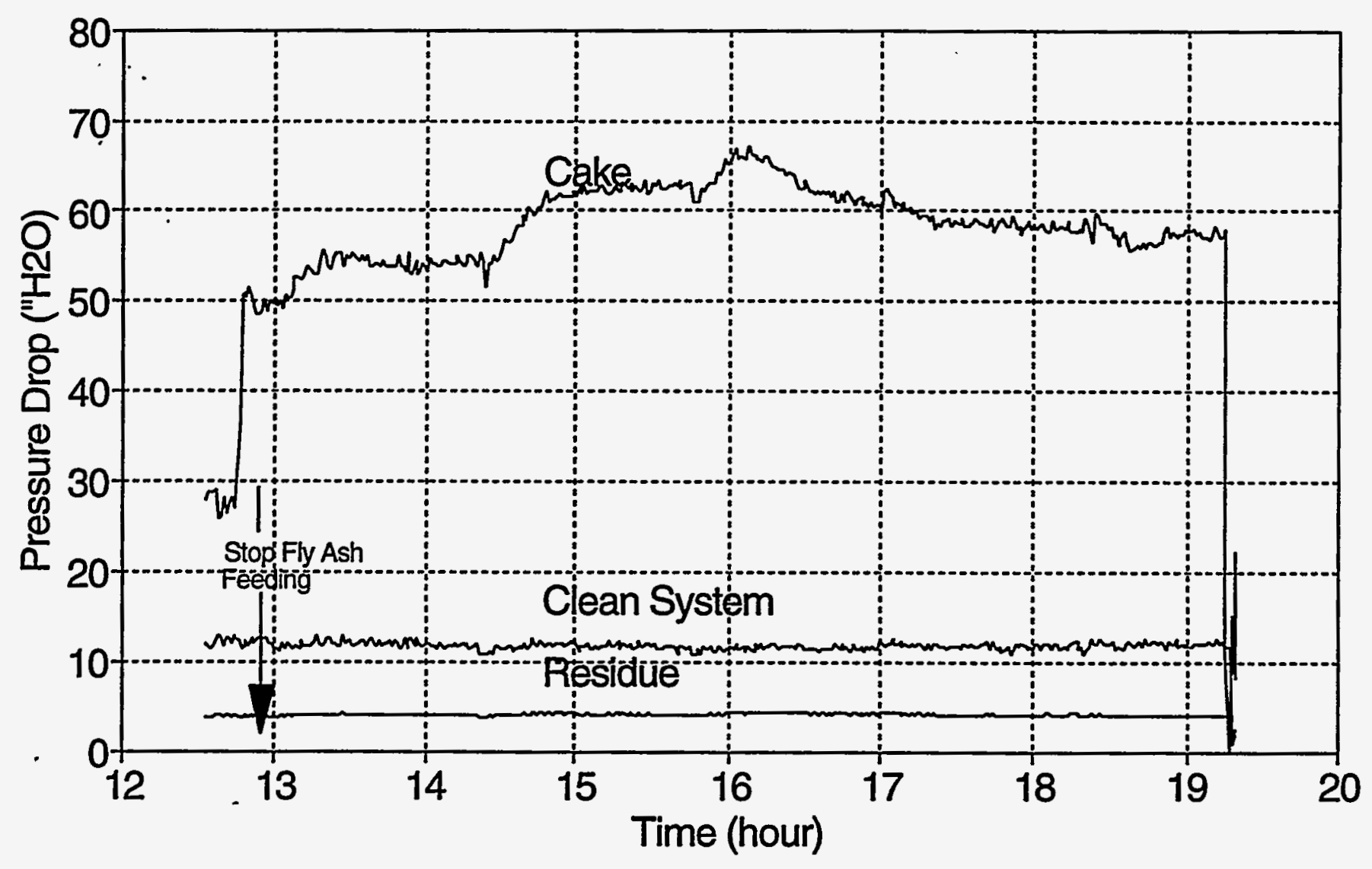




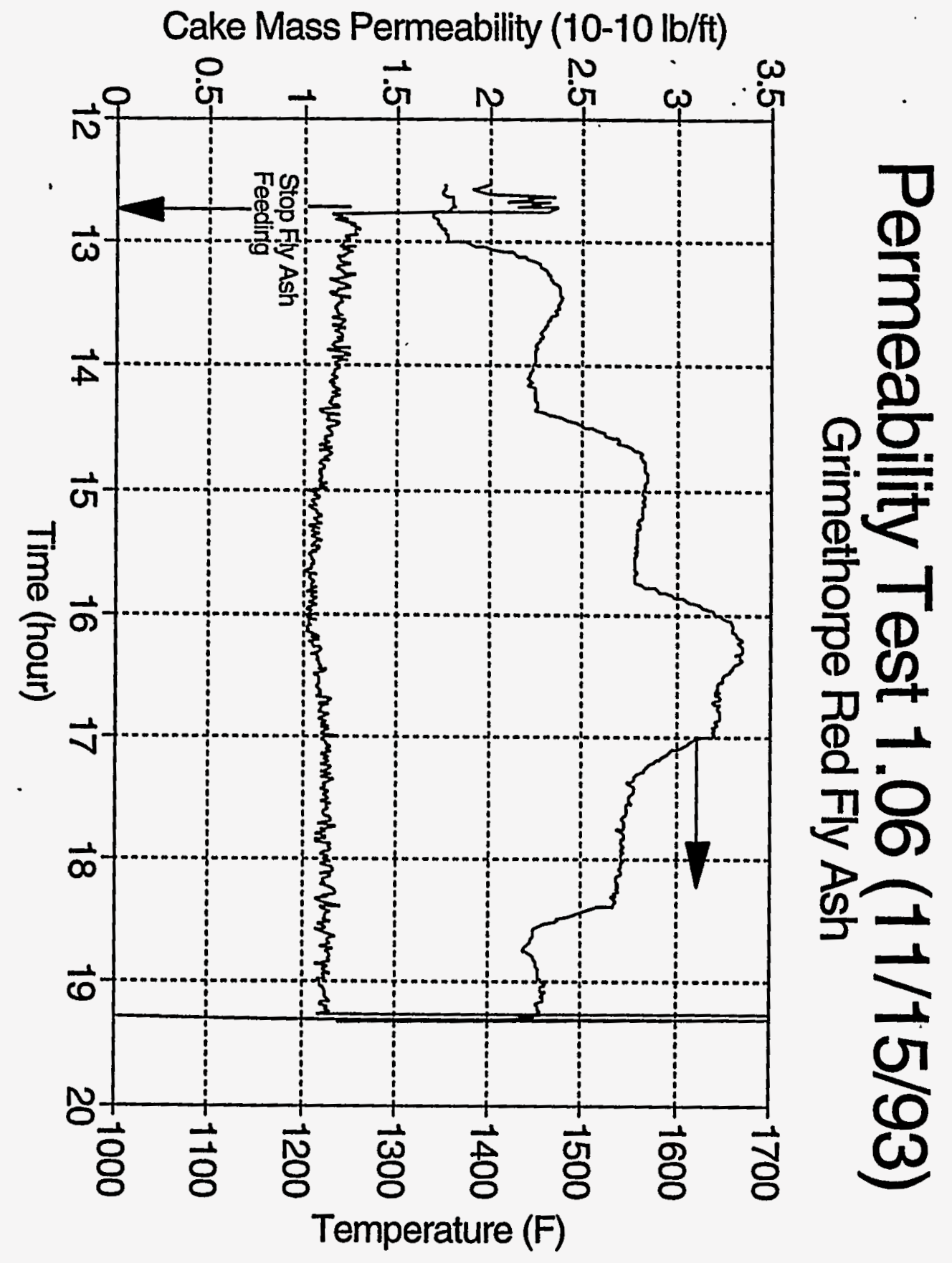




\section{Permeability Test 1.07 (11/16/93) Karhula I Fly Ash}

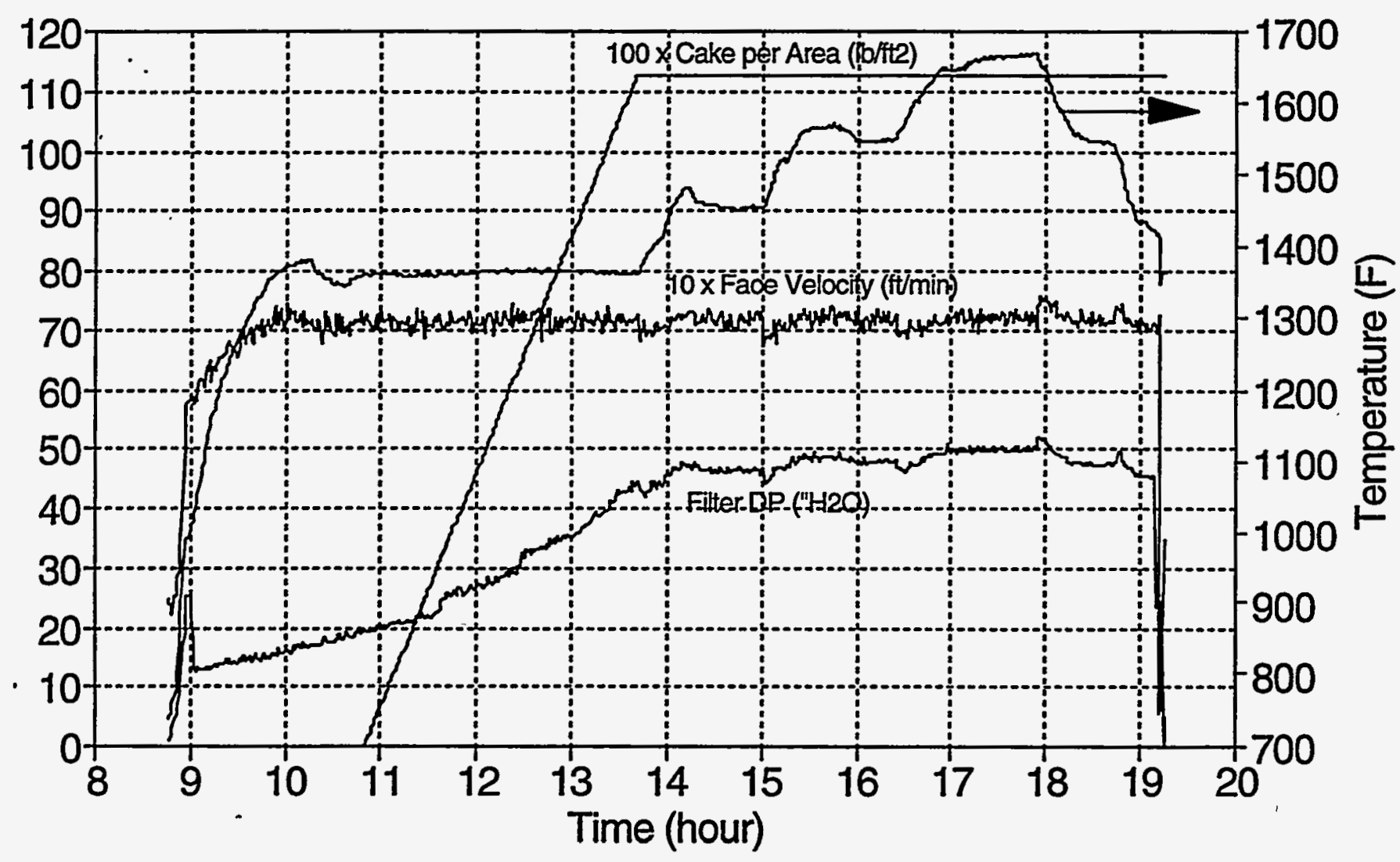




\section{Permeability Test 1.07 (11/16/93)}

Karhula I Fly Ash

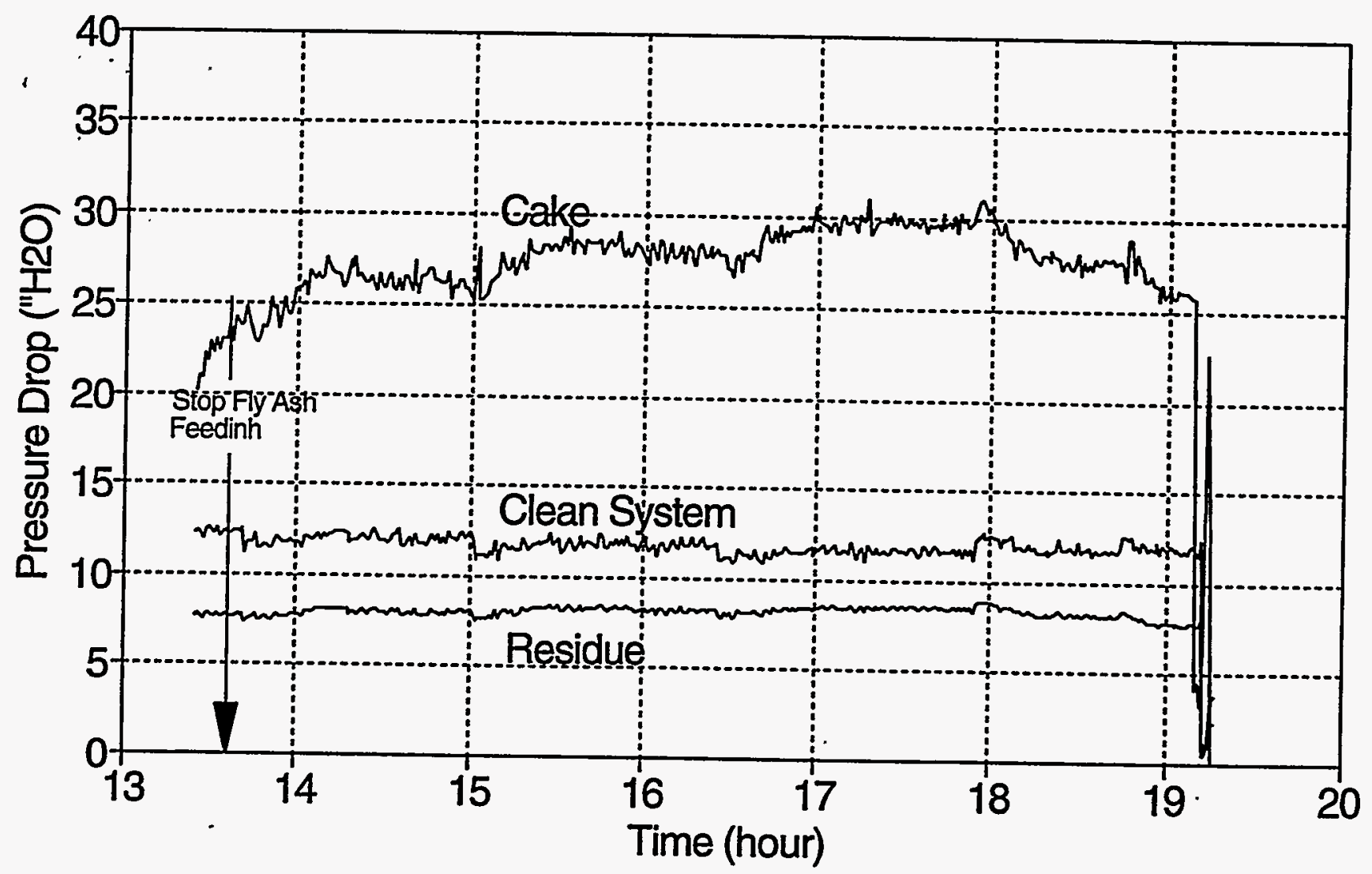




\section{Permeability Test 1.07 (11/16/93) Karhula I Fly Ash}

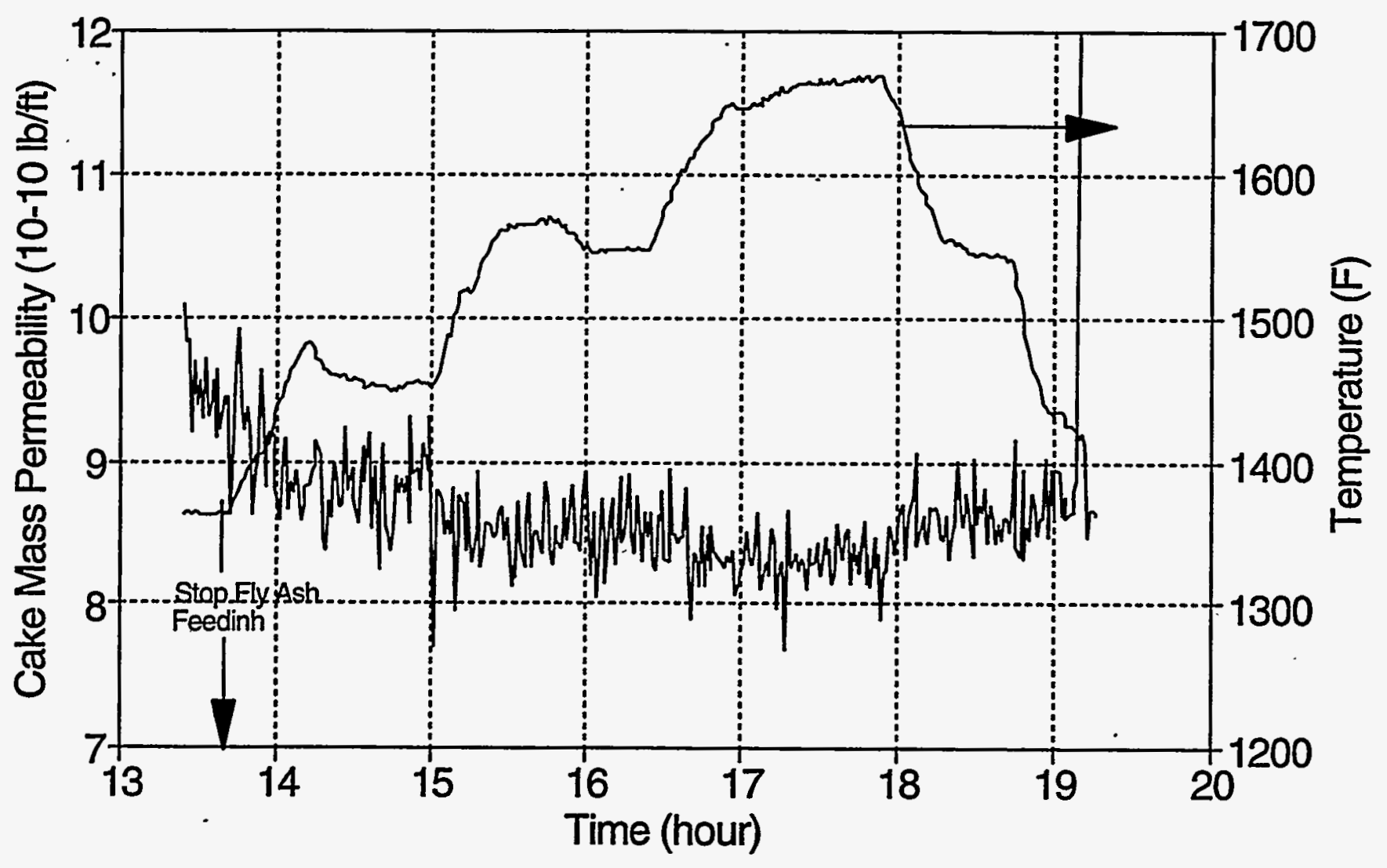




\section{Permeability Test 1.08 (11/17/93) No Fly Ash Fed}

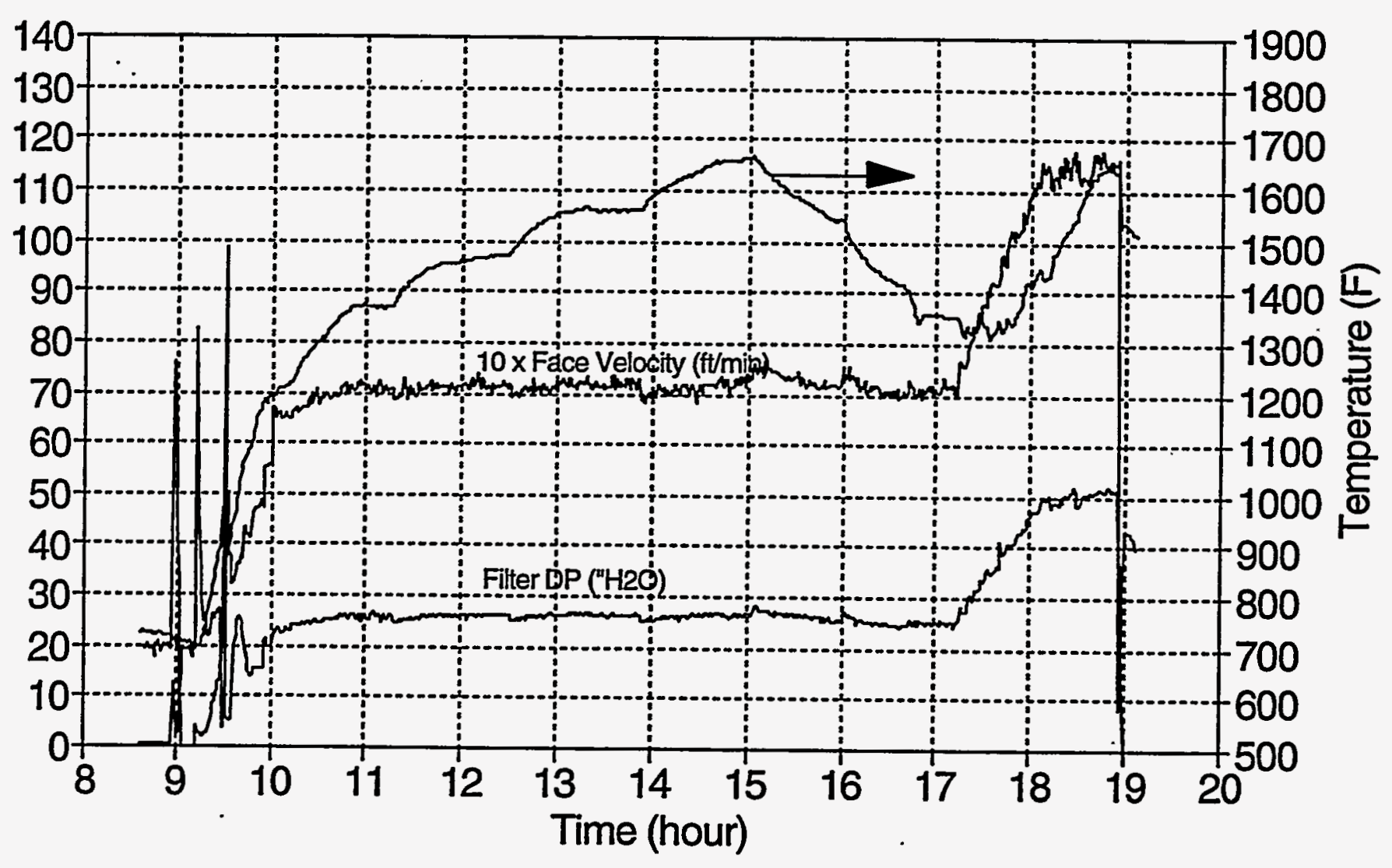




\section{Permeability Test 1.08 (11/17/93) No Fly Ash Fed}

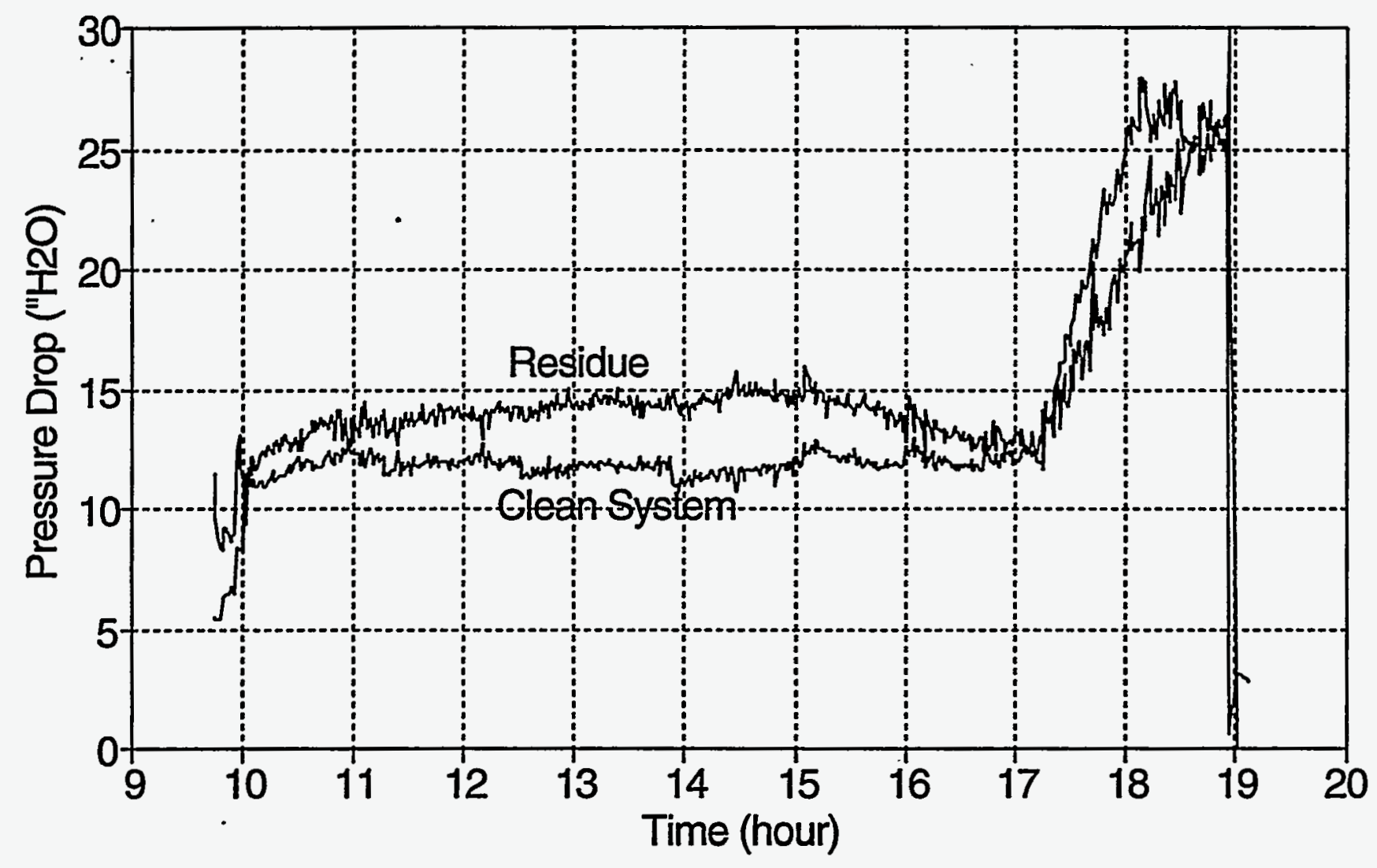




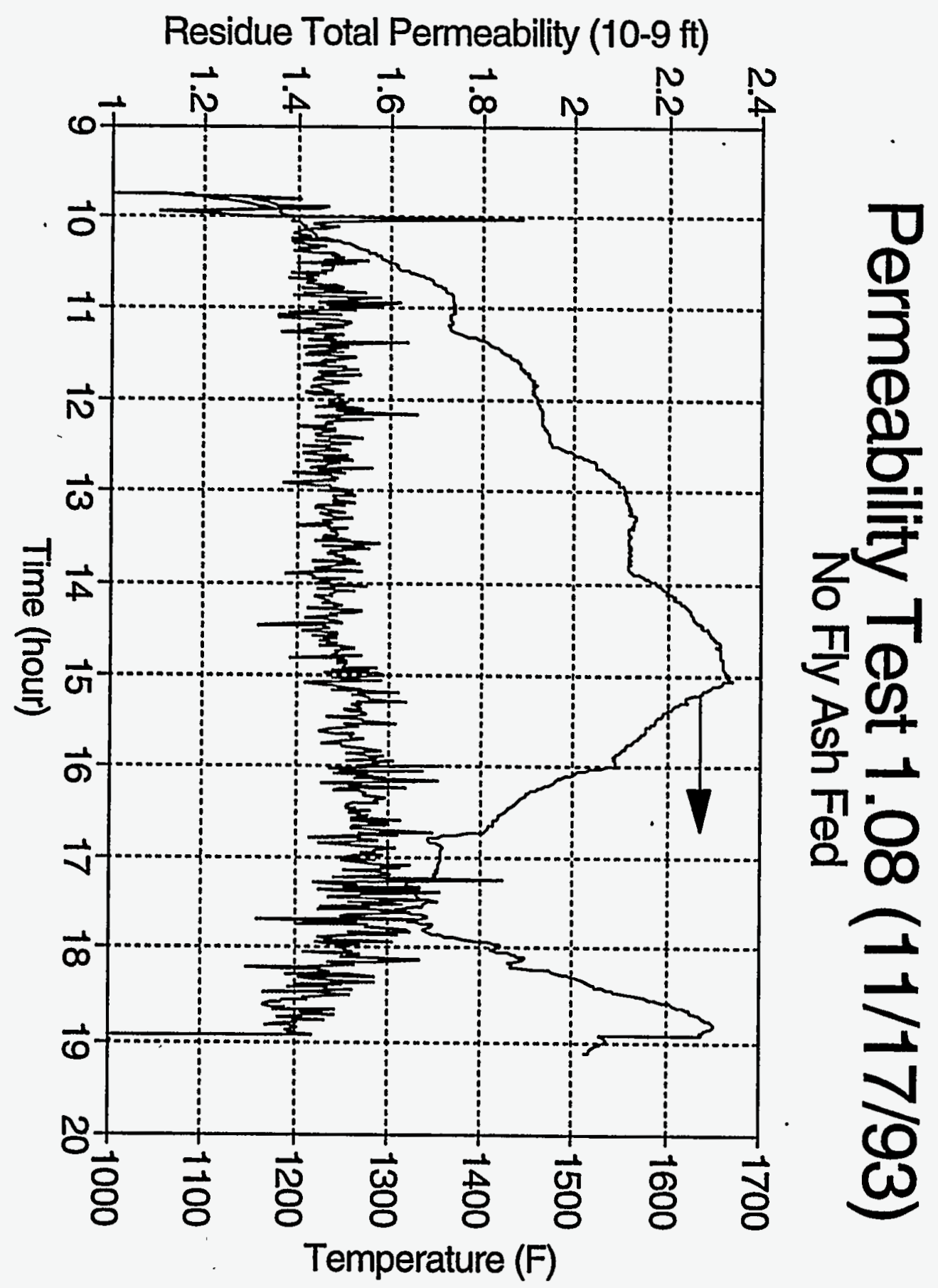




\section{Permeability Test 1.09 (11/23/93) Tidd Fine Fly Ash (150 psig)}

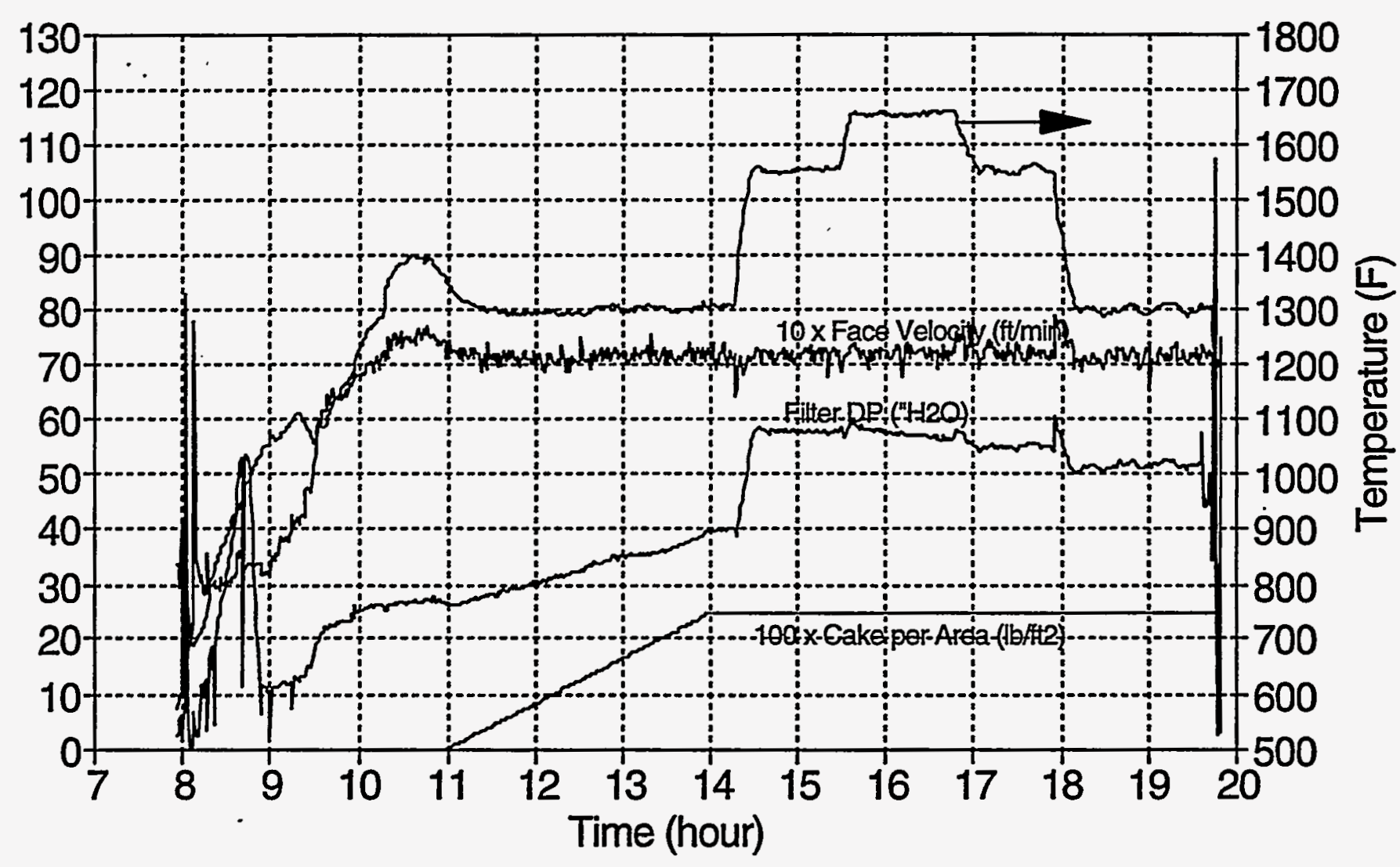




\section{Permeability Test 1.09 (11/23/93) Tidd Fine Fly Ash (150 psig)}

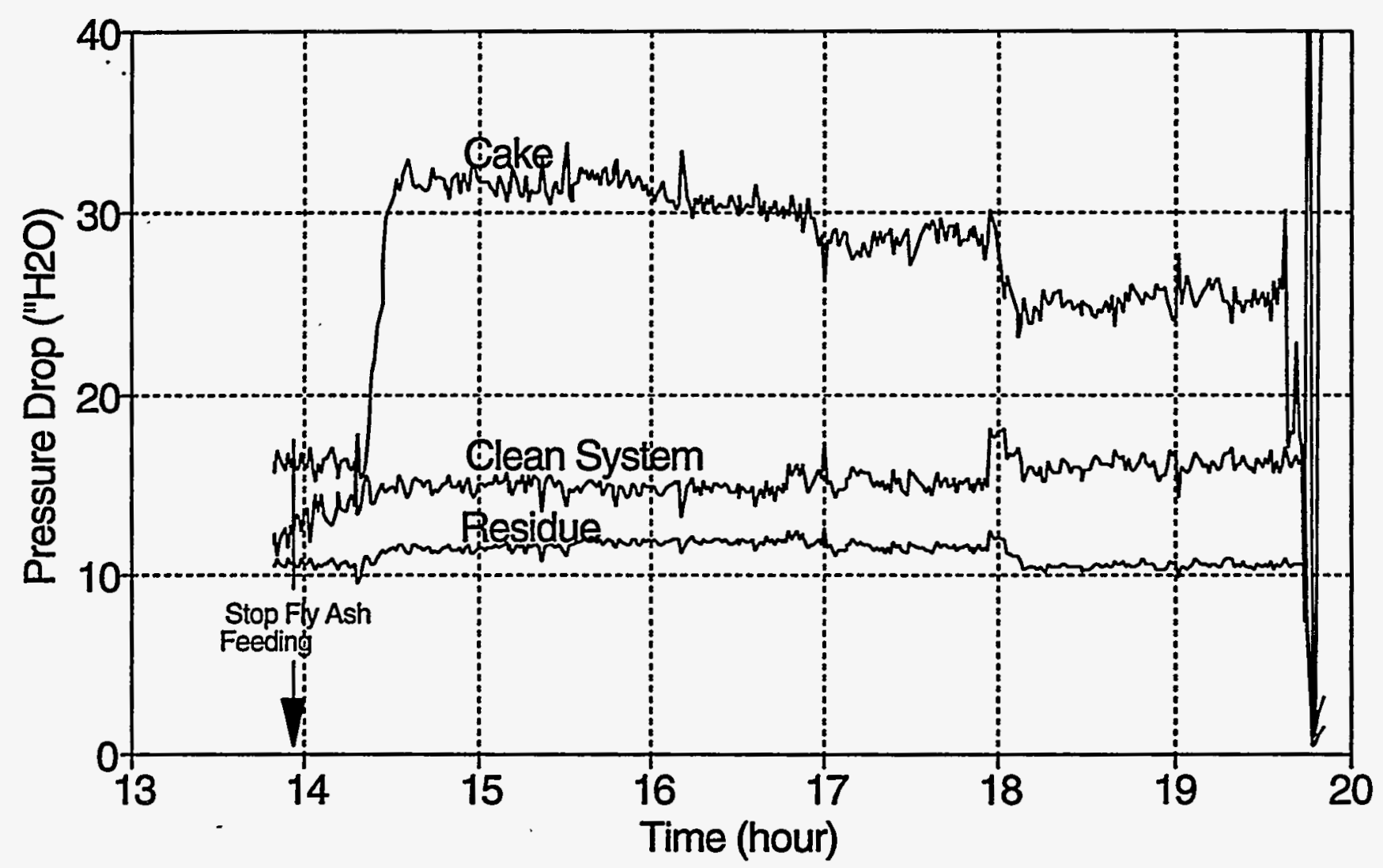




\section{Permeability Test 1.09 (11/23/93) Tidd Fine Fly Ash (150 psig)}

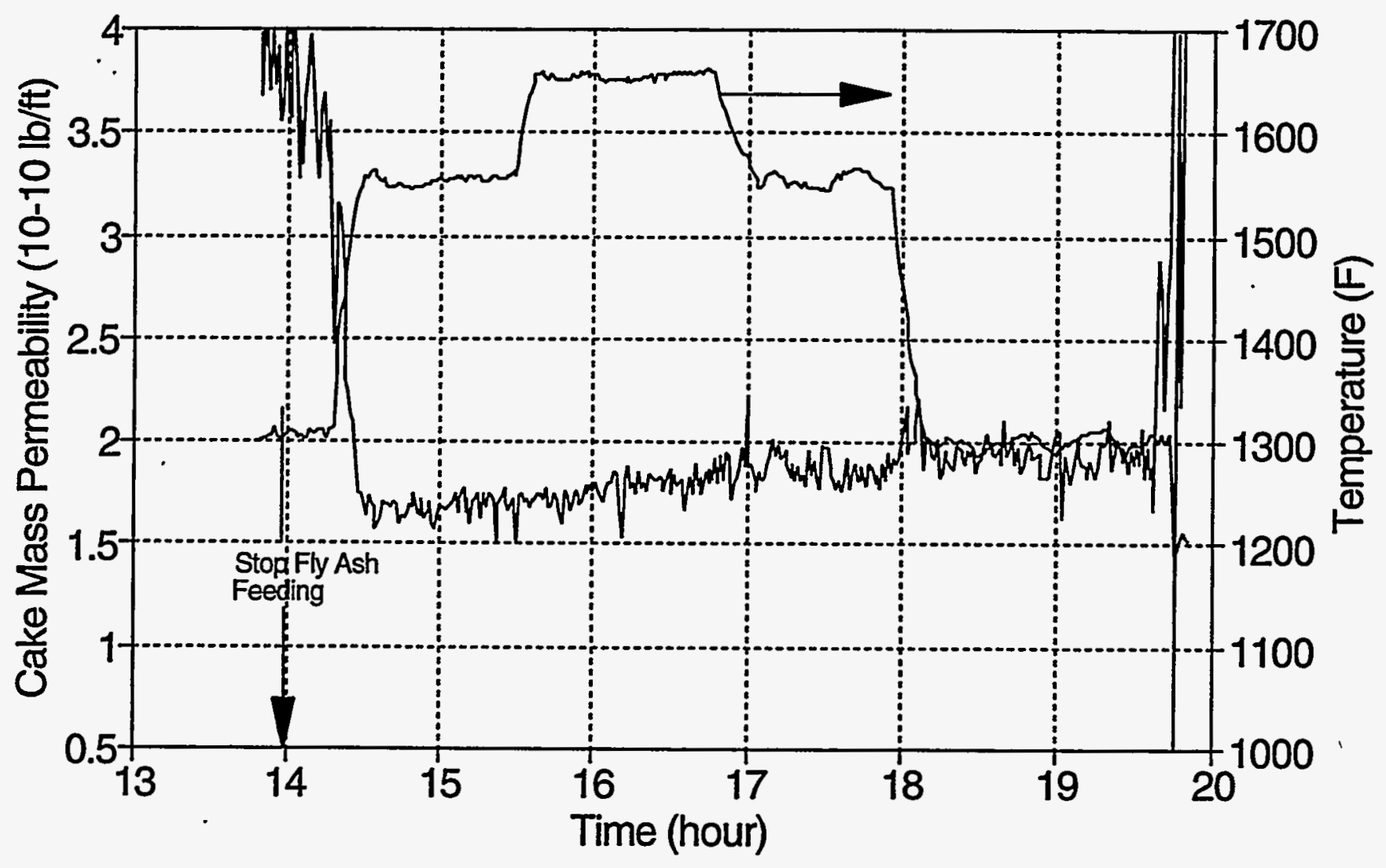




\section{Permeability Test 1.10 (2/21/94) Tidd Cyclone Drain '}

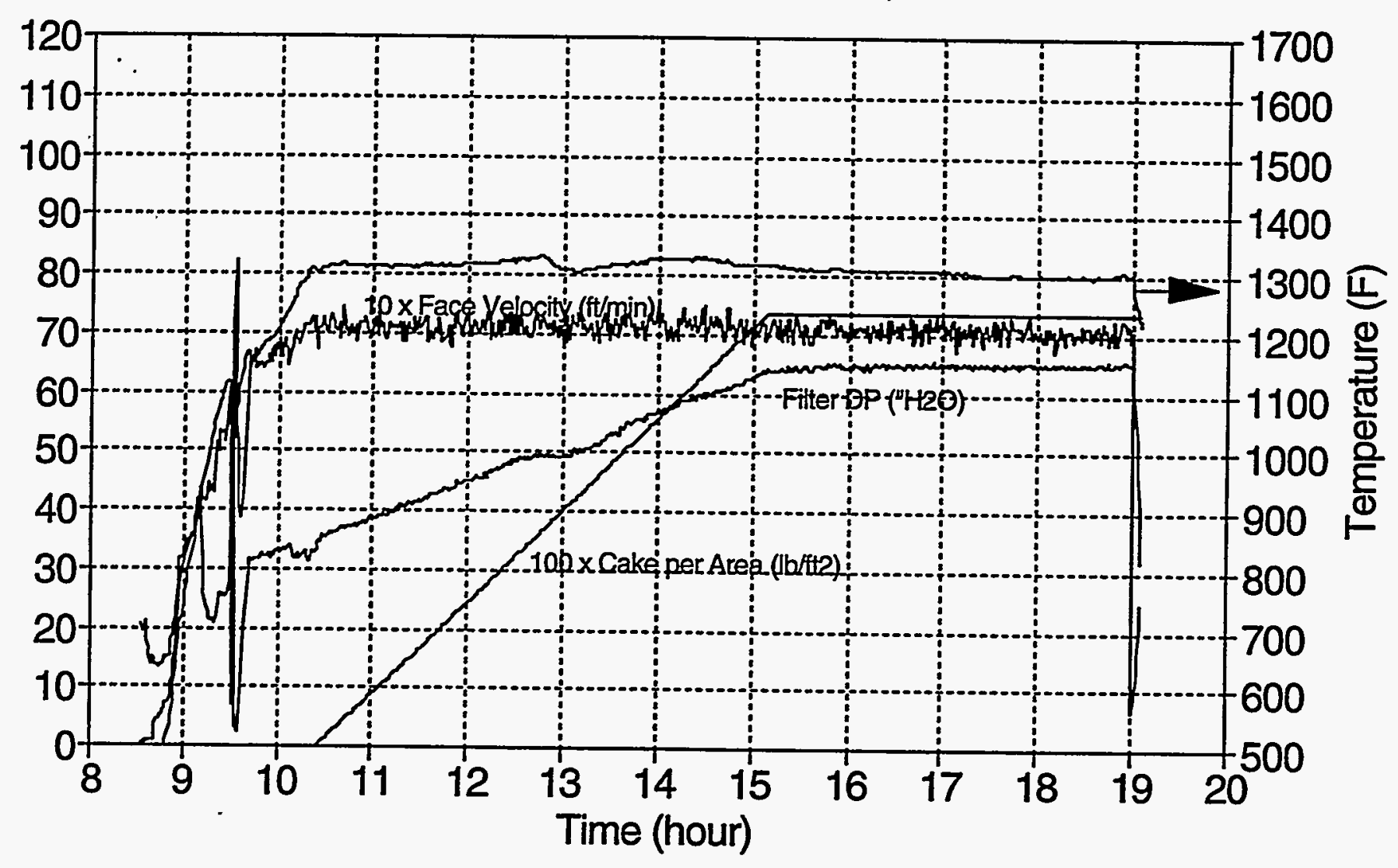




\section{Permeability Test 1.10 (2/21/94) Tidd Cyclone Drain}

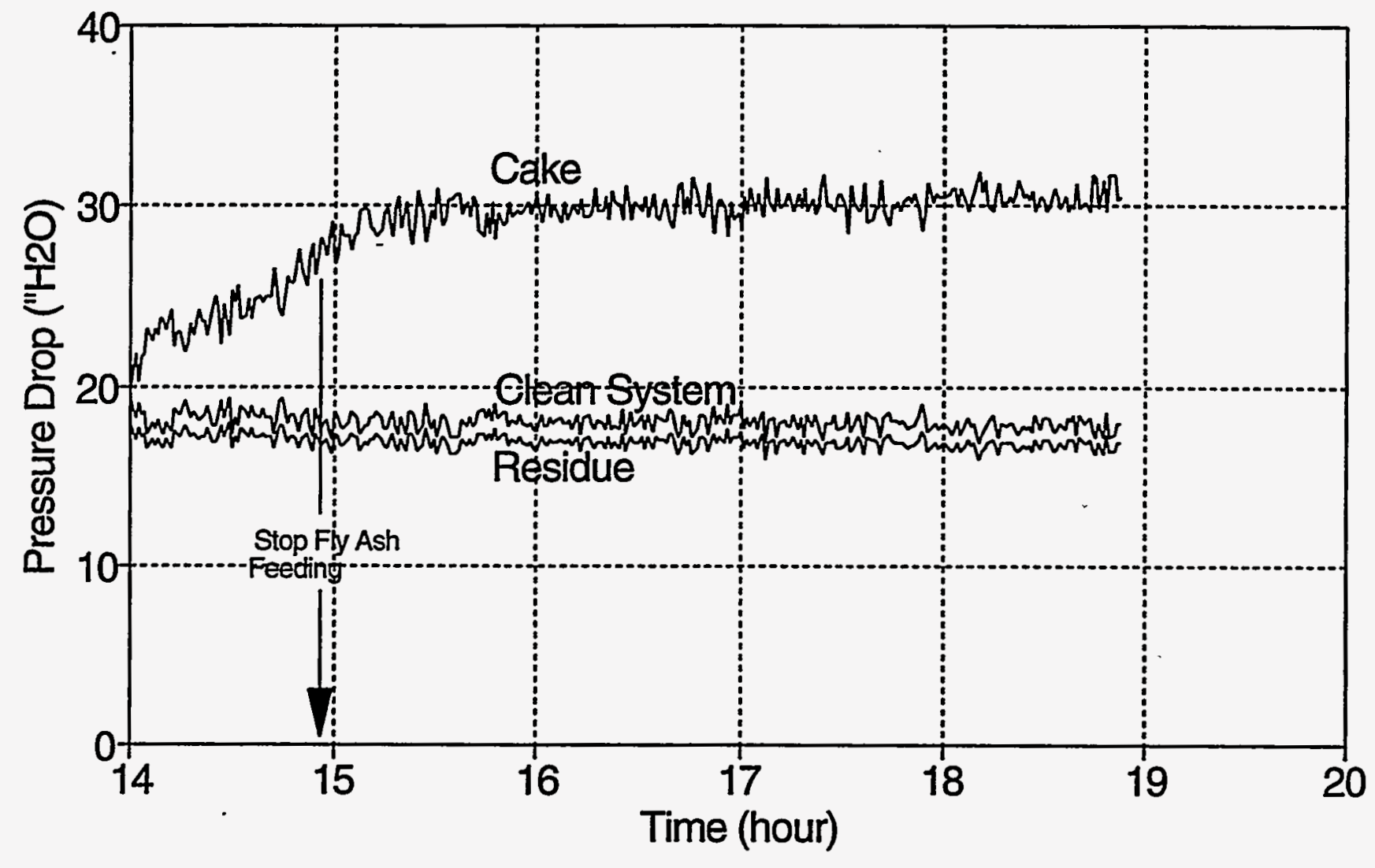




\section{Permeability Test 1.10 (2/21/94) Tidd Cyclone Drain}

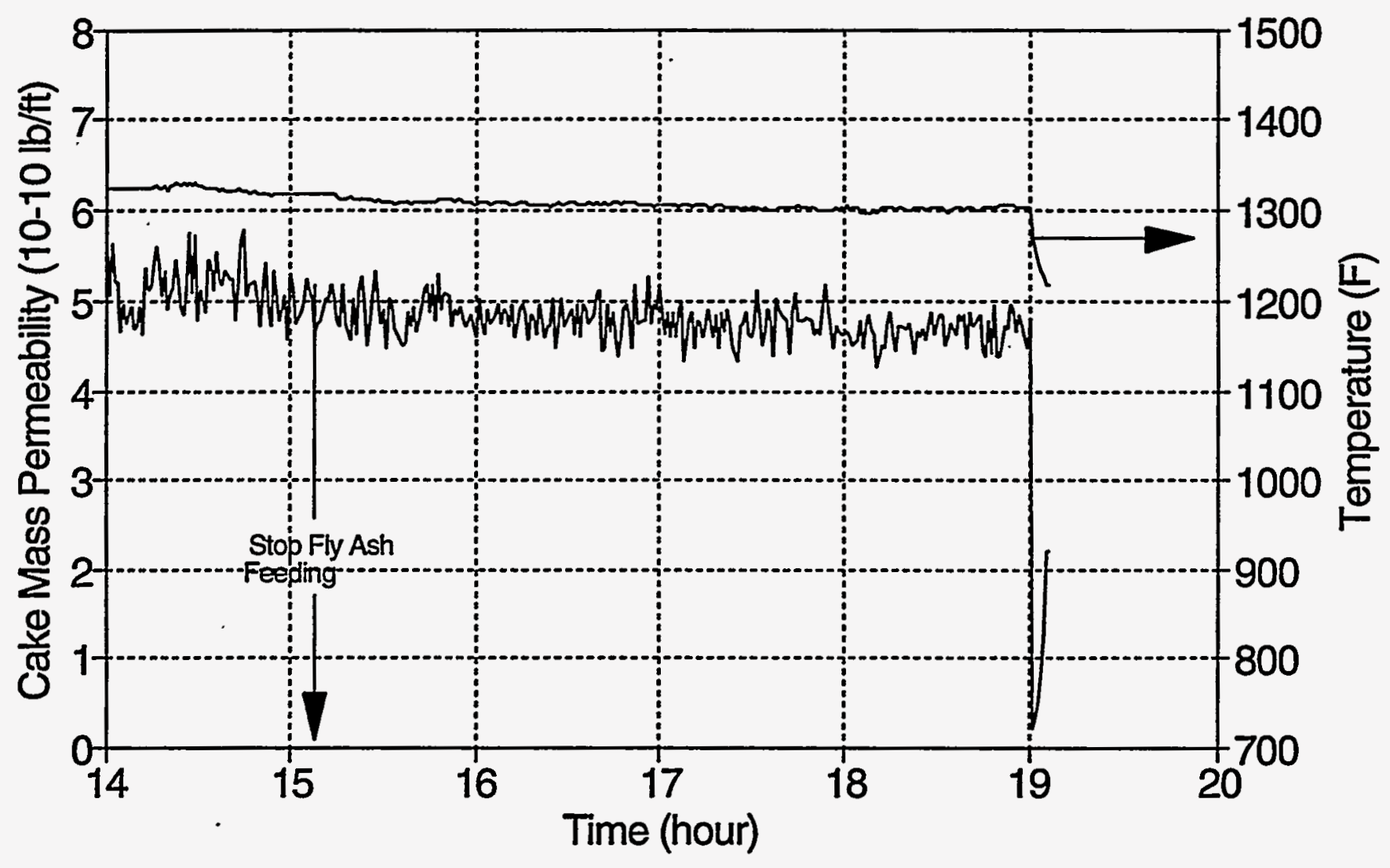




\section{Permeability Test 1.10 (2/22/94) Tidd Cyclone Drain}

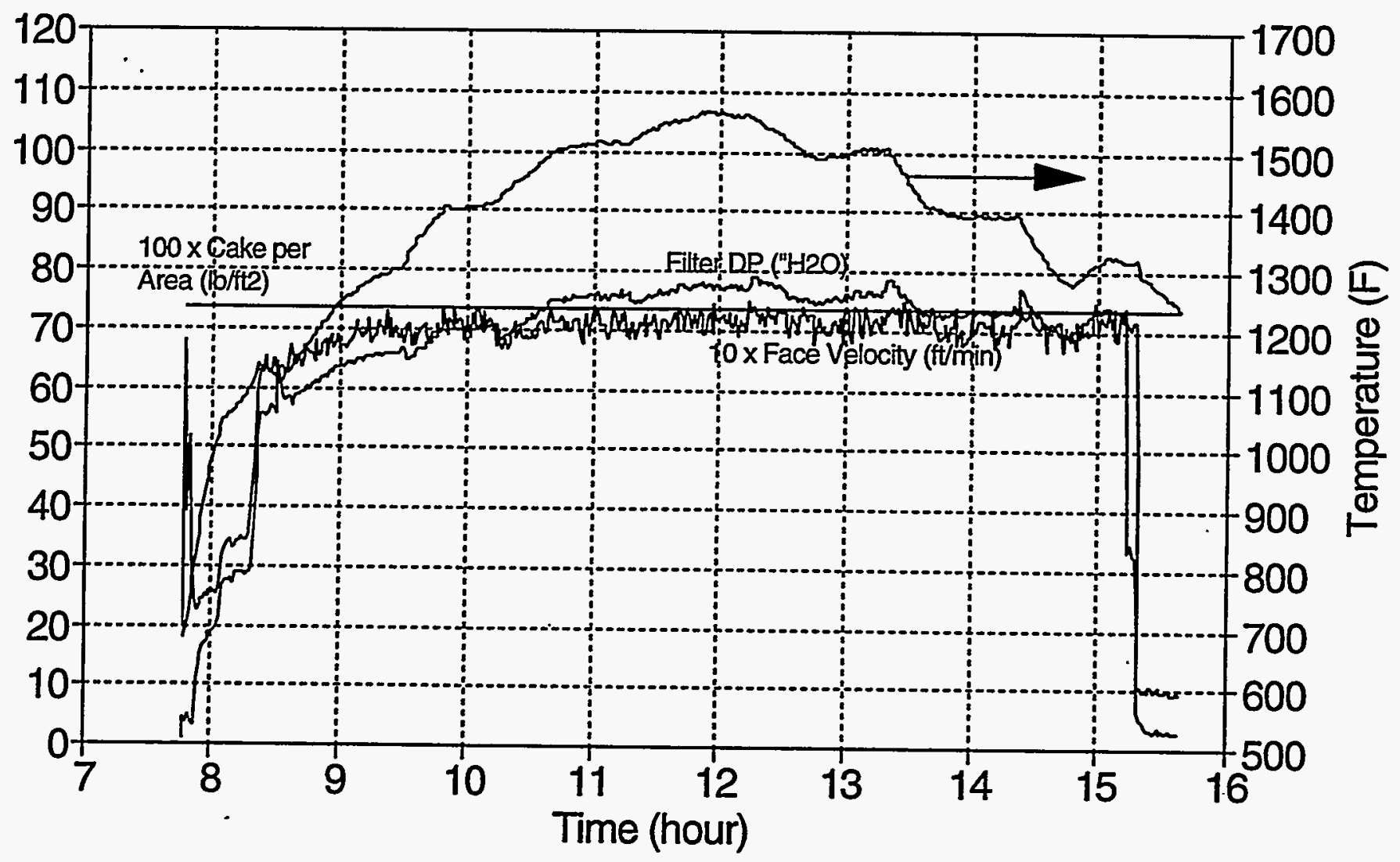




\section{Permeability Test 1.10 (2/22/94) Tidd Cyclone Drain}

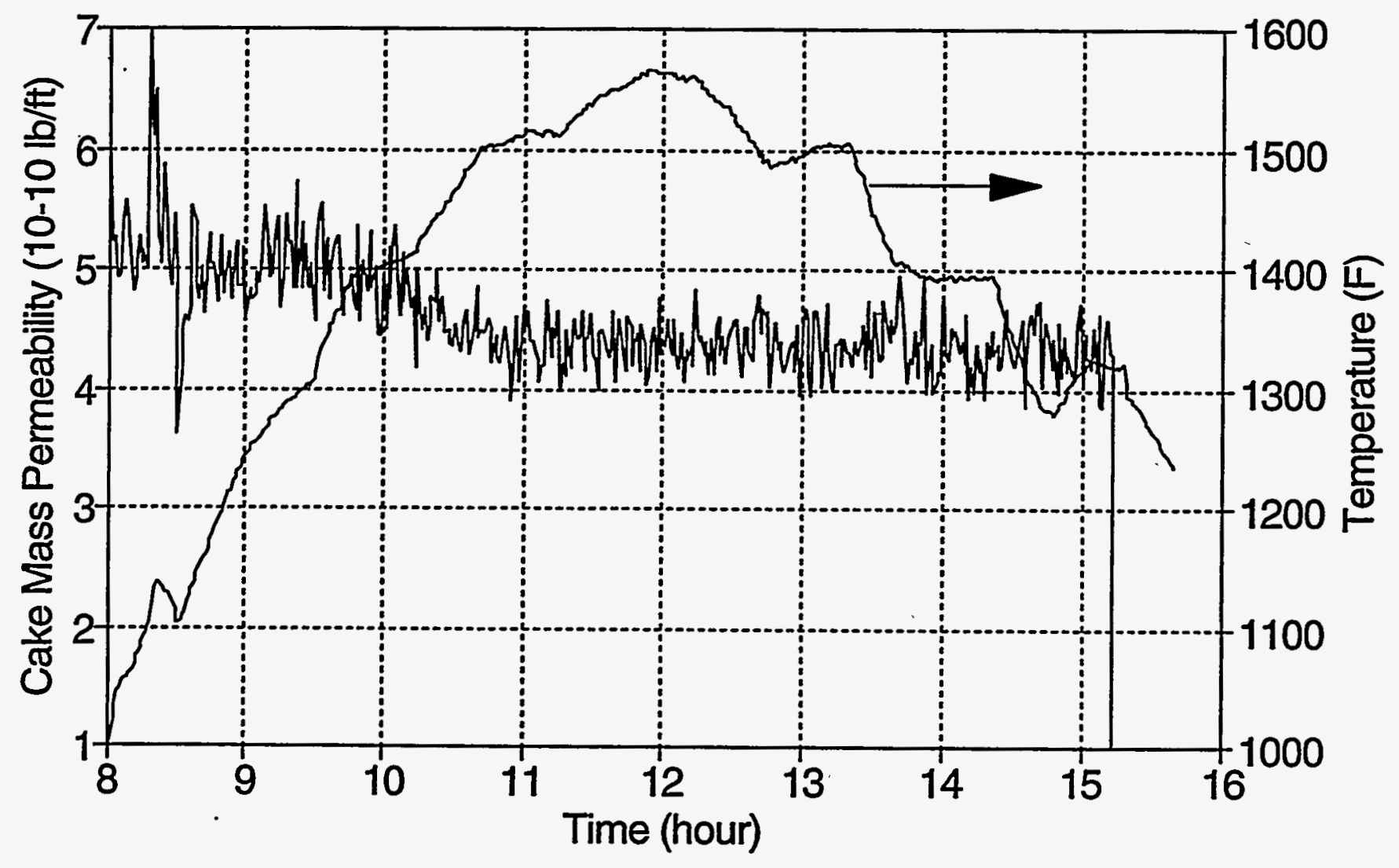




\section{Permeability Test 1.10 (2/22/94) Tidd Cyclone Drain}

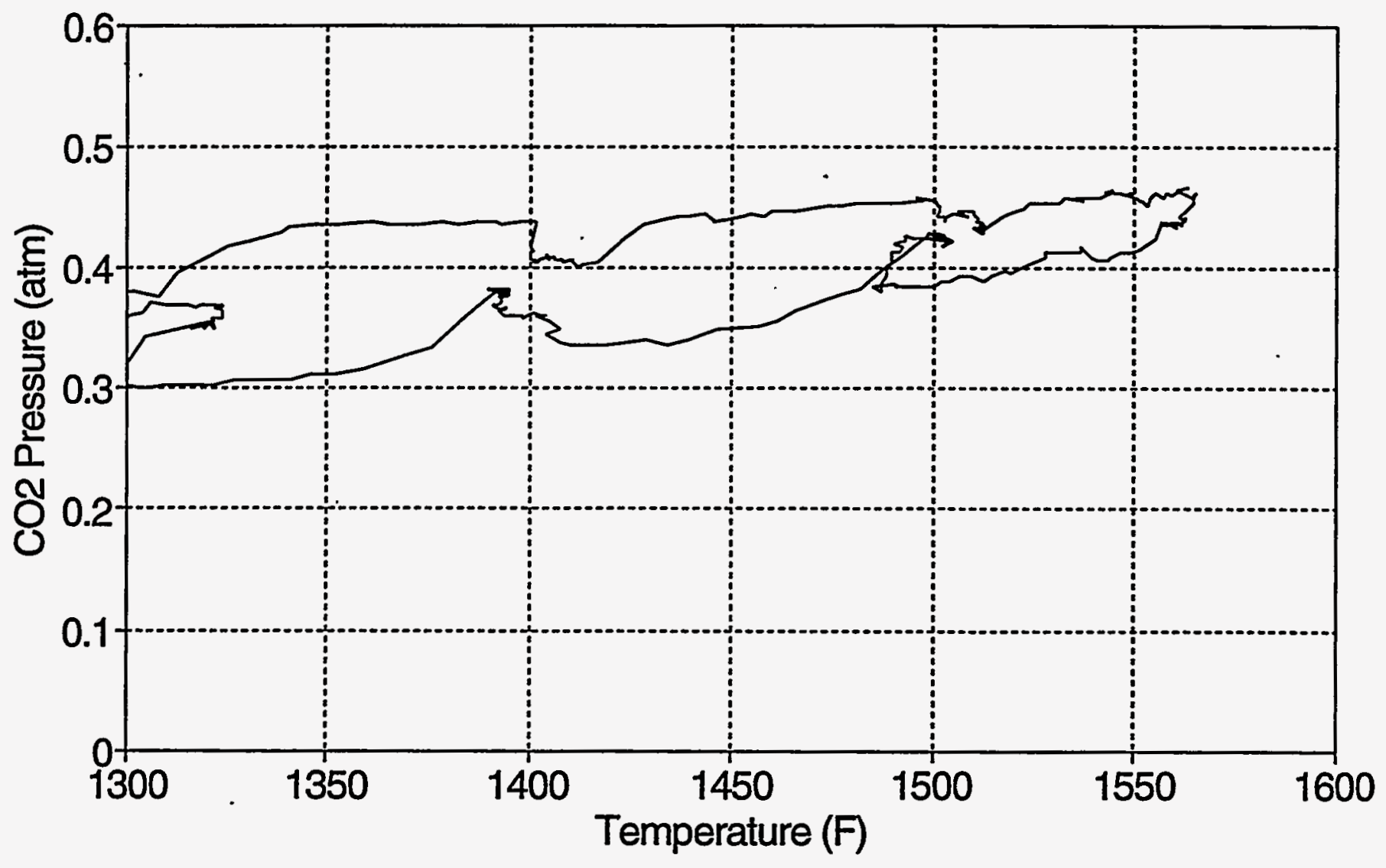




\section{Permeability Test 1.11 (3/1/94) Karhula I Fly Ash (150 psig)}

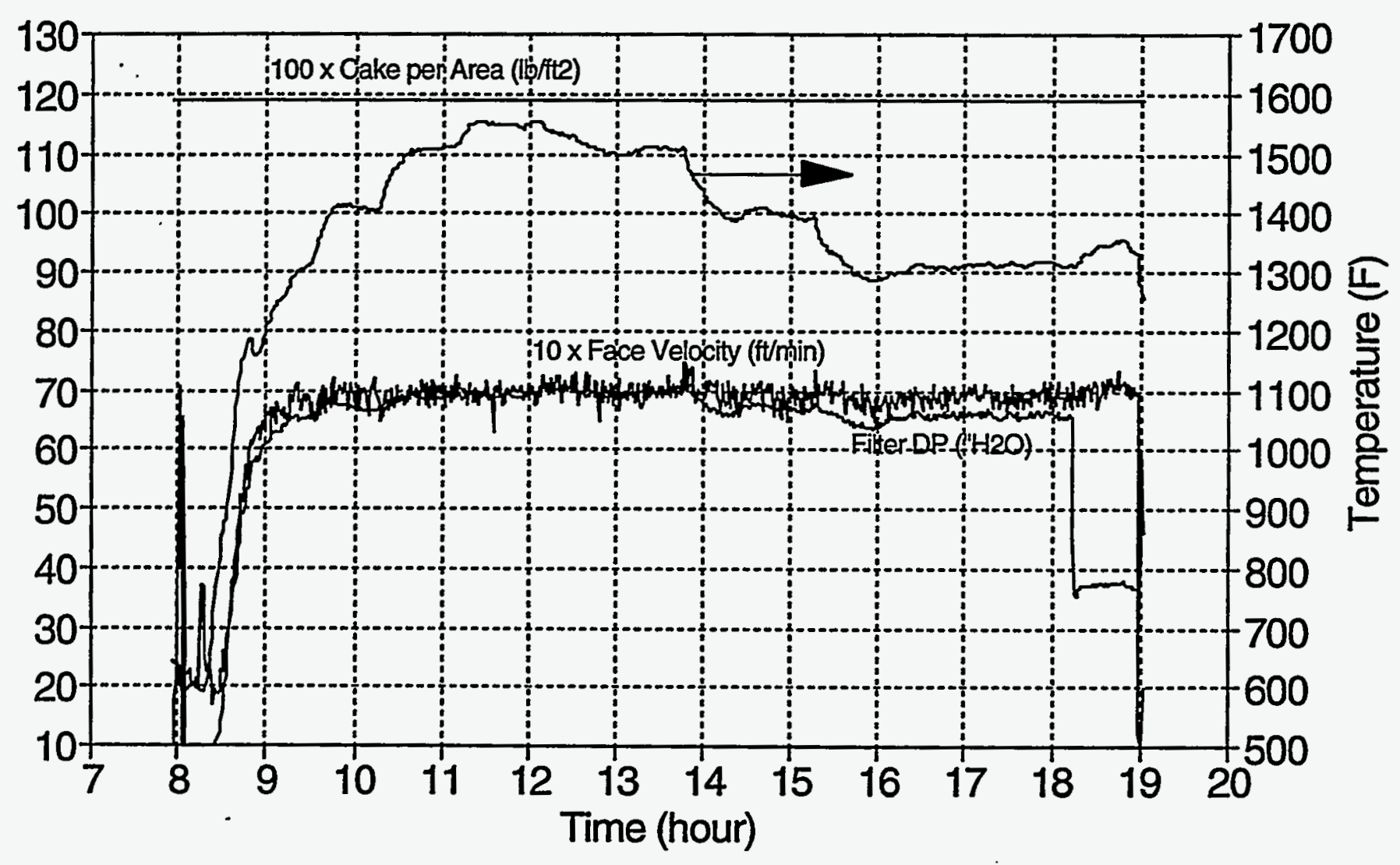




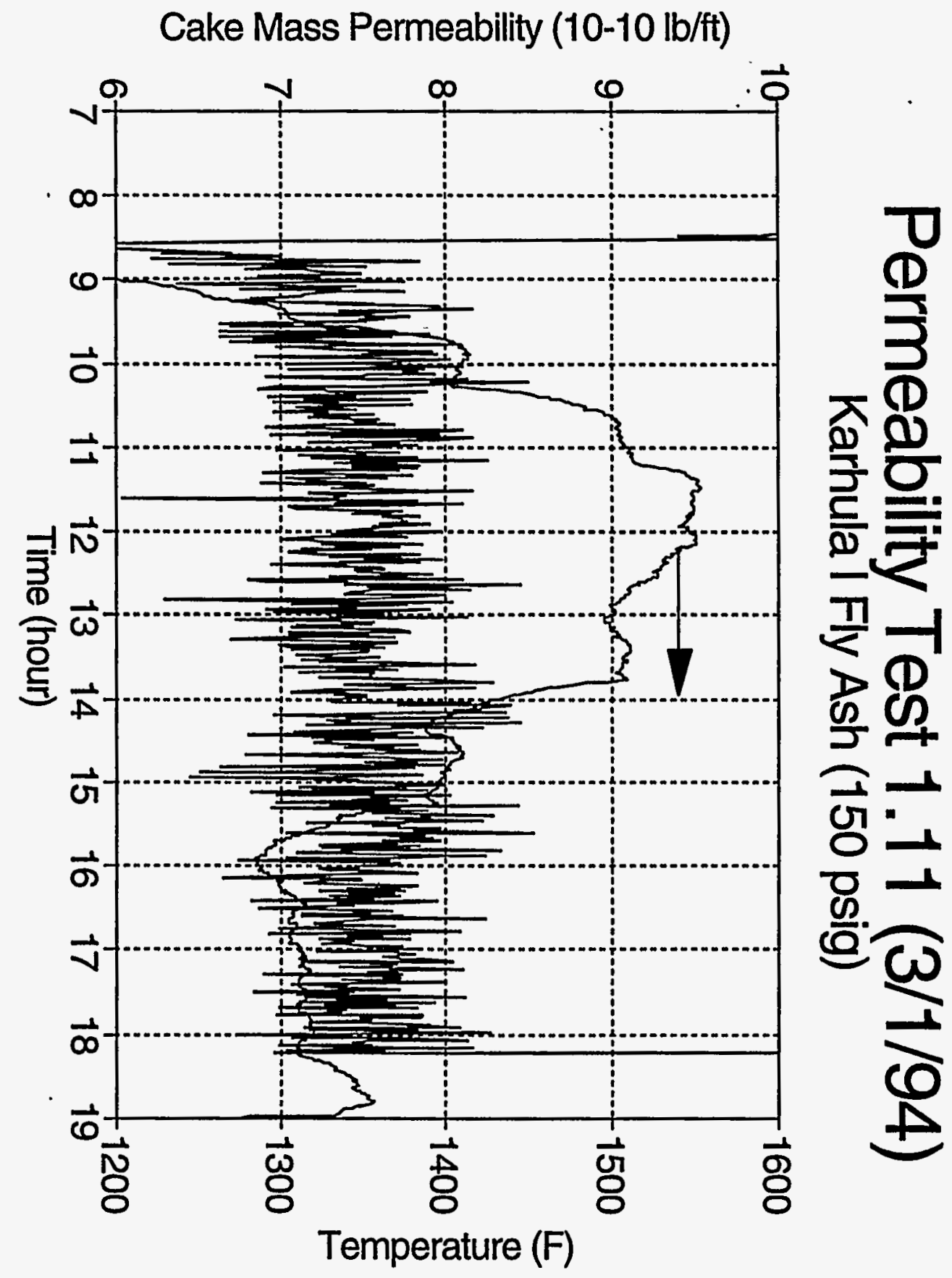




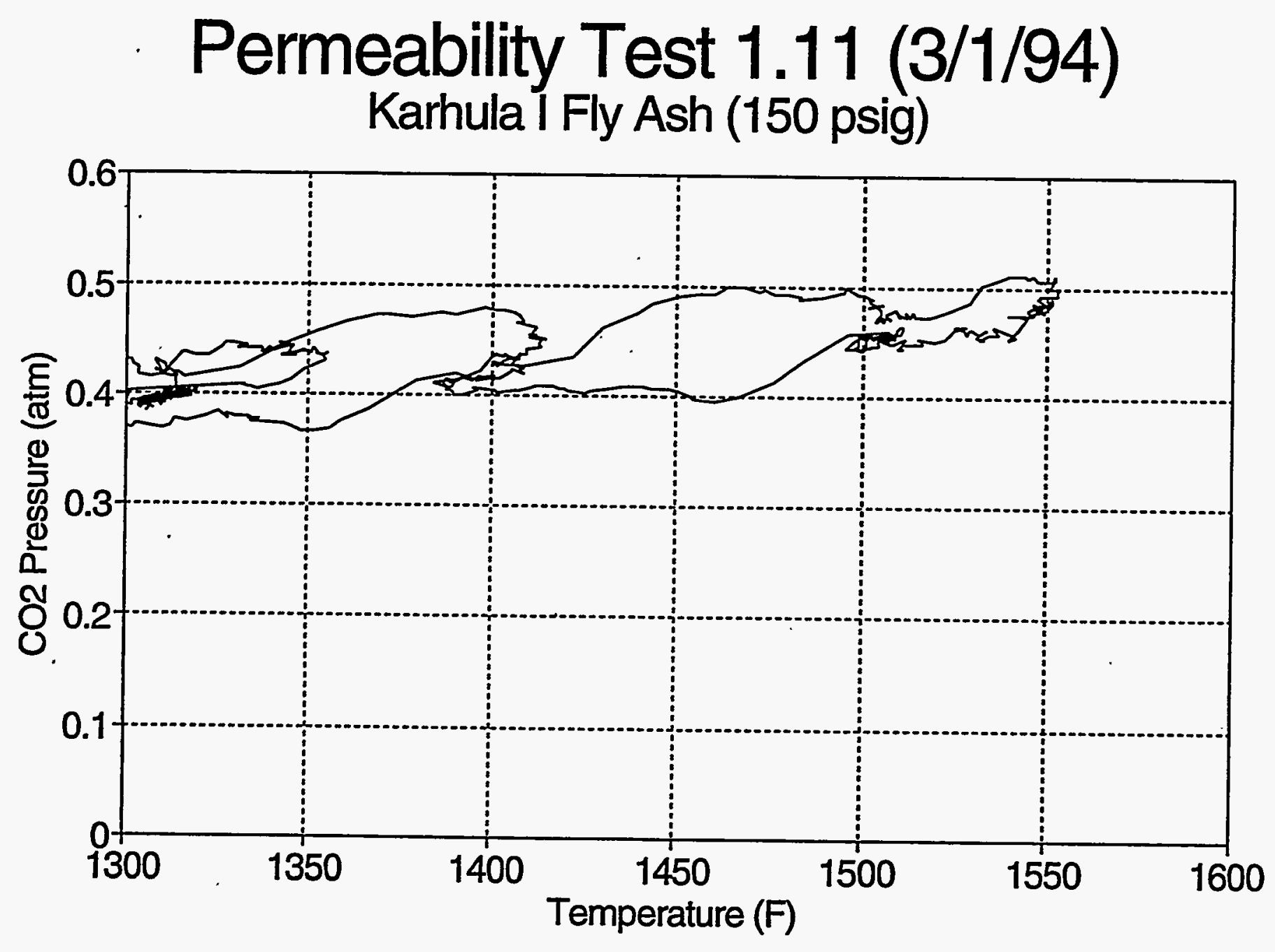




\section{Permeability Test 1.12 (3/4/94) Karhula I Fly Ash (50 psig)}

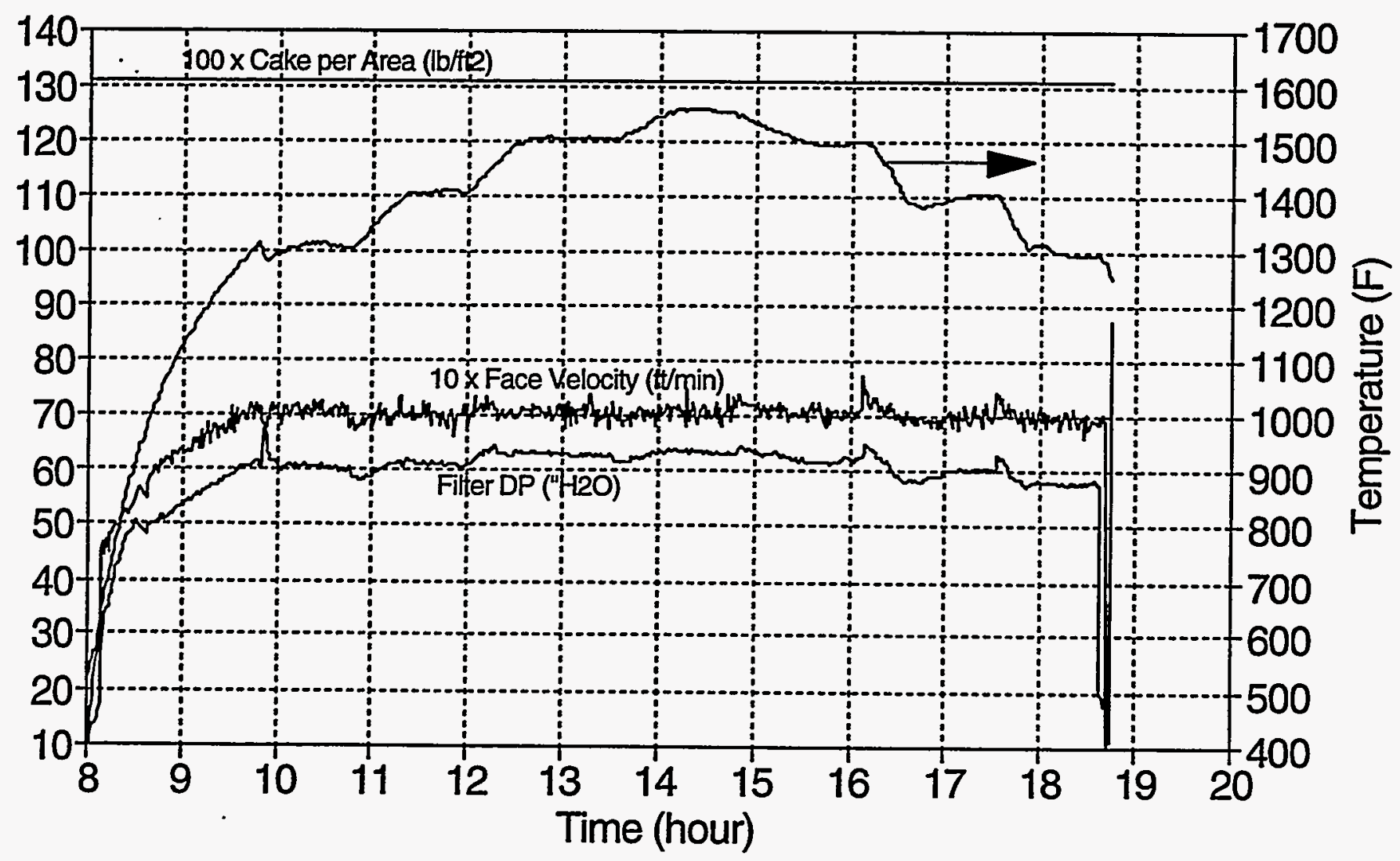




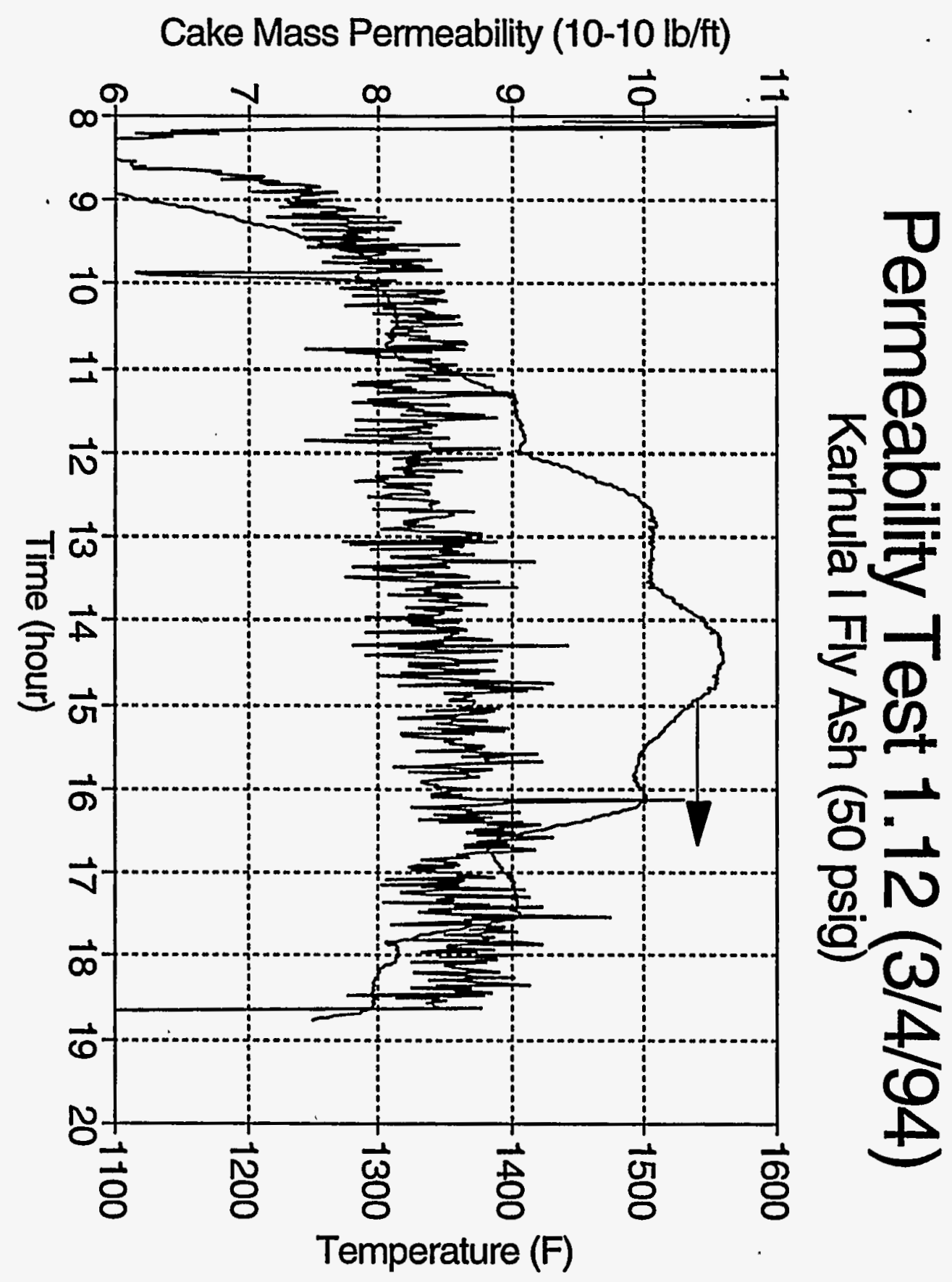




\section{Permeability Test 1.13 (3/9/94) Tidd Fine Fly Ash (50 psig)}

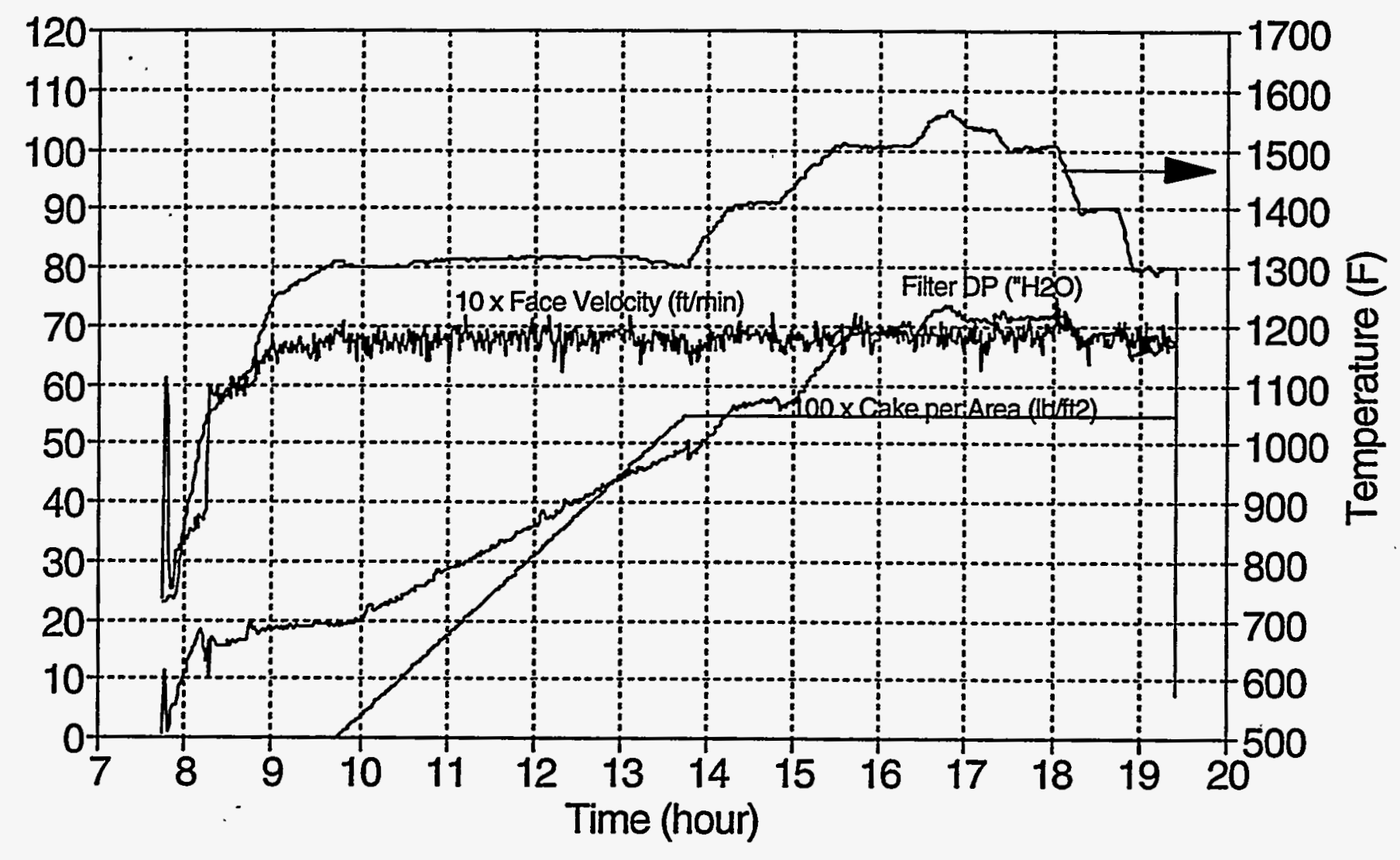




\section{Permeability Test 1.13 (3/9/94) Tidd Fine Fly Ash (50 psig)}

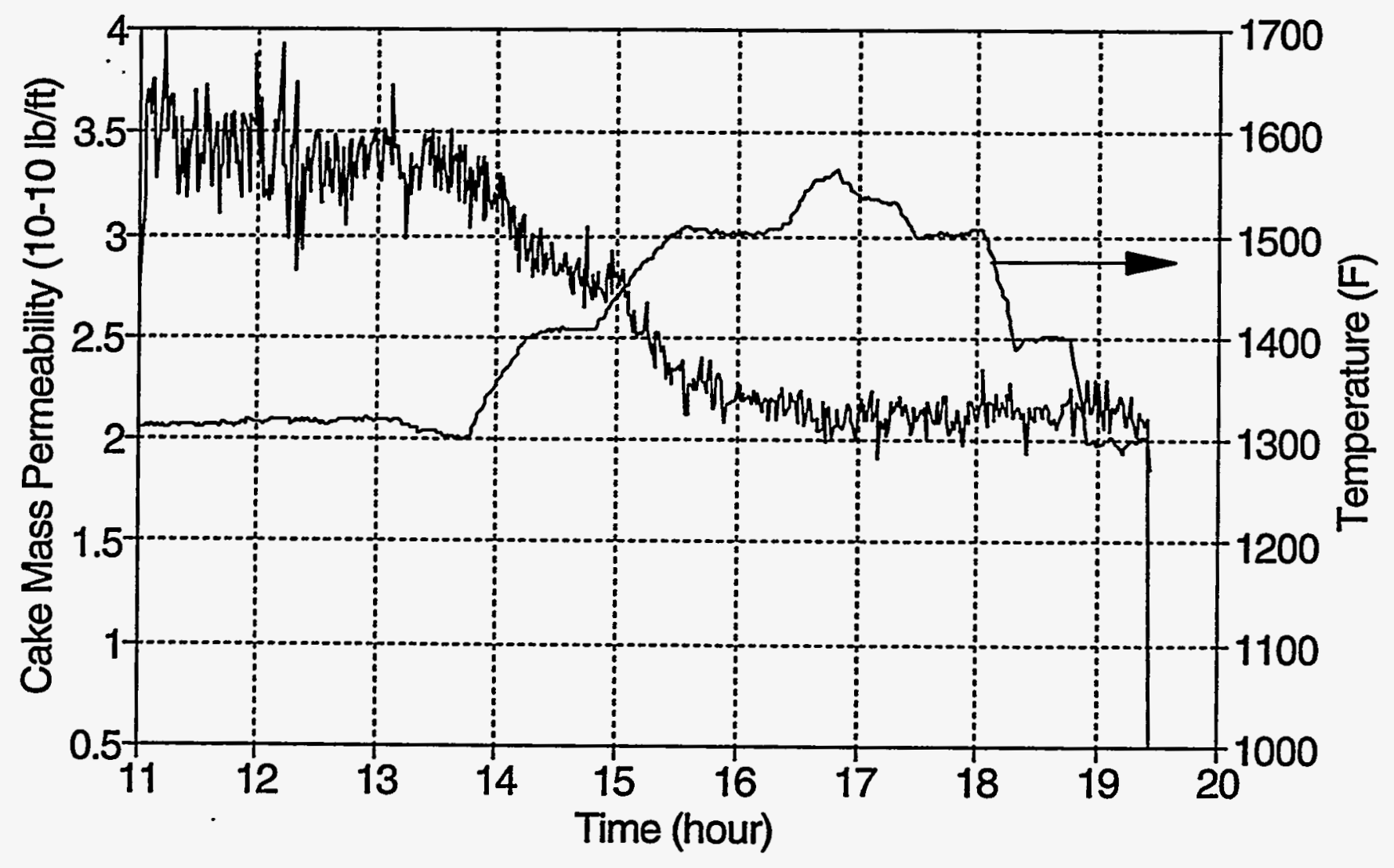




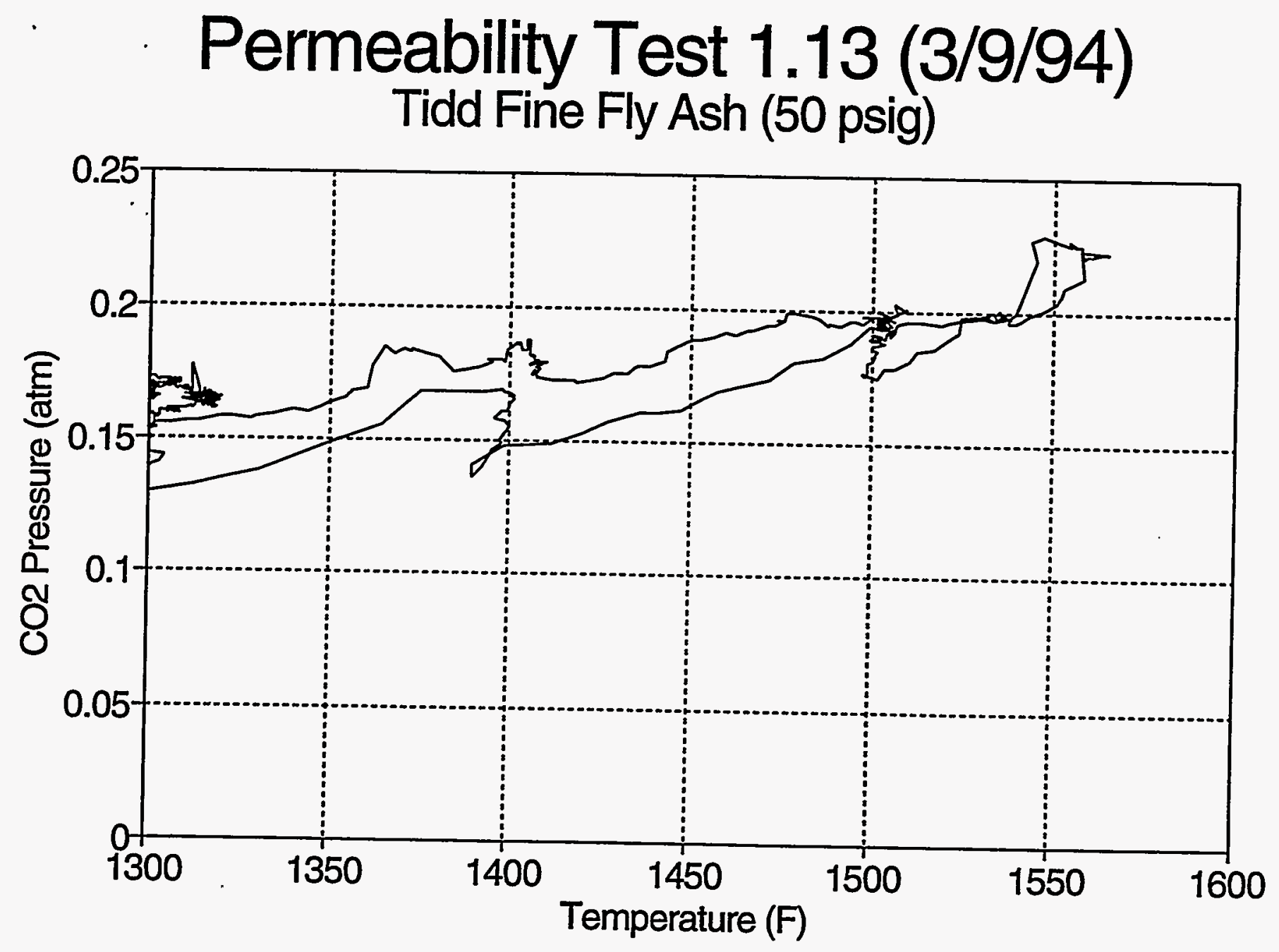




\section{Permeability Test 1.14 (7/6/94)}

FWDC TRC5 Fly Ash

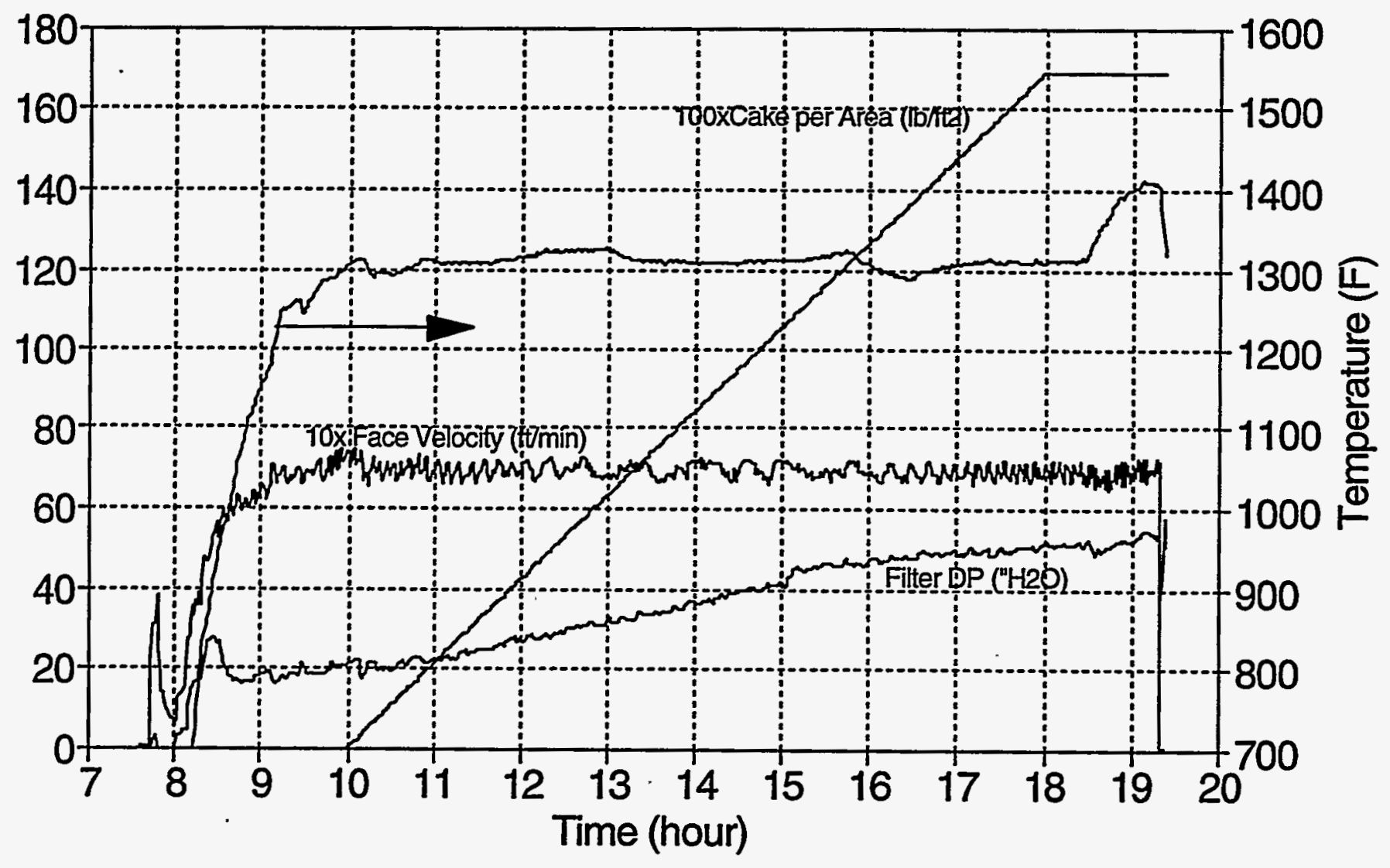




\section{Permeability Test 1.14 (7/6/94)}

FWDC TRC5 Fly Ash

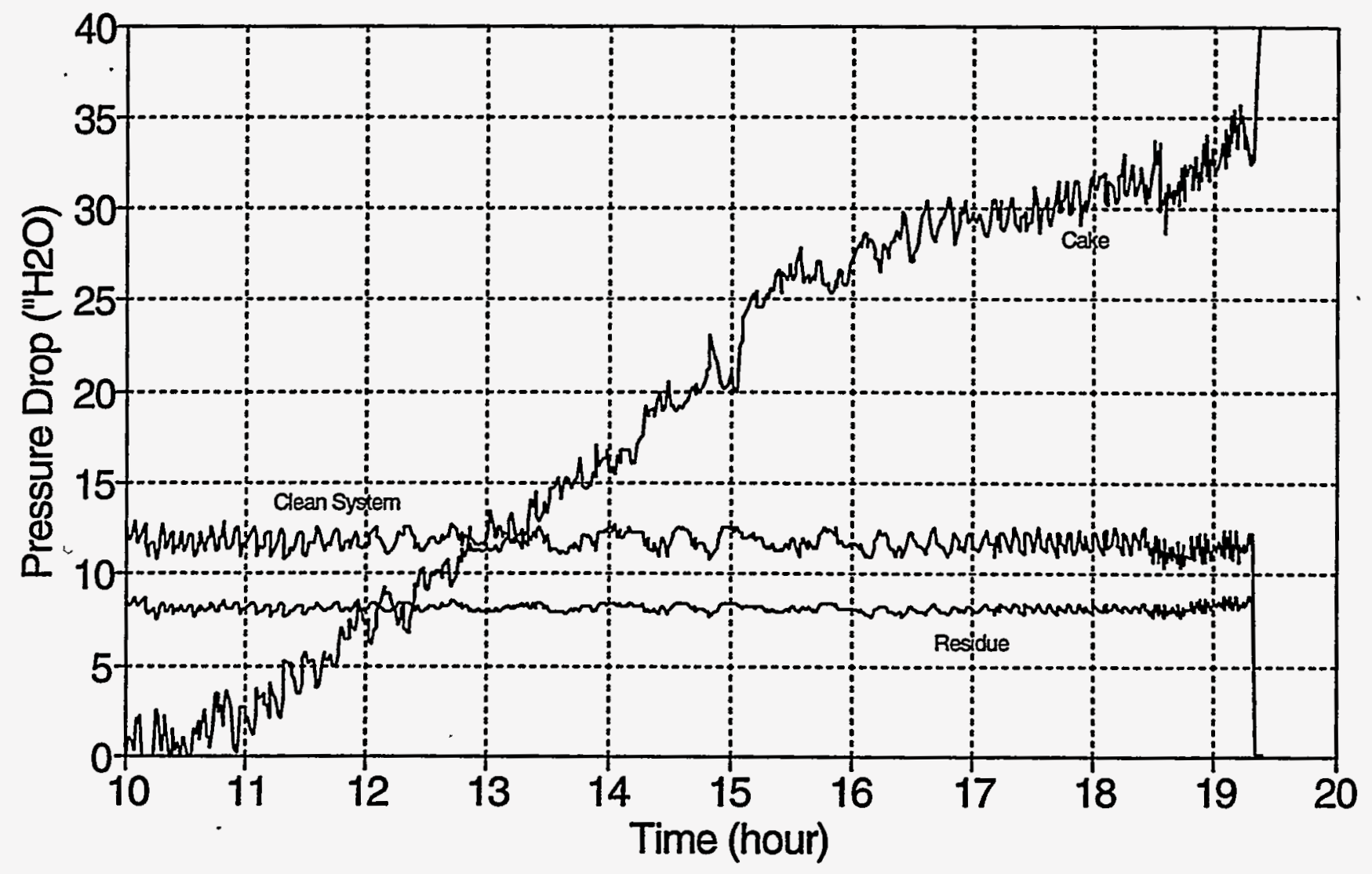




\section{Permeability Test 1.14 (7/6/94) FWDC TRC5 Fly Ash}

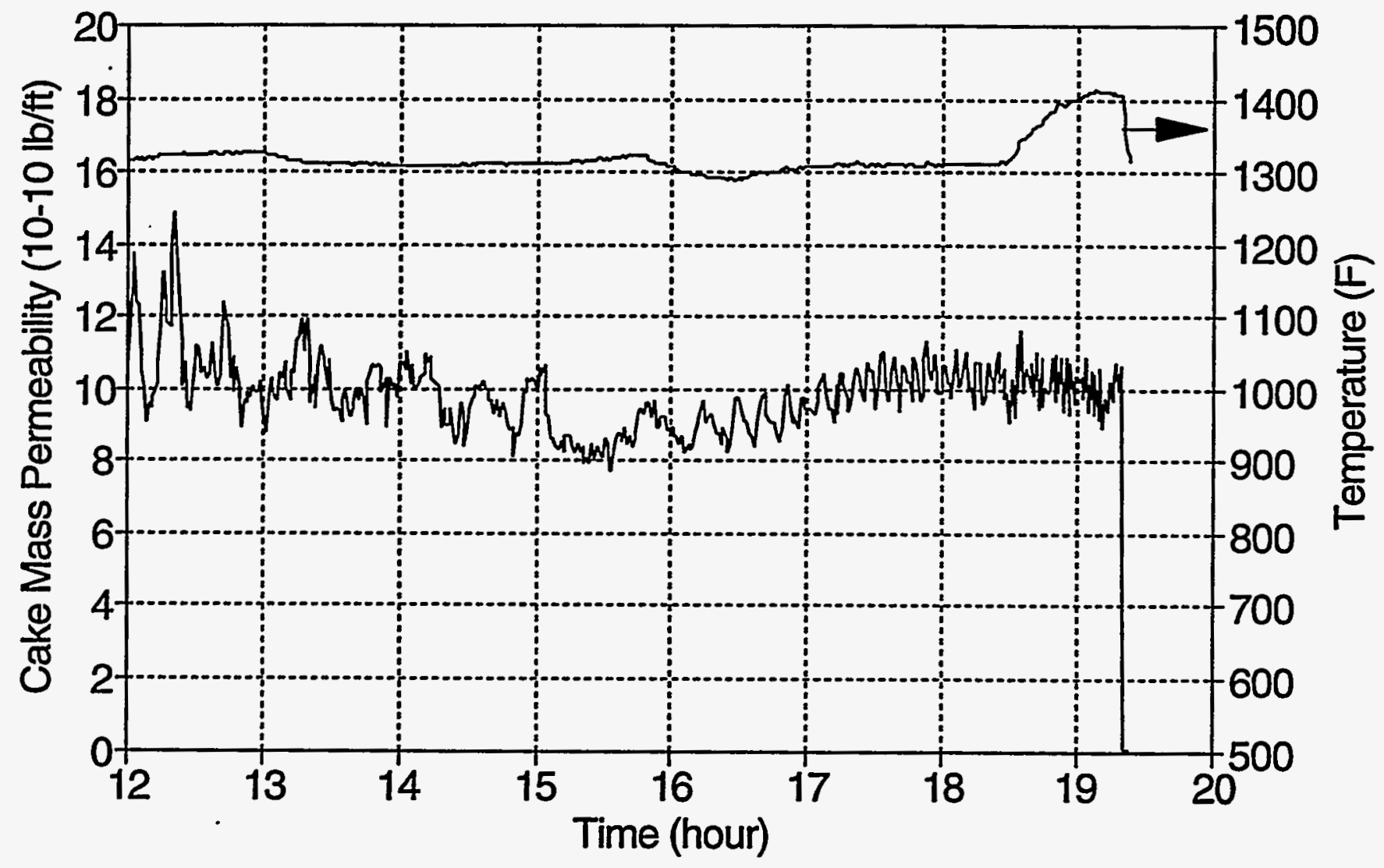




\section{Permeability Test 1.14 (7/7/94) FWDC TRC5 Fly Ash}

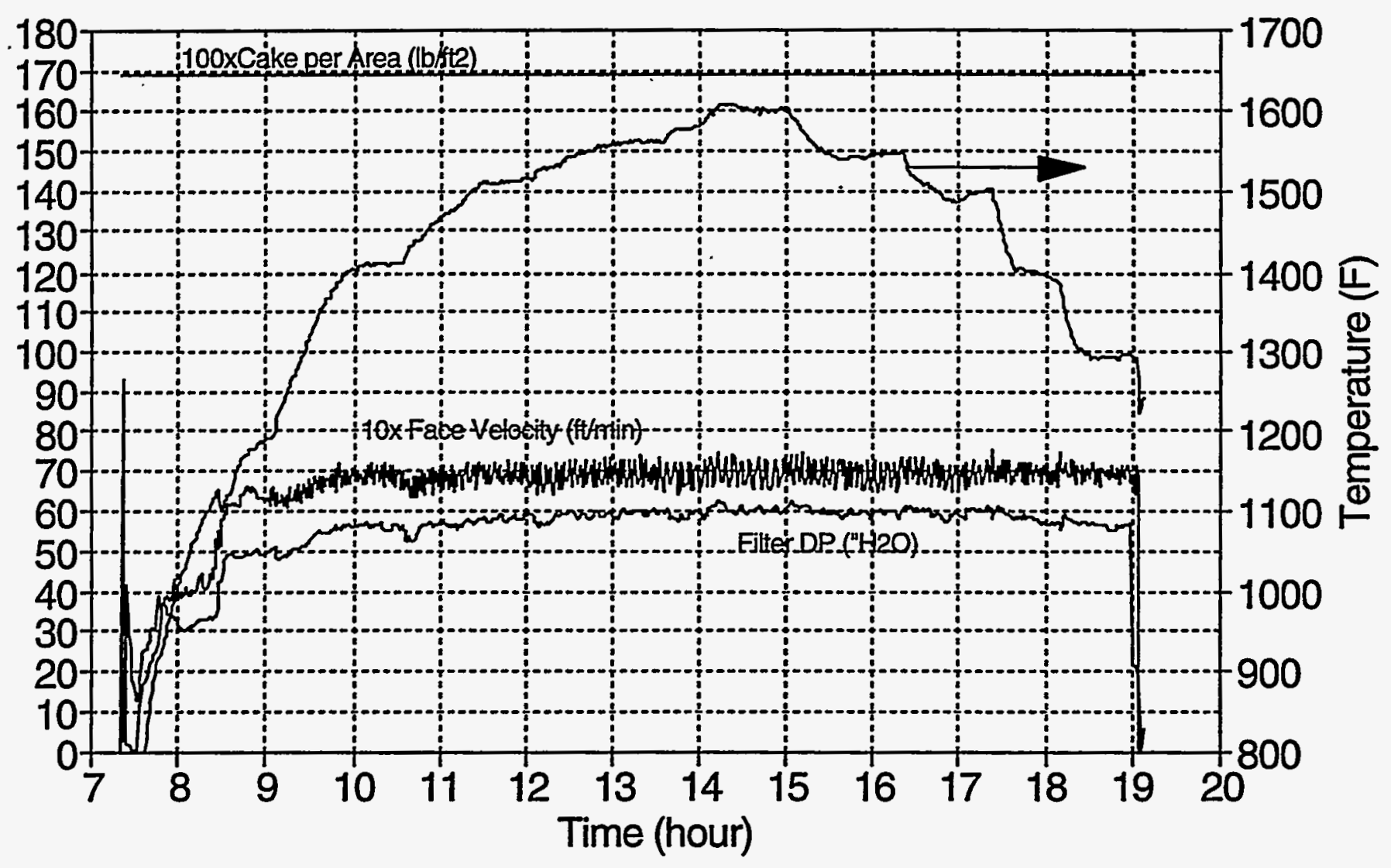




\section{Permeability Test 1.14 (7/7/94) FWDC TRC5 Fly Ash}

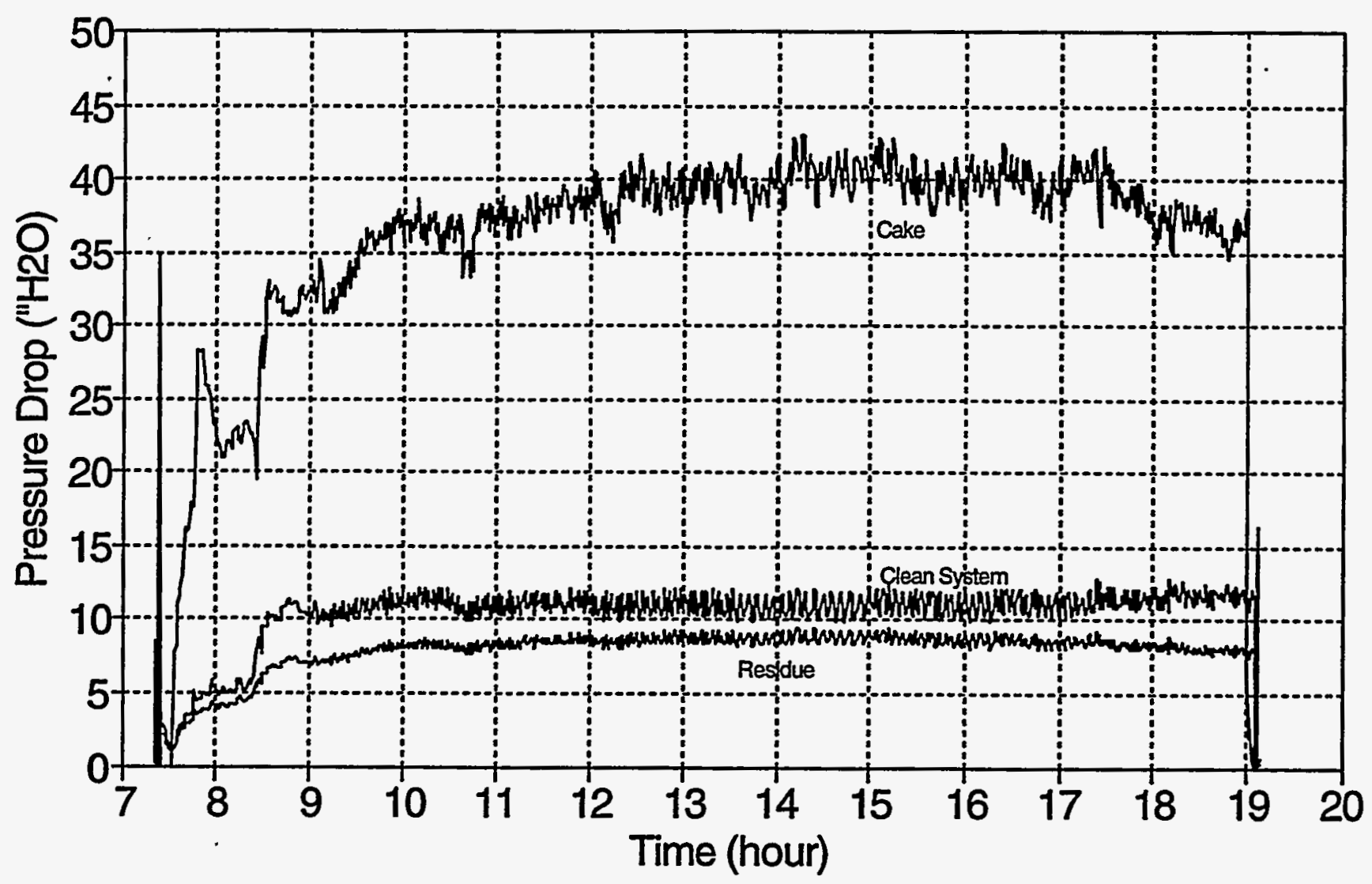




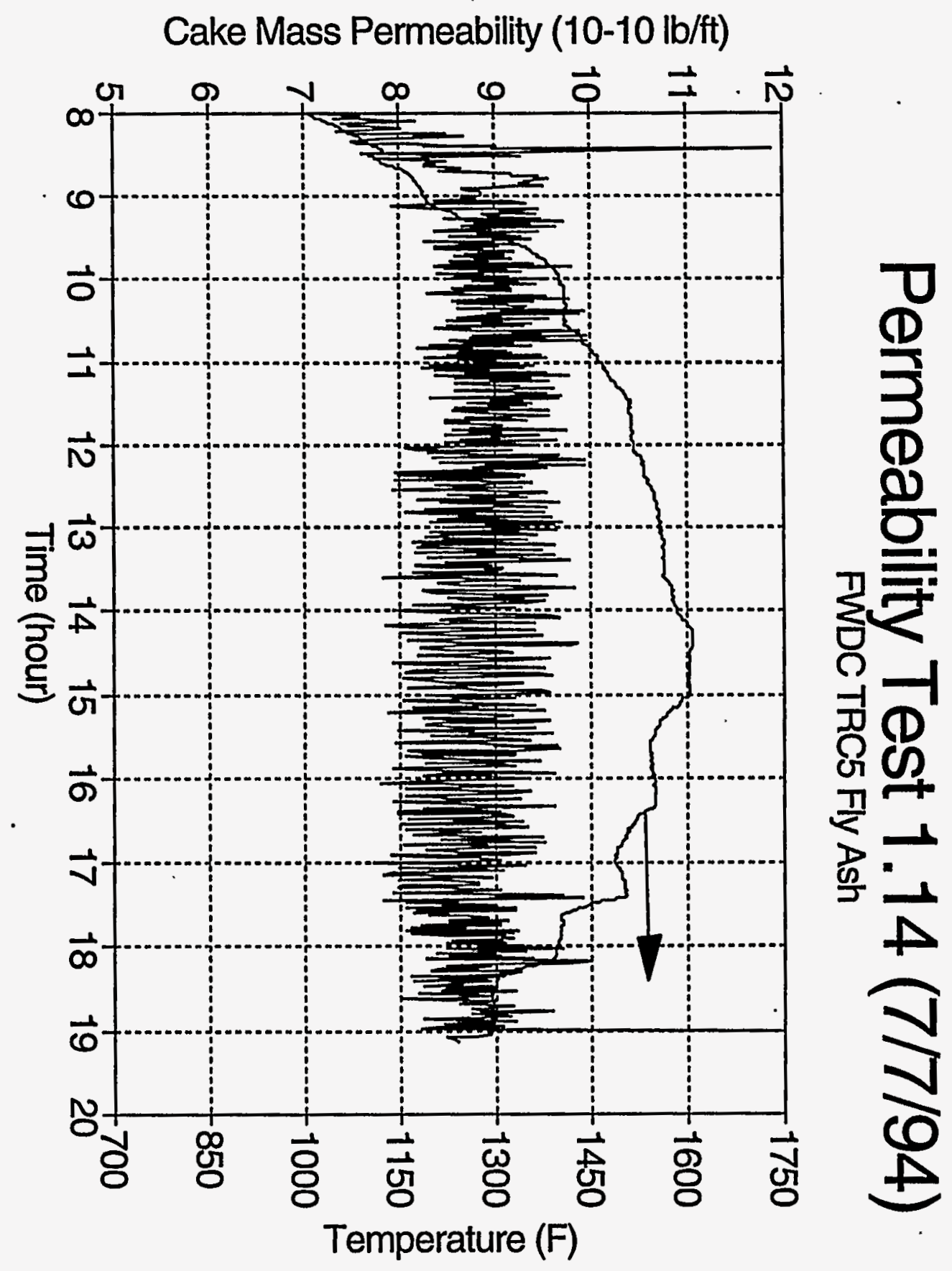




\section{Permeability Test 1.15 (7/11/94) \\ Tidd Spoiled Cyclone Fly Ash}

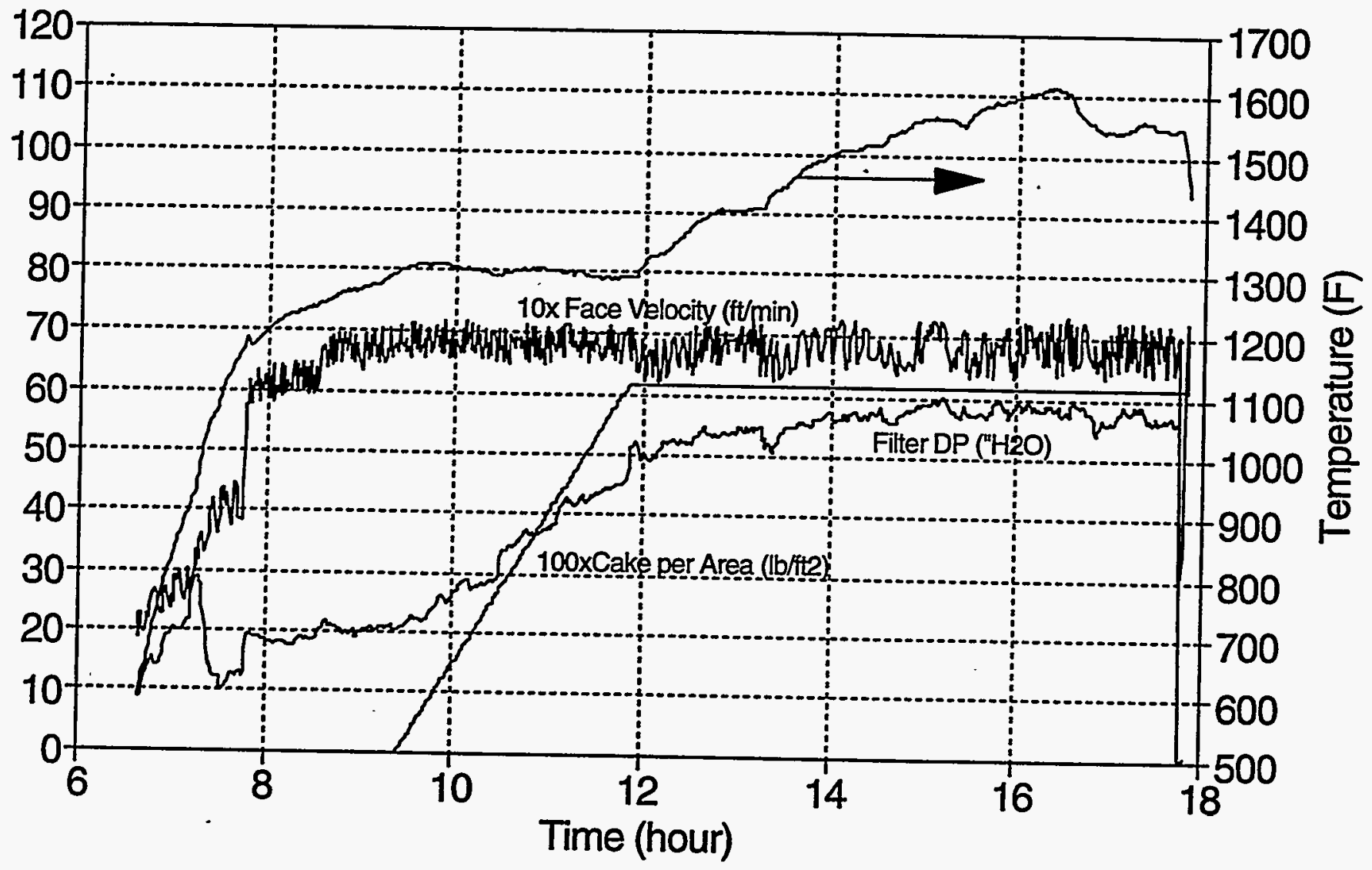




\section{Permeability Test 1.15 (7/11/94) \\ Tidd Spoiled Cyclone Fly Ash}

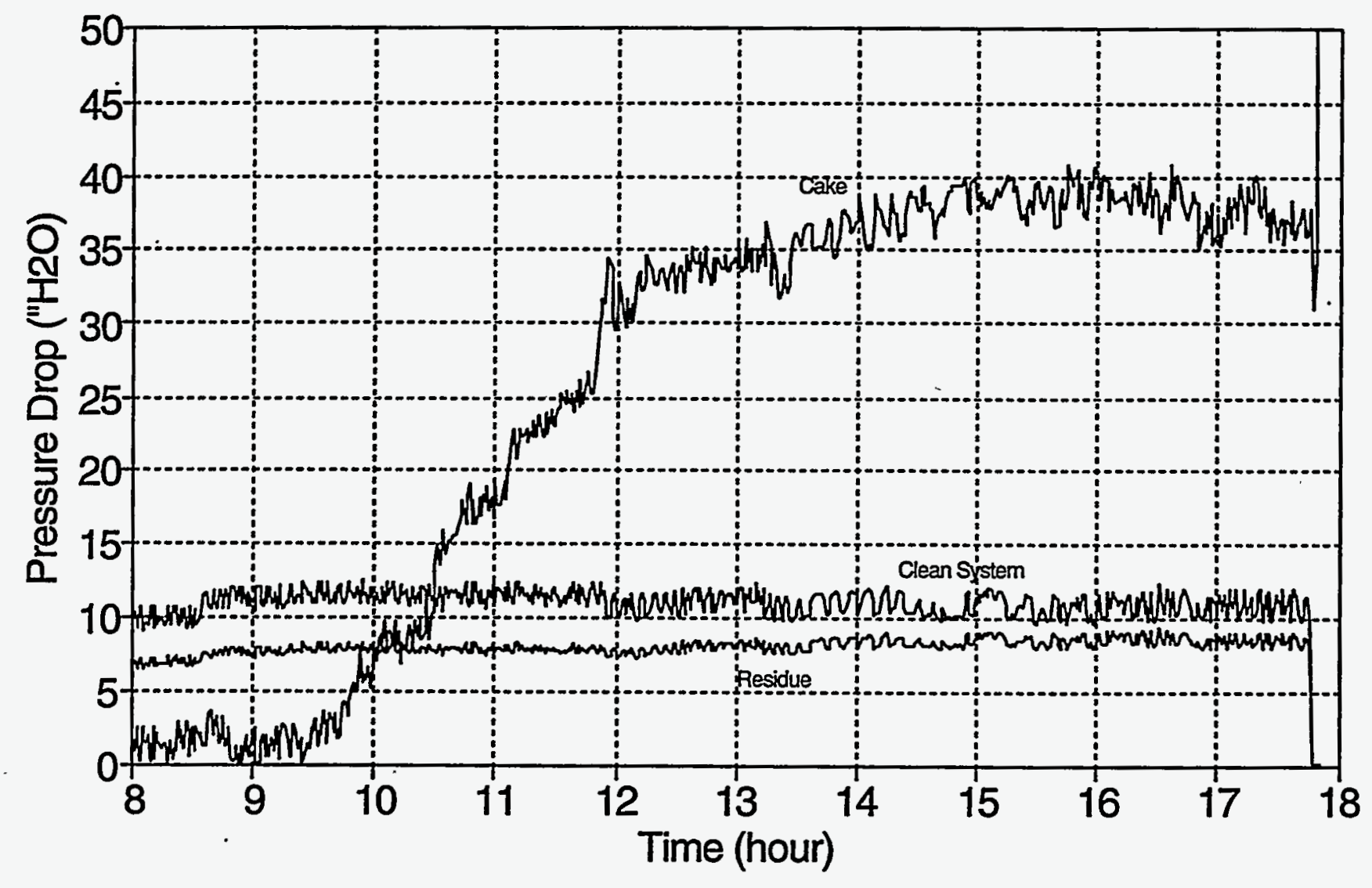




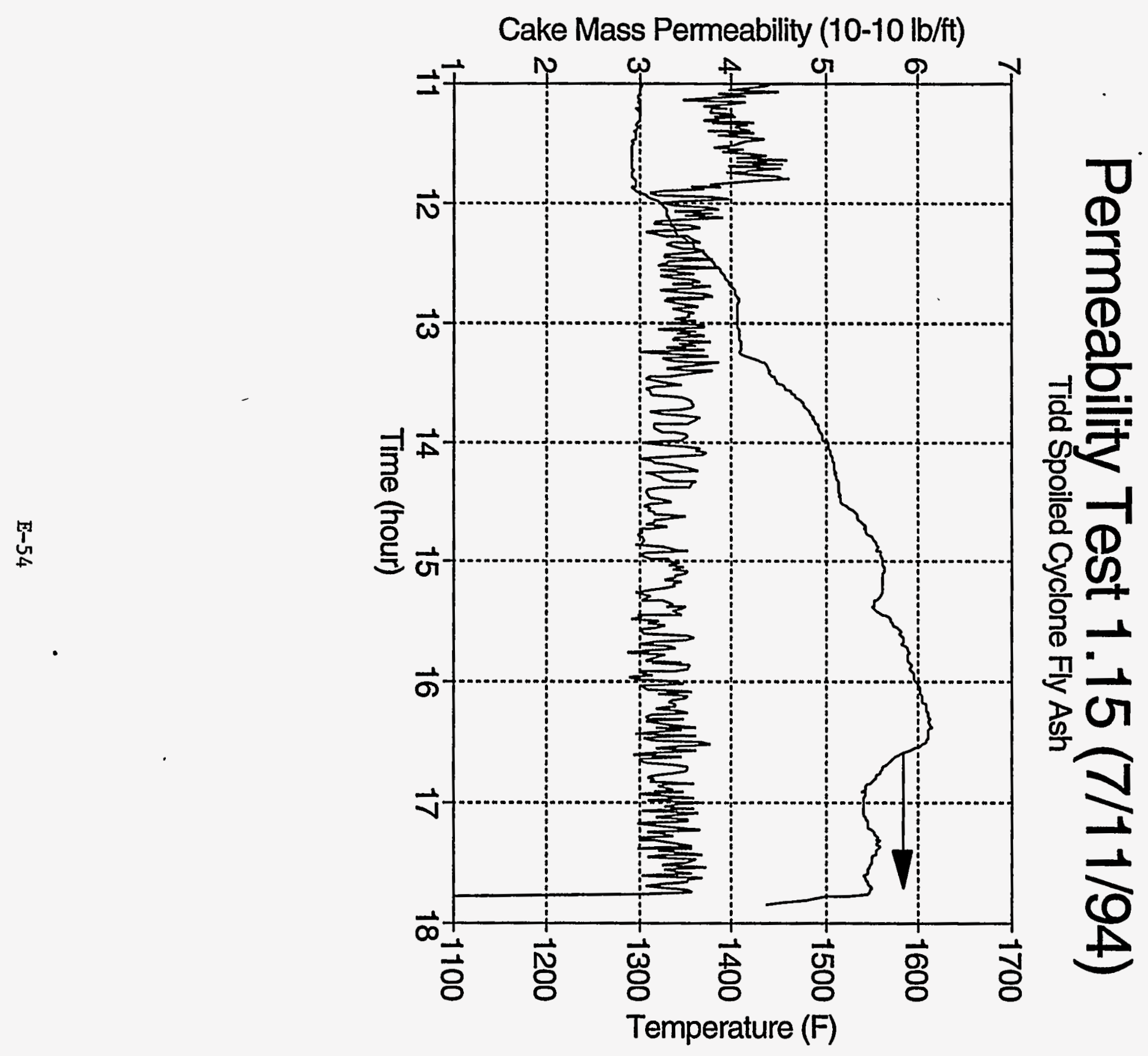




\section{Permeability Test 1.15 (7/12/94) Tidd Spoiled Cyclone Fly Ash}

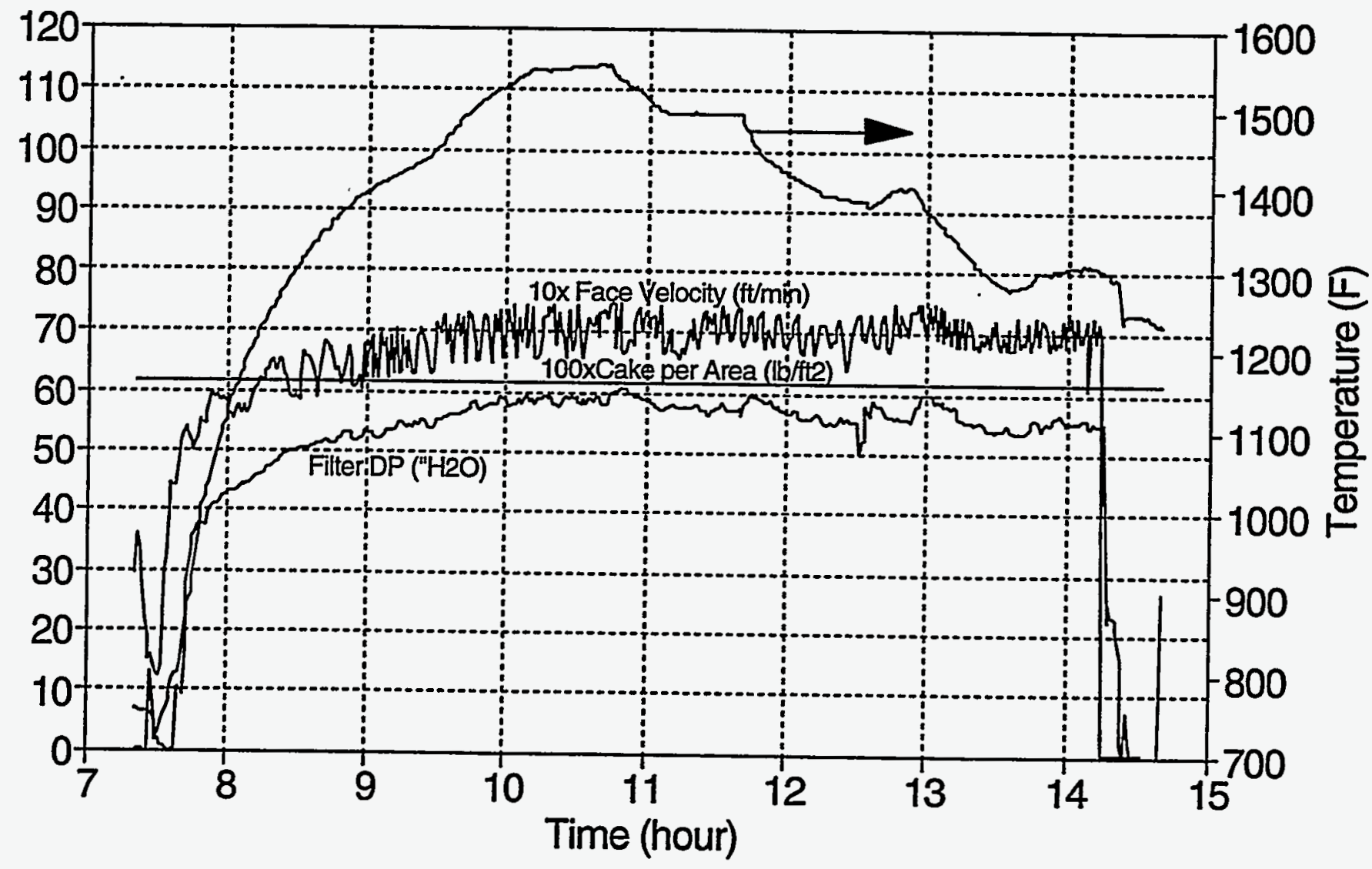




\section{Permeability Test 1.15 (7/12/94) Tidd Spoiled Cyclone Fly Ash}

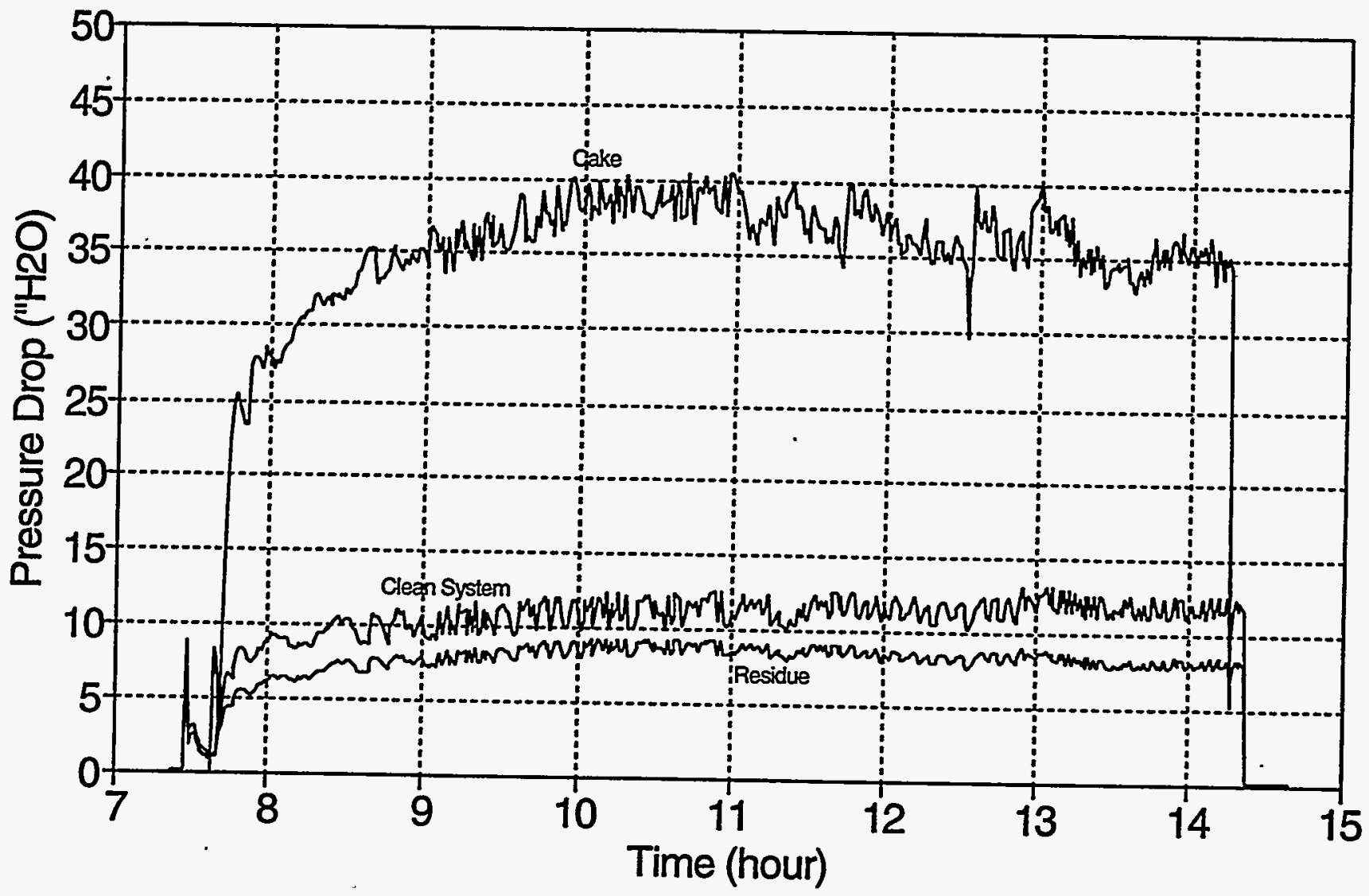




\section{Permeability Test 1.15 (7/12/94) Tidd Spoiled Cyclone Fly Ash}

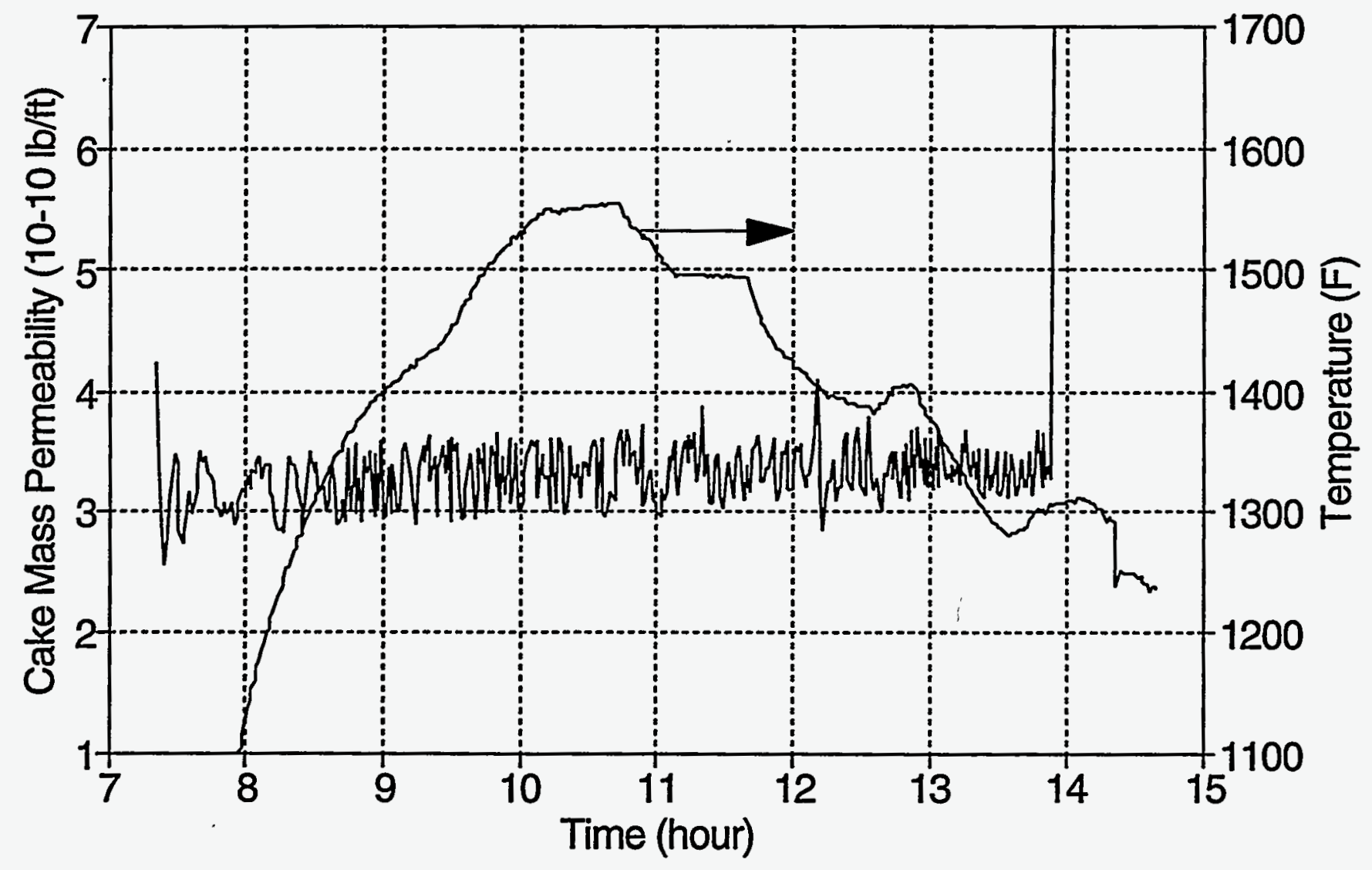




\section{Permeability Test 1.16 (4/24/95) Tidd No Cyclone Ash}

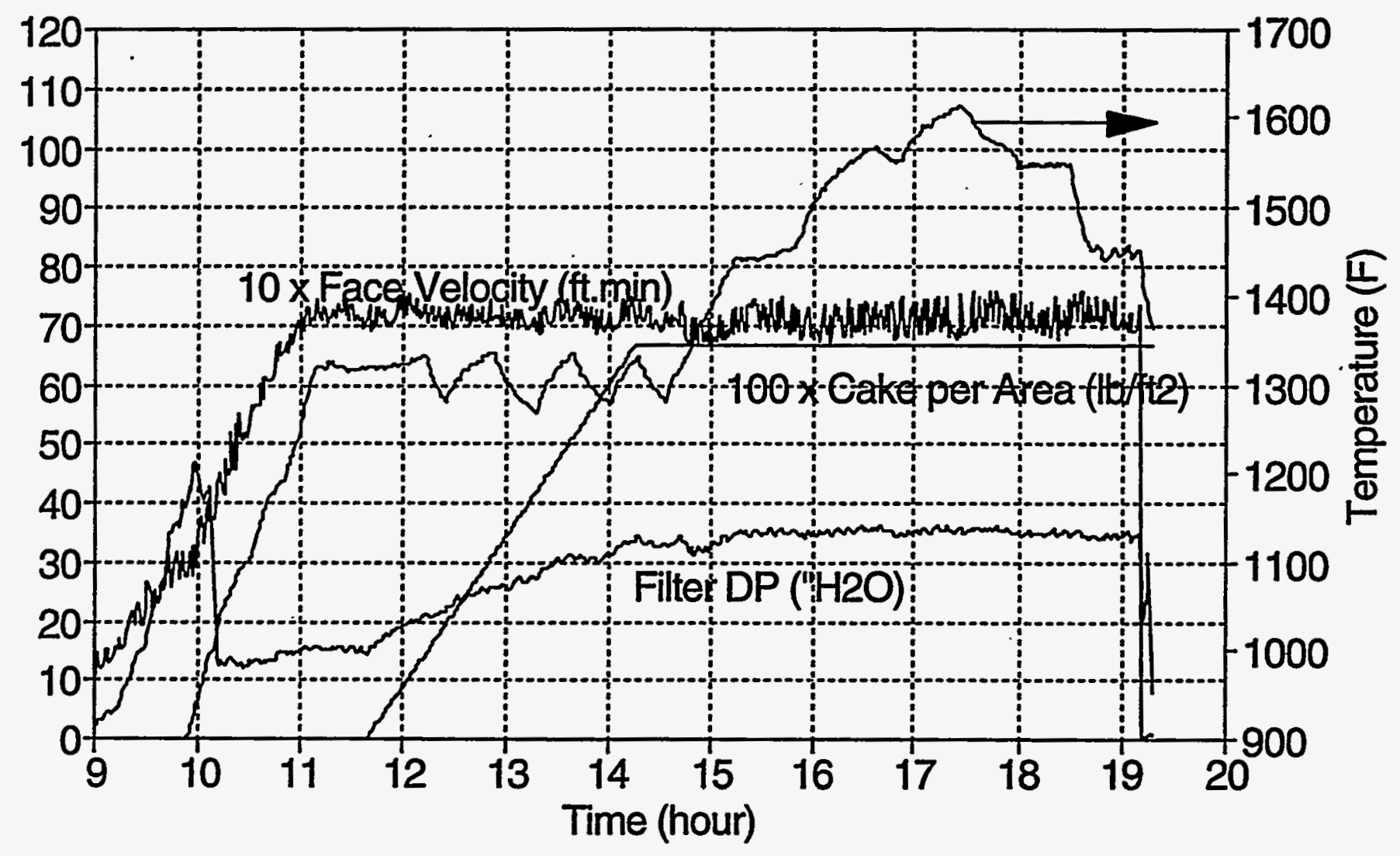




\section{Permeability Test 1.16 (4/24/95) Tidd No Cyclone Ash}

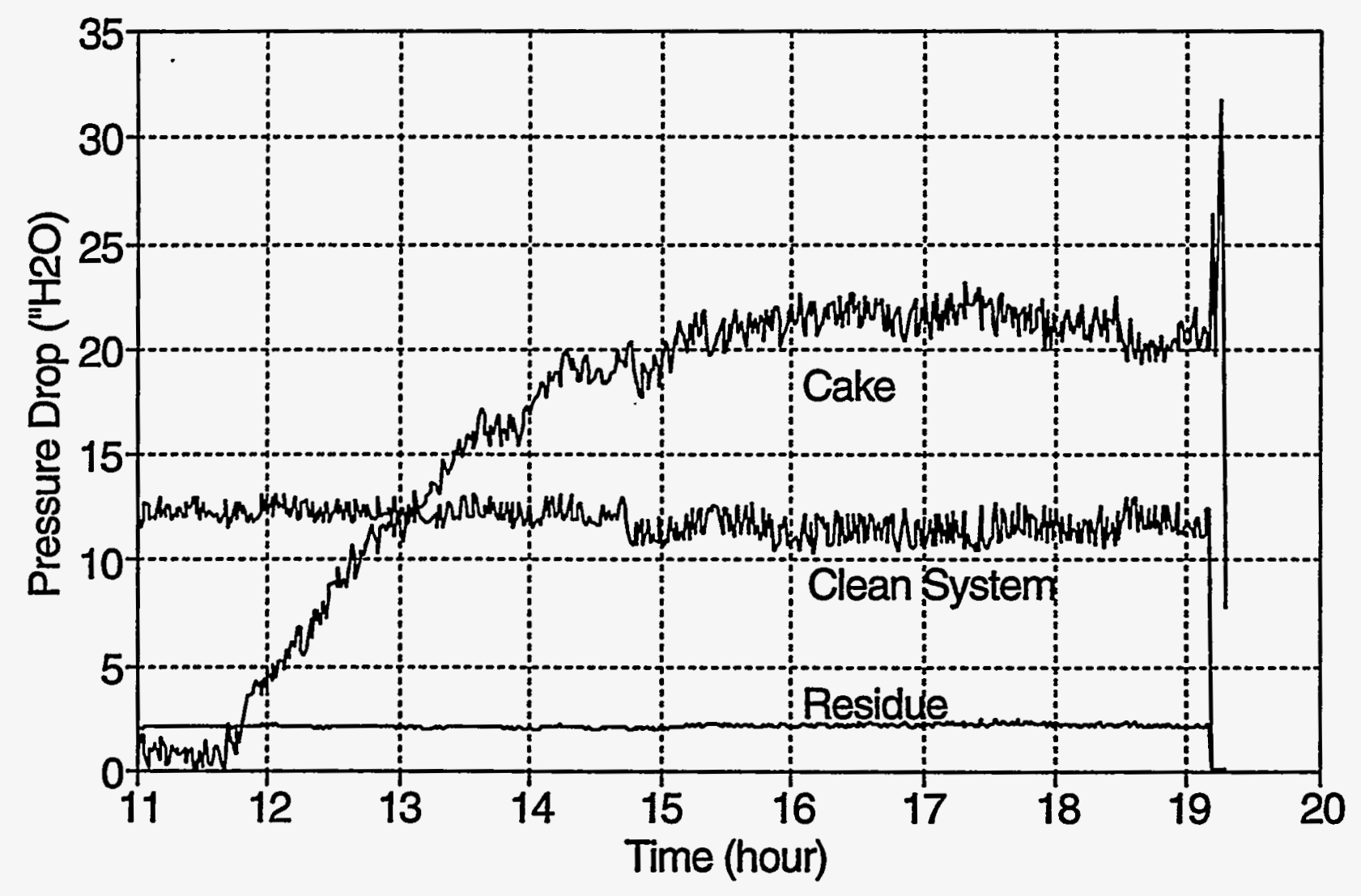




\section{Permeability Test 1.16 (4/24/95) Tidd No Cyclone Ash}

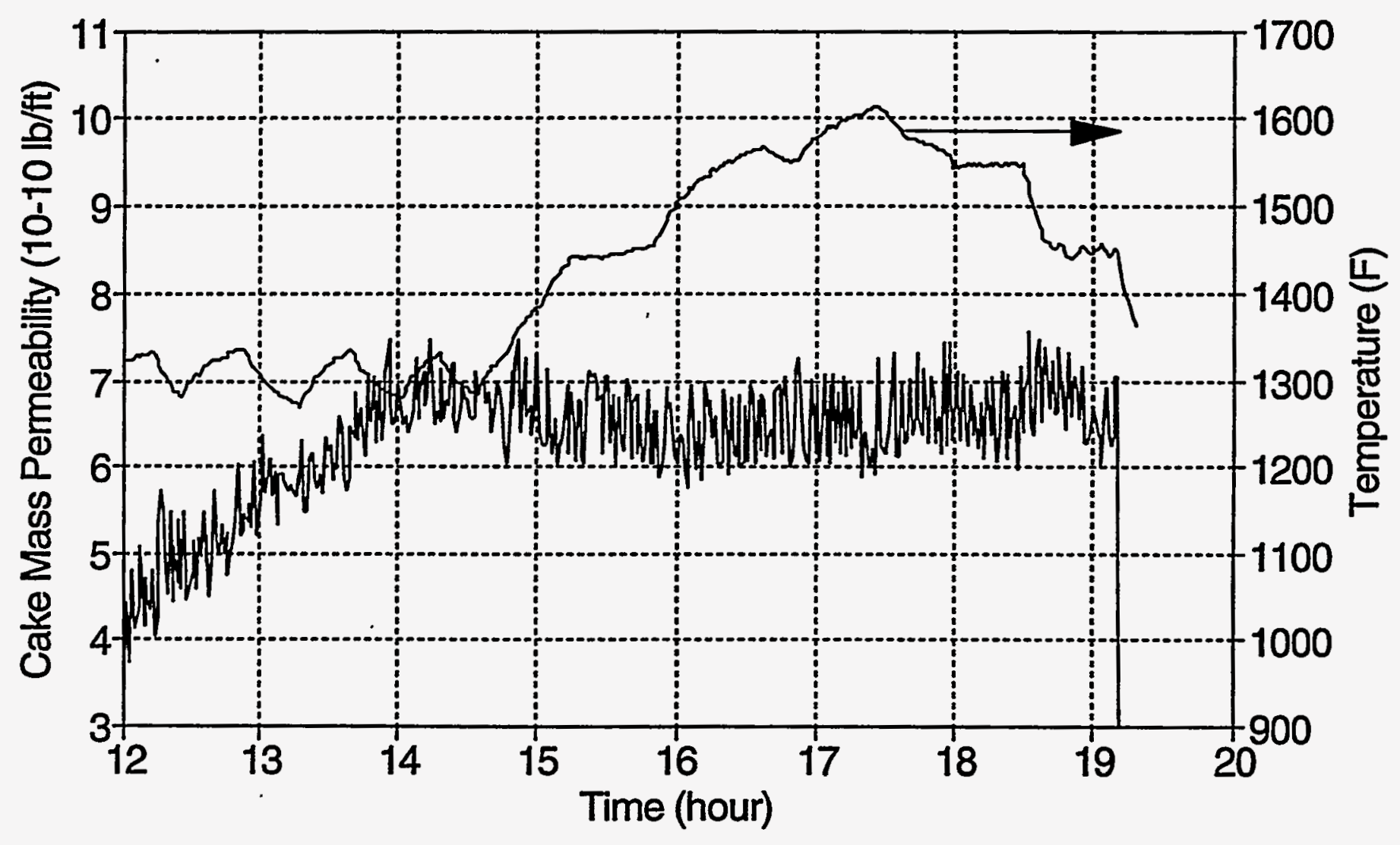


ADDITIVE TESTS (SERIES 2) 


\section{Additive Test 2.01 (11/24/93) Tidd Fine Fly Ash + 10 wt\% Dolomite}

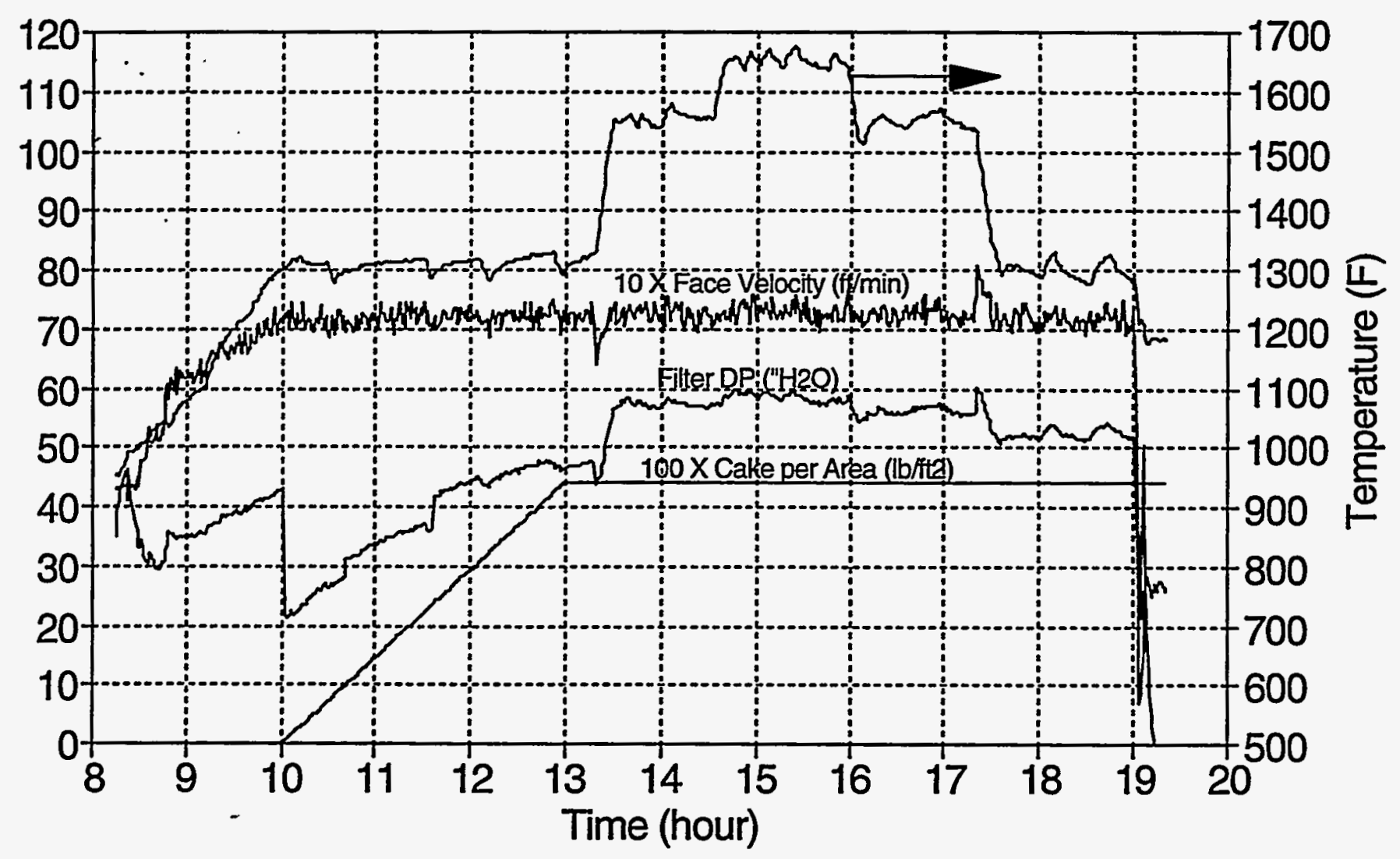




\section{Additive Test 2.01 (11/24/93) Tidd Fine Fly Ash + 10 wt\% Dolomite}

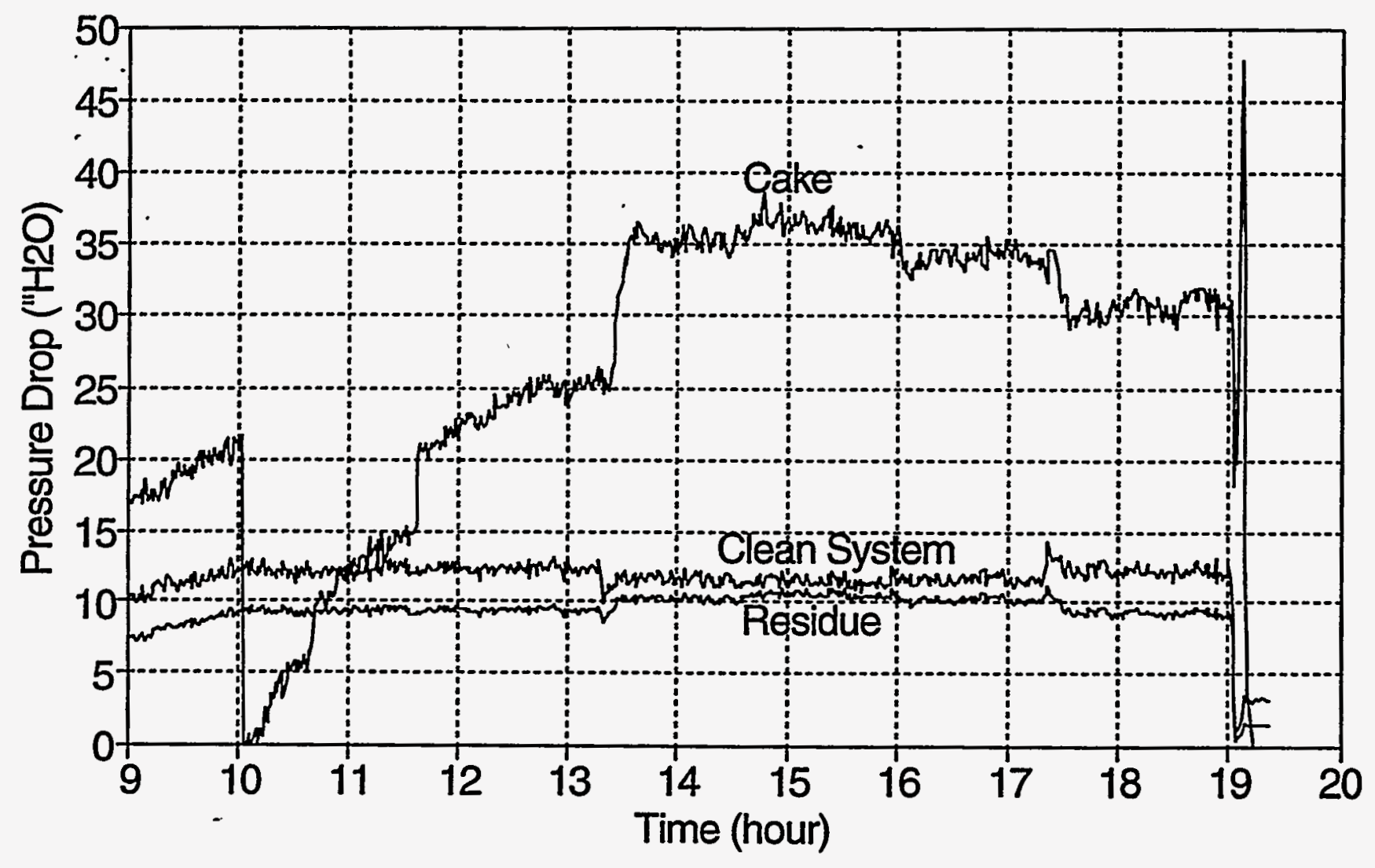




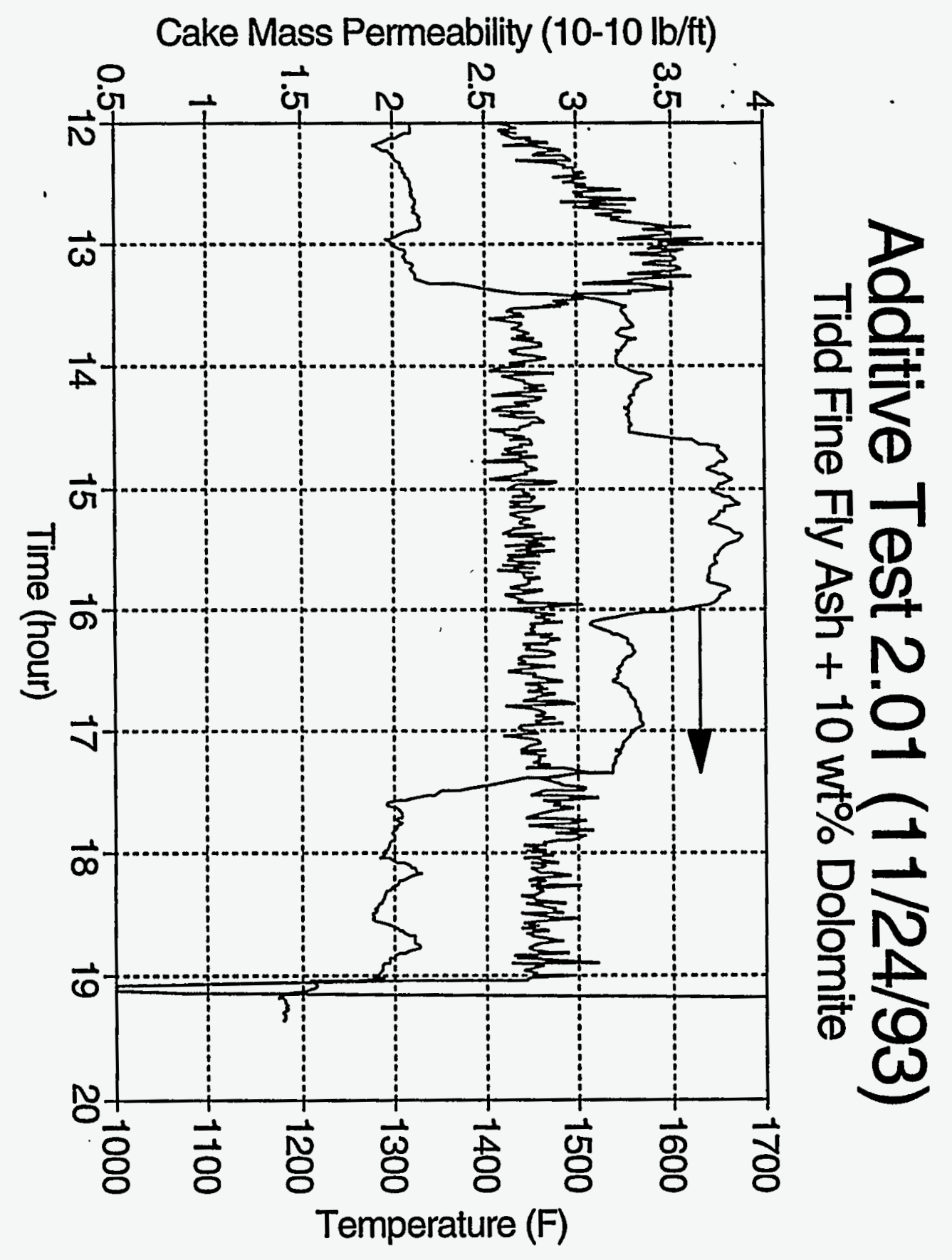




\section{Additive Test 2.02 (1/24/94) Neutralite Precoat}

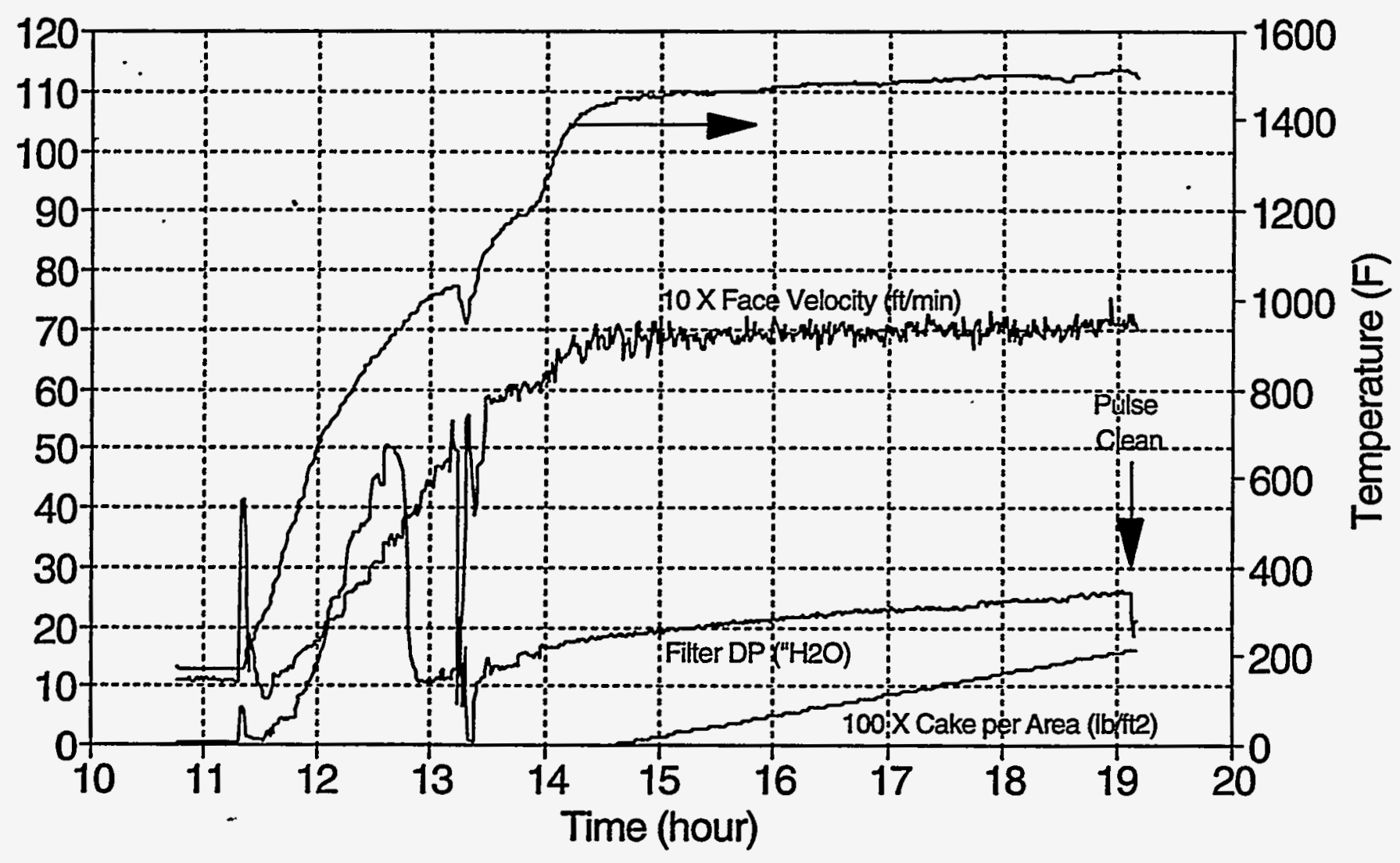




\section{Additive Test 2.02 (1/25/94) Neutralite Precoat}

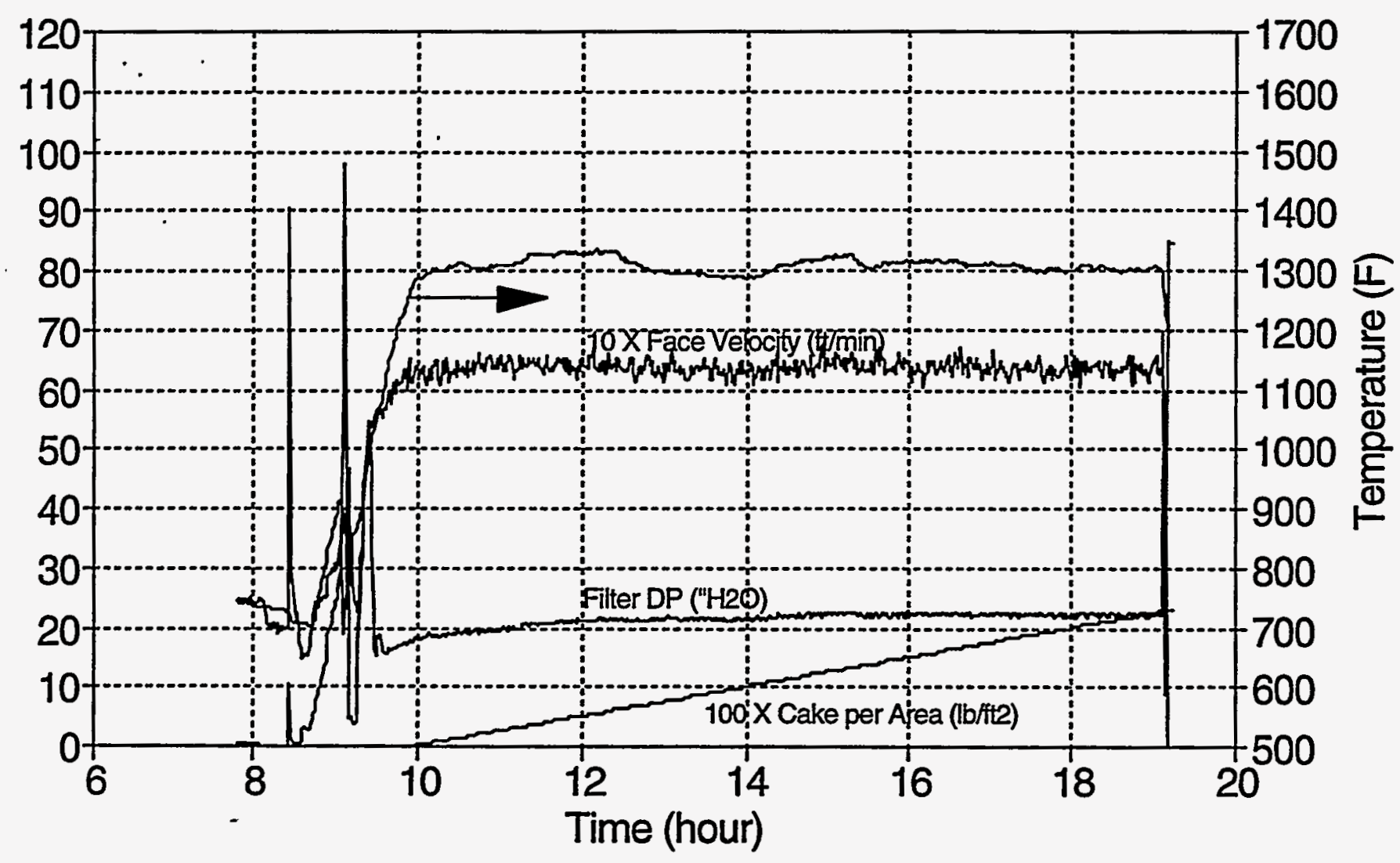




\section{Additive Test 2.02 (1/26/94) Neutralite Precoat}

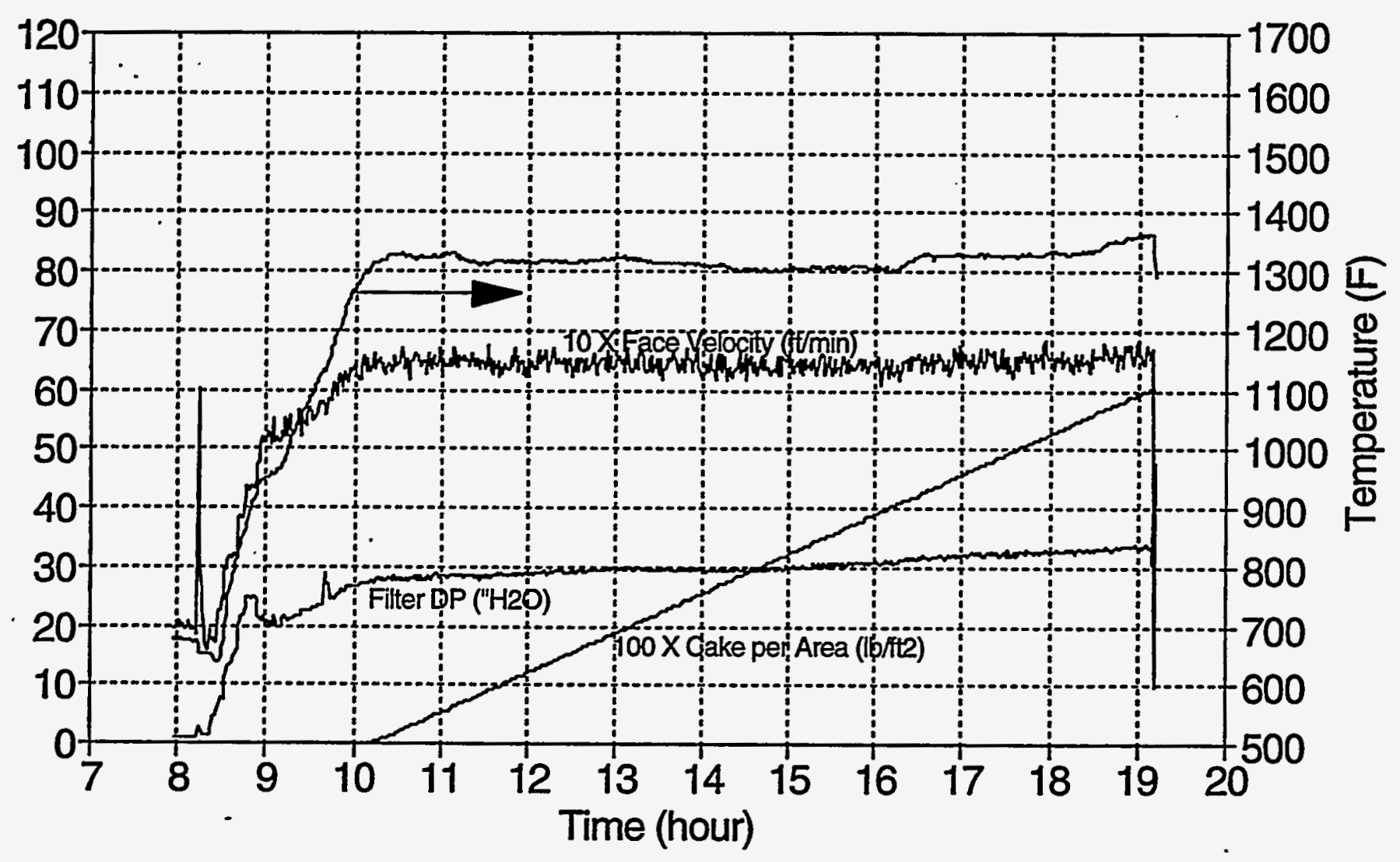




\section{Additive Test 2.02 (1/27/94) Neutralite Precoat}

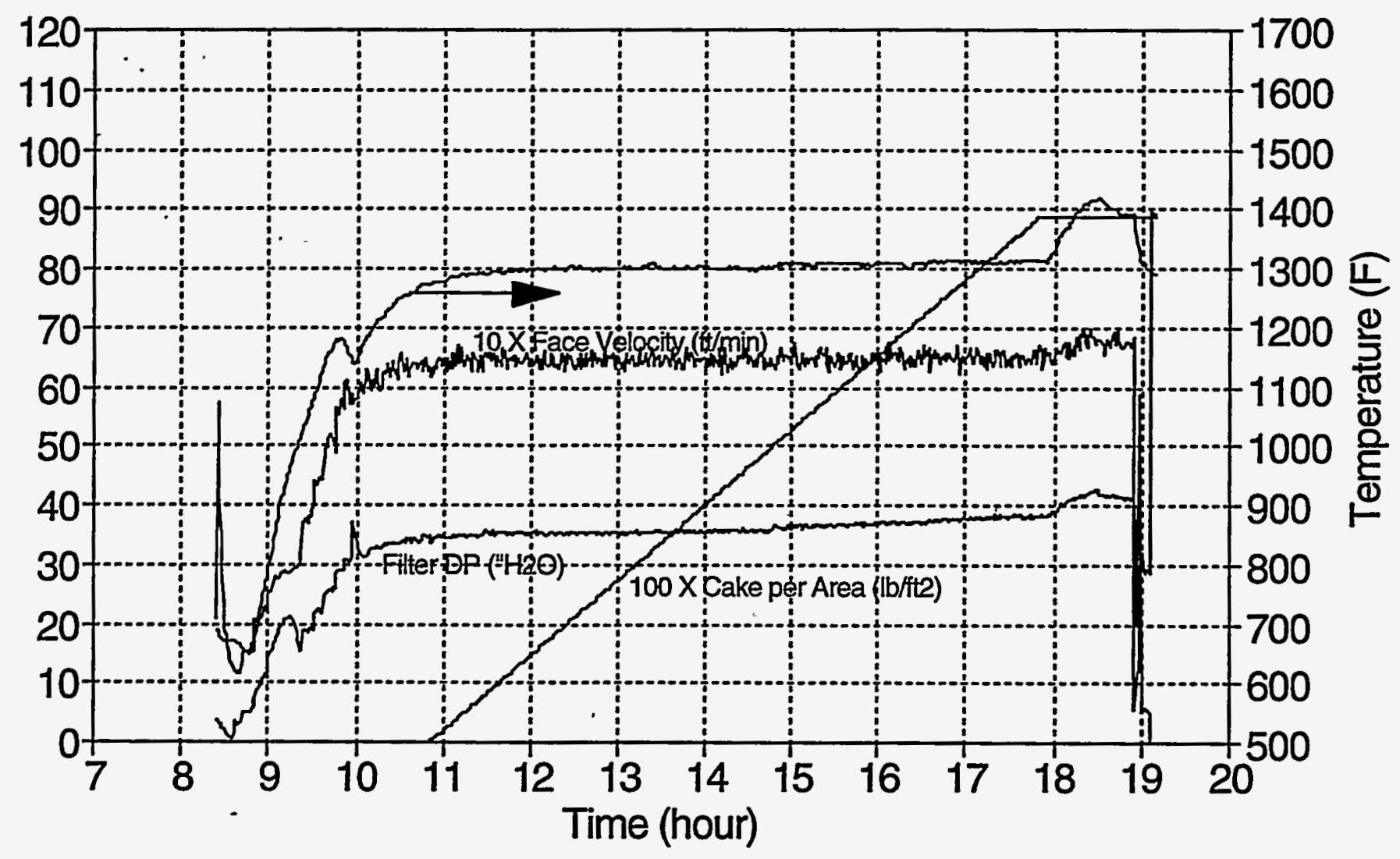




\section{Additive Test 2.02 (1/28/94) Neutralite Precoat}

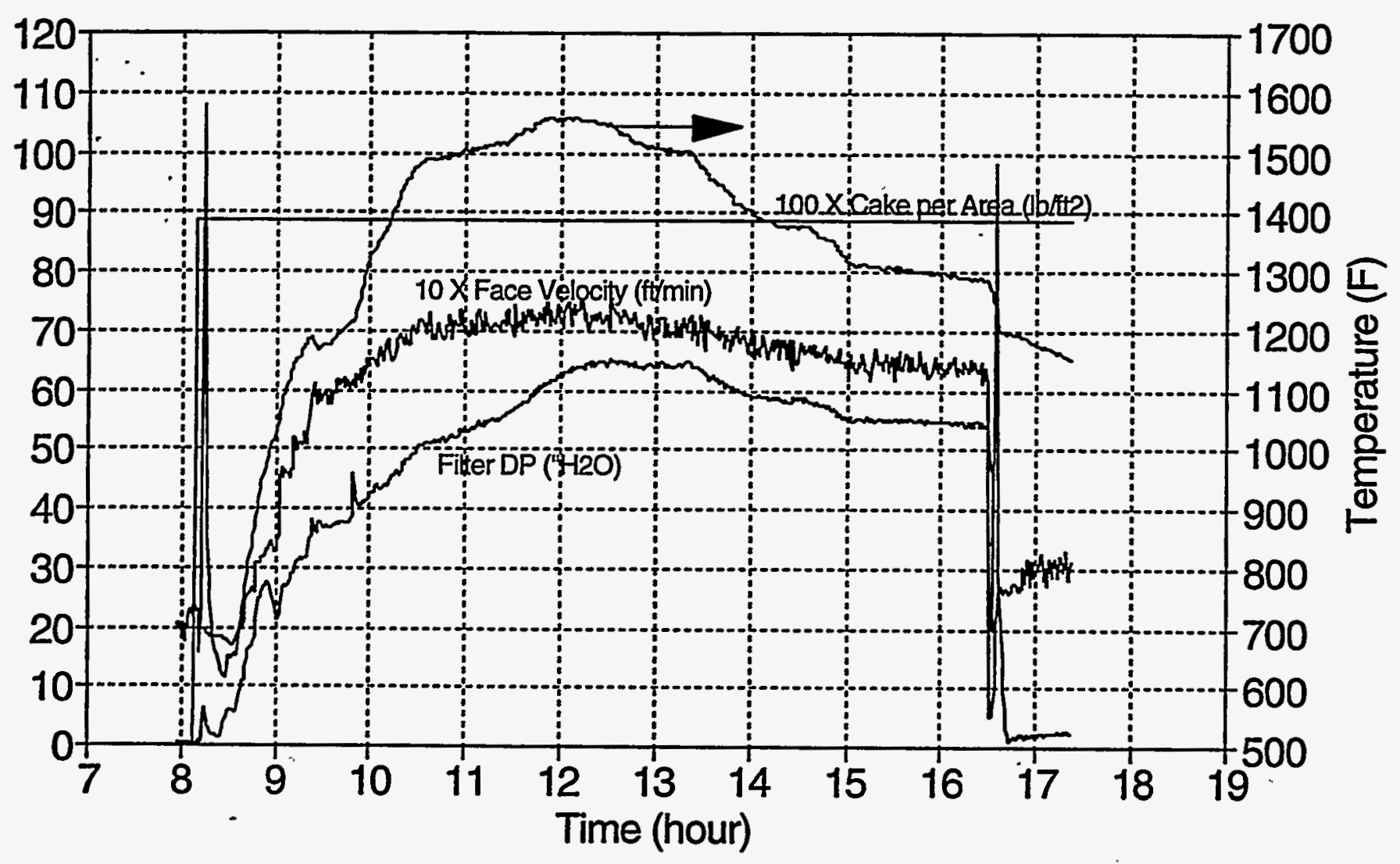




\section{Additive Test 2.02 (1/28/94) Neutralite Precoat}

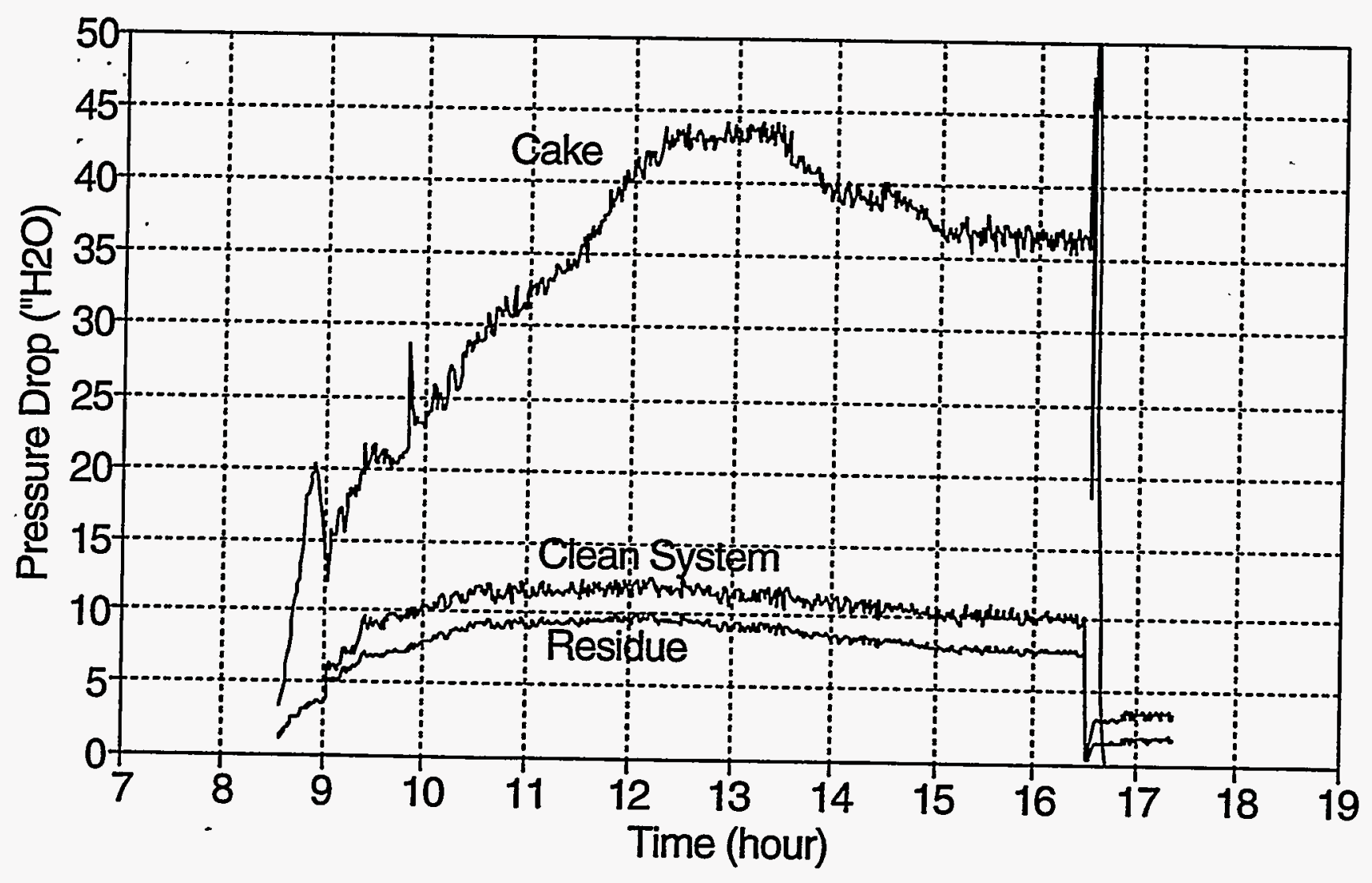




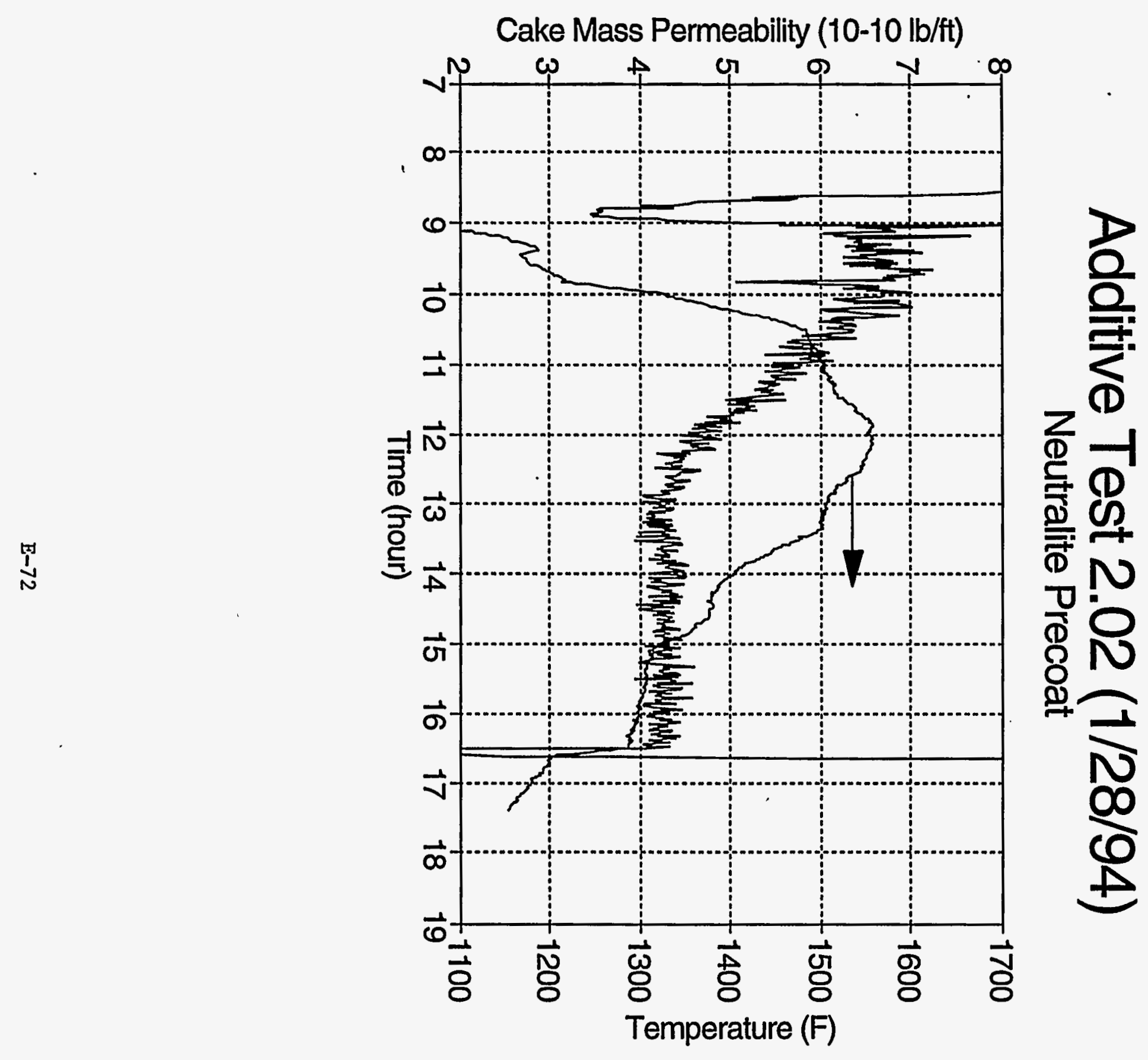




\section{Additive Test 2.02 (2/02/94) Neutralite Precoat}

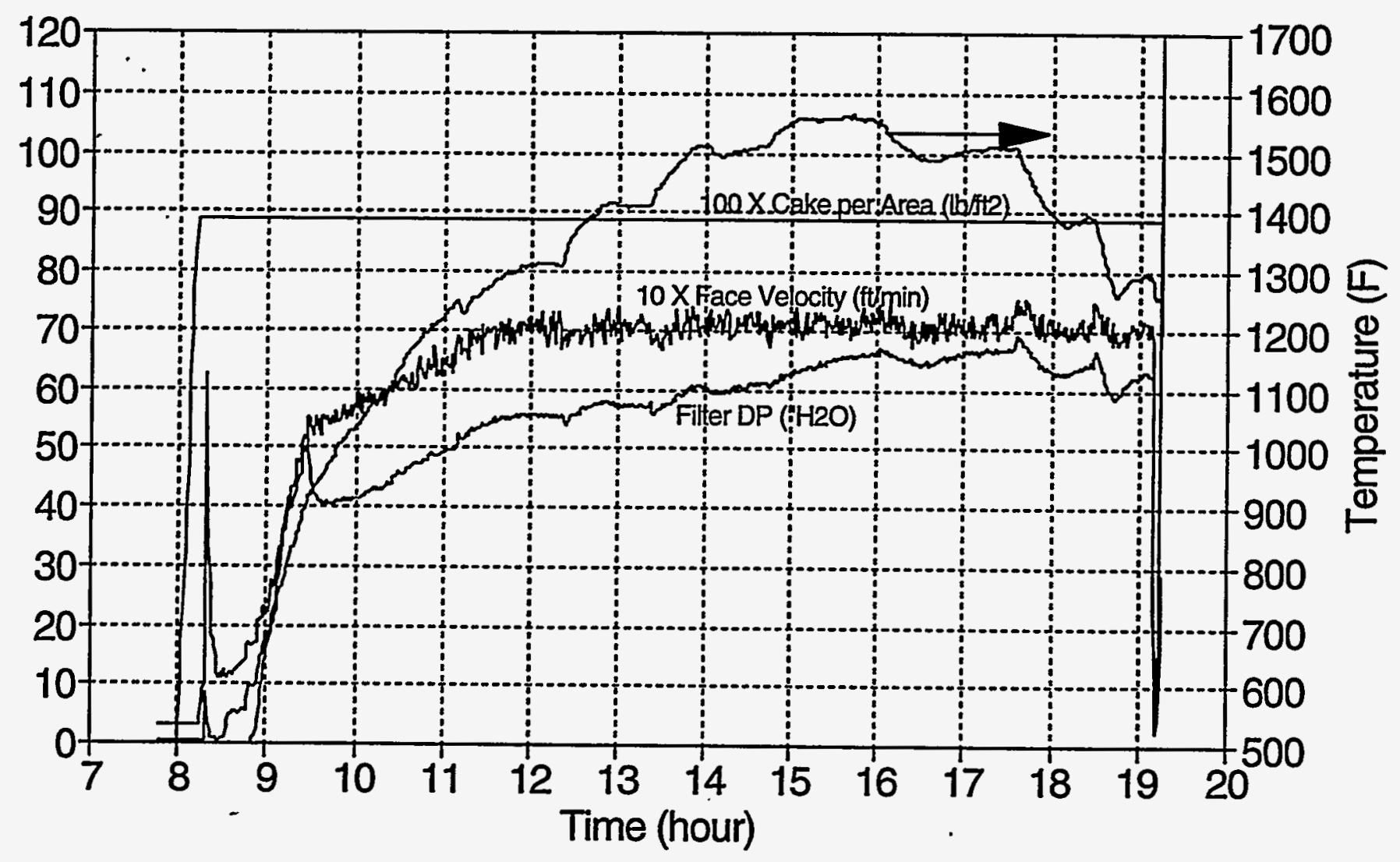




\section{Additive Test 2.02 (2/02/94) Neutralite Precoat}

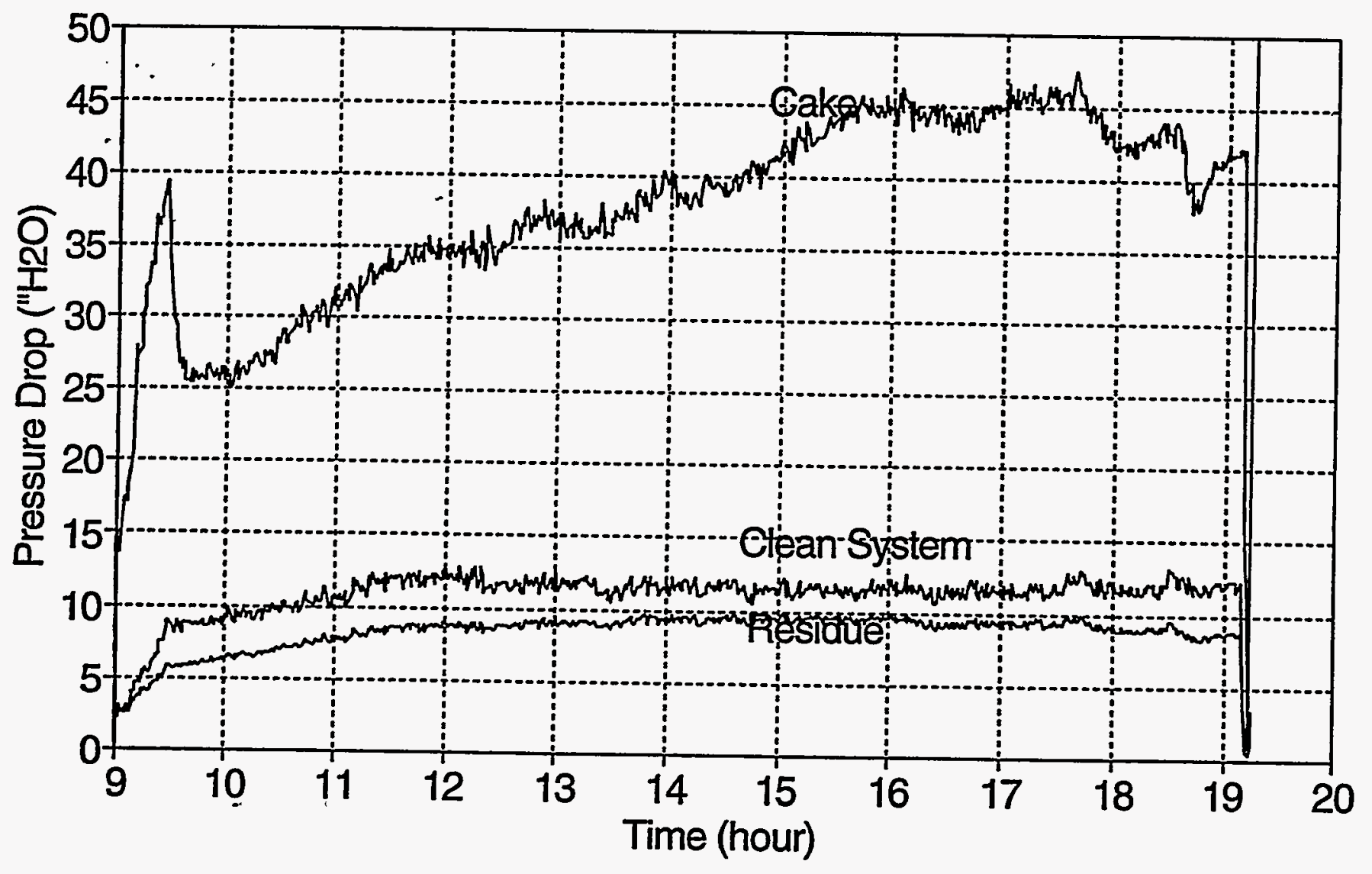




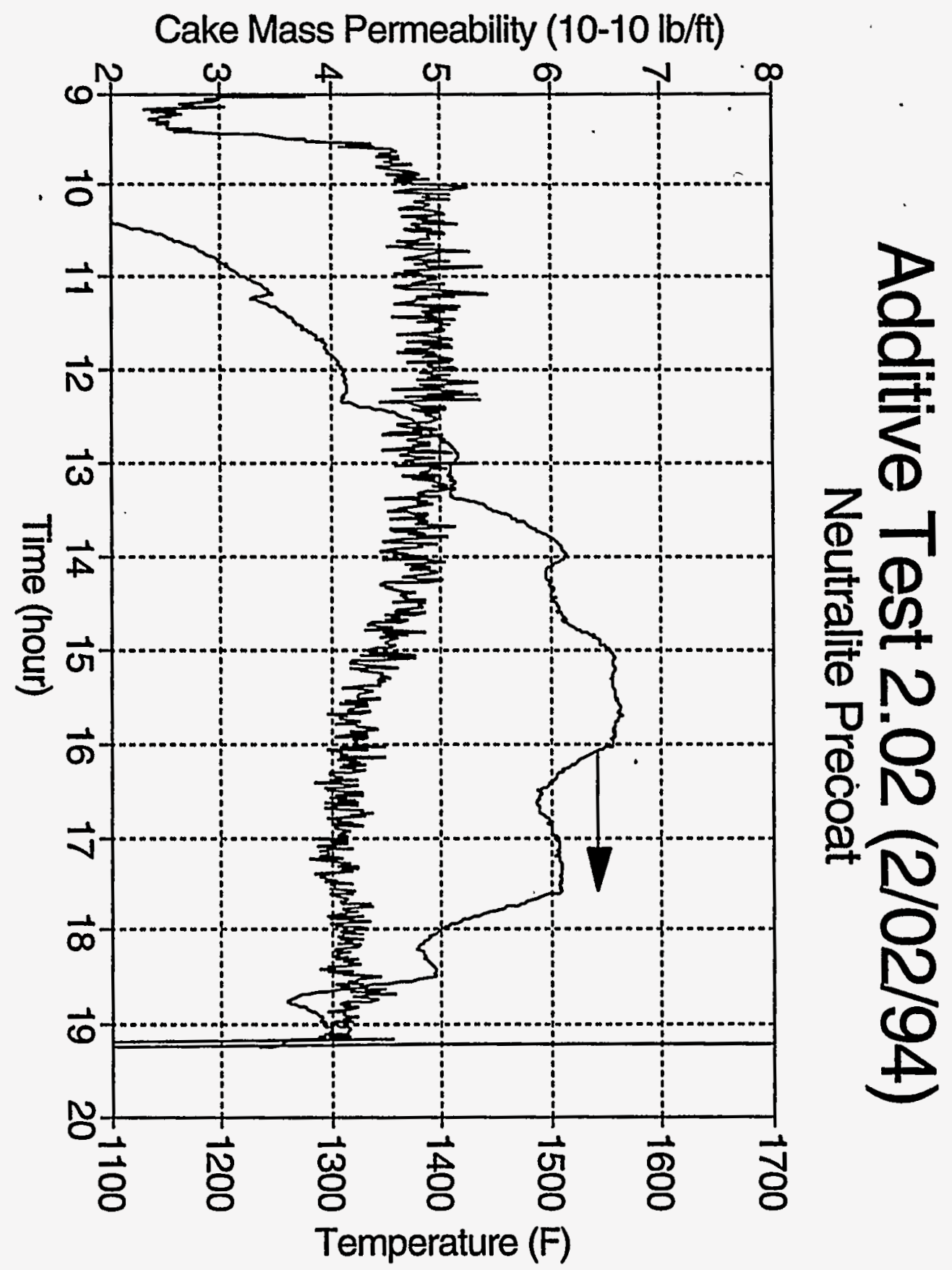




\section{Additive Test 2.03 (2/03/94) Grimethorpe Red on Neutralite Precoat}

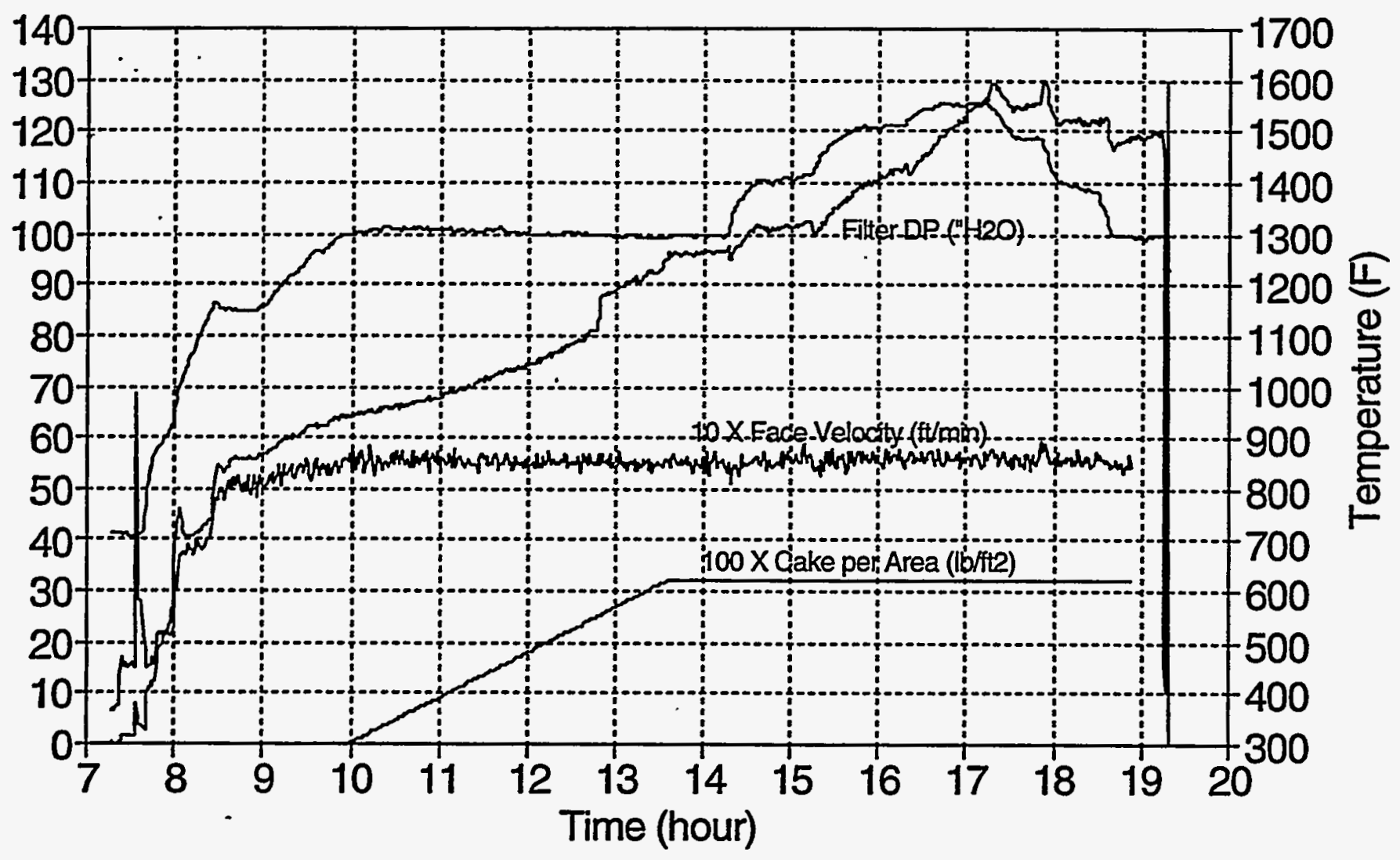




\section{Additive Test 2.03 (2/03/94) Grimethorpe Red on Neutralite Precoat .}

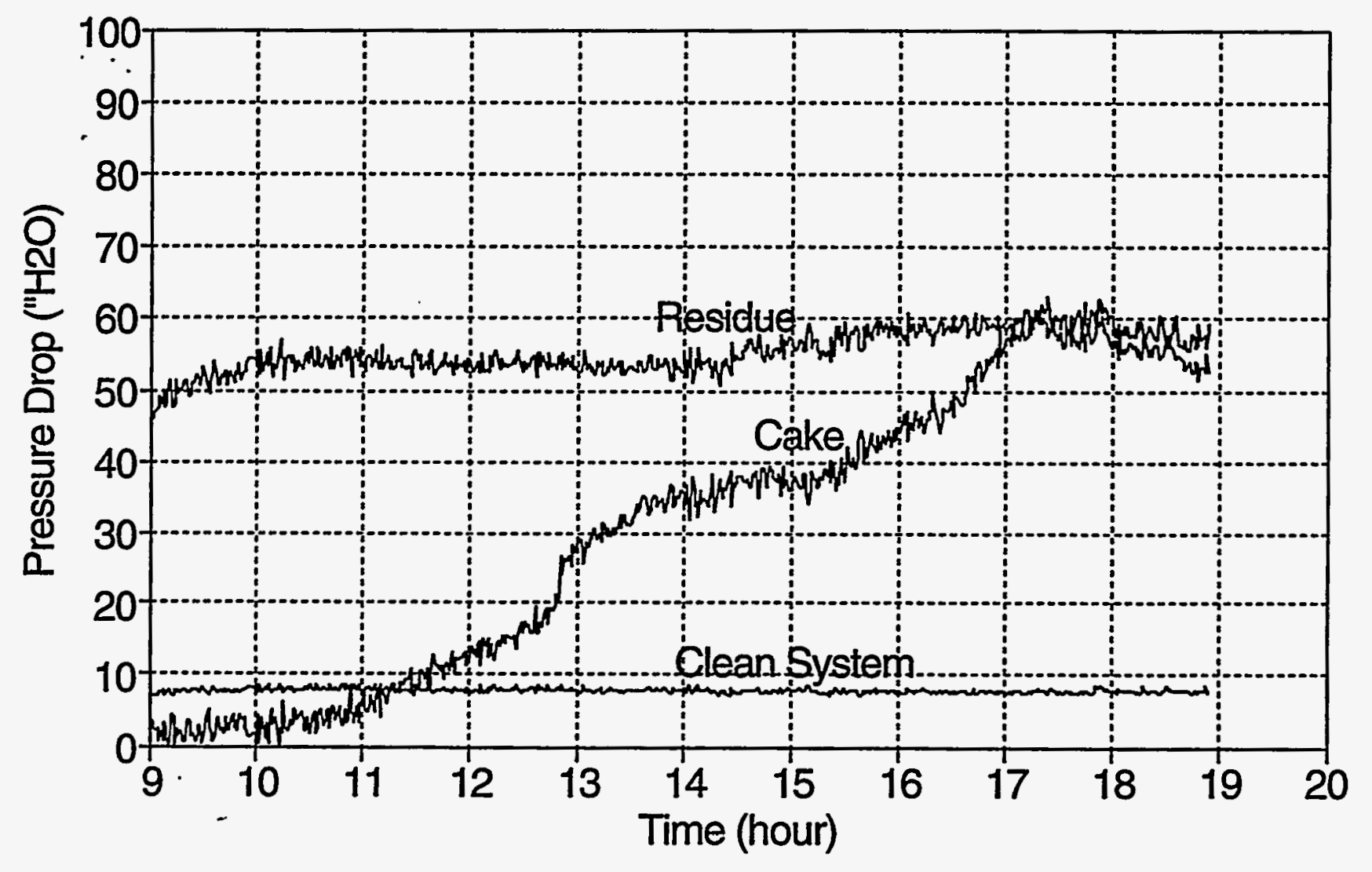




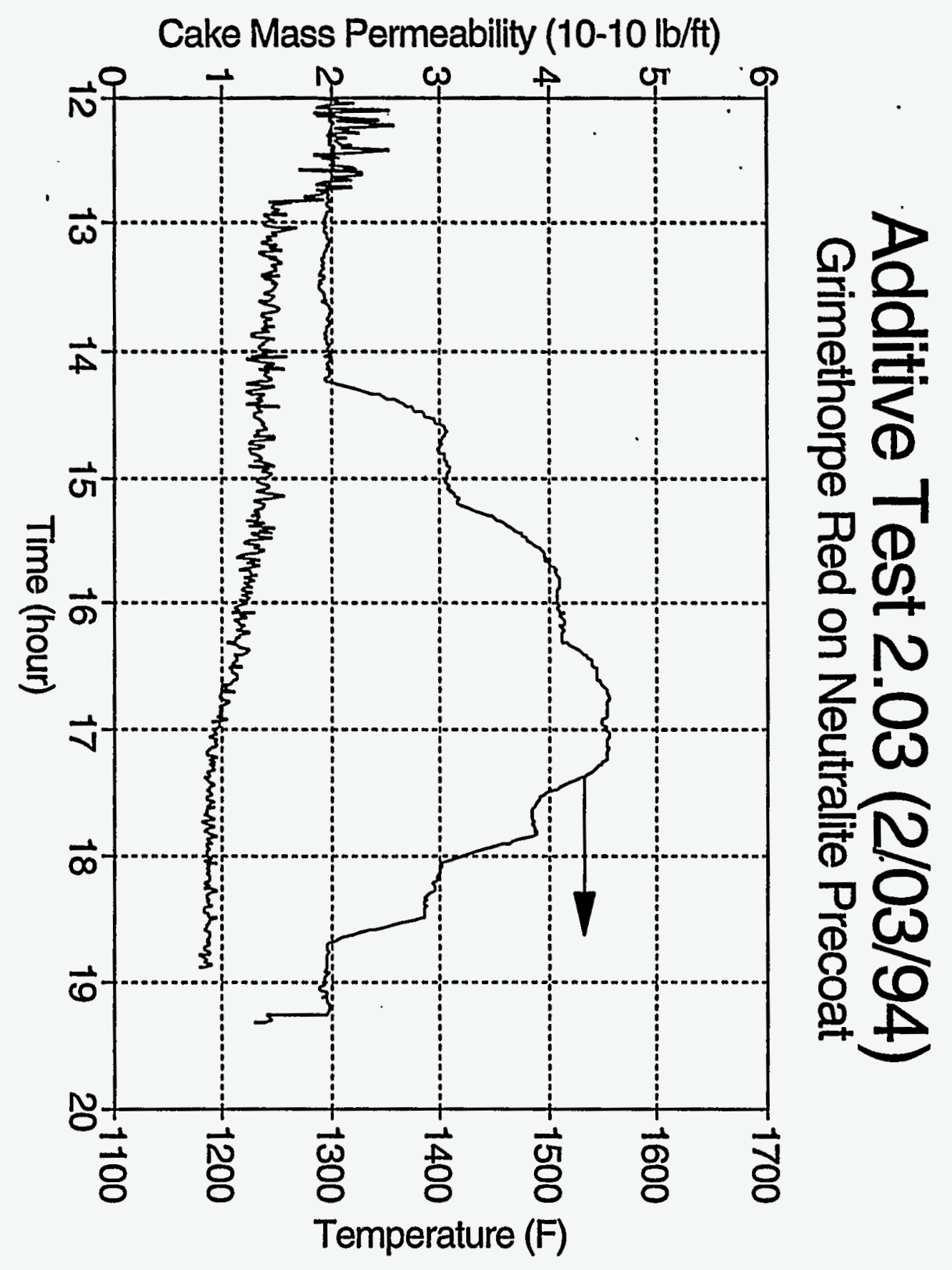




\section{Additive Test 2.04 (2/04/94) Grimethorpe Red +5 wt\% Neutralite}

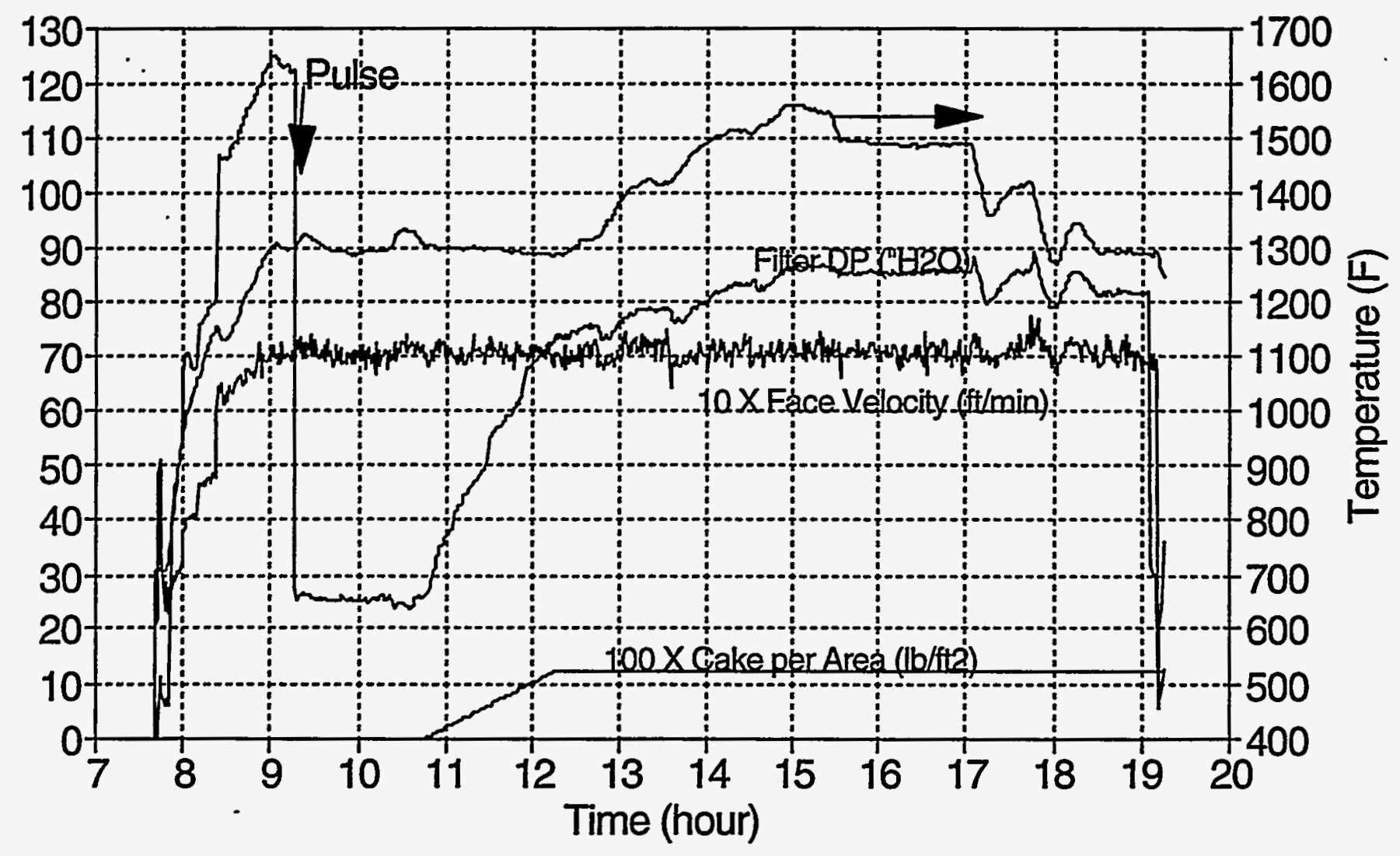




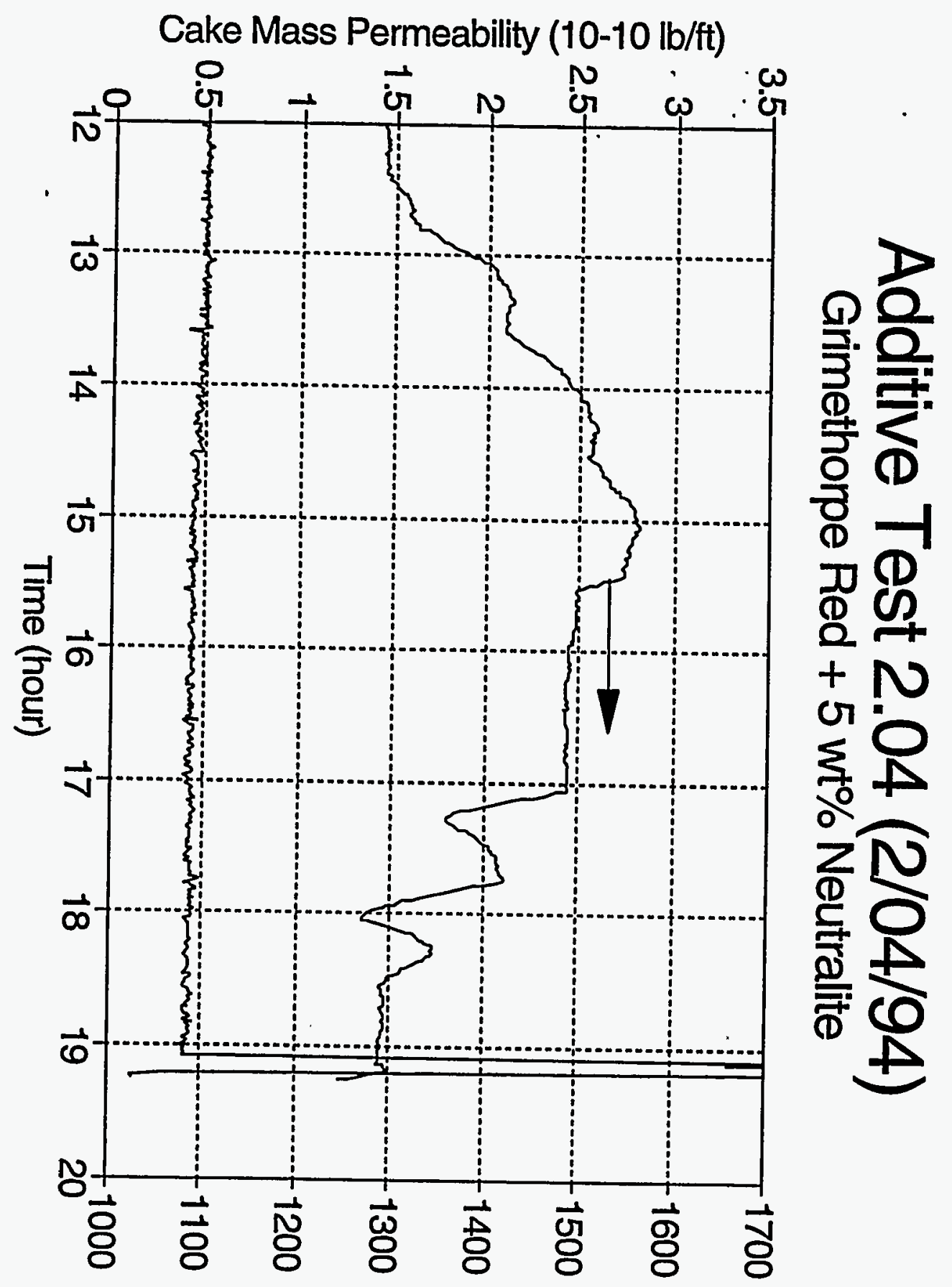




\section{Additive Test 2.04 (2/07/94) Grimethorpe Red $+5 \mathrm{wt} \%$ Neutralite}

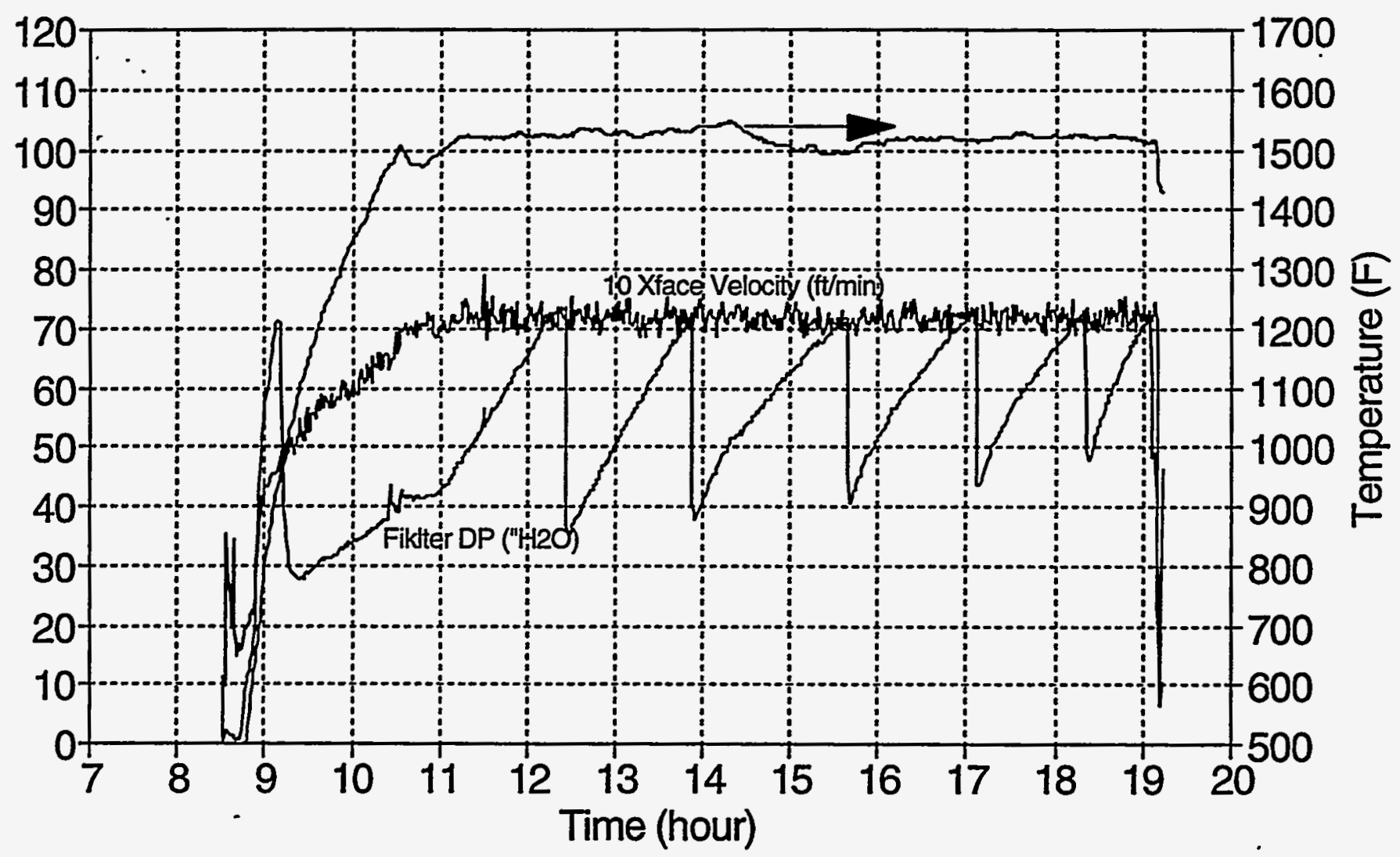




\section{Additive Test 2.05 (2/16/94) Grimethorpe Red + 10 wt\% Kaolin}

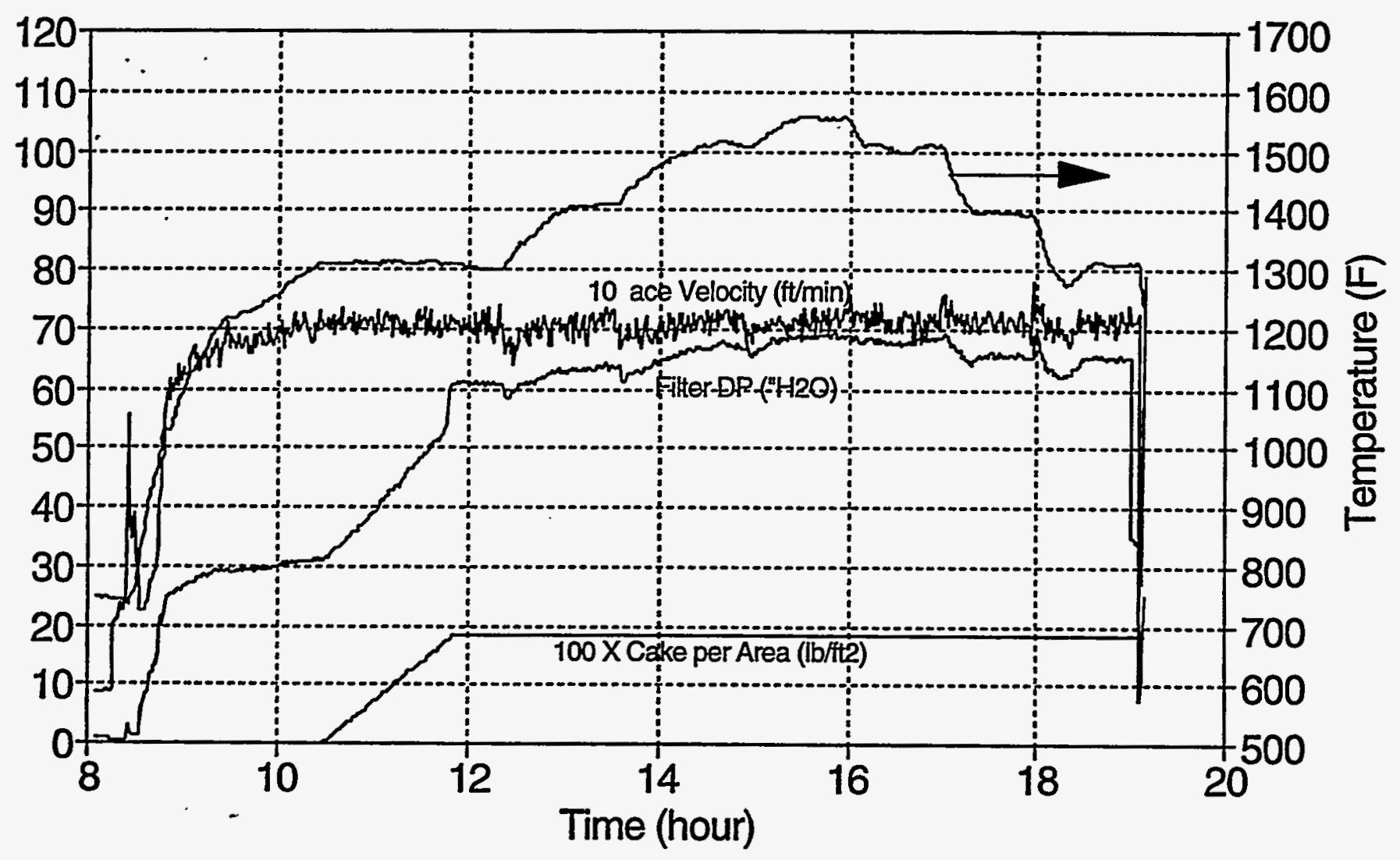




\section{Additive Test 2.05 (2/16/94) Grimethorpe Red + 10 wt\% Kaolin}

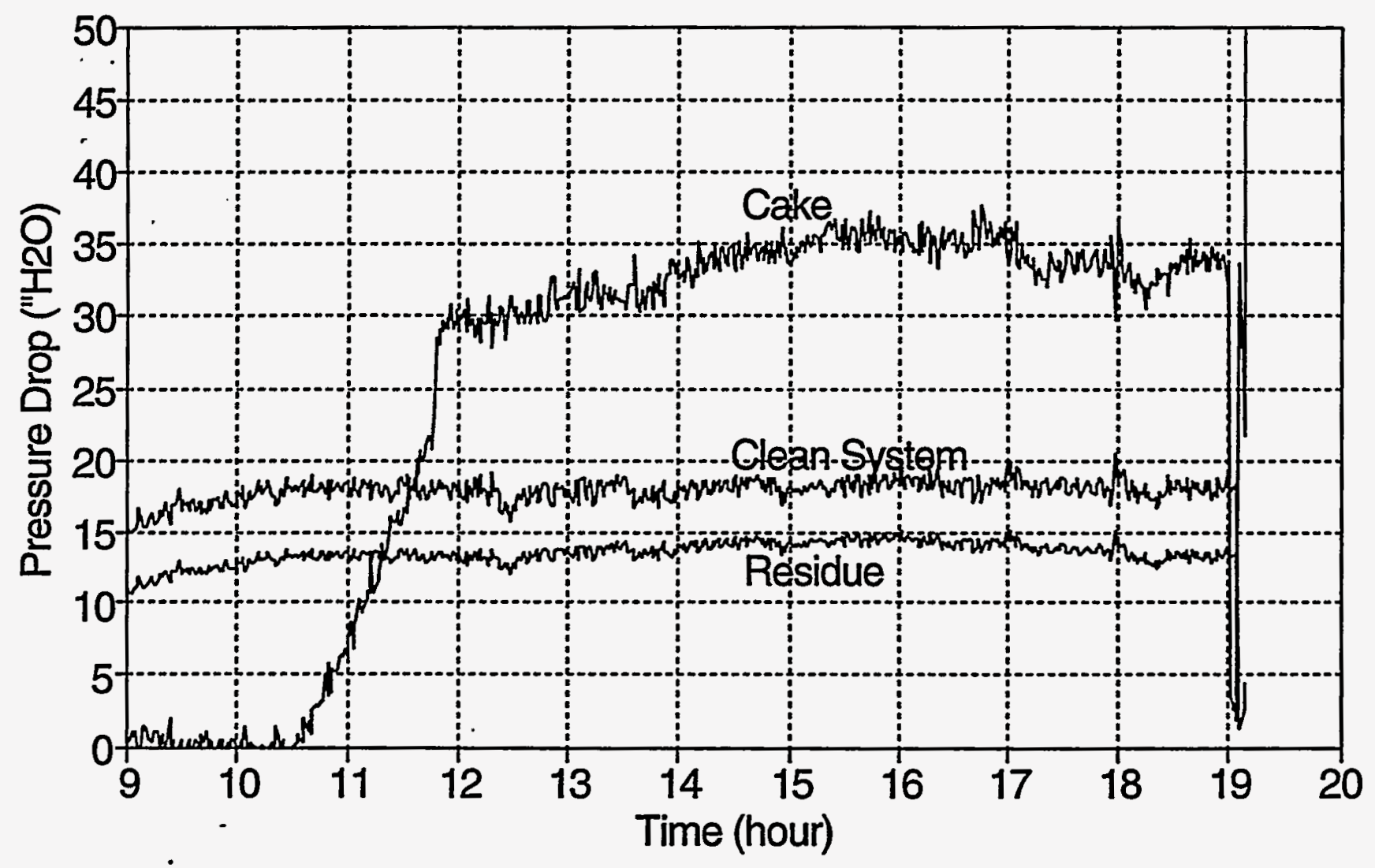




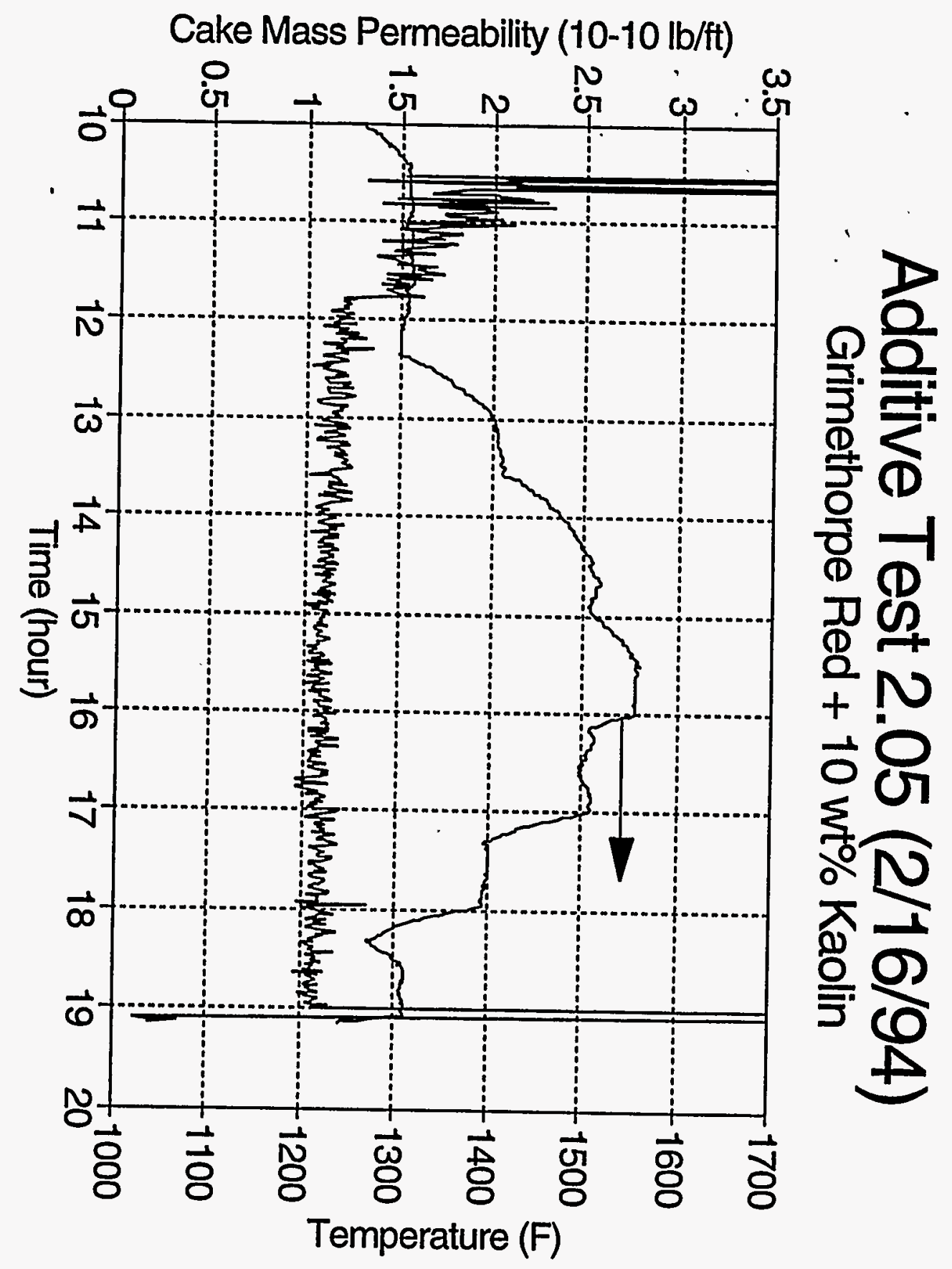


PULSE CLEANING TESTS (SERIES 3) 


\section{Pulse Cleaning Test 3.11 (5/23/94) Tidd Fine Fly Ash (1300F)}

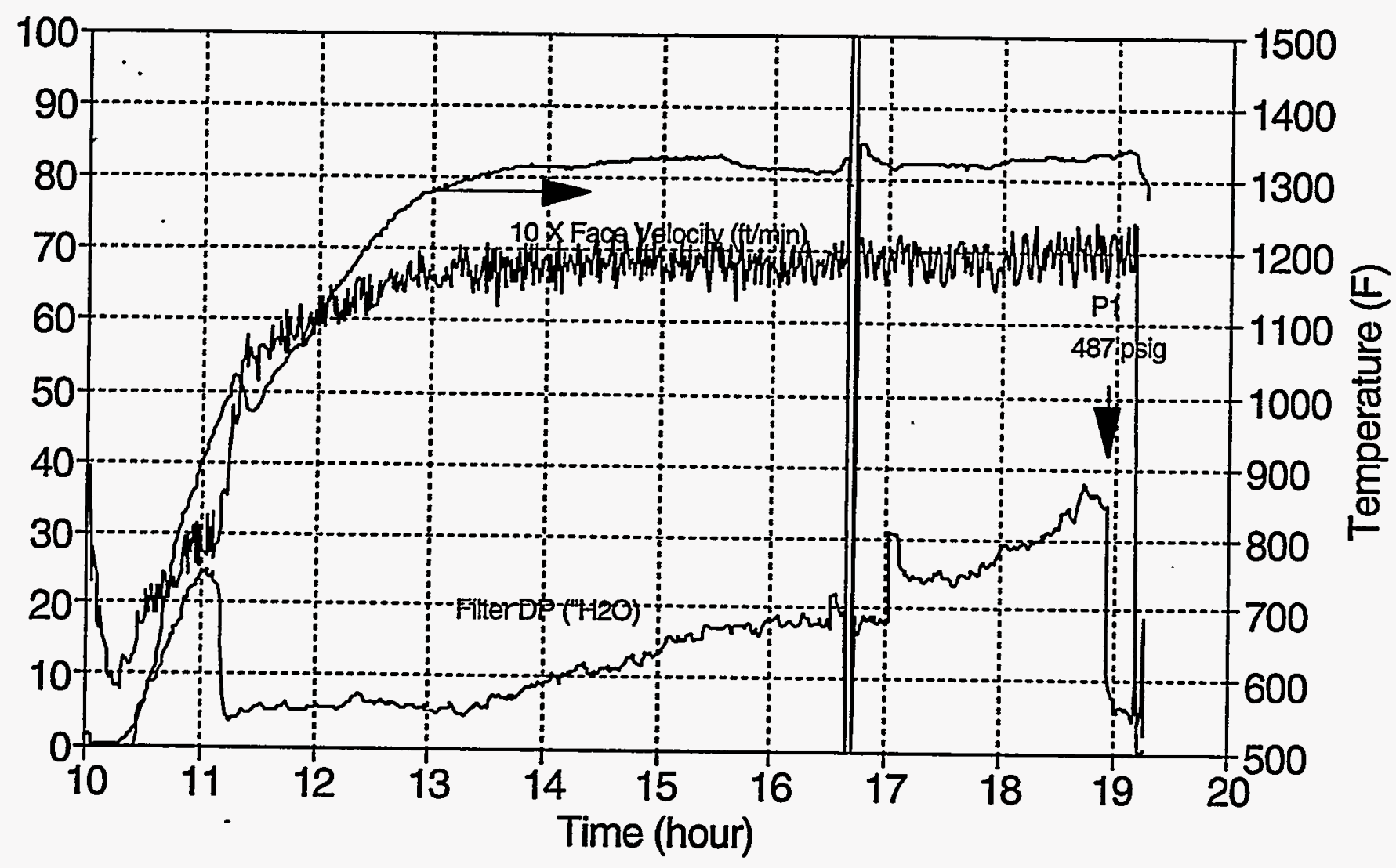




\section{Pulse Cleaning Test 3.11 (5/24/94) Tidd Fine Fly Ash (1300F)}

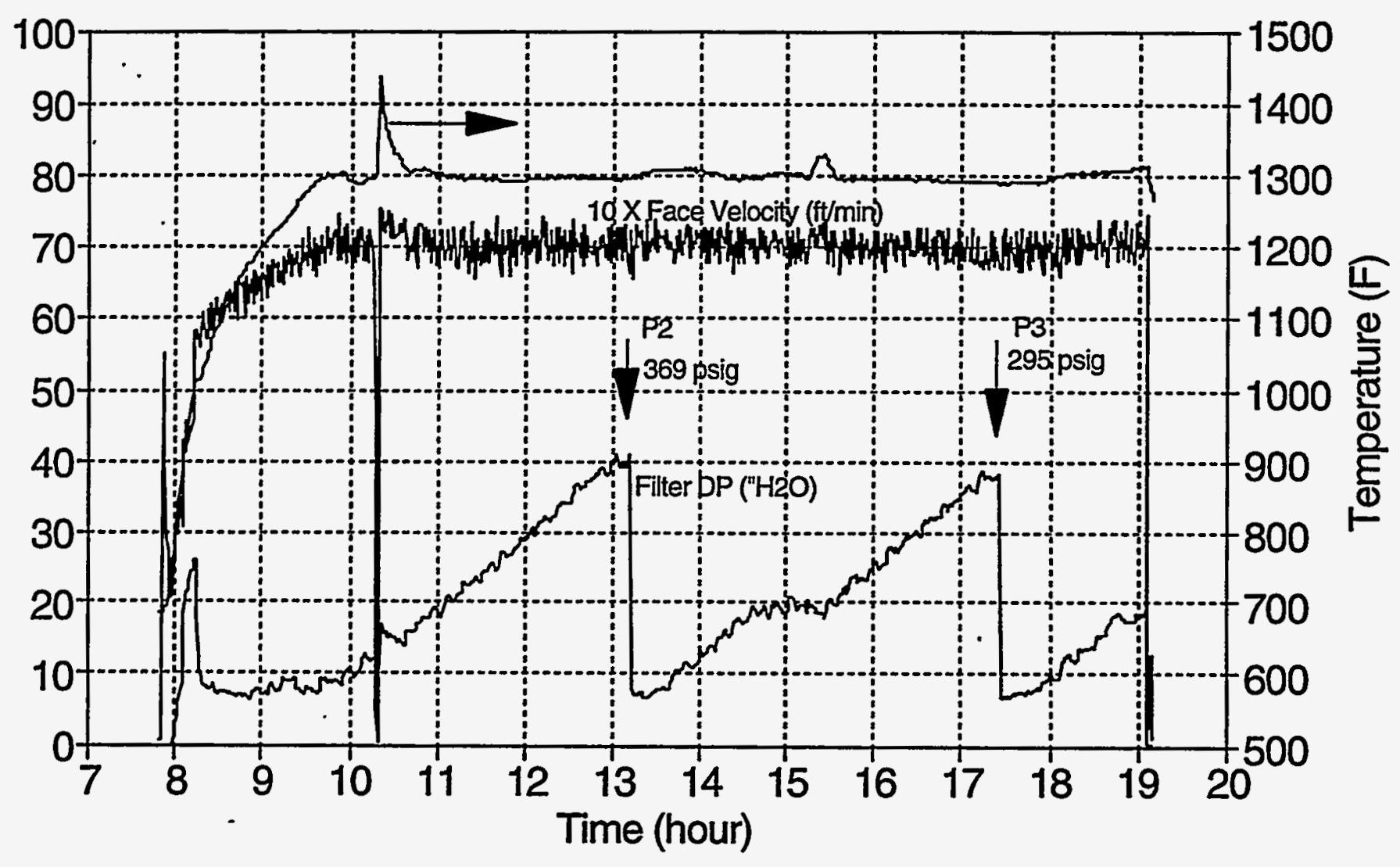




\section{Pulse Cleaning Test 3.11 (5/25/94) Tidd Fine Fly Ash (1300F)}

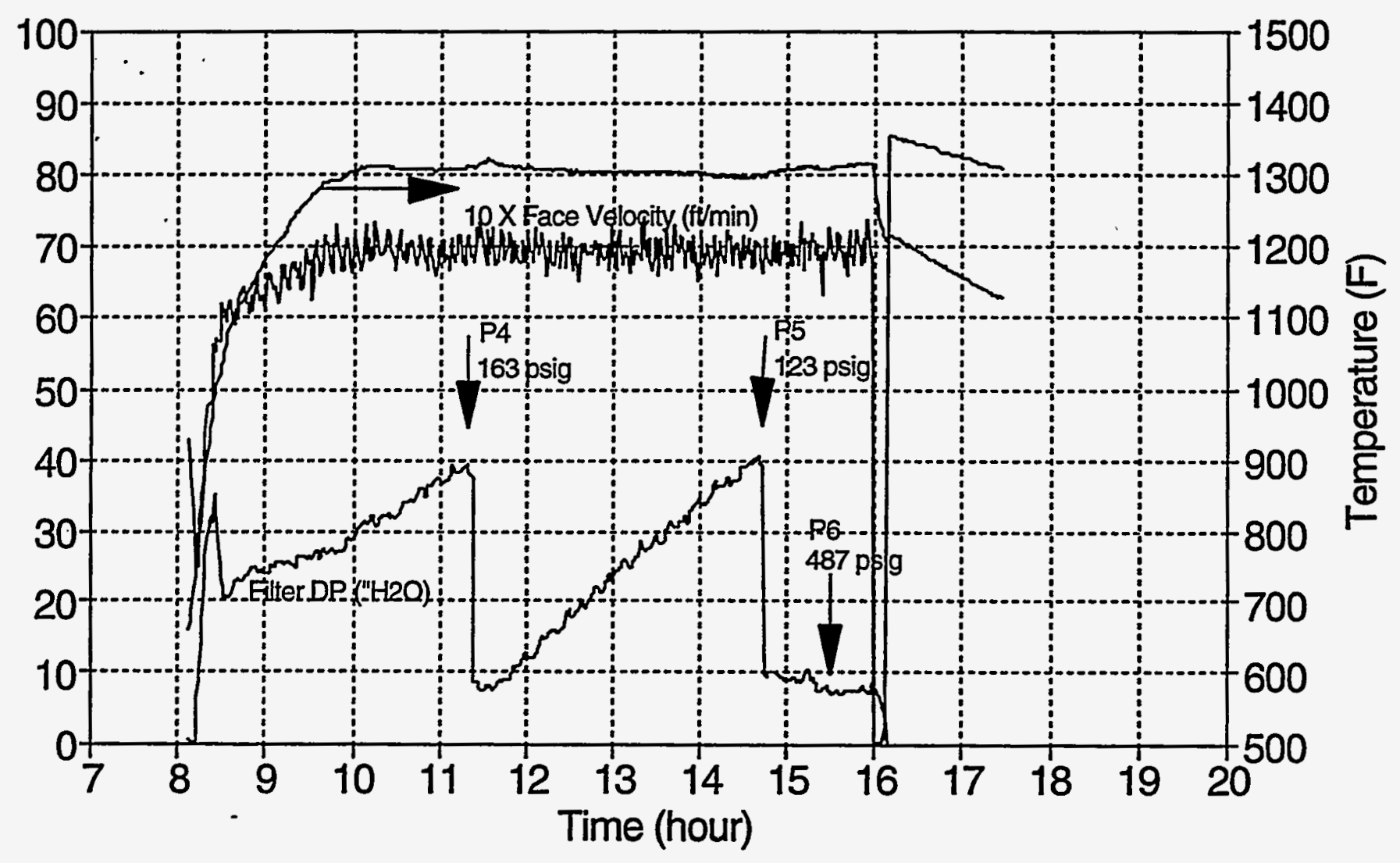




\section{Pulse Cleaning Test 3.12 (5/27/94) Tidd Fine Fly Ash (1450F)}

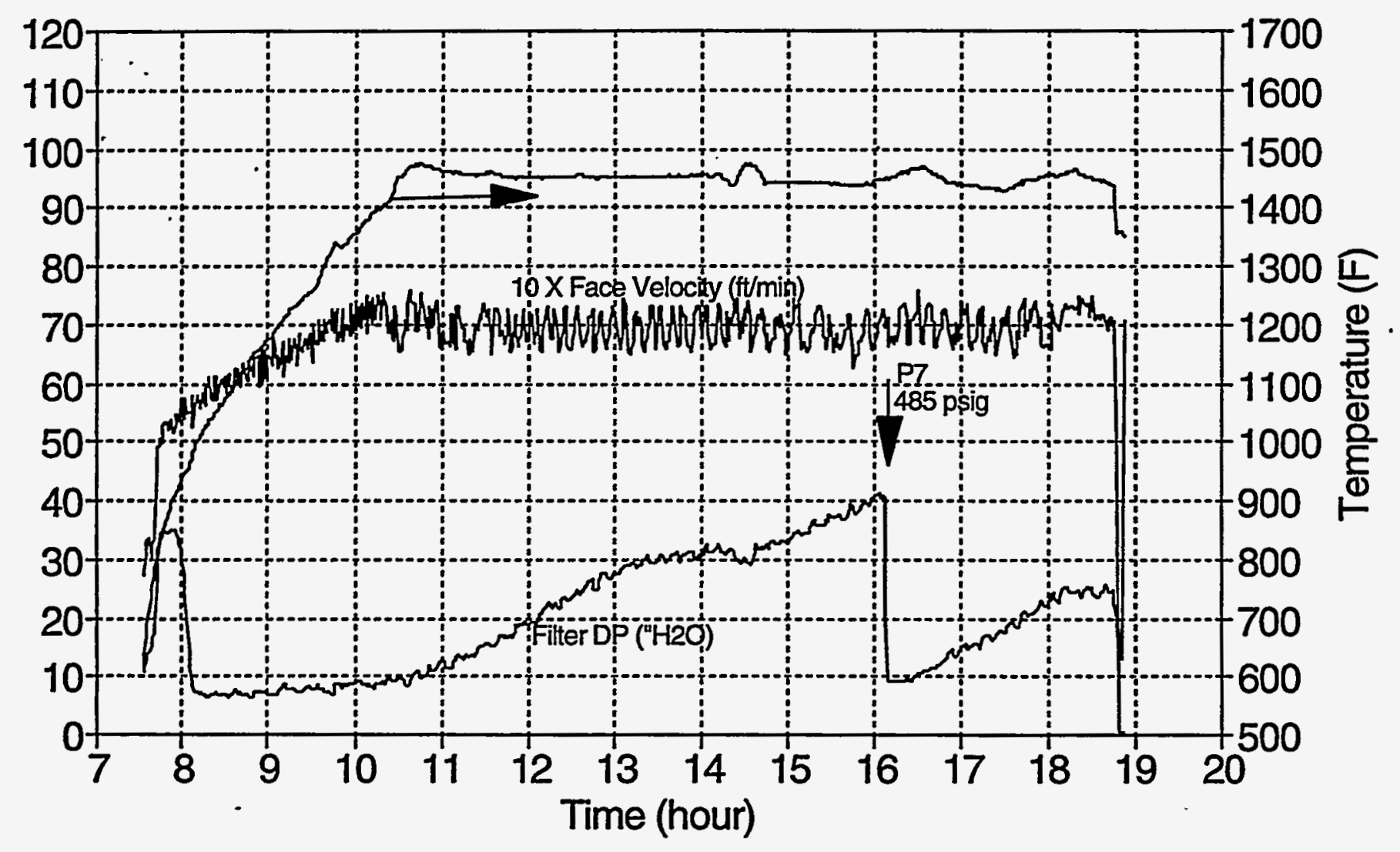




\section{Pulse Cleaning Test 3.12 (5/31/94) Tidd Fine Fly Ash (1450F)}

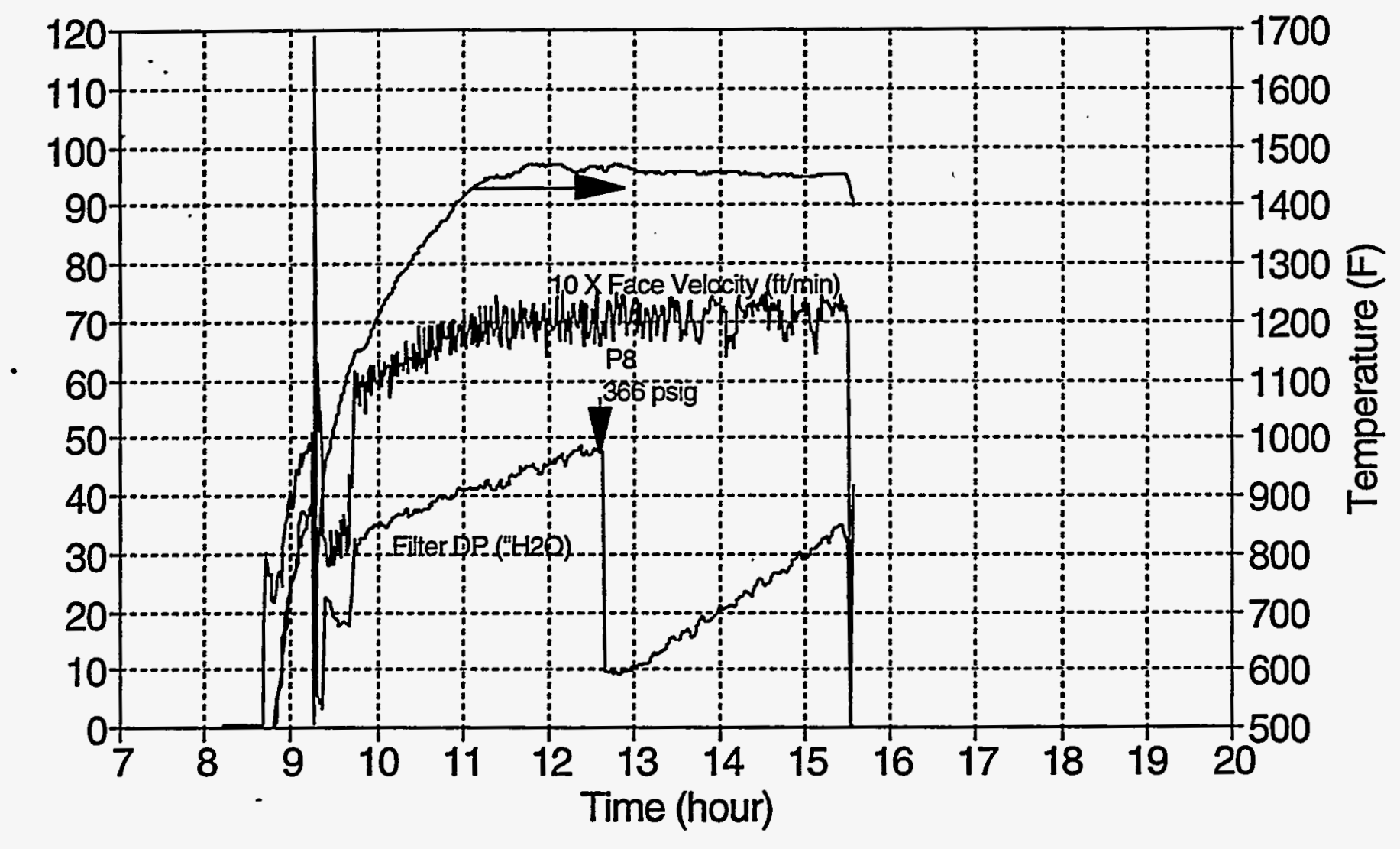




\section{Pulse Cleaning Test 3.12 (6/01/94) Tidd Fine Fly Ash (1450F)}

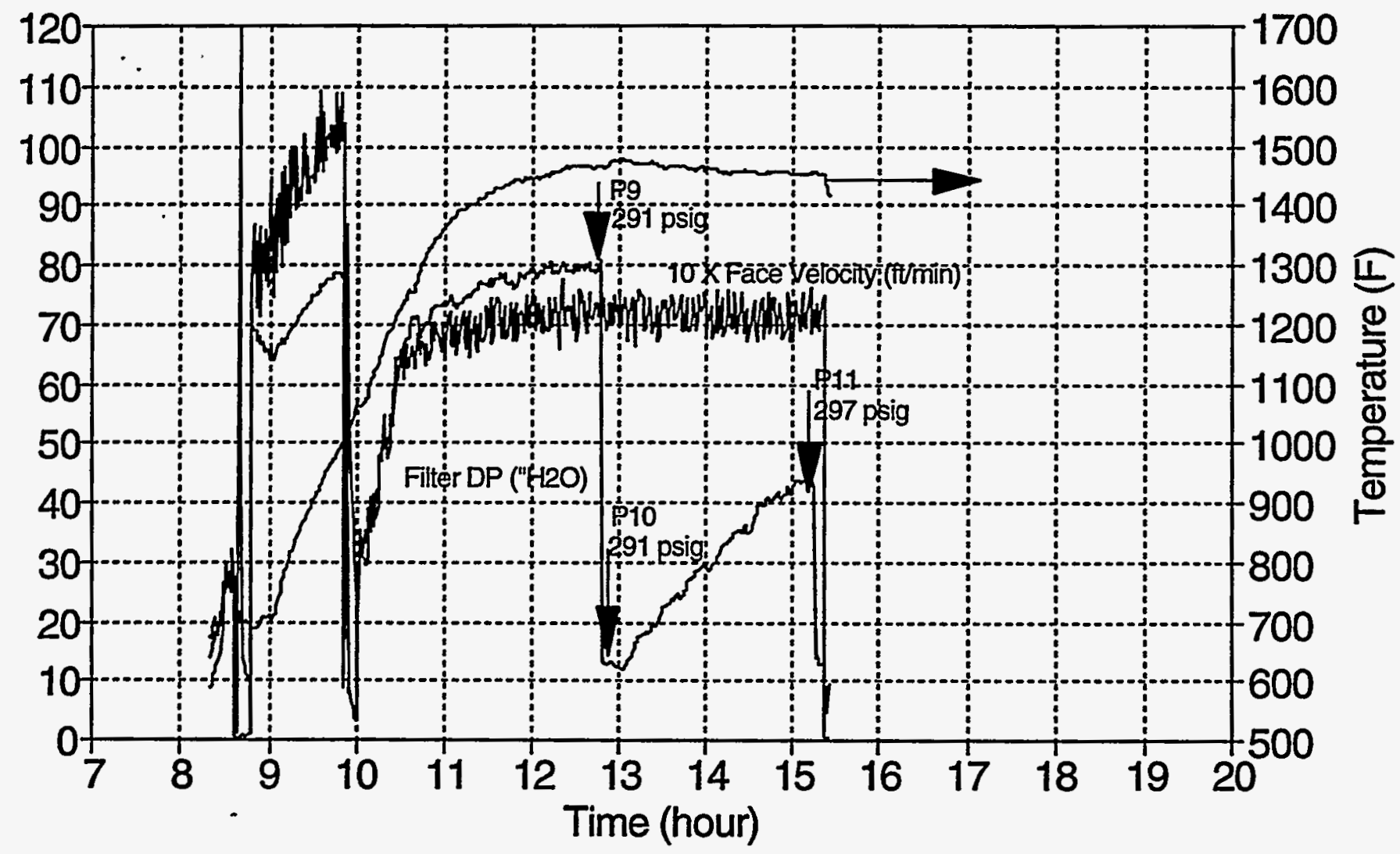




\section{Pulse Cleaning Test 3.12 (6/02/94) Tidd Fine Fly Ash (1450F)}

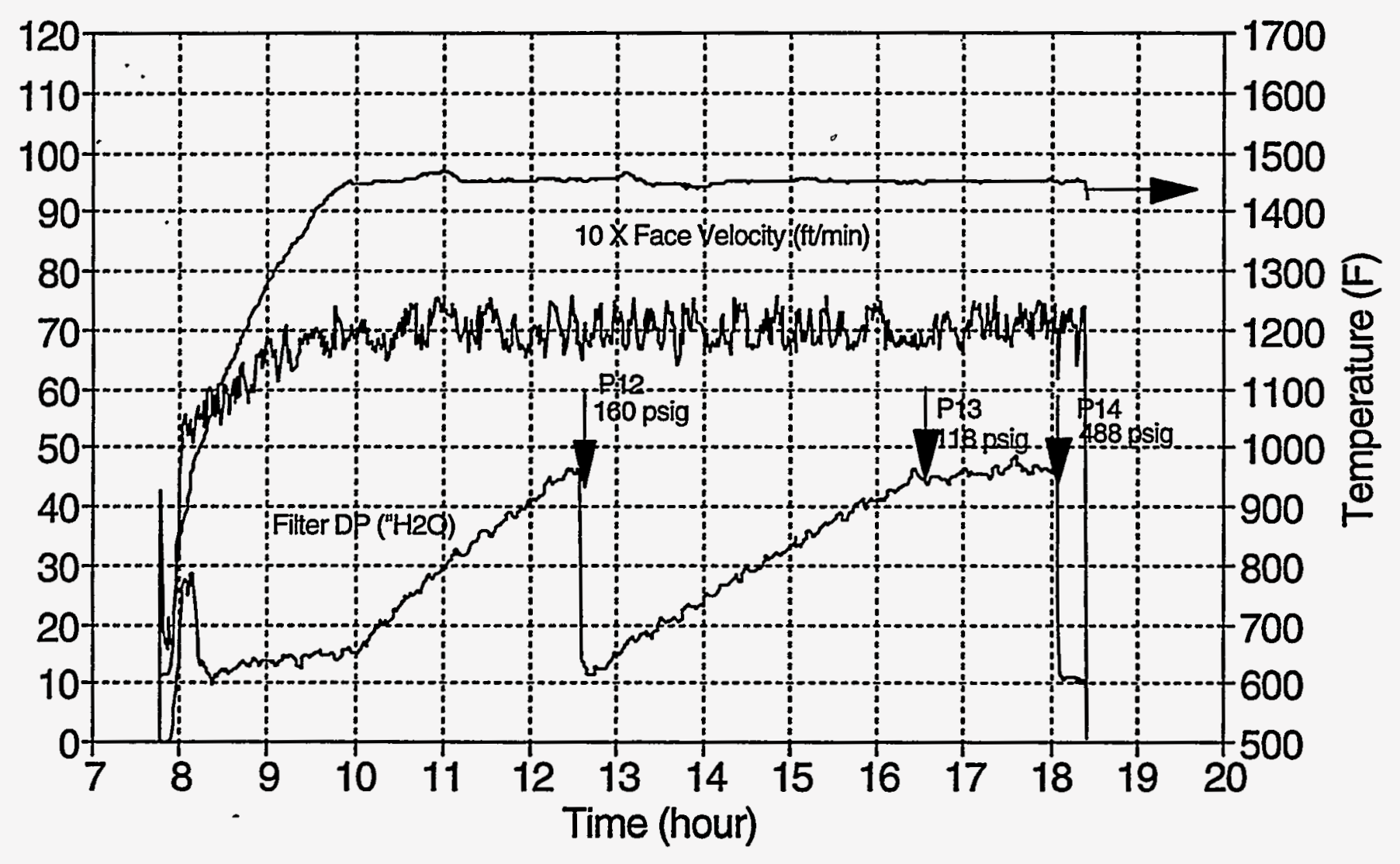




\section{Pulse Cleaning Test 3.13 (6/08/94) Tidd Fine Fly Ash (1550F)}

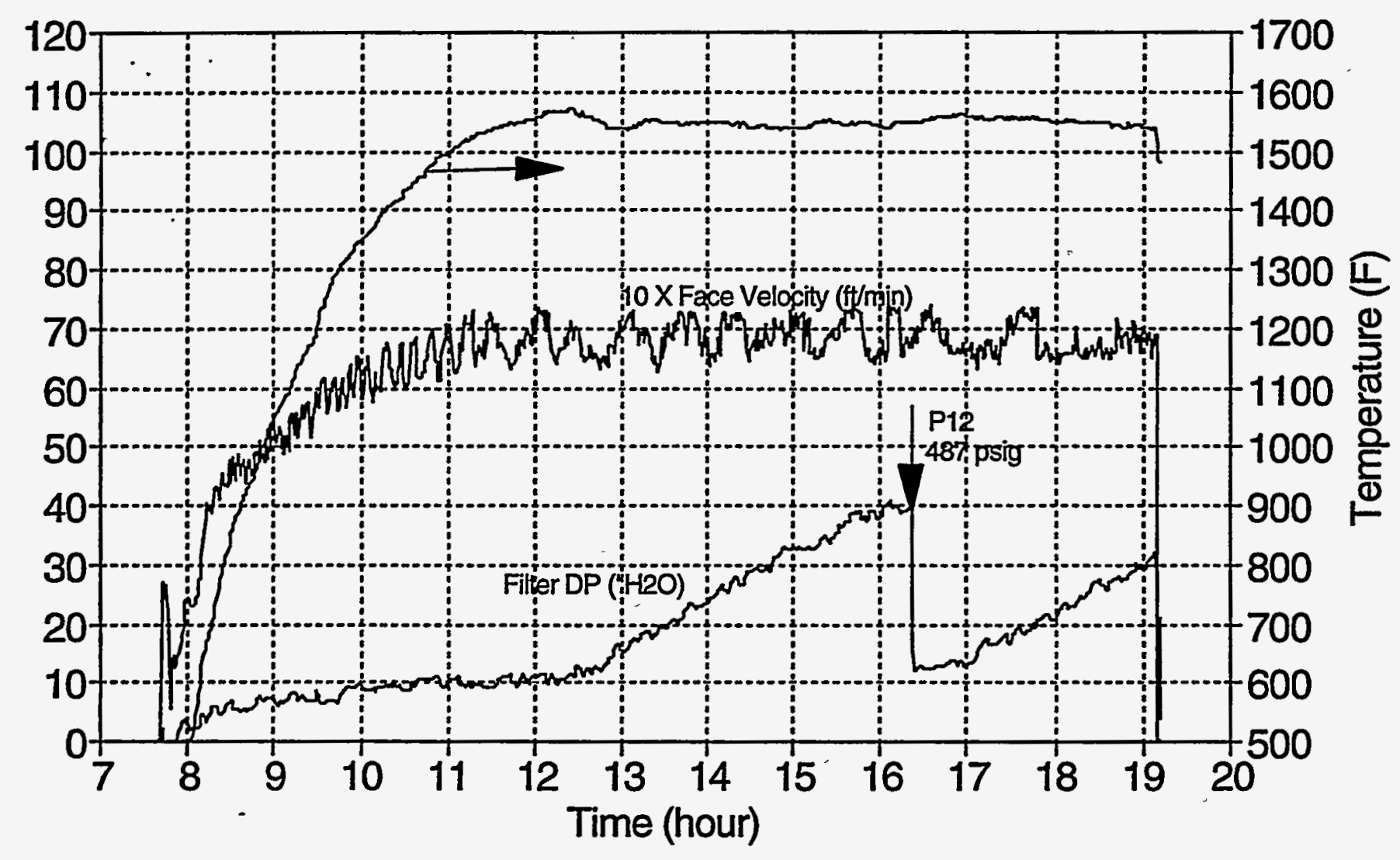




\section{Pulse Cleaning Test 3.13 (6/09/94) Tidd Fine Fly Ash (1550F)}

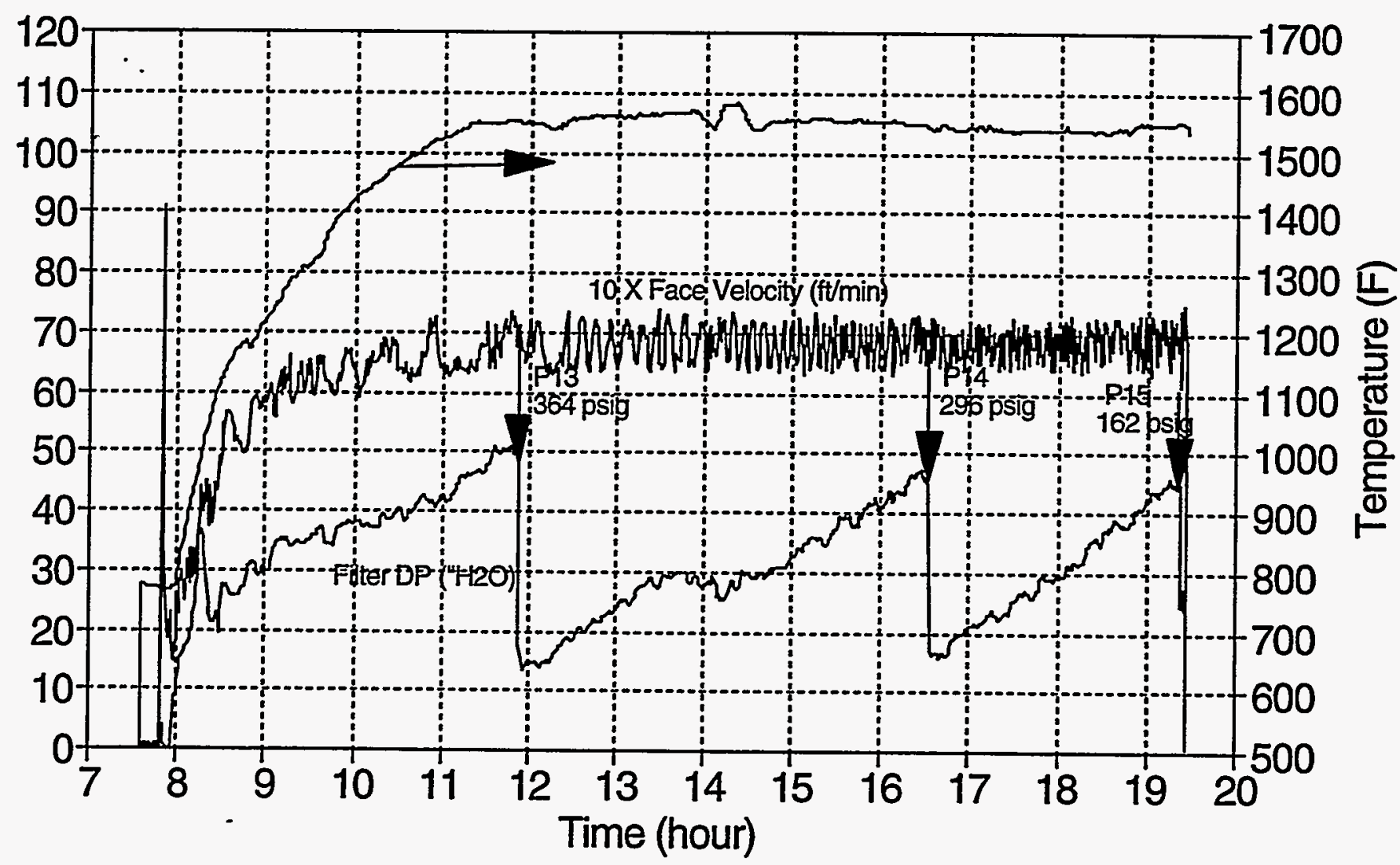




\section{Pulse Cleaning Test 3.13 (6/10/94) Tidd Fine Fly Ash (1550F)}

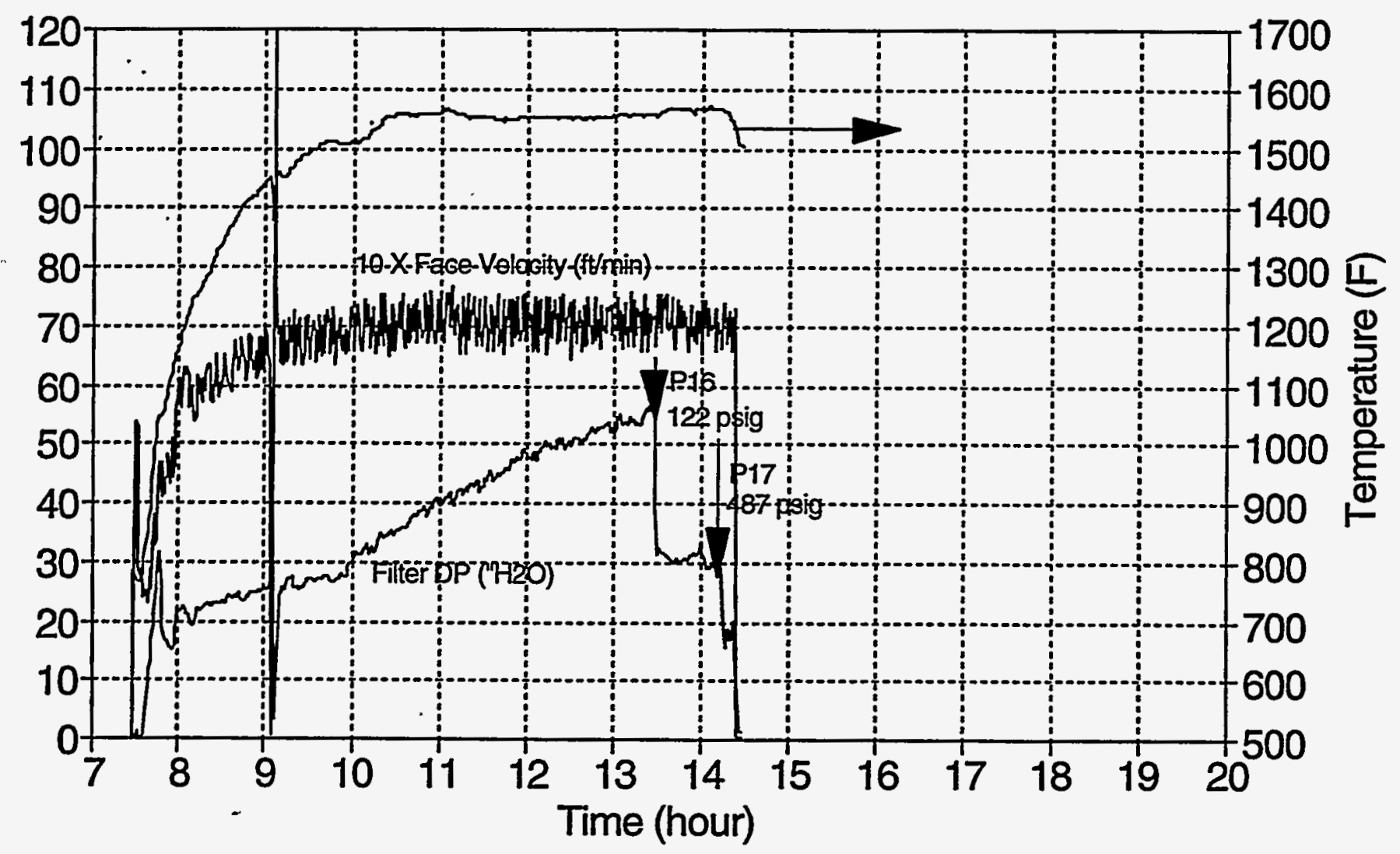


SULFUR REMOVAL TESTS (SERIES 4)

E-97 


\section{Sulfur Test 4.0 (1/17/95) Calibration (No Fly Ash or Sorbent)}

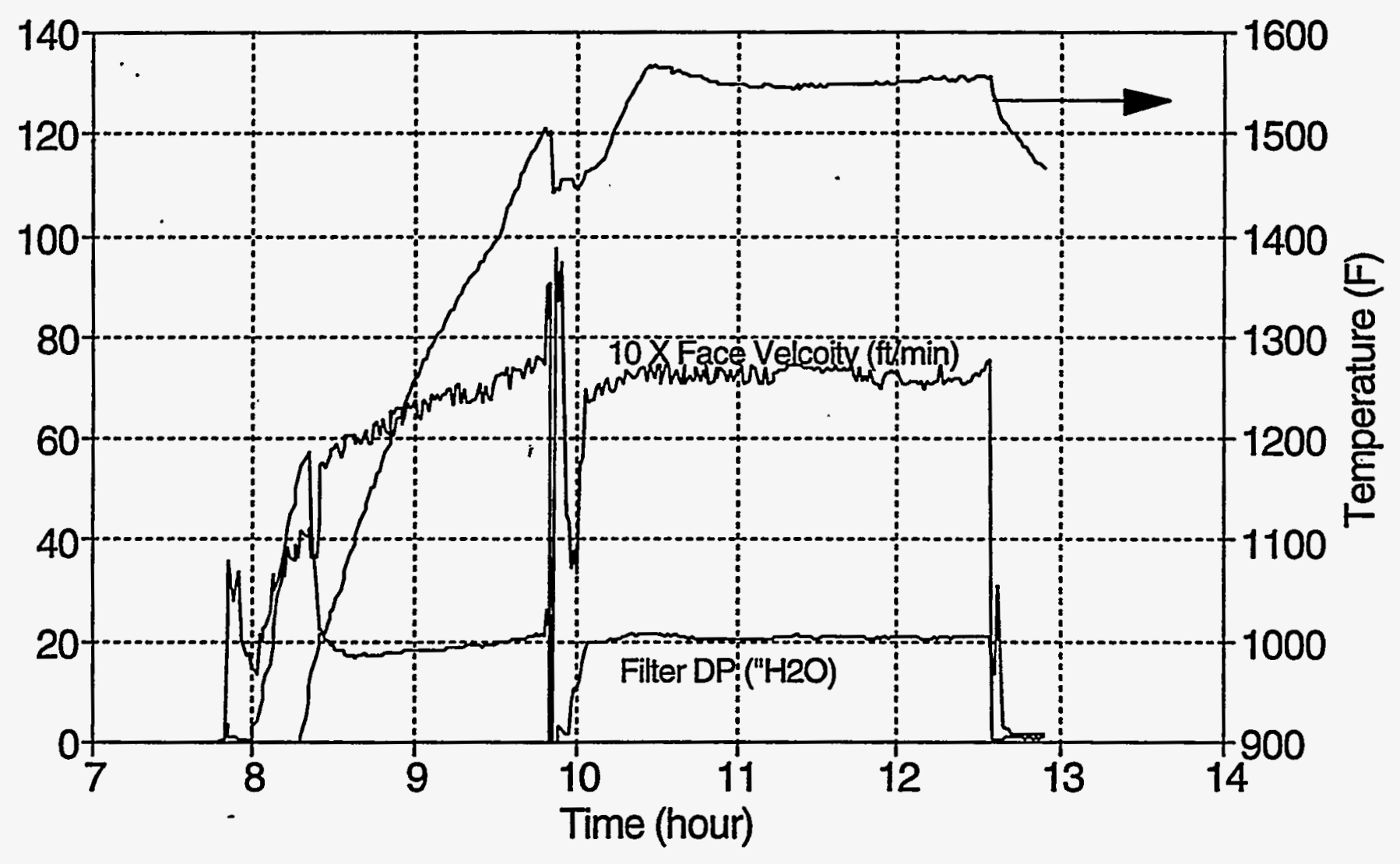




\section{Sulfur Test 4.0 (1/17/95) Calibration (No Fly Ash or Sorbent)}

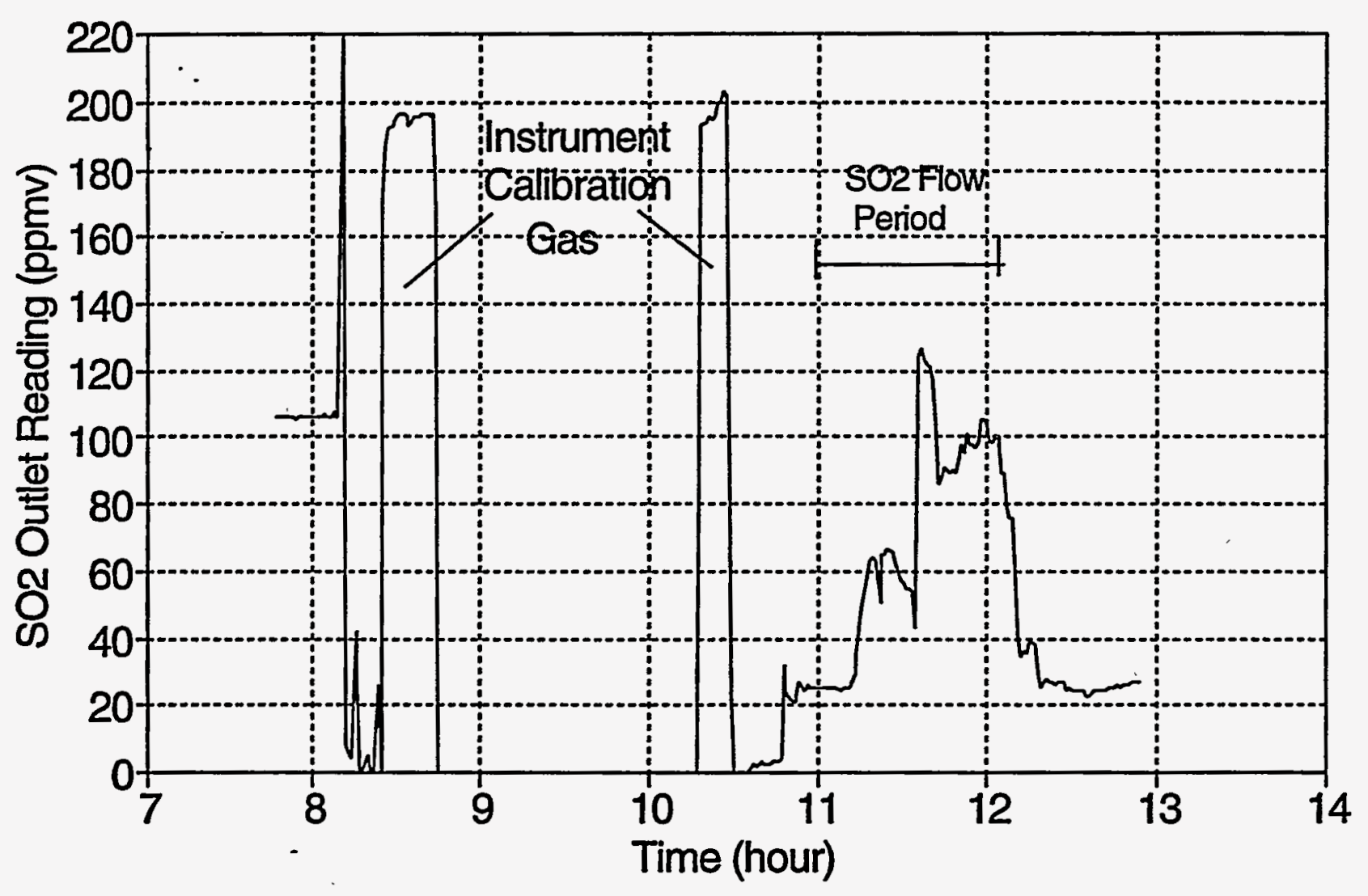




\section{Sulfur Test 4.0 (1/18/95) Calibration (No Fly Ash or Sorbent)}

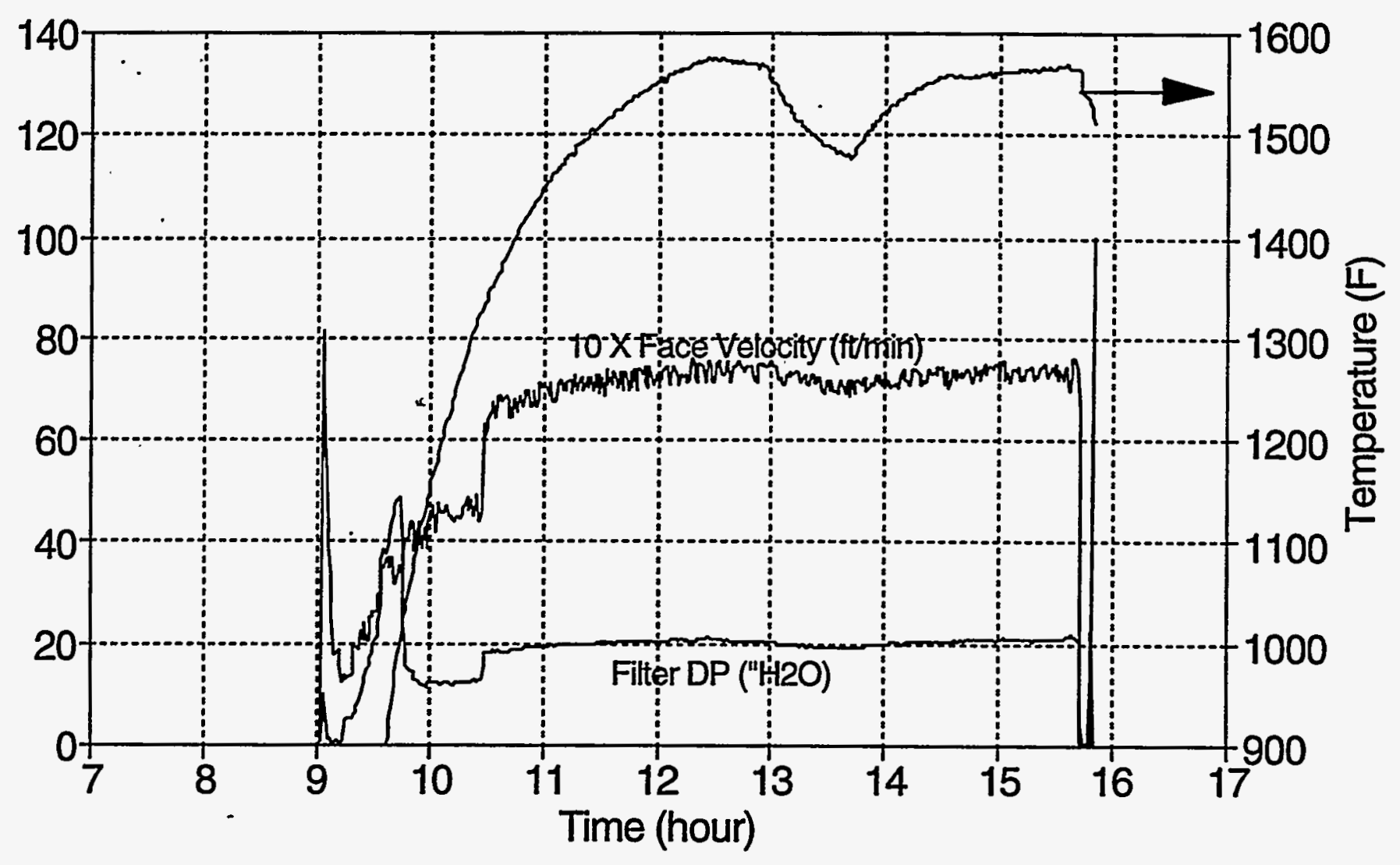




\section{Sulfur Test 4.0 (1/18/95) Calibration (No Fly Ash or Sorbent)}

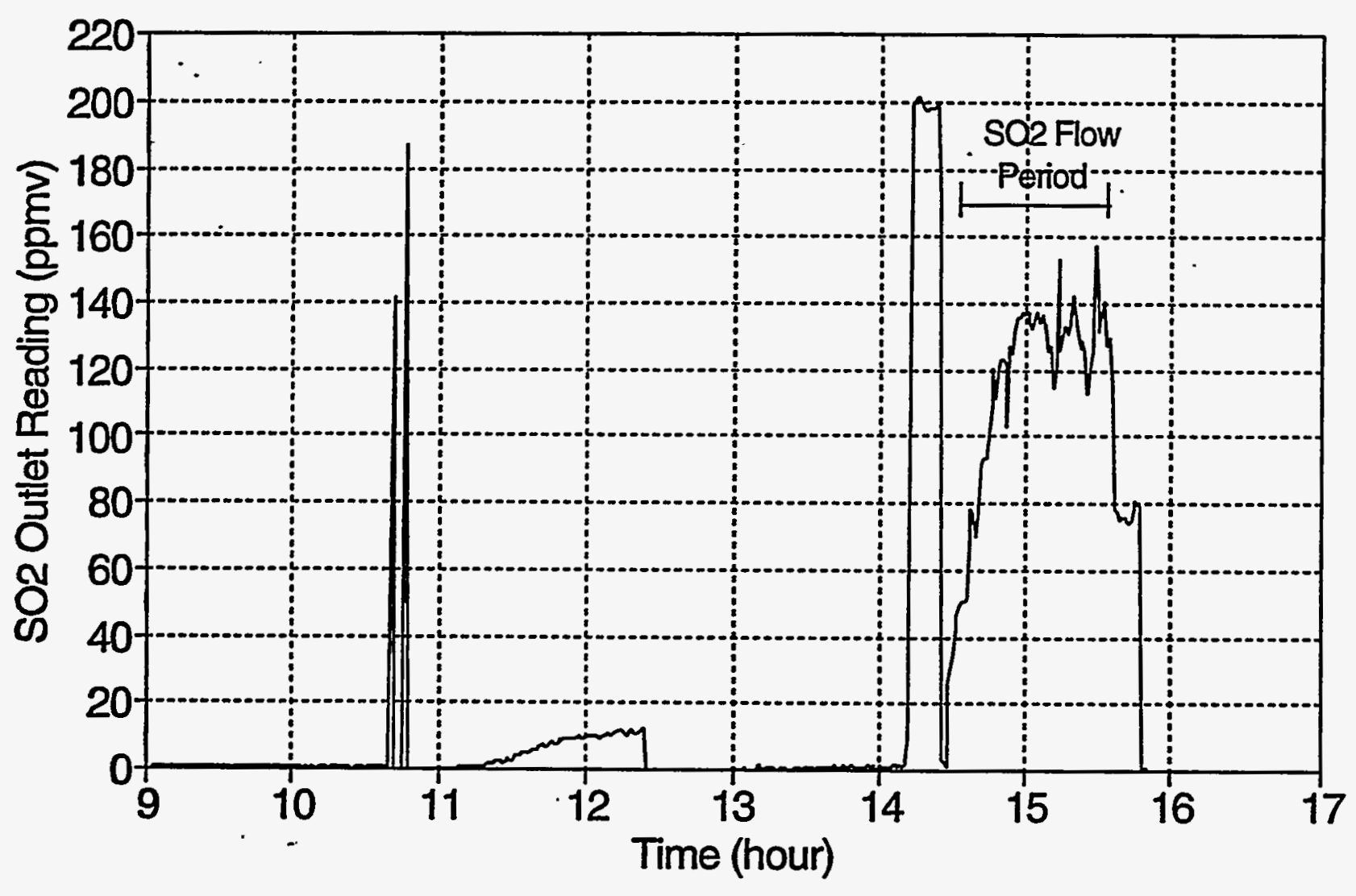




\section{Sulfur Test $4.1(1 / 19 / 95)$ \\ Tidd Spoiled Cyclone Fly Ash/ No SO2}

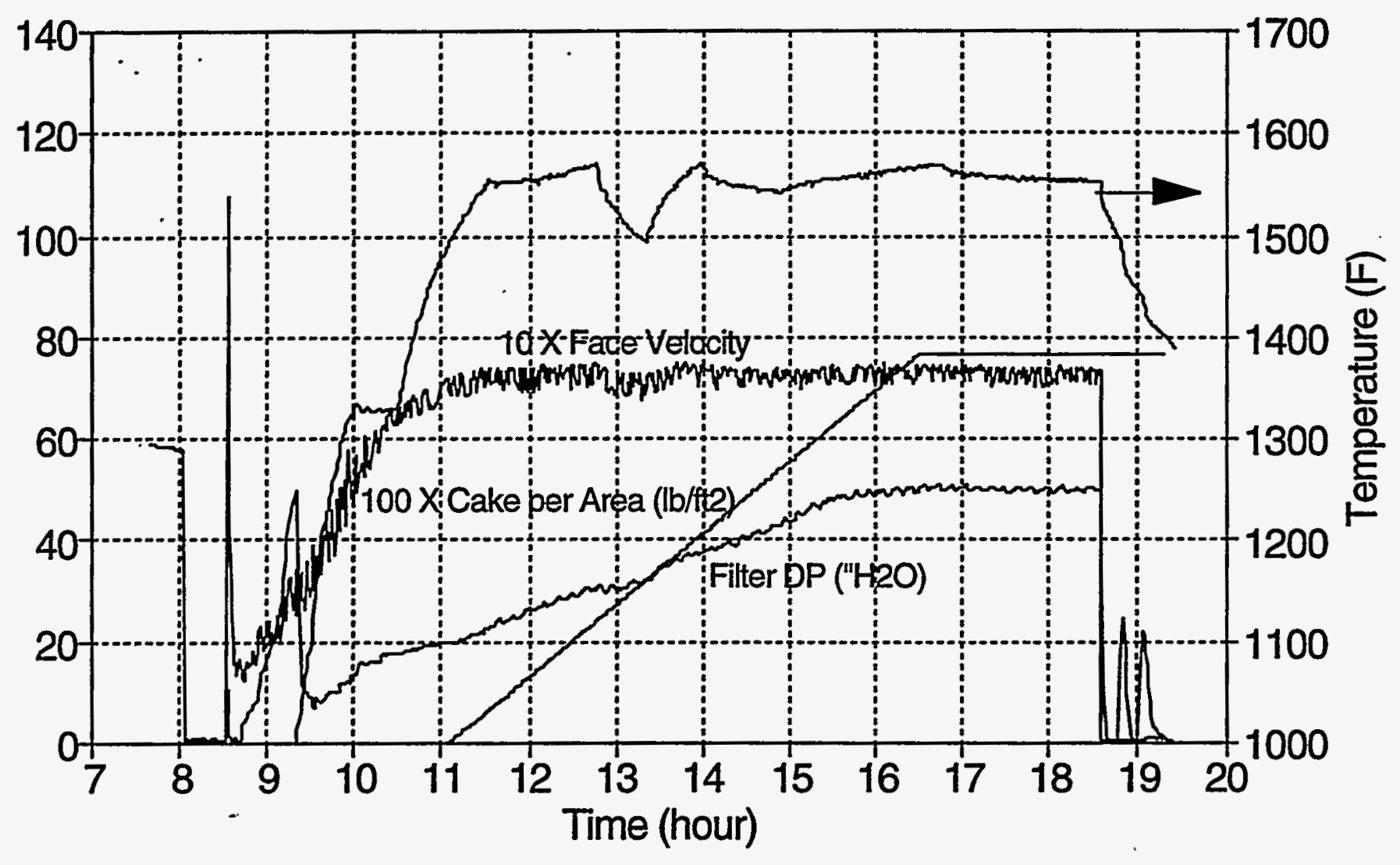




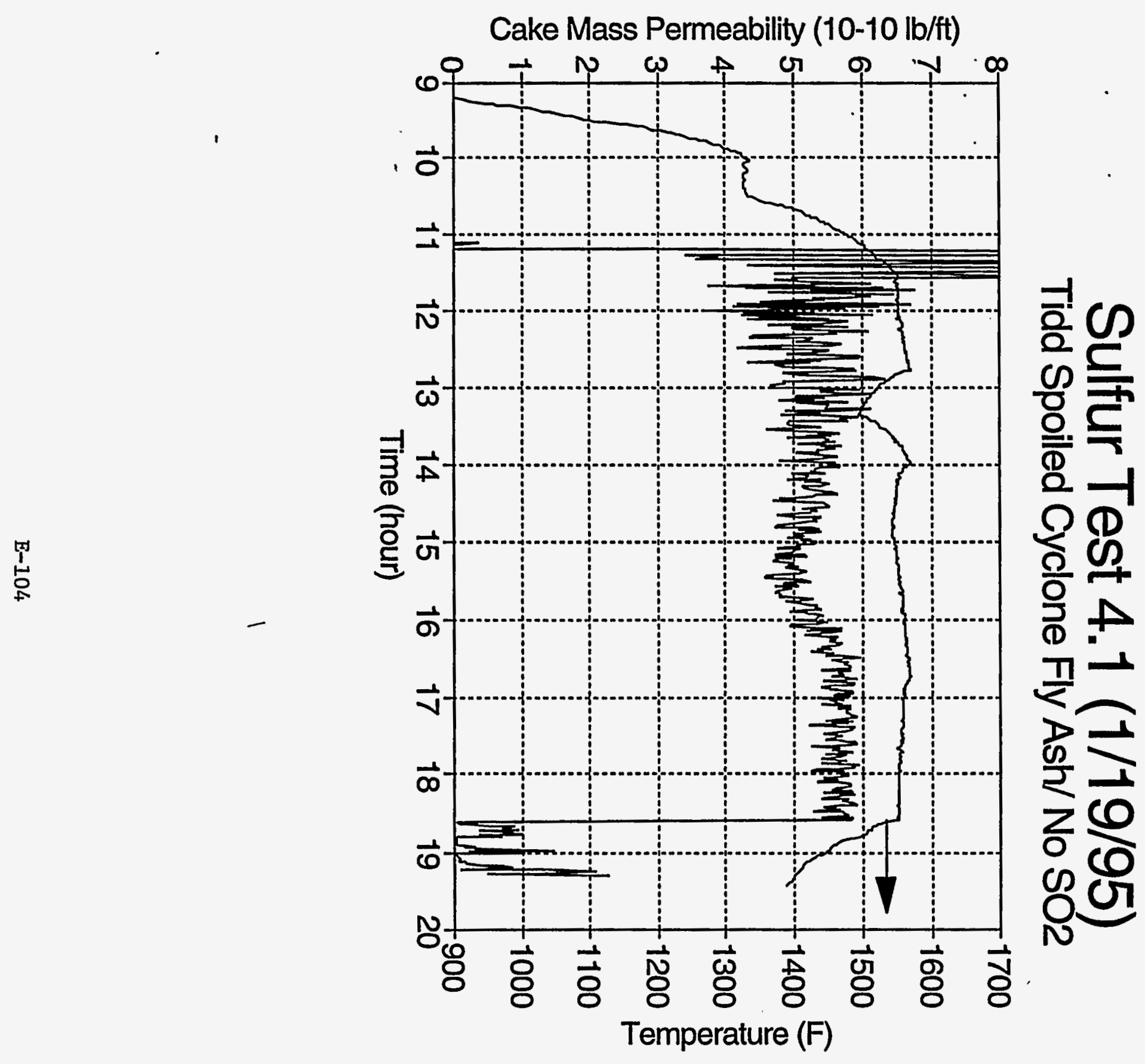




\section{Sulfur Test 4.1 (1/19/95) Tidd Spoiled Cyclone Fly Ash/ No SO2}

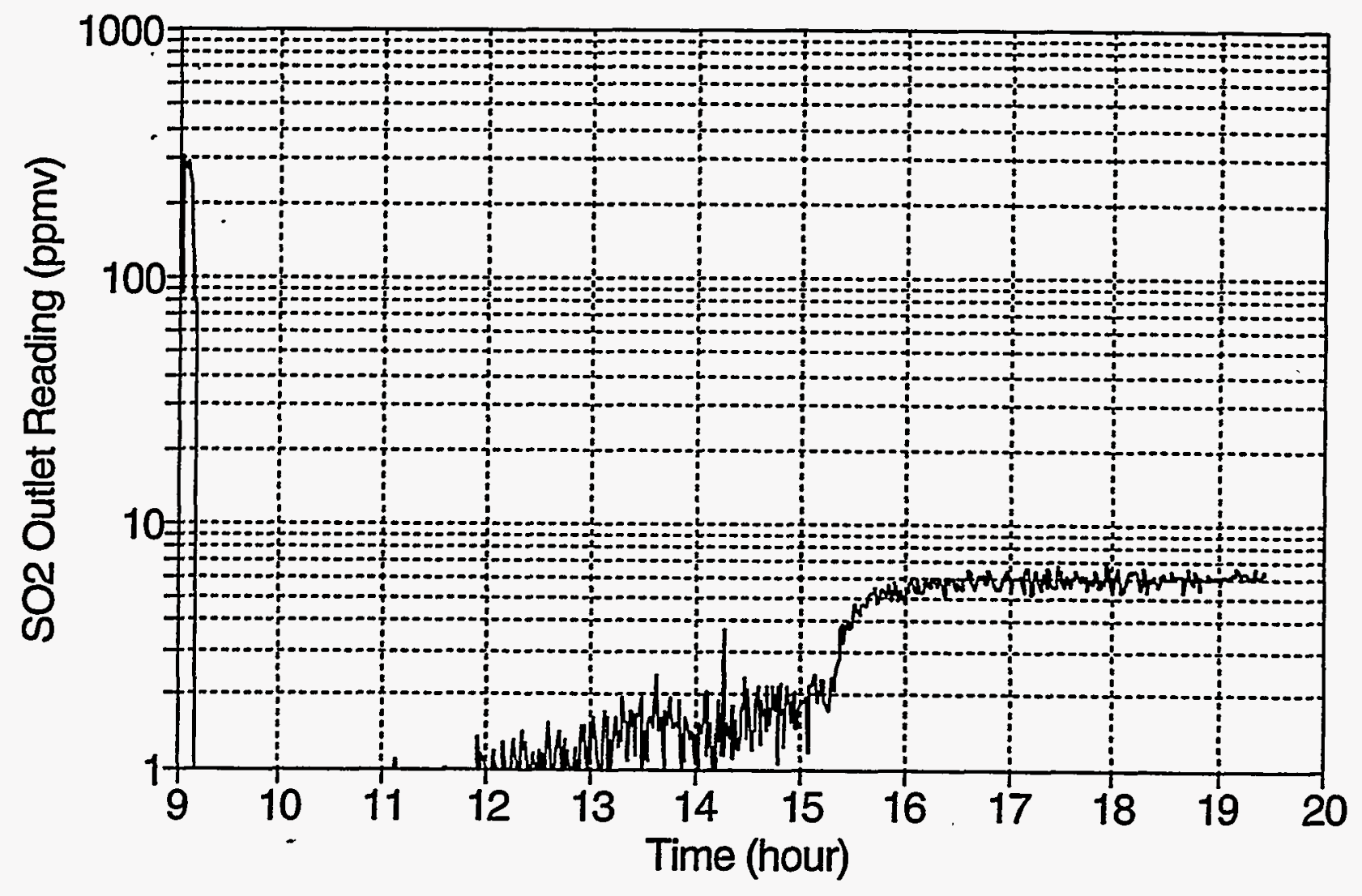




\section{Sulfur Test 4.1 (1/20/95) Tidd Spoiled Cyclone Fly Ash/ No SO2}

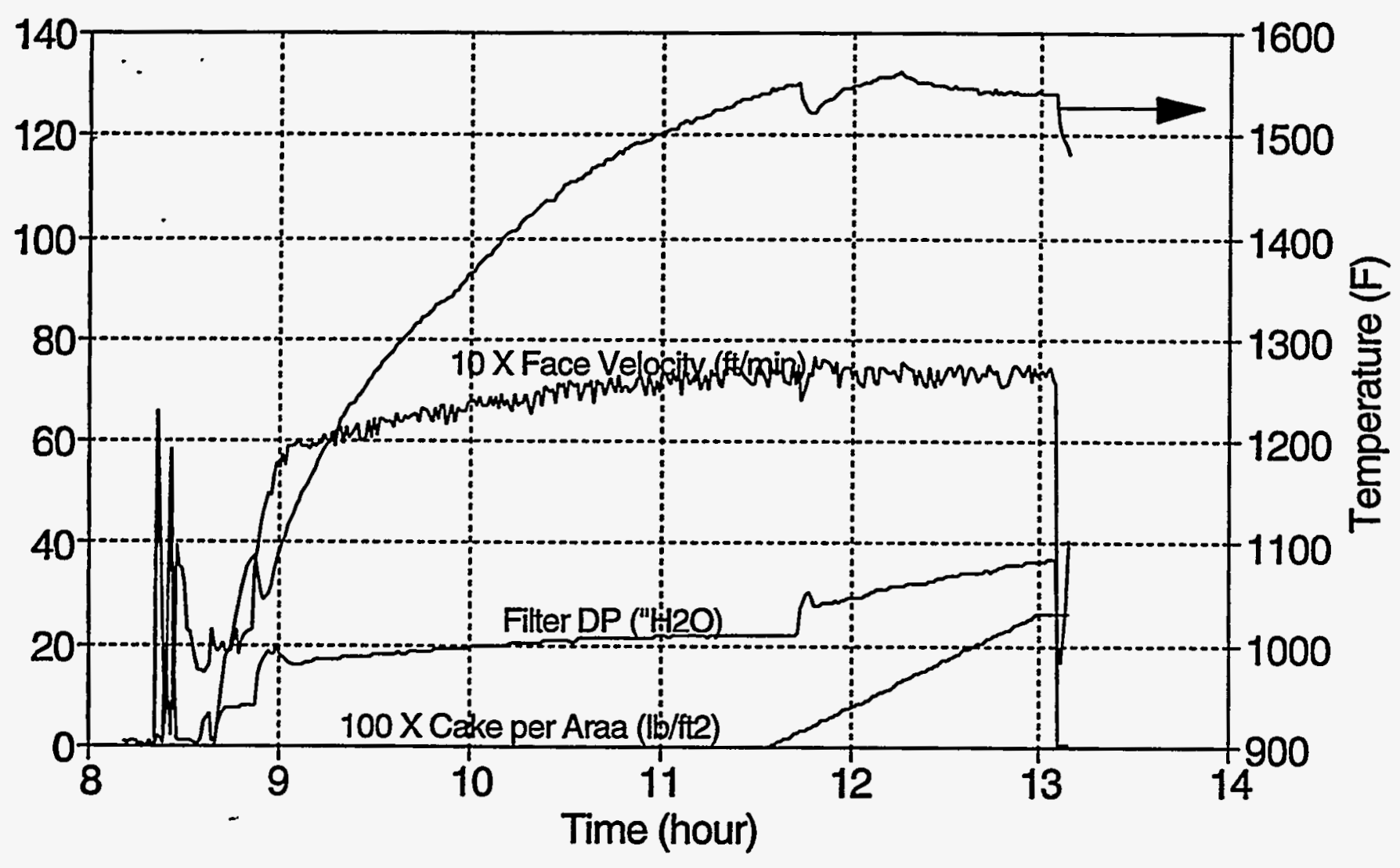




\section{Sulfur Test 4.1 (1/20/95) Tidd Spoiled Cyclone Fly Ash/ No SO2}

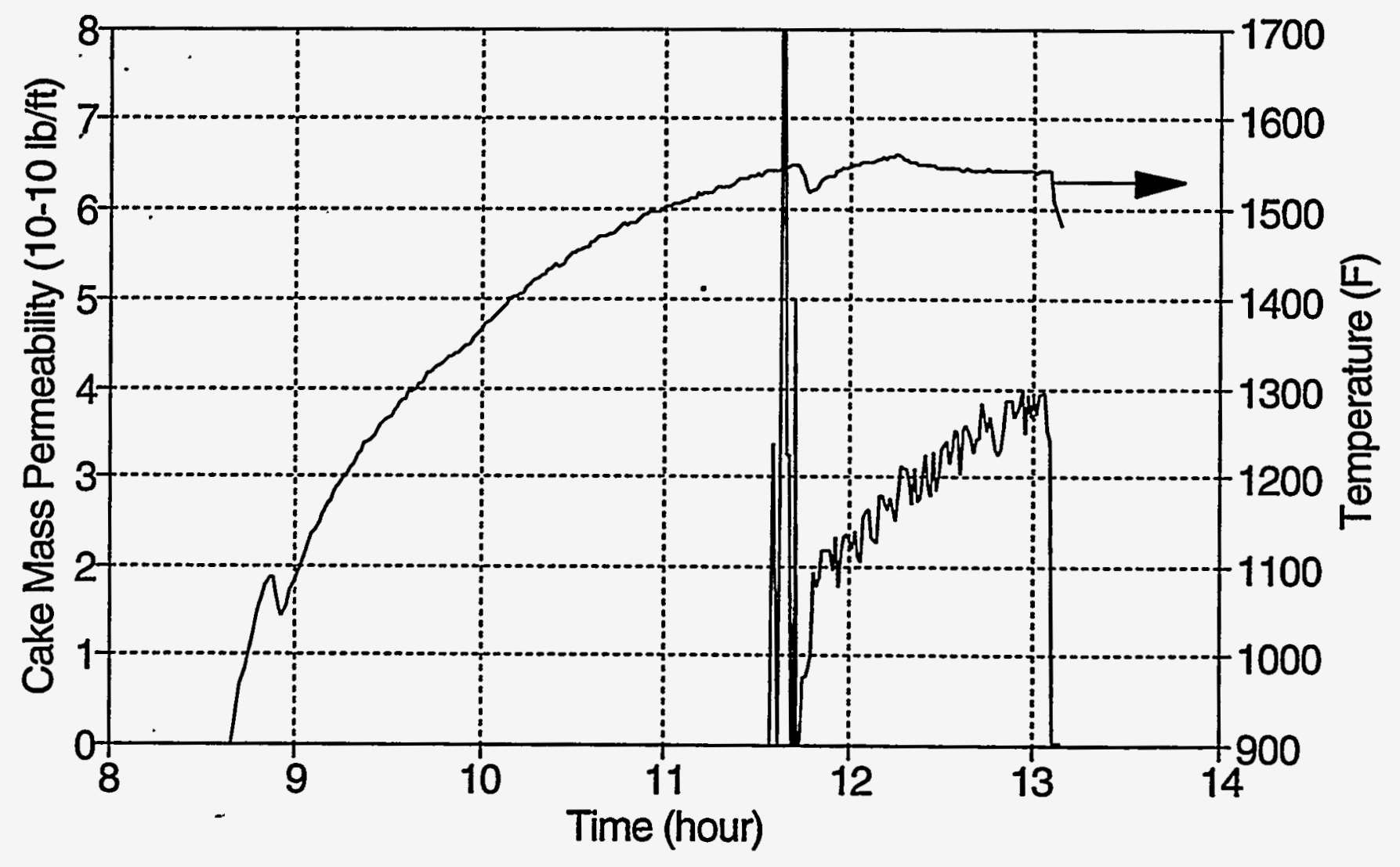




\section{Sulfur Test 4.1 (1/23/95) \\ Tidd Spoiled Cyclone Fly Ash/With SO2}

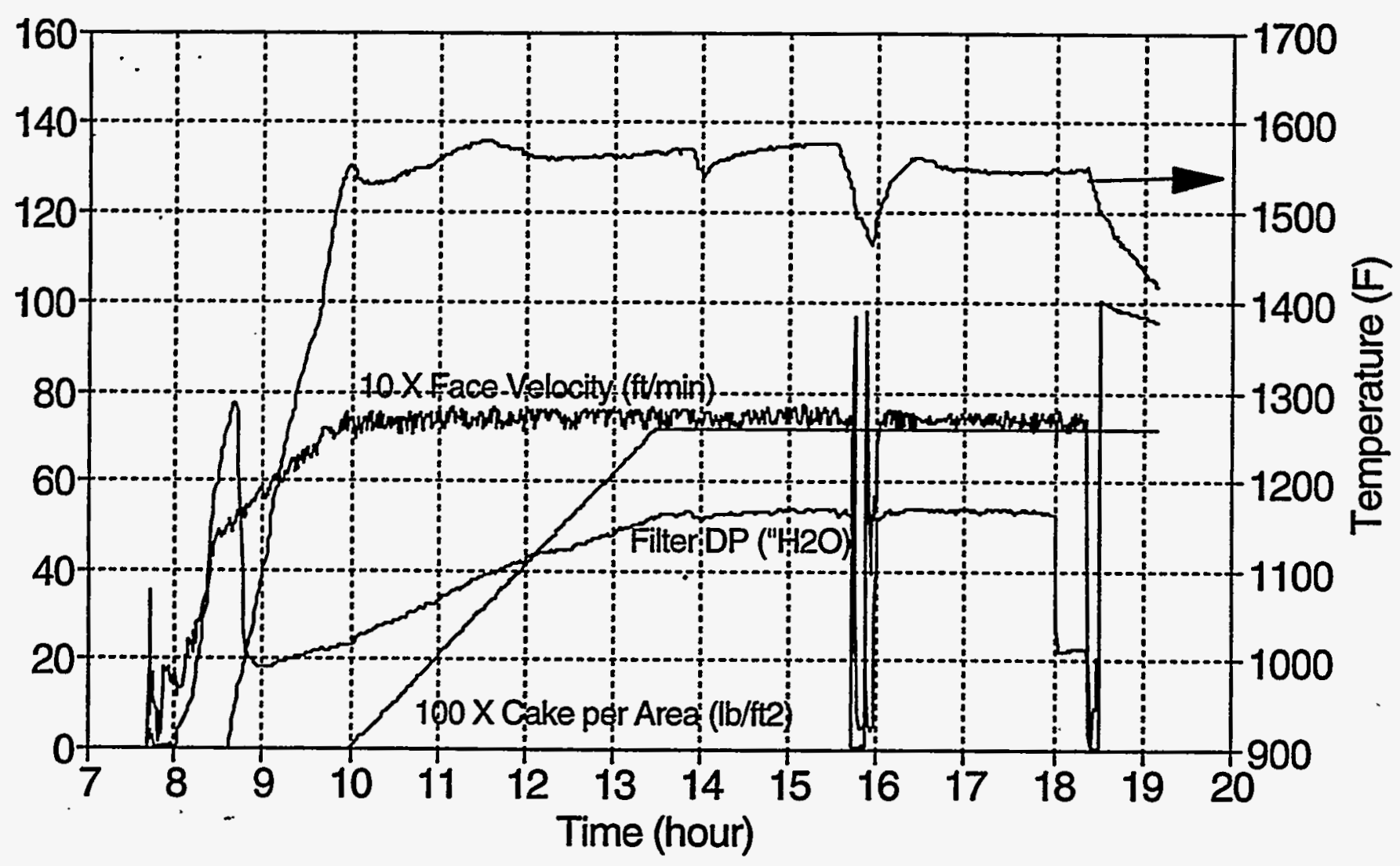




\section{Sulfur Test 4.1 (1/23/95) Tidd Spoiled Cyclone Fly Ash/With SO2}

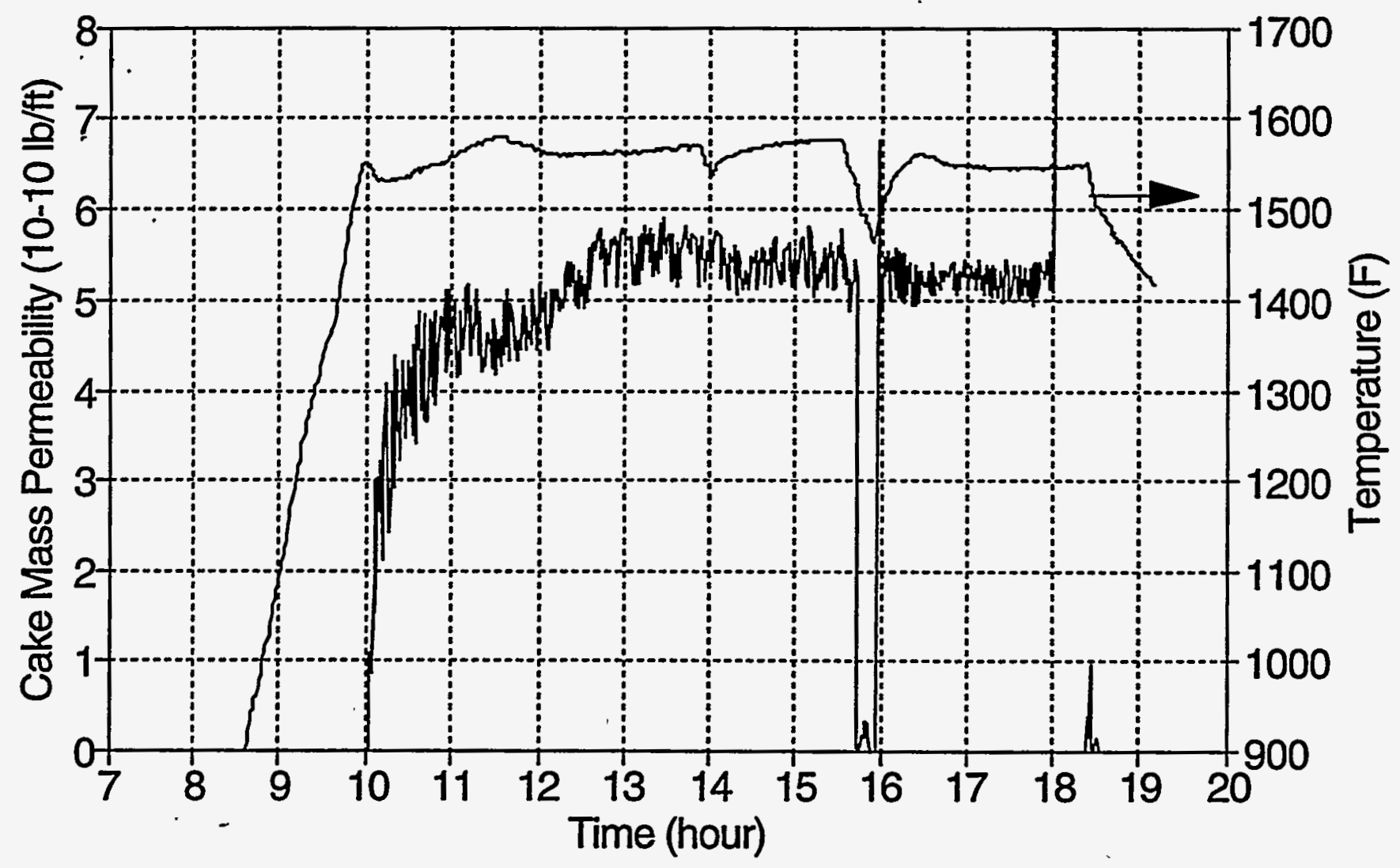




\section{Sulfur Test 4.1 (1/23/95) Tidd Spoiled Cyclone Fly Ash/ With SO2}

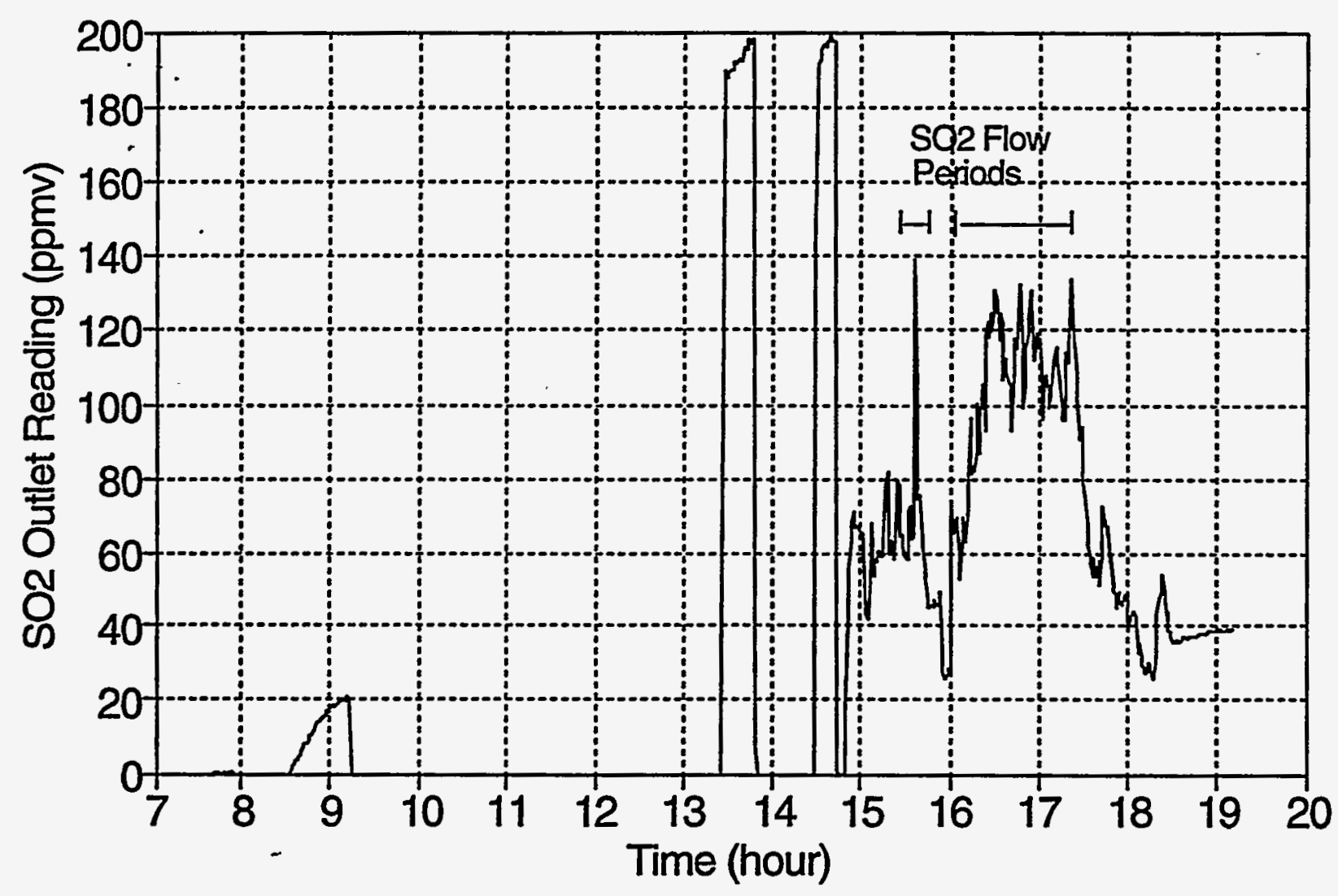




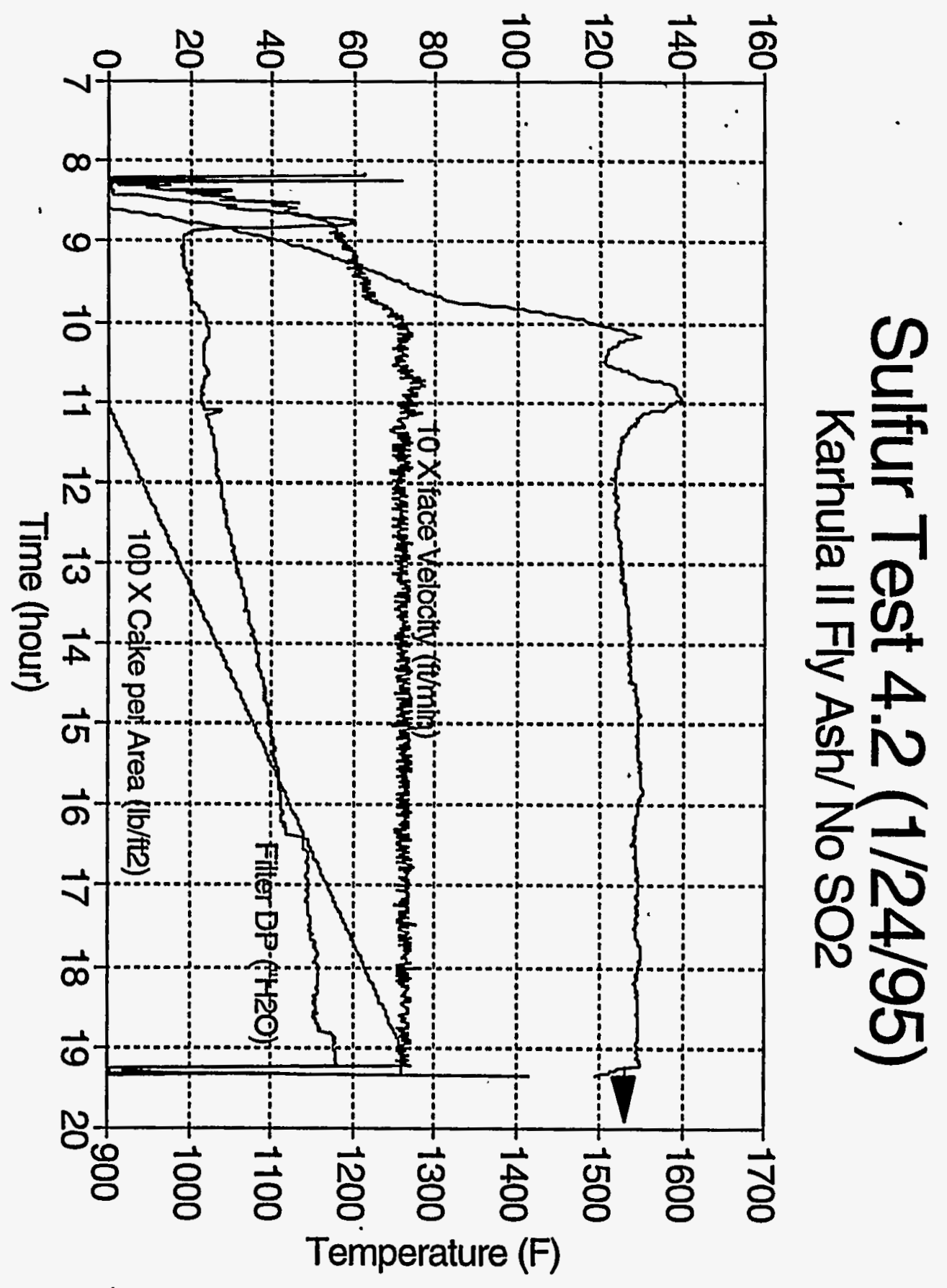




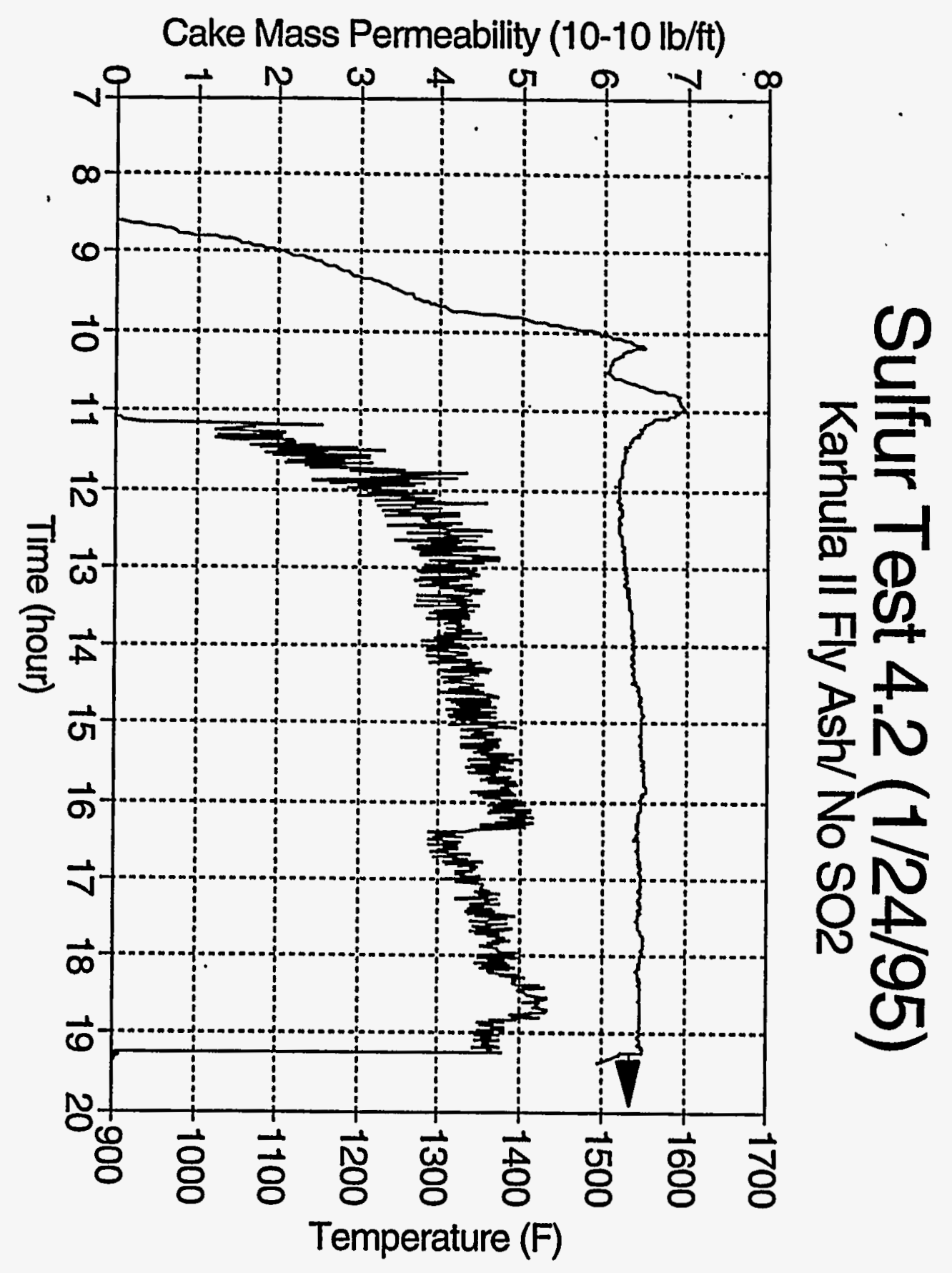




\section{Sulfur Test $4.2(1 / 25 / 95)$ Karhula II Fly Ash/With SO2}

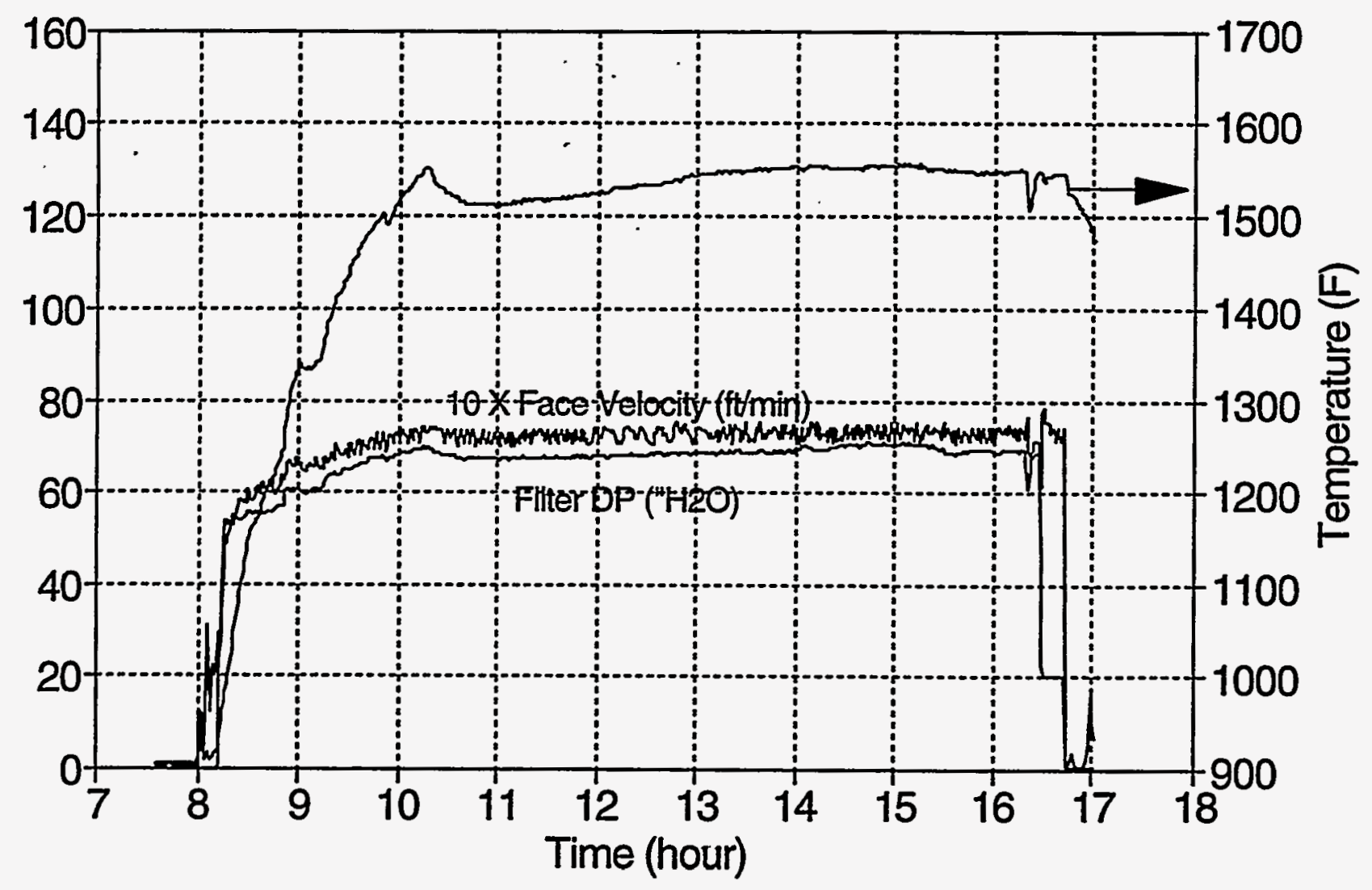




\section{Sulfur Test $4.2(1 / 25 / 95)$ Karhula II Fly Ash/ With SO2}

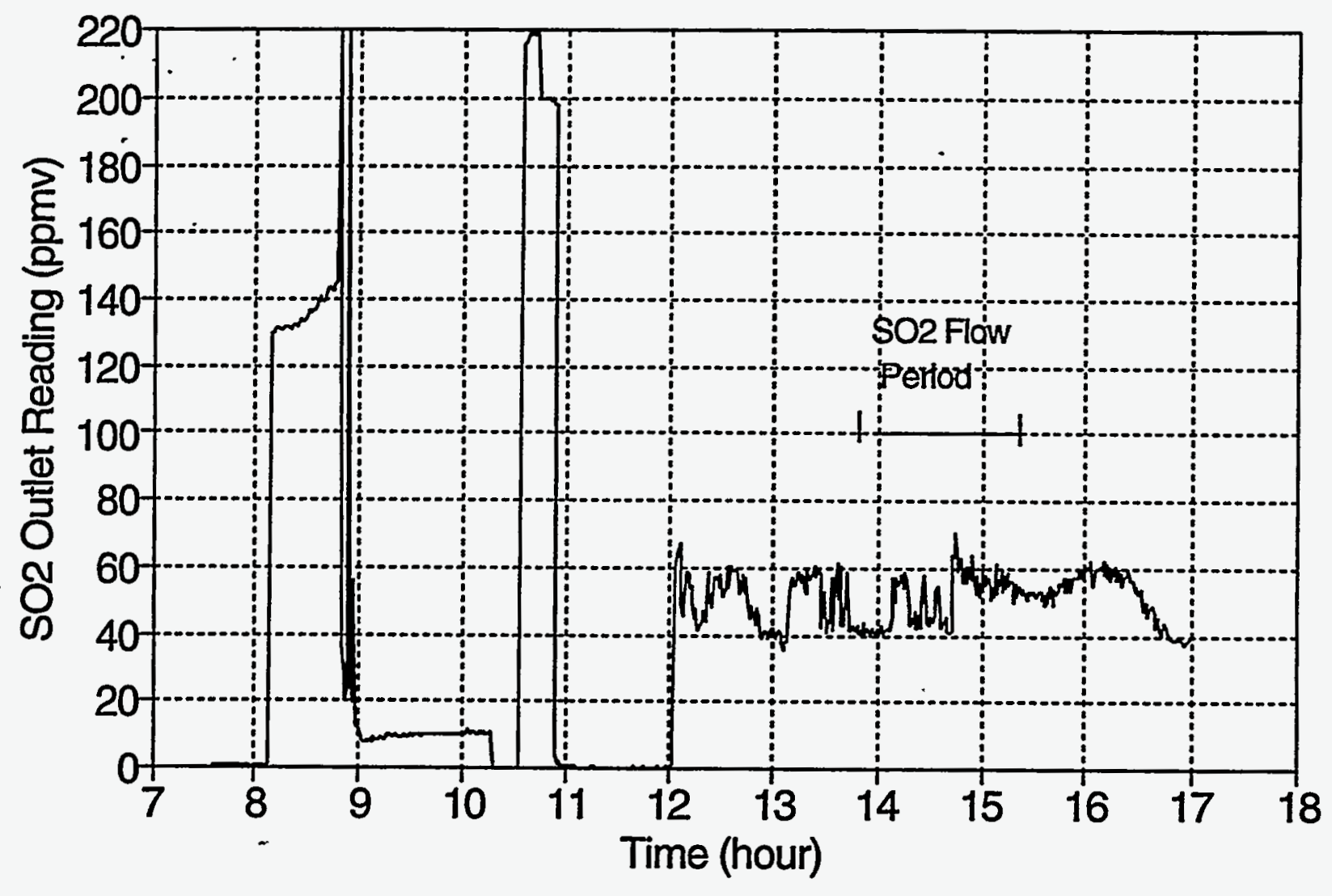




\section{Sulfur Test 4.3 (1/26/95) Dolomite/ With $\mathrm{SO} 2$}

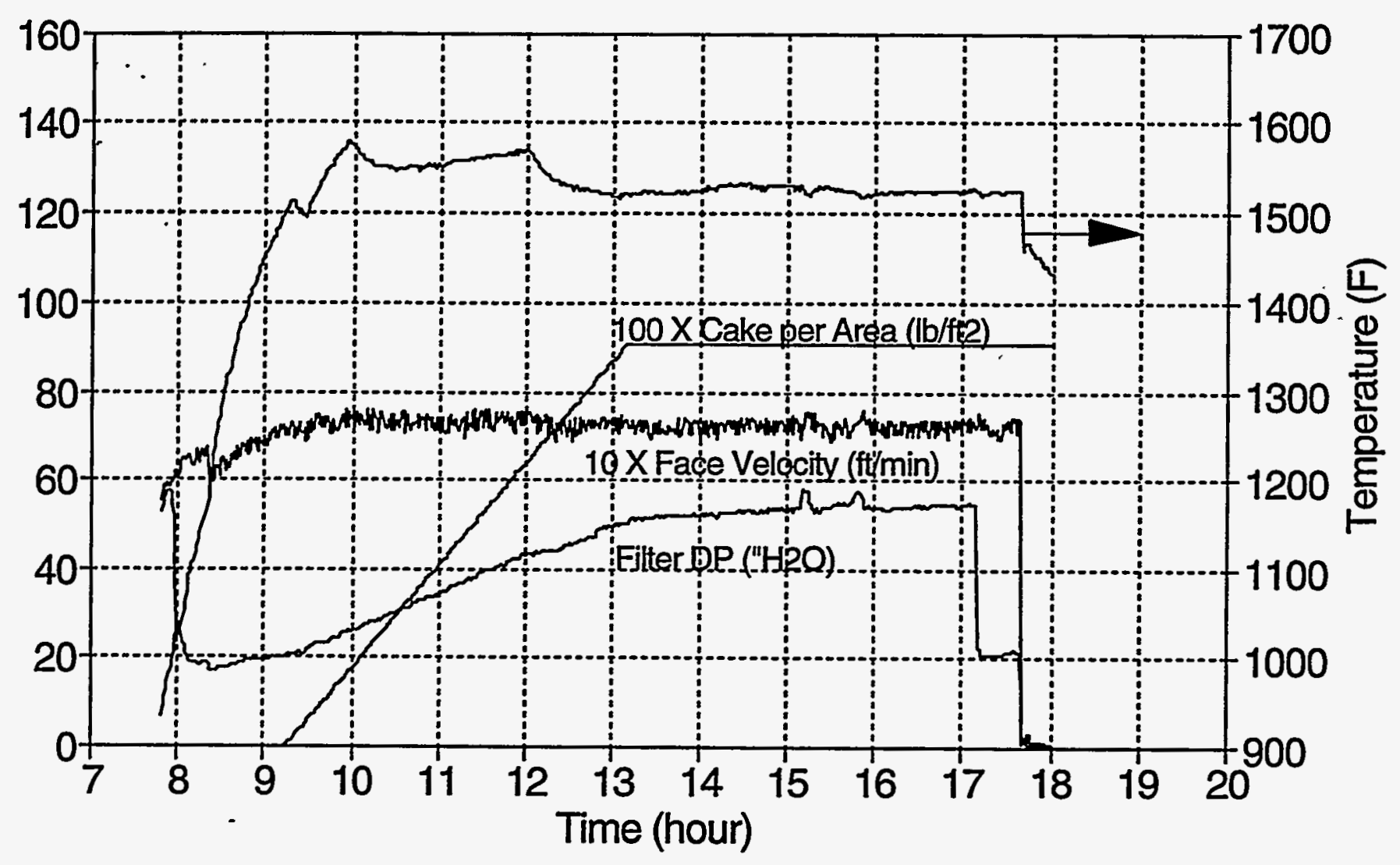




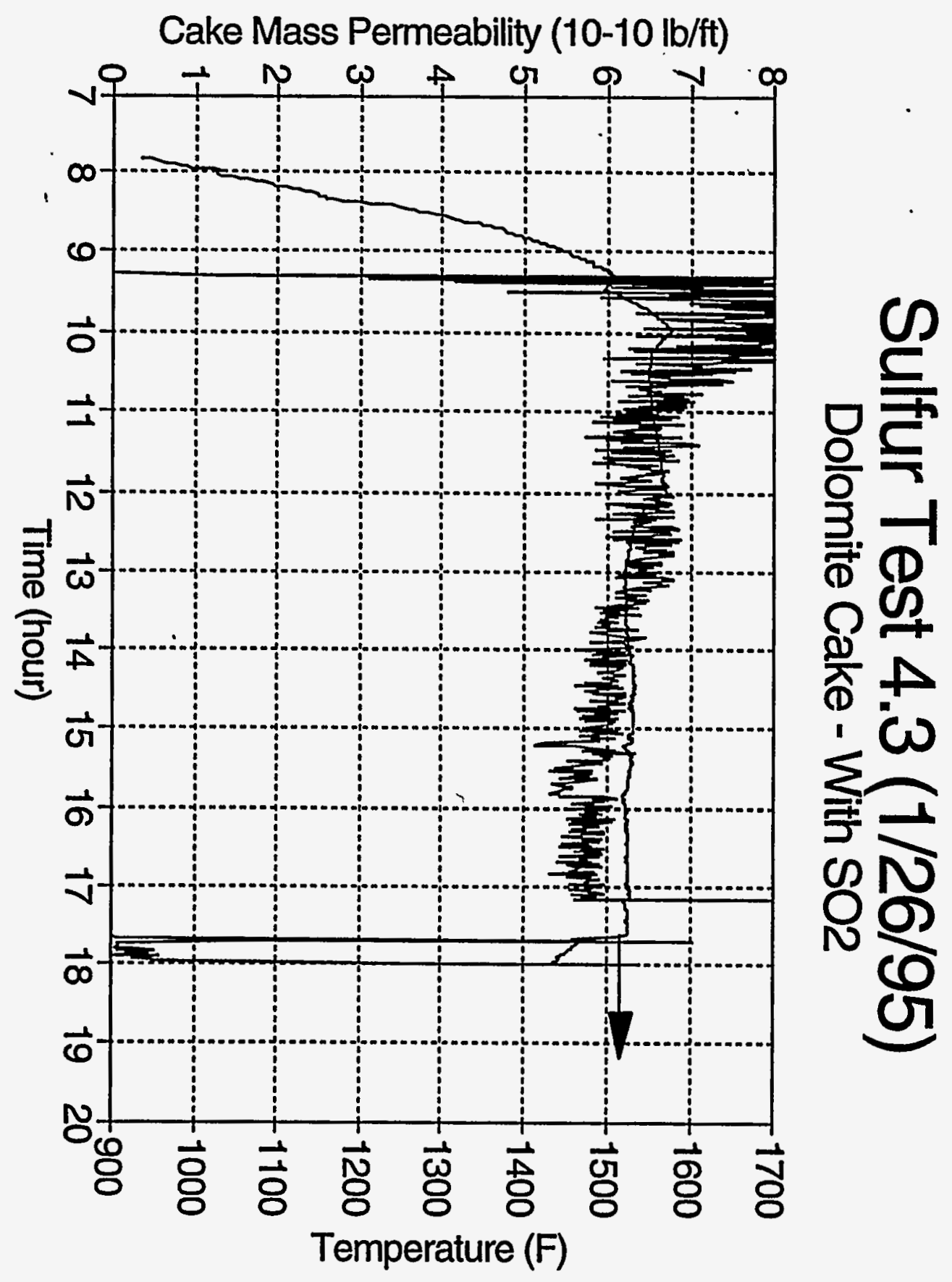




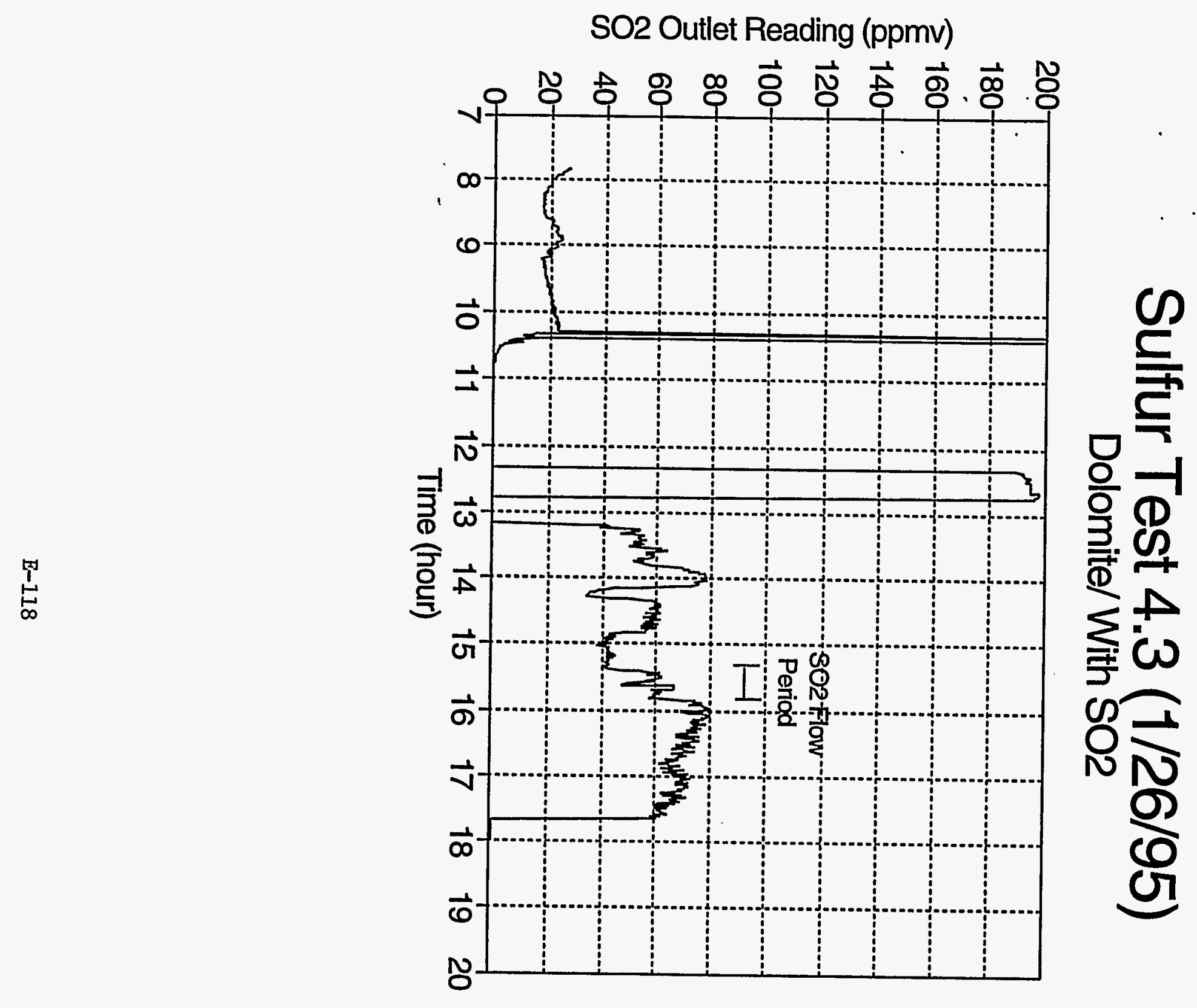




\section{Sulfur Test 4.4 (1/27/95) Dolomite Continuous Feed/ With SO2}

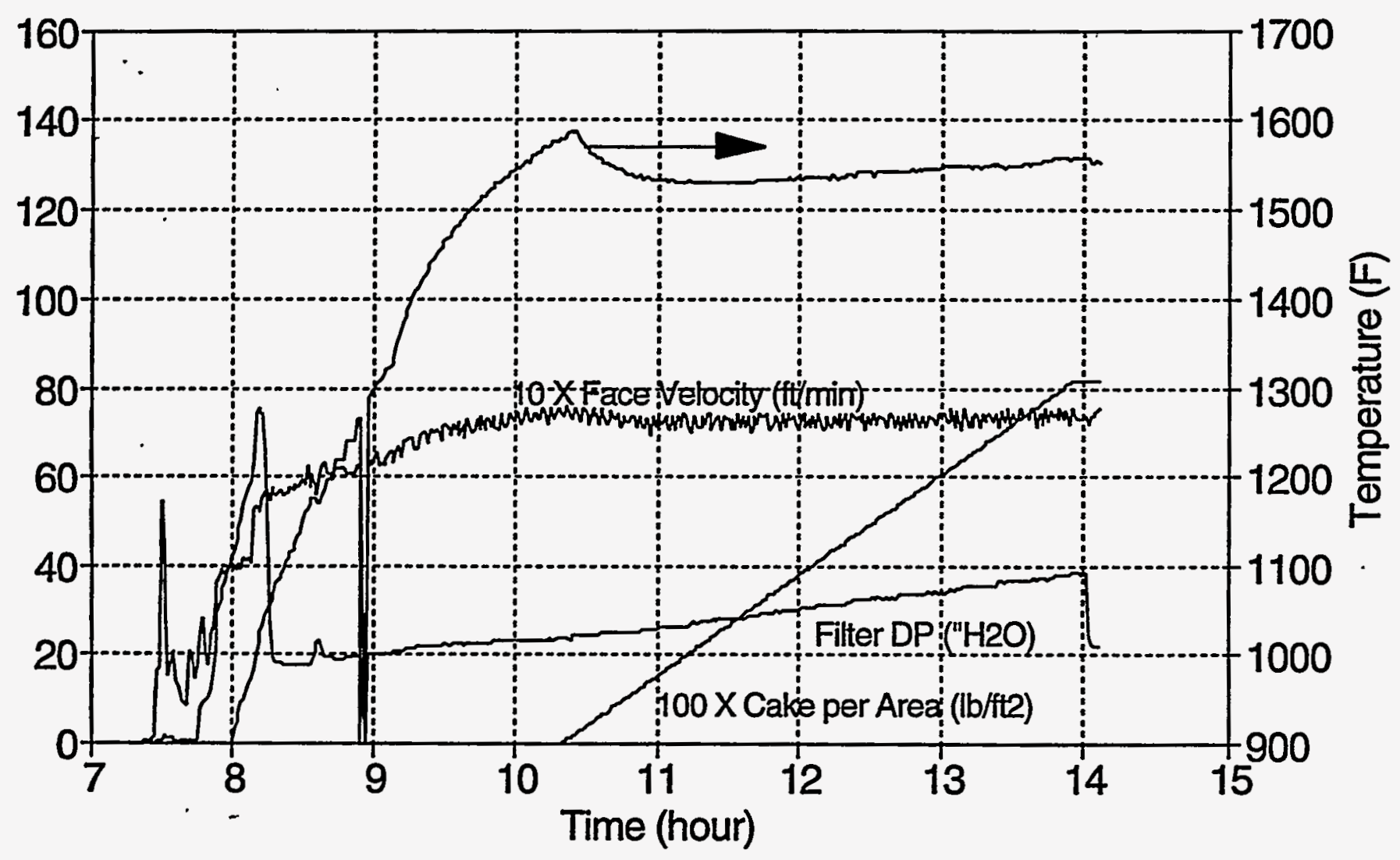




\section{Sulfur Test 4.4 (1/27/95) Dolomite Continuous Feed/With SO2}

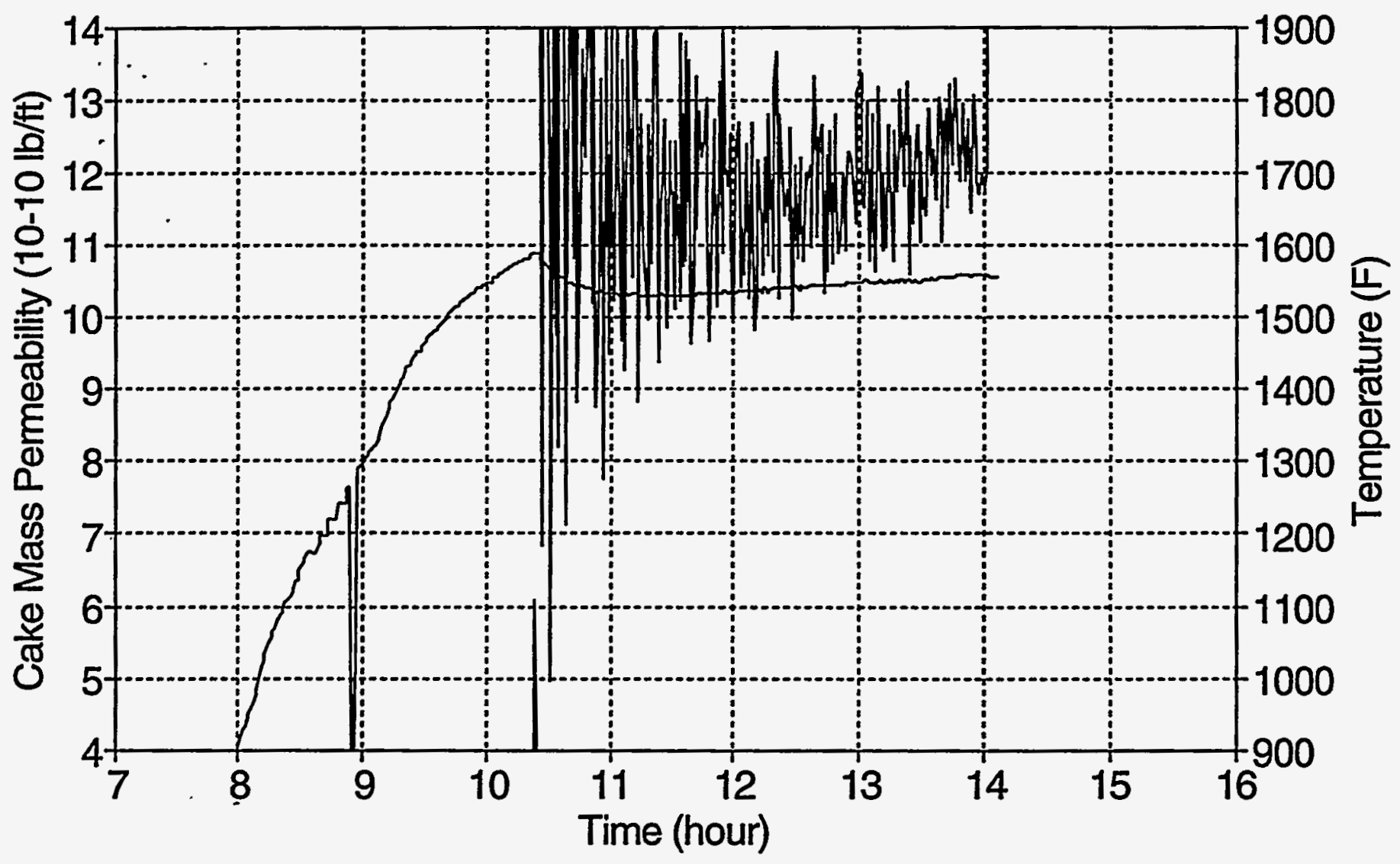




\section{Sulfur Test 4.4 (1/27/95) Dolomite Continuous Feed/ With SO2}

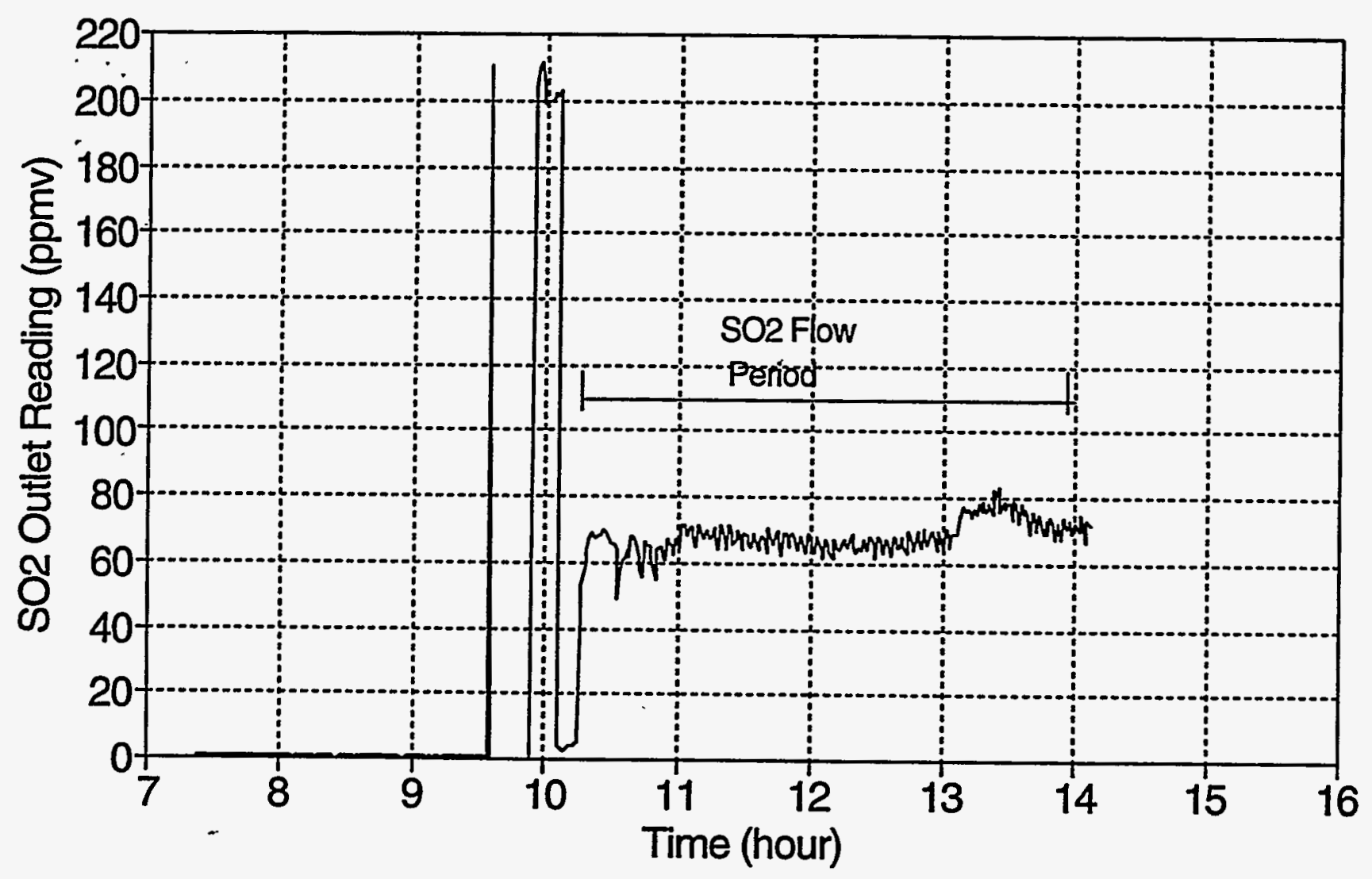




\section{Sulfur Test 4.5 (1/30/95) \\ Tidd Spoiled Cyclone and Dolomite(50\%)}

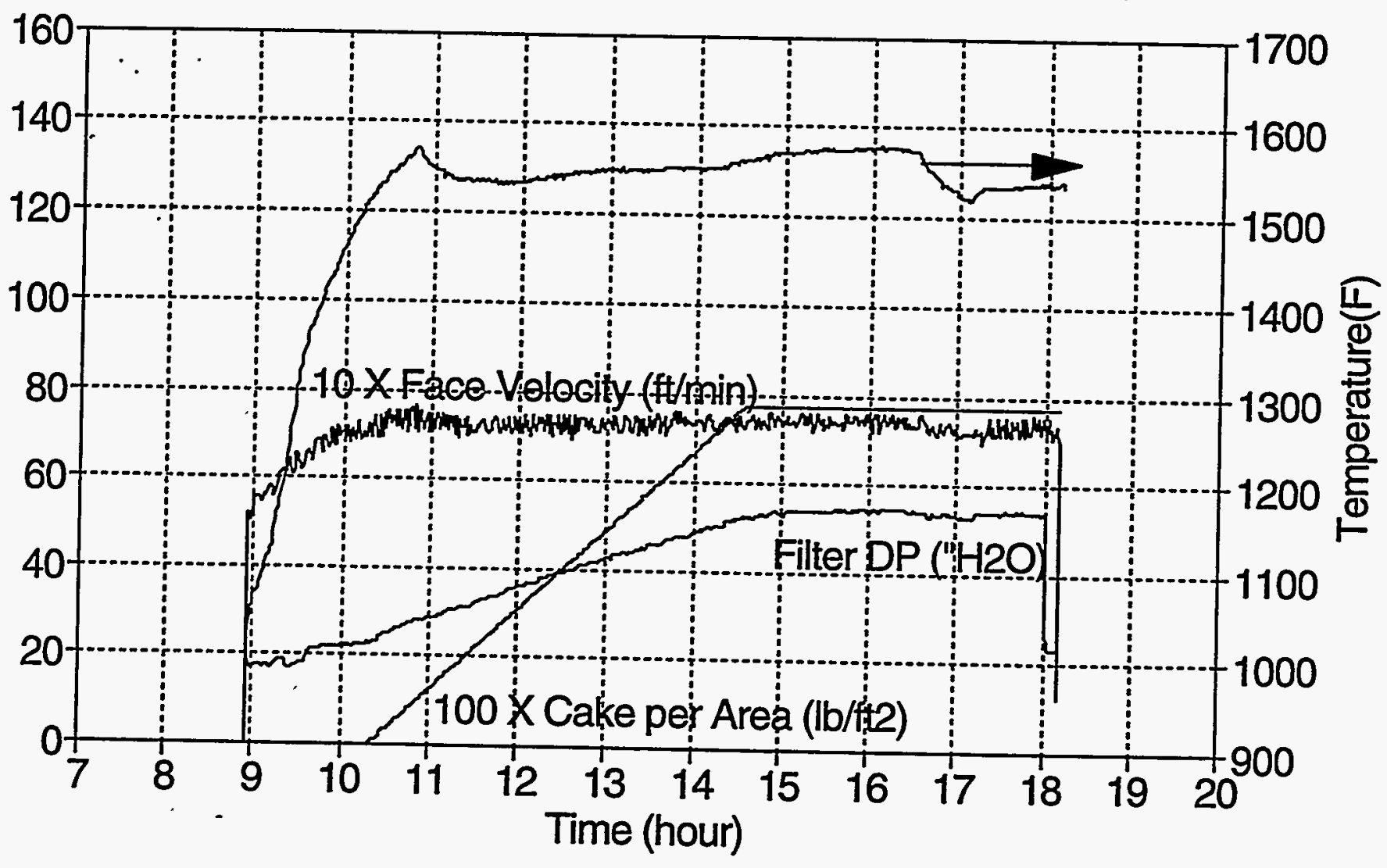




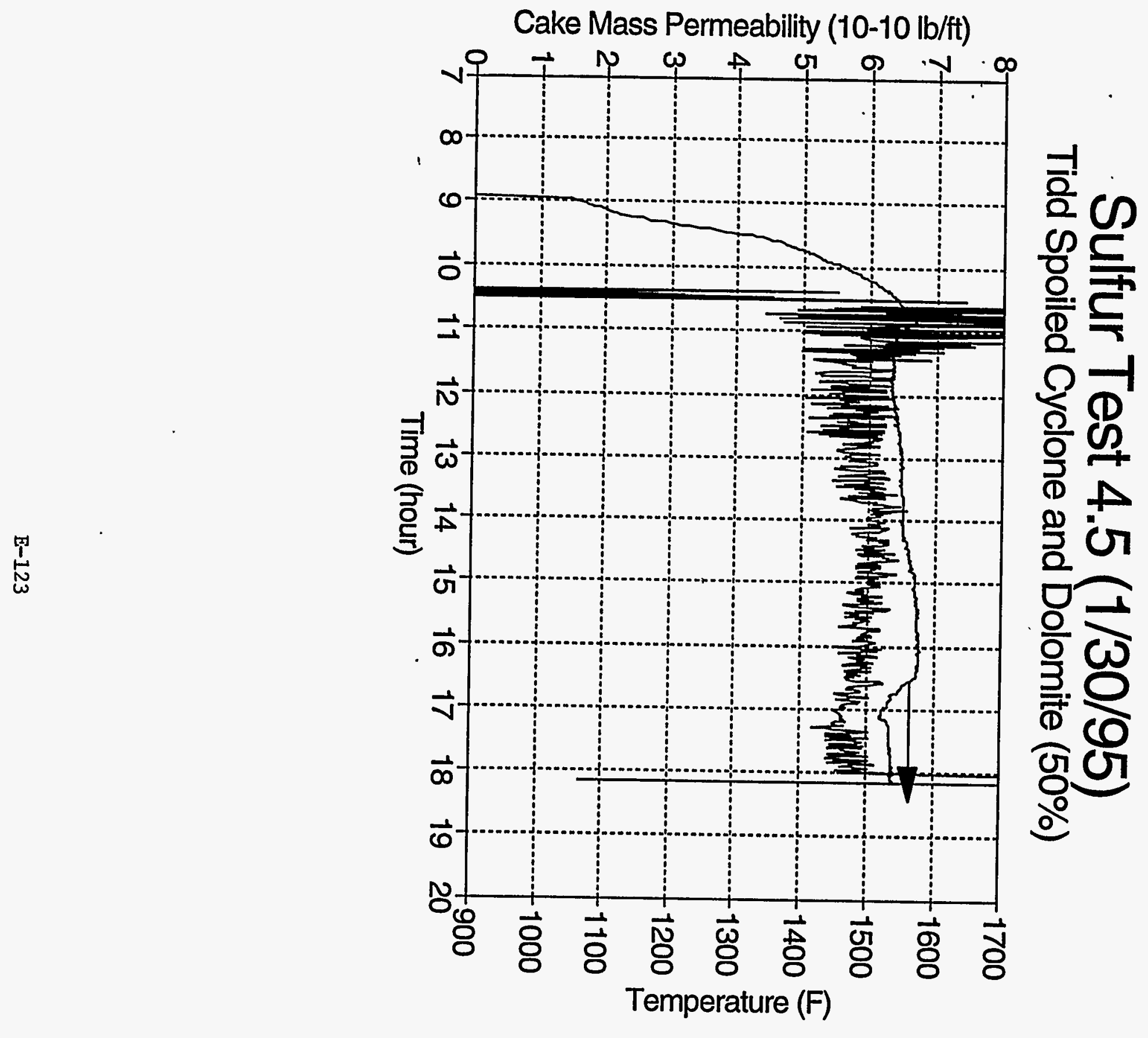




\section{Sulfur Test 4.5 (1/30/95) \\ Tidd Spoiled Cyclone and Dolomite (50\%)}

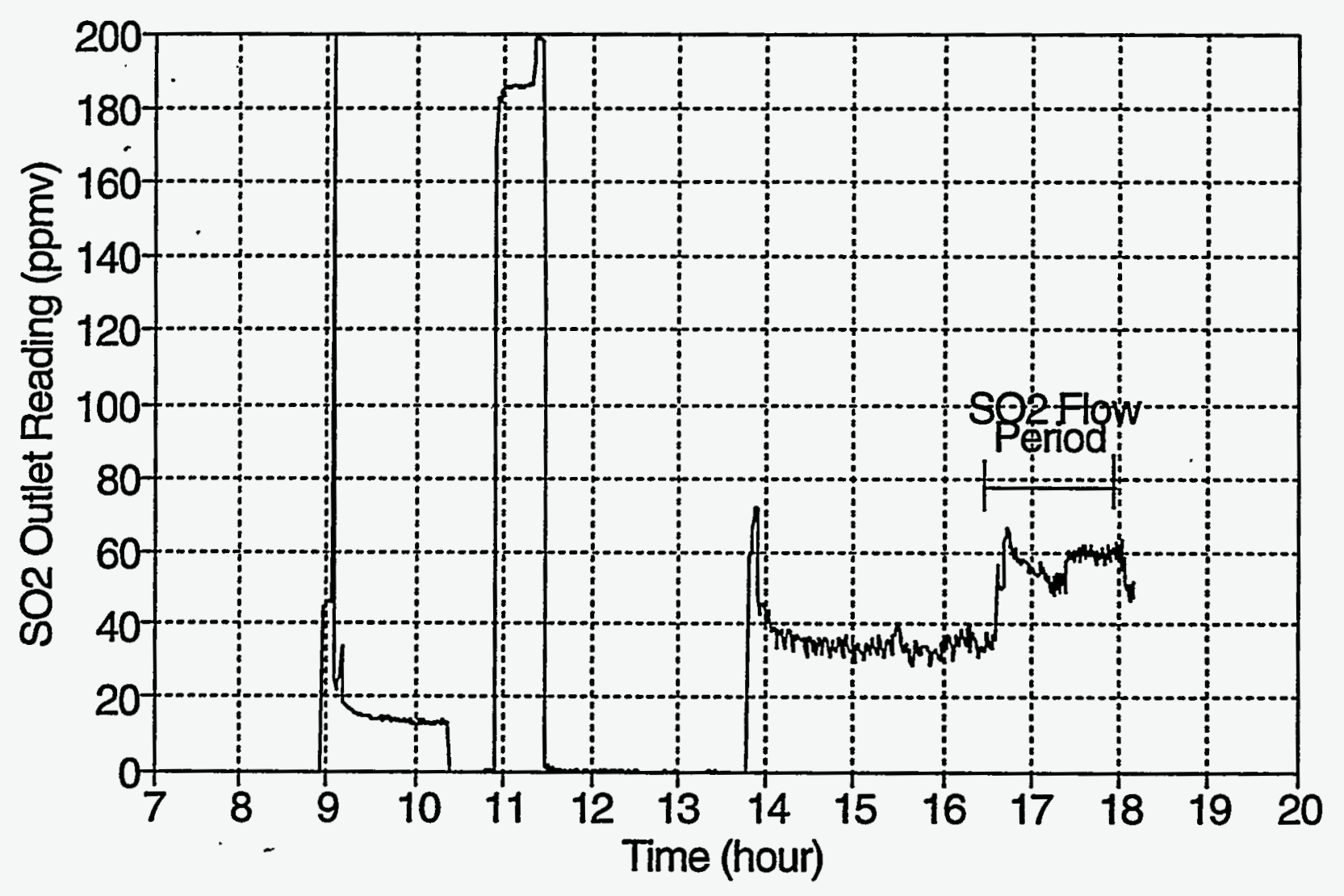




\section{Sulfur Test $4.6(1 / 31 / 95)$ \\ Karhula II Fly Ash and Dolomite (50\%)}

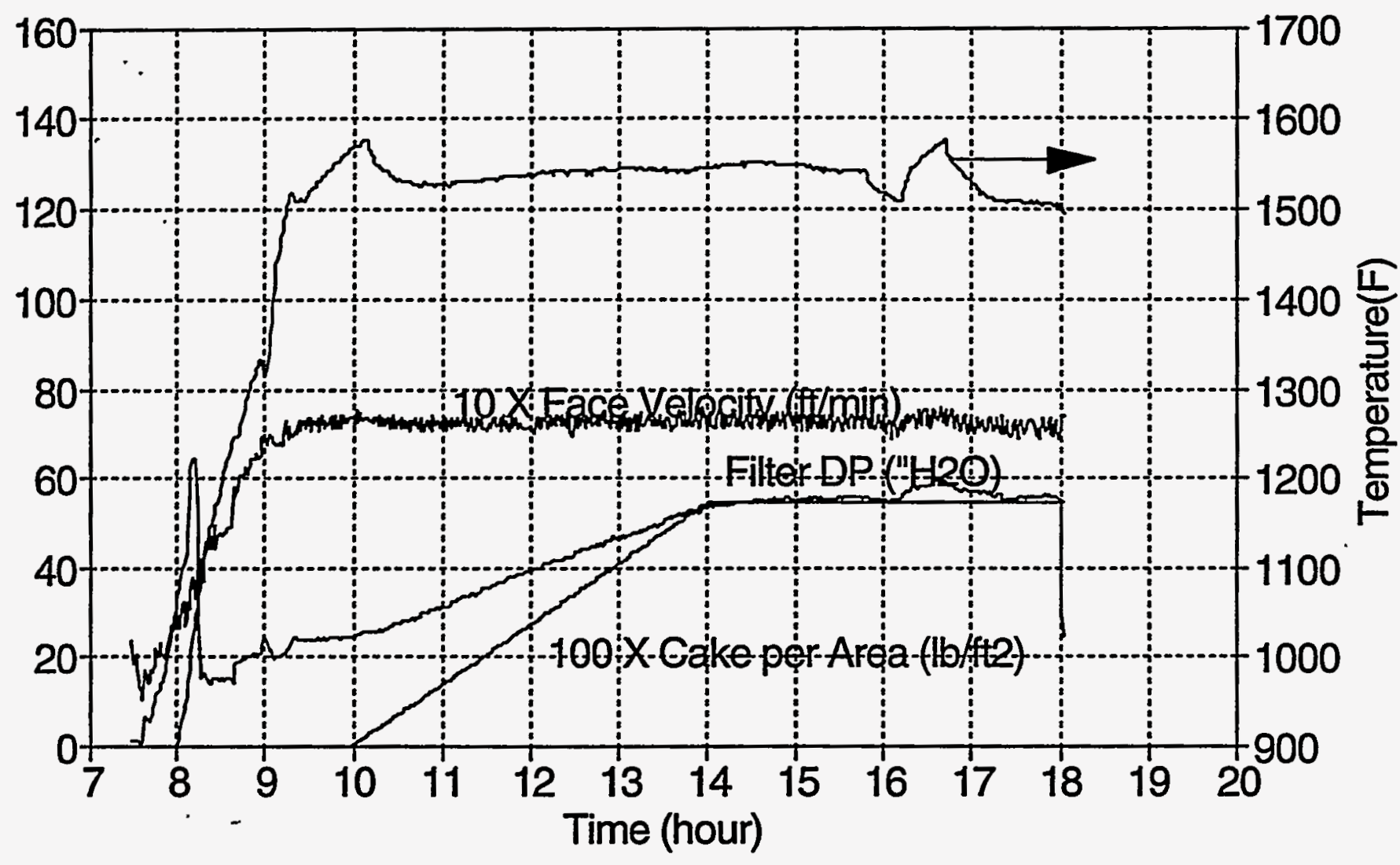




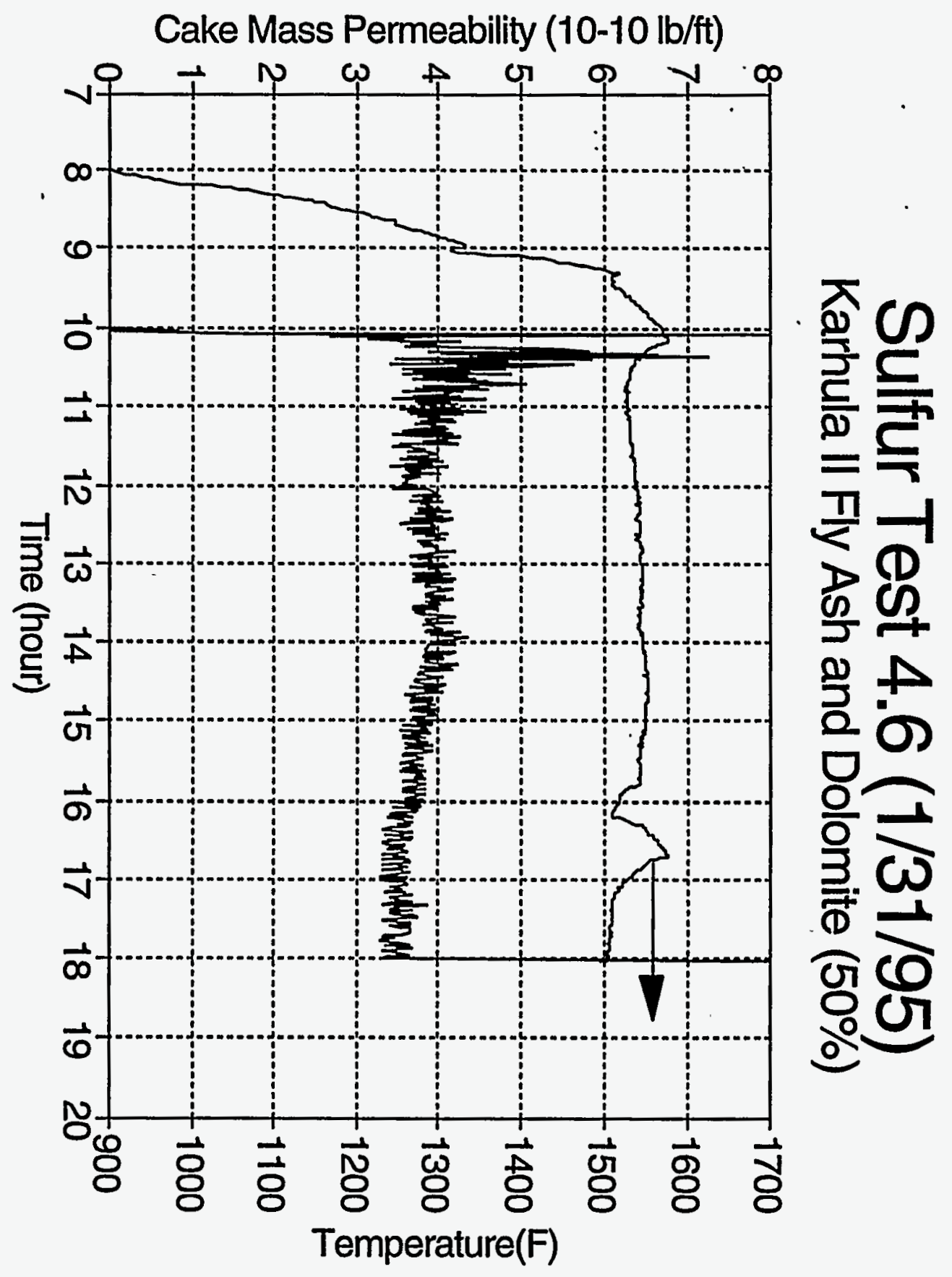




\section{Sulfur Test 4.6 (1/31/95) Karhula II Fly Ash and Dolomite (50\%)}

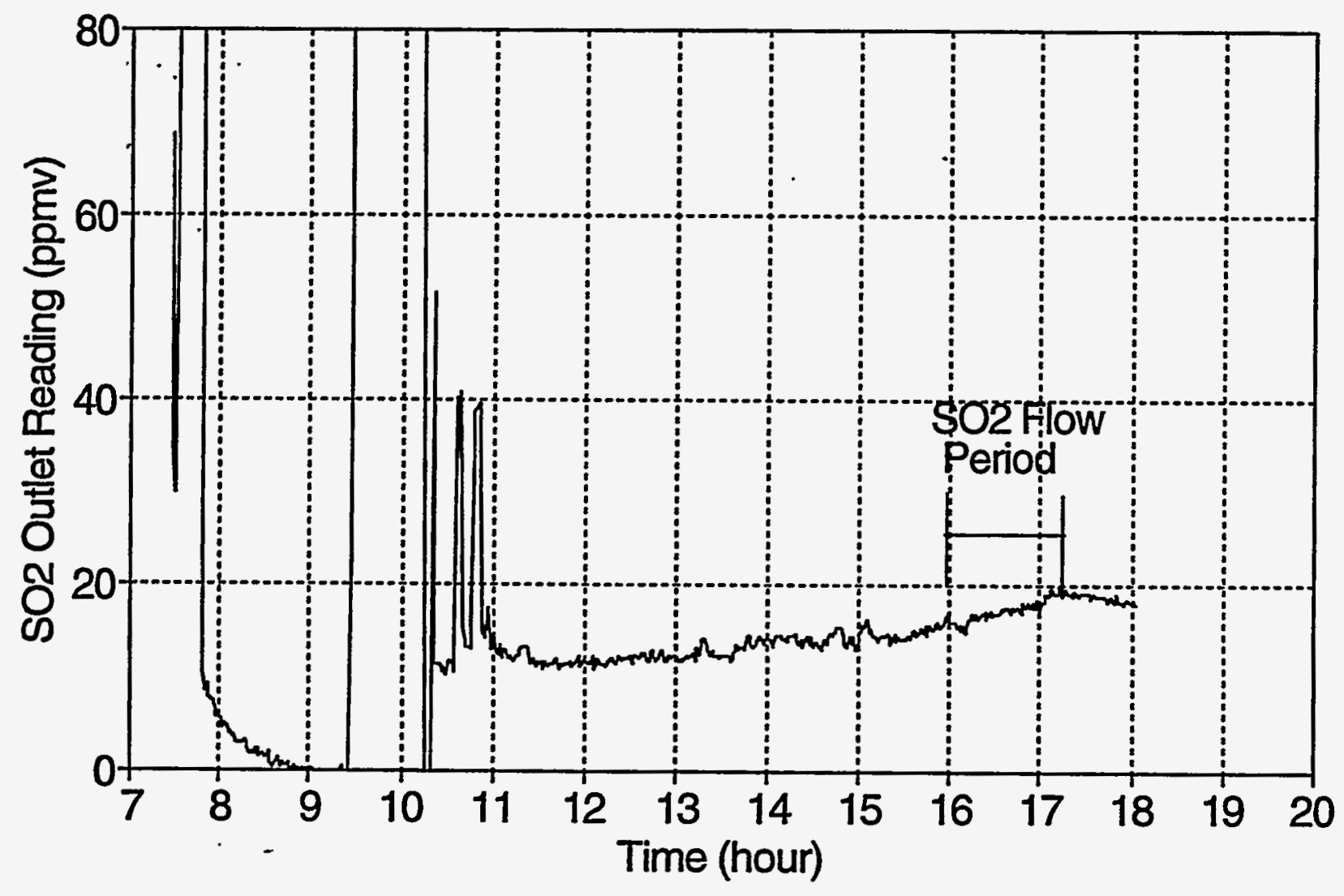




\section{Sulfur Test 4.7 (2/01/95) Dolomite/ With SO2}

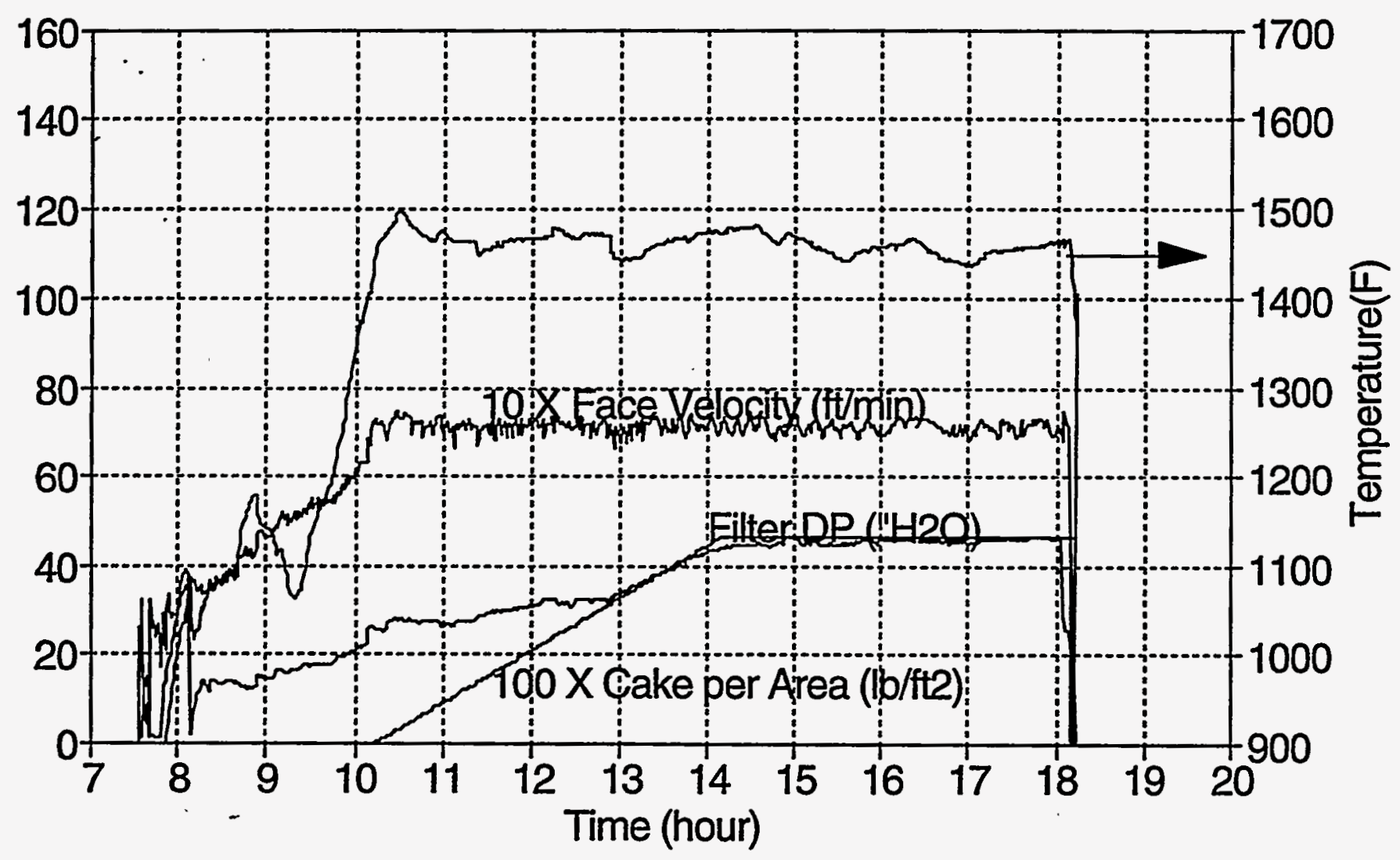




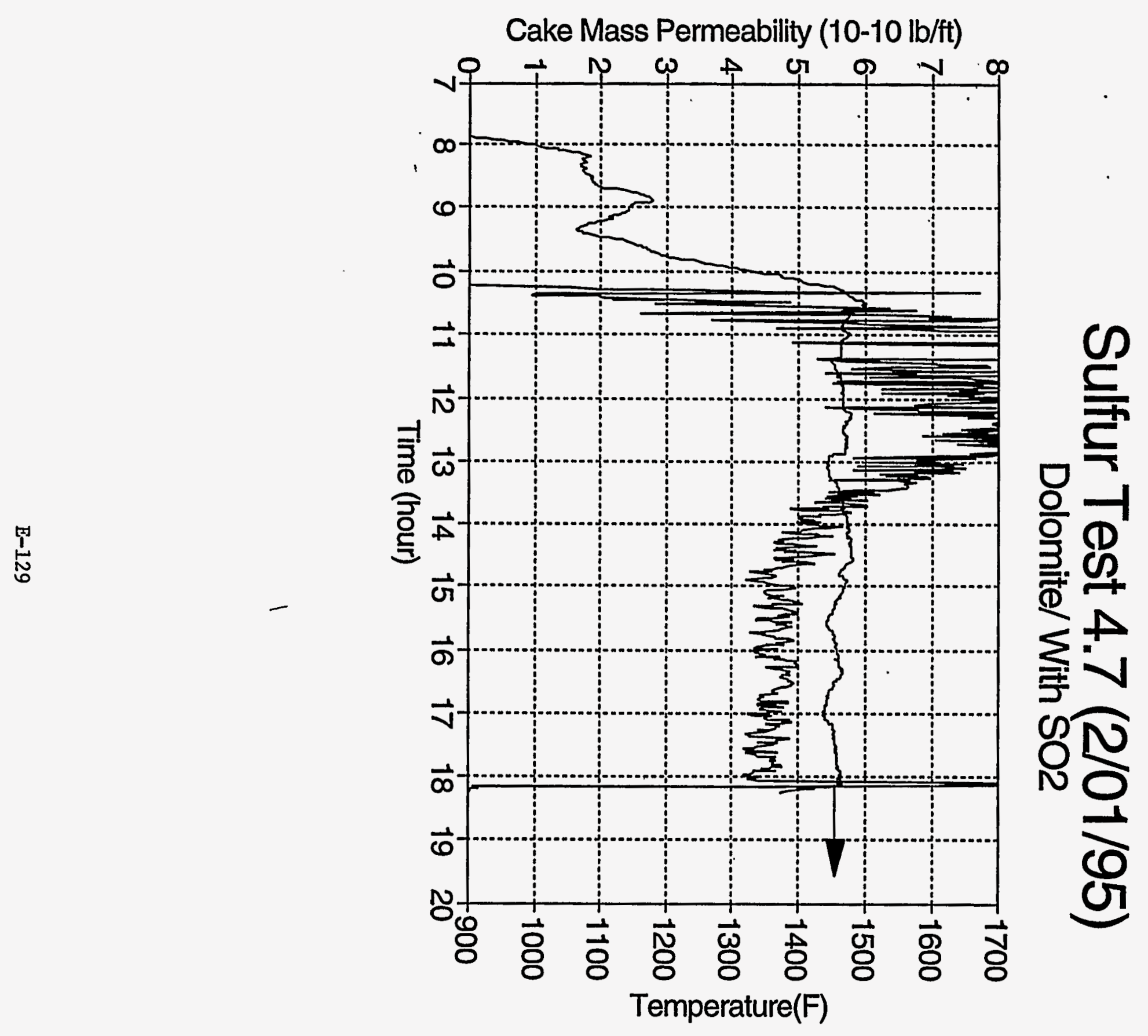




\section{Sulfur Test 4.7 (2/01/95) Dolomite/ With SO2}

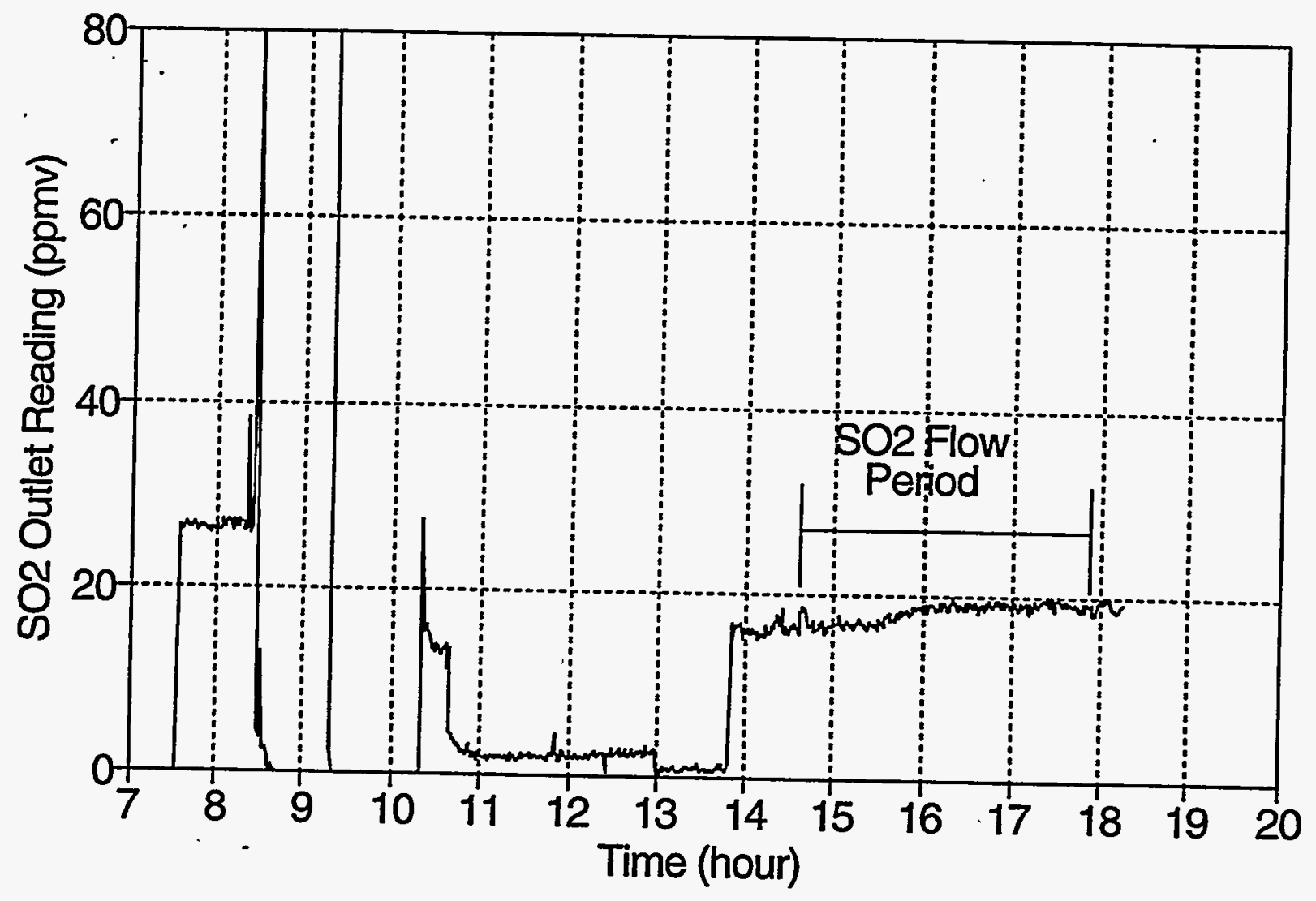




\section{Sulfur Test 4.8 (2/02/95) Dolomite/ With SO2}

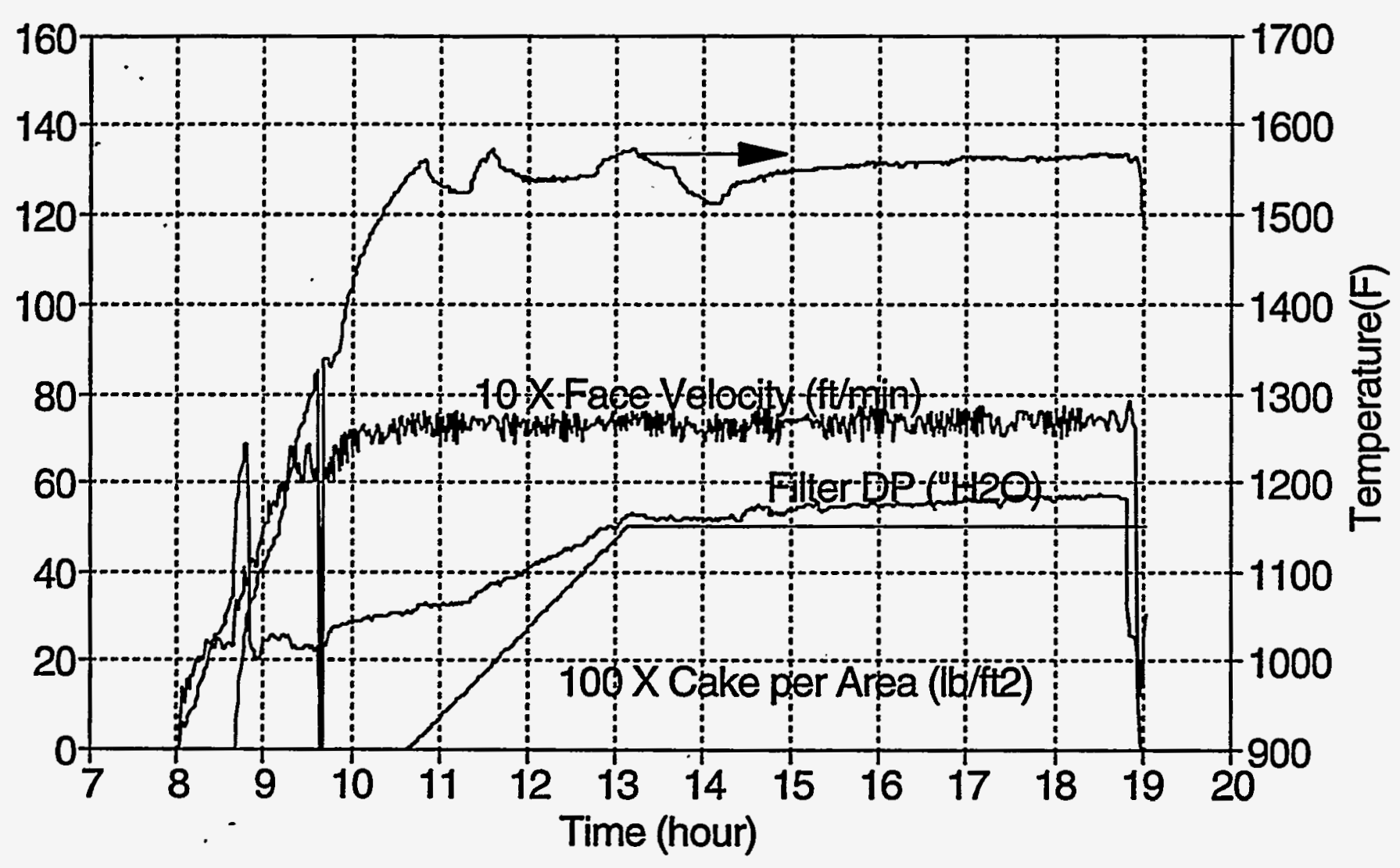




\section{Sulfur Test 4.8 (2/02/95) Dolomite/ With SO2}

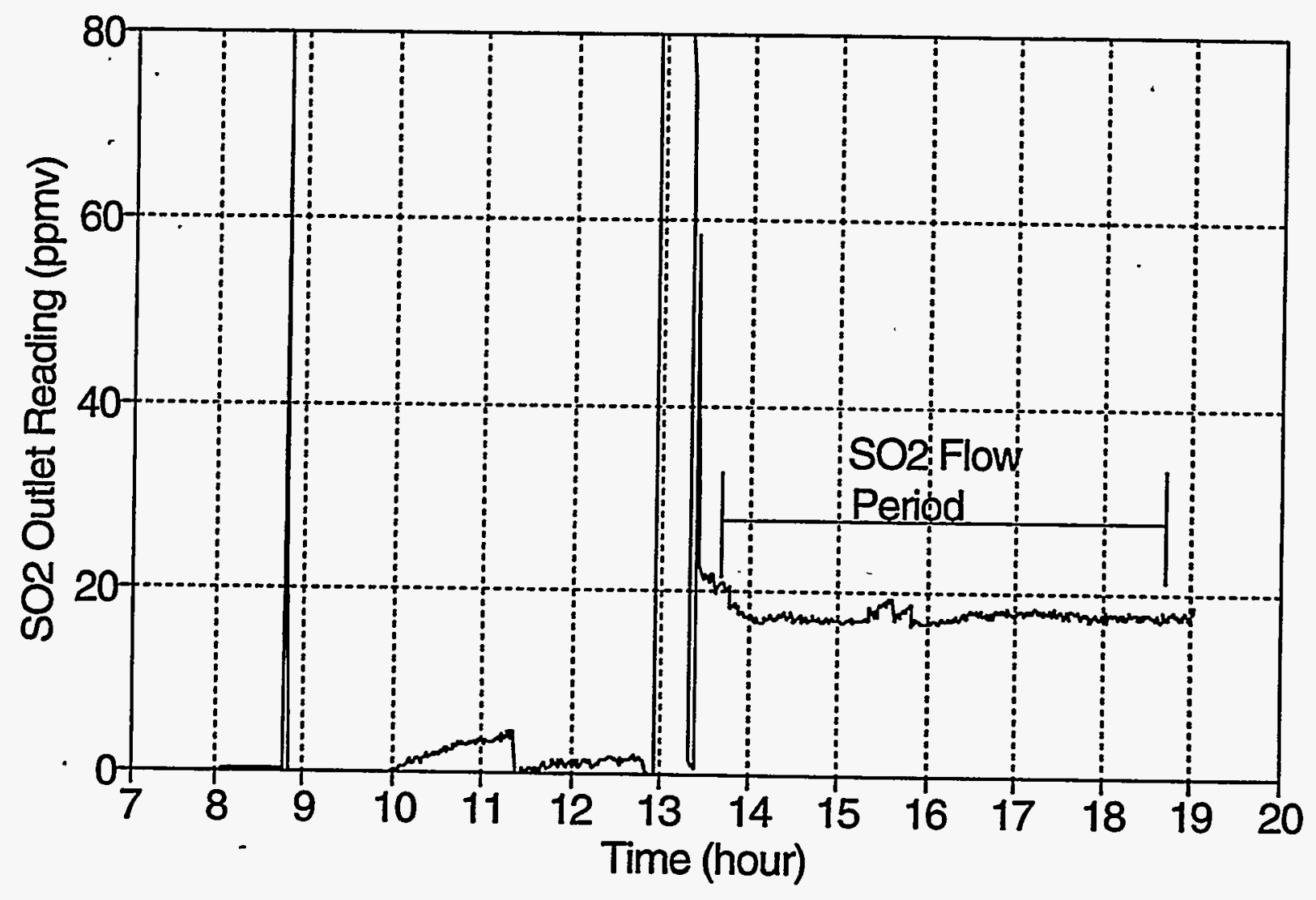




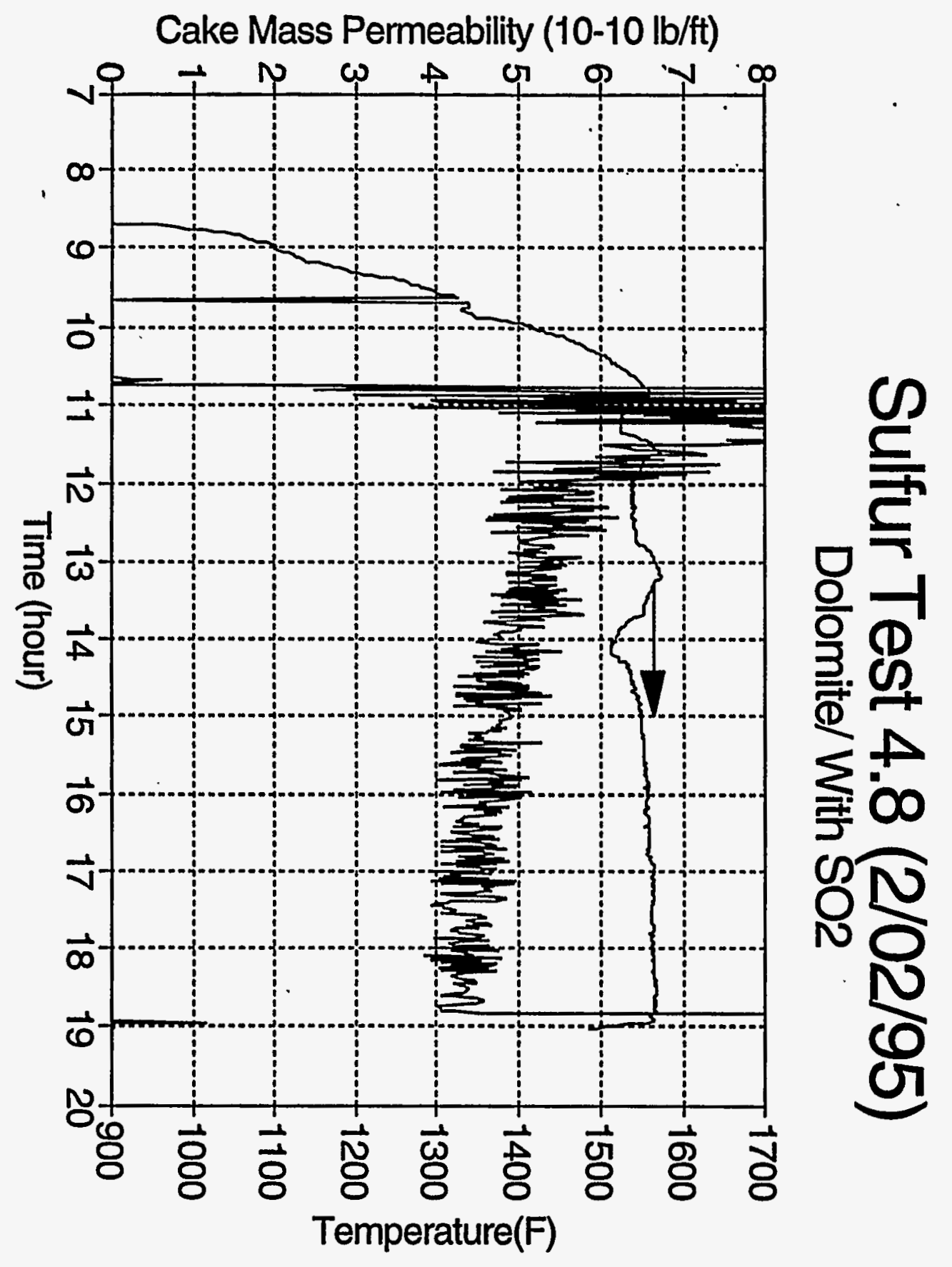


ALKALI REMOVAL TESTS (SERIES 5)

E-135 


\section{Alkali Test 5.01 (7/14/94) \\ Emathlite with $\mathrm{No} \mathrm{NaCl}$}

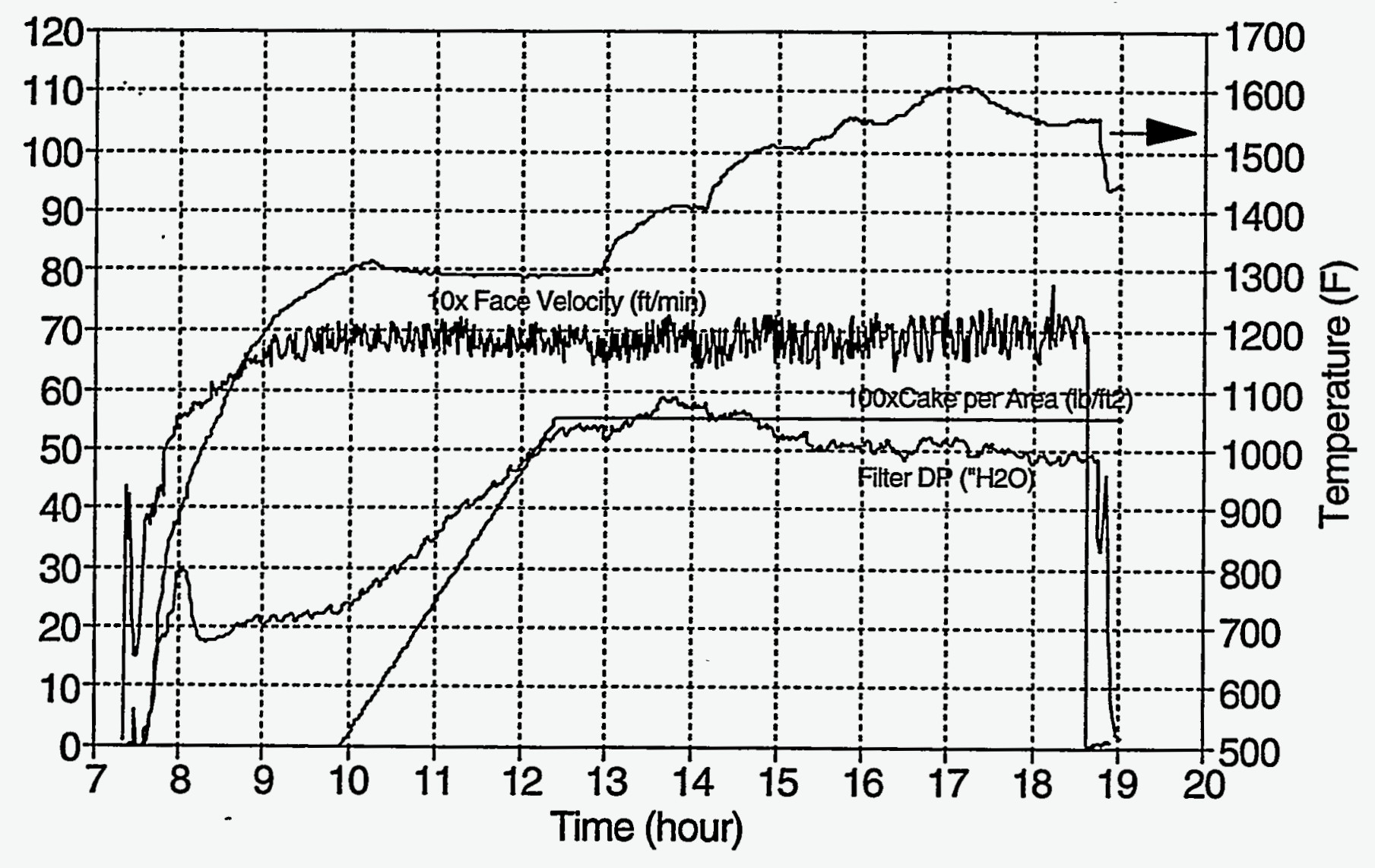




\section{Alkali Test 5.01 (7/14/94) \\ Emathlite with $\mathrm{No} \mathrm{NaCl}$}

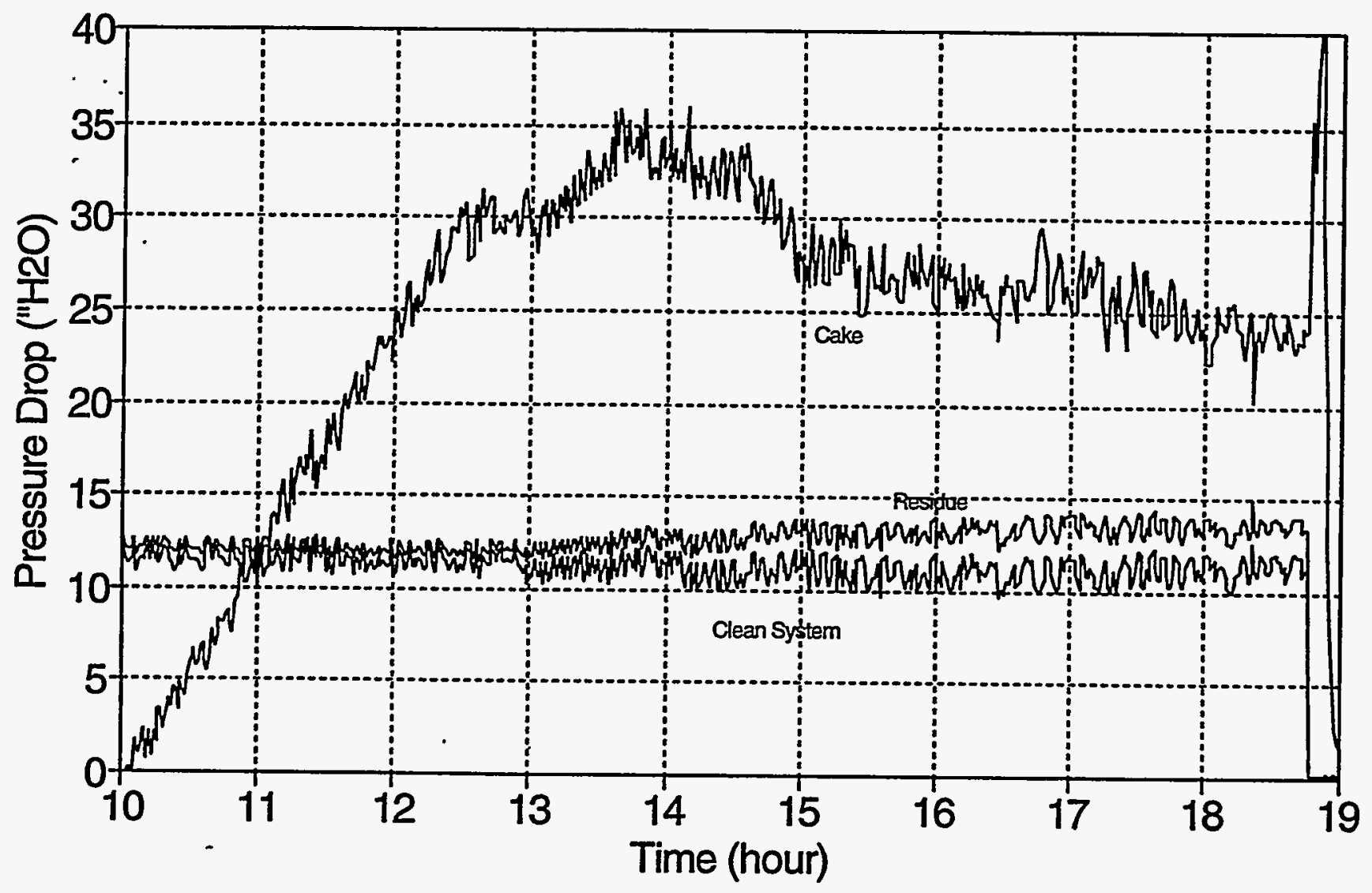




\section{Alkali Test 5.01 (7/14/94)}

Emathlite with $\mathrm{No} \mathrm{NaCl}$

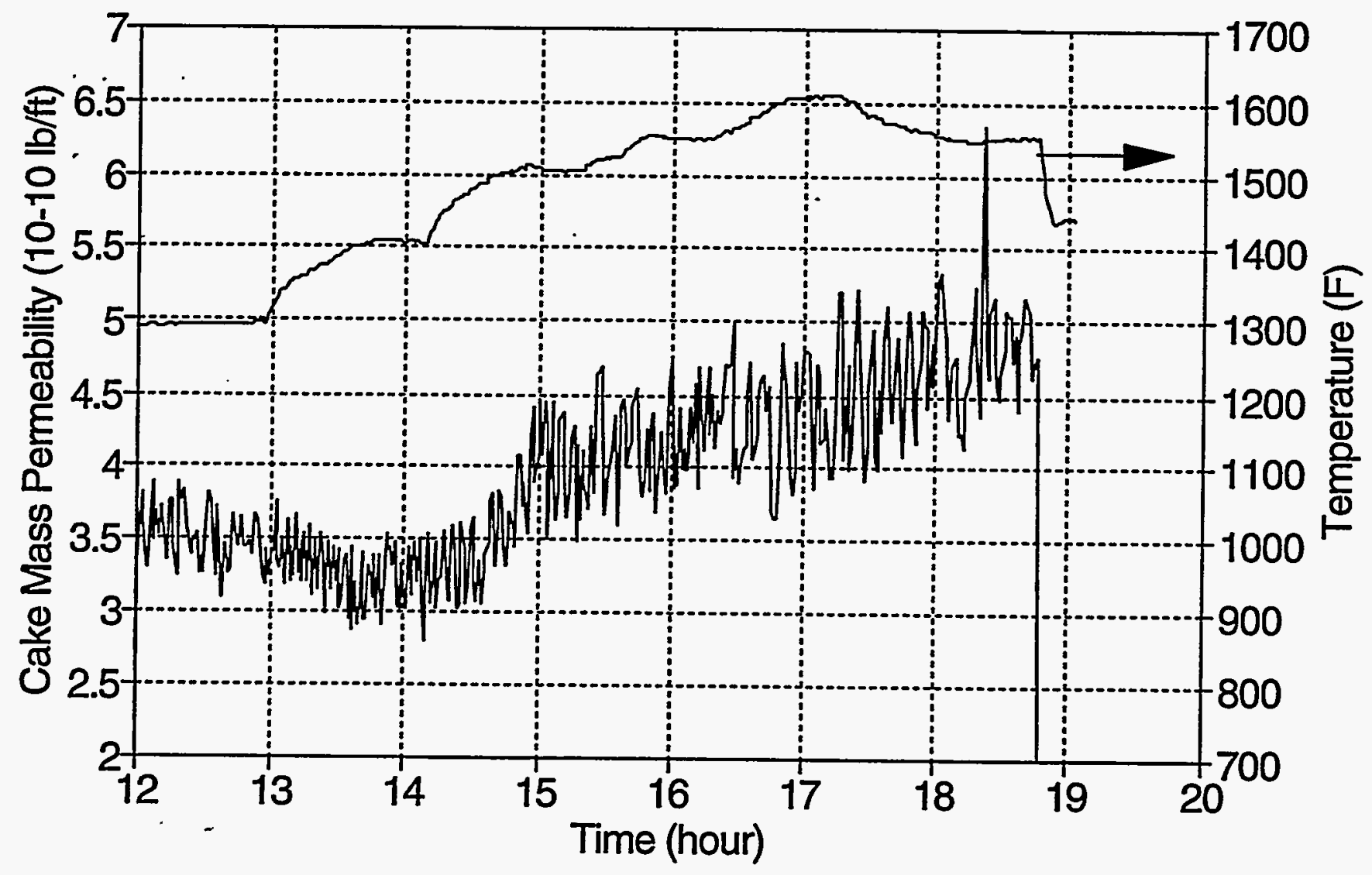




\section{Alkali Test 5.01 (7/15/94) \\ Emathlite with $\mathrm{No} \mathrm{NaCl}$}

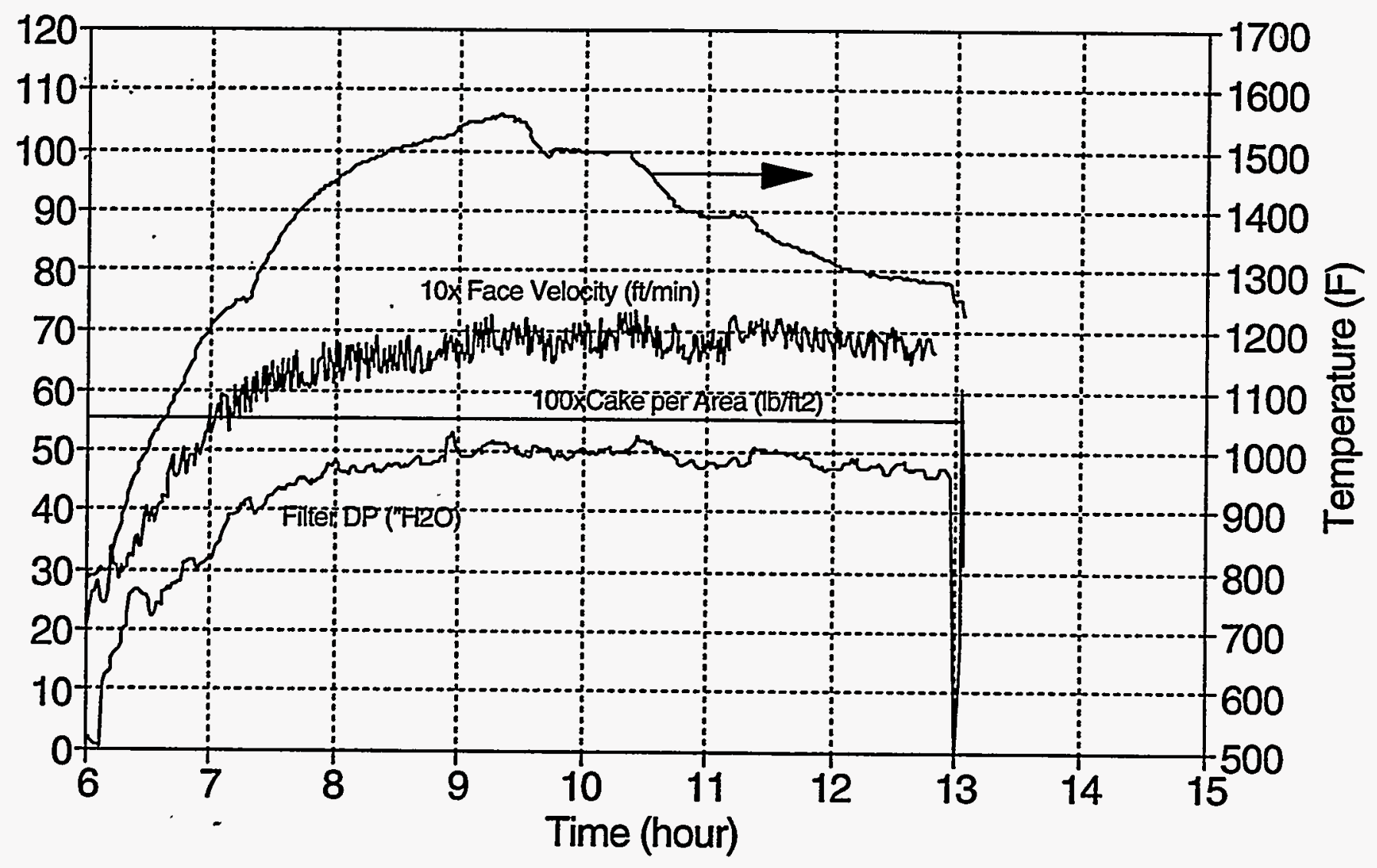




\section{Alkali Test 5.01 (7/15/94) \\ Emathlite with $\mathrm{No} \mathrm{NaCl}$}

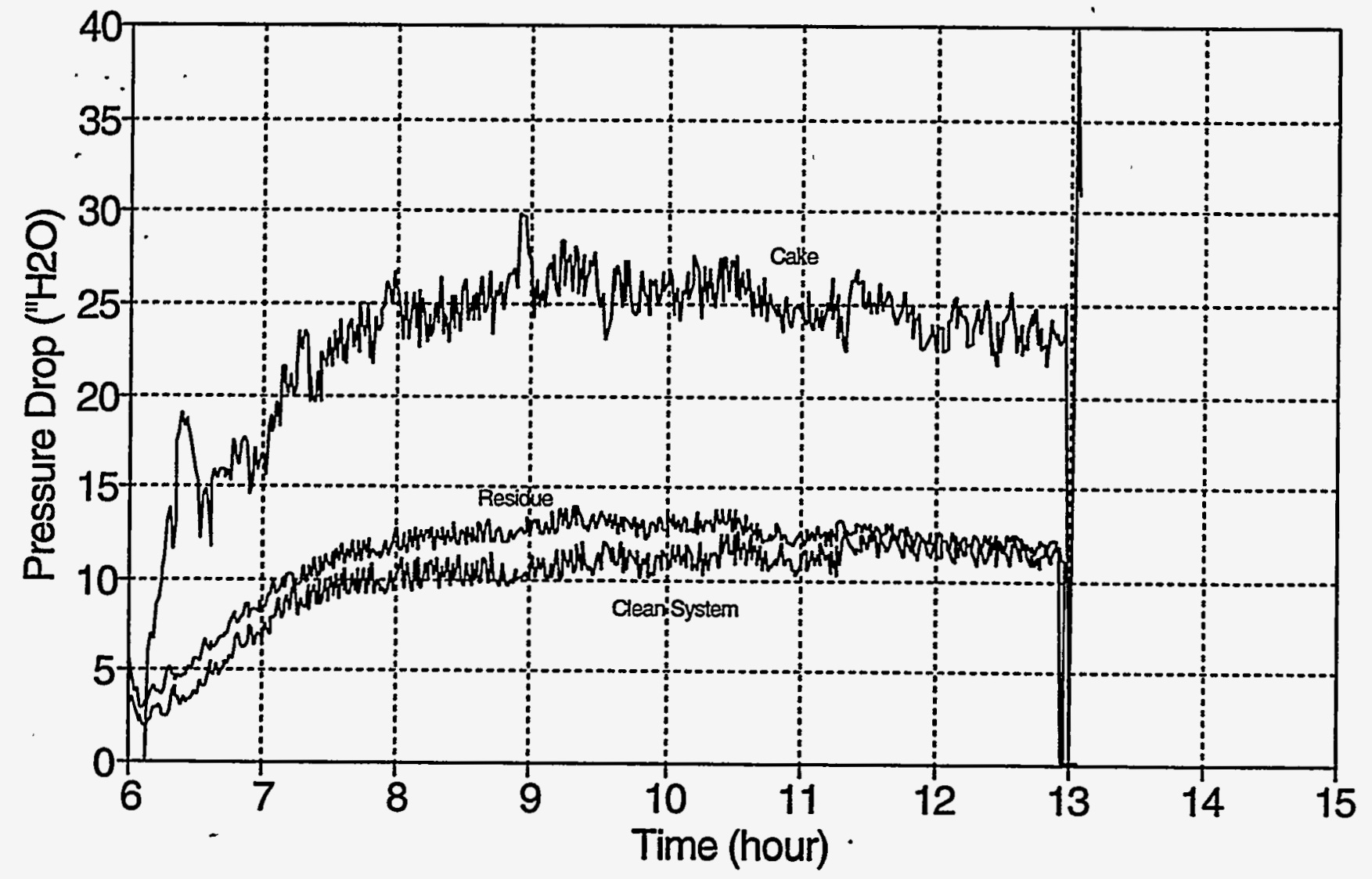




\section{Alkali Test 5.01 (7/15/94)}

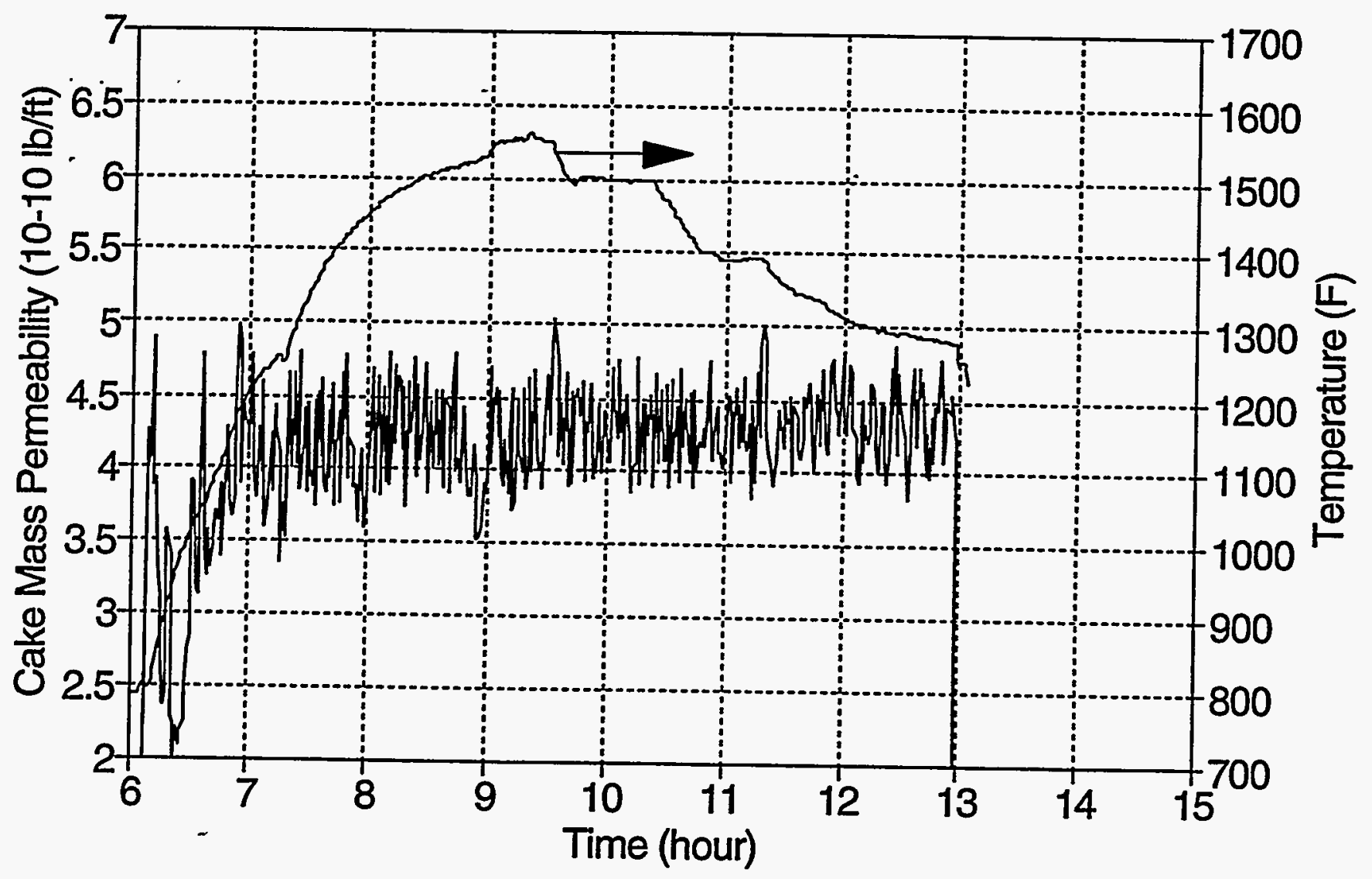




\section{Alkali Test $5.2(3 / 7 / 95)$ No Ash or Alkali}

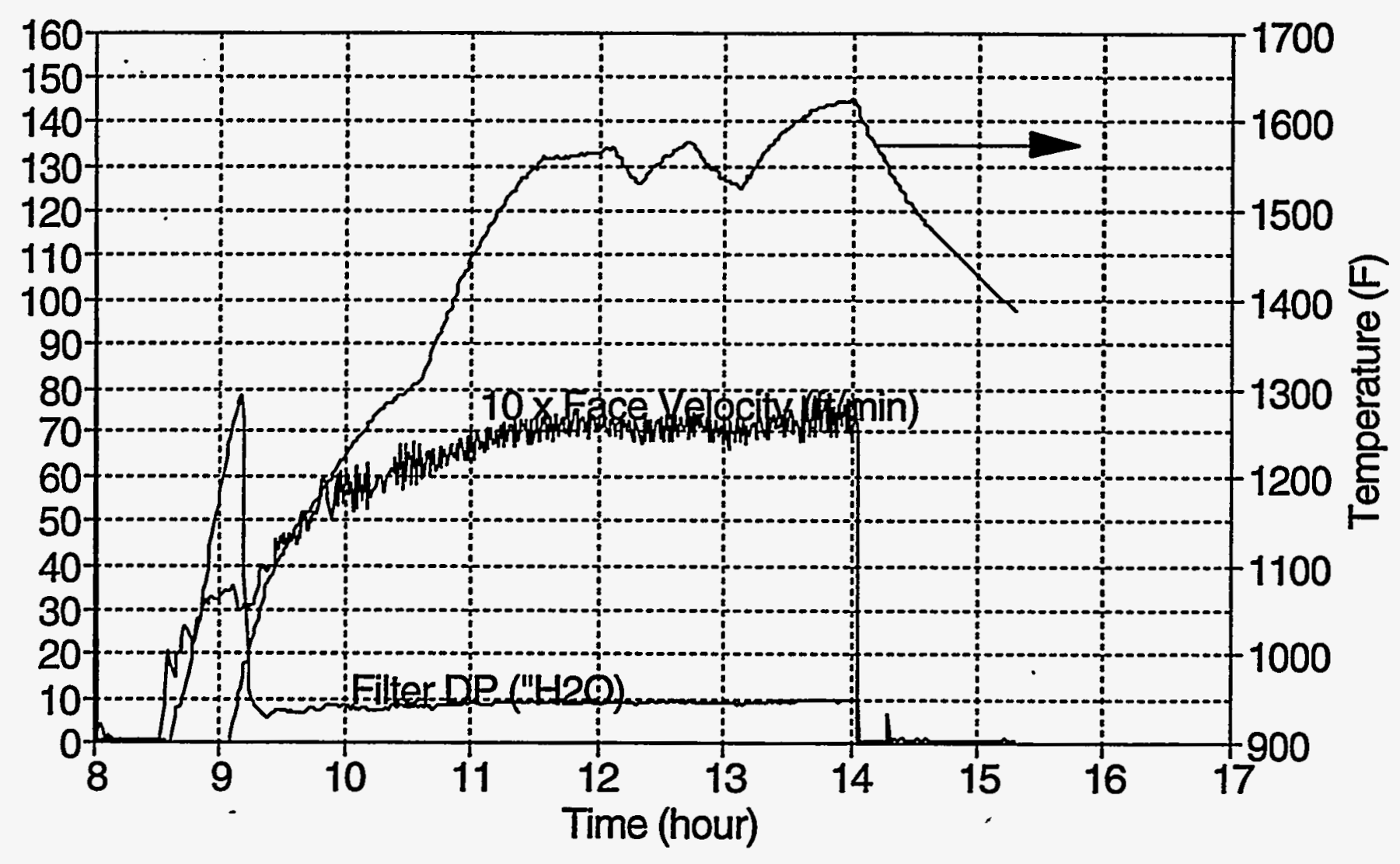




\section{Alkali Test 5.3 (3/8/95) Tidd Spoiled Cyclone Ash ( $5 \% \mathrm{NaCl})$}

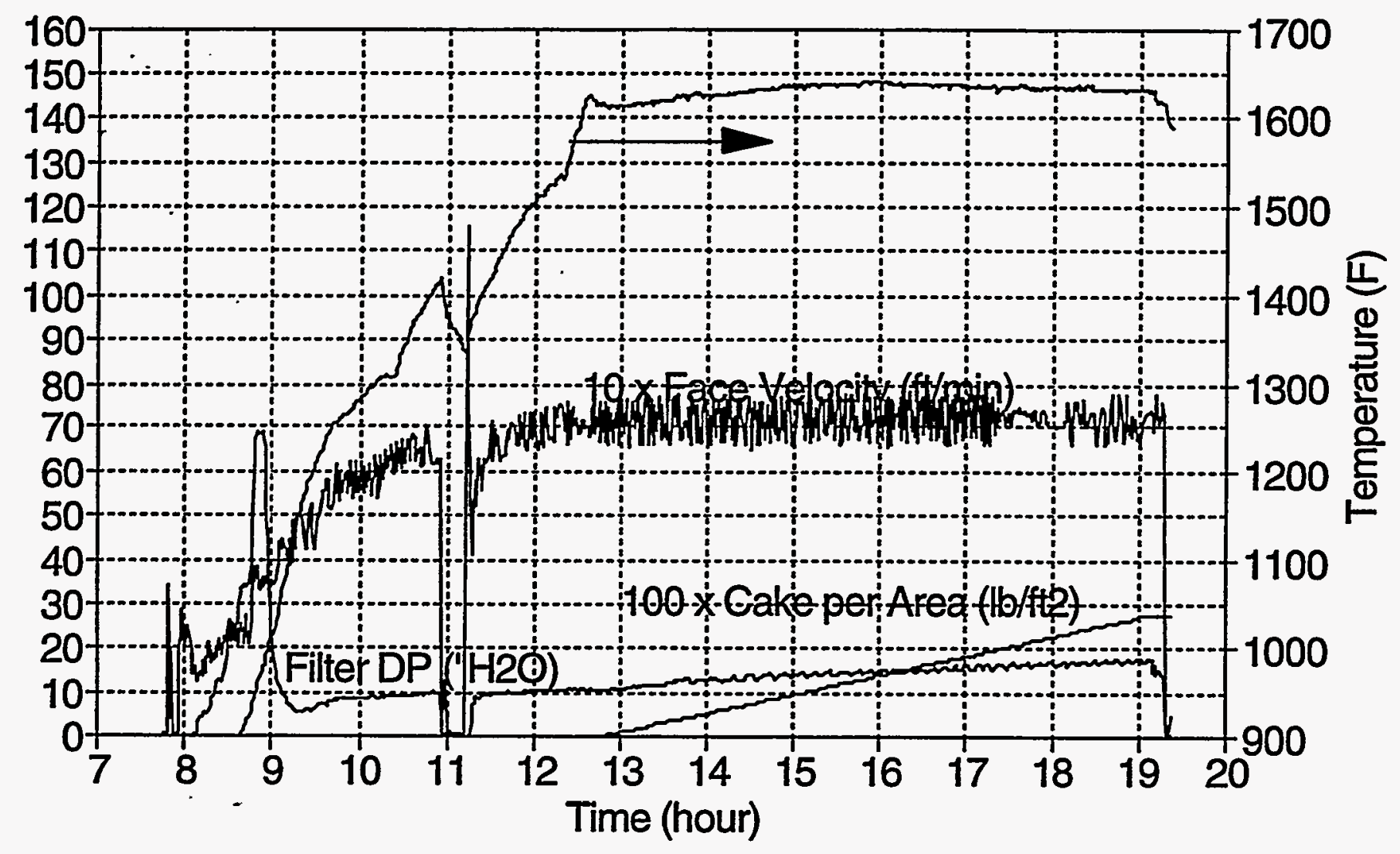




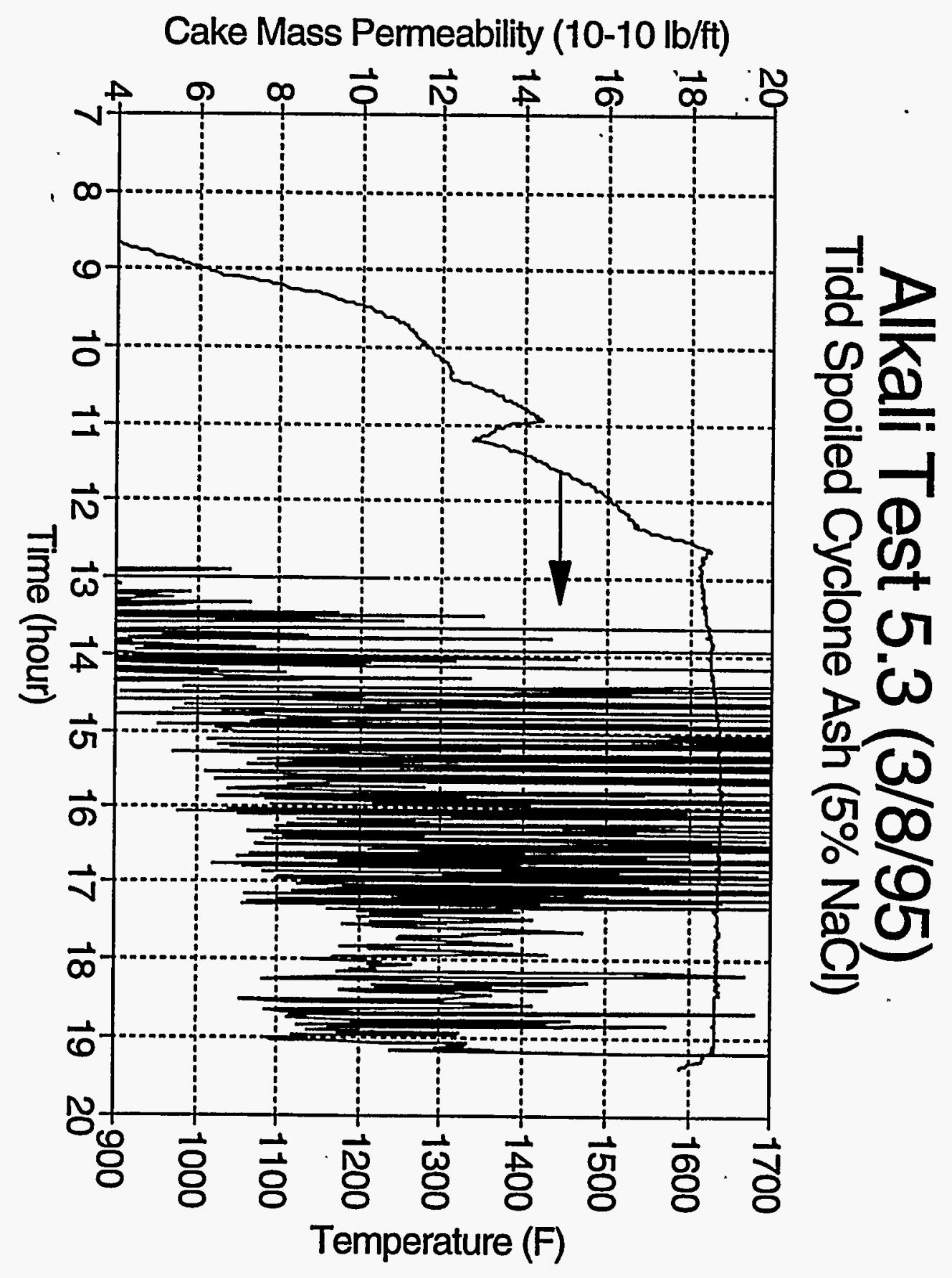




\section{Alkali Test 5.4 (3/9/95) Emathlite with $5 \% \mathrm{NaCl}$}

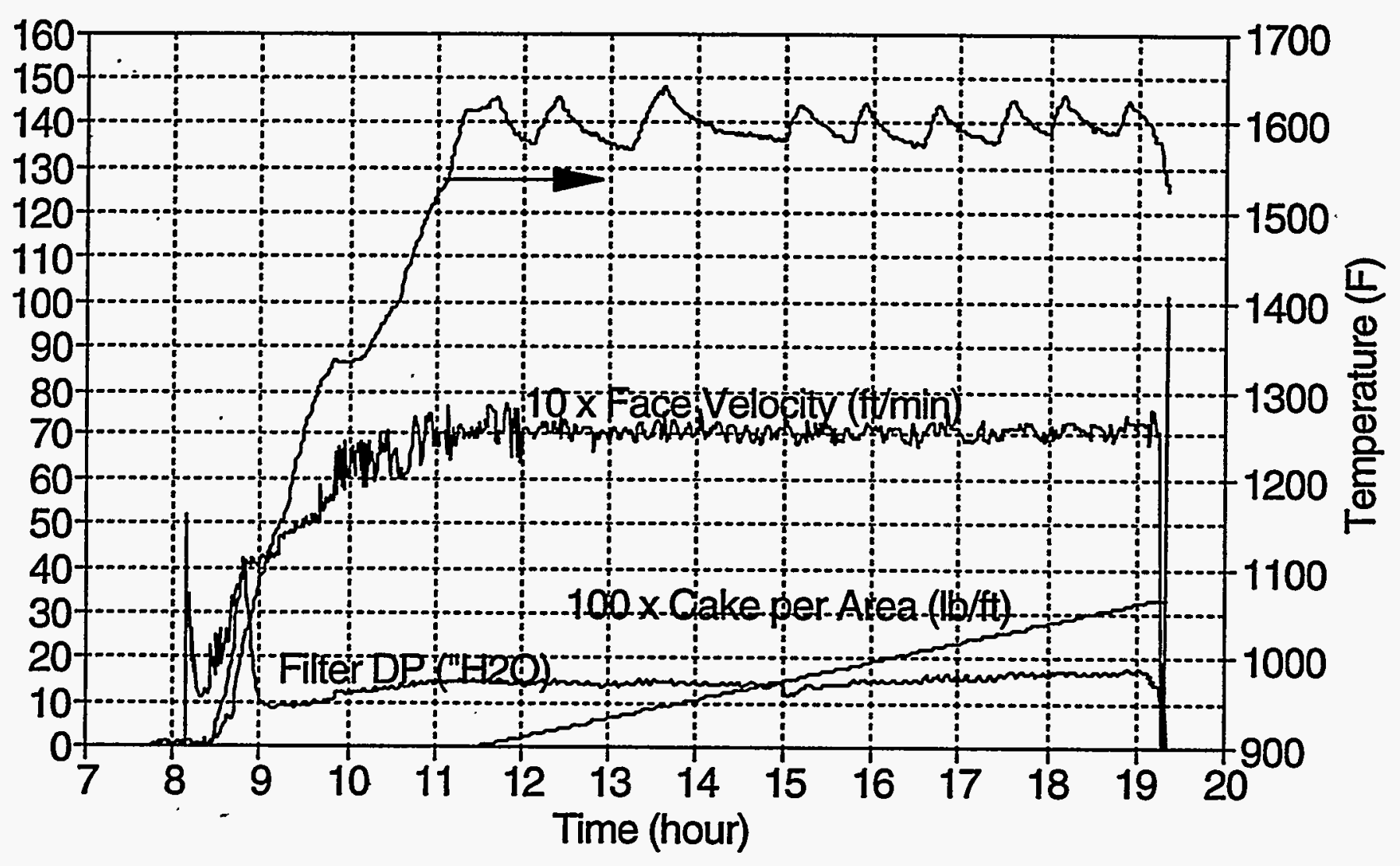




\section{Alkali Test 5.5 (3/14/95) Tidd Spoiled Cyclone Ash ( $5 \% \mathrm{NaCl})$}

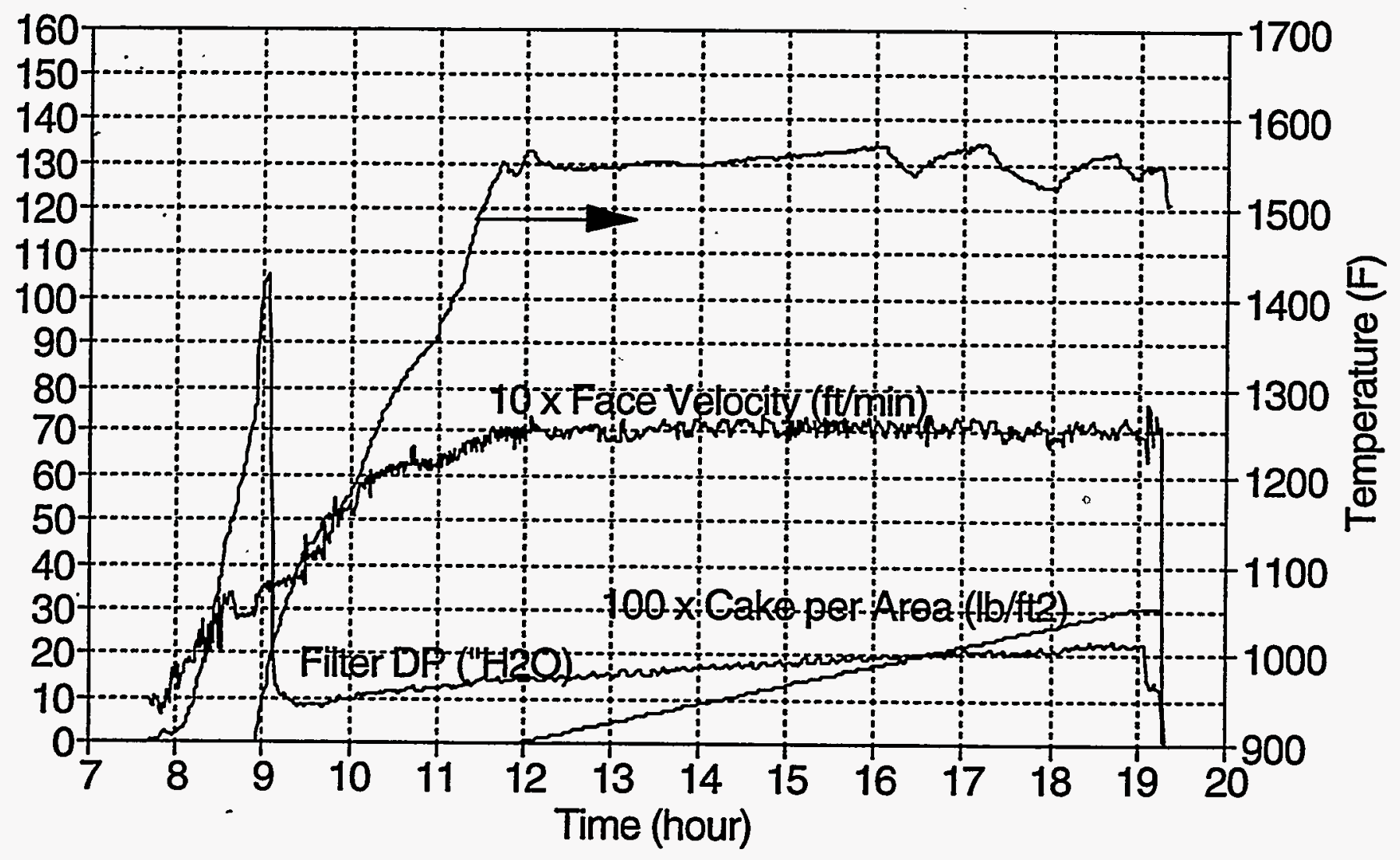




\section{Alkali Test 5.5 (3/14/95) Tidd Spoiled Cyclone Ash (5\% NaCl)}

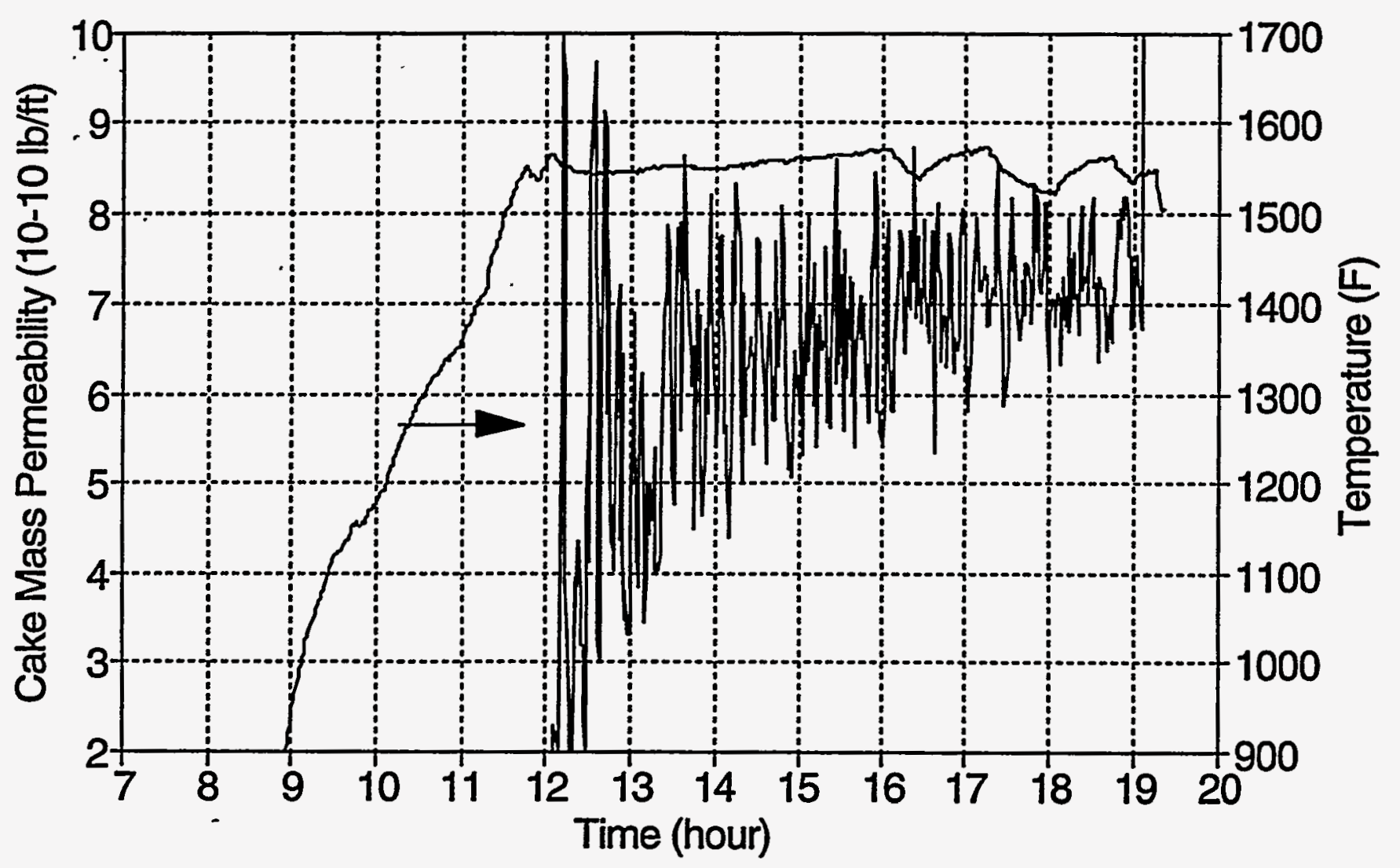




\section{Alkali Test $5.6(3 / 15 / 95)$ Emathlite with $5 \% \mathrm{NaCl}$}

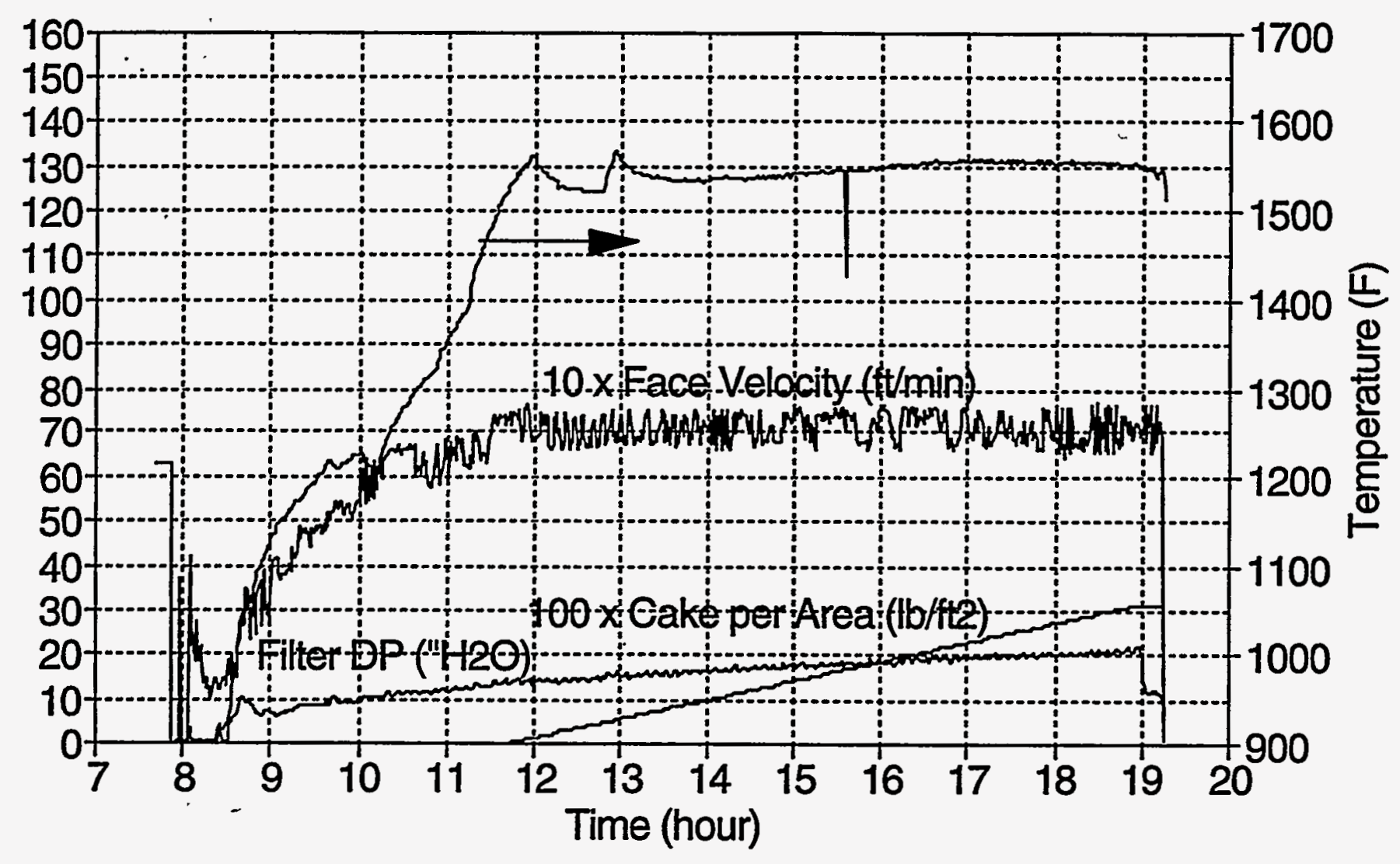




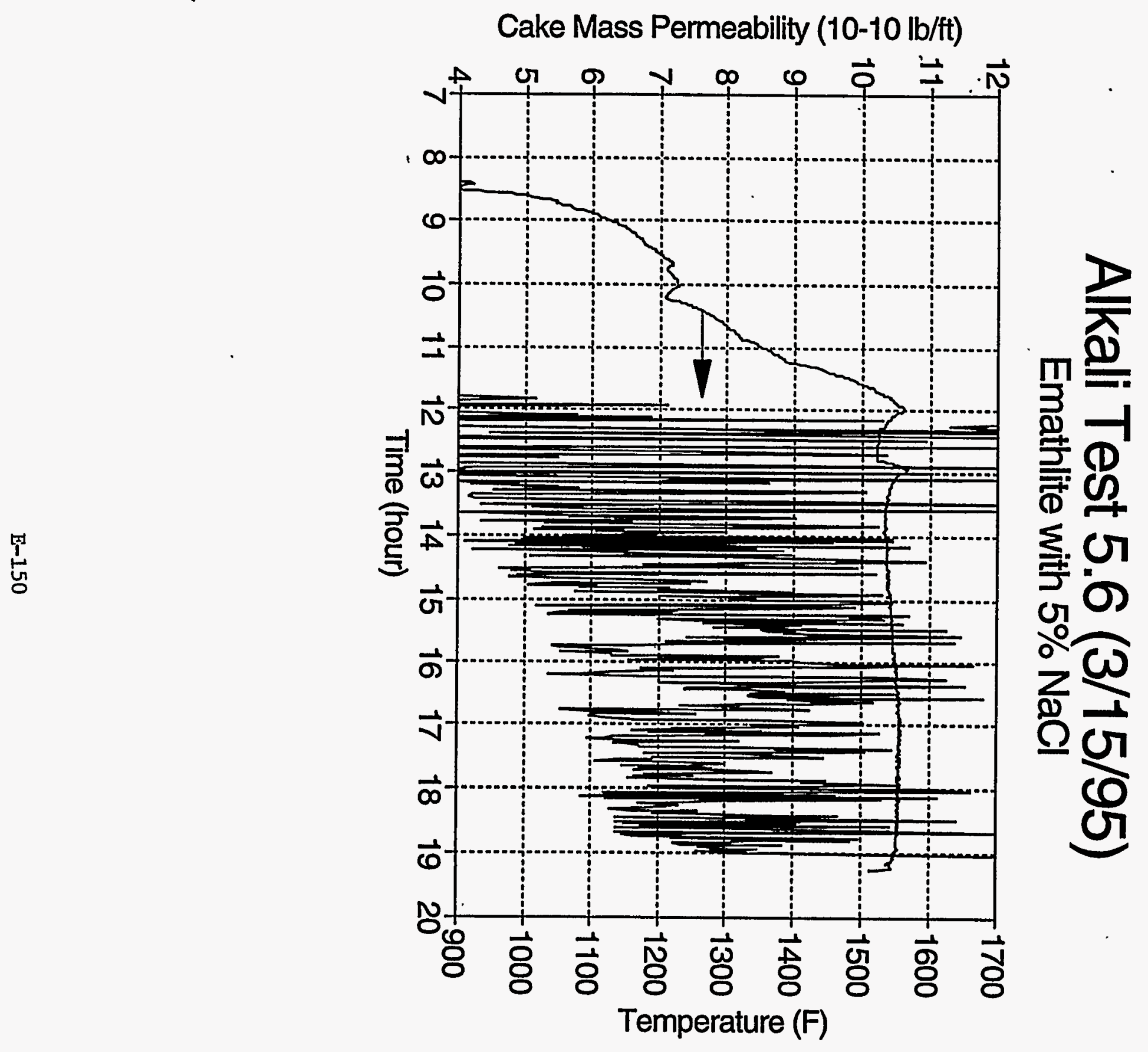




\section{Alkali Test 5.7 (3/23/95) Emathlite with $5 \% \mathrm{NaCl}$}

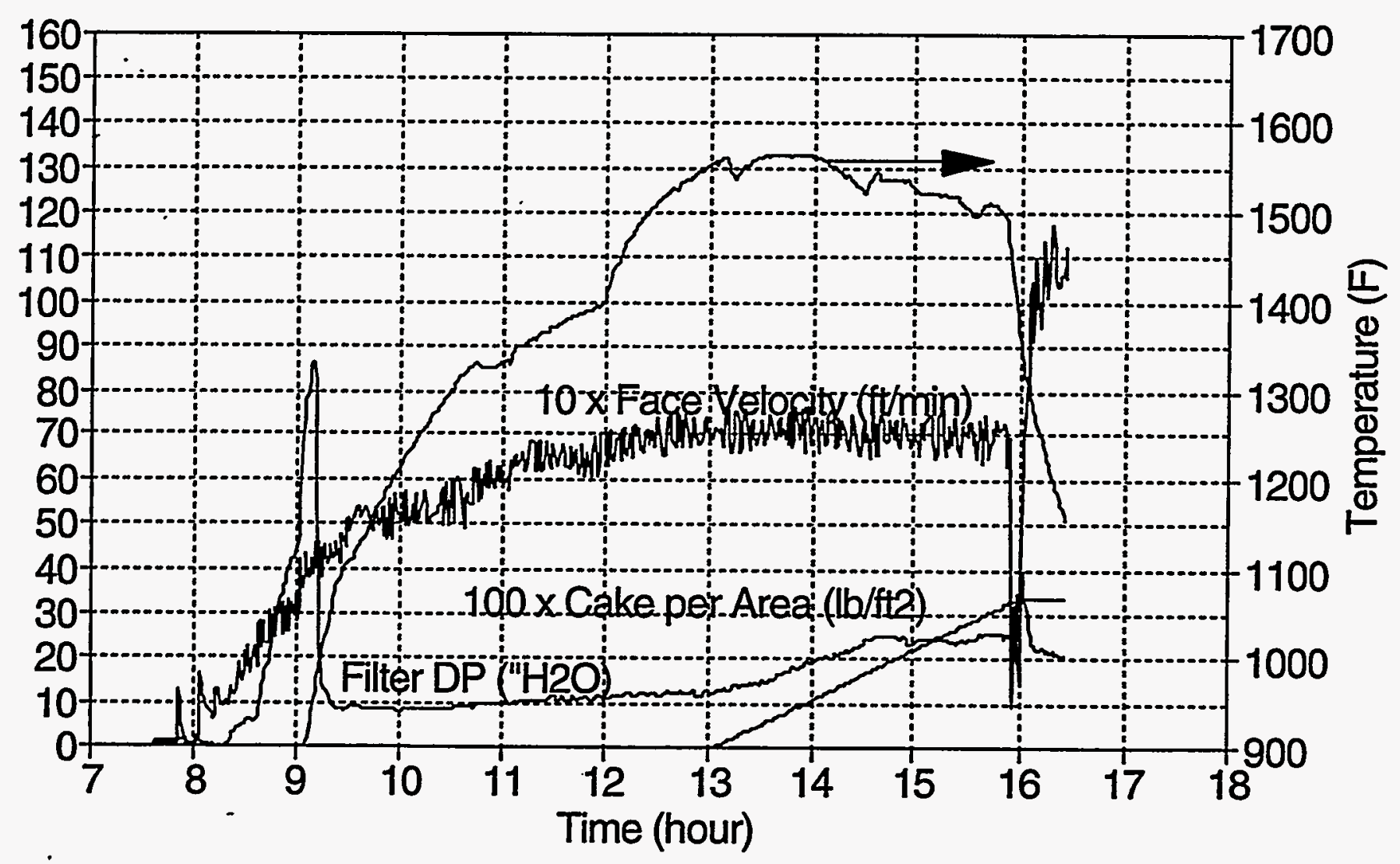




\section{Alkali Test $5.8(4 / 17 / 95)$ Emathlite with $5 \% \mathrm{NaCl}$}

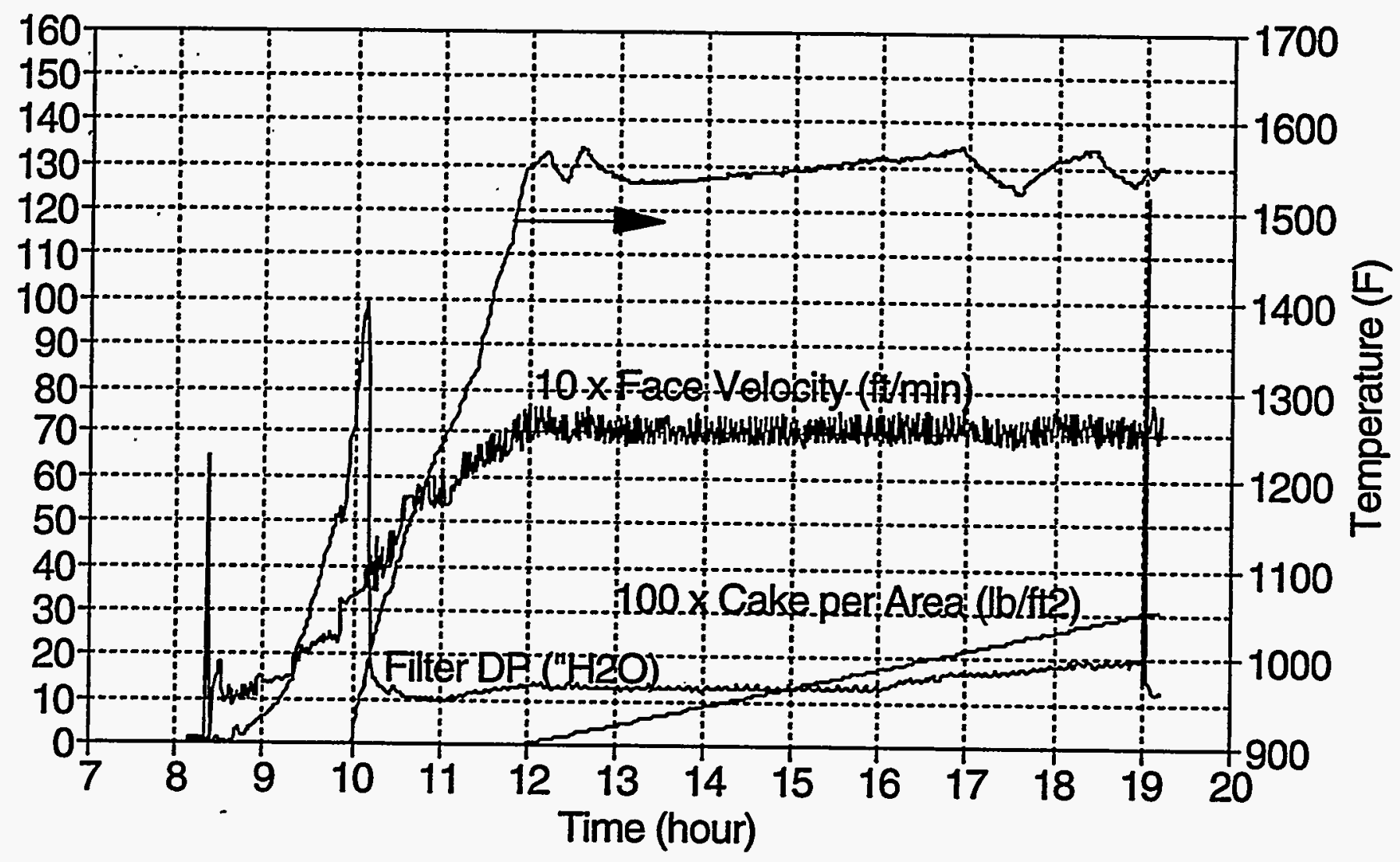




\section{Alkali Test 5.8 (4/17/95) Emathlite with $5 \% \mathrm{NaCl}$}

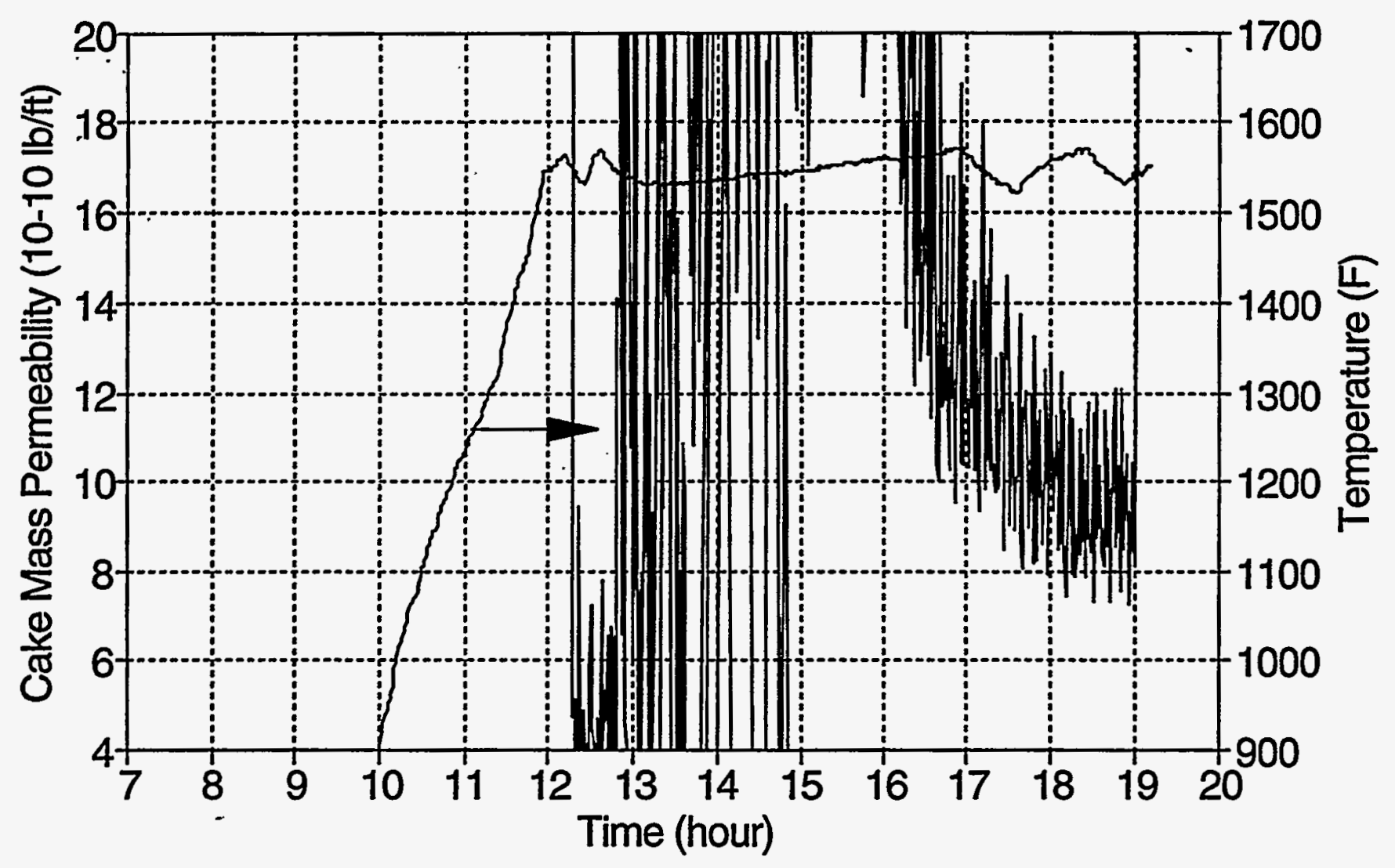




\section{Alkali Test 5.9 (4/19/95) Emathlite with $5 \% \mathrm{NaCl}$ and $\mathrm{SO} 2$}

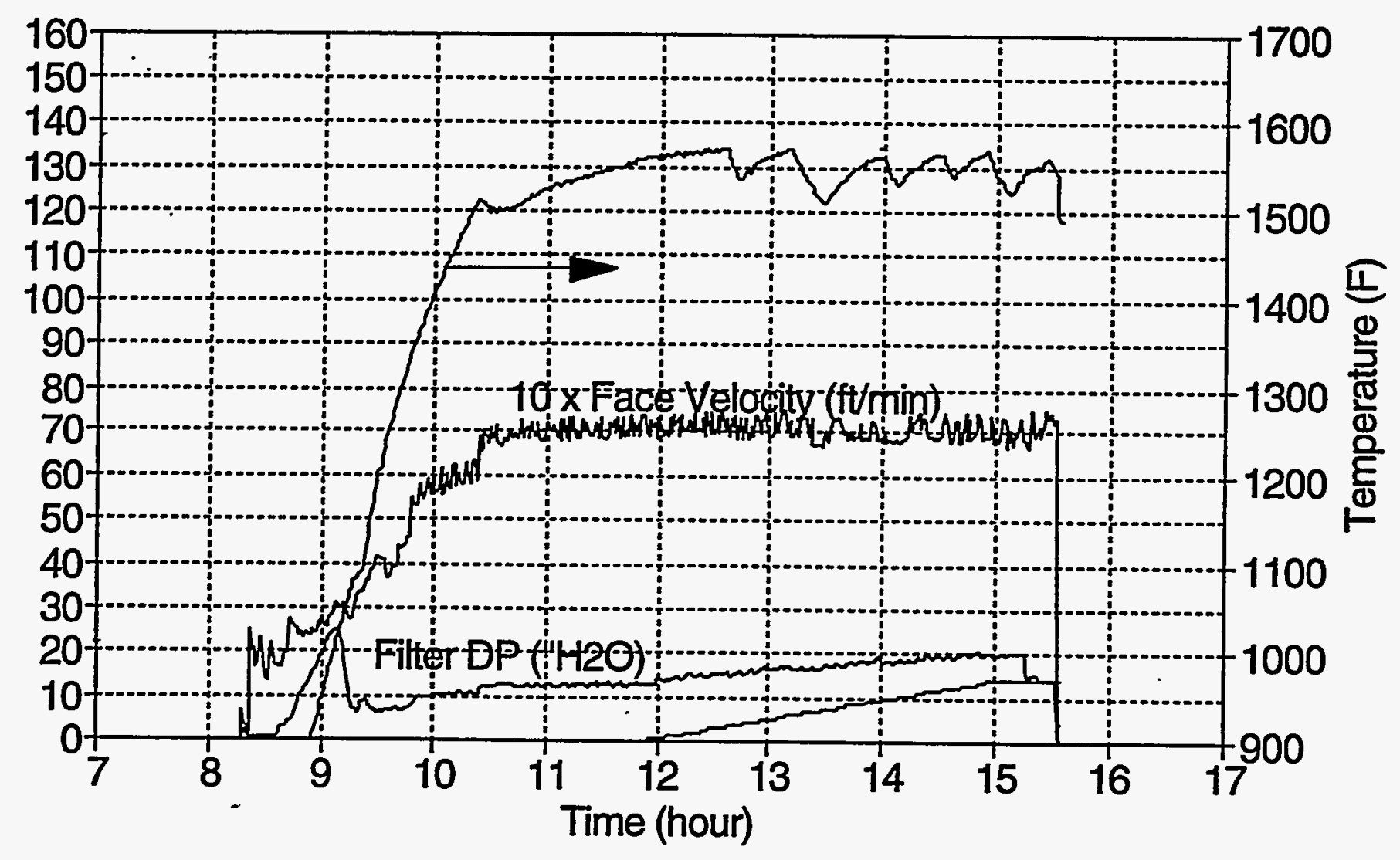




\section{Alkali Test 5.9 (4/19/95) Emathlite with $5 \% \mathrm{NaCl}$ and $\mathrm{SO} 2$}

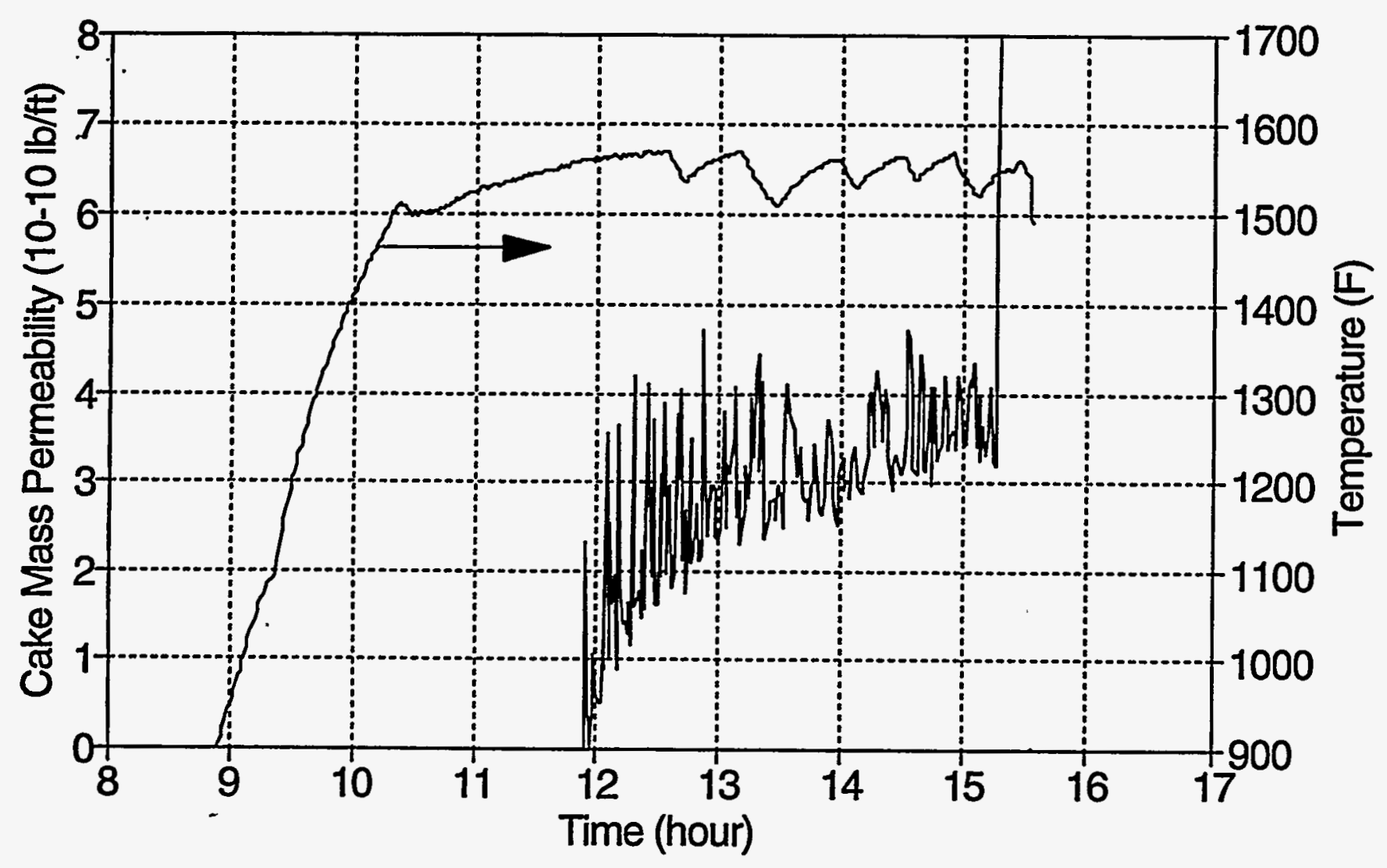




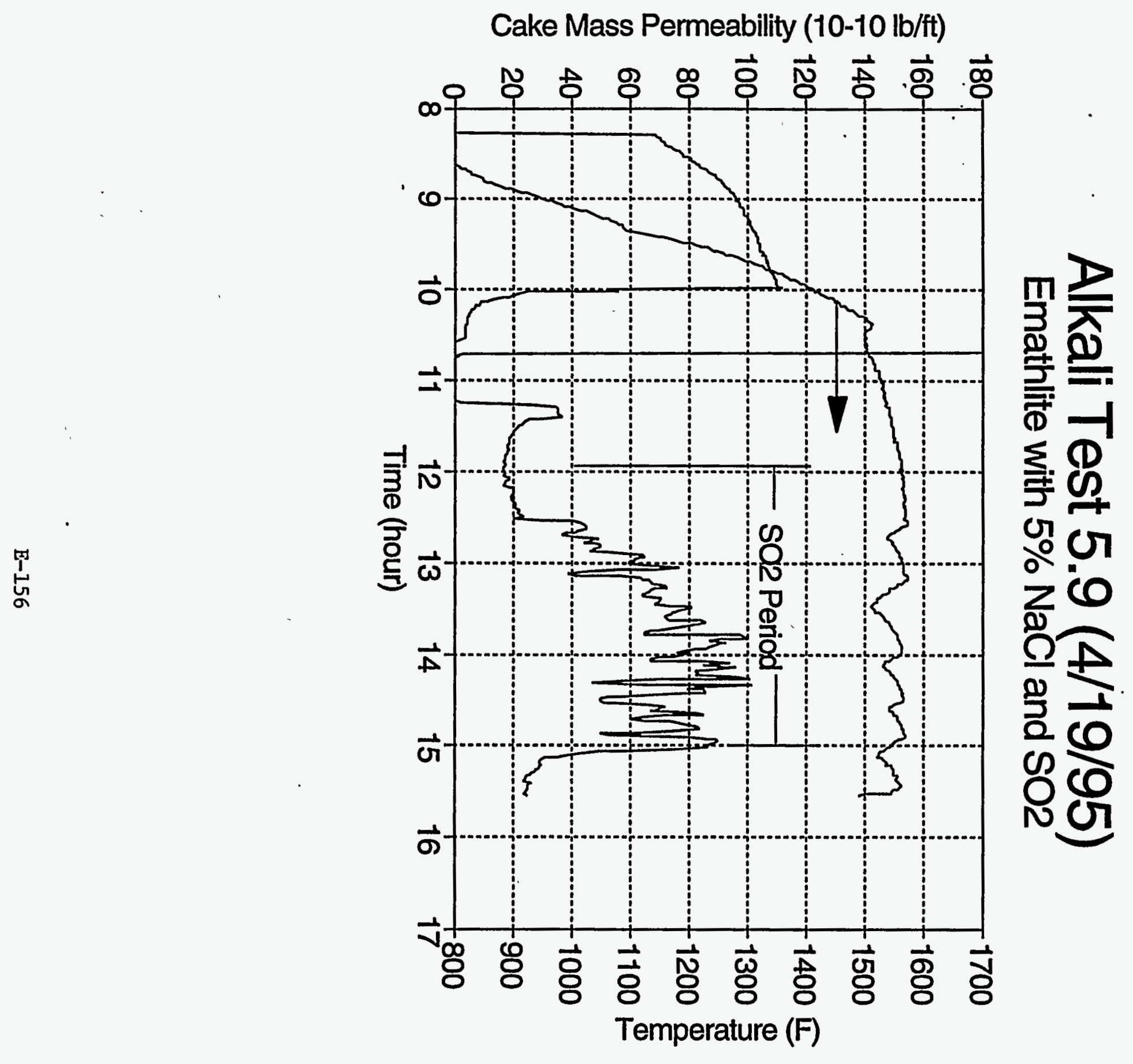




\section{Alkali Test 5.10 (4/28/95) Emathlite with $5 \% \mathrm{NaCl}$}

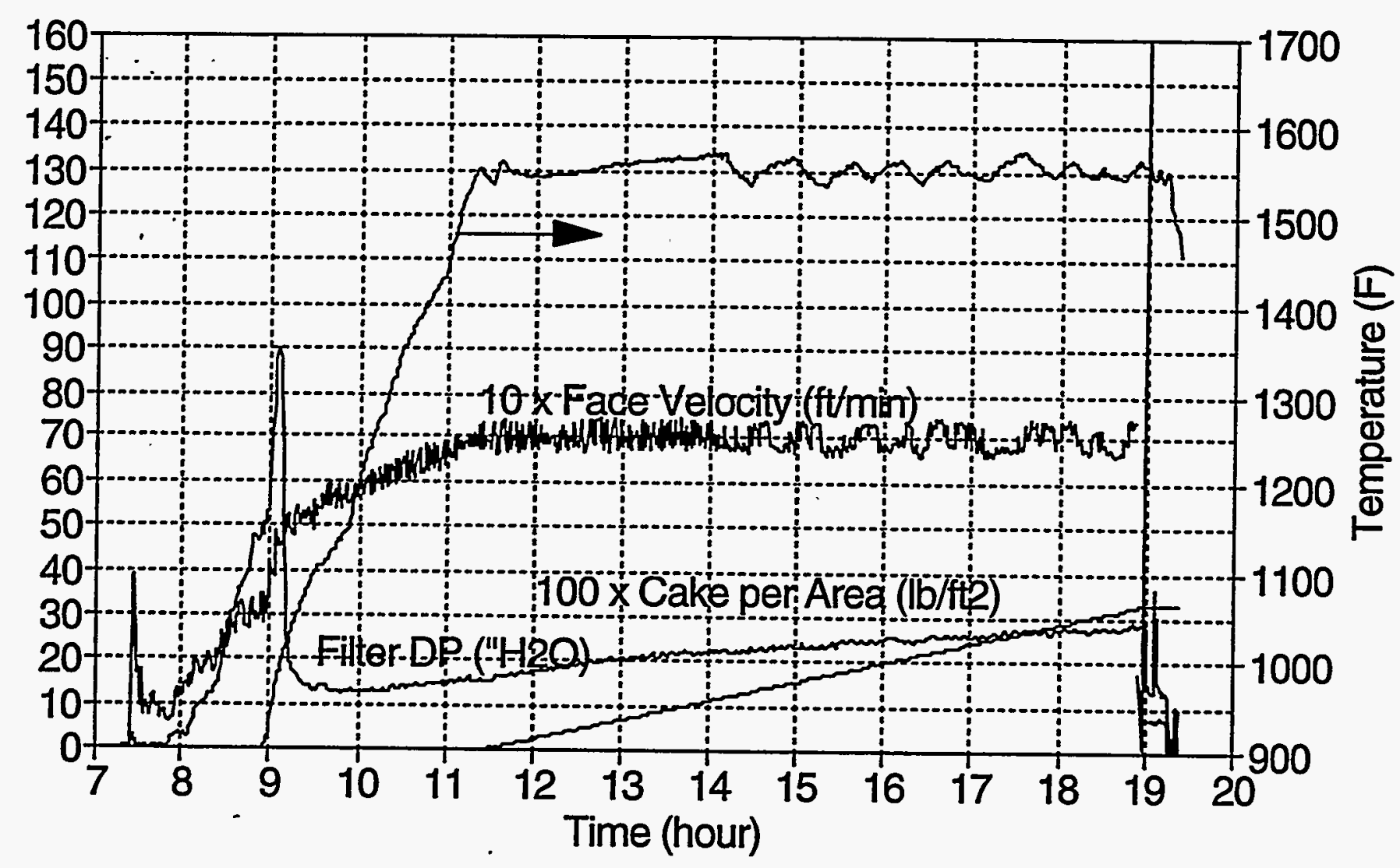




\section{Alkali Test 5.10 (4/28/95) Emathlite with $5 \% \mathrm{NaCl}$}

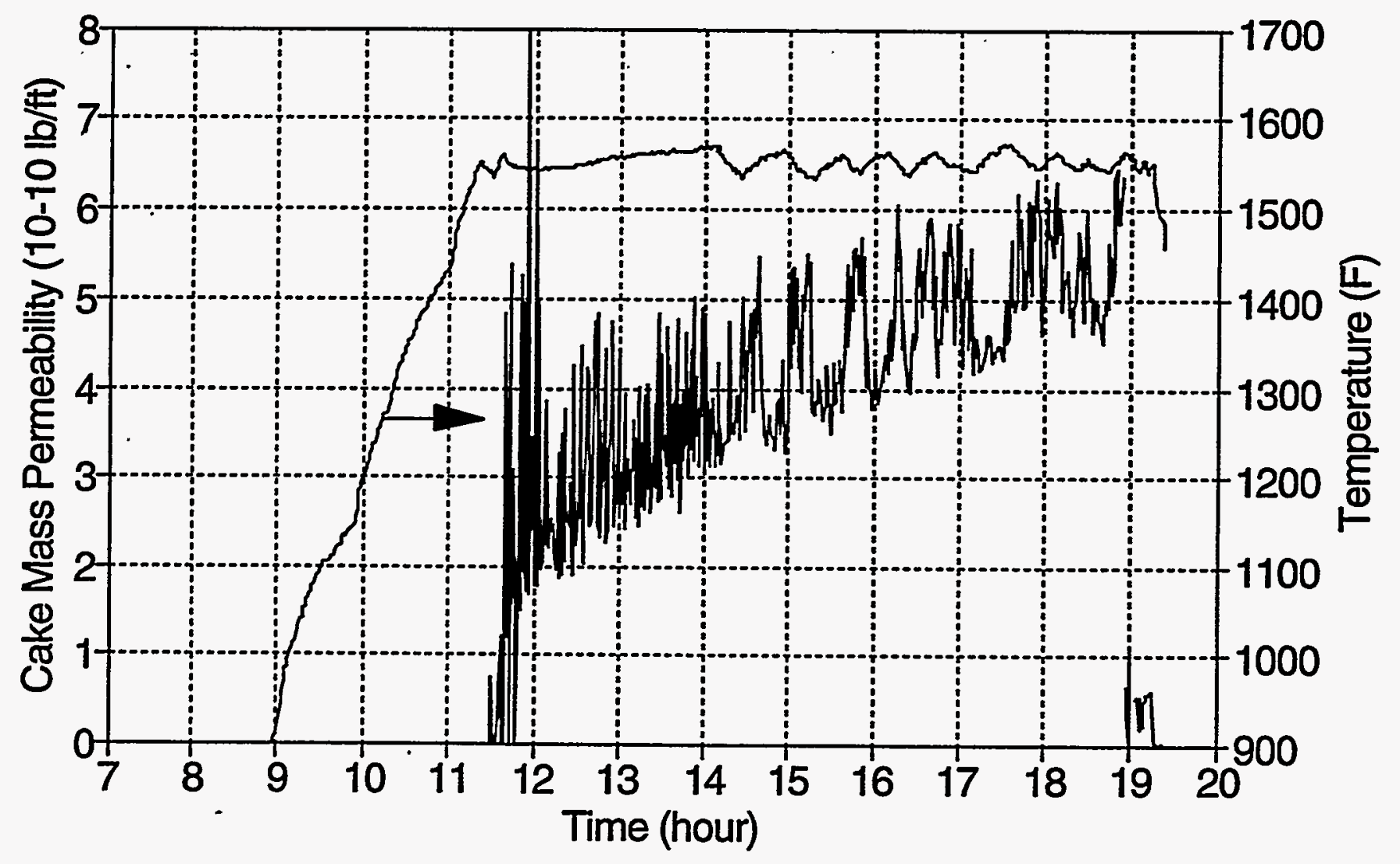


ة

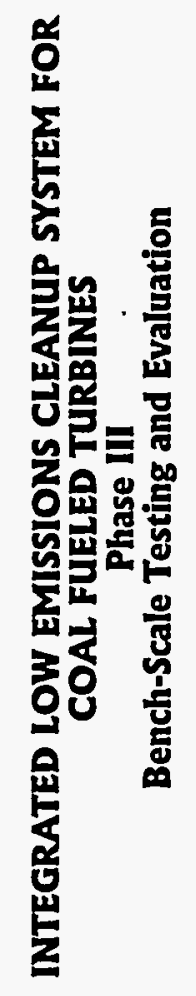

高

in 